This document was prepared in conjunction with work accomplished under Contract No. DE-AC09-96SR18500 with the U. S. Department of Energy.

\title{
DISCLAIMER
}

This report was prepared as an account of work sponsored by an agency of the United States Government. Neither the United States Government nor any agency thereof, nor any of their employees, nor any of their contractors, subcontractors or their employees, makes any warranty, express or implied, or assumes any legal liability or responsibility for the accuracy, completeness, or any third party's use or the results of such use of any information, apparatus, product, or process disclosed, or represents that its use would not infringe privately owned rights. Reference herein to any specific commercial product, process, or service by trade name, trademark, manufacturer, or otherwise, does not necessarily constitute or imply its endorsement, recommendation, or favoring by the United States Government or any agency thereof or its contractors or subcontractors. The views and opinions of authors expressed herein do not necessarily state or reflect those of the United States Government or any agency thereof. 


\section{NEPHELINE FORMATION STUDY FOR SLUDGE BATCH 4 (SB4): PHASE 2 EXPERIMENTAL RESULTS}

D.K. Peeler

T.B. Edwards

D.R. Best

I.A. Reamer

R.J. Workman

January 2006

Process Science and Engineering Section Savannah River National Laboratory Aiken, SC 29808

Prepared for the U.S. Department of Energy Under Contract Number DEAC09-96SR18500

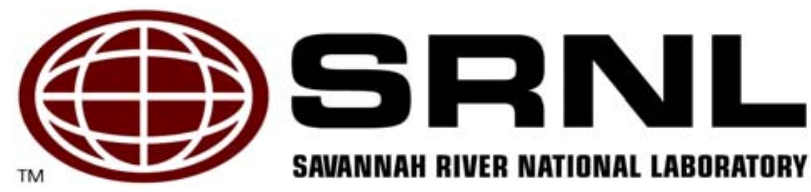




\section{DISCLAIMER}

This report was prepared by Washington Savannah River Company (WSRC) for the United States Department of Energy under Contract No. DE-AC09-96SR18500 and is an account of work performed under that contract. Neither the United States Department of Energy, nor WSRC, nor any of their employees makes any warranty, expressed or implied, or assumes any legal liability or responsibility for the accuracy, completeness, or usefulness, of any information, apparatus, or product or process disclosed herein or represents that its use will not infringe privately owned rights. Reference herein to any specific commercial product, process, or service by trademark, name, manufacturer or otherwise does not necessarily constitute or imply endorsement, recommendation, or favoring of same by WSRC or by the United States Government or any agency thereof. The views and opinions of the authors expressed herein do not necessarily state or reflect those of the United States Government or any agency thereof.

\section{Printed in the United States of America \\ Prepared For U.S. Department of Energy}

The Savannah River National Laboratory is operated for the U.S. Department of Energy by Washington Savannah River Company. 
Key Words: durability, crystallization, residual glass matrix effects

Retention: Permanent

\section{NEPHELINE FORMATION STUDY FOR SLUDGE BATCH 4 (SB4): PHASE 2 EXPERIMENTAL RESULTS}

D.K. Peeler

T.B. Edwards

D.R. Best

I.A. Reamer

R.J. Workman

January 2006

Process Science and Engineering Section Savannah River National Laboratory Aiken, SC 29808 


\section{REVIEWS AND APPROVALS}

\section{AUTHORS:}

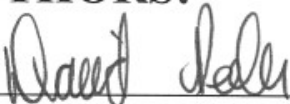

$2.15-06$

D.K. Peeler, Process Science and Engineering Section

Date

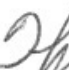

Mucia

T.B. Edwards, Statistical Consulting Section $2-11=06$

Date

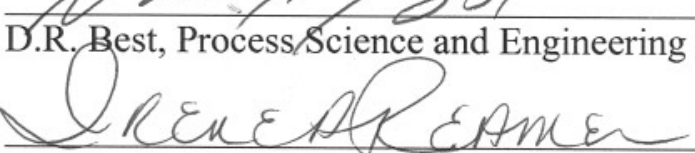

I.A. Reamer, Process Science and Engineering Section

Q. G. Werkmon -

R.J. Workman, Process Science and Engineering Section

$$
2 \cdot 15-06
$$

Date

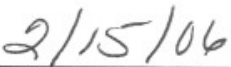

Date $2-15-06$

Date

\section{TECHNICAL REVIEWER:}

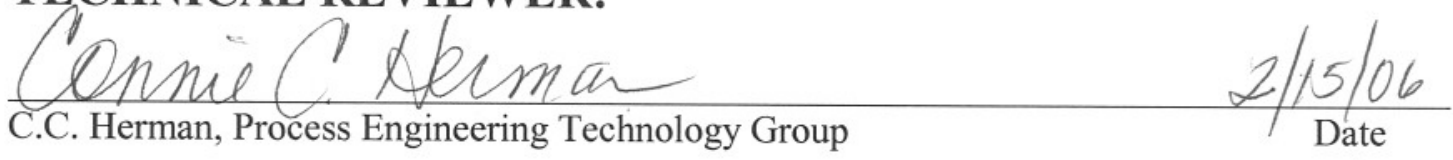

\section{APPROVERS:}

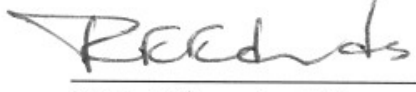

R.E. Edwards, Manager, Process Science and Engineering Section

$$
\frac{3 / 3 / 06}{\text { Date }}
$$

Qunid C.

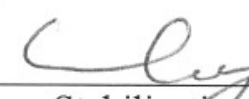

D.A. Crowley, Manager, Stabilization Science Research Group

J.E. Occhipinti, Manager,

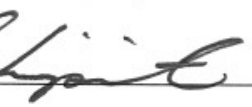

Process Cognizant Engineer - Waste Solidification Engineering $2 / 15 / 16$

Date 


\section{EXECUTIVE SUMMARY}

The impact of devitrification on durability is complex and depends on several interrelated factors including the change in residual glass composition, the formation of internal stress or microcracks, and the preferential attack at the glass-crystal interface. As noted from previous experimental studies, perhaps the most significant effects are the type and extent (or fraction) of crystallization and the resulting change to the residual glass composition. Conceptually, the formation of crystalline phases within a glass matrix ultimately changes the composition of the host glass phase as specific elements/oxides are extracted from the glass matrix to form the crystals. The formation of nepheline $\left(\mathrm{NaAlSiO}_{4}\right)$ can have a negative impact on durability as it produces an $\mathrm{Al}_{2} \mathrm{O}_{3}$ and $\mathrm{SiO}_{2}$ deficient continuous glass matrix (relative to the same composition which is void of crystals). The primary driver for the reduction in durability is the fact that nepheline removes three moles of glass forming oxides $\left(\mathrm{Al}_{2} \mathrm{O}_{3}\right.$ and $\left.2 \mathrm{SiO}_{2}\right)$ per each mole of $\mathrm{Na}_{2} \mathrm{O}$ from the continuous glass phase. The magnitude of the reduction in durability ultimately depends on the extent (i.e., volume \%) of crystallization. The formation of nepheline and/or other aluminum/silicon-containing crystals is a potential problem in the Sludge Batch 4 (SB4) system based on the projected compositional views recently evaluated coupled with the frit development strategy.

Twenty-eight Phase 2 glasses were identified that intentionally challenged the "nepheline discriminator" value for the $1.6 \mathrm{M} \mathrm{Na}, 40$ " and 1.6M Na, 127" sludge options as defined by the Closure Business Unit (CBU) (Elder 2005a and 2005b). The glasses were fabricated and the durability (as defined by the Product Consistency Test (PCT)) assessed for both quenched and centerline canister cooled (ccc) samples.

All of the Phase 2 quenched glasses have normalized boron releases (NL [B]) less than $1.19 \mathrm{~g} / \mathrm{L}$ which in terms of acceptability are approximately an order of magnitude better than the Environmental Assessment (EA) benchmark glass which has a reported NL [B] of $16.695 \mathrm{~g} / \mathrm{L}$. However, the potential for crystallization was suppressed in the quenched glasses in terms of kinetics. That is, the glasses may be prone to nepheline formation but the rapid cooling limited (or eliminated) the formation of nepheline (or other crystalline phases).

For the ccc glasses, visual observations suggested that in general, as the targeted waste loading (WL) within a specific frit - sludge system was increased, the degree of crystallization or devitrification appeared to be more extensive. This is not unexpected as the slower cooling provides a thermodynamically favorable glass (i.e., a composition within the nepheline primary phase field) the kinetic opportunity to devitrify. X-ray diffraction (XRD) results indicated the presence of nepheline $\left(\mathrm{NaAlSiO}_{4}\right)$, trevorite $\left(\mathrm{NiFe}_{2} \mathrm{O}_{4}\right)$, and/or lithium silicate $\left(\mathrm{Li}_{2} \mathrm{SiO}_{3}\right)$ in select Phase 2 ccc glasses. In general, as the WL increases within a specific frit - sludge system, the crystalline phase(s) detected transitioned from amorphous or spinels (at the lowest WL), to spinel and nepheline (at the intermediate WL), and ultimately to spinel, nepheline, and lithium silicate (at the highest WL). As a result, the difference between the quenched and ccc PCT response for each specific frit system increased as WL increased. Coupling this trend with the crystallization results, one can easily explain the durability responses as a function of WL. More specifically, as WL increases within a specific frit - sludge system, the durability of the ccc based glasses decreases due to the formation of nepheline and/or lithium silicate. The trends are in agreement with previous observations that the impact on durability is dependent upon the type and extent of crystallization and the resulting change to the residual glass composition. As previously noted, nepheline formation can result in a severe deterioration of the chemical durability of the glass through residual glass compositional changes (i.e., a continuous glass matrix which is $\mathrm{Al}_{2} \mathrm{O}_{3}$ and/or $\mathrm{SiO}_{2}$ deficient). 
The results of the Phase 1 and Phase 2 studies suggest that the 0.62 value appears to be a reasonable guide to monitor SB4 - frit systems with respect to potential nepheline formation upon ccc. ${ }^{1}$ The significance of "ccc" in this sentence is based on the fact that none of the Phase 1 or Phase 2 quenched glasses showed any sign of nepheline formation (based on the PCT response) although some of the Phase 2 glasses had nepheline discriminator values as low as 0.541 . The PCT responses for all of the quenched glasses were very acceptable. It is only when the glass is provided the kinetic opportunity to devitrify through the slow ccc schedule that nepheline forms and ultimately has an adverse impact on durability.

In Phase 2, the lower WL glasses showed no significant or practical differences in durability when comparing quenched and ccc glasses - this is consistent with the Phase 1 results. It was only at the higher WLs (in Phase 2) that nepheline formation had a significantly negative impact on durability. The practical implication to DWPF is that higher WL glasses should be avoided for these types of glass systems (i.e., high $\mathrm{Al}_{2} \mathrm{O}_{3}$ and $\mathrm{Na}_{2} \mathrm{O}$ ). The primary question becomes how can potential nepheline formation regions be avoided or controlled in DWPF if necessary? Although a formal recommendation of the specific path is not made in this report, a general discussion is provided on options that are available. These include (but are not limited to): (1) use of an administrative control on waste loading, (2) implementation of a nepheline discriminator value in the process control system, or (3) strategic frit development efforts to mitigate nepheline formation. It should be noted that although nepheline formation is a real and potentially significant issue, other constraints or alternatives may arise (e.g., pumping issues in the Chemical Process Cell (CPC) or melt rate) which could result in targeting lower WLs where nepheline is not an issue.

${ }^{1} \mathrm{Li}$ et al. (1997 and 2003) indicated that sodium alumino-borosilicate glasses are prone to nepheline crystallization if their compositions projected on the $\mathrm{Na}_{2} \mathrm{O}-\mathrm{Al}_{2} \mathrm{O}_{3}-\mathrm{SiO}_{2}$ ternary fall within or close to the nepheline primary phase field. In particular, glasses with $\mathrm{SiO}_{2} /\left(\mathrm{SiO}_{2}+\mathrm{Na}_{2} \mathrm{O}+\mathrm{Al}_{2} \mathrm{O}_{3}\right)>0.62$, where the chemical formula stands for the mass fractions in the glass, do not tend to precipitate nepheline as their primary phase. 


\section{TABLE OF CONTENTS}

EXECUTIVE SUMMARY iv

LIST OF FIGURES viii

LIST OF TABLES viii

LIST OF ACRONYMS rix

1.0 INTRODUCTION 1

2.0 GLASS SELECTION 4

3.0 EXPERIMENTAL 8

3.1 Glass Fabrication $\quad 8$

3.2 Property Measurements $\quad 8$

3.2.1 Compositional Analysis 8

3.2.2 Product Consistency Test (PCT) 9

3.2.3 X-Ray Diffraction (XRD) Analysis 9

4.0 RESULTS 11

4.1 A Statistical Review 11

4.1.1 Measurements in Analytical Sequence 11

4.1.2 Batch 1 and Uranium Standard Results 12

4.1.3 Composition Measurements by Glass Number 13

$\begin{array}{ll}\text { 4.1.4 Measured versus Targeted Compositions } & 13\end{array}$

$\begin{array}{ll}\text { 4.1.5 } \mathrm{SO}_{4} \text { Retention or Solubility } & 14\end{array}$

4.2 A Statistical Review of the PCT Measurements 15

4.2.1 Measurements in Analytical Sequence 16

4.2.2 Results for the Samples of the Multi-Element Solution Standard 16

$\begin{array}{ll}\text { 4.2.3 Measurements by Glass Number } & 17\end{array}$

$\begin{array}{ll}\text { 4.2.4 Normalized PCT Results } & 17\end{array}$

4.2.5 Predicted versus Measured PCTs 26

4.3 Homogeneity 28

4.3.1 Visual Observations 31

4.3.2 XRD Results 31

5.0 PRACTICAL IMPACTS TO DWPF 35

6.0 SUMMARY 39

$\begin{array}{ll}7.0 \text { PATH FORWARD } & 42\end{array}$

8.0 REFERENCES $\quad 43$ 
WSRC-TR-2006-00006

Revision 0

APPENDIX A

46

APPENDIX B

55

APPENDIX C

75

APPENDIX D

154 


\section{LIST OF FIGURES}

Figure 2-1. Operating Windows for Select SB4 Glass Systems.......................................... 4

Figure 4-1. Targeted Versus Measured SO4 Values. .......................................................... 15

Figure 4-2. Normalized Boron Release for the 127" Phase 2 Glasses...................................... 24

Figure 4-3. Normalized Boron Release for the 40" Phase 2 Glasses...................................... 25

Figure 4-4. $\log$ NL [B] Versus $\Delta \mathrm{G}_{\mathrm{P}}$ for the Quenched Phase 2 Glasses................................ 27

Figure 4-5. $\log$ NL [B] Versus $\Delta \mathrm{G}_{\mathrm{P}}$ for the ccc Phase 2 Glasses........................................ 27

Figure 4-6. PCT Response of the ccc Phase 2 Glasses as a Function of Crystalline Type and WL.

Figure 5-1. $\log$ NL [B] (g/L) Versus Computed Nepheline Discriminator Value for the Phase 2

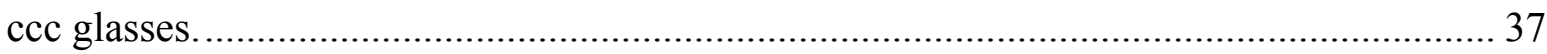

\section{LIST OF TABLES}

Table 2-1. Target Compositions of the SB4-1.6M-127” Based Phase 2 Glasses. (as wt\%'s)...... 6

Table 2-2. Target Compositions of the SB4-1.6M-40" Based Phase 2 Glasses. (as wt\%'s)........ 7

Table 4-1. Results from Samples of the Multi-Element Solution Standard. ............................. 16

Table 4-2. Normalized Release Values for the 127' SB3 Heel Based Phase 2 Glasses............. 19

Table 4-3. Normalized Release Values for the 40" SB3 Heel Based Phase 2 Glasses............... 21

Table 4-4. Visual and XRD Results for the SB4 Nepheline Phase 2 Glasses Based on the 1.6M,

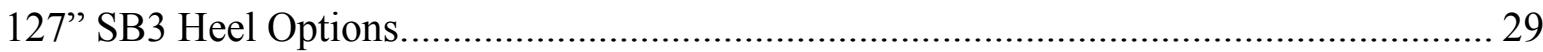

Table 4-5. Visual and XRD Results for the SB4 Nepheline Phase 2 Glasses Based on the 1.6M,

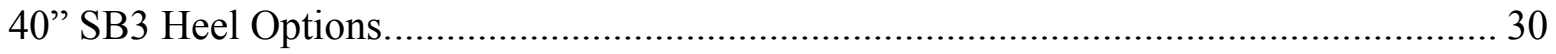




\section{LIST OF ACRONYMS}

\begin{tabular}{|c|c|}
\hline $\mathrm{AD}$ & Analytical Development \\
\hline ANOVA & analysis of variance \\
\hline ARM & Approved Reference Material \\
\hline ARP & Actinide Removal Process \\
\hline ASTM & American Society for Testing and Materials \\
\hline $\mathrm{bc}$ & bias-corrected \\
\hline $\mathrm{CBU}$ & Closure Business Unit \\
\hline $\operatorname{ccc}$ & centerline canister cooled \\
\hline $\mathrm{CPC}$ & Chemical Process Cell \\
\hline DWPF & Defense Waste Processing Facility \\
\hline EA & Environmental Assessment \\
\hline delGP or $\Delta \mathrm{G}_{\mathrm{P}}$ & preliminary glass dissolution estimator \\
\hline $\mathrm{g} / \mathrm{L}$ & grams per liter \\
\hline HLW & high-level waste \\
\hline ICP-AES & Inductively-Coupled Plasma - Atomic Emission Spectroscopy \\
\hline LM & lithium-metaborate \\
\hline MAR & Measurement Acceptability Region \\
\hline NL & normalized leachate (or normalized release) \\
\hline PCCS & Product Composition Control System \\
\hline PCT & Product Consistency Test \\
\hline $\mathrm{PF}$ & peroxide fusion \\
\hline PSAL & Process Science Analytical Laboratory \\
\hline ppm & parts per million \\
\hline SB3 & Sludge Batch 3 \\
\hline SB4 & Sludge Batch 4 \\
\hline SME & Slurry Mix Evaporator \\
\hline SRL & Savannah River Laboratory \\
\hline SRNL & Savannah River National Laboratory \\
\hline $\mathrm{T}_{\mathrm{L}}$ & liquidus temperature \\
\hline $\mathrm{U}_{\text {std }}$ & uranium standard \\
\hline WL & waste loading \\
\hline WQR & Waste Qualification Report \\
\hline XRD & $\mathrm{X}$-ray diffraction \\
\hline
\end{tabular}




\subsection{INTRODUCTION}

Crystallization (or devitrification) in nuclear waste glasses is an important consideration in terms of processing and product performance. With respect to the impact of crystallization on processability, the Defense Waste Processing Facility (DWPF) uses a liquidus temperature $\left(\mathrm{T}_{\mathrm{L}}\right)$ model (Brown et al., 2001) and an imposed $\mathrm{T}_{\mathrm{L}}$ limit for feed acceptability to avoid bulk devitrification within the melter. In terms of product quality or the durability of the waste form, the impact of devitrification depends on the type and extent of crystallization.

Although not summarized here, numerous studies (e.g., Bickford and Jantzen (1984 and 1986), Jantzen et al. (1984), Spilman et al. (1986), Marra and Jantzen (1993), Li et al. (1997), and Riley et al. (2001)) have assessed the devitrification potential of various high level waste (HLW) glasses and the impact on durability. In general, these studies agree that the impact of devitrification on durability is dependent upon the type and extent of crystallization. For example, a strong increase in glass dissolution (or decrease in durability) was observed in previous studies (Jantzen et al. (1984); Cicero et al. (1993); and Kim et al. (1995)) in glasses that formed aluminum-containing crystals, such as $\mathrm{NaAlSiO}_{4}$ (nepheline) and $\mathrm{LiAlSi}_{2} \mathrm{O}_{6}$, or crystalline $\mathrm{SiO}_{2}$. This is in contrast to the results from Bickford and Jantzen (1984) that indicated that the formation of spinel had little or no effect on the durability of Savannah River Laboratory (SRL) 165- or SRL 131-based glasses, while the formation of acmite produced a small but noticeable increase in the rate of dissolution of the matrix glass. The impact of devitrification on durability is complex and depends on several interrelated factors including the change in residual glass composition, the formation of internal stress or microcracks, and the preferential attack at the glass-crystal interface. As noted from previous experimental studies, perhaps the most significant effects are the type and extent (or fraction) of crystallization and the resulting change to the residual glass composition.

While it is well known that the addition of $\mathrm{Al}_{2} \mathrm{O}_{3}$ to borosilicate glasses generally enhances the durability of the waste form (through creation of network-forming tetrahedral $\mathrm{Na}^{+}-\left[\mathrm{AlO}_{4 / 2}\right]^{-}$pairs), nepheline formation, which depends in part on the $\mathrm{Al}_{2} \mathrm{O}_{3}$ content, can result in a severe deterioration of the chemical durability of the glass through residual glass compositional changes. The primary driver for the reduction in durability is the fact that nepheline removes three moles of glass forming oxides $\left(\mathrm{Al}_{2} \mathrm{O}_{3}\right.$ and $\left.2 \mathrm{SiO}_{2}\right)$ per each mole of $\mathrm{Na}_{2} \mathrm{O}$ from the continuous glass phase. Therefore, nepheline formation produces an $\mathrm{Al}_{2} \mathrm{O}_{3}$ and $\mathrm{SiO}_{2}$ deficient continuous glass matrix (relative to the same composition which is void of crystals) which reduces the durability of the final product. The magnitude of the reduction ultimately depends on the extent (e.g., volume \%) of crystallization.

Li et al. (1997 and 2003) indicated that sodium alumino-borosilicate glasses are prone to nepheline crystallization if their compositions projected on the $\mathrm{Na}_{2} \mathrm{O}-\mathrm{Al}_{2} \mathrm{O}_{3}-\mathrm{SiO}_{2}$ ternary fall within or close to the nepheline primary phase field. In particular, glasses with $\mathrm{SiO}_{2} /\left(\mathrm{SiO}_{2}+\mathrm{Na}_{2} \mathrm{O}+\mathrm{Al}_{2} \mathrm{O}_{3}\right)>0.62$, where the chemical formula stands for the mass fractions in the glass, do not tend to precipitate nepheline as their primary phase. The formation of nepheline and/or other aluminum/silicon-containing crystals is a potential in the Sludge Batch 4 (SB4) system due to the projected compositional views recently evaluated coupled with the frit development strategy. Compositional projections of SB4 by Lilliston (2005) indicate the sludge will be enriched in $\mathrm{Al}_{2} \mathrm{O}_{3}$ (relative to the $\mathrm{Al}_{2} \mathrm{O}_{3}$ concentrations of previous sludge batches processed through the DWPF). Peeler and Edwards (2005a) have identified candidate frits (ranging in $\mathrm{Na}_{2} \mathrm{O}$ concentration from $8-13 \%$ by mass) for the SB4 compositional projections. The combination of high $\mathrm{Al}_{2} \mathrm{O}_{3}$ and $\mathrm{Na}_{2} \mathrm{O}$ concentrations, coupled with lower $\mathrm{SiO}_{2}$ concentrations as waste loadings increase (given the primary source of $\mathrm{SiO}_{2}$ is from the frit), can lead to the formation of nepheline. 
Peeler et al. (2005a and 2005b) provided insight into the potential impact of nepheline formation for SB4 glasses based on the Lilliston (2005) compositional projections. In that study (referred to as Phase 1), twelve SB4-based glasses were fabricated (only two of which were prone to nepheline formation using the 0.62 value developed by $\mathrm{Li}$ et al. (2003) as a guide) and their durabilities measured. ${ }^{2}$ In terms of "acceptability," the results indicated that all of the study glasses (both quenched and centerline canister cooled (ccc)) were acceptable with respect to durability as defined by the Product Consistency Test (PCT) (ASTM 2002). More specifically, the normalized boron release (NL [B]) values for all the Phase 1 nepheline glasses were much lower than the Environmental Assessment (EA) glass value of $16.695 \mathrm{~g} / \mathrm{L}$ as defined by Jantzen et al. (1993). The most durable glass was NEPH-04 (quenched) with a NL [B] of 0.61 $\mathrm{g} / \mathrm{L}$, while the least durable glass was NEPH-01 (ccc) with an NL [B] of $2.47 \mathrm{~g} / \mathrm{L}$ (based on the measured composition).

The Phase 1 PCT results suggested that for the two glasses prone to nepheline formation (NEPH-01 and NEPH-02), a statistically significant difference in PCT response was observed between the quenched and ccc versions but the impact on durability was of little or no practical concern. When the PCT responses were coupled with the X-Ray Diffraction (XRD) results and/or visual observations, it was concluded that the formation of nepheline in these glasses did have a negative impact on durability. However, the impact was only a statistical difference - and not of practical significance or concern.

The results of the Phase 1 study not only suggested that the 0.62 value appeared to be a reasonable guide to monitor alumino-borosilicate based glass systems with respect to potential nepheline formation, but also that the presence of nepheline, although statistically significant, has little or no practical impact in the SB4 system on durability as measured by the PCT. This latter statement must be qualified to some extent given that only two glasses were selected which were actually prone to nepheline formation based on the general guide and that the volume $\%$ of nepheline formed based on XRD results was relatively low $(\sim 0.5$ vol\%). Given the waste loadings (WLs) for the Phase 1 glasses were limited to $40 \%$, if higher WLs were considered, the potential for nepheline formation (and potentially the vol\%) could increase and the likelihood of observing a significant and practical difference in PCT response could be realized.

Since the issuance of the Phase 1 report, revised compositional projections from the Closure Business Unit (CBU) for SB4 have been issued (Elder 2005a, Elder 2005b). These revised compositional projections were framed around three decision areas: the sodium molarity of the sludge (at values of $1 \mathrm{M}$ $\mathrm{Na}$ and $1.6 \mathrm{M} \mathrm{Na}$ ), the Sludge Batch 3 (SB3) heel that will be included in the batch (expressed in inches of SB3 sludge with values of 0, 40, and 127'), and the introduction of an Actinide Removal Process (ARP) stream into the sludge (which is represented by six options: no ARP, ARP-A, ARP-E, ARP-K, ARP-M, and ARP-V). In response to these revised projections, Peeler and Edwards (2005b) have identified candidate frits (via a paper study approach) whose operating windows (i.e., waste loading intervals that meet Product Composition Control System (PCCS) Measurement Acceptability Region (MAR) criteria) are robust to and/or selectively optimal for these sludge options. The results of that paper study indicated that candidate frits are available for the various SB4 options which provide relatively large operating windows. Besides the revised compositional projections, the primary difference between this second assessment (Peeler and Edwards 2005b) and the first (Peeler and Edwards 2005a) was the fact that the 0.62 nepheline value was used as a screening tool to evaluate the potential impact of nepheline formation on the projected operating windows in the most recent assessment. The results of activating the nepheline discriminator (Peeler and Edwards 2005b) indicated that access to higher WLs for almost all frit - sludge options was possible assuming that the nepheline discriminator value was "challenged." That is, a relatively large WL interval was available in which all PCCS MAR criteria were satisfied except for the nepheline discriminator value. This suggested possible issues associated with crystallization and

\footnotetext{
2 Both NEPH-01 and NEPH-02 had nepheline discriminator values of approximately 0.61 - just below the 0.62 cut-
} off value as defined by Li et al. (2003). 
ultimately a possible impact on durability. In response to this finding, Edwards and Peeler (2005) identified 28 Phase 2 glasses that intentionally challenged the "nepheline discriminator" value based on the 1.6M Na, 40" and 1.6M Na, 127" sludge options as defined by Elder (2005a and 2005b). The Phase 2 glasses were selected to complement the Phase 1 study (Peeler et al. 2005b) by continuing the investigation into the ability of the nepheline constraint to predict the occurrence of this primary phase for SB4 glasses and the potential for such a crystalline phase to have an impact on durability. In general, the Phase 2 glasses were selected to cover WLs over which nepheline was the only criterion restricting acceptability (see Section 2.0 for more details). It should be noted that the primary difference between the Phase 1 and Phase 2 nepheline studies is that Phase 2 "pushes the envelope" or challenges the nepheline predictor for all glasses - not just a few select glasses as in Phase 1. In order to meet this objective, WLs of $\sim 40 \%$ or higher were targeted for the Phase 2 glasses where $40 \%$ was the maximum WL used during Phase 1. As previously mentioned, as WL increases, the probability of nepheline formation increases given the $\mathrm{Al}_{2} \mathrm{O}_{3}$ and $\mathrm{Na}_{2} \mathrm{O}$ concentrations increase and $\mathrm{SiO}_{2}$ concentrations decrease.

The Phase 2 glasses were batched and fabricated using standard procedures. Visual observations and other analytical techniques were used, as needed, to assess the presence of crystals and specifically, nepheline. The durability of these glasses (both quenched and ccc versions) were measured using the ASTM PCT (ASTM 2002). This report documents the experimental results of the Phase 2 nepheline study.

An overview of the Phase 2 glass selection process is provided in Section 2.0. The experimental approach is described in Section 3.0. In Section 4.0, the results of the study are presented and discussed. More specifically, an assessment of the target versus measured compositions is provided to ensure the objectives of the task can be met. In addition, the PCT results for both quenched and ccc glasses are presented for each study glass. The PCT results are discussed in terms of acceptability and model predictability. The results of both visual and XRD analyses are also presented and discussed in relation to the objectives of the task. The impacts to DWPF are discussed in Section 5.0. Section 6.0 and Section 7.0 provide a summary and path forward, respectively.

The results of this study will provide valuable input for the frit development efforts and subsequent feedback to the CBU regarding the relative viability of the various SB4 options under consideration. Specifically, if the formation of nepheline for SB4 glasses is found through this study to have an impact on durability that is overly detrimental, then candidate frits, that lessen the likelihood of the formation of nepheline over an interval of waste loadings of interest to the DWPF, would move up the list of preferred frits. On the other hand, if the presence of nepheline has no appreciable, adverse impact on durability, then as decisions regarding the viability of the SB4 options and the down select of candidate frits are pursued, little weight will be given to minimizing the likelihood of nepheline and the decisions will be dominated by waste throughput criteria. 


\subsection{GLASS SELECTION}

Edwards and Peeler (2005) provide a detailed description of the selection process for the twenty-eight Phase 2 glasses. For completeness, a brief overview is provided below. Fourteen of the 28 Phase 2 glasses were based on the nominal $1.6 \mathrm{M} \mathrm{Na}^{+}$with a 40 " SB3 heel option while the other 14 glasses were based on the nominal 1.6 $\mathrm{M} \mathrm{Na}^{+}$with a 127" SB3 heel - both "sludge-only" based flowsheets with no addition of ARP. Each of these nominal sludge options was combined with frits 320,417, 418, 425, and 426 at WLs from 25 through $60 \%$ (in WL increments of 1\%) to provide the initial set of glass compositions from which the twenty-eight nepheline glasses were selected. Figure 2-1 summarizes the MAR-based operating windows for these SB4 glass systems. For this plot the interpretation of the colors is as follows: red indicates WLs that are restricted by PCCS, blue indicates WLs that are "restricted" only by the concern for the potential for the formation of a nepheline primary phase field using a 0.62 value, and green indicates WLs that are acceptable by PCCS.

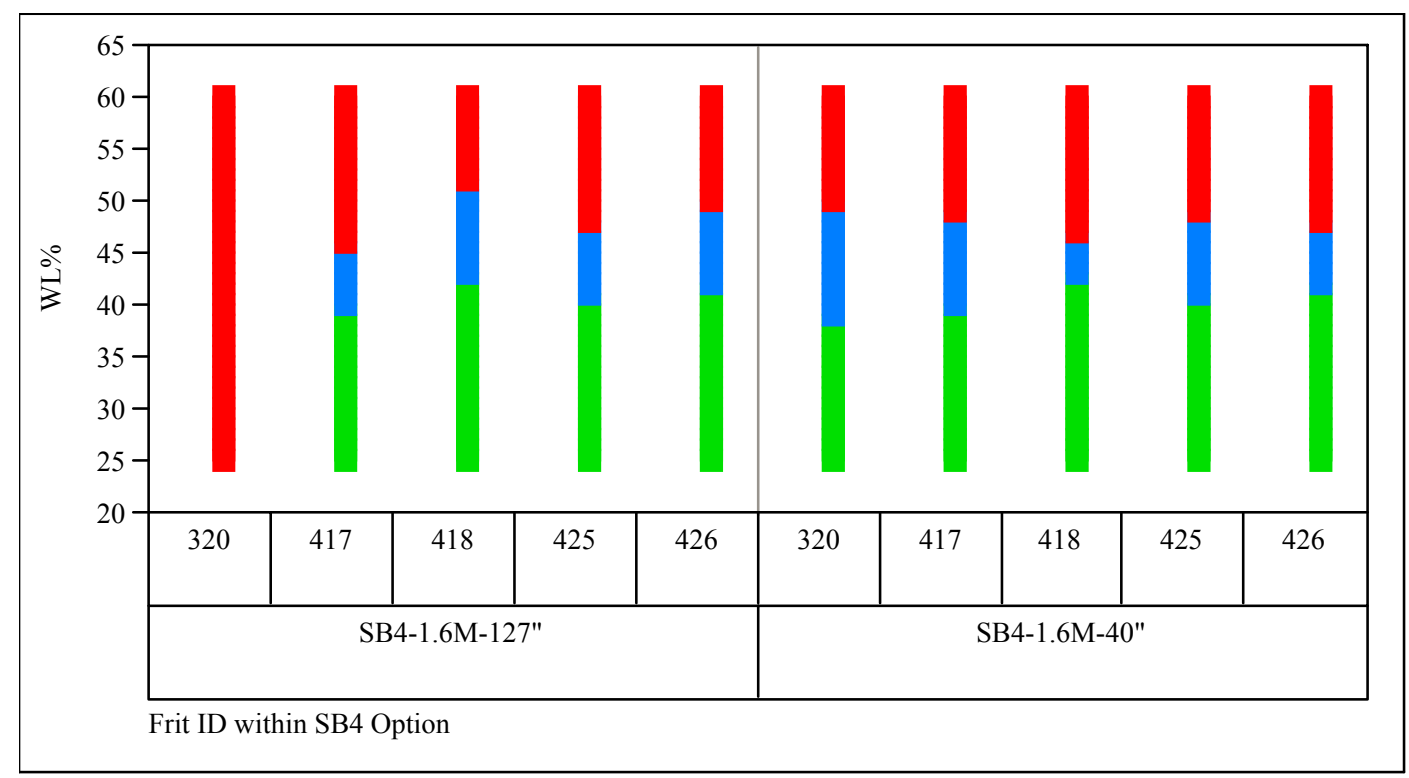

Figure 2-1. Operating Windows for Select SB4 Glass Systems.

With the exception of the Frit 320 - 1.6M-127" option, the plots indicate that the operating window for each system would be expanded if the nepheline constraint were challenged (i.e., the "blue" WL range). The MAR-based assessment was used for selecting the Phase 2 nepheline study glasses - glasses that were prone to nepheline formation without failing any PCCS constraint. In general (and when applicable), three glasses spanning the "blue WL range" were selected for each SB4 - frit system. Within a specific frit - SB4 system, the lowest WL glass selected represents a transition from a non-nepheline prone glass ("green" region) to a glass that is anticipated to form nepheline ("blue" region). These lower WL glasses have nepheline discriminator values falling just below the 0.62 guide. On the opposite end of the WL spectrum, the maximum WL selected for the Phase 2 glasses (within each specific frit - sludge system) targets the transition from "blue" to "red" which suggests that not only is nepheline a concern but a PCCS property (such as $T_{L}$, viscosity, or durability) is close to failing its MAR criterion. The maximum WL targeted for the Phase 2 glasses represents the highest WL that is still considered acceptable by all PCCS criteria but does not satisfy the nepheline discriminator value. In fact, the glasses targeting the higher WLs for all frit - sludge systems represent the lowest nepheline discriminator values which could 
translate into a higher propensity to form nepheline (and/or a higher volume \%) and ultimately a more significant impact on durability. A third glass was selected at an intermediate WL within each frit sludge option (when appropriate).

The glass compositions generated by this process are given in Table 2-1 and Table 2-2. Table 2-1 summarizes the 14 glasses based on the 127" SB3 heel option. Table 2-2 summarizes the 14 glasses based on the 40" SB3 heel option. Unique identifiers for these glasses are provided in the first row of each table, and the value of the nepheline discriminator for each glass is also included in these tables. As previously mentioned, within a specific frit - sludge system, the nepheline discriminator value decreases with increased WLs.

For the Frit $320-1.6 \mathrm{M}, 127$ " option, the entire WL interval from $25-60 \%$ is restricted by predictions of durability given the high content of $\mathrm{Na}_{2} \mathrm{O}$ in the sludge as well as the frit. For this system, two glasses were selected - NEPH2-13 and NEPH2-14. These glasses target 39 and 42\% WL and represent the WL interval which challenges nepheline when one ignores predictions of durability. These two glasses will provide insight into possible conservatism in the durability model even with the proposed durability limits as defined by Edwards, Peeler, and Marra (2003). For the Frit 418 - 1.6M, 40" SB3 heel option, the WL interval over which nepheline was challenged was 43 - 46\% WL (i.e., NEPH2-39 and NEPH2-40, respectively). Therefore selecting a third, intermediate WL for this system was not seen to be of much value. 
Table 2-1. Target Compositions of the SB4-1.6M-127" Based Phase 2 Glasses.

(as wt\%'s)

\begin{tabular}{|c|c|c|c|c|c|c|c|c|c|c|c|c|c|c|}
\hline \# & $\begin{array}{c}\text { NEPH2- } \\
13\end{array}$ & $\begin{array}{c}\text { NEPH2- } \\
14\end{array}$ & $\begin{array}{c}\text { NEPH2- } \\
15\end{array}$ & $\begin{array}{c}\text { NEPH2- } \\
16\end{array}$ & $\begin{array}{c}\text { NEPH2- } \\
17\end{array}$ & $\begin{array}{c}\text { NEPH2- } \\
18\end{array}$ & $\begin{array}{c}\text { NEPH2- } \\
19\end{array}$ & $\begin{array}{c}\text { NEPH2- } \\
20\end{array}$ & $\begin{array}{c}\text { NEPH2- } \\
21\end{array}$ & $\begin{array}{c}\text { NEPH2- } \\
22\end{array}$ & $\begin{array}{c}\text { NEPH2- } \\
23\end{array}$ & $\begin{array}{c}\text { NEPH2- } \\
24\end{array}$ & $\begin{array}{c}\text { NEPH2- } \\
25\end{array}$ & $\begin{array}{c}\text { NEPH2- } \\
26\end{array}$ \\
\hline Frit ID & 320 & 320 & 417 & 417 & 417 & 425 & 425 & 425 & 426 & 426 & 426 & 418 & 418 & 418 \\
\hline$\% \mathrm{WL}$ & 39 & 42 & 40 & 43 & 45 & 41 & 44 & 47 & 42 & 46 & 49 & 43 & 47 & 51 \\
\hline nepheline & 0.617 & 0.596 & 0.618 & 0.596 & 0.581 & 0.619 & 0.597 & 0.573 & 0.620 & 0.589 & 0.565 & 0.620 & 0.588 & 0.556 \\
\hline $\mathrm{Al}_{2} \mathrm{O}_{3}$ & 10.210 & 10.995 & 10.472 & 11.257 & 11.781 & 10.734 & 11.519 & 12.304 & 10.995 & 12.043 & 12.828 & 11.257 & 12.304 & 13.352 \\
\hline $\mathrm{B}_{2} \mathrm{O}_{3}$ & 4.880 & 4.640 & 4.800 & 4.560 & 4.400 & 4.720 & 4.480 & 4.240 & 4.640 & 4.320 & 4.080 & 4.560 & 4.240 & 3.920 \\
\hline $\mathrm{BaO}$ & 0.053 & 0.057 & 0.054 & 0.058 & 0.061 & 0.055 & 0.059 & 0.064 & 0.057 & 0.062 & 0.066 & 0.058 & 0.064 & 0.069 \\
\hline $\mathrm{CaO}$ & 0.776 & 0.836 & 0.796 & 0.856 & 0.896 & 0.816 & 0.876 & 0.936 & 0.836 & 0.916 & 0.976 & 0.856 & 0.936 & 1.015 \\
\hline $\mathrm{Ce}_{2} \mathrm{O}_{3}$ & 0.073 & 0.078 & 0.075 & 0.080 & 0.084 & 0.076 & 0.082 & 0.088 & 0.078 & 0.086 & 0.091 & 0.080 & 0.088 & 0.095 \\
\hline $\mathrm{Cr}_{2} \mathrm{O}_{3}$ & 0.091 & 0.098 & 0.093 & 0.100 & 0.105 & 0.095 & 0.102 & 0.109 & 0.098 & 0.107 & 0.114 & 0.100 & 0.109 & 0.119 \\
\hline $\mathrm{CuO}$ & 0.028 & 0.031 & 0.029 & 0.031 & 0.033 & 0.030 & 0.032 & 0.034 & 0.031 & 0.033 & 0.036 & 0.031 & 0.034 & 0.037 \\
\hline $\mathrm{Fe}_{2} \mathrm{O}_{3}$ & 8.648 & 9.313 & 8.870 & 9.535 & 9.979 & 9.092 & 9.757 & 10.422 & 9.313 & 10.200 & 10.866 & 9.535 & 10.422 & 11.309 \\
\hline $\mathrm{K} 2 \mathrm{O}$ & 0.545 & 0.587 & 0.559 & 0.601 & 0.629 & 0.573 & 0.615 & 0.657 & 0.587 & 0.643 & 0.685 & 0.601 & 0.657 & 0.713 \\
\hline $\mathrm{La}_{2} \mathrm{O}_{3}$ & 0.031 & 0.034 & 0.032 & 0.035 & 0.036 & 0.033 & 0.035 & 0.038 & 0.034 & 0.037 & 0.039 & 0.035 & 0.038 & 0.041 \\
\hline $\mathrm{Li}_{2} \mathrm{O}$ & 4.880 & 4.640 & 4.800 & 4.560 & 4.400 & 4.720 & 4.480 & 4.240 & 4.640 & 4.320 & 4.080 & 4.560 & 4.240 & 3.920 \\
\hline $\mathrm{MgO}$ & 0.548 & 0.590 & 0.562 & 0.604 & 0.633 & 0.576 & 0.618 & 0.661 & 0.590 & 0.647 & 0.689 & 0.604 & 0.661 & 0.717 \\
\hline $\mathrm{MnO}$ & 1.901 & 2.047 & 1.949 & 2.095 & 2.193 & 1.998 & 2.144 & 2.290 & 2.047 & 2.242 & 2.388 & 2.095 & 2.290 & 2.485 \\
\hline $\mathrm{Na}_{2} \mathrm{O}$ & 17.695 & 18.133 & 17.241 & 17.709 & 18.021 & 16.807 & 17.305 & 17.804 & 16.393 & 17.098 & 17.626 & 15.999 & 16.744 & 17.488 \\
\hline $\mathrm{NiO}$ & 1.192 & 1.284 & 1.223 & 1.314 & 1.375 & 1.253 & 1.345 & 1.437 & 1.284 & 1.406 & 1.498 & 1.314 & 1.437 & 1.559 \\
\hline $\mathrm{PbO}$ & 0.069 & 0.074 & 0.071 & 0.076 & 0.080 & 0.072 & 0.078 & 0.083 & 0.074 & 0.081 & 0.087 & 0.076 & 0.083 & 0.090 \\
\hline $\mathrm{SO}_{4}$ & 0.417 & 0.449 & 0.428 & 0.460 & 0.481 & 0.439 & 0.471 & 0.503 & 0.449 & 0.492 & 0.524 & 0.460 & 0.503 & 0.546 \\
\hline $\mathrm{SiO}_{2}$ & 44.964 & 42.884 & 44.871 & 42.761 & 41.355 & 44.758 & 42.618 & 40.478 & 44.624 & 41.731 & 39.562 & 44.471 & 41.538 & 38.605 \\
\hline $\mathrm{ThO}_{2}$ & 0.015 & 0.016 & 0.015 & 0.016 & 0.017 & 0.016 & 0.017 & 0.018 & 0.016 & 0.017 & 0.019 & 0.016 & 0.018 & 0.019 \\
\hline $\mathrm{TiO}_{2}$ & 0.007 & 0.008 & 0.008 & 0.008 & 0.008 & 0.008 & 0.008 & 0.009 & 0.008 & 0.009 & 0.009 & 0.008 & 0.009 & 0.010 \\
\hline $\mathrm{U}_{3} \mathrm{O}_{8}$ & 2.836 & 3.054 & 2.908 & 3.126 & 3.272 & 2.981 & 3.199 & 3.417 & 3.054 & 3.345 & 3.563 & 3.126 & 3.417 & 3.708 \\
\hline $\mathrm{ZnO}$ & 0.042 & 0.045 & 0.043 & 0.046 & 0.048 & 0.044 & 0.047 & 0.050 & 0.045 & 0.049 & 0.052 & 0.046 & 0.050 & 0.055 \\
\hline $\mathrm{ZrO}_{2}$ & 0.100 & 0.107 & 0.102 & 0.110 & 0.115 & 0.105 & 0.112 & 0.120 & 0.107 & 0.117 & 0.125 & 0.110 & 0.120 & 0.130 \\
\hline
\end{tabular}


Table 2-2. Target Compositions of the SB4-1.6M-40" Based Phase 2 Glasses.

(as wt\%'s)

\begin{tabular}{|c|c|c|c|c|c|c|c|c|c|c|c|c|c|c|}
\hline Glass ID \# & $\begin{array}{c}\text { NEPH2- } \\
27\end{array}$ & $\begin{array}{c}\text { NEPH2- } \\
28\end{array}$ & $\begin{array}{c}\text { NEPH2- } \\
29\end{array}$ & $\begin{array}{c}\text { NEPH2- } \\
30\end{array}$ & $\begin{array}{c}\text { NEPH2- } \\
31\end{array}$ & $\begin{array}{c}\text { NEPH2- } \\
32\end{array}$ & $\begin{array}{c}\text { NEPH2- } \\
33\end{array}$ & $\begin{array}{c}\text { NEPH2- } \\
34\end{array}$ & $\begin{array}{c}\text { NEPH2- } \\
35\end{array}$ & $\begin{array}{c}\text { NEPH2- } \\
36\end{array}$ & $\begin{array}{c}\text { NEPH2- } \\
37\end{array}$ & $\begin{array}{c}\text { NEPH2- } \\
38\end{array}$ & $\begin{array}{c}\text { NEPH2- } \\
39\end{array}$ & $\begin{array}{c}\text { NEPH2- } \\
40\end{array}$ \\
\hline Frit ID & 320 & 320 & 320 & 417 & 417 & 417 & 425 & 425 & 425 & 426 & 426 & 426 & 418 & 418 \\
\hline$\% \mathrm{WL}$ & 39 & 44 & 49 & 40 & 44 & 48 & 41 & 45 & 48 & 42 & 45 & 47 & 43 & 46 \\
\hline nepheline & 0.615 & 0.579 & 0.541 & 0.616 & 0.587 & 0.556 & 0.617 & 0.587 & 0.563 & 0.618 & 0.594 & 0.579 & 0.618 & 0.594 \\
\hline $\mathrm{Al}_{2} \mathrm{O}_{3}$ & 11.641 & 13.133 & 14.626 & 11.939 & 13.133 & 14.327 & 12.238 & 13.432 & 14.327 & 12.536 & 13.432 & 14.029 & 12.835 & 13.730 \\
\hline $\mathrm{B}_{2} \mathrm{O}_{3}$ & 4.880 & 4.480 & 4.080 & 4.800 & 4.480 & 4.160 & 4.720 & 4.400 & 4.160 & 4.640 & 4.400 & 4.240 & 4.560 & 4.320 \\
\hline $\mathrm{BaO}$ & 0.056 & 0.063 & 0.071 & 0.058 & 0.063 & 0.069 & 0.059 & 0.065 & 0.069 & 0.060 & 0.065 & 0.068 & 0.062 & 0.066 \\
\hline $\mathrm{CaO}$ & 0.749 & 0.845 & 0.941 & 0.769 & 0.845 & 0.922 & 0.788 & 0.865 & 0.922 & 0.807 & 0.865 & 0.903 & 0.826 & 0.884 \\
\hline $\mathrm{Ce}_{2} \mathrm{O}_{3}$ & 0.075 & 0.085 & 0.095 & 0.077 & 0.085 & 0.093 & 0.079 & 0.087 & 0.093 & 0.081 & 0.087 & 0.091 & 0.083 & 0.089 \\
\hline $\mathrm{Cr}_{2} \mathrm{O}_{3}$ & 0.098 & 0.110 & 0.123 & 0.100 & 0.110 & 0.120 & 0.103 & 0.113 & 0.120 & 0.105 & 0.113 & 0.118 & 0.108 & 0.115 \\
\hline $\mathrm{CuO}$ & 0.029 & 0.033 & 0.037 & 0.030 & 0.033 & 0.036 & 0.031 & 0.034 & 0.036 & 0.031 & 0.034 & 0.035 & 0.032 & 0.034 \\
\hline $\mathrm{Fe}_{2} \mathrm{O}_{3}$ & 8.330 & 9.398 & 10.466 & 8.544 & 9.398 & 10.252 & 8.757 & 9.612 & 10.252 & 8.971 & 9.612 & 10.039 & 9.184 & 9.825 \\
\hline $\mathrm{K} 2 \mathrm{O}$ & 0.669 & 0.755 & 0.840 & 0.686 & 0.755 & 0.823 & 0.703 & 0.772 & 0.823 & 0.720 & 0.772 & 0.806 & 0.737 & 0.789 \\
\hline $\mathrm{La}_{2} \mathrm{O}_{3}$ & 0.032 & 0.036 & 0.040 & 0.033 & 0.036 & 0.039 & 0.033 & 0.037 & 0.039 & 0.034 & 0.037 & 0.038 & 0.035 & 0.037 \\
\hline $\mathrm{Li}_{2} \mathrm{O}$ & 4.880 & 4.480 & 4.080 & 4.800 & 4.480 & 4.160 & 4.720 & 4.400 & 4.160 & 4.640 & 4.400 & 4.240 & 4.560 & 4.320 \\
\hline $\mathrm{MgO}$ & 0.415 & 0.468 & 0.522 & 0.426 & 0.468 & 0.511 & 0.436 & 0.479 & 0.511 & 0.447 & 0.479 & 0.500 & 0.458 & 0.490 \\
\hline $\mathrm{MnO}$ & 1.872 & 2.112 & 2.352 & 1.920 & 2.112 & 2.304 & 1.968 & 2.160 & 2.304 & 2.016 & 2.160 & 2.256 & 2.064 & 2.208 \\
\hline $\mathrm{Na}_{2} \mathrm{O}$ & 16.514 & 17.093 & 17.671 & 16.030 & 16.533 & 17.036 & 15.565 & 16.108 & 16.516 & 15.121 & 15.558 & 15.850 & 14.697 & 15.164 \\
\hline $\mathrm{NiO}$ & 1.358 & 1.532 & 1.706 & 1.393 & 1.532 & 1.672 & 1.428 & 1.567 & 1.672 & 1.463 & 1.567 & 1.637 & 1.498 & 1.602 \\
\hline $\mathrm{PbO}$ & 0.076 & 0.086 & 0.096 & 0.078 & 0.086 & 0.094 & 0.080 & 0.088 & 0.094 & 0.082 & 0.088 & 0.092 & 0.084 & 0.090 \\
\hline $\mathrm{SO}_{4}$ & 0.402 & 0.453 & 0.505 & 0.412 & 0.453 & 0.495 & 0.423 & 0.464 & 0.495 & 0.433 & 0.464 & 0.484 & 0.443 & 0.474 \\
\hline $\mathrm{SiO}_{2}$ & 44.987 & 41.524 & 38.061 & 44.894 & 42.084 & 39.273 & 44.782 & 41.931 & 39.793 & 44.649 & 42.481 & 41.036 & 44.497 & 42.299 \\
\hline $\mathrm{ThO}_{2}$ & 0.016 & 0.018 & 0.020 & 0.017 & 0.018 & 0.020 & 0.017 & 0.019 & 0.020 & 0.017 & 0.019 & 0.020 & 0.018 & 0.019 \\
\hline $\mathrm{TiO}_{2}$ & 0.007 & 0.008 & 0.009 & 0.007 & 0.008 & 0.009 & 0.008 & 0.008 & 0.009 & 0.008 & 0.008 & 0.009 & 0.008 & 0.009 \\
\hline $\mathrm{U}_{3} \mathrm{O}_{8}$ & 2.765 & 3.120 & 3.474 & 2.836 & 3.120 & 3.403 & 2.907 & 3.190 & 3.403 & 2.978 & 3.190 & 3.332 & 3.049 & 3.261 \\
\hline $\mathrm{ZnO}$ & 0.042 & 0.048 & 0.053 & 0.043 & 0.048 & 0.052 & 0.044 & 0.049 & 0.052 & 0.045 & 0.049 & 0.051 & 0.046 & 0.050 \\
\hline $\mathrm{ZrO}_{2}$ & 0.107 & 0.120 & 0.134 & 0.109 & 0.120 & 0.131 & 0.112 & 0.123 & 0.131 & 0.115 & 0.123 & 0.128 & 0.117 & 0.126 \\
\hline
\end{tabular}




\subsection{EXPERIMENTAL}

\subsection{Glass Fabrication}

Each Phase 2 glass, NEPH2-13 through NEPH2-40, was prepared from the proper proportions of reagent-grade metal oxides, carbonates, $\mathrm{H}_{3} \mathrm{BO}_{3}$, and salts in 150-g batches. Once batched (SRNL 2002a), the glasses were melted using Savannah River National Laboratory (SRNL) technical procedure "Glass Melting" (SRNL 2002b). In general, the raw materials were thoroughly mixed and placed into a $95 \%$ Platinum $/ 5 \%$ Gold $250-\mathrm{mL}$ crucible. The batch was placed into a hightemperature furnace at the target melt temperature of $1150^{\circ} \mathrm{C}$. After an isothermal hold at $1150^{\circ} \mathrm{C}$ for $1.0 \mathrm{~h}$, the crucible was removed, and the glass was poured onto a clean stainless steel plate and allowed to air cool (quench). The glass pour patty was used as a sampling stock for the various property measurements (i.e., chemical composition and durability).

In order to bound the effects of thermal history on the product performance, approximately $25 \mathrm{~g}$ of each glass was heat-treated to simulate cooling along the centerline of a DWPF-type canister (Marra and Jantzen, 1993). This cooling regime is commonly referred to as the centerline canister cooled (ccc) curve. ${ }^{3}$ Visual observations on both quenched and ccc glasses were documented. ${ }^{4}$

\subsection{Property Measurements}

This section provides a general discussion of the chemical composition analyses, the PCTs, and the XRD analyses of the nepheline study glasses.

\subsubsection{Compositional Analysis}

To confirm that the "as-fabricated" glasses corresponded to the defined target compositions, a representative sample from each glass was submitted to the SRNL Process Science Analytical Laboratory (PSAL) for chemical analysis under the auspices of an analytical plan. The plan (see Appendix A) identified the cations to be analyzed and the dissolution techniques (i.e., sodium peroxide fusion $[\mathrm{PF}]$ and lithium-metaborate $[\mathrm{LM}]$ ) to be used. The samples prepared by LM were used to measure for barium $(\mathrm{Ba})$, calcium $(\mathrm{Ca})$, cerium $(\mathrm{Ce})$, chromium $(\mathrm{Cr})$, copper $(\mathrm{Cu})$, potassium $(\mathrm{K})$, lanthanum $(\mathrm{La})$, magnesium $(\mathrm{Mg})$, sodium $(\mathrm{Na})$, lead $(\mathrm{Pb})$, sulfur $(\mathrm{S})$, thorium $(\mathrm{Th})$, titanium $(\mathrm{Ti})$, zinc $(\mathrm{Zn})$, and zirconium $(\mathrm{Zr})$ concentrations. Samples prepared by PF were used to measure for aluminum (Al), boron $(\mathrm{B})$, iron $(\mathrm{Fe})$, lithium (Li), manganese $(\mathrm{Mn})$, nickel (Ni), silicon ( $\mathrm{Si}$ ), and uranium (U). Each glass was prepared in duplicate for each cation dissolution technique (PF and LM). All of the prepared samples were analyzed (twice for each element of interest) by Inductively Coupled Plasma - Atomic Emission Spectroscopy (ICP-AES) (with the instrumentation being re-calibrated between the duplicate analyses). The analytical plan was developed in such a way as to provide the opportunity to evaluate potential sources of error. Glass standards were also intermittently run to assess the performance of the ICP-AES over the course of these analyses.

\footnotetext{
3 With respect to DWPF processing, there are two extremes in terms of the thermal history the glass being poured into the canister could experience. A certain fraction of the glass would be quenched as it contacts the DWPF canister and cools rapidly. On the other end of the spectrum, a certain fraction of the glass will experience a relatively slow cooling which occurs along the centerline of the canister as described by Marra and Jantzen (1993).

4 WSRC-NB-2005-00054 contains the visual observations of the quenched and ccc glasses as well as the results of the $\mathrm{XRD}$ and PCT analyses for the Phase 2 glasses.
} 
Although not the primary focus of the Phase 2 study, $\mathrm{SO}_{4}$ solubility is a secondary concern for this SB4 study. The compositional analysis, coupled with the visual observations of the asfabricated glasses, will serve as primary indicators that the current $0.6 \mathrm{wt} \% \mathrm{SO}_{4}$ limit (established for the Frit 418 - SB3 system by Peeler et al. (2004)) is still applicable for SB4. Previous tests have suggested that the use of reagent grade raw materials is conservative with respect to $\mathrm{SO}_{4}$ retention and/or volatility. ${ }^{5}$ Therefore, the ability of the Phase 2 glasses to retain the targeted $\mathrm{SO}_{4}$ concentrations (especially at the higher WLs) will provide valuable insight into the applicability of the $\mathrm{SO}_{4}$ limit for SB4. Although the concentrations in the Phase 2 glasses do not exceed the $0.6 \mathrm{wt} \%$ limit, the results when coupled with the preliminary SB4 results presented by Lorier et al. (2005) will provide part of the technical basis for the $\mathrm{SO}_{4}$ limit for SB4. As previously mentioned, both visual observations (i.e., the formation of a salt layer on the surface of the glass being indicative of exceeding the $\mathrm{SO}_{4}$ limit) and a comparison of measured versus targeted $\mathrm{SO}_{4}$ concentrations in glass will be the primary tools to support this assessment. From Table 2-1 and Table 2-2 the targeted $\mathrm{SO}_{4}$ concentrations in the Phase 2 glasses range from 0.402 (in NEPH2-27) to $0.546 \mathrm{wt} \%$ (NEPH2-26).

\subsubsection{Product Consistency Test (PCT)}

The PCT was performed in triplicate on each quenched and each ccc Phase 2 glass to assess chemical durability using technical procedure "Standard Test Methods for Determining Chemical Durability of Nuclear Waste Glasses: The Product Consistency Test (PCT)" (ASTM 2002). Also included in this experimental test matrix was the EA glass (Jantzen et al., 1993), the Approved Reference Material (ARM) glass, and blanks from the sample cleaning batch. Samples were ground, washed, and prepared according to procedure (ASTM 2002). Fifteen milliliters of Type I American Society for Testing and Materials (ASTM) water were added to $1.5 \mathrm{~g}$ of glass in stainless steel vessels. The vessels were closed, sealed, and placed in an oven at $90 \pm 2{ }^{\circ} \mathrm{C}$ where the samples were maintained for 7 days. The resulting solutions (once cooled) were sampled (filtered and acidified), labeled (according to the analytical plan), and analyzed under the auspices of two analytical plans (see Appendix B). ${ }^{6}$ The overall philosophy of the plans was to provide an opportunity to assess the consistency (repeatability) of the PCT and analytical procedures in an effort to evaluate chemical durability of the Phase 2 glasses. Normalized release rates were calculated based on targeted, measured, and bias-corrected (bc) compositions using the average of the logs of the leachate concentrations.

\subsubsection{X-Ray Diffraction (XRD) Analysis}

Although visual observations for crystallization were performed and documented, representative samples for all ccc Phase 2 glasses were submitted to the SRNL Analytical Development Section (ADS) for XRD analysis. ${ }^{7}$ Samples were run under conditions allowing a detection limit of approximately $0.5 \mathrm{vol} \%$. That is, if crystals (or undissolved solids) are present at $0.5 \mathrm{vol} \%$ (or

\footnotetext{
${ }^{5}$ Previous results have indicated that the use of raw materials (reagent grade chemicals) to produce the glasses minimizes $\mathrm{SO}_{4}$ volatilization during the fabrication process. This approach will provide a conservative measure of $\mathrm{SO}_{4}$ retention in the glass as volatilization is anticipated in slurry-fed melters. ${ }^{6}$ One analytical plan (SRNL-SCS-2005-00041) was developed to assess the PCT solutions resulting from the 127" SB3 heel based glasses (shown in Table 2-1); while a second plan (SRNL-SCS-2005-00044) was developed for the 40" SB3 heel glasses (shown in Table 2-2). Also provided in Appendix B is a third analytical plan (SRNL-SCS-2005-00051) which was developed to support the remeasurement of select Phase 2 glasses as will be discussed in Section 4.2.

${ }^{7}$ Based on visual observations and the PCT responses, the quenched glasses were not submitted for XRD analyses.
} 
greater), the diffractometer will not only be capable of detecting the crystals but will also allow a qualitative measure (i.e., determine the type of crystal[s] present). Otherwise, a characteristically high background devoid of crystalline spectral lines indicates that the glass product is amorphous (suggesting either a completely amorphous product or that the degree of crystallization is below the detection limit). 


\subsection{RESULTS}

In this section, the compositional assessment (targeted versus measured), the durability response (as measured by the PCT), and the XRD results are presented. Initially, the compositional results are presented to determine if the measured compositions are in-line with the targeted compositions (i.e., no significant batching errors were evident). The durability information for both quenched and ccc versions of each Phase 2 glass is then presented and discussed given it is the primary response variable of interest. The PCT results should provide a marker for those systems in which nepheline formation was likely. Significant differences observed between quenched and ccc versions of each glass will be highlighted and compared to the corresponding nepheline discriminator value. In addition, the acceptability of the Phase 2 glasses (measured releases compared to the EA glass benchmark) as well as the predictability of the glasses are also discussed. Finally, visual and XRD results are presented to provide a technical basis from which the impact (or lack thereof) of crystallization on durability can be assessed.

\subsection{A Statistical Review}

of the Chemical Composition Measurements for the Phase 2 Nepheline Glasses In this section, the measured versus targeted compositions of the 28 Phase 2 nepheline study glasses (NEPH2-13 through NEPH2-40) are presented and compared. The targeted compositions for these glasses were provided in Table 2-1 and Table 2-2 (also shown in Table C1 of Appendix C). A sum of oxides column is provided in this table as well. Chemical composition measurements for these glasses were conducted by the PSAL following the analytical plan provided in Appendix A as described in Section 3.2.1.

Table $\mathrm{C} 2$ in Appendix $\mathrm{C}$ provides the elemental concentration measurements derived from the samples prepared using LM, and Table $\mathrm{C} 3$ in Appendix $\mathrm{C}$ provides the measurements derived from the samples prepared using PF. Measurements for standards (Batch 1 and a uranium standard, $\mathrm{U}_{\text {std }}$ ) that were included in the PSAL analytical plans along with the study glasses are also provided in these two tables.

The elemental concentrations were converted to oxide concentrations by multiplying the values for each element by the gravimetric factor for the corresponding oxide. During this process, an elemental concentration that was determined to be below the detection limit of the analytical procedures used by the PSAL was reduced to half of that detection limit as the oxide concentration was determined.

In the sections that follow, the analytical sequences of the measurements are explored, the measurements of the standards are investigated and used for bias correction, the measurements for each glass are reviewed, the average chemical compositions (measured and bias-corrected) for each glass are determined, and comparisons are made between the measurements and the targeted compositions for the glasses.

\subsubsection{Measurements in Analytical Sequence}

Exhibit $\mathrm{C} 1$ in Appendix C provides plots of the measurements generated by the PSAL for samples prepared using the LM method. The plots are in analytical sequence with different 
symbols and colors being used to represent each of the study and standard glasses. Similar plots for the samples prepared using the PF method are provided in Exhibit C2 in Appendix C. These plots include all of the measurement data from Tables $\mathrm{C} 2$ and $\mathrm{C} 3$. A review of these plots indicates no significant patterns or trends in the analytical process over the course of these measurements, and there appear to be no obvious outliers in these chemical composition measurements.

\subsubsection{Batch 1 and Uranium Standard Results}

In this section, the PSAL measurements of the chemical compositions of the Batch 1 and uranium standard $\left(\mathrm{U}_{\text {std }}\right)$ glasses are reviewed. These measurements are investigated across the ICP-AES analytical blocks, and the results are used to bias correct the measurements for the study glasses.

Exhibit C3 in Appendix C provides statistical analyses of the Batch 1 and $\mathrm{U}_{\text {std }}$ results generated by the LM prep method by block for each oxide of interest. The results include analysis of variance (ANOVA) investigations looking for statistically significant differences among the block means for each of the oxides for each of the standards. The results from the statistical tests for significant differences for the Batch 1 standard may be summarized as follows: $\mathrm{BaO}, \mathrm{CaO}$, $\mathrm{Cr}_{2} \mathrm{O}_{3}, \mathrm{CuO}, \mathrm{K}_{2} \mathrm{O}, \mathrm{MgO}, \mathrm{TiO}_{2}$, and $\mathrm{ZrO}_{2}$ have measurements that indicate a significant ICP-AES calibration effect on the block averages at the 5\% significance level. For the $\mathrm{U}_{\text {std }}, \mathrm{CaO}, \mathrm{K}_{2} \mathrm{O}$, $\mathrm{MgO}, \mathrm{Na}_{2} \mathrm{O}$, and $\mathrm{TiO}_{2}$ have measurements that indicate a significant ICP-AES calibration effect on the block averages at the 5\% significance level. The reference values for the oxide concentrations of the standard are given in the header for each set of measurements in the exhibit.

Exhibit $\mathrm{C} 4$ in Appendix $\mathrm{C}$ provides a similar set of analyses for the measurements derived from samples prepared via the PF method. The results from the statistical tests for significant differences for the Batch 1 standard may be summarized as follows: $\mathrm{Al}_{2} \mathrm{O}_{3}, \mathrm{Fe}_{2} \mathrm{O}_{3}, \mathrm{Li}_{2} \mathrm{O}, \mathrm{NiO}$, and $\mathrm{SiO}_{2}$ have measurements that indicate a significant ICP-AES calibration effect on the block averages at the $5 \%$ significance level. For the $\mathrm{U}_{\text {std }}, \mathrm{Al}_{2} \mathrm{O}_{3}, \mathrm{Fe}_{2} \mathrm{O}_{3}, \mathrm{Li}_{2} \mathrm{O}, \mathrm{NiO}$, and $\mathrm{SiO}_{2}$ have measurements that indicate a significant ICP-AES calibration effect on the block averages at the $5 \%$ significance level. The reference values for the oxide concentrations of the standard are given in the header for each set of measurements in the exhibit.

These results provide incentive for adjusting the measurements by the effect of the ICP-AES calibration. Therefore, the oxide measurements of the study glasses were bias corrected for the effect of the ICP-AES calibration on each of the analytical blocks. The basis for this bias correction is presented as part of Exhibits $\mathrm{C} 3$ and $\mathrm{C} 4$ - the average measurement for Batch 1 for each ICP-AES block/sub-block for $\mathrm{Al}_{2} \mathrm{O}_{3}, \mathrm{~B}_{2} \mathrm{O}_{3}, \mathrm{BaO}, \mathrm{CaO}, \mathrm{Cr}_{2} \mathrm{O}_{3}, \mathrm{CuO}, \mathrm{Fe}_{2} \mathrm{O}_{3}, \mathrm{~K}_{2} \mathrm{O}, \mathrm{Li}_{2} \mathrm{O}$, $\mathrm{MgO}, \mathrm{MnO}, \mathrm{Na}_{2} \mathrm{O}, \mathrm{NiO}, \mathrm{SiO}_{2}$, and $\mathrm{TiO}_{2}$ and the average measurement for $\mathrm{U}_{\text {std }}$ for each ICP-AES block/sub-block for $\mathrm{U}_{3} \mathrm{O}_{8}$. The Batch 1 results served as the basis for bias correcting all of the oxides (that were bias corrected) except uranium. The $\mathrm{U}_{\text {std }}$ results were used to bias correct for uranium. For the other oxides, the Batch 1 results were used to conduct the bias correction as long as the reference value for the oxide concentration in the Batch 1 glass was greater than or equal to $0.1 \mathrm{wt} \%$. Thus, applying this approach and based upon the information in the exhibits, the Batch 1 results were used to bias correct the $\mathrm{Al}_{2} \mathrm{O}_{3}, \mathrm{~B}_{2} \mathrm{O}_{3}, \mathrm{BaO}, \mathrm{CaO}, \mathrm{Cr}_{2} \mathrm{O}_{3}, \mathrm{CuO}, \mathrm{Fe}_{2} \mathrm{O}_{3}$, $\mathrm{K}_{2} \mathrm{O}, \mathrm{Li}_{2} \mathrm{O}, \mathrm{MgO}, \mathrm{MnO}, \mathrm{Na}_{2} \mathrm{O}, \mathrm{NiO}, \mathrm{SiO}_{2}$, and $\mathrm{TiO}_{2}$ measurements. No bias correction was conducted for $\mathrm{Ce}_{2} \mathrm{O}_{3}, \mathrm{La}_{2} \mathrm{O}_{3}, \mathrm{PbO}, \mathrm{SO}_{4}, \mathrm{ThO}_{2}, \mathrm{ZnO}$, or $\mathrm{ZrO}_{2}$.

The bias correction was conducted as follows. For each oxide, let $\overline{\mathrm{a}}_{\mathrm{ij}}$ be the average measurement for the $\mathrm{i}^{\text {th }}$ oxide at analytical block $\mathrm{j}$ for Batch 1 (or $\mathrm{U}_{\text {std }}$ for uranium), and let $\mathrm{t}_{\mathrm{i}}$ be 
the reference value for the $\mathrm{i}^{\text {th }}$ oxide for Batch 1 (or for $\mathrm{U}_{\text {std }}$ if uranium). (The averages and reference values are provided in Exhibits $\mathrm{C} 3$ and C4.) Let $\overline{\mathrm{c}}_{\mathrm{ijk}}$ be the average measurement for the $\mathrm{i}^{\text {th }}$ oxide at analytical block $\mathrm{j}$ for the $\mathrm{k}^{\text {th }}$ glass. The bias adjustment was conducted as follows

$$
\bar{c}_{i j k} \bullet\left(1-\frac{\bar{a}_{i j}-t_{i}}{\bar{a}_{i j}}\right)=\bar{c}_{i j k} \bullet \frac{t_{i}}{\bar{a}_{i j}}
$$

Bias-corrected measurements are indicated by a "bc" suffix, and such adjustments were performed for all of the oxides of this study except for $\mathrm{Ce}_{2} \mathrm{O}_{3}, \mathrm{La}_{2} \mathrm{O}_{3}, \mathrm{PbO}, \mathrm{SO}_{4}, \mathrm{ThO}_{2}, \mathrm{ZnO}$, and $\mathrm{ZrO}_{2}$. Both measured and measured "bc" values are included in the discussion that follows. In these discussions, bias-corrected values for $\mathrm{Ce}_{2} \mathrm{O}_{3}, \mathrm{La}_{2} \mathrm{O}_{3}, \mathrm{PbO}, \mathrm{SO}_{4}, \mathrm{ThO}_{2}, \mathrm{ZnO}$, and $\mathrm{ZrO}_{2}$ are included for completeness (e.g., to allow a sum of oxides to be computed for the bias-corrected results). These bias-corrected values are the same as the original $\mathrm{Ce}_{2} \mathrm{O}_{3}, \mathrm{La}_{2} \mathrm{O}_{3}, \mathrm{PbO}, \mathrm{SO}_{4}, \mathrm{ThO}_{2}$, $\mathrm{ZnO}$, and $\mathrm{ZrO}_{2}$ values (i.e., once again, no bias correction was performed for this group of oxides).

\subsubsection{Composition Measurements by Glass Number}

Exhibits C5 and C6 in Appendix C provide plots of the oxide concentration measurements by Glass ID \# (including both Batch 1, labeled as glass numbered 100 and $\mathrm{U}_{\text {std }}$, labeled as glass numbered 200) for the measured and bias-corrected (bc) values for the LM and PF preparation methods, respectively. Different symbols and colors are used to represent the different glasses. These plots show the individual measurements across the duplicates of each preparation method and the two ICP-AES calibrations. A review of the plots presented in these exhibits reveals the repeatability of the four individual oxide values for each glass. There appears to be a good bit of scatter in the $\mathrm{Fe}_{2} \mathrm{O}_{3}$ values, in the $\mathrm{MnO}$ values, and in the $\mathrm{SiO}_{2}$ values. In addition, there appears to be inconsistencies between the two dissolutions for the $\mathrm{La}_{2} \mathrm{O}_{3}$ values for NEPH2-15 and -26 as well as an outlier in the $\mathrm{ZnO}$ concentration for one of the NEPH2-30 replicates. No other problems are evident in these plots.

More detailed discussions of the average, measured chemical compositions of the study glasses are provided in the sections that follow.

\subsubsection{Measured versus Targeted Compositions}

The four measurements for each oxide for each glass (over both preparation methods) were averaged to determine a representative chemical composition for each glass. These determinations were conducted both for the measured and for the bias-corrected data. A sum of oxides was also computed for each glass based upon both the measured and bias-corrected values. Exhibit C7 in Appendix C provides plots showing results for each glass for each oxide to help highlight the comparisons among the measured, bias-corrected, and targeted values.

Some observations from the plots of Exhibit C7 are offered: The measured values for NEPH2-21 for many of the oxides are consistently lower than their corresponding targets. NEPH2-27 and NEPH2-28 reveal a disturbing pattern in their measured versus targeted values for several of the oxides. The pattern reflects the potential of a batching issue (i.e., the glasses may have been switched) in that the measured values for NEPH2-27 and NEPH2-28 are close to the targeted values for the other glass. For nearly every nepheline study glass, the measured $\mathrm{Fe}_{2} \mathrm{O}_{3}$ values, the $\mathrm{NiO}$ values, and the $\mathrm{Ce}_{2} \mathrm{O}_{3}$ values are less than their respective targeted concentrations. As 
mentioned in Section 4.1.3, the $\mathrm{La}_{2} \mathrm{O}_{3}$ values for NEPH2-15 and -26 showed significant scatter among the replicates which results in the measured values being higher than targeted. Although no scatter was observed among the replicates for NEPH2-19, the measured $\mathrm{La}_{2} \mathrm{O}_{3}$ values are also higher than targeted. A review of the $\mathrm{ZnO}$ values for NEPH2-21 and NEPH2-30 suggests that the measured values are lower and higher, respectively, as compared to their corresponding targeted values.

Table C4 in Appendix C provides a summary of the average compositions as well as the targeted compositions and some associated differences and relative differences. Notice that the targeted sums of oxides for the standard glasses do not sum to $100 \%$ due to an incomplete coverage of the oxides in the Batch 1 (glass \# 100) and $\mathrm{U}_{\text {std }}$ (glass \# 200) glasses. All of the sums of oxides (both measured and bias-corrected) for the study glasses fall within the interval of 95 to $105 \mathrm{wt} \%$; the measured sum of oxides for NEPH2-21 was only 95.2\%, however. Entries in Table C4 show the relative differences between the measured or bias-corrected values and the targeted values. These differences are shaded when they are greater than or equal to $5 \%$. Overall, these comparisons between the measured and targeted compositions suggest that there were some difficulties in hitting the targeted compositions for some of the oxides for some of the glasses.

Specifically, the issues identified above for NEPH2-21, NEPH2-27, and NEPH2-28 led to the resubmission of samples of these glasses to PSAL for additional measurements. Table C5 in Appendix C provides the results generated by PSAL for these samples. Exhibit C8 in Appendix $\mathrm{C}$ provides comparison plots (measured, targeted, and re-measured) for the three glasses by oxide. Table C6 in Appendix C provides the average of these oxide values for each glass. While the remeasured values move more toward the target values for some oxides, it is not clear from these results what may have happened in the batching or measurement of these samples, although such problems are thought to have occurred. As a result, it is recommended that the three glasses (NEPH2-21, NEPH2-27, and NEPH2-28) not be included in any future modeling of durability responses. In the results that follow, the original measurements of these glasses will be used in the assessments of the durability of these three glasses.

\subsection{5 $\mathrm{SO}_{4}$ Retention or Solubility}

Although not the primary focus of the Phase 2 study, a secondary concern for SB4 is the potential need to redefine the $\mathrm{SO}_{4}$ solubility limit for $\mathrm{SB} 4$. The compositional analysis, coupled with the visual observations of the as-fabricated glasses (see Section 4.3.1), will serve as primary indicators that the current $0.6 \mathrm{wt} \% \mathrm{SO}_{4}$ limit (established for the Frit 418 - SB3 system by Peeler et al. (2004)) is still applicable for SB4. From Table 2-1 and Table 2-2, the targeted $\mathrm{SO}_{4}$ concentrations in the Phase 2 glasses range from 0.402 (in NEPH2-27) to $0.546 \mathrm{wt} \%$ (NEPH226).

Figure 4-1 summarizes the targeted versus measured $\mathrm{SO}_{4}$ concentrations in glass. The blue line represents the targeted concentrations as noted in Table 2-1 and Table 2-2. The red x's represent the measured $\mathrm{SO}_{4}$ concentrations in glass, while the green squares are the measured biascorrected values. Since there is no $\mathrm{SO}_{4}$ in either standard glass, the measured values could not be bias corrected. The data suggest essentially full retention in glass - i.e., no volatilization during the fabrication process. Although the visual observations are discussed in Section 4.3.1 in more detail, there were no signs of a salt layer on any of the Phase 2 glasses upon fabrication. Coupling the analytical measurements with visual observations of the as-fabricated glasses, the results suggest that the $0.6 \mathrm{wt} \% \mathrm{SO}_{4}$ limit is applicable for the $\mathrm{SB} 4$ system. If the $\mathrm{SO}_{4}$ concentration in the SB4 feed to DWPF contains the projected levels, then expectations are that no issues with $\mathrm{SO}_{4}$ solubility are anticipated. 


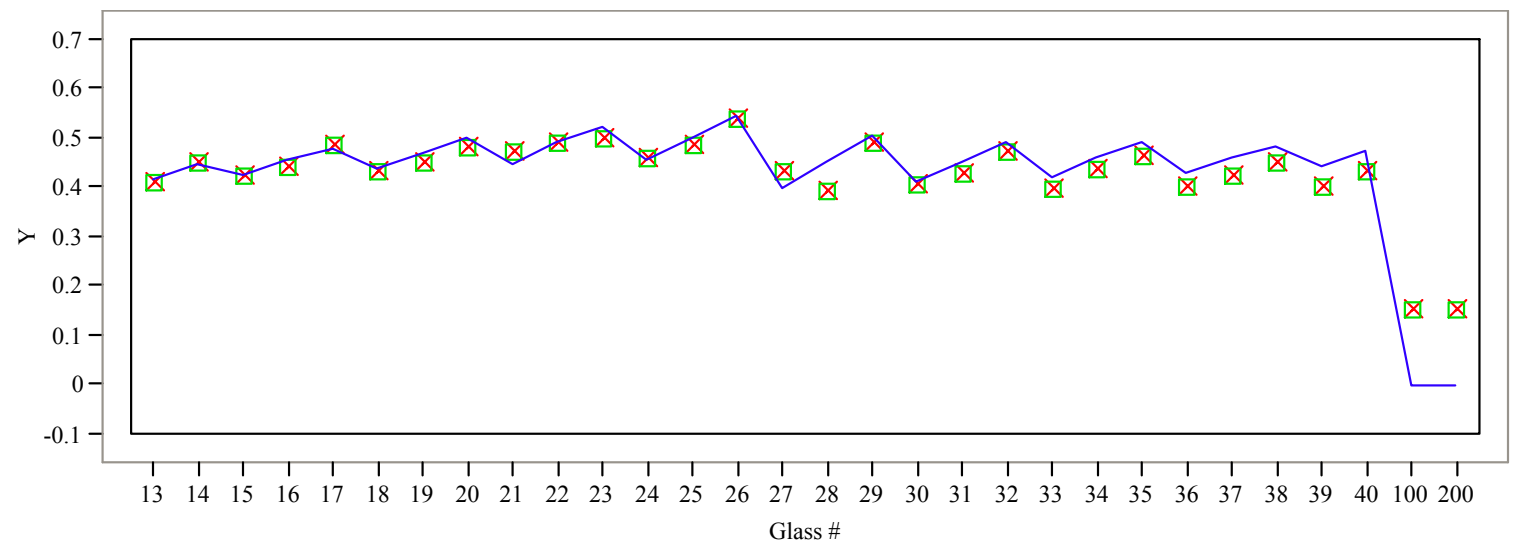

Figure 4-1. Targeted Versus Measured SO4 Values.

\subsection{A Statistical Review of the PCT Measurements}

The nepheline study glasses, after being batched and fabricated, were subjected to the PCT to assess their durabilities as described in Section 3.2.2. Table D1 in Appendix D provides the elemental leachate concentration measurements determined by the PSAL for the solution samples generated by the PCTs. One of the quality control checkpoints for the PCT procedure is solutionweight loss over the course of the 7-day test. None of these PCT results indicated a solutionweight loss problem. However, one sample (D92) was inadvertently spilled and lost (as indicated by its blank row in Table D1). ${ }^{8}$ No measurements were possible for this sample. Any measurement in Table D1 below the detection limit of the analytical procedure (indicated by a "<") was replaced by $1 / 2$ of the detection limit in subsequent analyses. In addition to adjustments for detection limits, the values were adjusted for the dilution factors: the values for the study glasses, the blanks, and the ARM glass in Table D1 were multiplied by 1.6667 to determine the values in parts per million (ppm) and the values for EA were multiplied by 16.6667. Table D2 in Appendix D provides the resulting measurements.

Initial screening of the results of Table D2 suggested some problems with the measurements for NEPH2-33, NEPH2-34, and NEPH2-35. Both heat treatments for these glasses were resubmitted for PCT testing and measurement by PSAL. An analytical plan was prepared for the samples and standards for these tests and the measurements generated by PSAL are included in Table D1 and Table D2 as Part 3. ${ }^{9}$ For the analyses that follow, the PCTs for NEPH2-33, NEPH2-34, and NEPH2-35 are those provided in Part 3 of these tables.

\footnotetext{
${ }^{8}$ D92 was one of the triplicate PCT solutions for the quenched version of NEPH2-34 glass.

${ }^{9}$ The analytical plan supporting this assessment was SRNL-SCS-2005-00051 (“An Analytical Plan for Measuring the PCT Solutions for Select Set of Glasses from the Phase 2 Nepheline Study") - see Appendix B.
} 
One of the important objectives of this study is the investigation of the effects of the heat treatment on the PCTs. In the sections that follow, the analytical sequence of the measurements is explored, the measurements of the standards are investigated and used to assess the overall accuracy of the ICP-AES measurement process, the measurements for each glass are reviewed, plots are provided that explore the effects of heat treatment on the PCTs for these glasses, the PCTs are normalized using the compositions (targeted, measured, and bias-corrected) presented in Table C4, and the normalized PCTs are compared to durability predictions for these compositions generated from the current DWPF models (Jantzen et al. 1995).

\subsubsection{Measurements in Analytical Sequence}

Exhibits D1 and D2 in Appendix D provide plots of the leachate (ppm) concentrations in analytical sequence as generated by the PSAL for all of the data and excluding EA, respectively. A different color and symbol is used for each study glass or standard. No problems are seen in these plots.

\subsubsection{Results for the Samples of the Multi-Element Solution Standard}

Exhibit D3 in Appendix D provides analyses of the PSAL measurements of the samples of the multi-element solution standard by ICP-AES analytical (or calibration) block. An ANOVA investigating for statistically significant differences among the part/block averages for these samples for each element of interest is included in these exhibits. These results indicate a statistically significant (at the 5\% level) difference among the B, Li, Na, and $\mathrm{Si}$ average measurements over these parts/blocks. However, no bias correction of the PCT results for the study glasses was conducted. This approach was taken since the triplicate PCTs for a single study glass were placed in different ICP-AES blocks. Averaging the ppm's for each set of triplicates helps to minimize the impact of the ICP-AES effects.

Table 4-1 summarizes the average measurements and the reference values for the 4 primary elements of interest. The results indicate consistent and accurate measurements from the PSAL processes used to conduct these analyses.

Table 4-1. Results from Samples of the Multi-Element Solution Standard.

\begin{tabular}{||c|c|c|c|c||}
\hline $\begin{array}{c}\text { Analytical } \\
\text { Part/Block }\end{array}$ & $\begin{array}{c}\text { Avg B } \\
(\mathbf{p p m})\end{array}$ & $\begin{array}{c}\text { Avg Li } \\
(\mathbf{p p m})\end{array}$ & $\begin{array}{c}\text { Avg Na } \\
(\mathbf{p p m})\end{array}$ & $\begin{array}{c}\text { Avg Si } \\
(\mathbf{p p m})\end{array}$ \\
\hline $1 / 1$ & 20.3 & 10.2 & 82.5 & 49.5 \\
\hline $1 / 2$ & 19.4 & 10.1 & 82.8 & 50.0 \\
\hline $1 / 3$ & 20.0 & 10.0 & 85.5 & 51.3 \\
\hline $2 / 1$ & 21.0 & 9.8 & 85.2 & 51.5 \\
\hline $2 / 2$ & 21.0 & 9.9 & 81.6 & 51.4 \\
\hline $2 / 3$ & 20.3 & 9.7 & 81.4 & 51.5 \\
\hline $3 / 1$ & 18.7 & 9.7 & 87.8 & 49.4 \\
\hline $3 / 2$ & 20.1 & 9.9 & 86.0 & 48.3 \\
\hline $3 / 3$ & 20.2 & 9.7 & 85.4 & 48.3 \\
\hline Grand Average & 20.1 & 9.9 & 84.2 & 50.1 \\
\hline Reference Value & 20 & 10 & 81 & 50 \\
\hline \% difference & $0.5 \%$ & $-1.1 \%$ & $4.0 \%$ & $0.3 \%$ \\
\hline \hline
\end{tabular}




\subsubsection{Measurements by Glass Number}

Exhibit D4 in Appendix D provides plots of the leachate concentrations for each type of submitted sample: the study glasses and the standards (EA, ARM, the multi-element solution standard, and blanks). Exhibit D5 in Appendix D provides plots of the leachate concentrations for the ccc results of the study glasses and for EA. These plots allow for the assessment of the repeatability of the measurements, which suggests some scatter in the triplicate values for some analytes for some of the glasses. Also, note that the results from the two heat treatments are shown for each study glass and that some differences between the two sets of values are evident.

\subsubsection{Normalized PCT Results}

PCT leachate concentrations are typically normalized using the cation composition (expressed as a weight percent) in the glass to obtain a grams-per-liter $(\mathrm{g} / \mathrm{L})$ leachate concentration. The normalization of the PCTs is usually conducted using the measured compositions of the glasses. This is the preferred normalization process for the PCTs. For completeness, the targeted cation and the bias-corrected cation compositions were also used to conduct this normalization.

As is the usual convention, the common logarithm of the normalized PCT (normalized leachate, $\mathrm{NL}$ ) for each element of interest was determined and used for comparison. To accomplish this computation, one must

1. Determine the common logarithm of the elemental parts per million $(\mathrm{ppm})$ leachate concentration for each of the triplicates and each of the elements of interest (these values are provided in Table D2 of Appendix D),

2. Average the common logarithms over the triplicates for each element of interest, and then

Normalizing Using Measured Composition (preferred method)

3. Subtract a quantity equal to 1 plus the common logarithm of the average cation measured concentration (expressed as a weight percent of the glass) from the average computed in step 2 .

Or Normalizing Using Target Composition

3. Subtract a quantity equal to 1 plus the common logarithm of the target cation concentration (expressed as a weight percent of the glass) from the average computed in step 2.

Or Normalizing Using Measured Bias-Corrected Composition

3. Subtract a quantity equal to 1 plus the common logarithm of the measured bias-corrected cation concentration (expressed as a weight percent of the glass) from the average computed in step 2.

Exhibit D6 in Appendix D provides scatter plots for these results and offers an opportunity to investigate the consistency in the leaching across the elements for the glasses of this study. All normalizations of the PCTs (i.e., those generated using the targeted, measured, and bias-corrected compositional views) and both heat treatments are represented in these plots. Consistency in the leaching across the elements is typically demonstrated by a high degree of linear correlation 
among the values for pairs of these elements. A high degree of correlation is seen for these data. The smallest correlation (93.48\%) is for the $\mathrm{Li}$ and $\mathrm{Na}$ data.

Table 4-2 and Table 4-3 summarize the normalized release values for the 1.6M, 127" SB3 heel and 1.6M, 40" SB3 heel option glasses, respectively. The quenched values for each glass are shaded gray. The PCT results have been normalized based on all three compositional views for both quenched and ccc based glasses.

All of the Phase 2 quenched glasses have normalized boron releases less than $1.19 \mathrm{~g} / \mathrm{L}$, which in terms of acceptability are approximately an order of magnitude better than the EA benchmark glass that has a reported NL [B] of $16.695 \mathrm{~g} / \mathrm{L}$ (Jantzen et al. 1993). The range of normalized boron releases for the quenched Phase 2 glasses is from $0.67 \mathrm{~g} / \mathrm{L}$ (NEPH2-27 based on the Frit $320-40$ " SB3 heel case at 39\% WL) to $1.19 \mathrm{~g} / \mathrm{L}$ (NEPH2-16 based on the Frit 417 - 127" SB3 heel case at $43 \% \mathrm{WL}$ ). The results suggest that even though the glasses are prone to nepheline formation based on the 0.62 guide value, all 28 Phase 2 quenched glasses are acceptable which may provide some technical basis for "challenging" nepheline formation to gain access to higher WLs for the various SB4 options - independent of frit composition. However, the potential for crystallization was suppressed in the quenched glasses in terms of kinetics. That is, the glasses may be prone to nepheline formation but the rapid cooling limited (or eliminated) the formation of nepheline (or other crystalline phases). As observed in the Phase 1 glasses, it was only in the slow cooled (ccc) NEPH-01 and NEPH-02 glasses where the impact of nepheline on the durability response was observed. Both of these glasses were prone to nepheline formation with a statistical (not practical) difference in PCT response being observed between the quenched and ccc versions. 
Table 4-2. Normalized Release Values for the 127" SB3 Heel Based Phase 2 Glasses. (NEPH2-13 through NEPH2-26)

\begin{tabular}{|c|c|c|c|c|c|c|c|c|c|c|}
\hline $\begin{array}{c}\text { Glass } \\
\text { ID }\end{array}$ & \begin{tabular}{c|c|} 
Heat \\
Treatment
\end{tabular} & Composition & $\begin{array}{c}\log \mathrm{NL} \\
{[\mathrm{B}(\mathrm{g} / \mathrm{L})]}\end{array}$ & $\begin{array}{c}\log \mathbf{N L} \\
{[\mathrm{Li}(\mathrm{g} / \mathrm{L})]} \\
\end{array}$ & $\begin{array}{c}\log N L \\
{[\mathrm{Na}(\mathrm{g} / \mathrm{L})]}\end{array}$ & \begin{tabular}{|c|}
$\log \mathbf{N L}$ \\
{$[\mathrm{Si}(\mathrm{g} / \mathrm{L})]$} \\
\end{tabular} & $\begin{array}{c}\mathbf{N L} \\
\mathbf{B}(\mathrm{g} / \mathrm{L}) \\
\end{array}$ & \begin{tabular}{|c|} 
NL \\
$\mathrm{Li}(\mathrm{g} / \mathrm{L})$ \\
\end{tabular} & $\begin{array}{c}\mathrm{NL} \\
\mathrm{Na}(\mathrm{g} / \mathrm{L}) \\
\end{array}$ & $\begin{array}{c}\mathrm{NL} \\
\mathrm{Si}(\mathrm{g} / \mathrm{L}) \\
\end{array}$ \\
\hline ARM & - & reference & -0.269 & -0.189 & -0.229 & -0.506 & 0.54 & 0.65 & 0.59 & 0.31 \\
\hline EA & - & reference & 1.252 & 0.991 & 1.142 & 0.610 & 17.85 & 9.80 & 13.86 & 4.07 \\
\hline NEPH2-13 & quenched & measured & -0.007 & 0.024 & 0.176 & -0.123 & 0.98 & 1.06 & 1.50 & 0.75 \\
\hline NEPH2-13 & quenched & measured bc & -0.012 & 0.015 & 0.195 & -0.128 & 0.97 & 1.04 & 1.57 & 0.74 \\
\hline NEPH2-13 & quenched & \begin{tabular}{|l|} 
target \\
\end{tabular} & -0.026 & 0.002 & 0.166 & -0.129 & 0.94 & 1.00 & 1.46 & 0.74 \\
\hline NEPH2-13 & $\mathrm{ccc}$ & measured & 0.020 & 0.077 & 0.151 & -0.113 & 1.05 & 1.19 & 1.42 & 0.77 \\
\hline NEPH2-13 & $\mathrm{ccc}$ & measured bc & 0.015 & 0.068 & 0.170 & -0.119 & 1.04 & 1.17 & 1.48 & 0.76 \\
\hline NEPH2-13 & $\mathrm{ccc}$ & target & 0.001 & 0.055 & 0.141 & -0.120 & 1.00 & 1.13 & 1.38 & 0.76 \\
\hline NEPH2-14 & quenched & measured & 0.049 & 0.035 & 0.207 & -0.116 & 1.12 & 1.09 & 1.61 & 0.77 \\
\hline NEPH2-14 & quenched & measured bc & 0.047 & 0.031 & 0.222 & -0.117 & 1.11 & 1.07 & 1.67 & 0.76 \\
\hline NEPH2-14 & quenched & target & 0.022 & 0.012 & 0.183 & -0.118 & 1.05 & 1.03 & 1.52 & 0.76 \\
\hline NEPH2-14 & $\operatorname{ccc}$ & measured & 0.322 & 0.278 & 0.277 & -0.007 & 2.10 & 1.90 & 1.89 & 0.98 \\
\hline NEPH2-14 & $\mathrm{ccc}$ & measured bc & 0.320 & 0.274 & 0.291 & -0.008 & 2.09 & 1.88 & 1.96 & 0.98 \\
\hline NEPH2-14 & $\mathrm{ccc}$ & target & 0.295 & 0.255 & 0.252 & -0.008 & 1.97 & 1.80 & 1.79 & 0.98 \\
\hline NEPH2-15 & quenched & measured & 0.035 & 0.005 & 0.137 & -0.134 & 1.08 & 1.01 & 1.37 & 0.73 \\
\hline NEPH2-15 & quenched & measured bc & 0.031 & -0.004 & 0.157 & -0.140 & 1.07 & 0.99 & 1.43 & 0.72 \\
\hline NEPH2-15 & quenched & target & 0.008 & -0.020 & 0.133 & -0.140 & 1.02 & 0.95 & 1.36 & 0.72 \\
\hline NEPH2-15 & $\mathrm{ccc}$ & measured & 0.023 & 0.070 & 0.111 & -0.137 & 1.05 & 1.17 & 1.29 & 0.73 \\
\hline NEPH2-15 & $\mathrm{ccc}$ & measured bc & 0.018 & 0.061 & 0.130 & -0.143 & 1.04 & 1.15 & 1.35 & 0.72 \\
\hline NEPH2-15 & ccc & target & -0.004 & 0.045 & 0.107 & -0.143 & 0.99 & 1.11 & 1.28 & 0.72 \\
\hline NEPH2-16 & quenched & measured & 0.077 & 0.008 & 0.156 & -0.126 & 1.19 & 1.02 & 1.43 & 0.75 \\
\hline NEPH2-16 & quenched & measured bc & 0.072 & 0.000 & 0.176 & -0.131 & 1.18 & 1.00 & 1.50 & 0.74 \\
\hline NEPH2-16 & quenched & \begin{tabular}{|l|} 
target \\
\end{tabular} & 0.060 & -0.004 & 0.155 & -0.137 & 1.15 & 0.99 & 1.43 & 0.73 \\
\hline NEPH2-16 & $\mathrm{ccc}$ & measured & 0.275 & 0.236 & 0.227 & -0.027 & 1.88 & 1.72 & 1.69 & 0.94 \\
\hline NEPH2-16 & $\mathrm{ccc}$ & measured bc & 0.270 & 0.227 & 0.246 & -0.033 & 1.86 & 1.69 & 1.76 & 0.93 \\
\hline NEPH2-16 & $\mathrm{ccc}$ & target & 0.258 & 0.224 & 0.226 & -0.039 & 1.81 & 1.67 & 1.68 & 0.91 \\
\hline NEPH2-17 & quenched & measured & 0.029 & 0.003 & 0.176 & -0.142 & 1.07 & 1.01 & 1.50 & 0.72 \\
\hline NEPH2-17 & quenched & measured bc & 0.027 & -0.002 & 0.191 & -0.144 & 1.06 & 1.00 & 1.55 & 0.72 \\
\hline NEPH2-17 & quenched & target & 0.015 & -0.005 & 0.168 & -0.140 & 1.04 & 0.99 & 1.47 & 0.72 \\
\hline NEPH2-17 & $\mathrm{ccc}$ & measured & 0.546 & 0.555 & 0.434 & 0.103 & 3.52 & 3.59 & 2.72 & 1.27 \\
\hline NEPH2-17 & $\mathrm{ccc}$ & measured bc & 0.544 & 0.550 & 0.449 & 0.102 & 3.50 & 3.55 & 2.81 & 1.26 \\
\hline NEPH2-17 & $\mathrm{ccc}$ & target & 0.532 & 0.547 & 0.425 & 0.105 & 3.40 & 3.53 & 2.66 & 1.27 \\
\hline NEPH2-18 & quenched & measured & -0.036 & -0.024 & 0.108 & -0.177 & 0.92 & 0.95 & 1.28 & 0.67 \\
\hline NEPH2-18 & quenched & measured bc & -0.039 & -0.028 & 0.122 & -0.178 & 0.91 & 0.94 & 1.32 & 0.66 \\
\hline NEPH2-18 & quenched & target & -0.048 & -0.042 & 0.101 & -0.179 & 0.89 & 0.91 & 1.26 & 0.66 \\
\hline NEPH2-18 & $\mathrm{ccc}$ & measured & -0.023 & 0.028 & 0.093 & -0.166 & 0.95 & 1.07 & 1.24 & 0.68 \\
\hline NEPH2-18 & $\mathrm{ccc}$ & measured bc & -0.026 & 0.023 & 0.108 & -0.167 & 0.94 & 1.05 & 1.28 & 0.68 \\
\hline NEPH2-18 & $\mathrm{ccc}$ & target & -0.035 & 0.009 & 0.086 & -0.168 & 0.92 & 1.02 & 1.22 & 0.68 \\
\hline NEPH2-19 & quenched & measured & -0.034 & -0.028 & 0.111 & -0.182 & 0.92 & 0.94 & 1.29 & 0.66 \\
\hline NEPH2-19 & quenched & measured bc & -0.039 & -0.037 & 0.130 & -0.187 & 0.91 & 0.92 & 1.35 & 0.65 \\
\hline NEPH2-19 & quenched & target & -0.028 & -0.039 & 0.118 & -0.178 & 0.94 & 0.91 & 1.31 & 0.66 \\
\hline NEPH2-19 & $\mathrm{ccc}$ & measured & 0.314 & 0.287 & 0.238 & -0.020 & 2.06 & 1.93 & 1.73 & 0.95 \\
\hline NEPH2-19 & $\mathrm{ccc}$ & measured bc & 0.309 & 0.278 & 0.257 & -0.026 & 2.04 & 1.90 & 1.81 & 0.94 \\
\hline NEPH2-19 & $\mathrm{ccc}$ & target & 0.320 & 0.275 & 0.245 & -0.016 & 2.09 & 1.88 & 1.76 & 0.96 \\
\hline NEPH2-20 & quenched & measured & 0.018 & -0.005 & 0.161 & -0.168 & 1.04 & 0.99 & 1.45 & 0.68 \\
\hline NEPH2-20 & quenched & measured bc & 0.014 & -0.014 & 0.180 & -0.173 & 1.03 & 0.97 & 1.51 & 0.67 \\
\hline NEPH2-20 & quenched & \begin{tabular}{c|} 
target \\
\end{tabular} & 0.009 & -0.021 & 0.163 & -0.155 & 1.02 & 0.95 & 1.46 & 0.70 \\
\hline NEPH2-20 & $\operatorname{ccc}$ & measured & 0.960 & 0.819 & 0.712 & 0.230 & 9.13 & 6.60 & 5.16 & 1.70 \\
\hline NEPH2-20 & $\mathrm{ccc}$ & measured bc & 0.956 & 0.811 & 0.732 & 0.225 & 9.04 & 6.47 & 5.39 & 1.68 \\
\hline NEPH2-20 & $\mathrm{ccc}$ & target & 0.952 & 0.804 & 0.714 & 0.243 & 8.94 & 6.36 & 5.18 & 1.75 \\
\hline NEPH2-21 & quenched & measured & 0.007 & -0.014 & 0.093 & -0.204 & 1.02 & 0.97 & 1.24 & 0.62 \\
\hline NEPH2-21 & quenched & measured bc & 0.004 & -0.018 & 0.107 & -0.205 & 1.01 & 0.96 & 1.28 & 0.62 \\
\hline NEPH2-21 & quenched & target & -0.046 & -0.064 & 0.079 & -0.214 & 0.90 & 0.86 & 1.20 & 0.61 \\
\hline NEPH2-21 & $\mathrm{ccc}$ & measured & 0.014 & 0.035 & 0.079 & -0.187 & 1.03 & 1.09 & 1.20 & 0.65 \\
\hline NEPH2-21 & $\mathrm{ccc}$ & measured bc & 0.011 & 0.031 & 0.093 & -0.188 & 1.03 & 1.07 & 1.24 & 0.65 \\
\hline NEPH2-21 & $\mathrm{ccc}$ & target & -0.040 & -0.015 & 0.065 & -0.197 & 0.91 & 0.97 & 1.16 & 0.64 \\
\hline NEPH2-22 & quenched & measured & -0.022 & -0.045 & 0.109 & -0.198 & 0.95 & 0.90 & 1.29 & 0.63 \\
\hline NEPH2-22 & quenched & measured bc & -0.025 & -0.050 & 0.124 & -0.199 & 0.94 & 0.89 & 1.33 & 0.63 \\
\hline NEPH2-22 & quenched & target & -0.038 & -0.057 & 0.095 & -0.191 & 0.92 & 0.88 & 1.24 & 0.64 \\
\hline
\end{tabular}




\begin{tabular}{|c|c|c|c|c|c|c|c|c|c|c|}
\hline $\begin{array}{c}\text { Glass } \\
\text { ID }\end{array}$ & \begin{tabular}{c|} 
Heat \\
Treatment
\end{tabular} & Composition & \begin{tabular}{|l|}
$\log \mathbf{~ N L}$ \\
{$[\mathrm{B}(\mathrm{g} / \mathrm{L})]$}
\end{tabular} & \begin{tabular}{|c|}
$\log N \mathrm{~L}$ \\
{$[\mathrm{Li}(\mathrm{g} / \mathrm{L})]$}
\end{tabular} & \begin{tabular}{|c|}
$\log \mathrm{NL}$ \\
{$[\mathrm{Na}(\mathrm{g} / \mathrm{L})]$}
\end{tabular} & \begin{tabular}{|c|}
$\log \mathbf{N L}$ \\
{$[\mathrm{Si}(\mathrm{g} / \mathrm{L})]$}
\end{tabular} & \begin{tabular}{|c|} 
NL \\
$B(g / L)$
\end{tabular} & \begin{tabular}{|c|}
$\mathrm{NL}$ \\
$\mathrm{Li}(\mathrm{g} / \mathrm{L})$
\end{tabular} & $\begin{array}{c}\mathrm{NL} \\
\mathrm{Na}(\mathrm{g} / \mathrm{L})\end{array}$ & $\begin{array}{c}\text { NL } \\
\mathrm{Si}(\mathrm{g} / \mathrm{L})\end{array}$ \\
\hline NEPH2-22 & \begin{tabular}{|l|}
$\mathrm{ccc}$ \\
\end{tabular} & measured & 0.402 & 0.435 & 0.281 & 0.036 & 2.52 & 2.72 & 1.91 & 1.09 \\
\hline NEPH2-22 & $\mathrm{ccc}$ & measured bc & 0.399 & 0.430 & 0.296 & 0.035 & 2.51 & 2.69 & 1.98 & 1.08 \\
\hline NEPH2-22 & $\mathrm{ccc}$ & target & 0.386 & 0.423 & 0.267 & 0.043 & 2.43 & 2.65 & 1.85 & 1.10 \\
\hline NEPH2-23 & quenched & measured & 0.044 & 0.001 & 0.162 & -0.152 & 1.11 & 1.00 & 1.45 & 0.70 \\
\hline NEPH2-23 & quenched & measured bc & 0.039 & -0.007 & 0.181 & -0.157 & 1.09 & 0.98 & 1.52 & 0.70 \\
\hline NEPH2-23 & quenched & target & 0.032 & -0.024 & 0.161 & -0.153 & 1.08 & 0.95 & 1.45 & 0.70 \\
\hline NEPH2-23 & $\mathrm{ccc}$ & measured & 1.012 & 0.867 & 0.749 & 0.224 & 10.29 & 7.37 & 5.61 & 1.68 \\
\hline NEPH2-23 & $\mathrm{ccc}$ & measured bc & 1.008 & 0.859 & 0.768 & 0.219 & 10.18 & 7.23 & 5.86 & 1.66 \\
\hline NEPH2-23 & $\mathrm{ccc}$ & target & 1.001 & 0.843 & 0.748 & 0.223 & 10.03 & 6.96 & 5.60 & 1.67 \\
\hline NEPH2-24 & quenched & measured & -0.064 & -0.044 & 0.081 & -0.202 & 0.86 & 0.90 & 1.21 & 0.63 \\
\hline NEPH2-24 & quenched & measured bc & -0.067 & -0.049 & 0.096 & -0.203 & 0.86 & 0.89 & 1.25 & 0.63 \\
\hline NEPH2-24 & quenched & target & -0.083 & -0.061 & 0.072 & -0.209 & 0.83 & 0.87 & 1.18 & 0.62 \\
\hline NEPH2-24 & $\mathrm{ccc}$ & measured & -0.032 & 0.001 & 0.052 & -0.204 & 0.93 & 1.00 & 1.13 & 0.63 \\
\hline NEPH2-24 & $\mathrm{ccc}$ & measured bc & -0.034 & -0.004 & 0.067 & -0.205 & 0.92 & 0.99 & 1.17 & 0.62 \\
\hline NEPH2-24 & ccc & target & -0.051 & -0.017 & 0.043 & -0.211 & 0.89 & 0.96 & 1.10 & 0.62 \\
\hline NEPH2-25 & quenched & measured & -0.008 & -0.025 & 0.109 & -0.192 & 0.98 & 0.94 & 1.28 & 0.64 \\
\hline NEPH2-25 & quenched & measured bc & -0.012 & -0.033 & 0.128 & -0.197 & 0.97 & 0.93 & 1.34 & 0.63 \\
\hline NEPH2-25 & quenched & target & -0.022 & -0.040 & 0.104 & -0.195 & 0.95 & 0.91 & 1.27 & 0.64 \\
\hline NEPH2-25 & $\mathrm{ccc}$ & measured & 0.688 & 0.654 & 0.495 & 0.130 & 4.87 & 4.51 & 3.12 & 1.35 \\
\hline NEPH2-25 & $\mathrm{ccc}$ & measured bc & 0.683 & 0.646 & 0.514 & 0.125 & 4.82 & 4.42 & 3.27 & 1.33 \\
\hline NEPH2-25 & $\mathrm{ccc}$ & target & 0.674 & 0.638 & 0.491 & 0.128 & 4.72 & 4.35 & 3.09 & 1.34 \\
\hline NEPH2-26 & quenched & measured & 0.020 & -0.011 & 0.179 & -0.150 & 1.05 & 0.98 & 1.51 & 0.71 \\
\hline NEPH2-26 & quenched & measured bc & 0.017 & -0.015 & 0.193 & -0.151 & 1.04 & 0.97 & 1.56 & 0.71 \\
\hline NEPH2-26 & quenched & target & 0.007 & -0.024 & 0.162 & -0.153 & 1.02 & 0.95 & 1.45 & 0.70 \\
\hline NEPH2-26 & $\mathrm{ccc}$ & measured & 1.590 & 1.123 & 1.245 & 0.738 & 38.94 & 13.28 & 17.59 & 5.47 \\
\hline NEPH2-26 & $\mathrm{ccc}$ & measured bc & 1.588 & 1.119 & 1.260 & 0.737 & 38.73 & 13.14 & 18.19 & 5.46 \\
\hline NEPH2-26 & $\mathrm{ccc}$ & target & 1.578 & 1.110 & 1.228 & 0.735 & 37.82 & 12.88 & 16.91 & 5.43 \\
\hline
\end{tabular}


Table 4-3. Normalized Release Values for the 40" SB3 Heel Based Phase 2 Glasses. (NEPH2-27 through NEPH2-40)

\begin{tabular}{|c|c|c|c|c|c|c|c|c|c|c|}
\hline $\begin{array}{c}\text { Glass } \\
\text { ID }\end{array}$ & $\begin{array}{c}\text { Heat } \\
\text { Treatment }\end{array}$ & Composition & \begin{tabular}{|l}
$\log N L$ \\
{$[\mathbf{B}(g / L)]$} \\
\end{tabular} & $\begin{array}{c}\log N \mathrm{NL} \\
{[\mathrm{Li}(\mathrm{g} / \mathrm{L})]}\end{array}$ & \begin{tabular}{|c|}
$\log \mathrm{NL}$ \\
{$[\mathrm{Na}(\mathrm{g} / \mathrm{L})]$}
\end{tabular} & \begin{tabular}{|l}
$\log \mathbf{N L}$ \\
{$[\mathrm{Si}(\mathrm{g} / \mathrm{L})]$} \\
\end{tabular} & $\begin{array}{c}\text { NL } \\
\text { B(g/L) }\end{array}$ & $\begin{array}{c}\mathbf{N L} \\
\mathbf{L i}(\mathrm{g} / \mathrm{L}) \\
\end{array}$ & $\begin{array}{c}\mathrm{NL} \\
\mathrm{Na}(\mathrm{g} / \mathrm{L}) \\
\end{array}$ & $\begin{array}{c}\text { NL } \\
\mathrm{Si}(\mathrm{g} / \mathrm{L}) \\
\end{array}$ \\
\hline ARM & - & reference & \begin{tabular}{|l|}
-0.269 \\
\end{tabular} & \begin{tabular}{|l|}
-0.189 \\
\end{tabular} & \begin{tabular}{|l}
-0.229 \\
\end{tabular} & \begin{tabular}{|l|}
-0.506 \\
\end{tabular} & 0.54 & 0.65 & \begin{tabular}{|l|}
0.59 \\
\end{tabular} & 0.31 \\
\hline EA & - & reference & 1.252 & 0.991 & 1.142 & 0.610 & 17.85 & 9.80 & 13.86 & 4.07 \\
\hline NEPH2-27 & quenched & measured & -0.095 & -0.115 & 0.074 & -0.234 & 0.80 & 0.77 & 1.19 & 0.58 \\
\hline NEPH2-27 & quenched & measured bc & -0.110 & -0.123 & 0.084 & -0.237 & 0.78 & 0.75 & 1.21 & 0.58 \\
\hline NEPH2-27 & quenched & target & -0.175 & -0.131 & 0.062 & -0.240 & 0.67 & 0.74 & 1.15 & 0.58 \\
\hline NEPH2-27 & $\mathrm{ccc}$ & measured & 0.385 & 0.380 & 0.224 & -0.002 & 2.42 & 2.40 & 1.68 & 0.99 \\
\hline NEPH2-27 & $\mathrm{ccc}$ & measured bc & 0.370 & 0.373 & 0.233 & -0.005 & 2.35 & 2.36 & 1.71 & 0.99 \\
\hline NEPH2-27 & $\mathrm{ccc}$ & target & 0.304 & 0.365 & 0.212 & -0.008 & 2.02 & 2.32 & 1.63 & 0.98 \\
\hline NEPH2-28 & quenched & measured & 0.047 & -0.066 & 0.103 & -0.188 & 1.11 & 0.86 & 1.27 & 0.65 \\
\hline NEPH2-28 & quenched & measured bc & 0.033 & -0.074 & 0.112 & -0.191 & 1.08 & 0.84 & 1.29 & 0.64 \\
\hline NEPH2-28 & quenched & target & 0.047 & -0.079 & 0.073 & -0.191 & 1.12 & 0.83 & 1.18 & 0.64 \\
\hline NEPH2-28 & $\mathrm{ccc}$ & measured & 0.379 & 0.319 & 0.249 & -0.010 & 2.40 & 2.08 & 1.78 & 0.98 \\
\hline NEPH2-28 & $\mathrm{ccc}$ & measured bc & 0.365 & 0.311 & 0.258 & -0.013 & 2.32 & 2.05 & 1.81 & 0.97 \\
\hline NEPH2-28 & $\mathrm{ccc}$ & target & 0.380 & 0.306 & 0.219 & -0.013 & 2.40 & 2.02 & 1.66 & 0.97 \\
\hline NEPH2-29 & quenched & measured & 0.020 & -0.066 & 0.129 & -0.165 & 1.05 & 0.86 & 1.35 & 0.68 \\
\hline NEPH2-29 & quenched & measured bc & 0.012 & -0.070 & 0.152 & -0.168 & 1.03 & 0.85 & 1.42 & 0.68 \\
\hline NEPH2-29 & quenched & target & -0.016 & -0.080 & 0.125 & -0.170 & 0.96 & 0.83 & 1.33 & 0.68 \\
\hline NEPH2-29 & $\mathrm{ccc}$ & measured & 1.640 & 1.046 & 1.249 & 0.662 & \begin{tabular}{|l|}
43.63 \\
\end{tabular} & 11.13 & 17.73 & 4.59 \\
\hline NEPH2-29 & $\mathrm{ccc}$ & measured bc & 1.632 & 1.042 & 1.272 & 0.659 & 42.84 & 11.02 & 18.70 & 4.56 \\
\hline NEPH2-29 & $\mathrm{ccc}$ & target & 1.603 & 1.033 & 1.245 & 0.658 & 40.11 & 10.79 & 17.59 & 4.55 \\
\hline NEPH2-30 & quenched & measured & -0.090 & -0.092 & 0.037 & -0.226 & 0.81 & 0.81 & 1.09 & 0.59 \\
\hline NEPH2-30 & quenched & measured bc & -0.104 & -0.099 & 0.047 & -0.229 & 0.79 & 0.80 & 1.11 & 0.59 \\
\hline NEPH2-30 & quenched & target & -0.122 & -0.108 & 0.034 & -0.228 & 0.76 & 0.78 & 1.08 & 0.59 \\
\hline NEPH2-30 & $\mathrm{ccc}$ & measured & 0.050 & -0.031 & 0.021 & -0.218 & 1.12 & 0.93 & 1.05 & 0.61 \\
\hline NEPH2-30 & $\mathrm{ccc}$ & measured bc & 0.036 & -0.039 & 0.030 & -0.221 & 1.09 & 0.91 & 1.07 & 0.60 \\
\hline NEPH2-30 & $\mathrm{ccc}$ & target & 0.018 & -0.047 & 0.018 & -0.220 & 1.04 & 0.90 & 1.04 & 0.60 \\
\hline NEPH2-31 & quenched & measured & -0.066 & -0.095 & 0.066 & -0.218 & 0.86 & 0.80 & 1.16 & 0.60 \\
\hline NEPH2-31 & quenched & measured bc & -0.074 & -0.099 & 0.089 & -0.221 & 0.84 & 0.80 & 1.23 & 0.60 \\
\hline NEPH2-31 & quenched & target & -0.086 & -0.106 & 0.058 & -0.224 & 0.82 & 0.78 & 1.14 & 0.60 \\
\hline NEPH2-31 & $\mathrm{ccc}$ & measured & 0.763 & 0.658 & 0.423 & 0.149 & 5.80 & 4.55 & 2.65 & 1.41 \\
\hline NEPH2-31 & $\mathrm{ccc}$ & measured bc & 0.755 & 0.654 & 0.446 & 0.147 & 5.69 & 4.50 & 2.79 & 1.40 \\
\hline NEPH2-31 & $\mathrm{ccc}$ & target & 0.743 & 0.647 & 0.415 & 0.144 & 5.53 & 4.43 & 2.60 & 1.39 \\
\hline NEPH2-32 & quenched & measured & 0.054 & -0.061 & 0.102 & -0.186 & 1.13 & 0.87 & 1.26 & 0.65 \\
\hline NEPH2-32 & quenched & measured bc & 0.040 & -0.069 & 0.111 & -0.189 & 1.10 & 0.85 & 1.29 & 0.65 \\
\hline NEPH2-32 & quenched & target & 0.003 & -0.096 & 0.092 & -0.200 & 1.01 & 0.80 & 1.24 & 0.63 \\
\hline NEPH2-32 & $\mathrm{ccc}$ & measured & 1.572 & 1.079 & 1.176 & 0.657 & 37.34 & 11.98 & 14.99 & 4.54 \\
\hline NEPH2-32 & $\mathrm{ccc}$ & measured bc & 1.558 & 1.071 & 1.185 & 0.654 & 36.15 & 11.77 & 15.31 & 4.51 \\
\hline NEPH2-32 & $\mathrm{ccc}$ & target & 1.522 & 1.044 & 1.167 & 0.643 & 33.24 & 11.07 & 14.68 & 4.39 \\
\hline NEPH2-33 & quenched & measured & -0.137 & -0.097 & 0.056 & -0.260 & 0.73 & 0.80 & 1.14 & 0.55 \\
\hline NEPH2-33 & quenched & measured bc & -0.151 & -0.105 & 0.065 & -0.262 & 0.71 & 0.79 & 1.16 & 0.55 \\
\hline NEPH2-33 & quenched & target & -0.169 & -0.115 & 0.046 & -0.265 & 0.68 & 0.77 & 1.11 & 0.54 \\
\hline NEPH2-33 & $\mathrm{ccc}$ & measured & 0.149 & 0.127 & 0.098 & -0.226 & 1.41 & 1.34 & 1.25 & 0.59 \\
\hline NEPH2-33 & $\mathrm{ccc}$ & measured bc & 0.135 & 0.119 & 0.107 & -0.228 & 1.36 & 1.32 & 1.28 & 0.59 \\
\hline NEPH2-33 & $\mathrm{ccc}$ & target & 0.117 & 0.109 & 0.087 & -0.231 & 1.31 & 1.29 & 1.22 & 0.59 \\
\hline NEPH2-34 & quenched & measured & -0.094 & -0.108 & 0.071 & -0.264 & 0.81 & 0.78 & 1.18 & 0.54 \\
\hline NEPH2-34 & quenched & measured bc & -0.102 & -0.112 & 0.094 & -0.267 & 0.79 & 0.77 & 1.24 & 0.54 \\
\hline NEPH2-34 & quenched & target & -0.126 & -0.116 & 0.076 & -0.262 & 0.75 & 0.76 & 1.19 & 0.55 \\
\hline NEPH2-34 & $\mathrm{ccc}$ & measured & 0.924 & 0.807 & 0.612 & 0.176 & 8.40 & 6.41 & 4.09 & 1.50 \\
\hline NEPH2-34 & $\mathrm{ccc}$ & measured bc & 0.917 & 0.802 & 0.635 & 0.173 & 8.25 & 6.34 & 4.32 & 1.49 \\
\hline NEPH2-34 & $\mathrm{ccc}$ & target & 0.893 & 0.798 & 0.617 & 0.177 & 7.81 & 6.29 & 4.14 & 1.50 \\
\hline NEPH2-35 & quenched & measured & -0.065 & -0.084 & 0.109 & -0.222 & 0.86 & 0.82 & 1.29 & 0.60 \\
\hline NEPH2-35 & quenched & measured bc & -0.073 & -0.089 & 0.132 & -0.225 & 0.85 & 0.82 & 1.36 & 0.60 \\
\hline NEPH2-35 & quenched & target & -0.111 & -0.098 & 0.108 & -0.229 & 0.77 & 0.80 & 1.28 & 0.59 \\
\hline NEPH2-35 & $\mathrm{ccc}$ & measured & 1.583 & 1.073 & 1.188 & 0.669 & 38.32 & 11.84 & 15.41 & 4.67 \\
\hline NEPH2-35 & $\mathrm{ccc}$ & measured bc & 1.576 & 1.069 & 1.211 & 0.667 & 37.63 & 11.72 & 16.25 & 4.64 \\
\hline NEPH2-35 & $\mathrm{ccc}$ & target & 1.538 & 1.060 & 1.186 & 0.663 & 34.48 & 11.47 & 15.35 & 4.60 \\
\hline
\end{tabular}




\begin{tabular}{|c|c|c|c|c|c|c|c|c|c|c|}
\hline $\begin{array}{c}\text { Glass } \\
\text { ID }\end{array}$ & $\begin{array}{c}\text { Heat } \\
\text { Treatment }\end{array}$ & Composition & \begin{tabular}{|l}
$\log \mathrm{NL}$ \\
{$[\mathrm{B}(\mathrm{g} / \mathrm{L})]$}
\end{tabular} & $\begin{array}{c}\log N L \\
{[\operatorname{Li}(g / L)]}\end{array}$ & \begin{tabular}{|c|}
$\log \mathrm{NL}$ \\
{$[\mathrm{Na}(\mathrm{g} / \mathrm{L})]$}
\end{tabular} & \begin{tabular}{|l}
$\log \mathbf{N L}$ \\
{$[\mathrm{Si}(\mathrm{g} / \mathrm{L})]$}
\end{tabular} & \begin{tabular}{|c|} 
NL \\
$B(g / L)$
\end{tabular} & \begin{tabular}{|c|}
$\mathrm{NL}$ \\
$\mathrm{Li}(\mathrm{g} / \mathrm{L})$
\end{tabular} & $\begin{array}{c}\mathrm{NL} \\
\mathrm{Na}(\mathrm{g} / \mathrm{L})\end{array}$ & $\begin{array}{c}\text { NL } \\
\mathrm{Si}(\mathrm{g} / \mathrm{L})\end{array}$ \\
\hline NEPH2-36 & quenched & measured & -0.070 & -0.124 & -0.042 & $\begin{array}{ll}-0.267 \\
\end{array}$ & 0.85 & 0.75 & 0.91 & 0.54 \\
\hline NEPH2-36 & quenched & measured bc & -0.084 & -0.131 & -0.033 & -0.270 & 0.82 & 0.74 & 0.93 & 0.54 \\
\hline NEPH2-36 & quenched & target & -0.113 & -0.145 & -0.037 & -0.269 & 0.77 & 0.72 & 0.92 & 0.54 \\
\hline NEPH2-36 & $\mathrm{ccc}$ & measured & 0.064 & 0.033 & 0.004 & -0.209 & 1.16 & 1.08 & 1.01 & 0.62 \\
\hline NEPH2-36 & $\mathrm{ccc}$ & measured bc & 0.050 & 0.026 & 0.013 & -0.212 & 1.12 & 1.06 & 1.03 & 0.61 \\
\hline NEPH2-36 & $\mathrm{ccc}$ & target & 0.021 & 0.012 & 0.009 & -0.211 & 1.05 & 1.03 & 1.02 & 0.62 \\
\hline NEPH2-37 & quenched & measured & -0.067 & -0.122 & -0.008 & -0.266 & 0.86 & 0.76 & 0.98 & 0.54 \\
\hline NEPH2-37 & quenched & measured bc & -0.075 & -0.126 & 0.015 & -0.269 & 0.84 & 0.75 & 1.03 & 0.54 \\
\hline NEPH2-37 & quenched & target & -0.105 & -0.146 & -0.003 & -0.269 & 0.79 & 0.72 & 0.99 & 0.54 \\
\hline NEPH2-37 & $\mathrm{ccc}$ & measured & 0.600 & 0.576 & 0.290 & 0.050 & 3.98 & 3.77 & 1.95 & 1.12 \\
\hline NEPH2-37 & $\mathrm{ccc}$ & measured bc & 0.592 & 0.572 & 0.313 & 0.047 & 3.91 & 3.73 & 2.05 & 1.12 \\
\hline NEPH2-37 & $\mathrm{ccc}$ & target & 0.562 & 0.553 & 0.295 & 0.048 & 3.65 & 3.57 & 1.97 & 1.12 \\
\hline NEPH2-38 & quenched & measured & -0.056 & -0.120 & 0.029 & -0.252 & 0.88 & 0.76 & 1.07 & 0.56 \\
\hline NEPH2-38 & quenched & measured bc & -0.064 & -0.124 & 0.052 & -0.254 & 0.86 & 0.75 & 1.13 & 0.56 \\
\hline NEPH2-38 & quenched & target & -0.080 & -0.126 & 0.036 & -0.244 & 0.83 & 0.75 & 1.09 & 0.57 \\
\hline NEPH2-38 & $\mathrm{ccc}$ & measured & 0.994 & 0.804 & 0.531 & 0.162 & 9.86 & 6.37 & 3.39 & 1.45 \\
\hline NEPH2-38 & $\mathrm{ccc}$ & measured bc & 0.986 & 0.800 & 0.554 & 0.160 & 9.68 & 6.31 & 3.58 & 1.44 \\
\hline NEPH2-38 & $\mathrm{ccc}$ & target & 0.969 & 0.798 & 0.538 & 0.169 & 9.32 & 6.28 & 3.45 & 1.48 \\
\hline NEPH2-39 & quenched & measured & -0.133 & -0.142 & -0.043 & -0.287 & 0.74 & 0.72 & 0.91 & 0.52 \\
\hline NEPH2-39 & quenched & measured bc & -0.147 & -0.150 & -0.034 & -0.289 & 0.71 & 0.71 & 0.92 & 0.51 \\
\hline NEPH2-39 & quenched & target & -0.155 & -0.149 & -0.050 & -0.284 & 0.70 & 0.71 & 0.89 & 0.52 \\
\hline NEPH2-39 & $\mathrm{ccc}$ & measured & 0.075 & 0.024 & -0.006 & -0.216 & 1.19 & 1.06 & 0.99 & 0.61 \\
\hline NEPH2-39 & $\mathrm{ccc}$ & measured bc & 0.061 & 0.017 & 0.003 & -0.219 & 1.15 & 1.04 & 1.01 & 0.60 \\
\hline NEPH2-39 & $\mathrm{ccc}$ & target & 0.053 & 0.018 & -0.013 & -0.214 & 1.13 & 1.04 & 0.97 & 0.61 \\
\hline NEPH2-40 & quenched & measured & 0.062 & -0.132 & -0.038 & -0.276 & 1.15 & 0.74 & 0.92 & 0.53 \\
\hline NEPH2-40 & quenched & measured bc & 0.055 & -0.137 & -0.015 & -0.278 & 1.13 & 0.73 & 0.97 & 0.53 \\
\hline NEPH2-40 & quenched & target & 0.028 & -0.149 & -0.029 & -0.277 & 1.07 & 0.71 & 0.93 & 0.53 \\
\hline NEPH2-40 & $\mathrm{ccc}$ & measured & 0.374 & 0.378 & 0.159 & -0.052 & 2.37 & 2.39 & 1.44 & 0.89 \\
\hline NEPH2-40 & $\mathrm{ccc}$ & measured bc & 0.366 & 0.373 & 0.182 & -0.055 & 2.33 & 2.36 & 1.52 & 0.88 \\
\hline NEPH2-40 & $\mathrm{ccc}$ & target & 0.340 & 0.361 & 0.167 & -0.053 & 2.19 & 2.30 & 1.47 & 0.88 \\
\hline
\end{tabular}


Prior to evaluating the ccc glasses, it should be noted that the two quenched glasses within the Frit $320-1.6 \mathrm{M}, 127$ " SB3 heel option (NEPH2-13 and NEPH2-14) were acceptable with NL [B]'s of 0.94 and $1.05 \mathrm{~g} / \mathrm{L}$ (based on the target composition), respectively. These results suggest that although the new proposed durability limits allow access to higher alkali compositional regions, there is still conservatism in the limits and/or model (i.e., the model predictions and limits suggested that the glasses would be unacceptable (see Figure 2-1) but the measured durability response shows otherwise).

Also shown in Table 4-2 and Table 4-3 are the normalized releases based on the ccc versions of each Phase 2 glass for each compositional view. As will be discussed in Section 4.3.1 (visual observations) and Section 4.3.2 (XRD results), the slow cooling of the Phase 2 glasses typically resulted in devitrification (partial or complete) with the severity (or degree) of crystallization being generally correlated to the targeted WL. In general, as the targeted WL within a specific frit - sludge system was increased, the degree of crystallization or devitrification appeared to be more extensive. This is not unexpected as the slower cooling provides a thermodynamically favorable (compositional-wise) glass the kinetic opportunity to devitrify. With the knowledge of devitrification in the Phase 2 ccc glasses, the questions of interest to this study are: "What is the impact on the PCT response?", "What are the crystalline phase(s) that formed?", and "Does the type and/or extent of crystallization agree with glass science theory in terms of their anticipated impact on the durability response?" These are the questions to be addressed in this section and the following subsections which will ultimately lead to potential decisions to be made in terms of the frit selection process for SB4.

Based on target compositions, the normalized boron releases for the 1.6M, 127" SB3 heel based ccc glasses range from $0.89 \mathrm{~g} / \mathrm{L}$ (NEPH2-24) to $37.82 \mathrm{~g} / \mathrm{L}$ (NEPH2-26). For the 1.6M, 40" ccc glasses the NL [B]'s (based on target compositions) range from $1.04 \mathrm{~g} / \mathrm{L}$ (NEPH2-30) to 40.11 $\mathrm{g} / \mathrm{L}$ (NEPH2-29). These values obviously span a much wider PCT response as compared to the quenched versions. In addition, and more importantly, the PCT results suggest that select Phase 2 glasses exceed the benchmark EA glass NL [B] of $16.695 \mathrm{~g} / \mathrm{L}$. An obvious question to ask is: "Which frit - sludge combinations and/or WLs result in these unacceptable durabilities?"

Figure 4-2 shows the PCT response (normalized based on targeted compositions) for both quenched and ccc glasses based on the 127" SB3 heel option. The "+"'s represent the quenched glasses while the solid circles represent the ccc versions. The PCT response (in log NL $[B] \mathrm{g} / \mathrm{L}$ ) is plotted on the y-axis with the fourteen 127" based glasses (NEPH2-13 through NEPH2-26) shown on the $\mathrm{x}$-axis. In addition to the glass identifications, the targeted WL, the frit, and the $\%$ $\mathrm{Na}_{2} \mathrm{O}$ in the frit are shown below the glass IDs. 


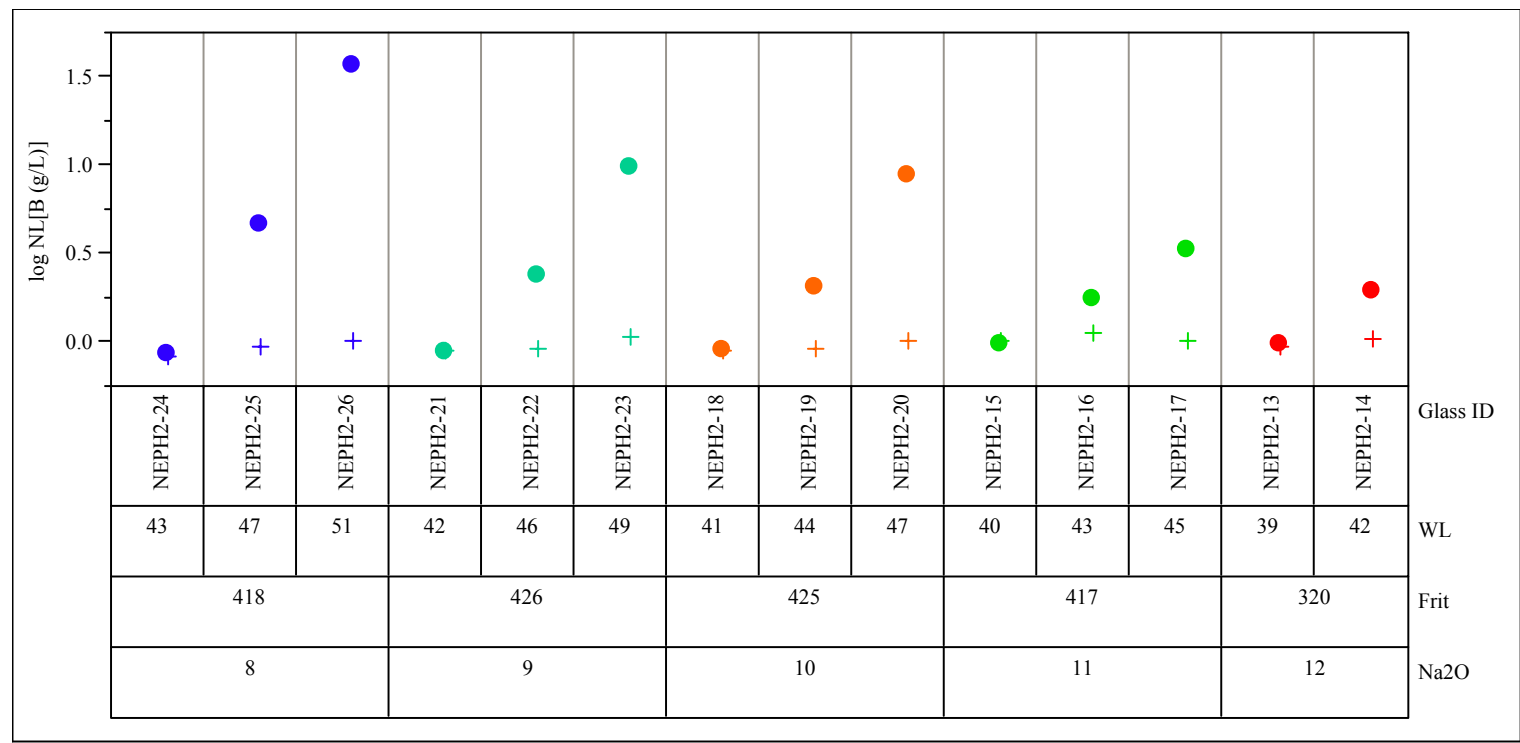

Figure 4-2. Normalized Boron Release for the 127" Phase 2 Glasses (quenched $(+)$ and $\operatorname{ccc}(\bullet))$.

The general trend within each specific frit system is that as WL increases, the difference between the quenched and ccc PCT response increases. For example, consider the Frit 418-1.6M, 127" SB3 heel glasses at 43, 47, and 51\% WL (represented by the blue "+"s and "•"s). At 43\% WL, the difference between the quenched and ccc versions is minimal and of no practical concern. More specifically, the NL [B] for the quenched and ccc versions of NEPH2-24 are $0.83 \mathrm{~g} / \mathrm{L}$ and $0.89 \mathrm{~g} / \mathrm{L}$, respectively. Although potentially of statistical significance, the practical impact is of no concern - similar to the Phase 1 results. As WL is increased in this system to $47 \% \mathrm{WL}$, the difference in the quenched and ccc glasses for NEPH2-25 shows a significant difference in PCT response $-0.95 \mathrm{~g} / \mathrm{L}$ versus $4.72 \mathrm{~g} / \mathrm{L}$, respectively. Although the ccc version of NEPH2-25 is still less than the EA benchmark of $16.695 \mathrm{~g} / \mathrm{L}$, the response is approaching a level that DWPF may wish to avoid. Further increases in WL within this system result in a continued decrease in durability. More specifically, the quenched and ccc responses for NEPH2-26 (targeting 51\% $\mathrm{WL}$ ) are $1.02 \mathrm{~g} / \mathrm{L}$ and $37.82 \mathrm{~g} / \mathrm{L}$, respectively. Although the quenched version of NEPH2-26 is very acceptable $(1.02 \mathrm{~g} / \mathrm{L})$, its ccc counterpart should be avoided in DWPF as the measured durability response exceeds the acceptable limit of the EA benchmark glass by a factor of 2 $(37.82 \mathrm{~g} / \mathrm{L}$ versus $16.695 \mathrm{~g} / \mathrm{L})$. Although not specifically discussed, this general trend (i.e., as WL increases the differences in PCT response between the quenched and ccc versions of the glass increase) holds for all other frit - sludge combinations (for both the 40" and 127" SB3 heel options as well). Figure 4-3 summarizes the PCT responses for the 40" SB3 heel options. 


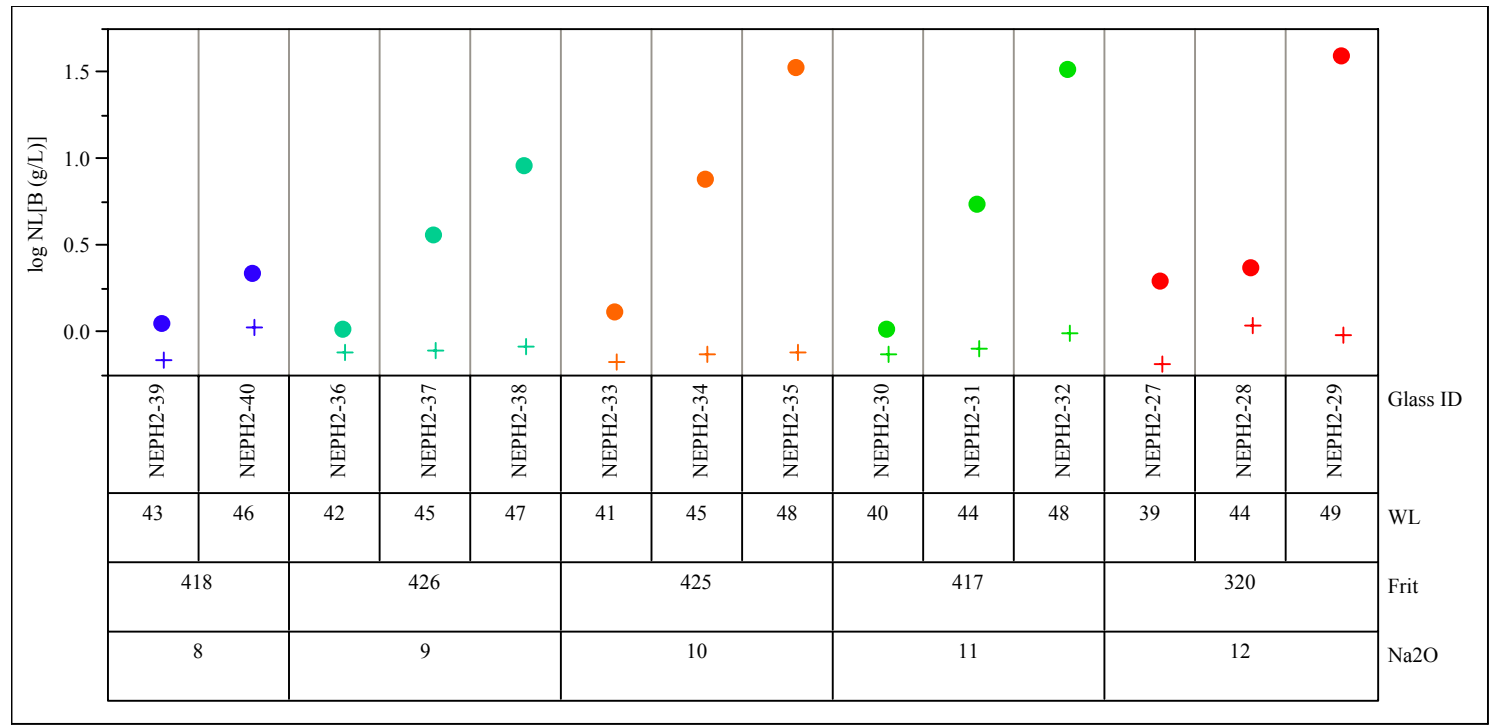

Figure 4-3. Normalized Boron Release for the 40" Phase 2 Glasses (quenched $(+)$ and $\operatorname{ccc}(\bullet))$.

One notable difference between the 127" SB3 heel and 40" SB3 heel glasses is the delta in PCT response for the quenched and ccc glass at the lowest WL (for each specific frit - sludge system). For the 127" cases (see Figure 4-2), the difference between the quenched and ccc versions of each glass is minimal (and of no practical concern) at the lowest WLs. For the 40" SB3 heel cases, there is a measurable difference in the PCT responses for the lowest WL glass between the quenched and ccc versions. Consider the Frit 418-1.6M, 40" option at 43\% WL (NEPH2-39). From Table 4-3, the quenched version of this glass has a measured NL [B] of $0.70 \mathrm{~g} / \mathrm{L}$ (based on target composition), while the ccc version has a NL [B] of $1.13 \mathrm{~g} / \mathrm{L}$ (again based on target composition). It should be noted that the difference in PCT response for these "lowest" WL glasses seems to generally increase as one transitions from left to right in Figure 4-3 (or as the \% $\mathrm{Na}_{2} \mathrm{O}$ in frit increases). Another important point when making these comparisons is to realize that the "lowest WL" glasses do not target the same WL as a function of frit composition. That is, as the $\mathrm{Na}_{2} \mathrm{O}$ concentration in frit increases (by $1 \%$ in moving from left to right) the "lowest WL" (i.e., the WL at which nepheline first becomes a prediction issue based on the 0.62 value) decreases by $1 \%$. The lowest WL for the Frit 418 system is $43 \%$ (NEPH2-39), while the "lowest" WL for the Frit 320 based glasses is 39\% (NEPH2-27). Although all the lower WL glasses (both quenched and ccc versions) are acceptable, there is some critical WL at which the Phase 2 glasses transition from acceptable to unacceptable when slow cooled. However, the specific WL transition depends upon the definition of "acceptable." In Section 4.4, an assessment of the importance of selecting the "acceptance value" (in terms of a maximum $\mathrm{g} / \mathrm{L}$ value to be produced) is discussed with respect to the possible impacts on DWPF processing.

Note the general trend for the Frit 320 - 127" SB3 heel glasses (NEPH2-27, -28, and -29) shown in Figure 4-3. Although there is a gradual decrease in durability for the ccc glasses, the difference between the PCT response of the 39\% (NEPH2-27) and 44\% (NEPH2-28) WL glasses is not that dramatic - not the "step-wise" function observed in other frit - sludge systems of this study. In fact, the NL [B]'s for these two ccc glasses are 2.02 and $2.40 \mathrm{~g} / \mathrm{L}$, respectively. The minimal difference in the PCT response can be related to (and triggered the review of) potential batching issues as discussed in Section 4.1.4. As noted in that section, these data points should not be used to support subsequent modeling activities. 
Exhibit D7 in Appendix D provides a closer look at the effects of heat treatment on the PCT response based on target compositions. Exhibit D8 in Appendix D provides a look at the effects of heat treatment on the PCT response based on measured compositions. Exhibit D9 in Appendix D provides a look at the effects of heat treatment on the PCT response based on measured biascorrected compositions. The behaviors of the differences between the PCTs for the quenched and ccc versions of the glasses are similar to those discussed above.

\subsubsection{Predicted versus Measured PCTs}

As seen in Table 4-2 and Table 4-3, the durabilities for select Phase 2 glasses fall into three distinct categories or classifications. The first category would envelope all of the quenched glasses which were classified as having acceptable PCT responses (i.e., NL [B]'s $<1.19 \mathrm{~g} / \mathrm{L}$ which in terms of acceptability are approximately an order of magnitude better than the EA benchmark glass). The second classification would be those ccc glasses that resulted in no detectable crystallization or which precipitated crystals that are known not to have an adverse impact on the PCT response. The final category would be those ccc glasses whose crystallization resulted in an extremely negative impact on PCT response. The primary difference between a glass falling into the second classification versus the latter was waste loading. As the WL increased, the probability that crystallization had a negative impact on durability increased. With respect to predictability, the current durability model is only applicable to homogeneous glasses. Therefore, applicability of the model to those ccc glasses which resulted in devitrification (especially the formation of nepheline) is not expected.

Exhibit D10 in Appendix D provides plots of the DWPF models that relate the logarithm of the normalized PCT (for each element of interest) to a linear function of a free energy of hydration term $\left(\Delta \mathrm{G}_{\mathrm{p}}, \mathrm{kcal} / 100 \mathrm{~g}\right.$ glass $)$ derived from all of the glass compositional views and heat treatments (Jantzen et al. 1995). Prediction limits (at a 95\% confidence) for an individual PCT result are also plotted along with the linear fit. The EA and ARM results are also indicated on these plots. Exhibit D11 in Appendix D provides a version of these plots for the quenched glasses only while Exhibit D12 provides a version for ccc glasses only. Figure 4-4 and Figure 4-5 show the log NL [B] versus $\Delta \mathrm{G}_{\mathrm{P}}$ for the quenched and ccc glasses, respectively.

In Figure 4-4, the open blocks are those Phase 2 glasses based on the 127" SB3 heel sludge; while the open circles are those based on the 40" SB3 heel nominal sludge composition. As shown in Figure 4-4, most of the study glasses are predictable by the $\Delta \mathrm{G}_{\mathrm{p}}$ model. Those that are not predictable (i.e., outside of the prediction limits) actually fall below the prediction interval (i.e., they are over predicted by the model) suggesting the model is conservative.

Although the model should not be applied to inhomogeneous glasses, Figure 4-5 shows the predictability (or lack thereof) for the ccc-based Phase 2 glasses. Over $1 / 2$ of the Phase 2 ccc glasses are predicted by the current durability model. These glasses are presumably those resulting in spinel formation upon slow cooling which has been shown not to have an impact on the PCT response (see Section 4.3 for a more detailed discussion of the crystalline phases). Therefore, the model should be applicable. Also shown in Figure 4-5 are several glasses that are not only unpredictable but, more importantly, fall above the prediction interval suggesting that the model is not conservative. Although not discussed as of yet, these glasses are presumably those in which nepheline formation occurred resulting in a dramatic reduction in durability leading to the inability of the durability model to adequately predict their response. The practical implication to DWPF is to eliminate the possibility of producing an unacceptable glass through the implementation of a nepheline discriminator function, limiting WL through an administrative 
control, or eliminating nepheline formation through strategic frit development efforts. The practical implications to DWPF are discussed in detail in Section 4.4.

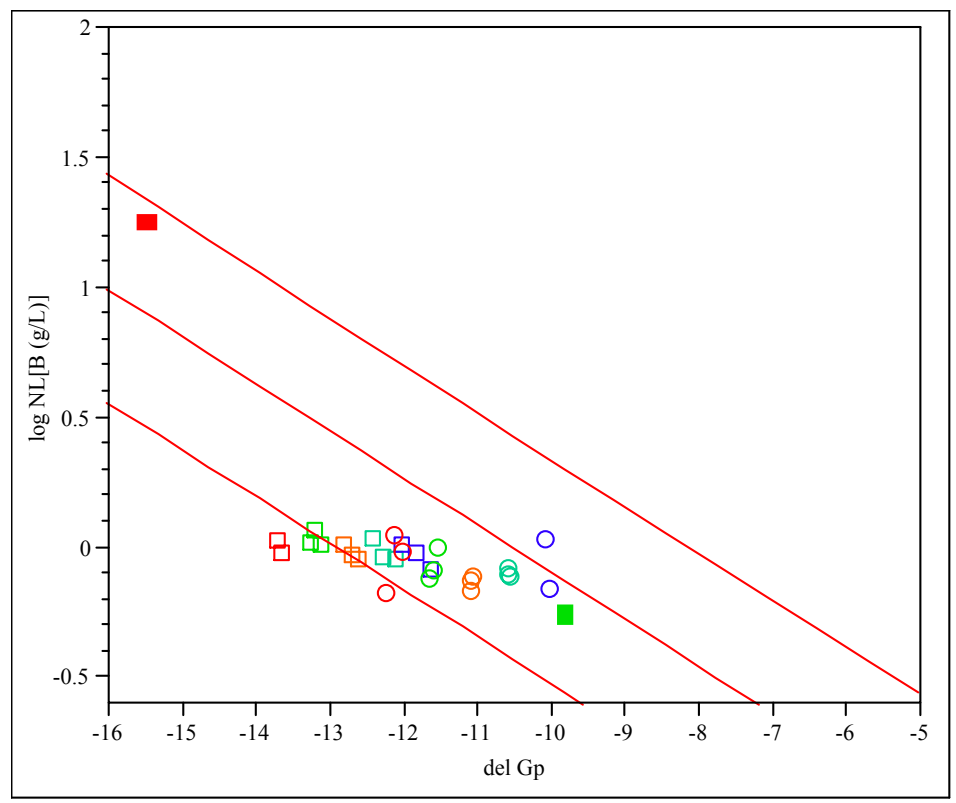

Figure 4-4. $\log$ NL [B] Versus $\Delta G_{\mathrm{P}}$ for the Quenched Phase 2 Glasses.

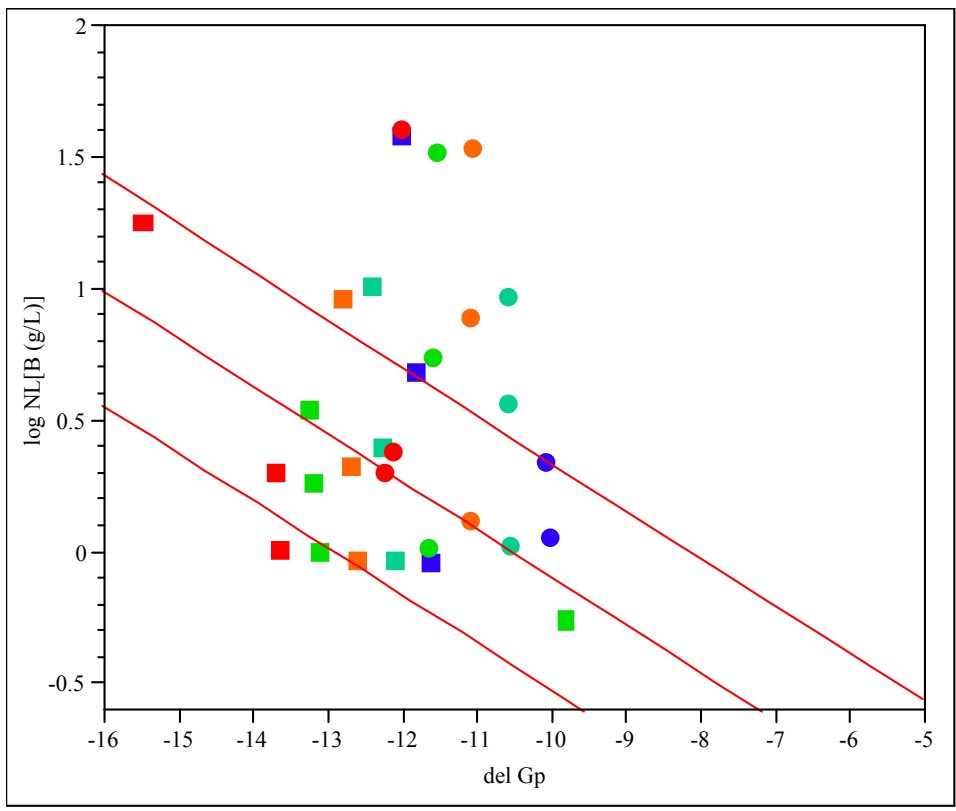

Figure 4-5. $\log \mathrm{NL}[\mathrm{B}]$ Versus $\Delta \mathrm{G}_{\mathrm{P}}$ for the cce Phase 2 Glasses. 


\subsection{Homogeneity}

In this section, the primary interest is the possible formation of nepheline (and/or other crystalline phases) in the ccc glasses which could be responsible for the measurable and significant difference in PCT response for the higher WL Phase 2 glasses as compared to their quenched counterparts. Table 4-4 (glasses based on the 127" SB3 heel option) and Table 4-5 (glasses based on the 40" SB3 heel option) summarize the visual and XRD results for the quenched and ccc Phase 2 nepheline study glasses, respectively. It should be noted that only the ccc versions of the Phase 2 glasses were submitted for XRD analysis given the durability response suggested no significant differences among all 28 quenched glasses. With NL [B]'s ranging from $0.67 \mathrm{~g} / \mathrm{L}$ to $1.19 \mathrm{~g} / \mathrm{L}$, there is no evidence of nepheline formation in the quenched glasses - even if present, the impact is of no practical concern.

In Table 4-4 and Table 4-5, glasses within a specific frit - sludge system are grouped (shaded or not) to aid in the discussions. Tracking the results of visual observations and/or XRD results as a function of WL will be of utmost interest given the differences in PCT response between the quenched and ccc as a function of WL.

Prior to discussing the results, a few words regarding the terminology used in the tables are warranted. The use of "homogeneous" for visual observations indicates that the sample was classified as a single-phase system (i.e., no evidence of crystallization). The term "surface crystals" (used as a descriptor for visual observations) implies that the surface of the glass was characterized by the presence of crystallization while the cross-section of bulk glass appeared homogeneous (i.e., single-phased, black and shiny). Surface crystallization in the Phase 2 glasses was apparent through the presence of a "textured" surface that ranged in appearance from a "dull or matte" surface to a "highly metallic-like" surface.

The XRD results are more qualitative in nature. As previously mentioned, only the ccc glasses were submitted for XRD analysis based on both the PCT responses as well as visual observations of the quenched glasses. The PCT responses of the quenched glasses were "acceptable and predictable" and visual observations suggested only the presence of surface devitrification on select glasses. Historically, surface devitrification occurs as WLs increase and for DWPF type glasses is typically the result of spinel formation. The Phase 2 PCT responses suggested that for those quenched glasses that were classified as having "surface crystallization" or a "metallic haze on the surface", spinel formation was highly probable - which is consistent with recent observations and the inert effect on the PCT response. For the ccc glasses, the XRD results suggested that the glass was either amorphous or contained some degree of crystallization. The presence of a characteristically high background devoid of crystalline spectral lines indicates that the glass product is amorphous (suggesting either a completely amorphous product or that the degree of crystallization is below the detection limit - approximately $0.5 \mathrm{vol} \%$ in glass). In terms of crystallization, the XRD results indicated the presence of spinel (Trevorite, $\mathrm{NiFe}_{2} \mathrm{O}_{4}$ ), nepheline $\left(\mathrm{NaAlSiO}_{4}\right)$, and/or lithium silicate $\left(\mathrm{Li}_{2} \mathrm{SiO}_{3}\right)$. For a more detailed description of the visual observations and XRD results of both the quenched and ccc glasses, see WSRC-NB-200500054 . 
Table 4-4. Visual and XRD Results for the SB4 Nepheline Phase 2 Glasses Based on the 1.6M, 127" SB3 Heel Options.

\begin{tabular}{|c|c|c|c|c|c|}
\hline Glass & $\begin{array}{c}\text { Frit } \\
\text { ID }\end{array}$ & $\begin{array}{c}\text { Target } \\
\text { WL }\end{array}$ & $\begin{array}{c}\text { Heat } \\
\text { Treatment }\end{array}$ & Visual & XRD \\
\hline NEPH-13 & 320 & 39 & quenched & Homogeneous & - \\
\hline NEPH-13 & 320 & 39 & $\operatorname{ccc}$ & Surface dull matte color with crystals, bulk homogeneous & Amorphous \\
\hline NEPH-14 & 320 & 42 & quenched & Slight metallic haze on surface, bulk homogeneous & - \\
\hline NEPH-14 & 320 & 42 & $\mathrm{ccc}$ & Surface dull matte color with crystals, bulk homogeneous & $\mathrm{NiFe}_{2} \mathrm{O}_{4}, \mathrm{NaAlSiO}_{4}$ \\
\hline NEPH-15 & 417 & 40 & quenched & Homogeneous & - \\
\hline NEPH-15 & 417 & 40 & $\mathrm{ccc}$ & Surface dull matte color with crystals, bulk homogeneous & Amorphous \\
\hline NEPH-16 & 417 & 43 & quenched & Slight metallic haze on surface, bulk was homogeneous & - \\
\hline NEPH-16 & 417 & 43 & $\mathrm{ccc}$ & Surface dull matte color with crystals, bulk homogeneous & $\mathrm{NiFe}_{2} \mathrm{O}_{4}, \mathrm{NaAlSiO}_{4}$ \\
\hline NEPH-17 & 417 & 45 & quenched & Slight metallic haze on surface, bulk was homogeneous & - \\
\hline NEPH-17 & 417 & 45 & $\operatorname{ccc}$ & Surface dull matte color with crystals, bulk homogeneous & $\mathrm{NiFe}_{2} \mathrm{O}_{4}, \mathrm{NaAlSiO}_{4}, \mathrm{Li}_{2} \mathrm{SiO}_{3}$ \\
\hline NEPH-18 & 425 & 41 & quenched & Homogeneous & - \\
\hline NEPH-18 & 425 & 41 & $\mathrm{ccc}$ & Surface dull matte color with crystals, bulk homogeneous & $\mathrm{NiFe}_{2} \mathrm{O}_{4}$ \\
\hline NEPH-19 & 425 & 44 & quenched & Metallic haze on surface, bulk was homogeneous & - \\
\hline NEPH-19 & 425 & 44 & $\mathrm{ccc}$ & Surface dull matte color with crystals, bulk homogeneous & $\mathrm{NiFe}_{2} \mathrm{O}_{4}, \mathrm{NaAlSiO}_{4}$ \\
\hline NEPH-20 & 425 & 47 & quenched & Metallic haze on surface, bulk was homogeneous & - \\
\hline NEPH-20 & 425 & 47 & $\mathrm{ccc}$ & Surface dull matte color with crystals, bulk devitrified & $\mathrm{NiFe}_{2} \mathrm{O}_{4}, \mathrm{NaAlSiO}_{4}, \mathrm{Li}_{2} \mathrm{SiO}_{3}$ \\
\hline NEPH-21 & 426 & 42 & quenched & Homogeneous & - \\
\hline NEPH-21 & 426 & 42 & $\operatorname{ccc}$ & Surface dull matte color with crystals, bulk homogeneous & Amorphous \\
\hline NEPH-22 & 426 & 46 & quenched & Metallic haze on surface, bulk was homogeneous & - \\
\hline NEPH-22 & 426 & 46 & $\mathrm{ccc}$ & Surface dull matte color with crystals, bulk partially devitrified & $\mathrm{NiFe}_{2} \mathrm{O}_{4}, \mathrm{NaAlSiO}_{4}$ \\
\hline NEPH-23 & 426 & 49 & quenched & Metallic haze on surface, bulk was homogeneous & - \\
\hline NEPH-23 & 426 & 49 & $\mathrm{ccc}$ & Surface dull matte color with crystals, bulk completely devitrified & $\mathrm{NiFe}_{2} \mathrm{O}_{4}, \mathrm{NaAlSiO}_{4}, \mathrm{Li}_{2} \mathrm{SiO}_{3}$ \\
\hline NEPH-24 & 418 & 43 & quenched & Metallic haze on surface, bulk was homogeneous & - \\
\hline NEPH-24 & 418 & 43 & $\operatorname{ccc}$ & Surface dull matte color with crystals, bulk homogeneous & Amorphous \\
\hline NEPH-25 & 418 & 47 & quenched & Metallic haze on surface, bulk was homogeneous & - \\
\hline NEPH-25 & 418 & 47 & $\operatorname{ccc}$ & Surface dull matte color with crystals, bulk devitrified & $\mathrm{NiFe}_{2} \mathrm{O}_{4}, \mathrm{NaAlSiO}_{4}$ \\
\hline NEPH-26 & 418 & 51 & quenched & Metallic haze on surface, bulk was homogeneous & - \\
\hline NEPH-26 & 418 & 51 & $\mathrm{ccc}$ & Surface dull matte color with crystals, bulk completely devitrified & $\mathrm{NiFe}_{2} \mathrm{O}_{4}, \mathrm{NaAlSiO}_{4}, \mathrm{Li}_{2} \mathrm{SiO}_{3}$ \\
\hline
\end{tabular}


Table 4-5. Visual and XRD Results for the SB4 Nepheline Phase 2 Glasses Based on the 1.6M, 40" SB3 Heel Options.

\begin{tabular}{|c|c|c|c|c|c|}
\hline Glass & $\begin{array}{l}\text { Frit } \\
\text { ID }\end{array}$ & $\begin{array}{l}\text { Target } \\
\text { WL }\end{array}$ & $\begin{array}{c}\text { Heat } \\
\text { Treatment }\end{array}$ & Visual & XRD \\
\hline NEPH-27 & 320 & 39 & quenched & Partial metallic haze on surface, bulk was homogeneous & - \\
\hline NEPH-27 & 320 & 39 & $\operatorname{ccc}$ & Surface dull matte color with crystals, bulk homogeneous & Amorphous \\
\hline NEPH-28 & 320 & 44 & quenched & Metallic haze on surface, bulk was homogeneous & - \\
\hline NEPH-28 & 320 & 44 & $\mathrm{ccc}$ & Surface dull matte color with crystals, questionable crystallization within bulk & $\mathrm{NiFe}_{2} \mathrm{O}_{4}$ \\
\hline NEPH-29 & 320 & 49 & quenched & Metallic haze on surface, bulk was homogeneous & - \\
\hline NEPH-29 & 320 & 49 & $\mathrm{ccc}$ & Surface dull matte color with crystals, bulk completely devitrified & $\mathrm{NiFe}_{2} \mathrm{O}_{4}, \mathrm{NaAlSiO}_{4}, \mathrm{Li}_{2} \mathrm{SiO}_{3}$ \\
\hline NEPH-30 & 417 & 40 & quenched & Minor metallic haze on surface, bulk was homogeneous & - \\
\hline NEPH-30 & 417 & 40 & $\operatorname{ccc}$ & Isolated crystals on surface, bulk homogeneous & Amorphous \\
\hline NEPH-31 & 417 & 44 & quenched & Metallic haze on surface, bulk was homogeneous & - \\
\hline NEPH-31 & 417 & 44 & $\mathrm{ccc}$ & Surface dull matte color with crystals, bulk partially devitrified & $\mathrm{NiFe}_{2} \mathrm{O}_{4}, \mathrm{NaAlSiO}_{4}, \mathrm{Li}_{2} \mathrm{SiO}_{3}$ \\
\hline NEPH-32 & 417 & 48 & quenched & Metallic haze on surface, bulk was homogeneous & - \\
\hline NEPH-32 & 417 & 48 & $\mathrm{ccc}$ & Surface dull matte color with crystals, bulk completely devitrified & $\mathrm{NiFe}_{2} \mathrm{O}_{4}, \mathrm{NaAlSiO}_{4}, \mathrm{Li}_{2} \mathrm{SiO}_{3}$ \\
\hline NEPH-33 & 425 & 41 & quenched & Metallic haze on surface, bulk was homogeneous & - \\
\hline NEPH-33 & 425 & 41 & $\operatorname{ccc}$ & Surface dull matte color with crystals, bulk homogeneous & $\mathrm{NiFe}_{2} \mathrm{O}_{4}$ \\
\hline NEPH-34 & 425 & 45 & quenched & Metallic haze on surface, bulk was homogeneous & - \\
\hline NEPH-34 & 425 & 45 & $\mathrm{ccc}$ & Surface dull matte color with crystals, bulk completely devitrified & $\mathrm{NiFe}_{2} \mathrm{O}_{4}, \mathrm{NaAlSiO}_{4}, \mathrm{Li}_{2} \mathrm{SiO}_{3}$ \\
\hline NEPH-35 & 425 & 48 & quenched & Metallic haze on surface, bulk partially devitrified & - \\
\hline NEPH-35 & 425 & 48 & $\mathrm{ccc}$ & Surface dull matte color with crystals, bulk completely devitrified & $\mathrm{NiFe}_{2} \mathrm{O}_{4}, \mathrm{NaAlSiO}_{4}, \mathrm{Li}_{2} \mathrm{SiO}_{3}$ \\
\hline NEPH-36 & 426 & 42 & quenched & Minor metallic haze on surface, bulk was homogeneous & - \\
\hline NEPH-36 & 426 & 42 & $\operatorname{ccc}$ & Surface dull matte color with crystals, bulk homogeneous & $\mathrm{NiFe}_{2} \mathrm{O}_{4}$ \\
\hline NEPH-37 & 426 & 45 & quenched & Metallic haze on surface, bulk was homogeneous & - \\
\hline NEPH-37 & 426 & 45 & $\mathrm{ccc}$ & Surface dull matte color with crystals, bulk partially devitrified & $\mathrm{NiFe}_{2} \mathrm{O}_{4}, \mathrm{NaAlSiO}_{4}$ \\
\hline NEPH-38 & 426 & 47 & quenched & Metallic haze on surface, bulk was homogeneous & - \\
\hline NEPH-38 & 426 & 47 & $\mathrm{ccc}$ & Surface dull matte color with crystals, bulk partially devitrified & $\mathrm{NiFe}_{2} \mathrm{O}_{4}, \mathrm{NaAlSiO}_{4}, \mathrm{Li}_{2} \mathrm{SiO}_{3}$ \\
\hline NEPH-39 & 418 & 43 & quenched & Metallic haze on surface, bulk was homogeneous & - \\
\hline NEPH-39 & 418 & 43 & $\mathrm{ccc}$ & Surface dull matte color with crystals, bulk partially devitrified & $\mathrm{NiFe}_{2} \mathrm{O}_{4}$ \\
\hline NEPH-40 & 418 & 46 & quenched & Metallic haze on surface, bulk was homogeneous & - \\
\hline NEPH-40 & 418 & 46 & $\mathrm{ccc}$ & Surface dull matte color with crystals, bulk partially devitrified & $\mathrm{NiFe}_{2} \mathrm{O}_{4}$ \\
\hline
\end{tabular}




\subsubsection{Visual Observations}

Visual observations on the quenched Phase 2 glasses indicated that four glasses were homogeneous, while the remaining 24 glasses were characterized by a metallic haze on the surface with the bulk (cross-section) being homogeneous. The four quenched glasses classified as visually homogeneous were NEPH2-13, NEPH2-15, NEPH2-18, and NEPH2-21 - all low WL glasses within their respective frit series and all based on the 127" option. No 40" SB3 heel option based glasses were visually characterized as homogeneous.

The noted surface crystallization on the remaining 24 glasses is consistent with historical visual observations of DWPF-based glasses especially those targeting higher waste loadings. More specifically, use of descriptions such as a dull or matte texture and/or metallic-like surface is common for DWPF-type glasses targeting higher WLs and/or having undergone a slow cooling schedule. Previous XRD analyses have typically indicated that the textured or metallic-like surfaces are a result of spinels that precipitate during the cooling process. This is in-line with glass theory that suggests that as WL increases, the concentrations of $\mathrm{Fe}_{2} \mathrm{O}_{3}, \mathrm{NiO}, \mathrm{Cr}_{2} \mathrm{O}_{3}$, and/or $\mathrm{MnO}$ also increase; thus enhancing the likelihood of spinel devitrification. Based on the PCT responses for the quenched Phase 2 glasses, spinel formation resulting in the metallic haze is reasonable as spinels have been shown to have no impact on the durability response.

A dull matte surface texture characterized the surface of all $28 \mathrm{ccc}$ glasses. The primary difference among the ccc glasses is the degree of devitrification visually observed within the bulk glass. That is, when examining the cross-sections of the heat treated samples, visual observations ranged from "homogeneous" to "completely devitrified". In general, the transition from homogeneous to partially devitrified and ultimately to completely devitrified resulted as WL increased within a specific frit - sludge system. For example, consider NEPH2-21 ccc through NEPH2-23ccc (from Table 4-4). The visual observations suggest that the bulk of the heat treated samples were homogeneous at $42 \% \mathrm{WL}$ (NEPH2-21ccc), partially devitrified at $46 \% \mathrm{WL}$ (NEPH2-22ccc), and completely devitrified at 49\% WL (NEPH2-23ccc).

In general, visual observations indicate that devitrification was more prevalent in the ccc glasses than in the quenched glasses, as expected, given kinetics are more favorable during the slower cooling cycle.

\subsubsection{XRD Results}

The XRD results shown in Table 4-4 and Table 4-5 provide a technical basis for making decisions regarding the impact of nepheline formation on durability. The PCT data (as shown in Figure 4-2 and Figure 4-3) indicated that as WL increased within a frit - sludge system, the difference in NL [B] between quenched and ccc glasses increased. Visual observations suggested that the ccc glasses became progressively more devitrified as WL increased, which is in agreement with the PCT response assuming precipitation of a phase such as nepheline. With all of the Phase 2 glasses being prone to nepheline formation based on the 0.62 value, expectations were that nepheline would form in these glasses, resulting in a decrease in durability, with only the magnitude being unknown. The XRD results confirm these expectations.

XRD results for all of the lower WL ccc glasses within each frit - sludge system indicate that the glasses were either amorphous or contained spinel (trevorite). For the 127"-based glasses, the PCT results suggested no measurable difference between the quenched and ccc glasses at the lower WLs. XRD results indicated that 4 of the 5 lower WL ccc glasses were amorphous with only one (NEPH2-18ccc) being characterized by spinel. The XRD results agree with the PCT 
responses given there was no significant or measurable difference in PCT response between the quenched and ccc glasses. When considering the 40"-based, lower WL ccc glasses, XRD results indicate that two of the five glasses were amorphous; while spinels characterized the remaining three. Expectations in terms of PCT response could be in-line with the 127'-based systems - no measurable difference in durability between quenched and ccc glasses. However, based on the measured PCT responses, this is not the case. That is (and as previously discussed), there appears to be a more significant and measurable difference in PCT response for these five lower WL glasses as compared to the 127" based glasses. This suggests that nepheline may be present (but below the XRD detection limit) in these 40" SB3 heel based ccc glasses but the impact on durability is minimal and of no practical concern - consistent with the Phase 1 results. The practical implication for DWPF is that blending the higher $\mathrm{Al}_{2} \mathrm{O}_{3}$ sludge with less of a SB3 heel would increase the probability of nepheline formation. More specifically, blending SB4 with a larger heel of SB3 would "dilute" the $\mathrm{Al}_{2} \mathrm{O}_{3}$ concentration, which would lessen the likelihood of nepheline formation.

The most significant change in PCT response between the quenched and ccc 40"-based, lower WL glasses was for NEPH2-27 with a $0.67 \mathrm{~g} / \mathrm{L} \mathrm{NL}$ [B] to $2.02 \mathrm{~g} / \mathrm{L}$ shift upon ccc. As with the Phase 1 glasses, this shift is a measurable difference but is not of practical concern (i.e., avoiding this glass system at WLs up to 39\% is not warranted). The bottom line is that all the quenched glasses and low WL ccc based glasses are very acceptable based on the measured PCT responses. This is not the case at higher WLs for the ccc glasses.

XRD results indicated the presence of nepheline $\left(\mathrm{NaAlSiO}_{4}\right)$, trevorite $\left(\left(\mathrm{NiFe}_{2} \mathrm{O}_{4}\right)\right.$, and/or lithium silicate $\left(\mathrm{Li}_{2} \mathrm{SiO}_{3}\right)$ in the Phase 2 glasses at higher WLs. In general, as the WL increases within a specific frit - sludge system, the crystalline phase(s) detected transition from amorphous or spinels (at the lowest WL), to spinel and nepheline (at the intermediate WL), and ultimately to spinel, nepheline, and lithium silicate (at the highest WL). Although numerous comparisons can be made, consider the series of NEPH2-24, -25, and -26 based on Frit 418 and the 127" SB3 heel option at 43,47 , and $51 \%$ WLs, respectively. XRD results indicate that NEPH2-24 ccc is amorphous (i.e., no crystallization identified at the detection limits of the X-ray diffractometer). Assuming the quenched version is amorphous as well, one would expect the PCT response between the quenched and ccc glasses to be essentially the same. Based on Table 4-2, the NL [B]'s for the quenched and ccc NEPH2-24 glasses were $0.83 \mathrm{~g} / \mathrm{L}$ and $0.89 \mathrm{~g} / \mathrm{L}$, respectively. As the WL is increased from 43 to $47 \%$, XRD results indicate the formation of spinel $\left(\mathrm{NiFe}_{2} \mathrm{O}_{4}\right)$ and nepheline $\left(\mathrm{NaAlSiO}_{4}\right)$. With the formation of spinels having no impact on the PCT response, the main question is what impact (if any) did the formation of nepheline have and to what extent? The NL [B]'s for the quenched and ccc glasses of NEPH2-25 (targeting the intermediate WL of $47 \%$ ) were $0.95 \mathrm{~g} / \mathrm{L}$ and $4.72 \mathrm{~g} / \mathrm{L}$, respectively. The impact of nepheline formation is not only a statistically significant difference but may be of practical significance as well (as discussed in Section 4.2.4). Prior to evaluating the highest WL glass in this series, a comparison among the quenched and ccc glasses at the two "lower" WLs is warranted. First, consider the quenched versions of NEPH2-24 and NEPH2-25. The NL [B] releases for these two glasses are $0.83 \mathrm{~g} / \mathrm{L}$ and $0.95 \mathrm{~g} / \mathrm{L}$, respectively. The decrease in durability between these two glasses is likely due to a change in glass composition - not a result of devitrification. That is, at the higher WL, the $\mathrm{SiO}_{2}$ content in the glass decreases and the $\mathrm{Na}_{2} \mathrm{O}$ content increases which typically results in a lower durability product - although the $\mathrm{Al}_{2} \mathrm{O}_{3}$ content in the glass increases. This gradual decrease in durability with increased WL is not only expected by glass science but predicted by the durability model. As previously noted, the NL [B]'s for the NEPH2-24ccc and NEPH2-25ccc are $0.89 \mathrm{~g} / \mathrm{L}$ and $4.72 \mathrm{~g} / \mathrm{L}$, respectively. This decrease in durability is primarily related to the formation of nepheline in the NEPH2-25ccc glass - given spinels have no impact on the PCT response in 
DWPF type glasses, but the increase in WL should have minimal impact on the durability response in the absence of any significant microstrutural changes.

As WL increases from $47 \%$ to $51 \%$, one would expect to observe a continual decrease in the durability of the quenched glasses (based on model predictions). Indeed this is the case as the NL [B] for NEPH2-26 quenched is $1.02 \mathrm{~g} / \mathrm{L}$ - up from the $0.95 \mathrm{~g} / \mathrm{L}$ for NEPH2-25 quenched at $47 \%$ WL. Although a slight decrease in durability, the glass is very acceptable, which agrees with model predictions. The same can not be said for the NEPH2-26ccc glass as the NL [B] release was $37.82 \mathrm{~g} / \mathrm{L}$ - compared to the $4.72 \mathrm{~g} / \mathrm{L}$ release of intermediate WL NEPH2-25ccc glass. The XRD results indicate the presence of spinel, nepheline, and lithium silicate in NEPH2-26ccc. Although quantitative XRD results (i.e., vol\% of each phase) were not obtained, given the significant shift in PCT response between the two higher WL glasses upon ccc, one of two possibilities exists. The first is to consider or assume that the formation of $\mathrm{Li}_{2} \mathrm{SiO}_{3}$ has no impact on durability. If true, then the results suggests that the vol\% of nepheline increases with increased WL, removing more and more $\mathrm{SiO}_{2}$ and $\mathrm{Al}_{2} \mathrm{O}_{3}$ from the continuous glass matrix, which continually reduces the durability of the final product. The other option is that both $\mathrm{Li}_{2} \mathrm{SiO}_{3}$ and nepheline have a negative impact on durability. In either case, the end result is a final product that is unacceptable in terms of durability.

The PCT results not only indicate an $8 \mathrm{x}$ decrease in durability when transitioning from 47 to $51 \%$ WL for the Frit 418 - 127" SB3 heel based glasses but, perhaps more importantly, classification as an "unacceptable" glass when compared to the EA benchmark glass. That is, regardless of where one may ultimately draw the "line of demarcation" between acceptable and unacceptable glasses (in terms of a NL [B] release), NEPH2-26ccc is "unacceptable" - with the practical implications to DWPF being that at some critical WL, unacceptable glasses (based on the ccc thermal history) could be produced. It should be noted that the quenched version of NEPH2-26 $(51 \% \mathrm{WL})$ is very acceptable with a $1.02 \mathrm{~g} / \mathrm{L} \mathrm{NL}[\mathrm{B}]$. It is only when the higher WL glasses are subjected to the ccc schedule leading to the formation of nepheline and/or $\mathrm{Li}_{2} \mathrm{SiO}_{3}$ that results in the potential for an "unacceptable" glass.

As previously noted, in general, as WL increases within a specific frit - sludge system, the crystalline phase(s) detected transition from amorphous or spinels (at the lowest WL), to spinel and nepheline (at the intermediate WL), and ultimately to spinel, nepheline, and lithium silicate (at the highest WL). The formation of nepheline can have a detrimental impact on the PCT response. The magnitude of the impact is likely related to the vol\% of nepheline formed (although not formally measured), which should be directly related to the targeted WL and the value of the nepheline discriminator. Although the formation of $\mathrm{Li}_{2} \mathrm{SiO}_{3}$ could potentially reduce durability as well, as WLs increase the nepheline discriminator values decrease which could reflect a higher propensity for nepheline formation. Coupling this trend with the known impact on PCT response, one can easily explain the general trends observed in Figure 4-2 and Figure 4-3. More specifically, as WL increases within a specific frit - sludge system, the durability of the ccc based glasses decreases.

Figure 4-6 summarizes the PCT response for the ccc Phase 2 glasses as a function of the type of crystallization (amorphous, spinel $\left(\mathrm{NiFe}_{2} \mathrm{O}_{4}\right)$, nepheline $\left(\mathrm{NaAlSiO}_{4}\right)$, and lithium silicate $\left.\left(\mathrm{Li}_{2} \mathrm{SiO}_{3}\right)\right)$ and $\mathrm{WL}$. The trends are in agreement with previous observations that the impact on durability is dependent upon the type and extent of crystallization and the resulting change to the residual glass composition. As previously noted, nepheline formation can result in a severe deterioration of the chemical durability of the glass through residual glass compositional changes (i.e., a continuous glass matrix which is $\mathrm{Al}_{2} \mathrm{O}_{3}$ and/or $\mathrm{SiO}_{2}$ deficient). The primary driver for the reduction in durability is the fact that nepheline removes three moles of glass forming oxides 
$\left(\mathrm{Al}_{2} \mathrm{O}_{3}\right.$ and $\left.2 \mathrm{SiO}_{2}\right)$ per each mole of $\mathrm{Na}_{2} \mathrm{O}$ from the continuous glass phase. Therefore, nepheline formation produces an $\mathrm{Al}_{2} \mathrm{O}_{3}$ and $\mathrm{SiO}_{2}$ deficient continuous glass matrix (relative to the same composition which is void of crystals), which reduces the durability of the final product. The magnitude of the reduction ultimately depends on the extent (e.g., vol\%) of crystallization.

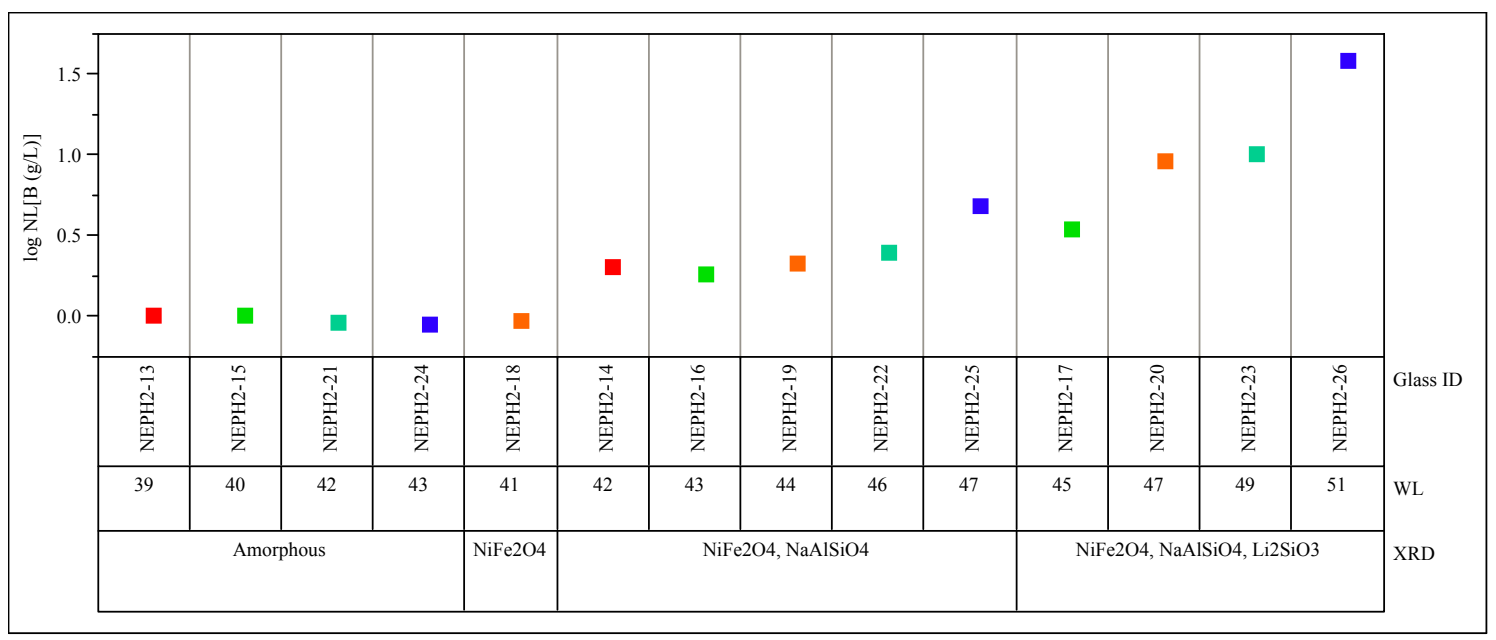

Figure 4-6. PCT Response of the ccc Phase 2 Glasses as a Function of Crystalline Type and WL. 


\subsection{PRACTICAL IMPACTS TO DWPF}

Edwards and Peeler (2005) selected the Phase 2 glasses in an effort to "challenge" the nepheline discriminator value of 0.62 . That is, all 28 Phase 2 glasses were prone to nepheline formation based on the nominal targeted compositions. The results suggest that the 0.62 value appears to be a reasonable guide to monitor SB4 - frit systems with respect to potential nepheline formation upon ccc. The significance of "ccc" in the latter sentence is based on the fact that none of the Phase 2 quenched glasses show any sign of nepheline formation (based on the PCT response) although some had nepheline discriminator values as low as 0.541 . The PCT responses for all of the quenched glasses were very acceptable with NL [B] values of $1.19 \mathrm{~g} / \mathrm{L}$ or less. It is only when the glass is provided a kinetic opportunity to devitrify through the slow ccc schedule does nepheline form and ultimately have an adverse impact on durability.

When comparing the Phase 2 results to Phase 1 (Peeler et al. 2005b), one may want to conclude that differences exist in their respective conclusions. That is, in Phase 1 it was concluded that the PCT responses for the two glasses prone to nepheline formation were statistically different but of no practical concern. The Phase 2 glasses show not only a statistical difference but a practical difference as well. Before making further comparisons between the two phases, one must review the targeted WLs. The WLs of Phase 1 were limited to a high of $40 \%$. The Phase 2 glasses were primarily based on glasses targeting $40 \%$ or higher. In Phase 2 , the lower WL glasses showed no significant or practical differences in durability when comparing quenched and ccc glasses - this is consistent with the Phase 1 results. It was only at the higher WLs (in Phase 2) that nepheline formation had a significantly negative impact on durability. The practical implication to DWPF is that higher WL glasses should be avoided for these types of glass systems (i.e., high $\mathrm{Al}_{2} \mathrm{O}_{3}$ ). The primary question becomes how should DWPF control or eliminate nepheline formation? Should the control be WL driven or strictly mitigated through the implementation of a nepheline discriminator value or administrative limit? If the former (WL), then how does one define the critical WL at which nepheline becomes an issue (given the Phase 2 data suggest that the critical WL may be frit and sludge dependent)? If the latter (nepheline discriminator or administrative limit), then what value should one use as a guide ( 0.62 or 0.60$)$ ? Or can strategic frit development efforts identify candidate frits that lessen the likelihood of nepheline formation, while meeting other critical process related goals (such as melt rate)? Although a formal recommendation of the specific path is not made in this report, a general discussion is provided on options that are available. It should be noted that although nepheline formation is a real and potentially significant issue, other constraints or alternatives may arise that would mitigate the impact as will be discussed.

Thus, the results of the Phase 2 study suggest that there is a real need to minimize and/or control the potential for nepheline formation during the processing of SB4 (based on the options currently being considered for this sludge). One strategy being pursued to support this effort is in the area of frit development. ${ }^{10}$ Specifically, as candidate frits are identified and evaluated, the nepheline discriminator will be used along with the more traditional PCCS MAR assessments. This will allow the frit development team to downselect the frits to those that offer attractive operating windows, provide the potential for acceptable melt rates, and lessen the likelihood (based on their evaluation using the nepheline discriminator) that the corresponding glass systems would form nepheline when kinetic conditions are favorable. This strategy alone may be sufficiently

\footnotetext{
${ }^{10}$ Based strictly on mathematics, frit development efforts to lower the $\mathrm{Na}_{2} \mathrm{O}$ and/or increase the $\mathrm{SiO}_{2}$ content (in the frit) should be evaluated to minimize the impacts of nepheline formation. Although this strategy may be advantageous with respect to nepheline formation, other processing properties (e.g., $T_{L}$, viscosity, or melt rate) may be negatively impacted.
} 
successful to provide DWPF adequate and defensible assurance for the "nepheline-free" processing of SB4. If not, then other options such as the implementation of administrative controls on WL or incorporation of a nepheline discriminator in DWPF's PCCS may have to be pursued.

Assuming strategic frit development efforts are not successful, DWPF could elect to use an administrative control on WL to avoid nepheline formation. However, selecting a single WL as a control based on the Phase 2 data may be ill-advised given the dependence upon the specific frit sludge system (until the specific SB4 sludge and frit is known) and the lack of a defined "acceptability bar". The "acceptability bar" referring to a $\mathrm{g} / \mathrm{L}$ value that one could use to differentiate acceptable versus unacceptable glasses relative to EA. For example, one could use a normalized boron release limit of $10 \mathrm{~g} / \mathrm{L}$ (consistent with Edwards and Brown (1998)) or a more conservative value of $4 \mathrm{~g} / \mathrm{L}$. Even if an "acceptability bar" is defined, establishing a WL limit to meet such a criterion would be dependent upon the specific frit - sludge system of interest. Given this dependence, DWPF may elect to use a nepheline "administrative control" limit value to avoid producing an unacceptable glass upon ccc. More specifically, a nepheline discriminator value (such as the 0.62 value proposed by Li et al. (2003)) may be determined for each Slurry Mix Evaporator (SME) batch to ensure that there are no negative impacts on durability. Regardless of the control method (i.e., a nepheline value or a WL constraint), the "acceptance bar" must be defined. For example, consider the use of a 0.62 nepheline "administrative control" limit and an "acceptance bar" value $4 \mathrm{~g} / \mathrm{L}$ ( or $0.5 \log \mathrm{NL}$ [B]).

Figure 5-1 shows the ccc PCT responses for Phase 2 glasses as a function of their nepheline discriminator values (computed based on targeted compositions). Using the $4.0 \mathrm{~g} / \mathrm{L}$ acceptance criteria (horizontal green line located at $0.6 \log \mathrm{NL}[\mathrm{B}]$ release), a nepheline discriminator value of $\sim 0.608$ would be required to ensure that the ccc versions of the SB4 based glasses do not exceed a $4 \mathrm{~g} / \mathrm{L}$ NL [B] limit (based solely on the Phase 2 data). In terms of DWPF processing, one could implement SME acceptability control based on either a 0.608 limit or a WL limit. Due to the added uncertainties associated with a potential WL assessment, if needed or required, it is recommended that the nepheline discriminator be used to control the possibility of making a glass (or a certain fraction of the glass which has undergone the ccc profile), which exceeds the $4 \mathrm{~g} / \mathrm{L}$ criteria - albeit arbitrary and well below the EA glass response of $16.695 \mathrm{~g} / \mathrm{L}$. Edwards and Brown (1998) used an acceptance criterion of $10 \mathrm{~g} / \mathrm{L}$ to assess the potential elimination of the homogeneity constraint through the use of an $\mathrm{Al}_{2} \mathrm{O}_{3}$ and/or sum of alkali criteria. If the $10 \mathrm{~g} / \mathrm{L}$ limit is used as the "acceptance criterion" (red horizontal line) then nepheline discriminator values of approximately 0.59 (or higher) would be acceptable to avoid making a DWPF glass that exceeds the $10 \mathrm{~g} / \mathrm{L}$ limit. On the other hand, lowering the acceptance limit to $2 \mathrm{~g} / \mathrm{L}$ (blue horizontal line), forces one to implement a nepheline discriminator value of approximately 0.62 (or greater). 


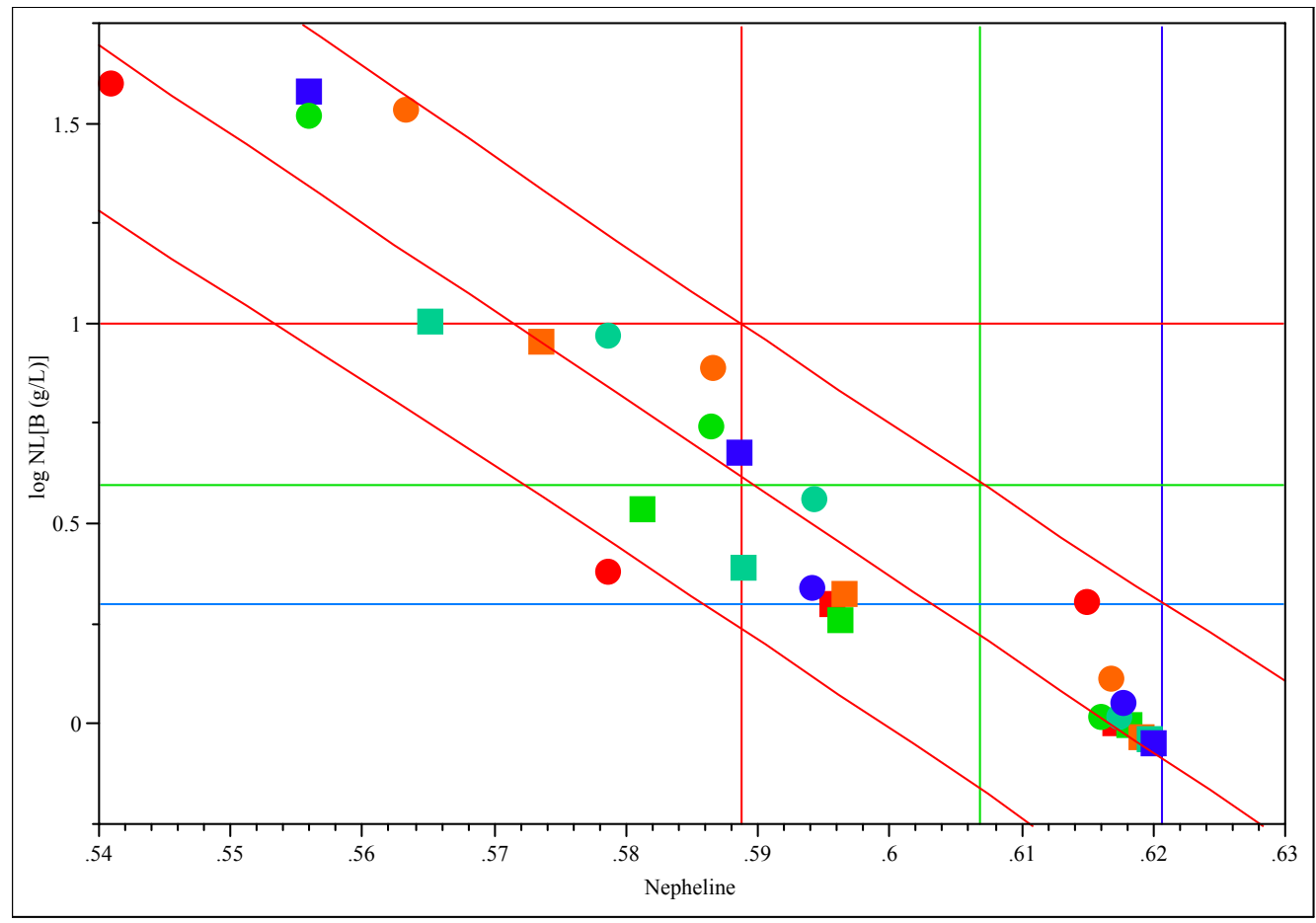

Figure 5-1. $\log$ NL [B] (g/L) Versus Computed Nepheline Discriminator Value for the Phase 2 ccc glasses.

Although perhaps initially conceived as a trivial matter, the practical implications of setting an "acceptance bar" are two-fold: First, one has to consider how far to push or challenge the Waste Qualification Report (WQR) acceptance criteria as they relate to the EA glass. In doing so, one also needs to balance the fact that allowing or setting a lower nepheline discriminator value allows access to higher WLs for all the SB4 - frit options that have been assessed. Obviously the higher WLs are attractive as there is potential to improve waste throughputs in DWPF assuming melt rate can be sustained at the higher WLs. Other processing criteria could also impact the targeted WL in DWPF. As an example, the ability to pump the sludge effectively may be inhibited as WL increases. If so, then WLs may be limited based on a processing issue that effectively pulls or removes the issue of nepheline formation and its ultimate impact on durability. Therefore, one may not need to implement such an administrative constraint in DWPF to control nepheline formation. As previously mentioned, historical melt rate trends suggest that as WL is increased, melt rate decreases. Although this potentially establishes a precedent to target lower WLs, it has also been shown that waste throughput (the amount of waste processed per unit time - the ultimate measure of success) is a compromise between melt rate and waste loading. Historically, maximum waste throughput has been achieved at some "intermediate" WL. If this trend holds for SB4, then not only could "processing" issues (such as pumpability as related to rheology) limit targeting higher WLs but melt rate and/or waste throughput issues could also limit WLs to the point where nepheline is not a concern. Therefore, as the SB4 flowsheet is refined, one must continue to assess which parameter may ultimately influence the targeted WLs. If nepheline becomes the limiting factor, then decisions regarding the "acceptance bar" should be defined and ultimately implemented into the DWPF process control scheme - potentially as an administrative control outside the realm of the SME acceptability decision.

The frit selection process for SB4 will ultimately be dependent on the strategy (or risks) one elects to take. More specifically, a conservative (and potentially bounding) strategy would be to 
avoid nepheline formation altogether through strategic frit development efforts or at least suppress it to WLs of $50 \%$ of higher. At these higher WLs, the probability of another property limiting acceptability is extremely high - thus taking nepheline and its potential negative impact out of the picture. To do this one may need to reduce the $\mathrm{Na}_{2} \mathrm{O}$ content and/or increase the $\mathrm{SiO}_{2}$ content of the frit, both of which may lead to relatively slow melt rates. The other extreme would be to push the $\mathrm{Na}_{2} \mathrm{O}$ concentration in glass to the point at which WL and/or melt rate may be optimized but could put DWPF on the edge of compromising product quality - a condition to be avoided. The answer may lie somewhere between these two extremes. That is, one needs to balance the probability (or possibility) to mitigate nepheline formation while gaining as much advantage in melt rate and/or WL space as possible. To perform such a balancing act, more information than presented in this report is required. The concept of frit selection to meet processing goals will be explored more thoroughly in the baseline report. 


\subsection{SUMMARY}

The impact of devitrification on durability is complex and depends on several interrelated factors including the change in residual glass composition, the formation of internal stress or microcracks, and the preferential attack at the glass-crystal interface. As noted from previous experimental studies, perhaps the most significant effects are the type and extent (or fraction) of crystallization and the resulting change to the residual glass composition. The formation of nepheline $\left(\mathrm{NaAlSiO}_{4}\right)$ can have a negative impact on durability as it produces an $\mathrm{Al}_{2} \mathrm{O}_{3}$ and $\mathrm{SiO}_{2}$ deficient continuous glass matrix (relative to the same composition which is void of crystals). The magnitude of the reduction ultimately depends on the extent (e.g., volume \%) of crystallization.

To assess the propensity of alumino-borosilicate glasses to precipitate nepheline, Li et al. (1997 and 2003) indicated that if the compositional projection falls within or close to the nepheline primary phase field (within the $\mathrm{Na}_{2} \mathrm{O}-\mathrm{Al}_{2} \mathrm{O}_{3}-\mathrm{SiO}_{2}$ ternary) the glass is prone to nepheline formation. Specifically, glasses with $\mathrm{SiO}_{2} /\left(\mathrm{SiO}_{2}+\mathrm{Na}_{2} \mathrm{O}+\mathrm{Al}_{2} \mathrm{O}_{3}\right)>0.62$, where the chemical formula stands for the mass fractions in the glass, do not tend to precipitate nepheline as their primary phase. The formation of nepheline and/or other aluminum/silicon-containing crystals is a potential in the SB4 system due to the projected compositional views recently evaluated coupled with the frit development strategy.

Peeler et al. (2005b) initially addressed this concern through a Phase 1 study. The results not only suggested that the 0.62 value appeared to be a reasonable guide to monitor aluminoborosilicate based glass systems with respect to potential nepheline formation, but also that the presence of nepheline, although statistically significant, had little or no practical impact in the SB4 system on durability as measured by the PCT. This latter statement was qualified to some extent given that only two glasses were selected that were actually prone to nepheline formation based on the general guide and that the volume $\%$ of nepheline formed based on XRD results was relatively low $(\sim 0.5 \mathrm{vol} \%)$. Given access to higher WLs may be anticipated, a subsequent study (referred to as Phase 2) was undertaken. The assumption was that targeting higher WLs may increase the potential for nepheline formation (and potentially the vol\%), which could ultimately lead to a significant and practical difference in PCT response - when considering differences in PCT response between the quenched and slow cooled version of the same glass.

Twenty-eight glasses were identified for the Phase 2 scope. The glasses were fabricated and the durability assessed for both quenched and centerline canister cooled samples. Fourteen of the 28 Phase 2 glasses were based on the nominal $1.6 \mathrm{M} \mathrm{Na}^{+}$with a 40 " SB3 heel option, while the other 14 glasses were based on the nominal $1.6 \mathrm{M} \mathrm{Na}^{+}$with a 127" SB3 heel - both "sludge-only" based flowsheets with no addition of ARP. Although high in $\mathrm{Al}_{2} \mathrm{O}_{3}$, these compositions are not considered the baseline or final projections.

All of the Phase 2 quenched glasses have normalized boron releases less than $1.19 \mathrm{~g} / \mathrm{L}$, which in terms of acceptability are approximately an order of magnitude better than the EA benchmark glass which has a reported NL [B] of $16.695 \mathrm{~g} / \mathrm{L}$ (Jantzen et al. 1993). The range of normalized releases for the quenched Phase 2 glasses is from $0.67 \mathrm{~g} / \mathrm{L}(\mathrm{NEPH} 2-27$ based on the Frit $320-$ 40 " SB3 heel case at 39\% WL) to $1.15 \mathrm{~g} / \mathrm{L}$ (NEPH2-16 based on the Frit $417-127$ " SB3 heel case at $43 \% \mathrm{WL}$ ). The results suggest that even though the glasses are prone to nepheline formation based on the 0.62 guide value, all 28 Phase 2 quenched glasses are acceptable (as well as predictable by the model), which may provide some technical basis for "challenging" nepheline formation to gain access to higher WLs for the various SB4 options - independent of 
frit composition. However, the potential for crystallization was suppressed in the quenched glasses in terms of kinetics. That is, the glasses may be prone to nepheline formation but the rapid cooling limited (or eliminated) the formation of nepheline (or other crystalline phases).

For the ccc glasses, visual observations suggested that in general, as the targeted WL within a specific frit - sludge system was increased, the degree of crystallization or devitrification appeared to be more extensive. This is not unexpected as the slower cooling provides a thermodynamically favorable (compositional-wise) glass the kinetic opportunity to devitrify. With the knowledge of devitrification, the questions of interest to this study were: "What is the impact on the PCT response?", "What are the crystalline phase(s) that formed?", and "Does the type and/or extent of crystallization agree with glass science theory in terms of their anticipated impact on the durability response?"

XRD results indicated the presence of nepheline $\left(\mathrm{NaAlSiO}_{4}\right)$, trevorite $\left(\left(\mathrm{NiFe}_{2} \mathrm{O}_{4}\right)\right.$, and /or lithium silicate $\left(\mathrm{Li}_{2} \mathrm{SiO}_{3}\right)$ in select Phase 2 ccc glasses. In general, as the WL increases within a specific frit - sludge system, the crystalline phase(s) detected transitioned from amorphous or spinels (at the lowest WL), to spinel and nepheline (at the intermediate WL), and ultimately to spinel, nepheline, and lithium silicate (at the highest WL). With the type of crystalline known, the focus shifted to the possible impact on durability.

The normalized boron releases for the 1.6M, 127" SB3 heel based ccc glasses ranged from 0.89 $\mathrm{g} / \mathrm{L}$ to $37.82 \mathrm{~g} / \mathrm{L}$. For the $1.6 \mathrm{M}, 40$ " ccc glasses the NL [B]'s ranged from $1.04 \mathrm{~g} / \mathrm{L}$ to $40.11 \mathrm{~g} / \mathrm{L}$. These values obviously span a much wider PCT response as compared to the quenched versions. In addition, and more importantly, the PCT results suggest that select Phase 2 glasses exceed the benchmark EA glass response of $16.695 \mathrm{~g} / \mathrm{L}$. The obvious question to ask is: "Which frit sludge combinations and/or WLs result in these unacceptable durabilities?" The general trend within each specific frit system is that as WL increases, the difference between the quenched and ccc PCT response increases. Coupling this trend with the crystallization results, one can easily explain the durability responses as a function of WL. More specifically, as WL increases within a specific frit - sludge system, the durability of the ccc based glasses decreases due to the formation of nepheline and/or lithium silicate. The trends are in agreement with previous observations that the impact on durability is dependent upon the type and extent of crystallization and the resulting change to the residual glass composition. As previously noted, nepheline formation can result in a severe deterioration of the chemical durability of the glass through residual glass compositional changes (i.e., a continuous glass matrix which is $\mathrm{Al}_{2} \mathrm{O}_{3}$ and/or $\mathrm{SiO}_{2}$ deficient).

The results of the Phase 1 and Phase 2 studies suggest that the 0.62 value appears to be a reasonable guide to monitor SB4 - frit systems with respect to potential nepheline formation upon ccc. The significance of "ccc" in the latter sentence is based on the fact that none of the Phase 1 or Phase 2 quenched glasses show any sign of nepheline formation (based on the PCT response) although some of the Phase 2 glasses had nepheline discriminator values as low as 0.541 . The PCT responses for all of the quenched glasses were very acceptable. It is only when the glass is provided the kinetic opportunity to devitrify through the slow ccc schedule that nepheline forms and ultimately has an adverse impact on durability.

In Phase 2, the lower WL glasses showed no significant or practical differences in durability when comparing quenched and ccc glasses - this is consistent with the Phase 1 results. It was only at the higher WLs (in Phase 2) that nepheline formation had a significantly negative impact on durability. The practical implication to DWPF is that higher WL glasses should be avoided for these types of glass systems (i.e., high $\mathrm{Al}_{2} \mathrm{O}_{3}$ and $\mathrm{Na}_{2} \mathrm{O}$ ). The primary question becomes how 
should DWPF control or eliminate nepheline formation? Should the control be WL driven or strictly mitigated through the implementation of a nepheline discriminator value or administrative limit? If the former (WL), then how does one define the critical WL at which nepheline becomes an issue (given the Phase 2 data suggest that the critical WL may be frit and sludge dependent)? If the latter (nepheline discriminator or administrative limit), then what value should one use as a guide (0.62 or 0.60$)$ ? Or can strategic frit development efforts identify candidate frits that lessen the likelihood of nepheline formation while meeting other critical process related goals (such as melt rate)? Although a formal recommendation of the specific path is not made in this report, a general discussion is provided on options that are available. It should be noted that although nepheline formation is a real and potentially significant issue, other constraints or alternatives may arise (e.g., pumping issues in the CPC) that would mitigate the impact as was discussed. 


\subsection{PATH FORWARD}

Based on the results and observations of this study, the following recommendations are made:

- Develop strategy to avoid nepheline formation in SB4 type glasses. Options include:

o Strategic frit development efforts

- Frit compositions targeting lower $\mathrm{Na}_{2} \mathrm{O}$ values and higher $\mathrm{SiO}_{2}$ values should (mathematically) minimize the possibility of nepheline formation for a given sludge composition. Although potentially effective for minimizing nepheline formation in SB4 glasses, the impact of these frit compositional changes on melt rate or waste throughput are unknown at this time and should be evaluated.

o Administrative control on WL

- In order to effectively identify or set an administrative control on WL, specific information regarding the sludge composition and frit should be known. This is due to the dependence of the "critical" WL at which nepheline is predicted to be active (using the 0.62 value) for the sludge and frit combinations used.

o Implementation of nepheline discriminator (with uncertainties applied)

- Although the 0.62 value appears to be a reasonable value to guide assessments of nepheline formation (and its potential impact on durability), there appears to be some "uncertainty" in the exact value to use (e.g., 0.62 or 0.60 given the lower WL Phase 1 and Phase 2 glasses showed no significant or practical impact). Or, if implemented in PCCS, should uncertainties be added to this value similar to those for other properties which would increase the discriminator value to potentially $>$ 0.62 ?

- Future frit development efforts for SB4 (or other higher $\mathrm{Al}_{2} \mathrm{O}_{3}$-based waste streams) should continue to use the nepheline discriminator value of 0.62 to assess nepheline formation potential.

- Ultimately, the Phase 1 and Phase 2 nepheline study data will play a major role in assessing the need for a variability study. The Phase 1 and Phase 2 data (along with other information that could support this assessment) should be integrated into the compiled composition - property database $\left(\mathrm{ComPro}^{\mathrm{TM}}\right)$ and validated per procedures or guidelines recommended by Taylor et al. (2004).

O It is recommended that the three Phase 2 glasses (NEPH2-21, NEPH2-27, and NEPH2-28) not be included in any future modeling of durability responses but classified as non-model data in $\mathrm{ComPro}^{\mathrm{TM}}$ due to the compositional uncertainties observed in this study. 


\subsection{REFERENCES}

ASTM 2002. "Standard Test Methods for Determining Chemical Durability of Nuclear Waste Glasses: The Product Consistency Test (PCT)," ASTM C-1285-2002.

Bickford, D.F. and C.M. Jantzen. 1984. "Devitrification of SRL Defense Waste Glass", Sci. Basis for Nuclear Waste Management, VII, G.L. McVay (ed). Elsevier Publ., New York, pgs. 557-565.

Bickford, D.F. and C.M. Jantzen. 1986. "Devitrification of Defense Nuclear Waste Glasses: Role of Melt Insolubles”, J. Non-Crystalline Solids, 84 [1-3], pgs. 299-307.

Brown, K.G., C.M. Jantzen, and G. Ritzhaupt. 2001. Relating Liquidus Temperature to Composition for Defense Waste Processing Facility (DWPF) Process Control, WSRC-TR-200100520, Westinghouse Savannah River Company, Aiken, South Carolina.

Cicero, C.A., S.L. Marra, and M.K. Andrews. 1993. Phase Stability Determinations of DWPF Waste Glasses (U), WSRC-TR-93-227, Revision 0, Westinghouse Savannah River Company, Aiken, South Carolina.

Edwards, T.B. and K.G. Brown. 1998. Evaluating the Glasses Batched for the Tank 42 Variability Study, SRT-SCS-98-017, Revision 0, Westinghouse Savannah River Company, Aiken, South Carolina.

Edwards, TB, DK Peeler, and SL Marra. 2003. Revisiting the Prediction Limits for Acceptable Durability, WSRC-TR-2003-00510, Revision 0, Westinghouse Savannah River Company, Aiken, South Carolina.

Edwards, T.B. and D.K. Peeler. 2005. Nepheline Formation Potential in Sludge Batch 4 (SB4) and Its Impact on Durability: Selecting Glasses for a Phase 2 Study, WSRC-TR-2005-00370, Revision 0, Westinghouse Savannah River Company, Aiken, South Carolina.

Elder, H.H. 2005a. Estimate of Sludge Batch 4 Calcine Composition, CBU-PIT-2005-00134, Revision 0, Westinghouse Savannah River Company, Aiken, South Carolina.

Elder, H.H. 2005b. Estimate of Sludge Batch 4 Calcine Composition Additional Cases, CBU-PIT-2005-00176, Revision 0, Westinghouse Savannah River Company, Aiken, South Carolina.

Jantzen, C.M., D.F. Bickford, D.G. Karraker, and G.G. Wicks. 1984. "Time-TemperatureTransformation Kinetics in SRL Waste Glass", Advances in Ceramics, Volume 8, American Ceramic Society, Westerville, OH, pgs. 30-38.

Jantzen, C.M., N.E. Bibler, D.C. Beam, C.L. Crawford, and M.A. Pickett. 1993. Characterization of the Defense Waste Processing Facility (DWPF) Environmental Assessment (EA) Glass Standard Reference Material, WSRC-TR-92-346, Revision 1, Westinghouse Savannah River Company, Aiken, South Carolina. 
Jantzen, C.M., J.B. Pickett, K.G. Brown, T.B. Edwards, and D.C. Beam. 1995. Process/Product Models for the Defense Waste Processing Facility (DWPF): Part I. Predicting Glass Durability from Composition Using a Thermodynamic Hydration Energy Reaction Model (THERMO) (U), WSRC-TR-93-672, Revision 1, Volume 1, Westinghouse Savannah River Company, Aiken, South Carolina.

Kim, D.S., D.K. Peeler, and P. Hrma. 1995. "Effect of Crystallization on the Chemical Durability of Simulated Nuclear Waste Glasses", Environmental Issues and Waste Management Technologies in the Ceramic and Nuclear Industries, Ceramic Transaction, Volume 61, pgs. 177 -185 .

Li, H., J.D. Vienna, P. Hrma, D.E. Smith, and M.J. Schwieger. 1997. "Nepheline Precipitation in High-Level Waste Glasses - Compositional Effects and Impact on the Waste Form Acceptability", Mat. Res. Soc. Proc., 465, pgs. 261- 268.

Li, H., P. Hrma, J.D. Vienna, M. Qian, Y. Su, and D.E. Smith. 2003. "Effects of $\mathrm{Al}_{2} \mathrm{O}_{3}, \mathrm{~B}_{2} \mathrm{O}_{3}$, $\mathrm{Na}_{2} \mathrm{O}$, and $\mathrm{SiO}_{2}$ on Nepheline Formation in Borosilicate Glasses: Chemical and Physical Correlations", Journal of Non-Crystalline Solids, 331, pgs. $202-216$.

Lilliston, GR. 2005. Development of Elemental Sludge Compositions for Variations of Sludge Batch 4 (SB4), CBU-PIT-2004-00011, Revision 1, Westinghouse Savannah River Company, Aiken, South Carolina.

Lorier, T.H., I.A. Reamer, and R.J. Workman. 2005. Initial Sulfate Solubility Study for Sludge Batch 4 (SB4), WSRC-TR-2005-00213, Revision 0, Westinghouse Savannah River Company, Aiken, South Carolina.

Marra, S.L. and C.M. Jantzen. 1993. Characterization of Projected DWPF Glass Heat Treated to Simulate Canister Centerline Cooling, WSRC-TR-92-142, Revision 1, Westinghouse Savannah River Company, Aiken, South Carolina.

Peeler, D.K. C.C. Herman, M.E. Smith, T.H. Lorier, D.R. Best, T.B. Edwards, and M.A. Baich. 2004. An Assessment of the Sulfate Solubility Limit for the Frit 418 - Sludge Batch 2/3 System, WSRC-TR-2004-00081, Revision 0, Westinghouse Savannah River Company, Aiken, South Carolina.

Peeler, D.K. and T.B. Edwards. 2005a. Frit Development Efforts for Sludge Batch 4 (SB4): Model-Based Assessments, WSRC-TR-2005-00103, Revision 0, Westinghouse Savannah River Company, Aiken, South Carolina.

Peeler, D.K., and T.B. Edwards. 2005b. Frit Development Efforts for Sludge Batch 4 (SB4): Nominal and Variation Stage Assessments, WSRC-TR-2005-00372, Revision 0, Westinghouse Savannah River Company, Aiken, South Carolina.

Peeler, D.K., T.B. Edwards, and T.H. Lorier. 2005a. Nepheline Formation Potential in Sludge Batch 4 (SB4) Glasses, WSRC-TR-2005-00153, Revision 0, Westinghouse Savannah River Company, Aiken, South Carolina.

Peeler, D.K., T.B. Edwards, I.A. Reamer, and R.J. Workman. 2005b. Nepheline Formation Study for Sludge Batch 4 (SB4): Phase 1 Experimental Results, WSRC-TR-2005-00371, Revision 0, Westinghouse Savannah River Company, Aiken, South Carolina. 
Riley, B.J., J.A. Rosario, and P. Hrma. 2001. Impact of HLW Glass Crystallinity on the PCT Response, PNNL-13491, Pacific Northwest National Laboratory, Richland, Washington.

Savannah River National Laboratory (SRNL). 2002a. "Glass Batching," SRTC Procedure Manual, L29, ITS-0001, Westinghouse Savannah River Company, Aiken, South Carolina.

Savannah River National Laboratory (SRNL). 2002b. "Glass Melting," SRTC Procedure Manual, L29, ITS-0003, Westinghouse Savannah River Company, Aiken, South Carolina.

Spilman, D.B., L.L. Hench, and D.E. Clark. 1986. "Devitrification and Subsequent Effects on the Leach Behavior of a Simulated Borosilicate Nuclear Waste Glass", Nuclear and Chemical Waste Management, Vol.6, pgs. 107 - 119.

Taylor, A.S., T.B. Edwards, J.C. George, T.K. Snyder, and D.K. Peeler, The SRNL Glass Composition - Properties (ComPro) Database, WSRC-RP-2004-00704, Revision 0, Westinghouse Savannah River Company, Aiken, South Carolina. 


\section{APPENDIX A \\ Analytical Plan Supporting the Chemical Composition Measurements (SRNL-SCS-2005-00042)}




\section{SRNL-SCS-2005-00042}

August 26, 2005

To:

D. K. Peeler, 999-W

cc:

R. A. Baker, 773-42A

D. R. Best, 786-1A (wo)

P. A. Toole, 786-1A (wo)

S. L. Marra, 999-W (es)

R. C. Tuckfield, $773-42 \mathrm{~A}$

I. A. Reamer, 999-1W

R. J. Workman, 999-1W

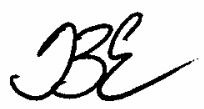

From: T. B. Edwards, 773-42A (5-5148)

Statistical Consulting Section

wo - without glass identifiers

es - executive summary only
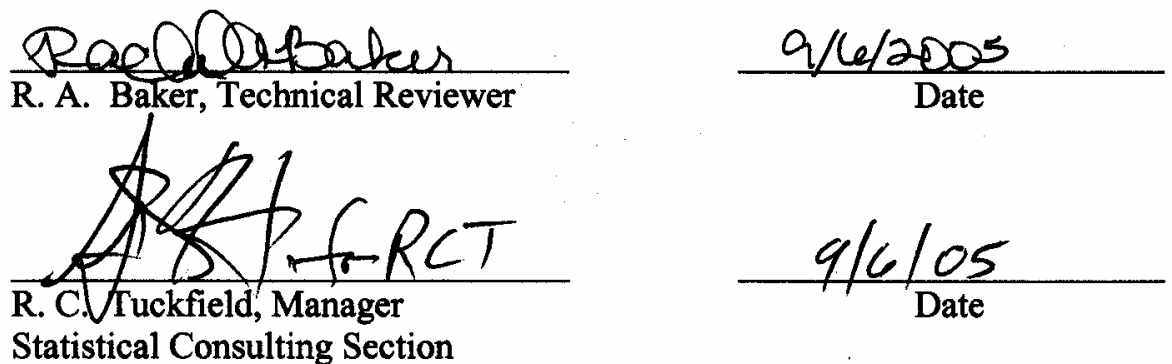

\section{AN ANALYTICAL PLAN FOR MEASURING THE CHEMICAL COMPOSITIONS OF THE NePHeline Phase 2 StUdy Glasses (U)}




\subsection{EXECUTIVE SUMMARY}

A study is being conducted by the Savannah River National Laboratory (SRNL) for the Defense Waste Processing Facility (DWPF) that involves investigating the potential impact of nepheline formation on the durability of high level waste glasses. To address this issue, twenty-eight glass compositions were identified for their potential for the formation of nepheline as part of the frit development activities for Sludge Batch 4 (SB4) and were selected to complement an earlier nepheline study. In general, the glasses cover waste loadings (WLs) over which nepheline was the only criterion restricting access to higher WLs, and they are to be investigated as Phase 2 of the study of the potential impact of nepheline for SB4.

The chemical compositions of these 28 Phase 2 glasses are to be determined by the Savannah River National Laboratory - Mobile Laboratory (SRNL-ML). This memorandum provides an analytical plan to direct and support these measurements at the SRNL-ML.

\subsection{INTRODUCTION}

A study is being conducted by the Savannah River National Laboratory (SRNL) for the Defense Waste Processing Facility (DWPF) that involves investigating the potential impact of nepheline formation on the durability of high level waste glasses [1]. To address this issue, twenty-eight glass compositions were identified for their potential for the formation of nepheline as part of the frit development activities for Sludge Batch 4 (SB4) and were selected to complement an earlier nepheline study. In general, the glasses cover waste loadings (WLs) over which nepheline was the only criterion restricting access to higher WLs, and they are to be investigated as Phase 2 of the study of the potential impact of nepheline for SB4.

The chemical compositions of the 28 Phase 2 glasses are to be determined by the Savannah River National Laboratory - Mobile Laboratory (SRNL-ML). This memorandum provides an analytical plan to direct and support these measurements at the SRNL-ML.

\subsection{Analytical Plan}

The analytical procedures used by the SRNL-ML to determine cation concentrations for a glass sample include steps for sample preparation and for instrument calibration. Each glass is to be prepared in duplicate by each of two dissolution methods: lithium metaborate fusion (LM) and sodium peroxide fusion (PF).

The primary measurements of interest are to be acquired as follows. The samples prepared by $\mathrm{LM}$ are to be measured for barium $(\mathrm{Ba})$, calcium $(\mathrm{Ca})$, cerium $(\mathrm{Ce})$, chromium $(\mathrm{Cr})$, copper $(\mathrm{Cu})$, potassium $(\mathrm{K})$, lanthanum $(\mathrm{La})$, magnesium $(\mathrm{Mg})$, sodium $(\mathrm{Na})$, lead $(\mathrm{Pb})$, sulfur $(\mathrm{S})$, thorium (Th), titanium (Ti), zinc (Zn), and zirconium ( $\mathrm{Zr}$ ) concentrations. Samples prepared by $\mathrm{PF}$ are to be measured for aluminum (Al), boron (B), iron (Fe), lithium ( $\mathrm{Li})$, manganese $(\mathrm{Mn})$, nickel $(\mathrm{Ni})$, silicon (Si), and uranium (U). Samples dissolved by both preparation methods are to be measured using Inductively Coupled Plasma - Atomic Emission Spectrometry (ICP-AES). It should be noted that some of these elements are minor components that may be near detection limits for most, if not all, of the study glasses.

Randomizing the preparation steps and blocking and randomizing the measurements for the ICPAES are of primary concern in the development of this analytical plan. The sources of 
uncertainty for the analytical procedure used by the SRNL-ML to determine the cation concentrations for the submitted glass samples are dominated by the dissolution step in the preparation of the sample and by the calibrations of the ICP-AES.

Samples of glass standards will be included in the analytical plan to provide an opportunity for checking the performance of the instrumentation over the course of the analyses and for potential bias correction. Specifically, several samples of Waste Compliance Plan (WCP) Batch 1 (BCH) [2] and a uranium standard glass (Ustd) are included in this analytical plan. The reference compositions of these glasses are provided in Table 1.

\section{Table 1: Oxide Compositions of WCP Batch 1 (BCH) (wt\%)}

\begin{tabular}{|ccc|}
\hline $\begin{array}{c}\text { Oxide/ } \\
\text { Anion }\end{array}$ & $\begin{array}{c}\text { BCH } \\
(\mathbf{w t ~ \% )}\end{array}$ & $\begin{array}{c}\text { Ustd } \\
\text { (wt \%) }\end{array}$ \\
$\mathrm{Al}_{2} \mathrm{O}_{3}$ & 4.877 & 4.1 \\
$\mathrm{~B}_{2} \mathrm{O}_{3}$ & 7.777 & 9.209 \\
$\mathrm{BaO}$ & 0.151 & 0 \\
$\mathrm{CaO}$ & 1.22 & 1.301 \\
$\mathrm{Cr}_{2} \mathrm{O}_{3}$ & 0.107 & 0 \\
$\mathrm{Cs} \mathrm{O}_{2} \mathrm{O}$ & 0.06 & 0 \\
$\mathrm{CuO}$ & 0.399 & 0 \\
$\mathrm{Fe}_{2} \mathrm{O}_{3}$ & 12.839 & 13.196 \\
$\mathrm{~K}_{2} \mathrm{O}$ & 3.327 & 2.999 \\
$\mathrm{Li} 2 \mathrm{O}$ & 4.429 & 3.057 \\
$\mathrm{MgO}$ & 1.419 & 1.21 \\
$\mathrm{MnO}$ & 1.726 & 2.892 \\
$\mathrm{Na}_{2} \mathrm{O}$ & 9.003 & 11.795 \\
$\mathrm{Nd}_{2} \mathrm{O}_{3}$ & 0.147 & 0 \\
$\mathrm{NiO}_{\mathrm{RuO}}$ & 0.751 & 1.12 \\
$\mathrm{RiO}_{2}$ & 0.0214 & 0 \\
$\mathrm{SO}_{3}$ & 50.22 & 45.353 \\
$\mathrm{TiO}_{2}$ & 0 & 0 \\
$\mathrm{U}_{3} \mathrm{O}_{8}$ & 0.677 & 1.049 \\
$\mathrm{ZrO}_{2}$ & 0 & 2.406 \\
\hline
\end{tabular}

Each glass sample submitted to the SRNL-ML will be prepared in duplicate by the LM and PF dissolution methods. Every prepared sample will be read twice by ICP-AES, with the instrument being calibrated before each of these two sets of readings. This will lead to four measurements for each cation of interest for each submitted glass.

Table 2 presents identifying codes, B01 through B28, for the 28 glasses fabricated for this nepheline study. The table provides a naming convention that is to be used in analyzing the glasses and reporting the measurements of their compositions. ${ }^{11}$

11 Renaming these samples helps to ensure that they will be processed as blind samples within the SRNL-ML. Table 2 is not shown in its entirety in the copy going to the SRNL-ML. 
Table 2: Glass Identifiers ${ }^{12}$ to Establish

Blind Samples for the SRNL-ML

\begin{tabular}{|cc|cc|}
\hline Glass & Sample & Glass & Sample \\
ID & ID & ID & ID \\
NEPH2-13 & B23 & NEPH2-27 & B18 \\
NEPH2-14 & B13 & NEPH2-28 & B20 \\
NEPH2-15 & B25 & NEPH2-29 & B07 \\
NEPH2-16 & B21 & NEPH2-30 & B14 \\
NEPH2-17 & B12 & NEPH2-31 & B08 \\
NEPH2-18 & B04 & NEPH2-32 & B28 \\
NEPH2-19 & B26 & NEPH2-33 & B15 \\
NEPH2-20 & B27 & NEPH2-34 & B01 \\
NEPH2-21 & B02 & NEPH2-35 & B09 \\
NEPH2-22 & B10 & NEPH2-36 & B22 \\
NEPH2-23 & B24 & NEPH2-37 & B05 \\
NEPH2-24 & B17 & NEPH2-38 & B11 \\
NEPH2-25 & B19 & NEPH2-39 & B16 \\
NEPH2-26 & B03 & NEPH2-40 & B06 \\
\hline
\end{tabular}

\subsection{PREPARATION OF THE SAMPLES}

Each of the 28 glasses included in this analytical plan is to be prepared in duplicate by the LM and PF dissolution methods. Thus, the total number of prepared glass samples is determined by $28 \cdot 2 \cdot 2=112$, not including the samples of the $\mathrm{BCH}$ and Ustd glass standards that are to be prepared.

Tables $3 \mathrm{a}$ and $3 \mathrm{~b}$ provide blocking and (random) sequencing schema for conducting the preparation steps of the analytical procedures. One block of preparation work is provided for each preparation method to facilitate the scheduling of activities by work shift. The identifier for each of the prepared samples indicates the sample identifier (ID), preparation method, and duplicate number.

12 The nomenclature NEPH2-13 stands for a nepheline glass ("NEPH”), Phase 2 (“2”), with the identifying number 13 (“-13"). The Phase 1 study contained twelve glasses, which leads to the use of the numbers 13-40 for this phase. 
Tables 3a and 3b: Preparation Blocks by Method

Table 3a: LM

(Lithium Metaborate)

Preparation Blocks

\begin{tabular}{|cc|} 
Block 1 & Block 2 \\
B25LM1 & B15LM1 \\
B24LM1 & B14LM1 \\
B19LM1 & B06LM1 \\
B25LM2 & B05LM1 \\
B13LM1 & B22LM1 \\
B04LM1 & B07LM1 \\
B21LM1 & B01LM1 \\
B17LM1 & B06LM2 \\
B23LM1 & B18LM1 \\
B19LM2 & B08LM1 \\
B02LM1 & B05LM2 \\
B10LM1 & B09LM1 \\
B13LM2 & B01LM2 \\
B21LM2 & B28LM1 \\
B27LM1 & B11LM1 \\
B03LM1 & B28LM2 \\
B12LM1 & B20LM1 \\
B17LM2 & B16LM1 \\
B24LM2 & B15LM2 \\
B26LM1 & B14LM2 \\
B23LM2 & B08LM2 \\
B02LM2 & B16LM2 \\
B04LM2 & B22LM2 \\
B03LM2 & B11LM2 \\
B27LM2 & B09LM2 \\
B26LM2 & B07LM2 \\
B10LM2 & B20LM2 \\
B12LM2 & B18LM2 \\
\hline
\end{tabular}

Table 3b: PF (Peroxide Fusion)

Preparation Blocks

Block 1 Block 2

B02PF1 B22PF1

B21PF1 B15PF1

B23PF1 B20PF1

B02PF2 B20PF2

B04PF1 B05PF1

B24PF1 B07PF1

B27PF1 B15PF2

B13PF1 B09PF1

B03PF1 B05PF2

B24PF2 B14PF1

B03PF2 B11PF1

B23PF2 B28PF1

B27PF2 B06PF1

B12PF1 B16PF1

B19PF1 B18PF1

B25PF1 B18PF2

B19PF2 B16PF2

B21PF2 B01PF1

B10PF1 B11PF2

B04PF2 B08PF1

B17PF1 B22PF2

B26PF1 B09PF2

B13PF2 B28PF2

B12PF2 B07PF2

B25PF2 B01PF2

B26PF2 B14PF2

B10PF2 B06PF2

$\mathrm{B} 17 \mathrm{PF} 2 \quad \mathrm{~B} 08 \mathrm{PF} 2$ 


\subsection{ICP-AES Calibration Blocks}

The glass samples prepared by the LM and PF dissolution methods are to be analyzed using ICPAES instrumentation calibrated for the particular preparation method. After the initial set of cation concentration measurements, the ICP-AES instrumentation is to be recalibrated and a second set of concentration measurements for the cations determined.

Randomized plans for measuring cation concentrations in the LM-prepared and PF-prepared samples are provided in Tables 4 and 5, respectively. The cations to be measured are specified in the header of each table. In the tables, the sample identifiers for the 28 study glasses have been modified by the addition of a suffix (a " 1 "or a " 2 ") to indicate whether the measurement was made during the first or second (respectively) calibration within each of the four ICP-AES blocks. The identifiers for the BCH and Ustd samples have been modified to indicate the ICP-AES block, the calibration, and that each of these prepared samples is to be read 3 times (mirrored in the corresponding suffix of 1,2 , or 3 ) per block and calibration.

Tables 4: ICP-AES Blocks \& Calibration Groups for the LM Glass Samples

(Used to Measure Elemental $\mathrm{Ba}, \mathrm{Ca}, \mathrm{Ce}, \mathrm{Cr}, \mathrm{Cu}, \mathrm{K}, \mathrm{La}, \mathrm{Mg}, \mathrm{Na}, \mathrm{Pb}, \mathrm{S}, \mathrm{Th}, \mathrm{Ti}, \mathrm{Zn}, \& \mathrm{Zr}$ )

\begin{tabular}{|c|c|c|c|c|c|c|c|}
\hline \multicolumn{2}{|c|}{ Block 1} & \multicolumn{2}{|c|}{ Block 2} & \multicolumn{2}{|c|}{ Block 3} & \multicolumn{2}{|c|}{ Block 4} \\
\hline Calibration & Calibration & Calibration & Calibration & Calibration & Calibration & Calibration & Calibration \\
\hline 1 & 2 & 1 & 2 & 1 & 2 & 1 & 2 \\
\hline BCHLM111 & BCHLM121 & BCHLM211 & BCHLM221 & BCHLM311 & BCHLM321 & BCHLM411 & BCHLM421 \\
\hline UstdLM111 & UstdLM121 & UstdLM211 & UstdLM221 & stdLM311 & UstdLM: & UstdLM411 & UstdLM421 \\
\hline B13LM11 & B02LM22 & 8LM21 & B11LM & B23LM21 & B23LN & B15LM11 & B20I \\
\hline B03LM11 & B04LM22 & B06LM11 & B11LM & B21LM11 & B19LN & M11 & B161 \\
\hline B10LM21 & B10LM22 & B11LI & $\mathrm{B} 01 \mathrm{Ll}$ & B27LM11 & B21L & & M12 \\
\hline B03LM21 & B02LM12 & & & & & & B15LM12 \\
\hline B12LM11 & B12LM12 & B05LM21 & B09LM & B21LM21 & & & B22LM12 \\
\hline B12LM21 & & & & & & & B14LM22 \\
\hline B02 & & & & & & & 122 \\
\hline $\mathrm{BCH}$ & $\mathrm{BCH}$ & $\mathrm{BC}$ & $\mathrm{BCF}$ & 312 & $\mathrm{BCH}$ & 1412 & $\mathrm{BCHI}$ \\
\hline Ustd & Ustd & Ust & Ustd & 4312 & Ust & 1412 & Ustc \\
\hline B10LM11 & B13 & B06LM21 & B06L & B23LM11 & B27L & B28LM11 & B18LI \\
\hline B02LM21 & B03L & 11LM21 & & LM21 & B24L & LM21 & B18LM22 \\
\hline B17LM21 & B10LM12 & B01LM11 & B05LM12 & B24LM11 & B25LM22 & B20LM21 & B20LM12 \\
\hline B04LM11 & B17LM12 & B09LM11 & B07LM22 & B24LM21 & & B28LM21 & B15LM22 \\
\hline B13LM21 & B13LM22 & B08LM11 & B05LM22 & B27LM21 & & B14LM11 & B28LM12 \\
\hline B04LM21 & & & & & & 18LM21 & B28LM22 \\
\hline & & & & & & B22LM11 & \\
\hline UstdLM113 & UstdLM123 & UstdLM213 & UstdLM223 & UstdLM313 & UstdLM323 & UstdLM413 & UstdLM423 \\
\hline BCHLM113 & BCHLM123 & BCHLM 213 & BCHLM223 & BCHLM313 & BCHLM323 & BCHLM413 & BCHLM423 \\
\hline
\end{tabular}


Tables 5: ICP-AES Blocks \& Calibration Groups for the PF Glass Samples

(Used to Measure Elemental Al, B, Fe, Li, Mn, Ni, Si, \& U)

\begin{tabular}{|c|c|c|c|c|c|c|c|}
\hline \multicolumn{2}{|c|}{ Block 1} & \multicolumn{2}{|c|}{ Block 2} & \multicolumn{2}{|c|}{ Block 3} & \multicolumn{2}{|c|}{ Block 4} \\
\hline $\begin{array}{c}\text { Calibration } \\
1\end{array}$ & $\begin{array}{c}\text { Calibration } \\
2\end{array}$ & $\begin{array}{c}\text { Calibration } \\
1\end{array}$ & $\begin{array}{c}\text { Calibration } \\
2\end{array}$ & $\begin{array}{c}\text { Calibration } \\
1\end{array}$ & $\begin{array}{c}\text { Calibration } \\
2\end{array}$ & $\begin{array}{c}\text { Calibration } \\
1\end{array}$ & $\begin{array}{c}\text { Calibration } \\
2\end{array}$ \\
\hline BCHPF111 & BCHPF121 & BCHPF 211 & BCHPF221 & BCHPF311 & BCHPF321 & BCHPF411 & BCHPF421 \\
\hline UstdPF111 & UstdPF121 & UstdPF211 & UstdPF221 & UstdPF311 & UstdPF321 & UstdPF411 & UstdPF421 \\
\hline B12PF11 & B03PF12 & B05PF21 & B09PF22 & B24PF11 & B19PF22 & B16PF11 & B18PF12 \\
\hline B13PF21 & B17PF22 & B06РF21 & B08PF12 & В26PF11 & B25PF12 & B22PF11 & B15PF12 \\
\hline B04PF21 & B12PF12 & B07PF11 & B07PF22 & B27PF21 & B23PF22 & B20PF21 & B18PF22 \\
\hline B10PF11 & B13PF12 & B11PF11 & B07PF12 & B21PF11 & B26PF22 & B28PF21 & B14PF12 \\
\hline B17PF21 & $\mathrm{B} 02 \mathrm{PF} 22$ & B05PF11 & B11PF22 & B25PF11 & B19PF12 & B14PF11 & B28PF22 \\
\hline B04PF11 & B02PF12 & B08PF11 & B09PF12 & B25PF21 & B24PF12 & В22PF21 & B14PF22 \\
\hline B02PF21 & B03PF22 & B01PF11 & B06PF22 & B19PF21 & B23PF12 & B15PF21 & B22PF12 \\
\hline BCHPF112 & BCHPF122 & BCHPF212 & BCHPF222 & BCHPF312 & BCHPF322 & BCHPF412 & BCHPF422 \\
\hline UstdPF112 & UstdPF122 & UstdPF212 & UstdPF222 & UstdPF312 & UstdPF322 & UstdPF412 & UstdPF422 \\
\hline B03PF21 & B17PF12 & B08PF21 & B08PF22 & B24PF21 & B26PF12 & B15PF11 & B16PF12 \\
\hline B03PF11 & B04PF12 & B11PF21 & B01PF22 & B23PF21 & B27PF12 & B14PF21 & B28PF12 \\
\hline B02PF11 & B10PF22 & B07PF21 & B05PF12 & B23PF11 & B21PF22 & B18PF21 & B22PF22 \\
\hline B17PF11 & B13PF22 & B09PF11 & B01PF12 & B27PF11 & B25PF22 & B18PF11 & B20PF22 \\
\hline B13PF11 & B04PF & B06PF11 & B06P & B21PF21 & B24I & B28PF11 & B20PF12 \\
\hline B10PF21 & B12PF & B01PF21 & B05PF22 & B19PF11 & B27PF22 & B16PF21 & B15PF22 \\
\hline B12PF21 & B10PF12 & B09PF21 & B11PF12 & B26PF21 & B21PF12 & B20PF11 & B16PF22 \\
\hline UstdPF113 & UstdPF 123 & UstdPF213 & UstdPF223 & UstdPF313 & UstdPF323 & UstdPF413 & UstdPF423 \\
\hline BCHPF113 & BCHPF123 & BCHPF213 & ВCHPF223 & BCHPF313 & BCHPF323 & BCHPF413 & BCHPF423 \\
\hline
\end{tabular}

\subsection{Concluding Comments}

In summary, this analytical plan identifies four preparation blocks in Tables $3 \mathrm{a}$ and $3 \mathrm{~b}$ and eight ICP-AES calibration blocks in Tables 4 and 5 for use by the SRNL-ML. The sequencing of the activities associated with each of the steps in the analytical procedures has been randomized. The size of each of the blocks was selected so that it could be completed in a single work shift.

If a problem is discovered while measuring samples in a calibration block, the instrument should be calibrated and the block of samples re-measured in its entirety. If for some reason the measurements are not conducted in the sequences presented in this report, a record should be made of the actual order used along with any explanative comments.

The analytical plan indicated in the preceding tables should be modified by the personnel of SRNL-ML to include any calibration check standards and/or other standards that are part of their routine operating procedures. It is also recommended that the solutions resulting from each of the prepared samples be archived for some period, considering the "shelf-life" of the solutions, in case questions arise during data analysis. This would allow for the solutions to be rerun without additional preparations, thus minimizing cost. 


\subsection{REFERENCES}

[1] Edwards, T.B. and D.K. Peeler, "Nepheline Formation Potential in Sludge Batch 4 (SB4) and Its Impact on Durability: Selecting Glasses for a Phase 2 Study," WSRCTR-2005-00370, Revision 0, 2005.

[2] Jantzen, C.M., J.B. Pickett, K.G. Brown, T.B. Edwards, and D.C. Beam, "Process/ Product Models for the Defense Waste Processing Facility (DWPF): Part I. Predicting Glass Durability from Composition Using a Thermodynamic Hydration Energy Reaction Model (THERMO ${ }^{\mathrm{TM}}$ ) (U), ' WSRC-TR-93-673, Revision 1, Volume 2, Table B.1, pp. B.9, 1995. 


\section{APPENDIX B}

An Analytical Plan for Measuring PCT Solutions for Glasses from the Phase 2 Nepheline Study - Part 1: 1.6M, 127” Heel Glasses

(SRNL-SCS-2005-00041) 


\section{SRNL-SCS-2005-00041}

August 23, 2005

To:

D. K. Peeler, 999-W

cc:

R. A. Baker, 773-42A

D. R. Best, 786-1A (wo)

P. A. Toole, 786-1A (wo)

S. L. Marra, 999-W (es)

R. C. Tuckfield, 773-42A

I. A. Reamer, 999-1W

R. J. Workman, 999-1W

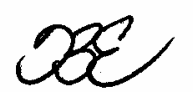

From: $\quad$ T. B. Edwards, 773-42A (5-5148)

Statistical Consulting Section

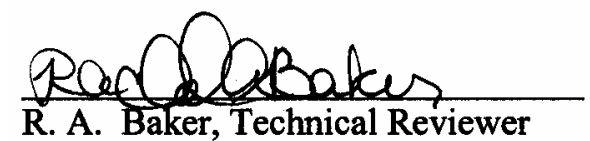

R. A. Baker, Technical Reviewer

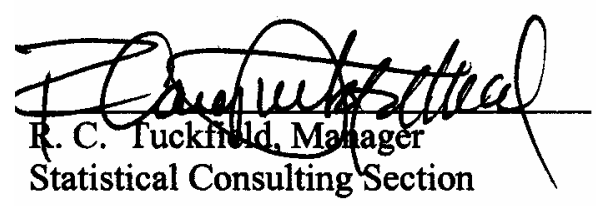

wo - without glass identifiers es - executive summary only
$8 / 26 / 2005$

Date

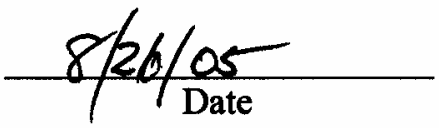

\section{AN ANALYTICAL PLAN FOR MEASURING PCT SOLUTIONS FOR GLASSES FROM THE PHASE 2 NEPHELINE STUDY - PART 1: 1.6M, 127" HeEl GLASSES (U)}




\subsection{EXECUTIVE SUMMARY}

A study is being conducted by the Savannah River National Laboratory (SRNL) for the Defense Waste Processing Facility (DWPF) that involves investigating the potential impact of nepheline formation on the durability of high level waste glasses. To address this issue, several glass compositions were identified for their potential for the formation of nepheline as part of the frit development activities for Sludge Batch 4 (SB4). Twenty-eight glasses were selected to be batched and fabricated as Phase 2 of the nepheline study; the durability of the glasses is to be measured using the Product Consistency Test (PCT) as defined in ASTM C-1285-2002. Two heat treatments were utilized during the fabrication of each of these glasses. Specifically, each of the 28 glasses was quenched (i.e., rapidly cooled) and cooled in accordance with the centerlinecanister-cooling (ccc) regime. Both heat treatments of each glass are to be subjected to the PCT. The 28 glasses have been grouped into two sets (or parts) based on the Sludge Batch 3 (SB3) heel volume option. The first set (which is covered in this memorandum) is based on the $1.6 \mathrm{M}, 127$ " SB3 heel volume while the second set is based on the 1.6M, 40" SB3 heel volume.

The Savannah River National Laboratory-Mobile Laboratory (SRNL-ML) is to be used to measure elemental concentrations of the resulting leachate solutions from the PCTs. This memorandum provides an analytical plan for the SRNL-ML to follow in measuring the compositions of the leachate solutions resulting from the first part of the PCT procedures, covering 14 of the Phase 2 nepheline study glasses (based on the 1.6M, 127" SB3 heel volume option). The analytical plan for the second part of the PCTs of the Phase 2 study glasses (based on the $1.6 \mathrm{M}, 40$ " SB3 heel volume option) will be addressed in a separate memorandum.

\subsection{INTRODUCTION}

A study is being conducted by the Savannah River National Laboratory (SRNL) for the Defense Waste Processing Facility (DWPF) that involves investigating the potential impact of nepheline formation on the durability of high level waste glasses [1]. To address this issue, 28 glass compositions were selected for their potential for the formation of nepheline as part of the frit development activities for Sludge Batch 4 (SB4). These glasses were selected to be batched and fabricated as Phase 2 of the nepheline study; the durability of the glasses is to be measured using the Product Consistency Test (PCT) as defined in ASTM C-1285-2002 [2]. Specifically, each of the 28 glasses was quenched (i.e., rapidly cooled) and cooled in accordance with the centerlinecanister-cooling (ccc) regime. Both heat treatments of each glass are to be subjected to the PCT. The 28 glasses have been grouped into two sets (or parts) based on the Sludge Batch 3 (SB3) heel volume option. The first set (which is covered in this memorandum) is based on the $1.6 \mathrm{M}, 127$ " SB3 heel volume while the second set is based on the 1.6M, 40" SB3 heel volume.

The Savannah River National Laboratory-Mobile Laboratory (SRNL-ML) is to be used to measure elemental concentrations of the resulting leachate solutions from the PCTs. This memorandum provides an analytical plan for the SRNL-ML to follow in measuring the compositions of the leachate solutions resulting from the first part of the PCT procedures, covering the glasses based on the 1.6M, 127" SB3 heel volume option as indicated in Table 1. The analytical plan for the second part of the PCTs of the Phase 2 study glasses (based on the $1.6 \mathrm{M}, 40$ ” SB3 heel volume option) will be addressed in a separate memorandum. 
Table 1: Identifiers for the Nepheline Study Glasses - Part $1^{13}$

\begin{tabular}{|c|c|}
\hline NEPH2-13 & NEPH2-20 \\
\hline NEPH2-13ccc & NEPH2-20ccc \\
\hline NEPH2-14 & NEPH2-21 \\
\hline NEPH2-14ccc & NEPH2-21ccc \\
\hline NEPH2-15 & NEPH2-22 \\
\hline NEPH2-15ccc & NEPH2-22ccc \\
\hline NEPH2-16 & NEPH2-23 \\
\hline NEPH2-16ccc & NEPH2-23ccc \\
\hline NEPH2-17 & NEPH2-24 \\
\hline NEPH2-17ccc & NEPH2-24ccc \\
\hline NEPH2-18 & NEPH2-25 \\
\hline NEPH2-18ccc & NEPH2-25ccc \\
\hline NEPH2-19 & NEPH2-26 \\
\hline NEPH2-19ccc & NEPH2-26ccc \\
\hline
\end{tabular}

\subsection{DisCUSSION}

Each of the study glasses of Table 1 is to be subjected to the PCT in triplicate. In addition to those for the 14 study glasses, triplicate PCTs are to be conducted on a sample of the Approved Reference Material (ARM-1) glass and a sample of the Environmental Assessment (EA) glass. Two reagent blank samples are also to be included in these tests. This results in 92 sample solutions being required to complete these PCTs.

The leachates from these tests will be diluted by adding $4 \mathrm{~mL}$ of $0.4 \mathrm{M} \mathrm{HNO}_{3}$ to $6 \mathrm{~mL}$ of the leachate (a 6:10 volume to volume, v:v, dilution) before being submitted to the SRNL-ML. The EA leachates will be further diluted $(1: 10 \mathrm{v}: \mathrm{v})$ with deionized water prior to submission to the SRNL-ML in order to prevent problems with the nebulizer.

Table 2 presents identifying codes, C01 through C92, for the individual solutions required for the PCTs of the study glasses and of the standards (EA, ARM-1, and blanks). This provides a naming convention that is to be used by the SRNL-ML in analyzing the solutions and reporting the relevant concentration measurements. ${ }^{14}$

\footnotetext{
13 The nomenclature NEPH2-13 stands for a nepheline glass (“NEPH”), Phase 2 (“2”), with the identifying number 13 (“-13"). The Phase 1 study contained twelve glasses, which leads to the use of the numbers $13-26$ for the first part of Phase 2 .

14

Renaming these samples ensures that they will be processed as blind samples by the SRNL-ML. This table does not contain the solution identifiers for those on the distribution list with a "wo" following their names.
} 
Table 2: Identifiers for the PCT Solutions - Part 1

\begin{tabular}{|c|c|c|c|c|c|}
\hline $\begin{array}{l}\text { Original } \\
\text { Sample }\end{array}$ & $\begin{array}{l}\text { Solution } \\
\text { Identifier }\end{array}$ & $\begin{array}{l}\text { Original } \\
\text { Sample }\end{array}$ & $\begin{array}{l}\text { Solution } \\
\text { Identifier }\end{array}$ & $\begin{array}{l}\text { Original } \\
\text { Sample }\end{array}$ & $\begin{array}{l}\text { Solution } \\
\text { Identifier }\end{array}$ \\
\hline NEPH2-13 & C89 & NEPH2-18ccc & $\mathrm{C} 15$ & NEPH2-24 & C34 \\
\hline NEPH2-13 & C64 & NEPH2-18ccc & C16 & NEPH2-24 & $\mathrm{C} 73$ \\
\hline NEPH2-13 & $\mathrm{C} 50$ & NEPH2-18ccc & $\mathrm{C} 05$ & NEPH2-24 & $\mathrm{C} 74$ \\
\hline NEPH2-13ccc & $\mathrm{C} 83$ & NEPH2-19 & C71 & NEPH2-24ccc & C49 \\
\hline NEPH2-13ccc & C62 & NEPH2-19 & $\mathrm{C} 07$ & NEPH2-24ccc & $\mathrm{C} 27$ \\
\hline NEPH2-13ccc & C87 & NEPH2-19 & C65 & NEPH2-24ccc & $\mathrm{C} 90$ \\
\hline NEPH2-14 & $\mathrm{C} 82$ & NEPH2-19ccc & C68 & NEPH2-25 & C66 \\
\hline NEPH2-14 & $\mathrm{C} 36$ & NEPH2-19ccc & C33 & NEPH2-25 & C88 \\
\hline NEPH2-14 & $\mathrm{C} 28$ & NEPH2-19ccc & C78 & NEPH2-25 & C79 \\
\hline NEPH2-14ccc & $\mathrm{C} 42$ & NEPH2-20 & $\mathrm{C} 06$ & NEPH2-25ccc & $\mathrm{C} 20$ \\
\hline NEPH2-14ccc & C18 & NEPH2-20 & $\mathrm{C} 40$ & NEPH2-25ccc & C55 \\
\hline NEPH2-14ccc & $\mathrm{C} 26$ & NEPH2-20 & C39 & NEPH2-25ccc & $\mathrm{C} 23$ \\
\hline NEPH2-15 & C52 & NEPH2-20ccc & C14 & NEPH2-26 & C59 \\
\hline NEPH2-15 & $\mathrm{C} 47$ & NEPH2-20ccc & $\mathrm{C} 08$ & NEPH2-26 & C63 \\
\hline NEPH2-15 & $\mathrm{C} 30$ & NEPH2-20ccc & C13 & NEPH2-26 & $\mathrm{C} 48$ \\
\hline NEPH2-15ccc & C76 & NEPH2-21 & $\mathrm{C} 03$ & NEPH2-26ccc & $\mathrm{C} 29$ \\
\hline NEPH2-15ccc & $\mathrm{C} 01$ & NEPH2-21 & $\mathrm{C} 43$ & NEPH2-26ccc & $\mathrm{C} 10$ \\
\hline NEPH2-15ccc & C37 & NEPH2-21 & C57 & NEPH2-26ccc & $\mathrm{C} 77$ \\
\hline NEPH2-16 & $\mathrm{C} 72$ & NEPH2-21ccc & C51 & EA & $\mathrm{C} 44$ \\
\hline NEPH2-16 & C19 & NEPH2-21ccc & $\mathrm{C} 02$ & EA & C53 \\
\hline NEPH2-16 & $\mathrm{C} 24$ & NEPH2-21ccc & $\mathrm{C} 60$ & EA & C61 \\
\hline NEPH2-16ccc & $\mathrm{C} 32$ & NEPH2-22 & C67 & ARM-1 & $\mathrm{C} 84$ \\
\hline NEPH2-16ccc & $\mathrm{C} 25$ & NEPH2-22 & $\mathrm{C} 17$ & ARM-1 & C38 \\
\hline NEPH2-16ccc & $\mathrm{C} 41$ & NEPH2-22 & C91 & ARM-1 & $\mathrm{C} 46$ \\
\hline NEPH2-17 & C92 & NEPH2-22ccc & C81 & blank & $\mathrm{C} 85$ \\
\hline NEPH2-17 & C58 & NEPH2-22ccc & $\mathrm{C} 35$ & blank & $\mathrm{C} 21$ \\
\hline NEPH2-17 & $\mathrm{C} 04$ & NEPH2-22ccc & $\mathrm{C} 45$ & & \\
\hline NEPH2-17ccc & $\mathrm{C} 09$ & NEPH2-23 & $\mathrm{C} 70$ & & \\
\hline NEPH2-17ccc & $\mathrm{C} 22$ & NEPH2-23 & $\mathrm{C} 11$ & & \\
\hline NEPH2-17ccc & $\mathrm{C} 80$ & NEPH2-23 & $\mathrm{C} 31$ & & \\
\hline NEPH2-18 & C69 & NEPH2-23ccc & C56 & & \\
\hline NEPH2-18 & $\mathrm{C} 75$ & NEPH2-23ccc & C86 & & \\
\hline NEPH2-18 & $\mathrm{C} 12$ & NEPH2-23ccc & C54 & & \\
\hline
\end{tabular}

\subsection{Analytical Plan}

The analytical plan for the SRNL-ML is provided in this section. Each of the solution samples submitted to the SRNL-ML is to be analyzed only once for each of the following: boron (B), barium $(\mathrm{Ba})$, cadmium $(\mathrm{Cd})$, chromium $(\mathrm{Cr})$, iron $(\mathrm{Fe})$, lithium $(\mathrm{Li})$, sodium $(\mathrm{Na})$, lead $(\mathrm{Pb})$, silicon $(\mathrm{Si})$, thorium $(\mathrm{Th})$, and uranium $(\mathrm{U})$. B, $\mathrm{Li}, \mathrm{Na}$, and $\mathrm{Si}$ are the elements that are to be used in the assessment of glass durability; the other elements are being monitored to address solution disposal issues in 773-A upon termination of the PCTs. The measurements are to be made in parts per million (ppm). The analytical procedure used by the SRNL-ML to determine the concentrations utilizes an Inductively Coupled Plasma - Atomic Emission Spectrometer (ICPAES). The PCT solutions (as identified in Table 2) are grouped in three ICP-AES blocks for processing by the SRNL-ML in Table 3. Each block requires a different calibration of the ICPAES. 
Table 3: ICP-AES Calibration Blocks for Leachate Measurements - Part 1

\begin{tabular}{|ccc|}
\hline Block 1 & Block 2 & Block 3 \\
std-b1-1 & std-b2-1 & std-b3-1 \\
C51 & C10 & C91 \\
C92 & C47 & C41 \\
C67 & C33 & C23 \\
C59 & C18 & C26 \\
C69 & C11 & C30 \\
C83 & C58 & C65 \\
C34 & C02 & C74 \\
C15 & C62 & C37 \\
C52 & C38 & C87 \\
C70 & C63 & C04 \\
C89 & C40 & C50 \\
C84 & C19 & C39 \\
C44 & C16 & C90 \\
C76 & C88 & C78 \\
C03 & C07 & C80 \\
std-b1-2 & std-b2-2 & std-b3-2 \\
C32 & C36 & C12 \\
C14 & C22 & C77 \\
C71 & C75 & C57 \\
C49 & C73 & C28 \\
C82 & C17 & C61 \\
C06 & C01 & C79 \\
C68 & C43 & C21 \\
C56 & C86 & C05 \\
C85 & C25 & C48 \\
C81 & C08 60 \\
C66 & C55 & C54 \\
C29 & C53 & C31 \\
C42 & C35 & C46 \\
C09 & C64 & C24 \\
C72 & C27 & C13 \\
C20 & std-b2-3 & C45 \\
std-b1-3 & & std-b3-3 \\
\hline & & \\
\hline
\end{tabular}

A multi-element solution standard (denoted by "std-bi-j" where $\mathrm{i}=1$ to 3 represents the block number and $\mathrm{j}=1,2$, and 3 represents the position in the block) was added at the beginning, middle, and end of each of the three blocks. This standard may be useful in checking and correcting for bias in the concentration measurements arising from the ICP calibrations.

\subsection{SUMMARY}

In summary, this analytical plan provides identifiers for the PCT solutions in Table 2 and three ICP-AES calibration blocks in Table 3 for the SRNL-ML to use in conducting the boron (B), barium $(\mathrm{Ba})$, cadmium $(\mathrm{Cd})$, chromium $(\mathrm{Cr})$, iron $(\mathrm{Fe})$, lithium $(\mathrm{Li})$, sodium $(\mathrm{Na})$, lead $(\mathrm{Pb})$, silicon ( $\mathrm{Si}$ ), thorium $(\mathrm{Th})$, and uranium (U) concentration measurements for the first part of the PCT study for the Phase 2 nepheline glasses. The sequencing of the activities associated with each of the steps in the analytical procedure has been randomized. The size of the blocks was 
selected so that the block could be completed in a single work shift. If for some reason the measurements are not conducted in the sequence presented in this memorandum, the actual order should be recorded along with any explanative comments.

The analytical plan indicated in the preceding tables should be modified by the personnel of the SRNL-ML to include any calibration check standards and/or other standards that are part of their standard operating procedures.

\subsection{REFERENCES}

[1] Edwards, T.B. and D.K. Peeler, "Nepheline Formation Potential in Sludge Batch 4 (SB4) and Its Impact on Durability: Selecting Glasses for a Phase 2 Study," WSRCTR-2005-00370, Revision 0, 2005.

[2] ASTM C-1285-2002, "Standard Test Methods for Determining Chemical Durability of Nuclear Waste Glasses: The Product Consistency Test (PCT),” ASTM, 2002. 


\section{SRNL-SCS-2005-00044}

August 31, 2005

To:

D. K. Peeler, 999-W

cc:

R. A. Baker, 773-42A

P. A. Toole, 786-1A (wo)

D. R. Best, 786-1A (wo)

R. C. Tuckfield, 773-42A

S. L. Marra, 999-W (es)

R. J. Workman, 999-1W

I. A. Reamer, 999-1W

From: T. B. Edwards, 773-42A (5-5148)

Statistical Consulting Section

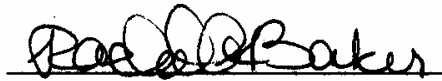

R. A. Baker, Technical Reviewer

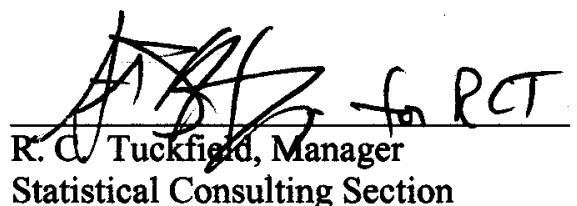

Statistical Consulting Section wo - without glass identifiers

es - executive summary only

\section{AN ANALYTICAL Plan FOR MEASURING PCT SOLUTIONS FOR GLASSES FROM THE Phase 2 NePHEline STUdY - PART 2: 1.6M, 40” HEEL GLASSES (U)}




\subsection{EXECUTIVE SUMMARY}

A study is being conducted by the Savannah River National Laboratory (SRNL) for the Defense Waste Processing Facility (DWPF) that involves investigating the potential impact of nepheline formation on the durability of high level waste glasses. To address this issue, several glass compositions were identified for their potential for the formation of nepheline as part of the frit development activities for Sludge Batch 4 (SB4). Twenty-eight of these glasses were selected to be batched and fabricated as Phase 2 of the nepheline study; the durability of the glasses is to be measured using the Product Consistency Test (PCT) as defined in ASTM C-1285-2002. Two heat treatments were utilized during the fabrication of each of these glasses. Specifically, each of the 28 glasses was quenched (i.e., rapidly cooled) and cooled in accordance with the centerlinecanister-cooling (ccc) regime. Both heat treatments of each glass are to be subjected to the PCT. The 28 glasses have been grouped into two sets (or parts) based on the Sludge Batch 3 (SB3) heel volume option. This memorandum covers the second part, the PCT study of the glasses based on the $1.6 \mathrm{M}, 40 " \mathrm{SB} 3$ heel volume.

The Savannah River National Laboratory-Mobile Laboratory (SRNL-ML) is to be used to measure elemental concentrations of the resulting leachate solutions from the PCTs. This memorandum provides an analytical plan for the SRNL-ML to follow in measuring the compositions of the leachate solutions resulting from the second part of the PCT procedures, covering 14 of the Phase 2 nepheline study glasses (based on the 1.6M, 40" SB3 heel volume). The analytical plan for the first part of the PCTs of the Phase 2 study glasses was addressed in a separate memorandum.

\subsection{INTRODUCTION}

A study is being conducted by the Savannah River National Laboratory (SRNL) for the Defense Waste Processing Facility (DWPF) that involves investigating the potential impact of nepheline formation on the durability of high level waste glasses [1]. To address this issue, 28 glass compositions were selected for their potential for the formation of nepheline as part of the frit development activities for Sludge Batch 4 (SB4). These glasses were selected to be batched and fabricated as Phase 2 of the nepheline study; the durability of the glasses is to be measured using the Product Consistency Test (PCT) as defined in ASTM C-1285-2002 [2]. Two heat treatments were utilized during the fabrication of each of these glasses. Specifically, each of the 28 glasses was quenched (i.e., rapidly cooled) and cooled in accordance with the centerline-canister-cooling (ccc) regime. Both heat treatments of each glass are to be subjected to the PCT. The 28 glasses have been grouped into two sets (or parts) based on the Sludge Batch 3 (SB3) heel volume option. This memorandum covers the second part, the PCT study of the glasses based on the 1.6M, 40" SB3 heel volume.

The Savannah River National Laboratory-Mobile Laboratory (SRNL-ML) is to be used to measure elemental concentrations of the resulting leachate solutions from the PCTs. This memorandum provides an analytical plan for the SRNL-ML to follow in measuring the compositions of the leachate solutions resulting from the second part of the PCT procedures, covering 14 of the Phase 2 nepheline study glasses as indicated in Table 1 . The analytical plan for the first part (based on the 1.6M, 127" SB3 heel volume) of the PCTs of the Phase 2 study glasses was addressed in a separate memorandum. 
WSRC-TR-2006-00006

Revision 0

Table 1: Identifiers for the Nepheline Study Glasses - Part $2^{15}$

\begin{tabular}{|c|c|}
\hline NEPH2-27 & NEPH2-34 \\
\hline NEPH2-27ccc & NEPH2-34ccc \\
\hline NEPH2-28 & NEPH2-35 \\
\hline NEPH2-28ccc & NEPH2-35ccc \\
\hline NEPH2-29 & NEPH2-36 \\
\hline NEPH2-29ccc & NEPH2-36ccc \\
\hline NEPH2-30 & NEPH2-37 \\
\hline NEPH2-30ccc & NEPH2-37ccc \\
\hline NEPH2-31 & NEPH2-38 \\
\hline NEPH2-31ccc & NEPH2-38ccc \\
\hline NEPH2-32 & NEPH2-39 \\
\hline NEPH2-32ccc & NEPH2-39ccc \\
\hline NEPH2-33 & NEPH2-40 \\
\hline NEPH2-33ccc & NEPH2-40ccc \\
\hline
\end{tabular}

\subsection{Discussion}

Each of the study glasses of Table 1 is to be subjected to the PCT in triplicate. In addition to those for the 14 study glasses, triplicate PCTs are to be conducted on a sample of the Approved Reference Material (ARM-1) glass and a sample of the Environmental Assessment (EA) glass. Two reagent blank samples are also to be included in these tests. This results in 92 sample solutions being required to complete these PCTs.

The leachates from these tests will be diluted by adding $4 \mathrm{~mL}$ of $0.4 \mathrm{M} \mathrm{HNO}_{3}$ to $6 \mathrm{~mL}$ of the leachate (a 6:10 volume to volume, v:v, dilution) before being submitted to the SRNL-ML. The EA leachates will be further diluted $(1: 10 \mathrm{v}: \mathrm{v})$ with deionized water prior to submission to the SRNL-ML in order to prevent problems with the nebulizer.

Table 2 presents identifying codes, D01 through D92, for the individual solutions required for the PCTs of the study glasses and of the standards (EA, ARM-1, and blanks). This provides a naming convention that is to be used by the SRNL-ML in analyzing the solutions and reporting the relevant concentration measurements. ${ }^{16}$

15 The nomenclature NEPH2-27 stands for a nepheline glass ("NEPH"), Phase 2 ("2"), with the identifying number 27 ("27"). The Phase 1 study contained twelve glasses and the first part of Phase 2 covered glasses 13 through 26, which leads to the use of the numbers $27-40$ for the second part of Phase 2 .

16

Renaming these samples ensures that they will be processed as blind samples by the SRNL-ML. This table does not contain the solution identifiers for those on the distribution list with a "wo" following their names. 
Table 2: Identifiers for the PCT Solutions - Part 2

\begin{tabular}{|c|c|c|c|c|c|}
\hline $\begin{array}{l}\text { Original } \\
\text { Sample }\end{array}$ & $\begin{array}{l}\text { Solution } \\
\text { Identifier }\end{array}$ & $\begin{array}{l}\text { Original } \\
\text { Sample }\end{array}$ & $\begin{array}{l}\text { Solution } \\
\text { Identifier }\end{array}$ & $\begin{array}{l}\text { Original } \\
\text { Sample }\end{array}$ & $\begin{array}{l}\text { Solution } \\
\text { Identifier }\end{array}$ \\
\hline NEPH2-27 & D19 & NEPH2-32ccc & D53 & NEPH2-38 & D01 \\
\hline NEPH2-27 & D24 & NEPH2-32ccc & D21 & NEPH2-38 & D84 \\
\hline NEPH2-27 & D80 & NEPH2-32ccc & D61 & NEPH2-38 & D66 \\
\hline NEPH2-27ccc & D49 & NEPH2-33 & D59 & NEPH2-38ccc & D20 \\
\hline NEPH2-27ccc & D71 & NEPH2-33 & D73 & NEPH2-38ccc & D89 \\
\hline NEPH2-27ccc & D26 & NEPH2-33 & D12 & NEPH2-38ccc & D28 \\
\hline NEPH2-28 & D44 & NEPH2-33ccc & D78 & NEPH2-39 & D58 \\
\hline NEPH2-28 & D22 & NEPH2-33ccc & D50 & NEPH2-39 & D55 \\
\hline NEPH2-28 & D29 & NEPH2-33ccc & D64 & NEPH2-39 & D11 \\
\hline NEPH2-28ccc & D37 & NEPH2-34 & D92 & NEPH2-39ccc & D56 \\
\hline NEPH2-28ccc & D15 & NEPH2-34 & D25 & NEPH2-39ccc & D57 \\
\hline NEPH2-28ccc & D23 & NEPH2-34 & D13 & NEPH2-39ccc & D46 \\
\hline NEPH2-29 & D05 & NEPH2-34ccc & D54 & NEPH2-40 & D03 \\
\hline NEPH2-29 & D67 & NEPH2-34ccc & D17 & NEPH2-40 & D86 \\
\hline NEPH2-29 & D82 & NEPH2-34ccc & D77 & NEPH2-40 & D33 \\
\hline NEPH2-29ccc & D02 & NEPH2-35 & D40 & NEPH2-40ccc & D10 \\
\hline NEPH2-29ccc & D04 & NEPH2-35 & D83 & NEPH2-40ccc & D38 \\
\hline NEPH2-29ccc & D48 & NEPH2-35 & D39 & NEPH2-40ccc & D60 \\
\hline NEPH2-30 & D32 & NEPH2-35ccc & D36 & EA & D07 \\
\hline NEPH2-30 & D69 & NEPH2-35ccc & D31 & EA & D27 \\
\hline NEPH2-30 & D88 & NEPH2-35ccc & D18 & EA & D65 \\
\hline NEPH2-30ccc & D06 & NEPH2-36 & D63 & ARM-1 & D81 \\
\hline NEPH2-30ccc & D68 & NEPH2-36 & D34 & ARM-1 & D75 \\
\hline NEPH2-30ccc & D47 & NEPH2-36 & D91 & ARM-1 & D90 \\
\hline NEPH2-31 & D45 & NEPH2-36ccc & D52 & blank & D76 \\
\hline NEPH2-31 & D51 & NEPH2-36ccc & D74 & blank & D72 \\
\hline NEPH2-31 & D62 & NEPH2-36ccc & D30 & & \\
\hline NEPH2-31ccc & D09 & NEPH2-37 & D16 & & \\
\hline NEPH2-31 ccc & D08 & NEPH2-37 & D70 & & \\
\hline NEPH2-31 ccc & D43 & NEPH2-37 & D42 & & \\
\hline NEPH2-32 & D87 & NEPH2-37ccc & D14 & & \\
\hline NEPH2-32 & D79 & NEPH2-37ccc & D35 & & \\
\hline NEPH2-32 & D85 & NEPH2-37ccc & D41 & & \\
\hline
\end{tabular}

\subsection{Analytical Plan}

The analytical plan for the SRNL-ML is provided in this section. Each of the solution samples submitted to the SRNL-ML is to be analyzed only once for each of the following: boron (B), barium $(\mathrm{Ba})$, cadmium $(\mathrm{Cd})$, chromium $(\mathrm{Cr})$, iron $(\mathrm{Fe})$, lithium $(\mathrm{Li})$, sodium $(\mathrm{Na})$, lead $(\mathrm{Pb})$, silicon $(\mathrm{Si})$, thorium $(\mathrm{Th})$, and uranium $(\mathrm{U}) . \mathrm{B}, \mathrm{Li}, \mathrm{Na}$, and $\mathrm{Si}$ are the elements that are to be used in the assessment of glass durability; the other elements are being monitored to address solution disposal issues in 773-A upon termination of the PCTs. The measurements are to be made in parts per million (ppm). The analytical procedure used by the SRNL-ML to determine the concentrations utilizes an Inductively Coupled Plasma - Atomic Emission Spectrometer (ICPAES). The PCT solutions (as identified in Table 2) are grouped in three ICP-AES blocks for processing by the SRNL-ML in Table 3. Each block requires a different calibration of the ICPAES. 
WSRC-TR-2006-00006

Revision 0

Table 3: ICP-AES Calibration Blocks for Leachate Measurements - Part 2

\begin{tabular}{|ccc|}
\hline Block 1 & Block 2 & Block 3 \\
std-b1-1 & std-b2-1 & std-b3-1 \\
D49 & D74 & D91 \\
D63 & D38 & D42 \\
D78 & D69 & D48 \\
D56 & D51 & D33 \\
D05 & D31 & D72 \\
D53 & D04 & D85 \\
D87 & D68 & D11 \\
D09 & D50 & D66 \\
D02 & D57 & D61 \\
D44 & D67 & D77 \\
D36 & D84 & D43 \\
D37 & D71 & D46 \\
D54 & D22 & D64 \\
D07 & D89 & D90 \\
D20 & D08 & D30 \\
std-b1-2 & std-b2-2 & std-b3-2 \\
D01 & D83 & D28 \\
D03 & D75 & D47 \\
D32 & D35 & D12 \\
D45 & D73 & D60 \\
D52 & D79 & D18 \\
D10 & D24 & D26 \\
D92 & D15 & D41 \\
D16 & D17 & D13 \\
D14 & D21 & D82 \\
D06 & D86 & D65 \\
D58 & D34 & D39 \\
D40 & D25 & D62 \\
D81 & D27 & D23 \\
D76 & D70 & D80 \\
D19 & D55 & D29 \\
D59 & std-b2-3 & D88 \\
std-b1-3 & & std-b3-3 \\
\hline & & \\
\hline
\end{tabular}

A multi-element solution standard (denoted by "std-bi-j" where $\mathrm{i}=1$ to 3 represents the block number and $\mathrm{j}=1,2$, and 3 represents the position in the block) was added at the beginning, middle, and end of each of the three blocks. This standard may be useful in checking and correcting for bias in the concentration measurements arising from the ICP calibrations.

\subsection{SUMMARY}

In summary, this analytical plan provides identifiers for the PCT solutions in Table 2 and three ICP-AES calibration blocks in Table 3 for the SRNL-ML to use in conducting the boron (B), barium $(\mathrm{Ba})$, cadmium $(\mathrm{Cd})$, chromium $(\mathrm{Cr})$, iron $(\mathrm{Fe})$, lithium $(\mathrm{Li})$, sodium $(\mathrm{Na})$, lead $(\mathrm{Pb})$, silicon $(\mathrm{Si})$, thorium $(\mathrm{Th})$, and uranium $(\mathrm{U})$ concentration measurements for the second part of the 
PCT study for the Phase 2 nepheline glasses. The sequencing of the activities associated with each of the steps in the analytical procedure has been randomized. The size of the blocks was selected so that the block could be completed in a single work shift. If for some reason the measurements are not conducted in the sequence presented in this memorandum, the actual order should be recorded along with any explanative comments.

The analytical plan indicated in the preceding tables should be modified by the personnel of the SRNL-ML to include any calibration check standards and/or other standards that are part of their standard operating procedures.

\subsection{REFERENCES}

[1] Edwards, T.B. and D.K. Peeler, "Nepheline Formation Potential in Sludge Batch 4 (SB4) and Its Impact on Durability: Selecting Glasses for a Phase 2 Study," WSRCTR-2005-00370, Revision 0, 2005.

[2] ASTM C-1285-2002, "Standard Test Methods for Determining Chemical Durability of Nuclear Waste Glasses: The Product Consistency Test (PCT)," ASTM, 2002. 


\section{SRNL-SCS-2005-00051}

October 17, 2005

To:

D. K. Peeler, 999-W

cc:

R. A. Baker, 773-42A

P. A. Toole, 786-1A (wo)

D. R. Best, 786-1A (wo)

R. C. Tuckfield, 773-42A

S. L. Marra, 999-W (es)

R. J. Workman, 999-1W

I. A. Reamer, 999-1W

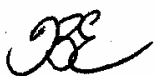

From: $\quad$ T. B. Edwards, 773-42A (5-5148)

Statistical Consulting Section

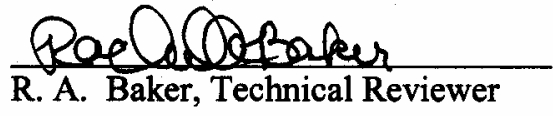

wo - without glass identifiers

es - executive summary only

R. A. Baker, Technical Reviewer
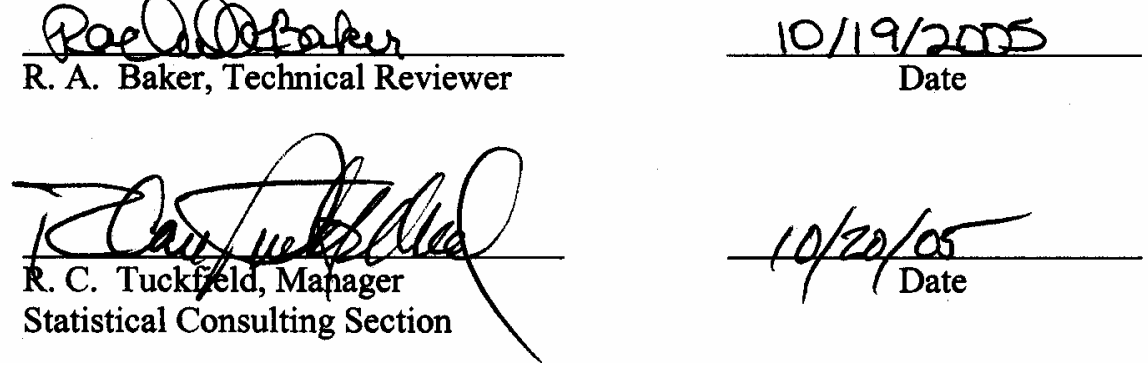

\section{An ANALYTICAl Plan FOR MEASURING PCT SOLUTIONS FOR SELECT SET OF GLASSES FROM THE PHASE 2 NEPHELINE STUDY (U)}




\subsection{EXECUTIVE SUMMARY}

A study is being conducted by the Savannah River National Laboratory (SRNL) for the Defense Waste Processing Facility (DWPF) that involves investigating the potential impact of nepheline formation on the durability of high level waste glasses. To address this issue, several glass compositions were identified for their potential for the formation of nepheline as part of the frit development activities for Sludge Batch 4 (SB4). Twenty-eight of these glasses were selected to be batched and fabricated as Phase 2 of the nepheline study; the durability of the glasses is to be measured using the Product Consistency Test (PCT) as defined in ASTM C-1285-2002. Two heat treatments were utilized during the fabrication of each of these glasses. Specifically, each of the 28 glasses was quenched (i.e., rapidly cooled) and cooled in accordance with the centerlinecanister-cooling ( $\mathrm{ccc}$ ) regime. Both heat treatments of each glass were subjected to the PCT. The 28 glasses were grouped into two sets (or parts) based on the Sludge Batch 3 (SB3) heel volume option. Both sets of PCTs (the 1.6M, 40" SB3 heel volume set and the 1.6M, 127" SB3 heel volume set) were submitted to the Savannah River National Laboratory-Mobile Laboratory (SRNL-ML) for measurement.

A review of the measurements generated by the SRNL-ML for these PCTs led to the identification of three glasses that are to be re-batched. The three glasses are to be fabricated using both heat treatments (i.e., they are to be quenched and centerline-canister-cooled), and both heat treatments of each glass are to be subjected to the PCT. This memorandum provides an analytical plan for the measurement of these PCTs by the SRNL-ML. 


\subsection{INTRODUCTION}

A study is being conducted by the Savannah River National Laboratory (SRNL) for the Defense Waste Processing Facility (DWPF) that involves investigating the potential impact of nepheline formation on the durability of high level waste glasses [1]. To address this issue, 28 glass compositions were selected for their potential for the formation of nepheline as part of the frit development activities for Sludge Batch 4 (SB4). These glasses were selected to be batched and fabricated as Phase 2 of the nepheline study; the durability of the glasses is to be measured using the Product Consistency Test (PCT) as defined in ASTM C-1285-2002 [2]. Two heat treatments were utilized during the fabrication of each of these glasses. Specifically, each of the 28 glasses was quenched (i.e., rapidly cooled) and cooled in accordance with the centerline-canister-cooling (ccc) regime. Both heat treatments of each glass were subjected to the PCT. The 28 glasses were grouped into two sets (or parts) based on the Sludge Batch 3 (SB3) heel volume option. Both sets of PCTs (the 1.6M, 40" SB3 heel volume set and the 1.6M, 127" SB3 heel volume set) were submitted to the Savannah River National Laboratory-Mobile Laboratory (SRNL-ML) for measurement.

A review of the measurements generated by the SRNL-ML for these PCTs led to the identification of three glasses that are to be re-batched. The three glasses are based on the $1.6 \mathrm{M}$, 40" SB3 heel volume option coupled with Frit 425 at waste loadings of 41, 45, and 48\%. The PCT results for the three glasses suggested that there may have been an inadvertent mislabeling of the glasses. More specifically, the PCT responses for all other Phase 2 glasses suggested a decrease in durability as waste loadings increased for a specific frit - sludge combination. The three Frit $425-1.6 \mathrm{M}, 40$ " SB3 heel glasses did not show this trend. The glass at the highest waste loading was the most durable of the three. The three glasses are to be fabricated using both heat treatments (i.e., they are to be quenched and centerline-canister-cooled), and both heat treatments of each glass are to be subjected to the PCT. See Table 1 for a listing of the glasses. This memorandum provides an analytical plan for the measurement of these PCTs by the SRNLML.

Table 1: Identifiers for Glasses Covered by this Plan' ${ }^{17}$

\begin{tabular}{|c|}
\hline NEPH2-33 \\
\hline NEPH2-33ccc \\
\hline NEPH2-34 \\
\hline NEPH2-34ccc \\
\hline NEPH2-35 \\
\hline NEPH2-35ccc \\
\hline
\end{tabular}

\subsection{DISCUSSION}

Each of the study glasses of Table 1 is to be subjected to the PCT in triplicate. In addition to those for the 6 study glasses, triplicate PCTs are to be conducted on a sample of the Approved Reference Material (ARM-1) glass and a sample of the Environmental Assessment (EA) glass. Two reagent blank samples are also to be included in these tests. This results in 26 sample solutions being required to complete these PCTs.

17 The nomenclature NEPH2-33 stands for a nepheline glass ("NEPH”), Phase 2 (“2”), with the identifying number 33 (“33"). The Phase 1 study contained twelve glasses and Phase 2 covered glasses 13 through 40. 
The leachates from these tests will be diluted by adding $4 \mathrm{~mL}$ of $0.4 \mathrm{M} \mathrm{HNO}_{3}$ to $6 \mathrm{~mL}$ of the leachate (a 6:10 volume to volume, v:v, dilution) before being submitted to the SRNL-ML. The leachates of EA will be further diluted $(1: 10 \mathrm{v}: \mathrm{v})$ with deionized water prior to submission to the SRNL-ML in order to prevent problems with the nebulizer. Note that additional dilutions for the ccc versions of one or more of the study glasses may be needed due to the anticipated low durability of at least two of the three glasses. Upon termination of the PCT, a decision is to be made (by the ITS technicians and an SRNL-ML representative) as to whether any other dilution is needed for these solutions to mitigate any potential gelling issues. Any extra dilutions are to be reported, and guidance is to be given as to how the dilutions are to be handled in the statistical assessment of the measurement data. More specifically, the SRNL-ML will be responsible for indicating if any additional dilutions were made and how they were, or how they should be, accounted for in the reported measurements.

Table 2 presents identifying codes, E01 through E26, for the individual solutions required for the PCTs of the select study glasses and of the standards (EA, ARM-1, and blanks). This provides a naming convention that is to be used by the SRNL-ML in analyzing the solutions and reporting the relevant concentration measurements. ${ }^{18}$

Table 2: Identifiers for the PCT Solutions Covered by this Plan

\begin{tabular}{|cc|}
\hline $\begin{array}{c}\text { Original } \\
\text { Sample }\end{array}$ & $\begin{array}{c}\text { Solution } \\
\text { Identifier }\end{array}$ \\
NEPH2-33 & E12 \\
NEPH2-33 & E04 \\
NEPH2-33 & E16 \\
NEPH2-33ccc & E24 \\
NEPH2-33ccc & E19 \\
NEPH2-33ccc & E17 \\
NEPH2-34 & E25 \\
NEPH2-34 & E13 \\
NEPH2-34 & E15 \\
NEPH2-34ccc & E21 \\
NEPH2-34ccc & E23 \\
NEPH2-34ccc & E26 \\
NEPH2-35 & E01 \\
NEPH2-35 & E14 \\
NEPH2-35 & E07 \\
NEPH2-35ccc & E05 \\
NEPH2-35ccc & E20 \\
NEPH2-35ccc & E08 \\
EA & E03 \\
EA & E02 \\
EA & E18 \\
ARM-1 & E06 \\
ARM-1 & E11 \\
ARM-1 & E09 \\
blank & E22 \\
blank & E10 \\
\hline
\end{tabular}




\subsection{Analytical Plan}

The analytical plan for the SRNL-ML is provided in this section. Each of the solution samples submitted to the SRNL-ML is to be analyzed only once for each of the following: boron (B), barium $(\mathrm{Ba})$, cadmium $(\mathrm{Cd})$, chromium $(\mathrm{Cr})$, iron $(\mathrm{Fe})$, lithium $(\mathrm{Li})$, sodium $(\mathrm{Na})$, lead $(\mathrm{Pb})$, silicon $(\mathrm{Si})$, thorium $(\mathrm{Th})$, and uranium $(\mathrm{U})$. B, $\mathrm{Li}, \mathrm{Na}$, and $\mathrm{Si}$ are the elements that are to be used in the assessment of glass durability; the other elements are being monitored to address solution disposal issues in 773-A upon termination of the PCTs. The measurements are to be made in parts per million (ppm). The analytical procedure used by the SRNL-ML to determine the concentrations utilizes an Inductively Coupled Plasma - Atomic Emission Spectrometer (ICPAES). The PCT solutions (as identified in Table 2) are grouped in three ICP-AES blocks for processing by the SRNL-ML in Table 3. Each block requires a different calibration of the ICPAES.

Table 3: ICP-AES Calibration Blocks for Leachate Measurements

\begin{tabular}{|ccc|}
\hline Block 1 & Block 2 & Block 3 \\
std-b1-1 & std-b2-1 & std-b3-1 \\
E06 & E19 & E18 \\
E03 & E13 & E09 \\
E01 & E02 & E10 \\
E12 & E11 & E08 \\
std-b1-2 & std-b2-2 & std-b3-2 \\
E25 & E14 & E17 \\
E24 & E20 & E26 \\
E05 & E04 & E15 \\
E21 & E23 & E07 \\
E22 & std-b2-3 & E16 \\
std-b1-3 & & std-b3-3 \\
\hline
\end{tabular}

A multi-element solution standard (denoted by "std-bi-j" where $\mathrm{i}=1$ to 3 represents the block number and $\mathrm{j}=1,2$, and 3 represents the position in the block) was added at the beginning, middle, and end of each of the three blocks. This standard may be useful in checking and correcting for bias in the concentration measurements arising from the ICP calibrations.

\subsection{SUMMARY}

In summary, this analytical plan provides identifiers for the PCT solutions in Table 2 and three ICP-AES calibration blocks in Table 3 for the SRNL-ML to use in conducting the boron (B), barium $(\mathrm{Ba})$, cadmium $(\mathrm{Cd})$, chromium $(\mathrm{Cr})$, iron $(\mathrm{Fe})$, lithium $(\mathrm{Li})$, sodium $(\mathrm{Na})$, lead $(\mathrm{Pb})$, silicon ( $\mathrm{Si}$ ), thorium (Th), and uranium (U) concentration measurements for the PCT study of this select subset of the Phase 2 nepheline glasses. The sequencing of the activities associated with each of the steps in the analytical procedure has been randomized. The size of the blocks was selected so that the block could be completed in a single work shift. If for some reason the measurements are not conducted in the sequence presented in this memorandum, the actual order should be recorded along with any explanative comments.

The analytical plan indicated in the preceding tables should be modified by the personnel of the SRNL-ML to include any calibration check standards and/or other standards that are part of their standard operating procedures. 


\subsection{REFERENCES}

[1] Edwards, T.B. and D.K. Peeler, "Nepheline Formation Potential in Sludge Batch 4 (SB4) and Its Impact on Durability: Selecting Glasses for a Phase 2 Study," WSRCTR-2005-00370, Revision 0, 2005.

[2] ASTM C-1285-2002, "Standard Test Methods for Determining Chemical Durability of Nuclear Waste Glasses: The Product Consistency Test (PCT)," ASTM, 2002. 


\section{APPENDIX C}

Tables and Exhibits Supporting the Analysis of the Chemical Composition Measurements of the Nepheline Phase 2 Study Glasses 


\section{Table C1. Targeted Oxide Concentrations (as wt\%'s) for the Phase 2 Nepheline Study Glasses}

\begin{tabular}{|c|c|c|c|c|c|c|c|c|c|c|c|c|c|c|c|c|c|c|c|c|c|c|c|c|}
\hline Glass \# & 1203 & B2O3 & $\mathrm{BaO}$ & $\mathrm{CaO}$ & $\mathrm{Ce} 2 \mathrm{O3}$ & Cr2O3 & $\mathrm{CuO}$ & Fe2O3 & $\mathrm{K} 2 \mathrm{O}$ & La2O3 & Li2O & MgO & MnO & $\mathrm{Na2O}$ & $\mathrm{NiO}$ & PbO & SO4 & $\mathrm{SiO2}$ & ThO2 & TiO2 & U308 & ZnO & $\mathrm{ZrO2}$ & Sum \\
\hline NEPH2-13 & 0.21 & .88 & 0.053 & .776 & & & & & & & & & & & 1.192 & & & 44.964 & & 0.007 & & 0.042 & 0.1 & 100.00 \\
\hline NEPH2-14 & .995 & 1.64 & 057 & 836 & 078 & & 031 & .313 & .587 & 034 & 4.64 & 0.59 & 2.047 & 8.133 & .284 & 0.074 & 449 & 2.884 & 0.016 & 0.008 & 3.054 & 0.045 & 0.107 & 100.00 \\
\hline NEPH2-15 & .472 & 4.8 & 054 & 796 & & & & & & & & & & & .223 & & & & & 0.008 & 2.908 & 0.043 & & 100.00 \\
\hline & & & & & & & & & & & & & & & .314 & & & & & & & & & \\
\hline & & & & & & & & & & & & & & & .375 & & & & & 0.008 & & .048 & & \\
\hline $\mathrm{NEPl}$ & & .72 & 55 & & & & & & & & & & & & 1.253 & & & & & 0.008 & & 0.044 & & \\
\hline NEPH2-19 & 1.519 & 4.48 & 0.059 & .876 & & & 0.032 & & 0.615 & & & 0.618 & 2.144 & 17.305 & 1.345 & 0.078 & & & 0.017 & 0.008 & 3.199 & 0.047 & 0.112 & 100.00 \\
\hline $\mathrm{NEPH}$ & & 4.2 & 0.064 & .936 & & & .034 & 10.422 & & & & 0.661 & & & 1.437 & & & 40.478 & & 0.009 & 3.417 & 0.05 & & 100.00 \\
\hline NEP & & 4.6 & 057 & & & & & & & & 64 & & & & .284 & & & & & 0.008 & 54 & 0.045 & & \\
\hline & & & 2 & & & & & & & & & & & & .406 & & & & & 0.009 & & .049 & & \\
\hline & & & 066 & 976 & & & & & & & & & & & 1.498 & 0.087 & & & & 0.009 & & 0.052 & .125 & \\
\hline NEPH2-24 & & 4.5 & 0.058 & .856 & & & & & & & & & & & 1.314 & 0.076 & & & & 0.008 & & 0.046 & & \\
\hline $\mathrm{NEPH}$ & & 4.2 & 0.064 & 0.936 & & & & & & & & & & & 1.437 & & & & & 0.009 & & 0.05 & & \\
\hline $\mathrm{NEPl}$ & 52 & & 069 & 1 & & & & & & & 3. & & & & 1.559 & & & & & 0.01 & 3.708 & 0.055 & & \\
\hline & & & 056 & 9 & & & & & & & & & & & 1.358 & .076 & & & & 0.007 & 2.765 & 0.042 & & \\
\hline & & 4.4 & 0.063 & 845 & & & & & 0.755 & & & & & & 1.532 & 0.086 & & & 18 & 0.008 & 3.12 & 0.048 & & \\
\hline NEPH2-29 & & 4.08 & 0.071 & 0.941 & & & 0.037 & & 0.84 & & 4.08 & 0.522 & 2.352 & 17.671 & 1.706 & 0.096 & & & & 0.009 & 3.474 & 0.053 & .134 & 100.00 \\
\hline NEPH2-30 & & 4.8 & 0.058 & 0.769 & & & & & & & & & & & 1.393 & 0.078 & & & & 0.007 & 2.836 & 0.043 & 09 & \\
\hline $\mathrm{NEPH}$ & & & 063 & & & & & & & & & & & & 1.532 & & & & & 0.008 & & 048 & & \\
\hline & & & 59 & 0 & & & & & & & & & & & 1.672 & 0.0 & & & & 0.009 & & 0.052 & & \\
\hline $\mathrm{NEPH}$ & 12.238 & 4.72 & 0.059 & 0.788 & 0.079 & & 0.031 & & 0.703 & & 4.72 & 0.436 & 1.9 & & 1.428 & 0.08 & 0.4 & 44.782 & 0.017 & 0.008 & 2.907 & 0.044 & & 100.00 \\
\hline NEPH2-34 & 13.432 & 4.4 & 0.065 & 0.865 & 0.087 & 0.113 & 0.034 & & 0.772 & & 4.4 & 0.479 & 2.16 & 16.108 & 1.567 & 0.088 & 0.464 & 41.931 & 0.019 & 0.008 & 3.19 & 0.049 & 123 & 100.00 \\
\hline NEPH2-35 & 4.327 & 4.16 & 0.069 & 0.922 & 0.093 & & 0.036 & 10.252 & 0.823 & 0.039 & 4.16 & 0.511 & 2.304 & 16.516 & 1.672 & 0.094 & 0.495 & 39.793 & 0.02 & 0.009 & 3.403 & 0.052 & 0.131 & 100.00 \\
\hline $\mathrm{NEPI}$ & & 4.64 & & 0.807 & & & & & & & 4.6 & & & & 1.463 & & & & 17 & 0.008 & 2.978 & 0.045 & & 100.00 \\
\hline & & & 0.065 & 0.865 & & & & & 0.772 & & & 0.479 & & & 1.567 & 0.088 & & & 0.019 & 0.008 & & 0.049 & & 100.00 \\
\hline NEPH2-38 & 14.029 & 4.24 & 0.068 & 0.903 & 0.091 & 0.118 & 0.035 & 10.039 & 0.806 & 0.038 & 4.24 & 0.5 & 2.256 & 15.85 & 1.637 & 0.092 & 0.484 & 41.036 & 0.02 & 0.009 & 3.332 & 0.051 & 0.128 & 100.00 \\
\hline NEPH2-39 & 12.835 & 4.56 & 0.062 & 0.826 & 0.083 & 0.108 & 0.032 & 9.184 & 0.737 & & 4.56 & 0.458 & 2.064 & 14.697 & 1.498 & 0.084 & 0.443 & \begin{tabular}{|l|}
44.497 \\
\end{tabular} & 0.018 & 0.008 & 3.049 & 0.046 & 0.117 & 100.00 \\
\hline NEPH2-40 & 13.73 & 4.32 & 0.066 & 0.884 & 0.089 & 0.115 & 0.034 & 9.825 & 0.789 & 0.037 & 4.32 & 0.49 & 2.208 & 15.164 & 1.602 & 0.09 & 0.474 & 42.299 & 0.019 & 0.009 & 3.261 & 0.05 & 0.126 & 100.00 \\
\hline
\end{tabular}


Table C2. Measured Elemental Concentrations (wt\%) for Samples Prepared Using Lithium Metaborate

\begin{tabular}{|c|c|c|c|c|c|c|c|c|c|c|c|c|c|c|c|c|c|c|c|c|}
\hline Glass & Laboratory & & Sub- & Analytical & & & & & & & & & & & & & & & & \\
\hline ID & ID & Block & Block & Sequence & $\mathbf{B a}$ & $\mathbf{C a}$ & $\mathrm{Ce}$ & $\mathrm{Cr}$ & $\mathrm{Cu}$ & $\mathbf{K}$ & La & Mg & Mn & $\mathrm{Na}$ & $\mathbf{P b}$ & $\mathbf{S}$ & Th & $\mathbf{T i}$ & $\mathbf{Z n}$ & $\mathrm{Zr}$ \\
\hline Batch 1 & BCHLM111 & 1 & 1 & 1 & 0.123 & 0.83 & $<0.010$ & 0.078 & 0.303 & 2.478 & $<0.010$ & 0.813 & 1.31 & 6.92 & $<0.010$ & $<0.100$ & $<0.100$ & 0.384 & $<0.010$ & 0.062 \\
\hline Ustd & UstdLM11 & 1 & 1 & 2 & $<0.010$ & 0.87 & $<0.010$ & 0.16 & $<0.010$ & 2.4 & $<0.010$ & 0.66 & 2.05 & 8.51 & $<0.010$ & $<0.100$ & $<0.100$ & 0.525 & $<0.010$ & $<0.010$ \\
\hline NEPH2-14 & B13LM11 & $\overline{1}$ & 1 & 3 & \begin{tabular}{|l|}
0.039 \\
\end{tabular} & 0.557 & \begin{tabular}{|l|}
0.049 \\
\end{tabular} & 0.068 & 0.031 & 0.526 & \begin{tabular}{|l|}
0.027 \\
\end{tabular} & 0.345 & 1.42 & 12.3 & 0.065 & \begin{tabular}{|l|}
0.151 \\
\end{tabular} & $<0.100$ & $<0.010$ & \begin{tabular}{|l|}
0.04 \\
\end{tabular} & 0.071 \\
\hline NEPH2-26 & B03LM11 & 1 & 1 & 4 & 0.053 & 0.672 & 0.062 & 0.073 & 0.042 & 0.636 & 0.079 & 0.411 & 1.71 & 12 & 0.075 & 0.18 & $\begin{array}{l}<0.100 \\
\end{array}$ & $<0.010$ & 0.049 & 0.086 \\
\hline NEPH2-22 & B10LM21 & 1 & 1 & 5 & 0.044 & 0.595 & 0.051 & 0.071 & 0.032 & 0.599 & 0.034 & 0.363 & 1.62 & 12 & 0.071 & 0.175 & \begin{tabular}{l|}
$<0.100$ \\
\end{tabular} & $<0.010$ & 0.043 & 0.075 \\
\hline NEPH2-26 & B03LM21 & 1 & 1 & 6 & 0.054 & 0.688 & 0.063 & 0.068 & 0.042 & 0.662 & 0.061 & 0.414 & 1.67 & 12.7 & 0.076 & 0.193 & $<0.100$ & $<0.010$ & 0.049 & 0.089 \\
\hline NEPH2-17 & B12LM11 & 1 & 1 & 7 & 0.045 & 0.59 & 0.048 & 0.069 & 0.033 & 0.543 & 0.029 & 0.369 & 1.66 & 13 & 0.07 & 0.167 & $<0.100$ & $<0.010$ & 0.044 & 0.08 \\
\hline NEPH2-17 & B12LM21 & 1 & 1 & 8 & 0.046 & 0.595 & 0.048 & 0.069 & 0.032 & 0.557 & 0.029 & 0.367 & 1.6 & 13 & 0.07 & 0.164 & $<0.100$ & $<0.010$ & 0.043 & 0.078 \\
\hline NEPH2-21 & B02LM11 & 1 & 1 & 9 & 0.042 & 0.546 & 0.051 & 0.071 & 0.029 & 0.516 & 0.029 & 0.348 & 1.48 & 11.6 & 0.064 & 0.159 & $<0.100$ & $<0.010$ & 0.012 & 0.073 \\
\hline Batch 1 & BCHLM112 & 1 & 1 & 10 & 0.122 & 0.812 & $<0.010$ & 0.078 & 0.299 & 2.446 & $<0.010$ & 0.808 & 1.27 & 6.74 & $<0.010$ & $<0.100$ & $<0.100$ & 0.377 & $<0.010$ & 0.061 \\
\hline Ustd & USTDLM112 & 1 & 1 & 11 & $<0.010$ & 0.857 & $<0.010$ & 0.159 & $<0.010$ & 2.356 & $<0.010$ & 0.653 & 2.1 & 8.53 & $<0.010$ & $<0.100$ & $<0.100$ & 0.515 & $<0.010$ & $<0.010$ \\
\hline NEPH2-22 & B10LM11 & 1 & 1 & 12 & 0.046 & 0.599 & 0.051 & 0.072 & 0.031 & 0.558 & 0.034 & 0.373 & 1.68 & 12.1 & 0.073 & 0.166 & $<0.100$ & $<0.010$ & 0.043 & 0.077 \\
\hline NEPH2-21 & B02LM & 1 & 1 & 13 & 0.039 & 0.535 & 0.049 & 0.068 & 0.029 & 0.567 & 0.028 & 0.327 & 1.51 & 11.5 & 0.058 & 0.168 & $<0.100$ & $<0.010$ & 0.012 & 0.068 \\
\hline NEPH2-24 & $\overline{\mathrm{B}}$ & $\overline{1}$ & 1 & 14 & 0.041 & 0.558 & 0.051 & 0.065 & 0.03 & 0.539 & 0.028 & 0.349 & 1.58 & 11.6 & 0.062 & 0.16 & $<0.100$ & $<0.010$ & 0.04 & 0.073 \\
\hline NEPH2-18 & & 1 & 1 & 15 & 0.041 & 0.546 & 0.046 & 0.065 & 0.032 & 0.522 & 0.027 & 0.33 & 1.48 & 12 & 0.057 & 0.152 & $\begin{array}{l}<0.100 \\
\end{array}$ & $<0.010$ & 0.039 & 0.067 \\
\hline NEPH2-14 & B13LM21 & 1 & 1 & 16 & 0.039 & 0.563 & 0.047 & 0.068 & 0.031 & 0.541 & 0.026 & 0.337 & 1.55 & 12.8 & 0.064 & 0.159 & $<0.100$ & $<0.010$ & 0.042 & 0.064 \\
\hline NEPH2-18 & B04LM21 & 1 & 1 & 17 & 0.04 & 0.549 & 0.045 & 0.066 & 0.03 & 0.535 & 0.027 & 0.324 & 1.52 & 12.3 & 0.055 & 0.154 & $<0.100$ & $<0.010$ & 0.04 & 0.068 \\
\hline NEPH2-24 & B17LM11 & 1 & 1 & 18 & 0.042 & 0.565 & 0.051 & 0.067 & 0.031 & 0.527 & 0.029 & 0.357 & 1.61 & 11.6 & 0.066 & 0.159 & $<0.100$ & $<0.010$ & 0.043 & 0.074 \\
\hline Ustd & USTDLM113 & 1 & 1 & 19 & $<0.010$ & 0.85 & $<0.010$ & 0.159 & $<0.010$ & 2.35 & $<0.010$ & 0.652 & 2.07 & 8.49 & $<0.010$ & $<0.100$ & $<0.100$ & 0.513 & $<0.010$ & $<0.010$ \\
\hline Batch 1 & BCHLM113 & 1 & 1 & 20 & 0.121 & 0.804 & $<0.010$ & 0.078 & 0.297 & 2.439 & $<0.010$ & 0.802 & 1.31 & 6.95 & $<0.010$ & $<0.100$ & $<0.100$ & 0.373 & $<0.010$ & 0.06 \\
\hline Batch 1 & BCHLM121 & 1 & 2 & 1 & 0.122 & 0.82 & $<0.010$ & 0.078 & 0.302 & 2.42 & $<0.010$ & 0.807 & 1.35 & 6.94 & $<0.010$ & $<0.100$ & $<0.100$ & 0.382 & $<0.010$ & 0.061 \\
\hline Ustd & USTDLM121 & 1 & 2 & 2 & $<0.010$ & 0.862 & $<0.010$ & 0.158 & $<0.010$ & 2.329 & $<0.010$ & 0.658 & 2.16 & 8.68 & $<0.010$ & $<0.100$ & $<0.100$ & 0.529 & $<0.010$ & $<0.010$ \\
\hline NEPH2-21 & B02LM22 & 1 & 2 & 3 & 0.039 & 0.554 & 0.052 & 0.068 & 0.03 & 0.559 & 0.028 & 0.328 & 1.6 & 12 & 0.058 & 0.156 & $<0.100$ & $<0.010$ & 0.011 & 0.069 \\
\hline NEPH2-18 & B04LM22 & 1 & 2 & 4 & 0.04 & 0.548 & 0.048 & 0.065 & 0.031 & 0.529 & 0.027 & 0.326 & 1.54 & 12.5 & 0.055 & 0.135 & $<0.100$ & $<0.010$ & 0.038 & 0.068 \\
\hline NEPH2-22 & B10LM22 & 1 & 2 & 5 & 0.043 & 0.588 & 0.052 & 0.069 & 0.032 & 0.587 & 0.033 & 0.36 & 1.72 & 12.7 & 0.067 & 0.156 & $<0.100$ & $<0.010$ & 0.041 & 0.074 \\
\hline NEPH2-21 & B02LM12 & 1 & 2 & 6 & 0.042 & 0.559 & 0.054 & 0.07 & 0.03 & 0.52 & 0.03 & 0.349 & 1.58 & 12 & 0.063 & 0.146 & $<0.100$ & $<0.010$ & 0.011 & 0.073 \\
\hline NEPH2-17 & B12LM12 & 1 & 2 & 7 & 0.045 & 0.599 & 0.05 & 0.068 & 0.034 & 0.542 & 0.029 & 0.368 & 1.68 & 13.2 & 0.067 & 0.161 & \begin{tabular}{|c|}
$<0.100$ \\
\end{tabular} & $<0.010$ & 0.044 & 0.089 \\
\hline NEPH2-18 & B04LM12 & 1 & 2 & 8 & 0.04 & 0.542 & 0.049 & 0.065 & 0.033 & 0.517 & 0.027 & 0.328 & 1.48 & 12.3 & 0.055 & 0.136 & $<0.100$ & $<0.010$ & 0.037 & 0.068 \\
\hline NEPH2-17 & B12LM22 & 1 & 2 & 9 & 0.045 & 0.596 & 0.05 & 0.068 & 0.032 & 0.553 & 0.029 & 0.367 & 1.65 & 13.2 & 0.067 & 0.156 & $<0.100$ & $<0.010$ & 0.041 & 0.077 \\
\hline Batch 1 & BCHLM122 & 1 & 2 & 10 & 0.121 & 0.819 & $<0.010$ & 0.078 & 0.301 & 2.418 & $<0.010$ & 0.804 & 1.27 & 6.89 & $<0.010$ & $<0.100$ & $<0.100$ & \begin{tabular}{|l|}
0.382 \\
\end{tabular} & $<0.010$ & 0.061 \\
\hline Ustd & USTDLM122 & 1 & 2 & 11 & $<0.010$ & 0.853 & $<0.010$ & 0.157 & $<0.010$ & 2.317 & $<0.010$ & 0.648 & 2.03 & 8.57 & $<0.010$ & $<0.100$ & $<0.100$ & 0.52 & $<0.010$ & $<0.010$ \\
\hline NEPH2-14 & B13LM12 & 1 & 2 & 12 & 0.038 & 0.558 & 0.051 & 0.066 & 0.031 & 0.517 & 0.027 & 0.34 & 1.51 & 13 & 0.063 & 0.143 & $<0.100$ & $<0.010$ & 0.038 & 0.067 \\
\hline NEPH2-26 & B03LM22 & 1 & 2 & 13 & 0.051 & 0.658 & 0.063 & 0.065 & 0.04 & 0.625 & 0.06 & 0.4 & 1.66 & 12.8 & 0.071 & 0.172 & $<0.100$ & $<0.010$ & 0.045 & 0.086 \\
\hline NEPH2-22 & B10LM12 & 1 & 2 & 14 & 0.045 & 0.585 & 0.054 & 0.071 & 0.032 & 0.551 & 0.034 & 0.374 & 1.64 & 12.3 & 0.072 & 0.155 & $<0.100$ & $<0.010$ & 0.041 & 0.078 \\
\hline NEPH2-24 & B17LM12 & 1 & 2 & 15 & 0.042 & 0.58 & 0.054 & 0.066 & 0.032 & 0.531 & 0.029 & 0.357 & 1.56 & 11.7 & 0.063 & 0.15 & $<0.100$ & $<0.010$ & 0.041 & 0.076 \\
\hline NEPH2-14 & B13LM22 & 1 & 2 & 16 & 0.038 & 0.565 & 0.05 & 0.067 & 0.032 & 0.544 & 0.026 & 0.336 & 1.47 & 12.8 & 0.063 & 0.149 & $<0.100$ & $<0.010$ & 0.04 & 0.065 \\
\hline NEPH2-26 & B03LM12 & 1 & 2 & 17 & 0.051 & 0.66 & 0.063 & 0.071 & 0.042 & 0.621 & 0.078 & 0.405 & 1.78 & 12.4 & 0.072 & 0.173 & $<0.100$ & $<0.010$ & 0.048 & 0.085 \\
\hline NEPH2-24 & B17LM22 & 1 & 2 & 18 & 0.04 & 0.568 & 0.053 & 0.064 & 0.031 & 0.538 & 0.028 & 0.347 & 1.57 & 11.6 & 0.06 & 0.141 & $<0.100$ & $<0.010$ & 0.038 & 0.073 \\
\hline Ustd & USTDLM123 & 1 & 2 & 19 & $<0.010$ & 0.854 & $<0.010$ & 0.157 & $<0.010$ & 2.33 & $<0.010$ & 0.65 & 2.06 & 8.63 & $<0.010$ & $<0.100$ & $<0.100$ & 0.522 & $<0.010$ & $<0.010$ \\
\hline Batch 1 & BCHLM123 & 1 & 2 & 20 & 0.121 & 0.81 & $<0.010$ & 0.077 & 0.301 & 2.423 & $<0.010$ & 0.803 & 1.27 & 7 & $<0.010$ & $<0.100$ & $<0.100$ & 0.379 & $<0.010$ & 0.061 \\
\hline
\end{tabular}


Table C2. Measured Elemental Concentrations (wt\%) for Samples Prepared Using Lithium Metaborate

\begin{tabular}{|c|c|c|c|c|c|c|c|c|c|c|c|c|c|c|c|c|c|c|c|c|}
\hline Glass & Laboratory & & Sub- & Analytical & & & & & & & & & & & & & & & & \\
\hline ID & ID & Block & Block & Sequence & $\mathbf{B a}$ & $\mathbf{C a}$ & $\mathrm{Ce}$ & $\mathrm{Cr}$ & $\mathbf{C u}$ & $\mathbf{K}$ & La & Mg & Mn & $\mathrm{Na}$ & $\mathbf{P b}$ & $\mathbf{S}$ & Th & $\mathbf{T i}$ & $\mathbf{Z n}$ & $\mathbf{Z r}$ \\
\hline Batch 1 & BCHLM211 & 2 & 1 & 1 & 0.124 & 0.824 & $<0.010$ & 0.079 & 0.305 & 2.441 & $<0.010$ & 0.82 & 1.31 & 7.06 & $<0.010$ & $<0.100$ & $<0.100$ & 0.387 & $<0.010$ & 0.063 \\
\hline Ustd & USTDLM211 & 2 & 1 & 2 & $<0.010$ & 0.875 & $<0.010$ & 0.159 & $<0.010$ & 2.353 & $<0.010$ & 0.661 & 2.09 & 8.67 & $<0.010$ & $<0.100$ & $<0.100$ & 0.534 & $<0.010$ & $<0.010$ \\
\hline NEPH2-31 & B08LM21 & 2 & 1 & 3 & 0.053 & 0.569 & 0.059 & 0.068 & 0.034 & 0.617 & 0.028 & 0.288 & 1.59 & 11.9 & 0.078 & \begin{tabular}{|l|}
0.144 \\
\end{tabular} & $<0.100$ & $<0.010$ & 0.042 & 0.085 \\
\hline NEPH2-40 & B06LM11 & 2 & 1 & 4 & 0.05 & 0.589 & 0.057 & 0.068 & 0.031 & 0.704 & 0.03 & 0.29 & 1.64 & 11.4 & 0.076 & 0.143 & \begin{tabular}{|c|}
$<0.100$ \\
\end{tabular} & $<0.010$ & 0.043 & 0.087 \\
\hline NEPH2-38 & B11LM11 & 2 & 1 & 5 & 0.058 & 0.604 & 0.055 & 0.082 & 0.036 & 0.695 & 0.028 & 0.304 & 1.69 & 11.9 & 0.082 & 0.152 & \begin{tabular}{|c|}
$<0.100$ \\
\end{tabular} & $<0.010$ & 0.044 & 0.09 \\
\hline NEPH2-35 & B09LM21 & 2 & 1 & 6 & 0.052 & 0.619 & 0.059 & 0.068 & 0.035 & 0.731 & 0.031 & 0.302 & 1.71 & 12.2 & 0.082 & 0.155 & $<0.100$ & $<0.010$ & 0.046 & 0.085 \\
\hline NEPH2-37 & B05LM21 & 2 & 1 & 7 & 0.049 & 0.574 & 0.058 & 0.071 & 0.031 & 0.695 & 0.028 & 0.282 & 1.63 & 11.9 & 0.069 & 0.144 & $<0.100$ & $<0.010$ & 0.041 & 0.083 \\
\hline NEPH2-34 & B01LM21 & 2 & 1 & 8 & 0.051 & 0.572 & 0.053 & 0.072 & 0.033 & 0.678 & 0.029 & 0.282 & 1.62 & 11.9 & 0.074 & 0.146 & $<0.100$ & $<0.010$ & 0.043 & 0.08 \\
\hline NEPH2-29 & B07LM21 & 2 & 1 & 9 & 0.053 & 0.63 & 0.069 & 0.073 & 0.033 & 0.718 & 0.034 & 0.314 & 1.73 & 12.8 & 0.082 & 0.16 & $<0.100$ & $<0.010$ & 0.047 & 0.091 \\
\hline Batch 1 & BCHLML212 & 2 & 1 & 10 & 0.125 & 0.835 & $<0.010$ & 0.078 & 0.307 & 2.456 & $<0.010$ & 0.82 & 1.26 & 6.96 & $<0.010$ & $<0.100$ & $<0.100$ & 0.391 & $<0.010$ & 0.063 \\
\hline Ustd & USTDLM212 & 2 & 1 & 11 & $<0.010$ & 0.876 & $<0.010$ & 0.16 & $<0.010$ & 2.362 & $<0.010$ & 0.66 & 2.07 & 8.75 & $<0.010$ & $<0.100$ & $<0.100$ & 0.533 & $<0.010$ & $<0.010$ \\
\hline NEPH2-40 & B06LM21 & 2 & 1 & 12 & 0.049 & 0.591 & 0.057 & 0.067 & 0.031 & 0.708 & 0.029 & 0.288 & 1.59 & 11.6 & 0.076 & 0.143 & $<0.100$ & $<0.010$ & 0.044 & 0.086 \\
\hline NEPH2-38 & B11 & 2 & 1 & 13 & 0.057 & 0.596 & 0.054 & 0.08 & 0.033 & 0.73 & 0.027 & 0.299 & 1.68 & 11.9 & 0.08 & 0.152 & $<0.100$ & $<0.010$ & 0.042 & 0.089 \\
\hline NEPH2-34 & B011 & 2 & 1 & 14 & 0.05 & 0.572 & 0.053 & 0.071 & 0.04 & 0.706 & 0.029 & 0.278 & 1.59 & 12.2 & 0.073 & 0.151 & \begin{tabular}{|c|}
$<0.100$ \\
\end{tabular} & $<0.010$ & 0.042 & 0.079 \\
\hline NEPH2-35 & B09 & 2 & 1 & 15 & 0.053 & 0.611 & 0.061 & 0.068 & 0.034 & 0.684 & 0.032 & 0.307 & 1.7 & 12.2 & 0.083 & 0.156 & $<0.100$ & $<0.010$ & 0.045 & 0.087 \\
\hline NEPH2-31 & B08LM & 2 & 1 & 16 & 0.051 & 0.572 & 0.057 & 0.065 & 0.037 & 0.659 & 0.028 & 0.282 & 1.58 & 12.2 & 0.074 & 0.144 & $<0.100$ & $<0.010$ & 0.043 & 0.084 \\
\hline NEPH2-37 & B05LM11 & 2 & 1 & 17 & 0.05 & 0.575 & 0.059 & 0.071 & 0.031 & 0.662 & 0.028 & 0.288 & 1.61 & 11.5 & 0.071 & 0.139 & $<0.100$ & $<0.010$ & 0.043 & 0.085 \\
\hline NEPH2-29 & B07LM11 & 2 & 1 & 18 & 0.055 & 0.638 & 0.068 & 0.076 & 0.034 & 0.708 & 0.036 & 0.322 & 1.74 & 13.3 & 0.084 & 0.167 & $<0.100$ & $<0.010$ & 0.049 & 0.094 \\
\hline Ustd & USTDLM213 & 2 & 1 & 19 & $<0.010$ & 0.86 & $<0.010$ & 0.16 & $<0.010$ & 2.358 & $<0.010$ & 0.664 & 2.03 & 8.76 & $<0.010$ & $<0.100$ & $<0.100$ & \begin{tabular}{|l|}
0.533 \\
\end{tabular} & $<0.010$ & $<0.010$ \\
\hline Batch 1 & BCHLM213 & 2 & 1 & 20 & 0.125 & 0.826 & $<0.010$ & 0.079 & 0.308 & 2.463 & $<0.010$ & 0.828 & 1.26 & 7.16 & $<0.010$ & $<0.100$ & $<0.100$ & 0.393 & $<0.010$ & 0.063 \\
\hline Batch 1 & BCHLM221 & 2 & 2 & 1 & 0.121 & 0.824 & $<0.010$ & 0.077 & 0.304 & 2.44 & $<0.010$ & 0.806 & 1.41 & 7 & $<0.010$ & $<0.100$ & $<0.100$ & 0.385 & $<0.010$ & 0.061 \\
\hline Ustd & USTDLM221 & 2 & 2 & 2 & $<0.010$ & 0.881 & $<0.010$ & 0.158 & $<0.010$ & 2.372 & $<0.010$ & 0.655 & 2.21 & 8.69 & $<0.010$ & $<0.100$ & $<0.100$ & 0.526 & $<0.010$ & $<0.010$ \\
\hline NEPH2-38 & B11LM22 & 2 & 2 & 3 & 0.055 & 0.591 & 0.053 & 0.078 & 0.033 & 0.721 & 0.027 & 0.291 & 1.82 & 11.8 & 0.078 & 0.147 & $<0.100$ & $<0.010$ & 0.041 & 0.086 \\
\hline NEPH2-38 & B11LM12 & 2 & 2 & 4 & 0.056 & 0.591 & 0.054 & 0.081 & 0.036 & 0.688 & 0.027 & 0.296 & 1.88 & 12.2 & 0.08 & 0.147 & $<0.100$ & $<0.010$ & 0.042 & 0.088 \\
\hline NEPH2-34 & B01LM22 & 2 & 2 & 5 & 0.049 & 0.566 & 0.051 & 0.07 & 0.033 & 0.674 & 0.029 & 0.276 & 1.76 & 12.1 & 0.072 & 0.144 & $<0.100$ & $<0.010$ & 0.042 & 0.078 \\
\hline NEPH2-40 & B06LM22 & 2 & 2 & 6 & 0.047 & 0.588 & 0.056 & 0.065 & 0.031 & 0.7 & 0.029 & 0.281 & 1.71 & 11.6 & 0.072 & 0.145 & $<0.100$ & $<0.010$ & 0.043 & 0.084 \\
\hline NEPH2-35 & B09LM22 & 2 & 2 & 7 & 0.05 & 0.607 & 0.058 & 0.066 & 0.035 & 0.726 & 0.031 & 0.293 & 1.79 & 12.3 & 0.079 & 0.148 & $<0.100$ & $<0.010$ & 0.045 & 0.082 \\
\hline NEPH2-31 & B08LM12 & 2 & 2 & 8 & 0.05 & 0.572 & 0.055 & 0.064 & 0.037 & 0.653 & 0.027 & 0.277 & 1.66 & 12.2 & 0.073 & 0.138 & $<0.100$ & $<0.010$ & 0.041 & 0.082 \\
\hline NEPH2-35 & B09LM12 & 2 & 2 & 9 & 0.051 & 0.606 & 0.059 & 0.066 & 0.034 & 0.68 & 0.031 & 0.3 & 1.78 & 12.1 & 0.082 & 0.157 & $<0.100$ & $<0.010$ & 0.044 & 0.085 \\
\hline Batch 1 & BCHLM222 & 2 & 2 & 10 & 0.12 & 0.823 & $<0.010$ & 0.076 & 0.305 & 2.447 & $<0.010$ & 0.799 & 1.31 & 6.98 & $<0.010$ & $<0.100$ & $<0.100$ & 0.38 & $<0.010$ & 0.062 \\
\hline Ustd & USTDLM222 & 2 & 2 & 11 & $<0.010$ & 0.878 & $<0.010$ & 0.156 & $<0.010$ & 2.361 & $<0.010$ & 0.643 & 2.2 & 8.69 & $<0.010$ & $<0.100$ & $<0.100$ & 0.522 & $<0.010$ & $<0.010$ \\
\hline NEPH2-40 & B06LM12 & 2 & 2 & 12 & 0.047 & 0.587 & 0.056 & 0.066 & 0.031 & 0.697 & 0.029 & 0.28 & 1.71 & 11.3 & 0.074 & 0.142 & $<0.100$ & $<0.010$ & 0.041 & 0.084 \\
\hline NEPH2-31 & B08LM22 & 2 & 2 & 13 & 0.051 & 0.57 & 0.059 & 0.066 & 0.035 & 0.622 & 0.028 & 0.28 & 1.64 & 11.9 & 0.076 & 0.143 & $<0.100$ & $<0.010$ & 0.04 & 0.084 \\
\hline NEPH2-37 & B05LM12 & 2 & 2 & 14 & 0.048 & 0.581 & 0.058 & 0.069 & 0.032 & 0.668 & 0.028 & 0.28 & 1.65 & 11.5 & 0.07 & 0.143 & $<0.100$ & $<0.010$ & 0.041 & 0.082 \\
\hline NEPH2-29 & B07LM22 & 2 & 2 & 15 & 0.051 & 0.627 & 0.068 & 0.072 & 0.034 & 0.718 & 0.034 & 0.306 & 1.77 & 12.8 & 0.079 & 0.163 & $<0.100$ & $<0.010$ & 0.046 & 0.089 \\
\hline NEPH2-37 & B05LM22 & 2 & 2 & 16 & 0.047 & 0.568 & 0.056 & 0.068 & 0.031 & 0.696 & 0.027 & 0.274 & 1.65 & 11.8 & 0.067 & 0.139 & $<0.100$ & $<0.010$ & 0.04 & 0.081 \\
\hline NEPH2-29 & B07LM12 & 2 & 2 & 17 & 0.053 & 0.636 & 0.067 & 0.075 & 0.034 & 0.71 & 0.035 & 0.314 & 1.83 & 13.1 & 0.081 & 0.16 & $<0.100$ & $<0.010$ & 0.048 & 0.091 \\
\hline NEPH2-34 & B01LM12 & 2 & 2 & 18 & 0.048 & 0.575 & 0.052 & 0.068 & 0.04 & 0.705 & 0.028 & 0.27 & 1.69 & 12.1 & 0.069 & 0.143 & $<0.100$ & $<0.010$ & 0.041 & 0.076 \\
\hline Batch 1 & BCHLM223 & 2 & 2 & 19 & 0.12 & 0.833 & $<0.010$ & 0.076 & 0.307 & 2.462 & $<0.010$ & 0.796 & 1.33 & 7.09 & $<0.010$ & $<0.100$ & $<0.100$ & 0.382 & $<0.010$ & 0.061 \\
\hline Ustd & USTDLM223 & 2 & 2 & 20 & $<0.010$ & 0.877 & $<0.010$ & 0.155 & $<0.010$ & 2.373 & $<0.010$ & 0.641 & 2.1 & 8.71 & $<0.010$ & $<0.100$ & $<0.100$ & 0.524 & $<0.010$ & $<0.010$ \\
\hline
\end{tabular}


Table C2. Measured Elemental Concentrations (wt\%) for Samples Prepared Using Lithium Metaborate

\begin{tabular}{|c|c|c|c|c|c|c|c|c|c|c|c|c|c|c|c|c|c|c|c|c|}
\hline Glass & Laboratory & & Sub- & Analytical & & & & & & & & & & & & & & & & \\
\hline ID & ID & Block & Block & Sequence & $\mathbf{B a}$ & $\mathbf{C a}$ & $\mathrm{Ce}$ & $\mathrm{Cr}$ & $\mathrm{Cu}$ & $\mathbf{K}$ & La & Mg & Mn & $\mathrm{Na}$ & $\mathbf{P b}$ & $\mathbf{S}$ & Th & $\mathbf{T i}$ & $\mathrm{Zn}$ & $\mathrm{Zr}$ \\
\hline Batch 1 & BCHLM311 & 3 & 1 & 1 & 0.123 & 0.832 & $<0.010$ & 0.078 & 0.306 & 2.486 & $<0.010$ & 0.807 & 1.35 & 7.13 & $<0.010$ & $<0.100$ & $<0.100$ & 0.383 & $<0.010$ & 0.061 \\
\hline Ustd & USTDLM311 & 3 & 1 & 2 & $<0.010$ & 0.878 & $<0.010$ & 0.158 & $<0.010$ & 2.375 & $<0.010$ & 0.65 & 2.12 & 8.77 & $<0.010$ & $<0.100$ & $<0.100$ & 0.524 & $<0.010$ & $<0.010$ \\
\hline NEPH2-13 & B23LM21 & 3 & 1 & 3 & 0.04 & 0.525 & \begin{tabular}{|l|}
0.045 \\
\end{tabular} & 0.064 & 0.029 & 0.528 & 0.025 & 0.303 & 1.4 & 12.9 & 0.057 & \begin{tabular}{|l|}
0.137 \\
\end{tabular} & $<0.100$ & $<0.010$ & \begin{tabular}{|l|}
0.037 \\
\end{tabular} & 0.06 \\
\hline NEPH2-16 & B21LM11 & 3 & 1 & 4 & 0.045 & 0.611 & 0.051 & 0.066 & 0.031 & 0.558 & 0.028 & 0.348 & 1.57 & 13 & 0.065 & 0.148 & $\begin{array}{l}<0.100 \\
\end{array}$ & $<0.010$ & 0.046 & 0.073 \\
\hline NEPH2-20 & B27LM11 & 3 & 1 & 5 & 0.048 & 0.62 & 0.053 & 0.073 & 0.034 & 0.579 & 0.03 & 0.382 & 1.71 & 12.9 & 0.074 & 0.161 & \begin{tabular}{l|}
$<0.100$ \\
\end{tabular} & $<0.010$ & 0.044 & 0.079 \\
\hline NEPH2-15 & B25LM21 & 3 & 1 & 6 & 0.042 & 0.549 & 0.05 & 0.078 & 0.03 & 0.49 & 0.027 & 0.329 & 1.46 & 12.7 & 0.064 & 0.14 & $<0.100$ & $<0.010$ & 0.039 & 0.068 \\
\hline NEPH2-16 & B21LM21 & 3 & 1 & 7 & 0.045 & 0.584 & 0.05 & 0.065 & 0.031 & 0.572 & 0.028 & 0.346 & 1.59 & 12.9 & 0.065 & 0.144 & $<0.100$ & $<0.010$ & 0.045 & 0.071 \\
\hline NEPH2-25 & B19LM11 & 3 & 1 & 8 & 0.048 & 0.636 & 0.055 & 0.073 & 0.033 & 0.603 & 0.037 & 0.383 & 1.8 & 12.5 & 0.069 & 0.161 & $<0.100$ & $<0.010$ & 0.045 & 0.08 \\
\hline NEPH2-19 & B26LM11 & 3 & 1 & 9 & 0.043 & 0.596 & 0.049 & 0.069 & 0.032 & 0.543 & 0.043 & 0.361 & 1.75 & 13.5 & 0.07 & 0.151 & $<0.100$ & $<0.010$ & 0.045 & 0.075 \\
\hline Batch 1 & BCHLM312 & 3 & 1 & 10 & 0.12 & 0.833 & $<0.010$ & 0.076 & 0.303 & 2.45 & $<0.010$ & 0.791 & 1.29 & 6.96 & $<0.010$ & $<0.100$ & $<0.100$ & 0.378 & $<0.010$ & 0.052 \\
\hline Ustd & USTDLM312 & 3 & 1 & 11 & $<0.010$ & 0.892 & $<0.010$ & 0.159 & $<0.010$ & 2.405 & $<0.010$ & 0.652 & 2.07 & 8.84 & $<0.010$ & $<0.100$ & $<0.100$ & 0.531 & $<0.010$ & $<0.010$ \\
\hline NEPH2-13 & B23LM11 & 3 & 1 & 12 & 0.041 & 0.533 & 0.047 & 0.065 & 0.03 & 0.504 & 0.026 & 0.313 & 1.44 & 12.6 & 0.061 & 0.139 & $<0.100$ & $<0.010$ & 0.038 & 0.062 \\
\hline NEPH2-19 & B26LM & 3 & 1 & 13 & 0.042 & 0.581 & 0.048 & 0.067 & 0.032 & 0.561 & 0.042 & 0.356 & 1.59 & 12.8 & 0.068 & 0.155 & $<0.100$ & $<0.010$ & 0.043 & 0.072 \\
\hline NEPH2-23 & $\mathrm{B} 24$ & 3 & 1 & 14 & 0.049 & 0.655 & 0.061 & 0.072 & 0.035 & 0.591 & 0.031 & 0.402 & 1.82 & 13 & 0.076 & 0.167 & $<0.100$ & $<0.010$ & 0.046 & 0.087 \\
\hline NEPH2-23 & & 3 & 1 & 15 & 0.048 & 0.653 & 0.061 & 0.068 & 0.035 & 0.564 & 0.031 & 0.392 & 1.79 & 13 & 0.073 & 0.164 & $\begin{array}{l}<0.100 \\
\end{array}$ & $<0.010$ & 0.043 & 0.086 \\
\hline NEPH2-20 & B27LM21 & 3 & 1 & 16 & 0.047 & 0.621 & 0.053 & 0.073 & 0.033 & 0.574 & 0.032 & 0.375 & 1.86 & 13.6 & 0.073 & 0.163 & $<0.100$ & $<0.010$ & 0.043 & 0.078 \\
\hline NEPH2-15 & B25LM11 & 3 & 1 & 17 & 0.041 & 0.551 & 0.05 & 0.077 & 0.031 & 0.488 & 0.077 & 0.324 & 1.52 & 12.6 & 0.062 & 0.147 & $<0.100$ & $<0.010$ & 0.042 & 0.068 \\
\hline NEPH2-25 & B19LM21 & 3 & 1 & 18 & 0.049 & 0.64 & 0.055 & 0.073 & 0.033 & 0.566 & 0.035 & 0.385 & 1.73 & 12 & 0.07 & 0.165 & $<0.100$ & $<0.010$ & 0.046 & 0.079 \\
\hline Batch 1 & BCHLM313 & 3 & 1 & 19 & 0.122 & 0.83 & $<0.010$ & 0.078 & 0.305 & 2.465 & $<0.010$ & 0.803 & 1.38 & 7.1 & $<0.010$ & $<0.100$ & $<0.100$ & 0.384 & $<0.010$ & 0.061 \\
\hline Ustd & USTDLM313 & 3 & 1 & 20 & $<0.010$ & 0.875 & $<0.010$ & 0.158 & $<0.010$ & 2.386 & $<0.010$ & 0.653 & 2.19 & 8.95 & $<0.010$ & $<0.100$ & $<0.100$ & 0.526 & $<0.010$ & $<0.010$ \\
\hline Batch 1 & BCHLM321 & 3 & 2 & 1 & 0.121 & 0.822 & $<0.010$ & 0.077 & 0.303 & 2.455 & $<0.010$ & 0.81 & 1.33 & 7.06 & $<0.010$ & $<0.100$ & $<0.100$ & 0.382 & $<0.010$ & 0.062 \\
\hline Ustd & USTDLM321 & 3 & 2 & 2 & $<0.010$ & 0.855 & $<0.010$ & 0.158 & $<0.010$ & 2.34 & $<0.010$ & 0.654 & 2.14 & 8.81 & $<0.010$ & $<0.100$ & $<0.100$ & 0.524 & $<0.010$ & $<0.010$ \\
\hline NEPH2-13 & B23LM12 & 3 & 2 & 3 & 0.039 & 0.519 & 0.046 & 0.063 & 0.029 & 0.491 & 0.025 & 0.313 & 1.41 & 12.7 & 0.058 & 0.135 & $<0.100$ & $<0.010$ & 0.035 & 0.063 \\
\hline NEPH2-25 & B19LM12 & 3 & 2 & 4 & 0.047 & 0.621 & 0.054 & 0.072 & 0.033 & 0.595 & 0.037 & 0.387 & 1.75 & 12.4 & 0.068 & 0.16 & $<0.100$ & $<0.010$ & 0.044 & 0.081 \\
\hline NEPH2-16 & B21LM12 & 3 & 2 & 5 & 0.044 & 0.605 & 0.051 & 0.065 & 0.031 & 0.557 & 0.028 & 0.353 & 1.62 & 13.2 & 0.064 & 0.147 & $<0.100$ & $<0.010$ & 0.045 & 0.074 \\
\hline NEPH2-13 & B23LM22 & 3 & 2 & 6 & 0.038 & 0.523 & 0.045 & 0.062 & 0.029 & 0.526 & 0.025 & 0.304 & 1.43 & 13.1 & 0.056 & 0.132 & $<0.100$ & $<0.010$ & 0.035 & 0.061 \\
\hline NEPH2-20 & B27LM22 & 3 & 2 & 7 & 0.045 & 0.618 & 0.052 & 0.071 & 0.033 & 0.57 & 0.032 & 0.379 & 1.85 & 13.5 & 0.071 & 0.156 & \begin{tabular}{|c|}
$<0.100$ \\
\end{tabular} & $<0.010$ & 0.04 & 0.079 \\
\hline NEPH2-16 & B21LM22 & 3 & 2 & 8 & 0.044 & 0.597 & 0.052 & 0.065 & 0.031 & 0.588 & 0.028 & 0.355 & 1.66 & 13.3 & 0.063 & 0.146 & $<0.100$ & $<0.010$ & 0.042 & 0.074 \\
\hline NEPH2-19 & B26LM12 & 3 & 2 & 9 & 0.042 & 0.584 & 0.049 & 0.068 & 0.032 & 0.54 & 0.043 & 0.367 & 1.72 & 13.1 & 0.068 & 0.149 & $<0.100$ & $<0.010$ & 0.043 & 0.077 \\
\hline Batch 1 & BCHLM322 & 3 & 2 & 10 & 0.121 & 0.816 & $<0.010$ & 0.077 & 0.302 & 2.438 & $<0.010$ & 0.813 & 1.29 & 6.97 & $<0.010$ & $<0.100$ & $<0.100$ & 0.385 & $<0.010$ & 0.062 \\
\hline Ustd & USTDLM322 & 3 & 2 & 11 & $<0.010$ & 0.868 & $<0.010$ & 0.157 & $<0.010$ & 2.338 & $<0.010$ & 0.655 & 2.14 & 8.89 & $<0.010$ & $<0.100$ & $<0.100$ & 0.528 & $<0.010$ & $<0.010$ \\
\hline NEPH2-20 & B27LM12 & 3 & 2 & 12 & 0.046 & 0.618 & 0.053 & 0.072 & 0.034 & 0.568 & 0.03 & 0.383 & 1.79 & 13.1 & 0.072 & 0.158 & $<0.100$ & $<0.010$ & 0.041 & 0.08 \\
\hline NEPH2-23 & B24LM12 & 3 & 2 & 13 & 0.047 & 0.64 & 0.061 & 0.07 & 0.035 & 0.581 & 0.031 & 0.404 & 1.87 & 13.1 & 0.074 & 0.165 & $<0.100$ & $<0.010$ & 0.043 & 0.09 \\
\hline NEPH2-15 & B25LM22 & 3 & 2 & 14 & 0.039 & 0.535 & 0.049 & 0.076 & 0.031 & 0.479 & 0.026 & 0.33 & 1.54 & 12.8 & 0.06 & 0.134 & $<0.100$ & $<0.010$ & 0.037 & 0.068 \\
\hline NEPH2-15 & B25LM12 & 3 & 2 & 15 & 0.04 & 0.547 & 0.05 & 0.077 & 0.032 & 0.482 & 0.078 & 0.332 & 1.53 & 12.6 & 0.061 & 0.142 & $<0.100$ & $<0.010$ & 0.041 & 0.069 \\
\hline NEPH2-23 & B24LM22 & 3 & 2 & 16 & 0.047 & 0.639 & 0.061 & 0.067 & 0.035 & 0.554 & 0.031 & 0.397 & 1.82 & 13.1 & 0.073 & 0.169 & $<0.100$ & $<0.010$ & 0.042 & 0.087 \\
\hline NEPH2-19 & B26LM22 & 3 & 2 & 17 & 0.04 & 0.578 & 0.048 & 0.066 & 0.033 & 0.552 & 0.042 & 0.358 & 1.66 & 12.8 & 0.067 & 0.144 & $<0.100$ & $<0.010$ & 0.041 & 0.074 \\
\hline NEPH2-25 & B19LM22 & 3 & 2 & 18 & 0.047 & 0.633 & 0.055 & 0.072 & 0.033 & 0.56 & 0.035 & 0.391 & 1.73 & 12.3 & 0.068 & 0.159 & $<0.100$ & $<0.010$ & 0.045 & 0.081 \\
\hline Batch 1 & BCHLM323 & 3 & 2 & 19 & 0.123 & 0.83 & $<0.010$ & 0.077 & 0.305 & 2.458 & $<0.010$ & 0.817 & 1.25 & 6.68 & $<0.010$ & $<0.100$ & $<0.100$ & \begin{tabular}{|l|}
0.391 \\
\end{tabular} & $<0.010$ & 0.063 \\
\hline Ustd & USTDLM323 & 3 & 2 & 20 & $<0.010$ & 0.869 & $<0.010$ & 0.159 & $<0.010$ & 2.356 & $<0.010$ & 0.661 & 2.17 & 8.93 & $<0.010$ & $<0.100$ & $<0.100$ & 0.533 & $<0.010$ & $<0.010$ \\
\hline
\end{tabular}


Table C2. Measured Elemental Concentrations (wt\%) for Samples Prepared Using Lithium Metaborate

\begin{tabular}{|c|c|c|c|c|c|c|c|c|c|c|c|c|c|c|c|c|c|c|c|c|}
\hline Glass & Laboratory & & Sub- & Analytical & & & & & & & & & & & & & & & & \\
\hline ID & ID & Block & Block & Sequence & $\mathbf{B a}$ & $\mathbf{C a}$ & $\mathrm{Ce}$ & $\mathrm{Cr}$ & $\mathrm{Cu}$ & $\mathbf{K}$ & La & Mg & Mn & $\mathrm{Na}$ & $\mathbf{P b}$ & $\mathbf{S}$ & Th & $\mathbf{T i}$ & $\mathrm{Zn}$ & $\mathrm{Zr}$ \\
\hline Batch 1 & BCHLM411 & 4 & 1 & 1 & 0.122 & 0.833 & $<0.010$ & 0.076 & 0.306 & 2.49 & $<0.010$ & 0.809 & 1.28 & 6.5 & $<0.010$ & $<0.100$ & $<0.100$ & 0.385 & $<0.010$ & 0.048 \\
\hline Ustd & USTDLM411 & 4 & 1 & 2 & $<0.010$ & 0.869 & $<0.010$ & 0.157 & $<0.010$ & 2.35 & $<0.010$ & 0.651 & 2.13 & 8.67 & $<0.010$ & $<0.100$ & $<0.100$ & 0.527 & $<0.010$ & $<0.010$ \\
\hline NEPH2-33 & B15LM11 & 4 & 1 & 3 & 0.044 & 0.533 & \begin{tabular}{|l|}
0.047 \\
\end{tabular} & 0.067 & 0.03 & 0.582 & \begin{tabular}{|l|}
0.03 \\
\end{tabular} & 0.261 & 1.5 & 10.7 & \begin{tabular}{|l|}
0.067 \\
\end{tabular} & \begin{tabular}{|l|}
0.133 \\
\end{tabular} & $<0.100$ & $<0.010$ & \begin{tabular}{|l|}
0.04 \\
\end{tabular} & 0.074 \\
\hline NEPH2-27 & B18LM11 & 4 & 1 & 4 & 0.045 & 0.561 & 0.042 & 0.063 & 0.03 & 0.64 & 0.028 & 0.272 & 1.6 & 12.1 & 0.057 & 0.145 & \begin{tabular}{|l|}
$<0.100$ \\
\end{tabular} & $<0.010$ & 0.039 & 0.076 \\
\hline NEPH2-39 & B16LM11 & 4 & 1 & 5 & 0.047 & 0.55 & 0.053 & 0.06 & 0.03 & 0.618 & 0.03 & 0.273 & 1.56 & 10.5 & 0.073 & 0.133 & $\begin{array}{l}<0.100 \\
\end{array}$ & $<0.010$ & 0.039 & 0.078 \\
\hline NEPH2-28 & B20LM11 & 4 & 1 & 6 & 0.041 & 0.52 & 0.048 & 0.07 & 0.029 & 0.594 & 0.026 & 0.245 & 1.41 & 11.7 & 0.074 & 0.133 & $<0.100$ & $<0.010$ & 0.038 & 0.072 \\
\hline NEPH2-39 & B16LM21 & 4 & 1 & 7 & 0.048 & 0.557 & 0.053 & 0.059 & 0.031 & 0.604 & 0.031 & 0.277 & 1.59 & 10.8 & 0.073 & 0.136 & $<0.100$ & $<0.010$ & 0.041 & 0.08 \\
\hline NEPH2-30 & B14LM21 & 4 & 1 & 8 & 0.043 & 0.532 & 0.049 & 0.066 & 0.03 & 0.574 & 0.03 & 0.255 & 1.47 & 11.8 & 0.069 & 0.132 & $<0.100$ & $<0.010$ & 0.038 & 0.075 \\
\hline NEPH2-36 & B22LM21 & 4 & 1 & 9 & 0.048 & 0.532 & 0.048 & 0.067 & 0.032 & 0.617 & 0.027 & 0.259 & 1.52 & 11.1 & 0.065 & 0.133 & $<0.100$ & $<0.010$ & 0.038 & 0.077 \\
\hline Batch 1 & BCHLM412 & 4 & 1 & 10 & 0.122 & 0.837 & $<0.010$ & 0.077 & 0.308 & 2.5 & $<0.010$ & 0.808 & 1.29 & 6.95 & $<0.010$ & $<0.100$ & $<0.100$ & 0.386 & $<0.010$ & 0.048 \\
\hline Ustd & USTDLM412 & 4 & 1 & 11 & $<0.010$ & 0.881 & $<0.010$ & 0.157 & $<0.010$ & 2.39 & $<0.010$ & 0.648 & 2.11 & 8.6 & $<0.010$ & $<0.100$ & $<0.100$ & 0.535 & $<0.010$ & $<0.010$ \\
\hline NEPH2-32 & B28LM11 & 4 & 1 & 12 & 0.051 & 0.611 & 0.054 & 0.071 & 0.033 & 0.753 & 0.029 & 0.291 & 1.75 & 12.5 & 0.07 & 0.16 & $<0.100$ & $<0.010$ & 0.044 & 0.084 \\
\hline NEPH2-33 & B15LM & 4 & 1 & 13 & 0.041 & 0.531 & 0.045 & 0.063 & 0.029 & 0.658 & 0.029 & 0.246 & 1.53 & 11.7 & 0.062 & 0.136 & $<0.100$ & $<0.010$ & 0.036 & 0.071 \\
\hline NEPH2-28 & $\mathrm{B} 20$ & 4 & 1 & 14 & 0.042 & 0.535 & 0.052 & 0.072 & 0.03 & 0.563 & 0.027 & 0.255 & 1.4 & 11.8 & 0.078 & 0.133 & $<0.100$ & $<0.010$ & 0.039 & 0.076 \\
\hline NEPH2-32 & & 4 & 1 & 15 & 0.05 & 0.613 & 0.054 & 0.069 & 0.033 & 0.762 & 0.029 & 0.289 & 1.62 & 12.2 & 0.069 & 0.158 & \begin{tabular}{|l|}
$<0.100$ \\
\end{tabular} & $<0.010$ & 0.044 & 0.085 \\
\hline NEPH2-30 & B14LM11 & 4 & 1 & 16 & 0.041 & 0.532 & 0.048 & 0.063 & 0.03 & 0.639 & 0.029 & 0.244 & 1.43 & 11.7 & 0.064 & 0.147 & $<0.100$ & $<0.010$ & 0.226 & 0.073 \\
\hline NEPH2-27 & B18LM21 & 4 & 1 & 17 & 0.045 & 0.565 & 0.044 & 0.065 & 0.032 & 0.651 & 0.028 & 0.278 & 1.5 & 11.7 & 0.059 & 0.154 & $<0.100$ & $<0.010$ & 0.041 & 0.079 \\
\hline NEPH2-36 & B22LM11 & 4 & 1 & 18 & 0.047 & 0.544 & 0.049 & 0.068 & 0.031 & 0.644 & 0.027 & 0.256 & 1.54 & 11.5 & 0.064 & 0.138 & $<0.100$ & $<0.010$ & 0.038 & 0.077 \\
\hline Batch 1 & BCHLM413 & 4 & 1 & 19 & 0.12 & 0.84 & $<0.010$ & 0.075 & 0.306 & 2.5 & $<0.010$ & 0.798 & 1.31 & 7 & $<0.010$ & $<0.100$ & $<0.100$ & 0.384 & $<0.010$ & 0.041 \\
\hline Ustd & USTDLM413 & 4 & 1 & 20 & $<0.010$ & 0.88 & $<0.010$ & 0.155 & $<0.010$ & 2.38 & $<0.010$ & 0.642 & 2.11 & 8.71 & $<0.010$ & $<0.100$ & $<0.100$ & 0.526 & $<0.010$ & $<0.010$ \\
\hline Batch 1 & BCHLM421 & 4 & 2 & 1 & 0.121 & 0.836 & $<0.010$ & 0.076 & 0.305 & 2.47 & $<0.010$ & 0.806 & 1.24 & 6.83 & $<0.010$ & $<0.100$ & $<0.100$ & 0.386 & $<0.010$ & 0.055 \\
\hline Ustd & USTDLM421 & 4 & 2 & 2 & $<0.010$ & 0.885 & $<0.010$ & 0.168 & $<0.010$ & 2.11 & $<0.010$ & 0.699 & 2.06 & 8.76 & $<0.010$ & $<0.100$ & $<0.100$ & 0.569 & $<0.010$ & $<0.010$ \\
\hline NEPH2-28 & B20LM22 & 4 & 2 & 3 & 0.042 & 0.525 & 0.05 & 0.073 & 0.03 & 0.552 & 0.026 & 0.256 & 1.38 & 11.9 & 0.077 & 0.127 & $<0.100$ & $<0.010$ & 0.039 & 0.077 \\
\hline NEPH2-39 & B16LM12 & 4 & 2 & 4 & 0.048 & 0.551 & 0.053 & 0.06 & 0.03 & 0.624 & 0.029 & 0.275 & 1.45 & 10.6 & 0.073 & 0.13 & $<0.100$ & $<0.010$ & 0.039 & 0.081 \\
\hline NEPH2-30 & B14LM12 & 4 & 2 & 5 & 0.041 & 0.524 & 0.047 & 0.064 & 0.029 & 0.624 & 0.028 & 0.245 & 1.44 & 11.8 & 0.064 & 0.133 & $<0.100$ & $<0.010$ & 0.036 & 0.076 \\
\hline NEPH2-33 & B15LM12 & 4 & 2 & 6 & 0.044 & 0.536 & 0.046 & 0.066 & 0.03 & 0.586 & 0.029 & 0.262 & 1.44 & 10.9 & 0.067 & 0.13 & $<0.100$ & $<0.010$ & 0.039 & 0.077 \\
\hline NEPH2-36 & B22LM12 & 4 & 2 & 7 & 0.047 & 0.545 & 0.049 & 0.068 & 0.031 & 0.643 & 0.026 & 0.257 & 1.51 & 11.6 & 0.064 & 0.135 & $\begin{array}{l}<0.100 \\
\end{array}$ & $<0.010$ & 0.038 & 0.079 \\
\hline NEPH2-30 & B14LM22 & 4 & 2 & 8 & 0.043 & 0.527 & 0.049 & 0.065 & 0.03 & 0.581 & 0.029 & 0.255 & 1.45 & 11.9 & 0.069 & 0.127 & $<0.100$ & $<0.010$ & 0.037 & 0.078 \\
\hline NEPH2-39 & B16LM22 & 4 & 2 & 9 & 0.048 & 0.559 & 0.053 & 0.059 & 0.032 & 0.608 & 0.03 & 0.277 & 1.52 & 11 & 0.074 & 0.133 & $<0.100$ & $<0.010$ & 0.042 & 0.082 \\
\hline Batch 1 & BCHLM422 & 4 & 2 & 10 & 0.121 & 0.831 & $<0.010$ & 0.077 & 0.307 & 2.5 & $<0.010$ & 0.808 & 1.26 & 7.01 & $<0.010$ & $<0.100$ & $<0.100$ & \begin{tabular}{|l|}
0.385 \\
\end{tabular} & $<0.010$ & 0.063 \\
\hline Ustd & USTDLM422 & 4 & 2 & 11 & $<0.010$ & 0.875 & $<0.010$ & 0.156 & $<0.010$ & 2.39 & $<0.010$ & 0.649 & 1.97 & 8.91 & $<0.010$ & $<0.100$ & $<0.100$ & 0.524 & $<0.010$ & $<0.010$ \\
\hline NEPH2-27 & B18LM12 & 4 & 2 & 12 & 0.044 & 0.558 & 0.041 & 0.063 & 0.029 & 0.648 & 0.026 & 0.271 & 1.54 & 12.2 & 0.057 & 0.138 & $<0.100$ & $<0.010$ & 0.037 & 0.078 \\
\hline NEPH2-27 & B18LM22 & 4 & 2 & 13 & 0.045 & 0.562 & 0.043 & 0.065 & 0.031 & 0.647 & 0.027 & 0.279 & 1.55 & 11.6 & 0.058 & 0.141 & $<0.100$ & $<0.010$ & 0.039 & 0.08 \\
\hline NEPH2-28 & B20LM12 & 4 & 2 & 14 & 0.04 & 0.529 & 0.048 & 0.07 & 0.029 & 0.6 & 0.025 & 0.244 & 1.38 & 11.9 & 0.074 & 0.127 & $<0.100$ & $<0.010$ & 0.038 & 0.075 \\
\hline NEPH2-33 & B15LM22 & 4 & 2 & 15 & 0.041 & 0.53 & 0.044 & 0.063 & 0.029 & 0.655 & 0.028 & 0.245 & 1.49 & 11.8 & 0.061 & 0.132 & $<0.100$ & $<0.010$ & 0.036 & 0.075 \\
\hline NEPH2-32 & B28LM12 & 4 & 2 & 16 & 0.05 & 0.612 & 0.053 & 0.07 & 0.032 & 0.75 & 0.028 & 0.289 & 1.72 & 12.5 & 0.068 & 0.152 & $<0.100$ & $<0.010$ & 0.043 & 0.087 \\
\hline NEPH2-32 & B28LM22 & 4 & 2 & 17 & 0.049 & 0.612 & 0.053 & 0.068 & 0.033 & 0.748 & 0.027 & 0.286 & 1.64 & 12.3 & 0.067 & 0.159 & $<0.100$ & $<0.010$ & 0.042 & 0.087 \\
\hline NEPH2-36 & B22LM22 & 4 & 2 & 18 & 0.048 & 0.539 & 0.048 & 0.066 & 0.032 & 0.624 & 0.026 & 0.257 & 1.52 & 11.2 & 0.064 & 0.131 & $\begin{array}{l}<0.100 \\
\end{array}$ & $<0.010$ & 0.037 & 0.08 \\
\hline Ustd & USTDLM423 & 4 & 2 & 19 & $<0.010$ & 0.875 & $<0.010$ & 0.166 & $<0.010$ & 2.11 & $<0.010$ & 0.694 & 2.11 & 8.75 & $<0.010$ & $<0.100$ & $<0.100$ & \begin{tabular}{|l|}
0.559 \\
\end{tabular} & $<0.010$ & $<0.010$ \\
\hline Batch 1 & BCHLM423 & 4 & 2 & 20 & 0.119 & 0.845 & $<0.010$ & 0.076 & 0.3 & 2.46 & $<0.010$ & 0.79 & 1.24 & 6.63 & $<0.010$ & $<0.100$ & $<0.100$ & 0.379 & $<0.010$ & 0.062 \\
\hline
\end{tabular}




\section{Table C3. Measured Elemental Concentrations (wt\%) for Samples Prepared Using Peroxide Fusion}

\begin{tabular}{|c|c|c|c|c|c|c|c|c|c|c|c|}
\hline Glass & PSAL & & Sub- & Analytical & & & & & & & \\
\hline ID & ID & Block & Block & Sequence & Al & B & $\mathbf{F e}$ & $\mathbf{L i}$ & $\mathrm{Ni}$ & Si & $\mathbf{U}$ \\
\hline Batch 1 & BCHPF111 & 1 & 1 & 1 & 2.56 & 2.49 & 8.73 & 2.01 & 0.545 & 23.1 & $<0.100$ \\
\hline Ustd & USTDPF111 & 1 & 1 & 2 & 2.12 & 2.80 & 8.64 & 1.37 & 0.750 & 20.4 & 1.93 \\
\hline NEPH2-17 & B12PF11 & 1 & 1 & 3 & 6.38 & 1.40 & 6.58 & 2.00 & 0.946 & 19.4 & 2.66 \\
\hline NEPH2-14 & B13PF21 & 1 & 1 & 4 & 5.51 & 1.35 & 5.87 & 1.95 & 0.844 & 19.7 & 2.32 \\
\hline NEPH2-18 & B04PF21 & 1 & 1 & 5 & 5.62 & 1.45 & 6.17 & 2.07 & 0.899 & 20.6 & 2.26 \\
\hline NEPH2-22 & B10PF11 & 1 & 1 & 6 & 6.34 & 1.31 & 6.63 & 1.91 & 0.942 & 19.7 & 2.66 \\
\hline NEPH2-24 & B17PF21 & 1 & 1 & 7 & 5.93 & 1.34 & 6.08 & 2.01 & 0.884 & 20.5 & 2.38 \\
\hline NEPH2-18 & B04PF11 & 1 & 1 & 8 & 5.66 & 1.44 & 6.16 & 2.08 & 0.887 & 20.7 & 2.29 \\
\hline NEPH2-21 & B02PF21 & 1 & 1 & 9 & 5.21 & 1.24 & 5.49 & 1.82 & 0.789 & 20.2 & 2.19 \\
\hline Batch 1 & BCHPF112 & 1 & 1 & 10 & 2.60 & 2.37 & 8.69 & 2.02 & 0.552 & 23.4 & $<0.100$ \\
\hline Ustd & \begin{tabular}{|l} 
USTDPF112 \\
\end{tabular} & 1 & 1 & 11 & 2.14 & 2.75 & 8.68 & 1.37 & 0.761 & 20.6 & 1.88 \\
\hline NEPH2-26 & B03PF21 & 1 & 1 & 12 & 7.06 & 1.31 & 7.20 & 1.74 & 1.08 & 17.8 & 2.91 \\
\hline NEPH2-26 & B03PF11 & 1 & 1 & 13 & 7.03 & 1.20 & 7.11 & 1.73 & 1.03 & 17.6 & 2.88 \\
\hline NEPH2-21 & B02PF11 & 1 & 1 & 14 & 5.58 & 1.35 & 5.86 & 1.96 & 0.882 & 20.1 & 2.36 \\
\hline NEPH2-24 & B17PF11 & 1 & 1 & 15 & 5.95 & 1.36 & 6.14 & 2.00 & 0.898 & 20.0 & 2.38 \\
\hline NEPH2-14 & B13PF11 & 1 & 1 & 16 & 5.97 & 1.43 & 6.30 & 2.10 & 0.910 & 20.0 & 2.46 \\
\hline NEPH2-22 & B10PF21 & 1 & 1 & 17 & 6.57 & 1.34 & 6.76 & 1.96 & 0.983 & 19.7 & 2.72 \\
\hline NEPH2-17 & B12PF21 & 1 & 1 & 18 & 6.32 & 1.32 & 6.37 & 1.97 & 0.920 & 19.0 & 2.61 \\
\hline Ustd & USTDPF113 & 1 & 1 & 19 & 2.16 & 2.72 & 8.53 & 1.38 & 0.762 & 20.4 & 1.90 \\
\hline Batch 1 & BCHPF113 & 1 & 1 & 20 & 2.63 & 2.39 & 8.52 & 2.04 & 0.552 & 23.3 & $<0.100$ \\
\hline Batch 1 & BCHPF121 & 1 & 2 & 1 & 2.58 & 2.45 & 8.55 & 2.02 & 0.568 & 23.2 & $<0.100$ \\
\hline Ustd & \begin{tabular}{|l} 
USTDPF121 \\
\end{tabular} & 1 & 2 & 2 & 2.13 & 2.75 & 8.71 & 1.38 & 0.786 & 20.5 & 1.94 \\
\hline NEPH2-26 & B03PF12 & 1 & 2 & 3 & 7.20 & 1.09 & 7.46 & 1.81 & 1.11 & 18.1 & 2.94 \\
\hline NEPH2-24 & B17PF22 & 1 & 2 & 4 & 6.08 & 1.30 & 6.36 & 2.07 & 0.943 & 20.6 & 2.47 \\
\hline NEPH2-17 & B12PF12 & 1 & 2 & 5 & 6.53 & 1.30 & 6.82 & 2.06 & 0.999 & 19.8 & 2.72 \\
\hline NEPH2-14 & B13PF12 & 1 & 2 & 6 & 6.05 & 1.37 & 6.55 & 2.14 & 0.958 & 20.5 & 2.52 \\
\hline NEPH2-21 & B02PF22 & 1 & 2 & 7 & 5.33 & 1.21 & 5.87 & 1.88 & 0.874 & 20.8 & 2.24 \\
\hline NEPH2-21 & B02PF12 & 1 & 2 & 8 & 5.68 & 1.30 & 6.23 & 2.02 & 0.941 & 20.5 & 2.45 \\
\hline NEPH2-26 & B03PF22 & 1 & 2 & 9 & 7.18 & 1.13 & 7.52 & 1.78 & 1.13 & 18.2 & 2.98 \\
\hline Batch 1 & BCHPF122 & 1 & 2 & 10 & 2.62 & 2.33 & 8.93 & 2.06 & 0.584 & 23.7 & $<0.100$ \\
\hline Ustd & \begin{tabular}{|l} 
USTDPF122 \\
\end{tabular} & 1 & 2 & 11 & 2.16 & 2.75 & 9.27 & 1.41 & 0.811 & 21.1 & 1.96 \\
\hline NEPH2-24 & B17PF12 & 1 & 2 & 12 & 6.07 & 1.42 & 6.41 & 2.06 & 0.962 & 20.7 & 2.45 \\
\hline NEPH2-18 & B04PF12 & 1 & 2 & 13 & 5.79 & 1.43 & 6.55 & 2.14 & 0.947 & 21.2 & 2.36 \\
\hline NEPH2-22 & B10PF22 & 1 & 2 & 14 & 6.67 & 1.29 & 7.08 & 2.01 & 1.01 & 20.3 & 2.77 \\
\hline NEPH2-14 & B13PF22 & 1 & 2 & 15 & 5.64 & 1.26 & 5.84 & 1.98 & 0.860 & 19.7 & 2.35 \\
\hline NEPH2-18 & B04PF22 & 1 & 2 & 16 & 5.75 & 1.38 & 6.27 & 2.11 & 0.921 & 20.9 & 2.36 \\
\hline NEPH2-17 & B12PF22 & 1 & 2 & 17 & 6.38 & 1.27 & 6.71 & 2.00 & 0.982 & 19.6 & 2.70 \\
\hline NEPH2-22 & B10PF12 & 1 & 2 & 18 & 6.45 & 1.24 & 6.81 & 1.93 & 0.996 & 19.7 & 2.71 \\
\hline Ustd & USTDPF123 & 1 & 2 & 19 & 2.14 & 2.65 & 8.85 & 1.38 & 0.798 & 20.6 & 1.98 \\
\hline Batch 1 & BCHPF123 & 1 & 2 & 20 & 2.62 & 2.38 & 9.06 & 2.06 & 0.595 & 23.8 & $<0.100$ \\
\hline Batch 1 & BHCPF211 & 2 & 1 & 1 & 2.58 & 2.50 & 8.70 & 2.03 & 0.542 & 23.2 & $<0.100$ \\
\hline Ustd & \begin{tabular}{|l} 
USTDPF211 \\
\end{tabular} & 2 & 1 & 2 & 2.13 & 2.74 & 8.65 & 1.37 & 0.745 & 20.4 & 1.90 \\
\hline NEPH2-37 & B05PF21 & 2 & 1 & 3 & 7.25 & 1.34 & 6.32 & 2.00 & 1.11 & 20.0 & 2.62 \\
\hline NEPH2-40 & B06PF21 & 2 & 1 & 4 & 7.37 & 1.27 & 6.29 & 1.95 & 1.08 & 19.7 & 2.67 \\
\hline NEPH2-29 & B07PF11 & 2 & 1 & 5 & 7.80 & 1.17 & 6.74 & 1.84 & 1.14 & 17.6 & 2.79 \\
\hline NEPH2-38 & B11PF11 & 2 & 1 & 6 & 7.51 & 1.21 & 6.61 & 1.91 & 1.15 & 19.1 & 2.69 \\
\hline NEPH2-37 & B05PF11 & 2 & 1 & 7 & 6.81 & 1.17 & 5.92 & 1.87 & 1.06 & 19.4 & 2.47 \\
\hline NEPH2-31 & B08PF11 & 2 & 1 & 8 & 7.11 & 1.26 & 5.93 & 2.03 & 1.01 & 19.4 & 2.47 \\
\hline NEPH2-34 & B01PF11 & 2 & 1 & 9 & 7.18 & 1.24 & 6.17 & 1.98 & 1.11 & 19.6 & 2.57 \\
\hline Batch 1 & BCHPF212 & 2 & 1 & 10 & 2.60 & 2.27 & 8.61 & 2.03 & 0.543 & 23.2 & $<0.100$ \\
\hline Ustd & USTDPF212 & 2 & 1 & 11 & 2.12 & 2.68 & 8.83 & 1.37 & 0.766 & 20.5 & 1.92 \\
\hline NEPH2-31 & B08PF21 & 2 & 1 & 12 & 7.04 & 1.36 & 5.90 & 2.01 & 1.02 & 19.2 & 2.56 \\
\hline NEPH2-38 & B11PF21 & 2 & 1 & 13 & 7.56 & 1.25 & 6.94 & 1.91 & 1.20 & 19.7 & 2.76 \\
\hline NEPH2-29 & B07PF21 & 2 & 1 & 14 & 7.53 & 1.15 & 6.57 & 1.82 & 1.12 & 17.5 & 2.76 \\
\hline NEPH2-35 & B09PF11 & 2 & 1 & 15 & 7.56 & 1.14 & 6.35 & 1.85 & 1.09 & 18.0 & 2.70 \\
\hline NEPH2-40 & B06PF11 & 2 & 1 & 16 & 7.24 & 1.20 & 6.00 & 1.90 & 1.06 & 19.7 & 2.60 \\
\hline NEPH2-34 & B01PF21 & 2 & 1 & 17 & 7.25 & 1.24 & 6.11 & 2.00 & 1.10 & 19.5 & 2.58 \\
\hline NEPH2-35 & B09PF21 & 2 & 1 & 18 & 7.67 & 1.16 & 6.65 & 1.88 & 1.15 & 18.5 & 2.74 \\
\hline Ustd & USTDPF213 & 2 & 1 & 19 & 2.16 & 2.64 & 8.62 & 1.39 & 0.747 & 20.4 & 1.94 \\
\hline
\end{tabular}




\section{Table C3. Measured Elemental Concentrations (wt\%) for Samples Prepared Using Peroxide Fusion}

\begin{tabular}{|c|c|c|c|c|c|c|c|c|c|c|c|}
\hline Glass & PSAL & & Sub- & Analytical & & & & & & & \\
\hline ID & ID & Block & Block & Sequence & Al & B & $\mathrm{Fe}$ & $\mathbf{L i}$ & $\mathbf{N i}$ & $\mathbf{S i}$ & $\mathbf{U}$ \\
\hline Batch 1 & BCHPF213 & 2 & 1 & 20 & 2.62 & 2.33 & 8.78 & 2.05 & 0.544 & 23.5 & $<0.100$ \\
\hline Batch 1 & BCHPF221 & 2 & 2 & 1 & 2.57 & 2.53 & 8.84 & 2.04 & 0.590 & 23.4 & $<0.100$ \\
\hline Ustd & USTDPF221 & 2 & 2 & 2 & 2.13 & 2.79 & 8.77 & 1.39 & 0.800 & 20.6 & 1.92 \\
\hline NEPH2-35 & B09PF22 & 2 & 2 & 3 & 7.60 & 1.17 & 6.66 & 1.89 & 1.17 & 18.4 & 2.67 \\
\hline NEPH2-31 & B08PF12 & 2 & 2 & 4 & 7.09 & 1.29 & 6.05 & 2.05 & 1.07 & 19.6 & 2.48 \\
\hline NEPH2-29 & B07PF22 & 2 & 2 & 5 & 7.56 & 1.17 & 6.61 & 1.84 & 1.17 & 17.7 & 2.80 \\
\hline NEPH2-29 & B07PF12 & 2 & 2 & 6 & 7.85 & 1.17 & 6.75 & 1.85 & 1.17 & 17.7 & 2.81 \\
\hline NEPH2-38 & B11PF22 & 2 & 2 & 7 & 7.81 & 1.29 & 7.39 & 2.00 & 1.32 & 19.9 & 2.88 \\
\hline NEPH2-35 & B09PF12 & 2 & 2 & 8 & 7.58 & 1.18 & 6.65 & 1.87 & 1.18 & 18.4 & 2.74 \\
\hline NEPH2-40 & B06PF22 & 2 & 2 & 9 & 7.32 & 1.25 & 6.32 & 1.94 & 1.12 & 19.7 & 2.66 \\
\hline Batch 1 & BCHPF222 & 2 & 2 & 10 & 2.58 & 2.29 & 8.65 & 2.03 & 0.582 & 23.3 & $<0.100$ \\
\hline Ustd & \begin{tabular}{|l|} 
USTDPF222 \\
\end{tabular} & 2 & 2 & 11 & 2.12 & 2.67 & 8.71 & 1.38 & 0.787 & 20.5 & 1.97 \\
\hline NEPH2-31 & B08PF22 & 2 & 2 & 12 & 6.98 & 1.40 & 6.20 & 2.02 & 1.09 & 19.5 & 2.54 \\
\hline NEPH2-34 & B01PF22 & 2 & 2 & 13 & 7.33 & 1.31 & 6.23 & 2.03 & 1.13 & 19.8 & 2.64 \\
\hline NEPH2-37 & B05PF12 & 2 & 2 & 14 & 6.84 & 1.23 & 6.07 & 1.88 & 1.10 & 19.6 & 2.47 \\
\hline NEPH2-34 & B01PF12 & 2 & 2 & 15 & 7.22 & 1.29 & 6.38 & 2.01 & 1.17 & 19.8 & 2.64 \\
\hline NEPH2-40 & B06PF12 & 2 & 2 & 16 & 7.30 & 1.24 & 6.31 & 1.94 & 1.11 & 19.8 & 2.63 \\
\hline NEPH2-37 & B05PF22 & 2 & 2 & 17 & 7.20 & 1.27 & 6.35 & 1.99 & 1.13 & 20.0 & 2.61 \\
\hline NEPH2-38 & B11PF12 & 2 & 2 & 18 & 7.63 & 1.23 & 6.72 & 1.95 & 1.19 & 19.3 & 2.77 \\
\hline Ustd & USTDPF223 & 2 & 2 & 19 & 2.15 & 2.66 & 8.87 & 1.39 & 0.810 & 20.7 & 1.96 \\
\hline Batch 1 & BCHPF223 & 2 & 2 & 20 & 2.58 & 2.31 & 8.91 & 2.04 & 0.581 & 23.4 & $<0.100$ \\
\hline Batch 1 & BCHPF311 & 3 & 1 & 1 & 2.60 & 2.54 & 8.97 & 2.06 & 0.610 & 23.6 & $<0.100$ \\
\hline Ustd & \begin{tabular}{|l|} 
USTDPF311 \\
\end{tabular} & 3 & 1 & 2 & 2.14 & 2.75 & 8.78 & 1.40 & 0.817 & 20.5 & 1.93 \\
\hline NEPH2-23 & B24PF11 & 3 & 1 & 3 & 6.69 & 1.25 & 7.30 & 1.83 & 1.09 & 18.4 & 2.89 \\
\hline NEPH2-19 & B26PF11 & 3 & 1 & 4 & 6.05 & 1.30 & 6.54 & 2.00 & 0.984 & 20.3 & 2.58 \\
\hline NEPH2-20 & B27PF21 & 3 & 1 & 5 & 6.44 & 1.23 & 6.94 & 1.89 & 1.05 & 19.8 & 2.76 \\
\hline NEPH2-16 & B21PF11 & 3 & 1 & 6 & 6.11 & 1.32 & 6.29 & 2.08 & 0.946 & 19.1 & 2.46 \\
\hline NEPH2-15 & B25PF11 & 3 & 1 & 7 & 5.12 & 1.27 & 5.98 & 1.97 & 0.915 & 20.2 & 2.22 \\
\hline NEPH2-15 & B25PF21 & 3 & 1 & 8 & 5.69 & 1.39 & 5.98 & 2.18 & 0.905 & 20.8 & 2.37 \\
\hline NEPH2-25 & B19PF21 & 3 & 1 & 9 & 6.53 & 1.23 & 6.96 & 1.91 & 1.06 & 19.3 & 2.71 \\
\hline Batch 1 & BCHPF312 & 3 & 1 & 10 & 2.61 & 2.31 & 8.91 & 2.06 & 0.611 & 23.6 & $<0.100$ \\
\hline Ustd & \begin{tabular}{|l} 
USTDPF312 \\
\end{tabular} & 3 & 1 & 11 & 2.16 & 2.69 & 8.95 & 1.40 & 0.815 & 20.7 & 1.98 \\
\hline NEPH2-23 & B24PF21 & 3 & 1 & 12 & 6.55 & 1.24 & 6.91 & 1.78 & 1.04 & 18.4 & 2.81 \\
\hline NEPH2-13 & B23PF21 & 3 & 1 & 13 & 5.57 & 1.47 & 5.81 & 2.24 & 0.896 & 20.9 & 2.37 \\
\hline NEPH2-13 & B23PF11 & 3 & 1 & 14 & 5.05 & 1.35 & 5.58 & 2.05 & 0.857 & 20.1 & 2.17 \\
\hline NEPH2-20 & B27PF11 & 3 & 1 & 15 & 6.65 & 1.25 & 7.13 & 1.95 & 1.08 & 19.0 & 2.78 \\
\hline NEPH2-16 & B21PF21 & 3 & 1 & 16 & 6.03 & 1.34 & 6.62 & 2.09 & 0.993 & 20.1 & 2.53 \\
\hline NEPH2-25 & B19PF11 & 3 & 1 & 17 & 6.57 & 1.22 & 7.00 & 1.92 & 1.04 & 19.3 & 2.76 \\
\hline NEPH2-19 & B26PF21 & 3 & 1 & 18 & 6.18 & 1.29 & 6.50 & 2.03 & 0.983 & 19.8 & 2.61 \\
\hline Ustd & USTDPF313 & 3 & 1 & 19 & 2.16 & 2.68 & 8.98 & 1.41 & 0.817 & 20.6 & 1.96 \\
\hline Batch 1 & BCHPF313 & 3 & 1 & 20 & 2.60 & 2.29 & 8.64 & 2.05 & 0.598 & 23.2 & $<0.100$ \\
\hline Batch 1 & BCHPF321 & 3 & 2 & 1 & 2.49 & 2.49 & 8.43 & 1.95 & 0.513 & 22.5 & $<0.100$ \\
\hline Ustd & \begin{tabular}{|l|} 
USTDPF321 \\
\end{tabular} & 3 & 2 & 2 & 2.12 & 2.84 & 8.91 & 1.36 & 0.762 & 20.7 & 1.94 \\
\hline NEPH2-25 & B19PF22 & 3 & 2 & 3 & 6.53 & 1.35 & 6.88 & 1.88 & 0.977 & 19.3 & 2.70 \\
\hline NEPH2-15 & B25PF12 & 3 & 2 & 4 & 5.60 & 1.50 & 6.64 & 2.14 & 0.967 & 20.8 & 2.36 \\
\hline NEPH2-13 & B23PF22 & 3 & 2 & 5 & 5.48 & 1.54 & 6.07 & 2.19 & 0.862 & 21.3 & 2.32 \\
\hline NEPH2-19 & B26PF22 & 3 & 2 & 6 & 6.23 & 1.37 & 6.43 & 2.01 & 0.913 & 19.9 & 2.58 \\
\hline NEPH2-25 & B19PF12 & 3 & 2 & 7 & 6.60 & 1.30 & 6.99 & 1.89 & 0.982 & 19.3 & 2.72 \\
\hline NEPH2-23 & B24PF12 & 3 & 2 & 8 & 6.65 & 1.22 & 7.06 & 1.77 & 0.998 & 18.1 & 2.79 \\
\hline NEPH2-13 & B23PF12 & 3 & 2 & 9 & 5.40 & 1.45 & 5.62 & 2.14 & 0.803 & 20.5 & 2.21 \\
\hline Batch 1 & BCHPF322 & 3 & 2 & 10 & 2.57 & 2.34 & 8.70 & 2.01 & 0.517 & 23.1 & $<0.100$ \\
\hline Ustd & USTDPF322 & 3 & 2 & 11 & 2.13 & 2.77 & 8.93 & 1.36 & 0.762 & 20.7 & 1.94 \\
\hline NEPH2-19 & B26PF12 & 3 & 2 & 12 & 6.40 & 1.68 & 6.87 & 2.07 & 0.966 & 20.5 & 2.70 \\
\hline NEPH2-20 & B27PF12 & 3 & 2 & 13 & 6.56 & 1.38 & 7.00 & 1.90 & 1.00 & 19.3 & 2.71 \\
\hline NEPH2-16 & B21PF22 & 3 & 2 & 14 & 5.96 & 1.39 & 6.12 & 2.02 & 0.863 & 19.4 & 2.44 \\
\hline NEPH2-15 & B25PF22 & 3 & 2 & 15 & 5.65 & 1.44 & 5.64 & 2.13 & 0.820 & 21.0 & 2.29 \\
\hline NEPH2-23 & B24PF22 & 3 & 2 & 16 & 6.71 & 1.23 & 7.06 & 1.78 & 1.02 & 18.9 & 2.83 \\
\hline NEPH2-20 & B27PF22 & 3 & 2 & 17 & 6.46 & 1.30 & 7.08 & 1.86 & 1.02 & 19.8 & 2.71 \\
\hline NEPH2-16 & B21PF12 & 3 & 2 & 18 & 6.08 & 1.40 & 6.52 & 2.05 & 0.915 & 19.2 & 2.47 \\
\hline
\end{tabular}




\section{Table C3. Measured Elemental Concentrations (wt\%) for Samples Prepared Using Peroxide Fusion}

\begin{tabular}{|c|c|c|c|c|c|c|c|c|c|c|c|}
\hline Glass & PSAL & & Sub- & Analytical & & & & & & & \\
\hline ID & ID & Block & Block & Sequence & Al & B & $\mathbf{F e}$ & $\mathbf{L i}$ & $\mathrm{Ni}$ & $\mathbf{S i}$ & $\mathbf{U}$ \\
\hline Ustd & \begin{tabular}{|l|} 
USTDPF323 \\
\end{tabular} & 3 & 2 & 19 & 2.06 & 2.67 & 8.75 & 1.32 & 0.755 & 20.0 & 1.92 \\
\hline Batch 1 & BCHPF323 & 3 & 2 & 20 & 2.52 & 2.37 & 8.97 & 1.98 & 0.534 & 23.1 & $<0.100$ \\
\hline Batch 1 & BCHPF411 & 4 & 1 & 1 & 2.56 & 2.45 & 8.49 & 2.02 & 0.552 & 23.0 & $<0.100$ \\
\hline Ustd & \begin{tabular}{|l|} 
USTDPF411 \\
\end{tabular} & 4 & 1 & 2 & 2.09 & 2.68 & 8.41 & 1.36 & 0.763 & 20.2 & 1.95 \\
\hline NEPH2-33 & B16PF11 & 4 & 1 & 3 & 6.84 & 1.35 & 5.83 & 2.03 & 1.01 & 20.4 & 2.41 \\
\hline NEPH2-36 & B22PF11 & 4 & 1 & 4 & 6.32 & 1.29 & 5.70 & 1.98 & 0.996 & 20.4 & 2.21 \\
\hline NEPH2-28 & B20PF21 & 4 & 1 & 5 & 6.06 & 1.39 & 6.09 & 1.98 & 1.08 & 18.9 & 2.42 \\
\hline NEPH2-32 & B28PF21 & 4 & 1 & 6 & 6.87 & 1.13 & 6.40 & 1.72 & 1.10 & 17.5 & 2.52 \\
\hline NEPH2-30 & B14PF11 & 4 & 1 & 7 & 6.34 & 1.39 & 5.59 & 2.16 & 0.991 & 20.8 & 2.26 \\
\hline NEPH2-36 & B22PF21 & 4 & 1 & 8 & 6.83 & 1.34 & 5.78 & 2.12 & 1.02 & 20.9 & 2.31 \\
\hline NEPH2-39 & B16PF21 & 4 & 1 & 9 & 6.71 & 1.34 & 5.41 & 2.17 & 0.982 & 20.8 & 2.26 \\
\hline Batch 1 & BCHPF412 & 4 & 1 & 10 & 2.52 & 2.20 & 8.49 & 1.98 & 0.542 & 22.5 & $<0.100$ \\
\hline Ustd & USTDPF412 & 4 & 1 & 11 & 2.11 & 2.60 & 8.35 & 1.37 & 0.760 & 20.2 & 1.87 \\
\hline NEPH2-33 & \begin{tabular}{|l|} 
B15PF11 \\
\end{tabular} & 4 & 1 & 12 & 6.47 & 1.41 & 5.47 & 2.11 & 0.992 & 20.5 & 2.28 \\
\hline NEPH2-30 & B14PF21 & 4 & 1 & 13 & 6.32 & 1.42 & 5.66 & 2.15 & 1.02 & 20.8 & 2.32 \\
\hline NEPH2-27 & B18PF21 & 4 & 1 & 14 & 6.95 & 1.28 & 5.36 & 2.18 & 0.943 & 20.8 & 2.10 \\
\hline NEPH2-27 & B18PF11 & 4 & 1 & 15 & 6.92 & 1.26 & 5.33 & 2.17 & 0.937 & 20.6 & 2.16 \\
\hline NEPH2-32 & B28PF11 & 4 & 1 & 16 & 7.37 & 1.14 & 6.16 & 1.83 & 1.06 & 17.5 & 2.67 \\
\hline NEPH2-39 & B16PF21 & 4 & 1 & 17 & 6.85 & 1.30 & 5.90 & 2.04 & 1.02 & 20.7 & 2.45 \\
\hline NEPH2-28 & B20PF11 & 4 & 1 & 18 & 6.32 & 1.40 & 6.10 & 2.05 & 1.07 & 19.5 & 2.51 \\
\hline Ustd & \begin{tabular}{|l|} 
USTDPF413 \\
\end{tabular} & 4 & 1 & 19 & 2.08 & 2.58 & 8.34 & 1.36 & 0.763 & 20.2 & 1.84 \\
\hline Batch 1 & BCHPF413 & 4 & 1 & 20 & 2.55 & 2.24 & 8.50 & 2.01 & 0.567 & 23.1 & $<0.100$ \\
\hline Batch 1 & BCHPF421 & 4 & 2 & 1 & 2.57 & 2.49 & 8.97 & 2.05 & 0.591 & 23.7 & $<0.100$ \\
\hline Ustd & \begin{tabular}{|l|} 
USTDPF421 \\
\end{tabular} & 4 & 2 & 2 & 2.11 & 2.78 & 9.03 & 1.38 & 0.818 & 20.9 & 1.92 \\
\hline NEPH2-27 & \begin{tabular}{|l|} 
B18PF12 \\
\end{tabular} & 4 & 2 & 3 & 7.05 & 1.26 & 5.69 & 2.24 & 0.982 & 21.2 & 2.20 \\
\hline NEPH2-33 & B15PF12 & 4 & 2 & 4 & 6.59 & 1.35 & 5.79 & 2.14 & 1.04 & 21.0 & 2.31 \\
\hline NEPH2-27 & B18PF22 & 4 & 2 & 5 & 6.95 & 1.24 & 5.24 & 2.16 & 0.930 & 20.5 & 2.20 \\
\hline NEPH2-30 & B14PF12 & 4 & 2 & 6 & 6.38 & 1.35 & 5.49 & 2.13 & 0.988 & 20.7 & 2.35 \\
\hline NEPH2-32 & B28PF22 & 4 & 2 & 7 & 6.94 & 1.09 & 6.38 & 1.70 & 1.11 & 17.5 & 2.63 \\
\hline NEPH2-30 & B14PF22 & 4 & 2 & 8 & 6.37 & 1.38 & 5.86 & 2.15 & 1.05 & 21.2 & 2.40 \\
\hline NEPH2-36 & B22PF12 & 4 & 2 & 9 & 6.39 & 1.24 & 5.65 & 1.98 & 0.991 & 20.7 & 2.27 \\
\hline Batch 1 & BCHPF422 & 4 & 2 & 10 & 2.55 & 2.32 & 9.16 & 2.04 & 0.609 & 23.8 & $<0.100$ \\
\hline Ustd & USTDPF422 & 4 & 2 & 11 & 2.13 & 2.74 & 9.42 & 1.40 & 0.844 & 21.2 & 1.96 \\
\hline NEPH2-39 & B16PF12 & 4 & 2 & 12 & 7.00 & 1.42 & 6.22 & 2.07 & 1.07 & 21.1 & 2.48 \\
\hline NEPH2-32 & B28PF12 & 4 & 2 & 13 & 7.64 & 1.24 & 7.03 & 1.89 & 1.21 & 18.6 & 2.77 \\
\hline NEPH2-36 & B22PF22 & 4 & 2 & 14 & 6.88 & 1.35 & 6.13 & 2.13 & 1.07 & 21.2 & 2.35 \\
\hline NEPH2-28 & B20PF22 & 4 & 2 & 15 & 6.16 & 1.37 & 6.16 & 1.99 & 1.07 & 19.1 & 2.51 \\
\hline NEPH2-28 & B20PF12 & 4 & 2 & 16 & 6.38 & 1.41 & 6.22 & 2.05 & 1.11 & 19.6 & 2.61 \\
\hline NEPH2-33 & B15PF22 & 4 & 2 & 17 & 6.65 & 1.33 & 5.65 & 2.14 & 1.03 & 20.8 & 2.29 \\
\hline NEPH2-39 & B16PF22 & 4 & 2 & 18 & 6.99 & 1.32 & 6.19 & 2.06 & 1.07 & 21.1 & 2.54 \\
\hline Ustd & USTDPF423 & 4 & 2 & 19 & 2.09 & 2.66 & 8.91 & 1.37 & 0.815 & 20.8 & 1.93 \\
\hline Batch 1 & BCHPF422 & 4 & 2 & 20 & 2.55 & 2.33 & 9.03 & 2.03 & 0.608 & 23.9 & $<0.100$ \\
\hline Batch 1 & BCHPF111 & 1 & 1 & 1 & 2.56 & 2.49 & 8.73 & 2.01 & 0.545 & 23.1 & $<0.100$ \\
\hline Ustd & \begin{tabular}{|l|} 
USTDPF111 \\
\end{tabular} & 1 & 1 & 2 & 2.12 & 2.80 & 8.64 & 1.37 & 0.750 & 20.4 & 1.93 \\
\hline NEPH2-17 & B12PF11 & 1 & 1 & 3 & 6.38 & 1.40 & 6.58 & 2.00 & 0.946 & 19.4 & 2.66 \\
\hline NEPH2-14 & B13PF21 & 1 & 1 & 4 & 5.51 & 1.35 & 5.87 & 1.95 & 0.844 & 19.7 & 2.32 \\
\hline NEPH2-18 & B04PF21 & 1 & 1 & 5 & 5.62 & 1.45 & 6.17 & 2.07 & 0.899 & 20.6 & 2.26 \\
\hline NEPH2-22 & B10PF11 & 1 & 1 & 6 & 6.34 & 1.31 & 6.63 & 1.91 & 0.942 & 19.7 & 2.66 \\
\hline NEPH2-24 & B17PF21 & 1 & 1 & 7 & 5.93 & 1.34 & 6.08 & 2.01 & 0.884 & 20.5 & 2.38 \\
\hline NEPH2-18 & B04PF11 & 1 & 1 & 8 & 5.66 & 1.44 & 6.16 & 2.08 & 0.887 & 20.7 & 2.29 \\
\hline NEPH2-21 & B02PF21 & 1 & 1 & 9 & 5.21 & 1.24 & 5.49 & 1.82 & 0.789 & 20.2 & 2.19 \\
\hline Batch 1 & BCHPF112 & 1 & 1 & 10 & 2.60 & 2.37 & 8.69 & 2.02 & 0.552 & 23.4 & $<0.100$ \\
\hline Ustd & USTDPF112 & 1 & 1 & 11 & 2.14 & 2.75 & 8.68 & 1.37 & 0.761 & 20.6 & 1.88 \\
\hline NEPH2-26 & B03PF21 & 1 & 1 & 12 & 7.06 & 1.31 & 7.20 & 1.74 & 1.08 & 17.8 & 2.91 \\
\hline NEPH2-26 & B03PF11 & 1 & 1 & 13 & 7.03 & 1.20 & 7.11 & 1.73 & 1.03 & 17.6 & 2.88 \\
\hline NEPH2-21 & B02PF11 & 1 & 1 & 14 & 5.58 & 1.35 & 5.86 & 1.96 & 0.882 & 20.1 & 2.36 \\
\hline NEPH2-24 & B17PF11 & 1 & 1 & 15 & 5.95 & 1.36 & 6.14 & 2.00 & 0.898 & 20.0 & 2.38 \\
\hline NEPH2-14 & B13PF11 & 1 & 1 & 16 & 5.97 & 1.43 & 6.30 & 2.10 & 0.910 & 20.0 & 2.46 \\
\hline NEPH2-22 & B10PF21 & 1 & 1 & 17 & 6.57 & 1.34 & 6.76 & 1.96 & 0.983 & 19.7 & 2.72 \\
\hline
\end{tabular}


Table C3. Measured Elemental Concentrations (wt\%) for Samples Prepared Using Peroxide Fusion

\begin{tabular}{|c|c|c|c|c|c|c|c|c|c|c|c|}
\hline Glass & PSAL & & Sub- & Analytical & & & & & & & \\
\hline ID & ID & Block & Block & Sequence & Al & B & $\mathbf{F e}$ & $\mathbf{L i}$ & $\mathbf{N i}$ & Si & $\mathbf{U}$ \\
\hline NEPH2-17 & B12PF21 & 1 & 1 & 18 & 6.32 & 1.32 & 6.37 & 1.97 & 0.920 & 19.0 & 2.61 \\
\hline Ustd & USTDPF113 & 1 & 1 & 19 & 2.16 & 2.72 & 8.53 & 1.38 & 0.762 & 20.4 & 1.90 \\
\hline Batch 1 & BCHPF113 & 1 & 1 & 20 & 2.63 & 2.39 & 8.52 & 2.04 & 0.552 & 23.3 & $<0.100$ \\
\hline Batch 1 & BCHPF121 & 1 & 2 & 1 & 2.58 & 2.45 & 8.55 & 2.02 & 0.568 & 23.2 & $<0.100$ \\
\hline Ustd & USTDPF121 & 1 & 2 & 2 & 2.13 & 2.75 & 8.71 & 1.38 & 0.786 & 20.5 & 1.94 \\
\hline NEPH2-26 & B03PF12 & 1 & 2 & 3 & 7.20 & 1.09 & 7.46 & 1.81 & 1.11 & 18.1 & 2.94 \\
\hline NEPH2-24 & B17PF22 & 1 & 2 & 4 & 6.08 & 1.30 & 6.36 & 2.07 & 0.943 & 20.6 & 2.47 \\
\hline NEPH2-17 & B12PF12 & 1 & 2 & 5 & 6.53 & 1.30 & 6.82 & 2.06 & 0.999 & 19.8 & 2.72 \\
\hline NEPH2-14 & B13PF12 & 1 & 2 & 6 & 6.05 & 1.37 & 6.55 & 2.14 & 0.958 & 20.5 & 2.52 \\
\hline NEPH2-21 & B02PF22 & 1 & 2 & 7 & 5.33 & 1.21 & 5.87 & 1.88 & 0.874 & 20.8 & 2.24 \\
\hline NEPH2-21 & B02PF12 & 1 & 2 & 8 & 5.68 & 1.30 & 6.23 & 2.02 & 0.941 & 20.5 & 2.45 \\
\hline NEPH2-26 & B03PF22 & 1 & 2 & 9 & 7.18 & 1.13 & 7.52 & 1.78 & 1.13 & 18.2 & 2.98 \\
\hline Batch 1 & BCHPF122 & 1 & 2 & 10 & 2.62 & 2.33 & 8.93 & 2.06 & 0.584 & 23.7 & $<0.100$ \\
\hline Ustd & USTDPF122 & 1 & 2 & 11 & 2.16 & 2.75 & 9.27 & 1.41 & 0.811 & 21.1 & 1.96 \\
\hline NEPH2-24 & B17PF12 & 1 & 2 & 12 & 6.07 & 1.42 & 6.41 & 2.06 & 0.962 & 20.7 & 2.45 \\
\hline NEPH2-18 & B04PF12 & 1 & 2 & 13 & 5.79 & 1.43 & 6.55 & 2.14 & 0.947 & 21.2 & 2.36 \\
\hline NEPH2-22 & B10PF22 & 1 & 2 & 14 & 6.67 & 1.29 & 7.08 & 2.01 & 1.01 & 20.3 & 2.77 \\
\hline NEPH2-14 & B13PF22 & 1 & 2 & 15 & 5.64 & 1.26 & 5.84 & 1.98 & 0.860 & 19.7 & 2.35 \\
\hline NEPH2-18 & B04PF22 & 1 & 2 & 16 & 5.75 & 1.38 & 6.27 & 2.11 & 0.921 & 20.9 & 2.36 \\
\hline NEPH2-17 & B12PF22 & 1 & 2 & 17 & 6.38 & 1.27 & 6.71 & 2.00 & 0.982 & 19.6 & 2.70 \\
\hline NEPH2-22 & B10PF12 & 1 & 2 & 18 & 6.45 & 1.24 & 6.81 & 1.93 & 0.996 & 19.7 & 2.71 \\
\hline Ustd & USTDPF123 & 1 & 2 & 19 & 2.14 & 2.65 & 8.85 & 1.38 & 0.798 & 20.6 & 1.98 \\
\hline Batch 1 & BCHPF123 & 1 & 2 & 20 & 2.62 & 2.38 & 9.06 & 2.06 & 0.595 & 23.8 & $<0.100$ \\
\hline Batch 1 & BHCPF211 & 2 & 1 & 1 & 2.58 & 2.50 & 8.70 & 2.03 & 0.542 & 23.2 & $<0.100$ \\
\hline Ustd & USTDPF211 & 2 & 1 & 2 & 2.13 & 2.74 & 8.65 & 1.37 & 0.745 & 20.4 & 1.90 \\
\hline NEPH2-37 & B05PF21 & 2 & 1 & 3 & 7.25 & 1.34 & 6.32 & 2.00 & 1.11 & 20.0 & 2.62 \\
\hline NEPH2-40 & B06PF21 & 2 & 1 & 4 & 7.37 & 1.27 & 6.29 & 1.95 & 1.08 & 19.7 & 2.67 \\
\hline NEPH2-29 & B07PF11 & 2 & 1 & 5 & 7.80 & 1.17 & 6.74 & 1.84 & 1.14 & 17.6 & 2.79 \\
\hline NEPH2-38 & B11PF11 & 2 & 1 & 6 & 7.51 & 1.21 & 6.61 & 1.91 & 1.15 & 19.1 & 2.69 \\
\hline NEPH2-37 & B05PF11 & 2 & 1 & 7 & 6.81 & 1.17 & 5.92 & 1.87 & 1.06 & 19.4 & 2.47 \\
\hline NEPH2-31 & B08PF11 & 2 & 1 & 8 & 7.11 & 1.26 & 5.93 & 2.03 & 1.01 & 19.4 & 2.47 \\
\hline NEPH2-34 & B01PF11 & 2 & 1 & 9 & 7.18 & 1.24 & 6.17 & 1.98 & 1.11 & 19.6 & 2.57 \\
\hline Batch 1 & BCHPF212 & 2 & 1 & 10 & 2.60 & 2.27 & 8.61 & 2.03 & 0.543 & 23.2 & $<0.100$ \\
\hline
\end{tabular}


Table C4. Average Measured and Bias-Corrected Chemical Compositions Versus Targeted Compositions by Oxide by Nepheline Study Glass

(100-Batch 1; $200-U$ std)

\begin{tabular}{|c|c|c|c|c|c|c|c|c|c|}
\hline & & & & Measured & & & & & \\
\hline & & & Measured & Bias-Corrected & Targeted & Diff of & Diff of & $\%$ Diff of & $\%$ Diff of \\
\hline Glass ID & Glass \# & Oxide & $(w t \%)$ & $(w t \%)$ & $(w t \%)$ & Measured & Meas BC & Measured & Meas BC \\
\hline NEPH2-13 & 13 & $\mathrm{Al} 2 \mathrm{O} 3$ & 10.1561 & 10.2240 & 10.2100 & -0.0539 & 0.0140 & $-0.5 \%$ & $0.1 \%$ \\
\hline NEPH2-13 & 13 & $\mathrm{~B} 2 \mathrm{O} 3$ & 4.6769 & 4.7259 & 4.8800 & -0.2031 & -0.1541 & $-4.2 \%$ & $-3.2 \%$ \\
\hline NEPH2-13 & 13 & $\mathrm{BaO}$ & 0.0441 & 0.0490 & 0.0530 & -0.0089 & -0.0040 & $-16.8 \%$ & $-7.5 \%$ \\
\hline NEPH2-13 & 13 & $\mathrm{CaO}$ & 0.7346 & 0.7743 & 0.7760 & -0.0414 & -0.0017 & $-5.3 \%$ & $-0.2 \%$ \\
\hline NEPH2-13 & 13 & $\mathrm{Ce} 2 \mathrm{O} 3$ & 0.0536 & 0.0536 & 0.0730 & -0.0194 & -0.0194 & $-26.6 \%$ & $-26.6 \%$ \\
\hline NEPH2-13 & 13 & $\mathrm{Cr} 2 \mathrm{O} 3$ & 0.0928 & 0.0880 & 0.0910 & 0.0018 & -0.0030 & $2.0 \%$ & $-3.2 \%$ \\
\hline NEPH2-13 & 13 & $\mathrm{CuO}$ & 0.0366 & 0.0384 & 0.0280 & 0.0086 & 0.0104 & $30.8 \%$ & $37.1 \%$ \\
\hline NEPH2-13 & 13 & $\mathrm{Fe} 2 \mathrm{O} 3$ & 8.2494 & 8.4485 & 8.6480 & -0.3986 & -0.1995 & $-4.6 \%$ & $-2.3 \%$ \\
\hline NEPH2-13 & 13 & $\mathrm{~K} 2 \mathrm{O}$ & 0.6171 & 0.6932 & 0.5450 & 0.0721 & 0.1482 & $13.2 \%$ & $27.2 \%$ \\
\hline NEPH2-13 & 13 & La2O3 & 0.0296 & 0.0296 & 0.0310 & -0.0014 & -0.0014 & $-4.5 \%$ & $-4.5 \%$ \\
\hline NEPH2-13 & 13 & $\mathrm{Li} 2 \mathrm{O}$ & 4.6395 & 4.7310 & 4.8800 & -0.2405 & -0.1490 & $-4.9 \%$ & $-3.1 \%$ \\
\hline NEPH2-13 & 13 & $\mathrm{MgO}$ & 0.5112 & 0.5422 & 0.5480 & -0.0368 & $\begin{array}{l}-0.0058 \\
\end{array}$ & $-6.7 \%$ & $-1.1 \%$ \\
\hline NEPH2-13 & 13 & $\mathrm{MnO}$ & 1.8335 & 1.8645 & 1.9010 & -0.0675 & -0.0365 & $-3.6 \%$ & $-1.9 \%$ \\
\hline NEPH2-13 & 13 & $\mathrm{Na} 2 \mathrm{O}$ & 17.2881 & 16.5374 & 17.6950 & -0.4069 & -1.1576 & $-2.3 \%$ & $-6.5 \%$ \\
\hline NEPH2-13 & 13 & $\mathrm{NiO}$ & 1.0874 & 1.1424 & 1.1920 & -0.1046 & -0.0496 & $-8.8 \%$ & $-4.2 \%$ \\
\hline NEPH2-13 & 13 & $\mathrm{PbO}$ & 0.0625 & 0.0625 & 0.0690 & -0.0065 & -0.0065 & $-9.5 \%$ & $-9.5 \%$ \\
\hline NEPH2-13 & 13 & $\mathrm{SO} 4$ & 0.4067 & 0.4067 & 0.4170 & -0.0103 & -0.0103 & $-2.5 \%$ & $-2.5 \%$ \\
\hline NEPH2-13 & 13 & $\mathrm{SiO} 2$ & 44.2835 & 44.8526 & 44.9640 & -0.6805 & -0.1114 & $-1.5 \%$ & $-0.2 \%$ \\
\hline NEPH2-13 & 13 & ThO2 & 0.0569 & 0.0569 & 0.0150 & 0.0419 & 0.0419 & $279.3 \%$ & $279.3 \%$ \\
\hline NEPH2-13 & 13 & $\mathrm{TiO} 2$ & 0.0083 & 0.0088 & 0.0070 & 0.0013 & 0.0018 & $19.1 \%$ & $26.0 \%$ \\
\hline NEPH2-13 & 13 & U3O8 & 2.6738 & 2.8050 & 2.8360 & -0.1622 & -0.0310 & $-5.7 \%$ & $-1.1 \%$ \\
\hline NEPH2-13 & 13 & $\mathrm{ZnO}$ & 0.0451 & 0.0451 & 0.0420 & 0.0031 & 0.0031 & $7.4 \%$ & $7.4 \%$ \\
\hline NEPH2-13 & 13 & $\mathrm{ZrO} 2$ & 0.0831 & 0.0831 & 0.1000 & -0.0169 & -0.0169 & $-16.9 \%$ & $-16.9 \%$ \\
\hline NEPH2-13 & 13 & Sum of Oxides & 97.6703 & 98.2627 & 100.0010 & -2.3307 & -1.7383 & $-2.3 \%$ & $-1.7 \%$ \\
\hline NEPH2-14 & 14 & $\mathrm{~A} 12 \mathrm{O} 3$ & 10.9449 & 10.8583 & 10.9950 & -0.0501 & -0.1367 & $-0.5 \%$ & $-1.2 \%$ \\
\hline NEPH2-14 & 14 & $\mathrm{~B} 2 \mathrm{O} 3$ & 4.3549 & 4.3791 & 4.6400 & -0.2851 & -0.2609 & $-6.1 \%$ & $-5.6 \%$ \\
\hline NEPH2-14 & 14 & $\mathrm{BaO}$ & 0.0430 & 0.0478 & 0.0570 & -0.0140 & -0.0092 & $-24.6 \%$ & $-16.2 \%$ \\
\hline NEPH2-14 & 14 & $\mathrm{CaO}$ & 0.7846 & 0.8386 & 0.8360 & -0.0514 & 0.0026 & $-6.1 \%$ & $0.3 \%$ \\
\hline NEPH2-14 & 14 & $\mathrm{Ce} 2 \mathrm{O} 3$ & 0.0577 & 0.0577 & 0.0780 & -0.0203 & -0.0203 & $-26.0 \%$ & $-26.0 \%$ \\
\hline NEPH2-14 & 14 & $\mathrm{Cr} 2 \mathrm{O} 3$ & 0.0983 & 0.0924 & 0.0980 & 0.0003 & -0.0056 & $0.3 \%$ & $-5.7 \%$ \\
\hline NEPH2-14 & 14 & $\mathrm{CuO}$ & 0.0391 & 0.0415 & 0.0310 & 0.0081 & 0.0105 & $26.2 \%$ & $33.8 \%$ \\
\hline NEPH2-14 & 14 & $\mathrm{Fe} 2 \mathrm{O} 3$ & 8.7784 & 9.0130 & 9.3130 & -0.5346 & -0.3000 & $-5.7 \%$ & $-3.2 \%$ \\
\hline NEPH2-14 & 14 & $\mathrm{~K} 2 \mathrm{O}$ & 0.6408 & 0.7262 & 0.5870 & 0.0538 & 0.1392 & $9.2 \%$ & $23.7 \%$ \\
\hline NEPH2-14 & 14 & $\mathrm{La} 2 \mathrm{O} 3$ & 0.0311 & 0.0311 & 0.0340 & -0.0029 & -0.0029 & $-8.6 \%$ & $-8.6 \%$ \\
\hline NEPH2-14 & 14 & $\mathrm{Li} 2 \mathrm{O}$ & 4.3973 & 4.4453 & 4.6400 & -0.2427 & -0.1947 & $-5.2 \%$ & $-4.2 \%$ \\
\hline NEPH2-14 & 14 & $\mathrm{MgO}$ & 0.5630 & 0.5976 & 0.5900 & -0.0270 & 0.0076 & $-4.6 \%$ & $1.3 \%$ \\
\hline NEPH2-14 & 14 & $\mathrm{MnO}$ & 1.9207 & 1.9800 & 2.0470 & -0.1263 & -0.0670 & $-6.2 \%$ & $-3.3 \%$ \\
\hline NEPH2-14 & 14 & $\mathrm{Na} 2 \mathrm{O}$ & 17.1533 & 16.5866 & 18.1330 & -0.9797 & -1.5464 & $-5.4 \%$ & $-8.5 \%$ \\
\hline NEPH2-14 & 14 & $\mathrm{NiO}$ & 1.1363 & 1.1853 & 1.2840 & -0.1477 & -0.0987 & $-11.5 \%$ & $-7.7 \%$ \\
\hline NEPH2-14 & 14 & $\mathrm{PbO}$ & 0.0687 & 0.0687 & 0.0740 & -0.0053 & -0.0053 & $-7.2 \%$ & $-7.2 \%$ \\
\hline NEPH2-14 & 14 & $\mathrm{SO} 4$ & 0.4509 & 0.4509 & 0.4490 & 0.0019 & 0.0019 & $0.4 \%$ & $0.4 \%$ \\
\hline NEPH2-14 & 14 & $\mathrm{SiO} 2$ & 42.7325 & 42.8389 & 42.8840 & -0.1515 & -0.0451 & $-0.4 \%$ & $-0.1 \%$ \\
\hline NEPH2-14 & 14 & ThO2 & 0.0569 & 0.0569 & 0.0160 & 0.0409 & 0.0409 & $255.6 \%$ & $255.6 \%$ \\
\hline NEPH2-14 & 14 & $\mathrm{TiO} 2$ & 0.0083 & 0.0089 & 0.0080 & 0.0003 & 0.0009 & $4.3 \%$ & $11.5 \%$ \\
\hline NEPH2-14 & 14 & U3O8 & 2.8448 & 3.0051 & 3.0540 & -0.2092 & -0.0489 & $-6.8 \%$ & $-1.6 \%$ \\
\hline NEPH2-14 & 14 & $\mathrm{ZnO}$ & 0.0498 & 0.0498 & 0.0450 & 0.0048 & 0.0048 & $10.6 \%$ & $10.6 \%$ \\
\hline NEPH2-14 & 14 & $\mathrm{ZrO} 2$ & 0.0902 & 0.0902 & 0.1070 & -0.0168 & -0.0168 & $-15.7 \%$ & $-15.7 \%$ \\
\hline NEPH2-14 & 14 & Sum of Oxides & 97.2455 & 97.4497 & 100.0000 & -2.7545 & -2.5503 & $-2.8 \%$ & $-2.6 \%$ \\
\hline NEPH2-15 & 15 & $\mathrm{~A} 12 \mathrm{O} 3$ & 10.4206 & 10.4915 & 10.4720 & -0.0514 & 0.0195 & $-0.5 \%$ & $0.2 \%$ \\
\hline NEPH2-15 & 15 & $\mathrm{~B} 2 \mathrm{O} 3$ & 4.5079 & 4.5547 & 4.8000 & -0.2921 & -0.2453 & $-6.1 \%$ & $-5.1 \%$ \\
\hline NEPH2-15 & 15 & $\mathrm{BaO}$ & 0.0452 & 0.0503 & 0.0540 & -0.0088 & -0.0037 & $-16.3 \%$ & $-6.9 \%$ \\
\hline NEPH2-15 & 15 & $\mathrm{CaO}$ & 0.7633 & 0.8046 & 0.7960 & -0.0327 & 0.0086 & $-4.1 \%$ & $1.1 \%$ \\
\hline NEPH2-15 & 15 & $\mathrm{Ce} 2 \mathrm{O} 3$ & 0.0583 & 0.0583 & 0.0750 & -0.0167 & -0.0167 & $-22.3 \%$ & $-22.3 \%$ \\
\hline NEPH2-15 & 15 & $\mathrm{Cr} 2 \mathrm{O} 3$ & 0.1125 & 0.1068 & 0.0930 & 0.0195 & 0.0138 & $21.0 \%$ & $14.8 \%$ \\
\hline NEPH2-15 & 15 & $\mathrm{CuO}$ & 0.0388 & 0.0407 & 0.0290 & 0.0098 & 0.0117 & $33.8 \%$ & $40.3 \%$ \\
\hline NEPH2-15 & 15 & $\mathrm{Fe} 2 \mathrm{O} 3$ & 8.6640 & 8.8732 & 8.8700 & -0.2060 & 0.0032 & $-2.3 \%$ & $0.0 \%$ \\
\hline
\end{tabular}


Table C4. Average Measured and Bias-Corrected Chemical Compositions Versus Targeted Compositions by Oxide by Nepheline Study Glass

(100-Batch 1; $200-U$ std)

\begin{tabular}{|c|c|c|c|c|c|c|c|c|c|}
\hline & & & & Measured & & & & & \\
\hline & & & Measured & Bias-Corrected & Targeted & Diff of & Diff of & $\%$ Diff of & $\%$ Diff of \\
\hline Glass ID & Glass \# & Oxide & $(w t \%)$ & $(w t \%)$ & $(w t \%)$ & Measured & Meas BC & Measured & Meas BC \\
\hline NEPH2-15 & \begin{tabular}{|l|}
15 \\
\end{tabular} & $\mathrm{~K} 2 \mathrm{O}$ & 0.5839 & 0.6559 & 0.5590 & 0.0249 & \begin{tabular}{|l|}
0.0969 \\
\end{tabular} & $4.5 \%$ & $17.3 \%$ \\
\hline NEPH2-15 & 15 & $\mathrm{La} 2 \mathrm{O} 3$ & 0.0610 & 0.0610 & 0.0320 & 0.0290 & 0.0290 & $90.6 \%$ & $90.6 \%$ \\
\hline NEPH2-15 & 15 & $\mathrm{Li} 2 \mathrm{O}$ & 4.5319 & 4.6221 & 4.8000 & -0.2681 & -0.1779 & $-5.6 \%$ & $-3.7 \%$ \\
\hline NEPH2-15 & 15 & $\mathrm{MgO}$ & 0.5452 & 0.5782 & 0.5620 & -0.0168 & 0.0162 & $-3.0 \%$ & $2.9 \%$ \\
\hline NEPH2-15 & 15 & $\mathrm{MnO}$ & 1.9529 & 1.9865 & 1.9490 & 0.0039 & 0.0375 & $0.2 \%$ & $1.9 \%$ \\
\hline NEPH2-15 & 15 & $\mathrm{Na} 2 \mathrm{O}$ & 17.0859 & 16.3433 & 17.2410 & -0.1551 & -0.8977 & $-0.9 \%$ & $-5.2 \%$ \\
\hline NEPH2-15 & 15 & $\mathrm{NiO}$ & 1.1475 & 1.2071 & 1.2230 & -0.0755 & -0.0159 & $-6.2 \%$ & $-1.3 \%$ \\
\hline NEPH2-15 & 15 & $\mathrm{PbO}$ & 0.0665 & 0.0665 & 0.0710 & -0.0045 & -0.0045 & $-6.3 \%$ & $-6.3 \%$ \\
\hline NEPH2-15 & 15 & $\mathrm{SO} 4$ & 0.4217 & 0.4217 & 0.4280 & -0.0063 & -0.0063 & $-1.5 \%$ & $-1.5 \%$ \\
\hline NEPH2-15 & 15 & $\mathrm{SiO} 2$ & 44.2835 & 44.8526 & 44.8710 & -0.5875 & -0.0184 & $-1.3 \%$ & $0.0 \%$ \\
\hline NEPH2-15 & 15 & $\mathrm{ThO} 2$ & 0.0569 & 0.0569 & 0.0150 & 0.0419 & 0.0419 & $279.3 \%$ & $279.3 \%$ \\
\hline NEPH2-15 & 15 & $\mathrm{TiO} 2$ & 0.0083 & 0.0088 & 0.0080 & 0.0003 & 0.0008 & $4.3 \%$ & $10.2 \%$ \\
\hline NEPH2-15 & 15 & $\mathrm{U} 3 \mathrm{O} 8$ & 2.7240 & 2.8577 & 2.9080 & -0.1840 & -0.0503 & $-6.3 \%$ & $-1.7 \%$ \\
\hline NEPH2-15 & 15 & $\mathrm{ZnO}$ & 0.0495 & 0.0495 & 0.0430 & 0.0065 & 0.0065 & $15.1 \%$ & $15.1 \%$ \\
\hline NEPH2-15 & 15 & $\mathrm{ZrO} 2$ & 0.0922 & 0.0922 & 0.1020 & -0.0098 & -0.0098 & $-9.6 \%$ & $-9.6 \%$ \\
\hline NEPH2-15 & 15 & Sum of Oxides & 98.2214 & 98.8399 & 100.0010 & -1.7796 & -1.1611 & $-1.8 \%$ & $-1.2 \%$ \\
\hline NEPH2-16 & 16 & $\mathrm{~A} 12 \mathrm{O} 3$ & 11.4220 & 11.4956 & 11.2570 & 0.1650 & 0.2386 & $1.5 \%$ & $2.1 \%$ \\
\hline NEPH2-16 & 16 & $\mathrm{~B} 2 \mathrm{O} 3$ & 4.3871 & 4.4332 & 4.5600 & -0.1729 & -0.1268 & $-3.8 \%$ & $-2.8 \%$ \\
\hline NEPH2-16 & 16 & $\mathrm{BaO}$ & 0.0497 & 0.0552 & 0.0580 & -0.0083 & -0.0028 & $-14.3 \%$ & $-4.8 \%$ \\
\hline NEPH2-16 & 16 & $\mathrm{CaO}$ & 0.8385 & 0.8839 & 0.8560 & -0.0175 & 0.0279 & $-2.0 \%$ & $3.3 \%$ \\
\hline NEPH2-16 & 16 & $\mathrm{Ce} 2 \mathrm{O} 3$ & 0.0597 & 0.0597 & 0.0800 & -0.0203 & -0.0203 & $-25.3 \%$ & $-25.3 \%$ \\
\hline NEPH2-16 & 16 & $\mathrm{Cr} 2 \mathrm{O} 3$ & 0.0954 & 0.0905 & 0.1000 & -0.0046 & -0.0095 & $-4.6 \%$ & $-9.5 \%$ \\
\hline NEPH2-16 & 16 & $\mathrm{CuO}$ & 0.0388 & 0.0407 & 0.0310 & 0.0078 & 0.0097 & $25.2 \%$ & $31.3 \%$ \\
\hline NEPH2-16 & 16 & $\mathrm{Fe} 2 \mathrm{O} 3$ & 9.1322 & 9.3509 & 9.5350 & -0.4028 & -0.1841 & $-4.2 \%$ & $-1.9 \%$ \\
\hline NEPH2-16 & 16 & $\mathrm{~K} 2 \mathrm{O}$ & 0.6851 & 0.7696 & 0.6010 & 0.0841 & 0.1686 & $14.0 \%$ & $28.1 \%$ \\
\hline NEPH2-16 & 16 & $\mathrm{La} 2 \mathrm{O} 3$ & 0.0328 & 0.0328 & 0.0350 & -0.0022 & -0.0022 & $-6.2 \%$ & $-6.2 \%$ \\
\hline NEPH2-16 & 16 & $\mathrm{Li} 2 \mathrm{O}$ & 4.4350 & 4.5210 & 4.5600 & -0.1250 & -0.0390 & $-2.7 \%$ & $-0.9 \%$ \\
\hline NEPH2-16 & 16 & $\mathrm{MgO}$ & 0.5812 & 0.6164 & 0.6040 & -0.0228 & 0.0124 & $-3.8 \%$ & $2.1 \%$ \\
\hline NEPH2-16 & 16 & $\mathrm{MnO}$ & 2.0788 & 2.1147 & 2.0950 & -0.0162 & 0.0197 & $-0.8 \%$ & $0.9 \%$ \\
\hline NEPH2-16 & 16 & $\mathrm{Na} 2 \mathrm{O}$ & 17.6588 & 16.8931 & 17.7090 & -0.0502 & -0.8159 & $-0.3 \%$ & $-4.6 \%$ \\
\hline NEPH2-16 & 16 & $\mathrm{NiO}$ & 1.1825 & 1.2407 & 1.3140 & -0.1315 & -0.0733 & $-10.0 \%$ & $-5.6 \%$ \\
\hline NEPH2-16 & 16 & $\mathrm{PbO}$ & 0.0692 & 0.0692 & 0.0760 & -0.0068 & -0.0068 & $-8.9 \%$ & $-8.9 \%$ \\
\hline NEPH2-16 & 16 & $\mathrm{SO} 4$ & 0.4382 & 0.4382 & 0.4600 & -0.0218 & -0.0218 & $-4.7 \%$ & $-4.7 \%$ \\
\hline NEPH2-16 & 16 & $\mathrm{SiO} 2$ & 41.6094 & 42.1351 & 42.7610 & -1.1516 & -0.6259 & $-2.7 \%$ & $-1.5 \%$ \\
\hline NEPH2-16 & 16 & ThO2 & 0.0569 & 0.0569 & 0.0160 & 0.0409 & 0.0409 & $255.6 \%$ & $255.6 \%$ \\
\hline NEPH2-16 & 16 & $\mathrm{TiO} 2$ & 0.0083 & 0.0088 & 0.0080 & 0.0003 & 0.0008 & $4.3 \%$ & $10.2 \%$ \\
\hline NEPH2-16 & 16 & $\mathrm{U} 3 \mathrm{O} 8$ & 2.9185 & 3.0616 & 3.1260 & -0.2075 & -0.0644 & $-6.6 \%$ & $-2.1 \%$ \\
\hline NEPH2-16 & 16 & $\mathrm{ZnO}$ & 0.0554 & 0.0554 & 0.0460 & 0.0094 & 0.0094 & $20.4 \%$ & $20.4 \%$ \\
\hline NEPH2-16 & 16 & $\mathrm{ZrO} 2$ & 0.0986 & 0.0986 & 0.1100 & -0.0114 & -0.0114 & $-10.4 \%$ & $-10.4 \%$ \\
\hline NEPH2-16 & 16 & Sum of Oxides & 97.9322 & 98.5220 & 99.9980 & -2.0658 & -1.4760 & $-2.1 \%$ & $-1.5 \%$ \\
\hline NEPH2-17 & 17 & $\mathrm{~A} 12 \mathrm{O} 3$ & 12.0975 & 12.0018 & 11.7810 & 0.3165 & 0.2208 & $2.7 \%$ & $1.9 \%$ \\
\hline NEPH2-17 & 17 & $\mathrm{~B} 2 \mathrm{O} 3$ & 4.2583 & 4.2819 & 4.4000 & -0.1417 & -0.1181 & $-3.2 \%$ & $-2.7 \%$ \\
\hline NEPH2-17 & 17 & $\mathrm{BaO}$ & 0.0505 & 0.0562 & 0.0610 & -0.0105 & -0.0048 & $-17.2 \%$ & $-7.9 \%$ \\
\hline NEPH2-17 & 17 & $\mathrm{CaO}$ & 0.8325 & 0.8898 & 0.8960 & -0.0635 & -0.0062 & $-7.1 \%$ & $-0.7 \%$ \\
\hline NEPH2-17 & 17 & $\mathrm{Ce} 2 \mathrm{O} 3$ & 0.0574 & 0.0574 & 0.0840 & -0.0266 & -0.0266 & $-31.7 \%$ & $-31.7 \%$ \\
\hline NEPH2-17 & 17 & $\mathrm{Cr} 2 \mathrm{O} 3$ & 0.1001 & 0.0942 & 0.1050 & -0.0049 & -0.0108 & $-4.6 \%$ & $-10.3 \%$ \\
\hline NEPH2-17 & 17 & $\mathrm{CuO}$ & 0.0410 & 0.0435 & 0.0330 & 0.0080 & 0.0105 & $24.2 \%$ & $31.8 \%$ \\
\hline NEPH2-17 & 17 & $\mathrm{Fe} 2 \mathrm{O} 3$ & 9.4646 & 9.7162 & 9.9790 & -0.5144 & -0.2628 & $-5.2 \%$ & $-2.6 \%$ \\
\hline NEPH2-17 & 17 & $\mathrm{~K} 2 \mathrm{O}$ & 0.6610 & 0.7491 & 0.6290 & 0.0320 & 0.1201 & $5.1 \%$ & $19.1 \%$ \\
\hline NEPH2-17 & 17 & $\mathrm{La} 2 \mathrm{O} 3$ & 0.0340 & 0.0340 & 0.0360 & -0.0020 & -0.0020 & $-5.5 \%$ & $-5.5 \%$ \\
\hline NEPH2-17 & 17 & $\mathrm{Li} 2 \mathrm{O}$ & 4.3219 & 4.3690 & 4.4000 & -0.0781 & -0.0310 & $-1.8 \%$ & $-0.7 \%$ \\
\hline NEPH2-17 & 17 & $\mathrm{MgO}$ & 0.6098 & 0.6473 & 0.6330 & -0.0232 & 0.0143 & $-3.7 \%$ & $2.3 \%$ \\
\hline NEPH2-17 & 17 & $\mathrm{MnO}$ & 2.1273 & 2.1930 & 2.1930 & -0.0657 & 0.0000 & $-3.0 \%$ & $0.0 \%$ \\
\hline NEPH2-17 & 17 & $\mathrm{Na} 2 \mathrm{O}$ & 17.6588 & 17.0759 & 18.0210 & -0.3622 & -0.9451 & $-2.0 \%$ & $-5.2 \%$ \\
\hline NEPH2-17 & 17 & $\mathrm{NiO}$ & 1.2238 & 1.2761 & 1.3750 & -0.1512 & -0.0989 & $-11.0 \%$ & $-7.2 \%$ \\
\hline NEPH2-17 & 17 & $\mathrm{PbO}$ & 0.0738 & 0.0738 & 0.0800 & -0.0062 & -0.0062 & $-7.8 \%$ & $-7.8 \%$ \\
\hline
\end{tabular}


Table C4. Average Measured and Bias-Corrected Chemical Compositions Versus Targeted Compositions by Oxide by Nepheline Study Glass

(100 -Batch 1; $200-U$ std)

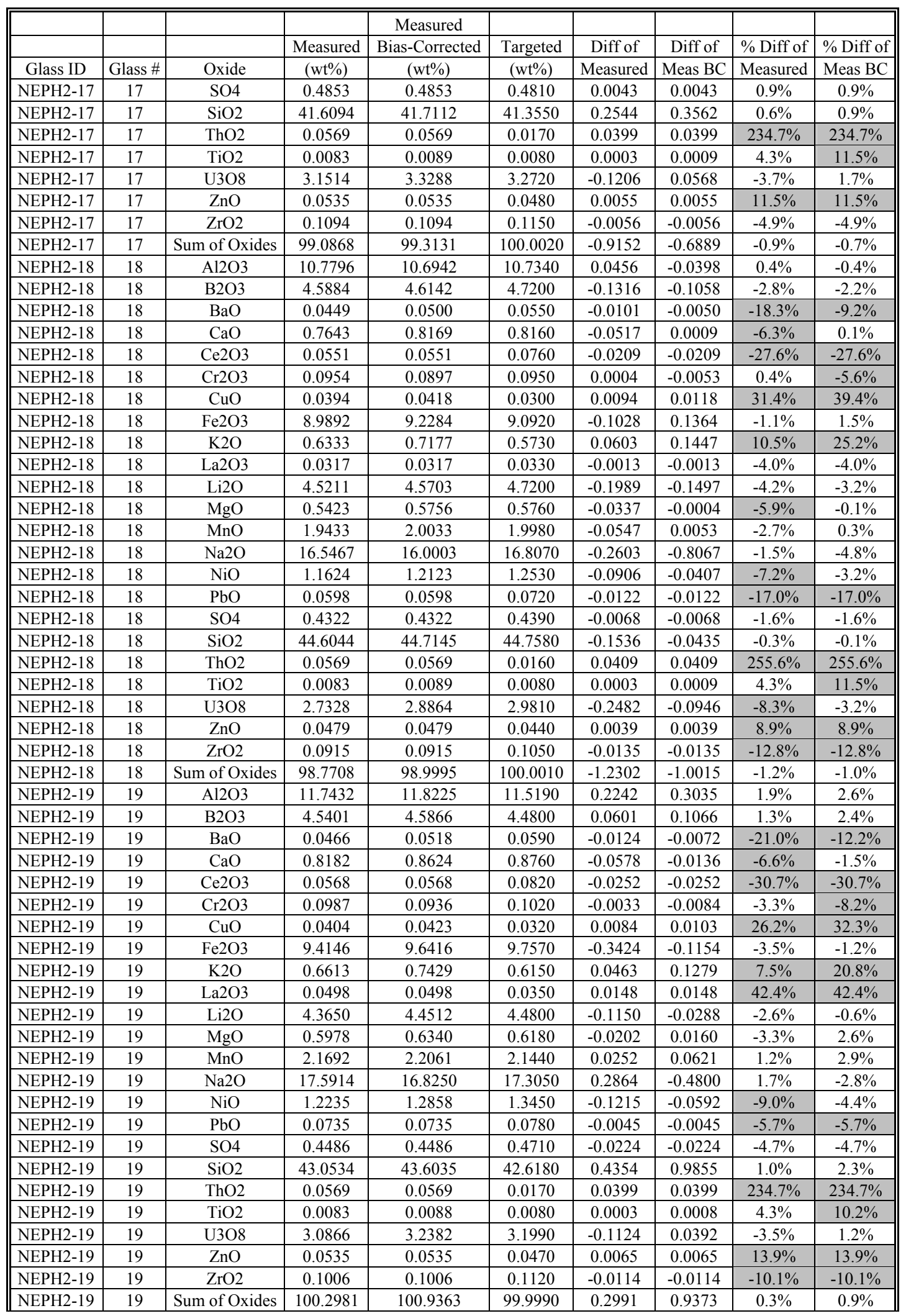


Table C4. Average Measured and Bias-Corrected Chemical Compositions Versus Targeted Compositions by Oxide by Nepheline Study Glass

(100-Batch 1; $200-U$ std)

\begin{tabular}{|c|c|c|c|c|c|c|c|c|c|}
\hline & & & & Measured & & & & & \\
\hline & & & Measured & Bias-Corrected & Targeted & Diff of & Diff of & $\%$ Diff of & $\%$ Diff of \\
\hline Glass ID & Glass \# & Oxide & $(w t \%)$ & $(w t \%)$ & $(w t \%)$ & Measured & Meas BC & Measured & Meas BC \\
\hline NEPH2-20 & 20 & $\mathrm{Al} 2 \mathrm{O} 3$ & 12.3337 & 12.4134 & 12.3040 & 0.0297 & 0.1094 & $0.2 \%$ & $0.9 \%$ \\
\hline NEPH2-20 & 20 & $\mathrm{~B} 2 \mathrm{O} 3$ & 4.1537 & 4.1970 & 4.2400 & -0.0863 & -0.0430 & $-2.0 \%$ & $-1.0 \%$ \\
\hline NEPH2-20 & 20 & $\mathrm{BaO}$ & 0.0519 & 0.0577 & 0.0640 & -0.0121 & -0.0063 & $-18.9 \%$ & $-9.8 \%$ \\
\hline NEPH2-20 & 20 & $\mathrm{CaO}$ & 0.8665 & 0.9134 & 0.9360 & -0.0695 & -0.0226 & $-7.4 \%$ & $-2.4 \%$ \\
\hline NEPH2-20 & 20 & $\mathrm{Ce} 2 \mathrm{O} 3$ & 0.0618 & 0.0618 & 0.0880 & -0.0262 & -0.0262 & $-29.8 \%$ & $-29.8 \%$ \\
\hline NEPH2-20 & 20 & $\mathrm{Cr} 2 \mathrm{O} 3$ & 0.1056 & 0.1002 & 0.1090 & -0.0034 & -0.0088 & $-3.1 \%$ & $-8.1 \%$ \\
\hline NEPH2-20 & 20 & $\mathrm{CuO}$ & 0.0419 & 0.0440 & 0.0340 & 0.0079 & 0.0100 & $23.3 \%$ & $29.3 \%$ \\
\hline NEPH2-20 & 20 & $\mathrm{Fe} 2 \mathrm{O} 3$ & 10.0615 & 10.3034 & 10.4220 & -0.3605 & -0.1186 & $-3.5 \%$ & $-1.1 \%$ \\
\hline NEPH2-20 & 20 & $\mathrm{~K} 2 \mathrm{O}$ & 0.6899 & 0.7750 & 0.6570 & 0.0329 & 0.1180 & $5.0 \%$ & $18.0 \%$ \\
\hline NEPH2-20 & 20 & $\mathrm{La} 2 \mathrm{O} 3$ & 0.0364 & 0.0364 & 0.0380 & -0.0016 & -0.0016 & $-4.3 \%$ & $-4.3 \%$ \\
\hline NEPH2-20 & 20 & $\mathrm{Li} 2 \mathrm{O}$ & 4.0905 & 4.1700 & 4.2400 & -0.1495 & -0.0700 & $-3.5 \%$ & $-1.7 \%$ \\
\hline NEPH2-20 & 20 & $\mathrm{MgO}$ & 0.6297 & 0.6679 & 0.6610 & -0.0313 & 0.0069 & $-4.7 \%$ & $1.0 \%$ \\
\hline NEPH2-20 & 20 & $\mathrm{MnO}$ & 2.3274 & 2.3672 & 2.2900 & 0.0374 & 0.0772 & $1.6 \%$ & $3.4 \%$ \\
\hline NEPH2-20 & 20 & $\mathrm{Na} 2 \mathrm{O}$ & 17.8947 & 17.1169 & 17.8040 & 0.0907 & -0.6871 & $0.5 \%$ & $-3.9 \%$ \\
\hline NEPH2-20 & 20 & $\mathrm{NiO}$ & 1.3202 & 1.3870 & 1.4370 & -0.1168 & -0.0500 & $-8.1 \%$ & $-3.5 \%$ \\
\hline NEPH2-20 & 20 & $\mathrm{PbO}$ & 0.0781 & 0.0781 & 0.0830 & -0.0049 & -0.0049 & $-5.9 \%$ & $-5.9 \%$ \\
\hline NEPH2-20 & 20 & $\mathrm{SO} 4$ & 0.4778 & 0.4778 & 0.5030 & -0.0252 & -0.0252 & $-5.0 \%$ & $-5.0 \%$ \\
\hline NEPH2-20 & 20 & $\mathrm{SiO} 2$ & 41.6629 & 42.1953 & 40.4780 & 1.1849 & 1.7173 & $2.9 \%$ & $4.2 \%$ \\
\hline NEPH2-20 & 20 & ThO2 & 0.0569 & 0.0569 & 0.0180 & 0.0389 & 0.0389 & $216.1 \%$ & $216.1 \%$ \\
\hline NEPH2-20 & 20 & $\mathrm{TiO} 2$ & 0.0083 & 0.0088 & 0.0090 & -0.0007 & -0.0002 & $-7.3 \%$ & $-2.0 \%$ \\
\hline NEPH2-20 & 20 & $\mathrm{U} 3 \mathrm{O} 8$ & 3.2310 & 3.3893 & 3.4170 & -0.1860 & -0.0277 & $-5.4 \%$ & $-0.8 \%$ \\
\hline NEPH2-20 & 20 & $\mathrm{ZnO}$ & 0.0523 & 0.0523 & 0.0500 & 0.0023 & 0.0023 & $4.6 \%$ & $4.6 \%$ \\
\hline NEPH2-20 & 20 & $\mathrm{ZrO} 2$ & 0.1067 & 0.1067 & 0.1200 & -0.0133 & -0.0133 & $-11.1 \%$ & $-11.1 \%$ \\
\hline NEPH2-20 & 20 & Sum of Oxides & 100.3395 & 100.9764 & 100.0020 & 0.3375 & 0.9744 & $0.3 \%$ & $1.0 \%$ \\
\hline NEPH2-21 & 21 & $\mathrm{~A} 12 \mathrm{O} 3$ & 10.2978 & 10.2162 & 10.9950 & -0.6972 & -0.7788 & $-6.3 \%$ & $-7.1 \%$ \\
\hline NEPH2-21 & 21 & $\mathrm{~B} 2 \mathrm{O} 3$ & 4.1054 & 4.1284 & 4.6400 & -0.5346 & -0.5116 & $-11.5 \%$ & $-11.0 \%$ \\
\hline NEPH2-21 & 21 & $\mathrm{BaO}$ & 0.0452 & 0.0503 & 0.0570 & -0.0118 & -0.0067 & $-20.7 \%$ & $-11.8 \%$ \\
\hline NEPH2-21 & 21 & $\mathrm{CaO}$ & 0.7675 & 0.8202 & 0.8360 & -0.0685 & -0.0158 & $-8.2 \%$ & $-1.9 \%$ \\
\hline NEPH2-21 & 21 & $\mathrm{Ce} 2 \mathrm{O} 3$ & 0.0603 & 0.0603 & 0.0780 & -0.0177 & -0.0177 & $-22.7 \%$ & $-22.7 \%$ \\
\hline NEPH2-21 & 21 & $\mathrm{Cr} 2 \mathrm{O} 3$ & 0.1012 & 0.0952 & 0.0980 & 0.0032 & -0.0028 & $3.3 \%$ & $-2.9 \%$ \\
\hline NEPH2-21 & 21 & $\mathrm{CuO}$ & 0.0369 & 0.0392 & 0.0310 & 0.0059 & 0.0082 & $19.1 \%$ & $26.3 \%$ \\
\hline NEPH2-21 & 21 & $\mathrm{Fe} 2 \mathrm{O} 3$ & 8.3816 & 8.6034 & 9.3130 & -0.9314 & -0.7096 & $-10.0 \%$ & $-7.6 \%$ \\
\hline NEPH2-21 & 21 & $\mathrm{~K} 2 \mathrm{O}$ & 0.6511 & 0.7378 & 0.5870 & 0.0641 & 0.1508 & $10.9 \%$ & $25.7 \%$ \\
\hline NEPH2-21 & 21 & $\mathrm{La} 2 \mathrm{O} 3$ & 0.0337 & 0.0337 & 0.0340 & -0.0003 & -0.0003 & $-0.8 \%$ & $-0.8 \%$ \\
\hline NEPH2-21 & 21 & $\mathrm{Li} 2 \mathrm{O}$ & 4.1336 & 4.1785 & 4.6400 & -0.5064 & -0.4615 & $-10.9 \%$ & $-9.9 \%$ \\
\hline NEPH2-21 & 21 & $\mathrm{MgO}$ & 0.5605 & 0.5949 & 0.5900 & -0.0295 & 0.0049 & $-5.0 \%$ & $0.8 \%$ \\
\hline NEPH2-21 & 21 & $\mathrm{MnO}$ & 1.9917 & 2.0532 & 2.0470 & -0.0553 & 0.0062 & $-2.7 \%$ & $0.3 \%$ \\
\hline NEPH2-21 & 21 & $\mathrm{Na} 2 \mathrm{O}$ & 15.8727 & 15.3479 & 16.3930 & -0.5203 & -1.0451 & $-3.2 \%$ & $-6.4 \%$ \\
\hline NEPH2-21 & 21 & $\mathrm{NiO}$ & 1.1090 & 1.1559 & 1.2840 & -0.1750 & -0.1281 & $-13.6 \%$ & $-10.0 \%$ \\
\hline NEPH2-21 & 21 & $\mathrm{PbO}$ & 0.0654 & 0.0654 & 0.0740 & -0.0086 & -0.0086 & $-11.6 \%$ & $-11.6 \%$ \\
\hline NEPH2-21 & 21 & $\mathrm{SO} 4$ & 0.4711 & 0.4711 & 0.4490 & 0.0221 & 0.0221 & $4.9 \%$ & $4.9 \%$ \\
\hline NEPH2-21 & 21 & $\mathrm{SiO} 2$ & 43.6417 & 43.7487 & 44.6240 & -0.9823 & -0.8753 & $-2.2 \%$ & $-2.0 \%$ \\
\hline NEPH2-21 & 21 & $\mathrm{ThO} 2$ & 0.0569 & 0.0569 & 0.0160 & 0.0409 & 0.0409 & $255.6 \%$ & $255.6 \%$ \\
\hline NEPH2-21 & 21 & $\mathrm{TiO} 2$ & 0.0083 & 0.0089 & 0.0080 & 0.0003 & 0.0009 & $4.3 \%$ & $11.5 \%$ \\
\hline NEPH2-21 & 21 & U3O8 & 2.7240 & 2.8772 & 3.0540 & -0.3300 & -0.1768 & $-10.8 \%$ & $-5.8 \%$ \\
\hline NEPH2-21 & 21 & $\mathrm{ZnO}$ & 0.0143 & 0.0143 & 0.0450 & -0.0307 & -0.0307 & $-68.2 \%$ & $-68.2 \%$ \\
\hline NEPH2-21 & 21 & $\mathrm{ZrO} 2$ & 0.0956 & 0.0956 & 0.1070 & -0.0114 & -0.0114 & $-10.7 \%$ & $-10.7 \%$ \\
\hline NEPH2-21 & 21 & Sum of Oxides & 95.2255 & 95.4534 & 100.0000 & -4.7745 & -4.5466 & $-4.8 \%$ & $-4.5 \%$ \\
\hline NEPH2-22 & 22 & $\mathrm{~A} 12 \mathrm{O} 3$ & 12.2959 & 12.1986 & 12.0430 & 0.2529 & 0.1556 & $2.1 \%$ & $1.3 \%$ \\
\hline NEPH2-22 & 22 & $\mathrm{~B} 2 \mathrm{O} 3$ & 4.1698 & 4.1930 & 4.3200 & -0.1502 & -0.1270 & $-3.5 \%$ & $-2.9 \%$ \\
\hline NEPH2-22 & 22 & $\mathrm{BaO}$ & 0.0497 & 0.0552 & 0.0620 & -0.0123 & -0.0068 & $-19.9 \%$ & $-10.9 \%$ \\
\hline NEPH2-22 & 22 & $\mathrm{CaO}$ & 0.8280 & 0.8849 & 0.9160 & -0.0880 & -0.0311 & $-9.6 \%$ & $-3.4 \%$ \\
\hline NEPH2-22 & 22 & $\mathrm{Ce} 2 \mathrm{O} 3$ & 0.0609 & 0.0609 & 0.0860 & -0.0251 & -0.0251 & $-29.2 \%$ & $-29.2 \%$ \\
\hline NEPH2-22 & 22 & $\mathrm{Cr} 2 \mathrm{O} 3$ & 0.1034 & 0.0973 & 0.1070 & -0.0036 & -0.0097 & $-3.4 \%$ & $-9.1 \%$ \\
\hline NEPH2-22 & 22 & $\mathrm{CuO}$ & 0.0397 & 0.0422 & 0.0330 & 0.0067 & 0.0092 & $20.4 \%$ & $27.7 \%$ \\
\hline NEPH2-22 & 22 & $\mathrm{Fe} 2 \mathrm{O} 3$ & 9.7506 & 10.0101 & 10.2000 & -0.4494 & -0.1899 & $-4.4 \%$ & $-1.9 \%$ \\
\hline
\end{tabular}


Table C4. Average Measured and Bias-Corrected Chemical Compositions Versus Targeted Compositions by Oxide by Nepheline Study Glass

(100 -Batch 1; $200-U$ std)

\begin{tabular}{|c|c|c|c|c|c|c|c|c|c|}
\hline & & & & Measured & & & & & \\
\hline & & & Measured & Bias-Corrected & Targeted & Diff of & Diff of & $\%$ Diff of & $\%$ Diff of \\
\hline Glass ID & Glass \# & Oxide & $(w t \%)$ & $(w t \%)$ & $(w t \%)$ & Measured & Meas BC & Measured & Meas BC \\
\hline NEPH2-22 & 22 & $\mathrm{~K} 2 \mathrm{O}$ & 0.6911 & 0.7832 & 0.6430 & 0.0481 & 0.1402 & $7.5 \%$ & $21.8 \%$ \\
\hline NEPH2-22 & 22 & $\mathrm{La} 2 \mathrm{O} 3$ & 0.0396 & 0.0396 & 0.0370 & 0.0026 & 0.0026 & $7.0 \%$ & $7.0 \%$ \\
\hline NEPH2-22 & 22 & $\mathrm{Li} 2 \mathrm{O}$ & 4.2035 & 4.2494 & 4.3200 & -0.1165 & -0.0706 & $-2.7 \%$ & $-1.6 \%$ \\
\hline NEPH2-22 & 22 & $\mathrm{MgO}$ & 0.6094 & 0.6469 & 0.6470 & -0.0376 & -0.0001 & $-5.8 \%$ & $0.0 \%$ \\
\hline NEPH2-22 & 22 & $\mathrm{MnO}$ & 2.1498 & 2.2163 & 2.2420 & -0.0922 & -0.0257 & $-4.1 \%$ & $-1.1 \%$ \\
\hline NEPH2-22 & 22 & $\mathrm{Na} 2 \mathrm{O}$ & 16.5467 & 15.9996 & 17.0980 & -0.5513 & -1.0984 & $-3.2 \%$ & $-6.4 \%$ \\
\hline NEPH2-22 & 22 & $\mathrm{NiO}$ & 1.2505 & 1.3043 & 1.4060 & -0.1555 & -0.1017 & $-11.1 \%$ & $-7.2 \%$ \\
\hline NEPH2-22 & 22 & $\mathrm{PbO}$ & 0.0762 & 0.0762 & 0.0810 & -0.0048 & -0.0048 & $-5.9 \%$ & $-5.9 \%$ \\
\hline NEPH2-22 & 22 & $\mathrm{SO} 4$ & 0.4883 & 0.4883 & 0.4920 & -0.0037 & -0.0037 & $-0.7 \%$ & $-0.7 \%$ \\
\hline NEPH2-22 & 22 & $\mathrm{SiO} 2$ & 42.4651 & 42.5705 & 41.7310 & 0.7341 & 0.8395 & $1.8 \%$ & $2.0 \%$ \\
\hline NEPH2-22 & 22 & ThO2 & 0.0569 & 0.0569 & 0.0170 & 0.0399 & 0.0399 & $234.7 \%$ & $234.7 \%$ \\
\hline NEPH2-22 & 22 & $\mathrm{TiO} 2$ & 0.0083 & 0.0089 & 0.0090 & -0.0007 & -0.0001 & $-7.3 \%$ & $-0.9 \%$ \\
\hline NEPH2-22 & 22 & $\mathrm{U} 3 \mathrm{O} 8$ & 3.2015 & 3.3820 & 3.3450 & -0.1435 & 0.0370 & $-4.3 \%$ & $1.1 \%$ \\
\hline NEPH2-22 & 22 & $\mathrm{ZnO}$ & 0.0523 & 0.0523 & 0.0490 & 0.0033 & 0.0033 & $6.7 \%$ & $6.7 \%$ \\
\hline NEPH2-22 & 22 & $\mathrm{ZrO} 2$ & 0.1027 & 0.1027 & 0.1170 & -0.0143 & -0.0143 & $-12.3 \%$ & $-12.3 \%$ \\
\hline NEPH2-22 & 22 & Sum of Oxides & 99.2401 & 99.5191 & 100.0010 & -0.7609 & -0.4819 & $-0.8 \%$ & $-0.5 \%$ \\
\hline NEPH2-23 & 23 & $\mathrm{~A} 12 \mathrm{O} 3$ & 12.5652 & 12.6477 & 12.8280 & -0.2628 & -0.1803 & $-2.0 \%$ & $-1.4 \%$ \\
\hline NEPH2-23 & 23 & $\mathrm{~B} 2 \mathrm{O} 3$ & 3.9766 & 4.0189 & 4.0800 & -0.1034 & -0.0611 & $-2.5 \%$ & $-1.5 \%$ \\
\hline NEPH2-23 & 23 & $\mathrm{BaO}$ & 0.0533 & 0.0593 & 0.0660 & -0.0127 & -0.0067 & $-19.2 \%$ & $-10.2 \%$ \\
\hline NEPH2-23 & 23 & $\mathrm{CaO}$ & 0.9049 & 0.9539 & 0.9760 & -0.0711 & -0.0221 & $-7.3 \%$ & $-2.3 \%$ \\
\hline NEPH2-23 & 23 & $\mathrm{Ce} 2 \mathrm{O} 3$ & 0.0714 & 0.0714 & 0.0910 & -0.0196 & -0.0196 & $-21.5 \%$ & $-21.5 \%$ \\
\hline NEPH2-23 & 23 & $\mathrm{Cr} 2 \mathrm{O} 3$ & 0.1012 & 0.0960 & 0.1140 & -0.0128 & -0.0180 & $-11.2 \%$ & $-15.8 \%$ \\
\hline NEPH2-23 & 23 & $\mathrm{CuO}$ & 0.0438 & 0.0459 & 0.0360 & 0.0078 & 0.0099 & $21.7 \%$ & $27.6 \%$ \\
\hline NEPH2-23 & 23 & $\mathrm{Fe} 2 \mathrm{O} 3$ & 10.1259 & 10.3690 & 10.8660 & -0.7401 & -0.4970 & $-6.8 \%$ & $-4.6 \%$ \\
\hline NEPH2-23 & 23 & $\mathrm{~K} 2 \mathrm{O}$ & 0.6896 & 0.7747 & 0.6850 & 0.0046 & 0.0897 & $0.7 \%$ & $13.1 \%$ \\
\hline NEPH2-23 & 23 & $\mathrm{La} 2 \mathrm{O} 3$ & 0.0364 & 0.0364 & 0.0390 & -0.0026 & -0.0026 & $-6.8 \%$ & $-6.8 \%$ \\
\hline NEPH2-23 & 23 & $\mathrm{Li} 2 \mathrm{O}$ & 3.8537 & 3.9287 & 4.0800 & -0.2263 & -0.1513 & $-5.5 \%$ & $-3.7 \%$ \\
\hline NEPH2-23 & 23 & $\mathrm{MgO}$ & 0.6612 & 0.7013 & 0.6890 & -0.0278 & 0.0123 & $-4.0 \%$ & $1.8 \%$ \\
\hline NEPH2-23 & 23 & $\mathrm{MnO}$ & 2.3564 & 2.3968 & 2.3880 & -0.0316 & 0.0088 & $-1.3 \%$ & $0.4 \%$ \\
\hline NEPH2-23 & 23 & $\mathrm{Na} 2 \mathrm{O}$ & 17.5914 & 16.8272 & 17.6260 & -0.0346 & -0.7988 & $-0.2 \%$ & $-4.5 \%$ \\
\hline NEPH2-23 & 23 & $\mathrm{NiO}$ & 1.3196 & 1.3863 & 1.4980 & -0.1784 & -0.1117 & $-11.9 \%$ & $-7.5 \%$ \\
\hline NEPH2-23 & 23 & $\mathrm{PbO}$ & 0.0797 & 0.0797 & 0.0870 & -0.0073 & -0.0073 & $-8.4 \%$ & $-8.4 \%$ \\
\hline NEPH2-23 & 23 & $\mathrm{SO} 4$ & 0.4981 & 0.4981 & 0.5240 & -0.0259 & -0.0259 & $-4.9 \%$ & $-4.9 \%$ \\
\hline NEPH2-23 & 23 & $\mathrm{SiO} 2$ & 39.4701 & 39.9739 & 39.5620 & -0.0919 & 0.4119 & $-0.2 \%$ & $1.0 \%$ \\
\hline NEPH2-23 & 23 & ThO2 & 0.0569 & 0.0569 & 0.0190 & 0.0379 & 0.0379 & $199.4 \%$ & $199.4 \%$ \\
\hline NEPH2-23 & 23 & $\mathrm{TiO} 2$ & 0.0083 & 0.0088 & 0.0090 & -0.0007 & -0.0002 & $-7.3 \%$ & $-2.0 \%$ \\
\hline NEPH2-23 & 23 & $\mathrm{U} 3 \mathrm{O} 8$ & 3.3371 & 3.5007 & 3.5630 & -0.2259 & -0.0623 & $-6.3 \%$ & $-1.7 \%$ \\
\hline NEPH2-23 & 23 & $\mathrm{ZnO}$ & 0.0541 & 0.0541 & 0.0520 & 0.0021 & 0.0021 & $4.1 \%$ & $4.1 \%$ \\
\hline NEPH2-23 & 23 & $\mathrm{ZrO} 2$ & 0.1182 & 0.1182 & 0.1250 & -0.0068 & -0.0068 & $-5.4 \%$ & $-5.4 \%$ \\
\hline NEPH2-23 & 23 & Sum of Oxides & 97.9733 & 98.6039 & 100.0030 & -2.0297 & -1.3991 & $-2.0 \%$ & $-1.4 \%$ \\
\hline NEPH2-24 & 24 & $\mathrm{Al} 2 \mathrm{O} 3$ & 11.3512 & 11.2613 & 11.2570 & 0.0942 & 0.0043 & $0.8 \%$ & $0.0 \%$ \\
\hline NEPH2-24 & 24 & $\mathrm{~B} 2 \mathrm{O} 3$ & 4.3630 & 4.3880 & 4.5600 & -0.1970 & -0.1720 & $-4.3 \%$ & $-3.8 \%$ \\
\hline NEPH2-24 & 24 & $\mathrm{BaO}$ & 0.0461 & 0.0512 & 0.0580 & -0.0119 & -0.0068 & $-20.6 \%$ & $-11.7 \%$ \\
\hline NEPH2-24 & 24 & $\mathrm{CaO}$ & 0.7944 & 0.8490 & 0.8560 & -0.0616 & -0.0070 & $-7.2 \%$ & $-0.8 \%$ \\
\hline NEPH2-24 & 24 & $\mathrm{Ce} 2 \mathrm{O} 3$ & 0.0612 & 0.0612 & 0.0800 & -0.0188 & -0.0188 & $-23.5 \%$ & $-23.5 \%$ \\
\hline NEPH2-24 & 24 & $\mathrm{Cr} 2 \mathrm{O} 3$ & 0.0957 & 0.0900 & 0.1000 & -0.0043 & -0.0100 & $-4.3 \%$ & $-10.0 \%$ \\
\hline NEPH2-24 & 24 & $\mathrm{CuO}$ & 0.0388 & 0.0412 & 0.0310 & 0.0078 & 0.0102 & $25.2 \%$ & $32.8 \%$ \\
\hline NEPH2-24 & 24 & $\mathrm{Fe} 2 \mathrm{O} 3$ & 8.9321 & 9.1694 & 9.5350 & -0.6029 & -0.3656 & $-6.3 \%$ & $-3.8 \%$ \\
\hline NEPH2-24 & 24 & $\mathrm{~K} 2 \mathrm{O}$ & 0.6430 & 0.7286 & 0.6010 & 0.0420 & 0.1276 & $7.0 \%$ & $21.2 \%$ \\
\hline NEPH2-24 & 24 & $\mathrm{La} 2 \mathrm{O} 3$ & 0.0334 & 0.0334 & 0.0350 & -0.0016 & -0.0016 & $-4.5 \%$ & $-4.5 \%$ \\
\hline NEPH2-24 & 24 & $\mathrm{Li} 2 \mathrm{O}$ & 4.3812 & 4.4288 & 4.5600 & -0.1788 & -0.1312 & $-3.9 \%$ & $-2.9 \%$ \\
\hline NEPH2-24 & 24 & $\mathrm{MgO}$ & 0.5846 & 0.6205 & 0.6040 & -0.0194 & 0.0165 & $-3.2 \%$ & $2.7 \%$ \\
\hline NEPH2-24 & 24 & $\mathrm{MnO}$ & 2.0401 & 2.1031 & 2.0950 & -0.0549 & 0.0081 & $-2.6 \%$ & $0.4 \%$ \\
\hline NEPH2-24 & 24 & $\mathrm{Na} 2 \mathrm{O}$ & 15.6705 & 15.1537 & 15.9990 & -0.3285 & -0.8453 & $-2.1 \%$ & $-5.3 \%$ \\
\hline NEPH2-24 & 24 & $\mathrm{NiO}$ & 1.1729 & 1.2229 & 1.3140 & -0.1411 & -0.0911 & $-10.7 \%$ & $-6.9 \%$ \\
\hline NEPH2-24 & 24 & $\mathrm{PbO}$ & 0.0676 & 0.0676 & 0.0760 & -0.0084 & -0.0084 & $-11.1 \%$ & $-11.1 \%$ \\
\hline
\end{tabular}


Table C4. Average Measured and Bias-Corrected Chemical Compositions Versus Targeted Compositions by Oxide by Nepheline Study Glass

(100-Batch 1; $200-U$ std)

\begin{tabular}{|c|c|c|c|c|c|c|c|c|c|}
\hline & & & & Measured & & & & & \\
\hline & & & Measured & Bias-Corrected & Targeted & Diff of & Diff of & $\%$ Diff of & $\%$ Diff of \\
\hline Glass ID & Glass \# & Oxide & $(w t \%)$ & $(w t \%)$ & $(w t \%)$ & Measured & Meas BC & Measured & Meas BC \\
\hline NEPH2-24 & 24 & $\mathrm{SO} 4$ & 0.4569 & 0.4569 & 0.4600 & -0.0031 & -0.0031 & $-0.7 \%$ & $-0.7 \%$ \\
\hline NEPH2-24 & 24 & $\mathrm{SiO} 2$ & 43.7487 & 43.8566 & 44.4710 & -0.7223 & -0.6144 & $-1.6 \%$ & $-1.4 \%$ \\
\hline NEPH2-24 & 24 & ThO2 & 0.0569 & 0.0569 & 0.0160 & 0.0409 & 0.0409 & $255.6 \%$ & $255.6 \%$ \\
\hline NEPH2-24 & 24 & $\mathrm{TiO} 2$ & 0.0083 & 0.0089 & 0.0080 & 0.0003 & 0.0009 & $4.3 \%$ & $11.5 \%$ \\
\hline NEPH2-24 & 24 & $\mathrm{U} 3 \mathrm{O} 8$ & 2.8537 & 3.0142 & 3.1260 & -0.2723 & -0.1118 & $-8.7 \%$ & $-3.6 \%$ \\
\hline NEPH2-24 & 24 & $\mathrm{ZnO}$ & 0.0504 & 0.0504 & 0.0460 & 0.0044 & 0.0044 & $9.6 \%$ & $9.6 \%$ \\
\hline NEPH2-24 & 24 & $\mathrm{ZrO} 2$ & 0.1000 & 0.1000 & 0.1100 & -0.0100 & -0.0100 & $-9.1 \%$ & $-9.1 \%$ \\
\hline NEPH2-24 & 24 & Sum of Oxides & 97.5504 & 97.8138 & 99.9980 & -2.4476 & -2.1842 & $-2.4 \%$ & $-2.2 \%$ \\
\hline NEPH2-25 & 25 & $\mathrm{~A} 12 \mathrm{O} 3$ & 12.3904 & 12.4712 & 12.3040 & 0.0864 & 0.1672 & $0.7 \%$ & $1.4 \%$ \\
\hline NEPH2-25 & 25 & $\mathrm{~B} 2 \mathrm{O} 3$ & 4.1054 & 4.1482 & 4.2400 & -0.1346 & -0.0918 & $-3.2 \%$ & $-2.2 \%$ \\
\hline NEPH2-25 & 25 & $\mathrm{BaO}$ & 0.0533 & 0.0593 & 0.0640 & -0.0107 & -0.0047 & $-16.7 \%$ & $-7.4 \%$ \\
\hline NEPH2-25 & 25 & $\mathrm{CaO}$ & 0.8850 & 0.9329 & 0.9360 & -0.0510 & $\begin{array}{l}-0.0031 \\
\end{array}$ & $-5.4 \%$ & $-0.3 \%$ \\
\hline NEPH2-25 & 25 & $\mathrm{Ce} 2 \mathrm{O} 3$ & 0.0641 & 0.0641 & 0.0880 & -0.0239 & -0.0239 & $-27.1 \%$ & $-27.1 \%$ \\
\hline NEPH2-25 & 25 & $\mathrm{Cr} 2 \mathrm{O} 3$ & 0.1060 & 0.1005 & 0.1090 & -0.0030 & -0.0085 & $-2.8 \%$ & $-7.8 \%$ \\
\hline NEPH2-25 & 25 & $\mathrm{CuO}$ & 0.0413 & 0.0433 & 0.0340 & 0.0073 & 0.0093 & $21.5 \%$ & $27.4 \%$ \\
\hline NEPH2-25 & 25 & $\mathrm{Fe} 2 \mathrm{O} 3$ & 9.9471 & 10.1860 & 10.4220 & -0.4749 & -0.2360 & $-4.6 \%$ & $-2.3 \%$ \\
\hline NEPH2-25 & 25 & $\mathrm{~K} 2 \mathrm{O}$ & 0.6999 & 0.7862 & 0.6570 & 0.0429 & 0.1292 & $6.5 \%$ & $19.7 \%$ \\
\hline NEPH2-25 & 25 & $\mathrm{La} 2 \mathrm{O} 3$ & 0.0422 & 0.0422 & 0.0380 & 0.0042 & 0.0042 & $11.1 \%$ & $11.1 \%$ \\
\hline NEPH2-25 & 25 & $\mathrm{Li} 2 \mathrm{O}$ & 4.0905 & 4.1702 & 4.2400 & -0.1495 & -0.0698 & $-3.5 \%$ & $-1.6 \%$ \\
\hline NEPH2-25 & 25 & $\mathrm{MgO}$ & 0.6409 & 0.6798 & 0.6610 & -0.0201 & 0.0188 & $-3.0 \%$ & $2.8 \%$ \\
\hline NEPH2-25 & 25 & $\mathrm{MnO}$ & 2.2628 & 2.3008 & 2.2900 & -0.0272 & 0.0108 & $-1.2 \%$ & $0.5 \%$ \\
\hline NEPH2-25 & 25 & $\mathrm{Na} 2 \mathrm{O}$ & 16.5804 & 15.8601 & 16.7440 & -0.1636 & -0.8839 & $-1.0 \%$ & $-5.3 \%$ \\
\hline NEPH2-25 & 25 & $\mathrm{NiO}$ & 1.2913 & 1.3558 & 1.4370 & -0.1457 & -0.0812 & $-10.1 \%$ & $-5.7 \%$ \\
\hline NEPH2-25 & 25 & $\mathrm{PbO}$ & 0.0741 & 0.0741 & 0.0830 & -0.0089 & -0.0089 & $-10.8 \%$ & $-10.8 \%$ \\
\hline NEPH2-25 & 25 & $\mathrm{SO} 4$ & 0.4831 & 0.4831 & 0.5030 & -0.0199 & -0.0199 & $-4.0 \%$ & $-4.0 \%$ \\
\hline NEPH2-25 & 25 & $\mathrm{SiO} 2$ & 41.2885 & 41.8141 & 41.5380 & -0.2495 & 0.2761 & $-0.6 \%$ & $0.7 \%$ \\
\hline NEPH2-25 & 25 & ThO2 & 0.0569 & 0.0569 & 0.0180 & 0.0389 & 0.0389 & $216.1 \%$ & $216.1 \%$ \\
\hline NEPH2-25 & 25 & $\mathrm{TiO} 2$ & 0.0083 & 0.0088 & 0.0090 & -0.0007 & -0.0002 & $-7.3 \%$ & $-2.0 \%$ \\
\hline NEPH2-25 & 25 & U3O8 & 3.2104 & 3.3678 & 3.4170 & -0.2066 & -0.0492 & $-6.0 \%$ & $-1.4 \%$ \\
\hline NEPH2-25 & 25 & $\mathrm{ZnO}$ & 0.0560 & 0.0560 & 0.0500 & 0.0060 & 0.0060 & $12.0 \%$ & $12.0 \%$ \\
\hline NEPH2-25 & 25 & $\mathrm{ZrO} 2$ & 0.1084 & 0.1084 & 0.1200 & -0.0116 & -0.0116 & $-9.7 \%$ & $-9.7 \%$ \\
\hline NEPH2-25 & 25 & Sum of Oxides & 98.4863 & 99.1697 & 100.0020 & -1.5157 & -0.8323 & $-1.5 \%$ & $-0.8 \%$ \\
\hline NEPH2-26 & 26 & $\mathrm{~A} 12 \mathrm{O} 3$ & 13.4485 & 13.3420 & 13.3520 & 0.0965 & -0.0100 & $0.7 \%$ & $-0.1 \%$ \\
\hline NEPH2-26 & 26 & $\mathrm{~B} 2 \mathrm{O} 3$ & 3.8075 & 3.8278 & 3.9200 & -0.1125 & -0.0922 & $-2.9 \%$ & $-2.4 \%$ \\
\hline NEPH2-26 & 26 & $\mathrm{BaO}$ & 0.0583 & 0.0648 & 0.0690 & -0.0107 & -0.0042 & $-15.5 \%$ & $-6.0 \%$ \\
\hline NEPH2-26 & 26 & $\mathrm{CaO}$ & 0.9368 & 1.0012 & 1.0150 & -0.0782 & -0.0138 & $-7.7 \%$ & $-1.4 \%$ \\
\hline NEPH2-26 & 26 & $\mathrm{Ce} 2 \mathrm{O} 3$ & 0.0735 & 0.0735 & 0.0950 & -0.0215 & -0.0215 & $-22.6 \%$ & $-22.6 \%$ \\
\hline NEPH2-26 & 26 & $\mathrm{Cr} 2 \mathrm{O} 3$ & 0.1012 & 0.0952 & 0.1190 & -0.0178 & -0.0238 & $-14.9 \%$ & $-20.0 \%$ \\
\hline NEPH2-26 & 26 & $\mathrm{CuO}$ & 0.0519 & 0.0551 & 0.0370 & 0.0149 & 0.0181 & $40.4 \%$ & $48.9 \%$ \\
\hline NEPH2-26 & 26 & $\mathrm{Fe} 2 \mathrm{O} 3$ & 10.4690 & 10.7471 & 11.3090 & -0.8400 & -0.5619 & $-7.4 \%$ & $-5.0 \%$ \\
\hline NEPH2-26 & 26 & $\mathrm{~K} 2 \mathrm{O}$ & 0.7661 & 0.8681 & 0.7130 & 0.0531 & 0.1551 & $7.5 \%$ & $21.7 \%$ \\
\hline NEPH2-26 & 26 & $\mathrm{La} 2 \mathrm{O} 3$ & 0.0815 & 0.0815 & 0.0410 & 0.0405 & 0.0405 & $98.8 \%$ & $98.8 \%$ \\
\hline NEPH2-26 & 26 & $\mathrm{Li} 2 \mathrm{O}$ & 3.7999 & 3.8411 & 3.9200 & -0.1201 & -0.0789 & $-3.1 \%$ & $-2.0 \%$ \\
\hline NEPH2-26 & 26 & $\mathrm{MgO}$ & 0.6758 & 0.7173 & 0.7170 & -0.0412 & 0.0003 & $-5.8 \%$ & $0.0 \%$ \\
\hline NEPH2-26 & 26 & $\mathrm{MnO}$ & 2.2015 & 2.2695 & 2.4850 & -0.2835 & -0.2155 & $-11.4 \%$ & $-8.7 \%$ \\
\hline NEPH2-26 & 26 & $\mathrm{Na} 2 \mathrm{O}$ & 16.8163 & 16.2610 & 17.4880 & -0.6717 & -1.2270 & $-3.8 \%$ & $-7.0 \%$ \\
\hline NEPH2-26 & 26 & $\mathrm{NiO}$ & 1.3838 & 1.4429 & 1.5590 & -0.1752 & -0.1161 & $-11.2 \%$ & $-7.4 \%$ \\
\hline NEPH2-26 & 26 & $\mathrm{PbO}$ & 0.0792 & 0.0792 & 0.0900 & $\begin{array}{l}-0.0108 \\
\end{array}$ & -0.0108 & $-12.0 \%$ & $-12.0 \%$ \\
\hline NEPH2-26 & 26 & $\mathrm{SO} 4$ & 0.5378 & 0.5378 & 0.5460 & -0.0082 & -0.0082 & $-1.5 \%$ & $-1.5 \%$ \\
\hline NEPH2-26 & 26 & $\mathrm{SiO} 2$ & 38.3470 & 38.4409 & 38.6050 & -0.2580 & -0.1641 & $-0.7 \%$ & $-0.4 \%$ \\
\hline NEPH2-26 & 26 & $\mathrm{ThO} 2$ & 0.0569 & 0.0569 & 0.0190 & 0.0379 & 0.0379 & $199.4 \%$ & $199.4 \%$ \\
\hline NEPH2-26 & 26 & $\mathrm{TiO} 2$ & 0.0083 & 0.0089 & 0.0100 & -0.0017 & -0.0011 & $-16.6 \%$ & $-10.8 \%$ \\
\hline NEPH2-26 & 26 & U3O8 & 3.4521 & 3.6466 & 3.7080 & -0.2559 & -0.0614 & $-6.9 \%$ & $-1.7 \%$ \\
\hline NEPH2-26 & 26 & $\mathrm{ZnO}$ & 0.0594 & 0.0594 & 0.0550 & 0.0044 & 0.0044 & $8.1 \%$ & $8.1 \%$ \\
\hline NEPH2-26 & 26 & $\mathrm{ZrO} 2$ & 0.1168 & 0.1168 & 0.1300 & -0.0132 & -0.0132 & $-10.1 \%$ & $-10.1 \%$ \\
\hline NEPH2-26 & 26 & Sum of Oxides & 97.3292 & 97.6347 & 100.0020 & -2.6728 & -2.3673 & $-2.7 \%$ & $-2.4 \%$ \\
\hline
\end{tabular}


Table C4. Average Measured and Bias-Corrected Chemical Compositions Versus Targeted Compositions by Oxide by Nepheline Study Glass

(100 -Batch 1; $200-U$ std)

\begin{tabular}{|c|c|c|c|c|c|c|c|c|c|}
\hline & & & & Measured & & & & & \\
\hline & & & Measured & Bias-Corrected & Targeted & Diff of & Diff of & $\%$ Diff of & $\%$ Diff of \\
\hline Glass ID & Glass \# & Oxide & $(w t \%)$ & $(w t \%)$ & $(w t \%)$ & Measured & Meas BC & Measured & Meas BC \\
\hline NEPH2-27 & 27 & $\mathrm{Al} 2 \mathrm{O} 3$ & 13.1651 & 13.3256 & 11.6410 & 1.5241 & 1.6846 & $13.1 \%$ & $14.5 \%$ \\
\hline NEPH2-27 & 27 & $\mathrm{~B} 2 \mathrm{O} 3$ & 4.0571 & 4.1925 & 4.8800 & -0.8229 & -0.6875 & $-16.9 \%$ & $-14.1 \%$ \\
\hline NEPH2-27 & 27 & $\mathrm{BaO}$ & 0.0500 & 0.0559 & 0.0560 & -0.0060 & -0.0001 & $-10.8 \%$ & $-0.1 \%$ \\
\hline NEPH2-27 & 27 & $\mathrm{CaO}$ & 0.7857 & 0.8184 & 0.7490 & 0.0367 & 0.0694 & $4.9 \%$ & $9.3 \%$ \\
\hline NEPH2-27 & 27 & $\mathrm{Ce} 2 \mathrm{O} 3$ & 0.0498 & 0.0498 & 0.0750 & -0.0252 & -0.0252 & $-33.6 \%$ & $-33.6 \%$ \\
\hline NEPH2-27 & 27 & $\mathrm{Cr} 2 \mathrm{O} 3$ & 0.0935 & 0.0899 & 0.0980 & -0.0045 & -0.0081 & $-4.5 \%$ & $-8.3 \%$ \\
\hline NEPH2-27 & 27 & $\mathrm{CuO}$ & 0.0382 & 0.0399 & 0.0290 & 0.0092 & 0.0109 & $31.7 \%$ & $37.4 \%$ \\
\hline NEPH2-27 & 27 & $\mathrm{Fe} 2 \mathrm{O} 3$ & 7.7275 & 7.9150 & 8.3300 & -0.6025 & -0.4150 & $-7.2 \%$ & $-5.0 \%$ \\
\hline NEPH2-27 & 27 & $\mathrm{~K} 2 \mathrm{O}$ & 0.7788 & 0.8650 & 0.6690 & 0.1098 & 0.1960 & $16.4 \%$ & $29.3 \%$ \\
\hline NEPH2-27 & 27 & $\mathrm{La} 2 \mathrm{O} 3$ & 0.0320 & 0.0320 & 0.0320 & 0.0000 & 0.0000 & $-0.1 \%$ & $-0.1 \%$ \\
\hline NEPH2-27 & 27 & $\mathrm{Li} 2 \mathrm{O}$ & 4.7095 & 4.7924 & 4.8800 & -0.1705 & -0.0876 & $-3.5 \%$ & $-1.8 \%$ \\
\hline NEPH2-27 & 27 & $\mathrm{MgO}$ & 0.4560 & 0.4859 & 0.4150 & 0.0410 & 0.0709 & $9.9 \%$ & $17.1 \%$ \\
\hline NEPH2-27 & 27 & $\mathrm{MnO}$ & 1.9981 & 2.1038 & 1.8720 & 0.1261 & 0.2318 & $6.7 \%$ & $12.4 \%$ \\
\hline NEPH2-27 & 27 & $\mathrm{Na} 2 \mathrm{O}$ & 16.0412 & 15.7091 & 16.5140 & -0.4728 & -0.8049 & $-2.9 \%$ & $-4.9 \%$ \\
\hline NEPH2-27 & 27 & $\mathrm{NiO}$ & 1.2063 & 1.2332 & 1.3580 & -0.1517 & -0.1248 & $-11.2 \%$ & $-9.2 \%$ \\
\hline NEPH2-27 & 27 & $\mathrm{PbO}$ & 0.0622 & 0.0622 & 0.0760 & -0.0138 & -0.0138 & $-18.1 \%$ & $-18.1 \%$ \\
\hline NEPH2-27 & 27 & $\mathrm{SO} 4$ & 0.4329 & 0.4329 & 0.4020 & 0.0309 & 0.0309 & $7.7 \%$ & $7.7 \%$ \\
\hline NEPH2-27 & 27 & $\mathrm{SiO} 2$ & 44.4440 & 44.7284 & 44.9870 & -0.5430 & -0.2586 & $-1.2 \%$ & $-0.6 \%$ \\
\hline NEPH2-27 & 27 & ThO2 & 0.0569 & 0.0569 & 0.0160 & 0.0409 & 0.0409 & $255.6 \%$ & $255.6 \%$ \\
\hline NEPH2-27 & 27 & $\mathrm{TiO} 2$ & 0.0083 & 0.0088 & 0.0070 & 0.0013 & 0.0018 & $19.1 \%$ & $25.9 \%$ \\
\hline NEPH2-27 & 27 & $\mathrm{U} 3 \mathrm{O} 8$ & 2.5530 & 2.7247 & 2.7650 & -0.2120 & -0.0403 & $-7.7 \%$ & $-1.5 \%$ \\
\hline NEPH2-27 & 27 & $\mathrm{ZnO}$ & 0.0485 & 0.0485 & 0.0420 & 0.0065 & 0.0065 & $15.6 \%$ & $15.6 \%$ \\
\hline NEPH2-27 & 27 & $\mathrm{ZrO} 2$ & 0.1057 & 0.1057 & 0.1070 & -0.0013 & -0.0013 & $-1.2 \%$ & $-1.2 \%$ \\
\hline NEPH2-27 & 27 & Sum of Oxides & 98.9002 & 99.8765 & 100.0000 & -1.0998 & -0.1235 & $-1.1 \%$ & $-0.1 \%$ \\
\hline NEPH2-28 & 28 & $\mathrm{Al} 2 \mathrm{O} 3$ & 11.7716 & 11.9151 & 13.1330 & -1.3614 & -1.2179 & $-10.4 \%$ & $-9.3 \%$ \\
\hline NEPH2-28 & 28 & $\mathrm{~B} 2 \mathrm{O} 3$ & 4.4837 & 4.6329 & 4.4800 & 0.0037 & 0.1529 & $0.1 \%$ & $3.4 \%$ \\
\hline NEPH2-28 & 28 & $\mathrm{BaO}$ & 0.0461 & 0.0515 & 0.0630 & -0.0169 & -0.0115 & $-26.9 \%$ & $-18.2 \%$ \\
\hline NEPH2-28 & 28 & $\mathrm{CaO}$ & 0.7377 & 0.7685 & 0.8450 & -0.1073 & -0.0765 & $-12.7 \%$ & $-9.1 \%$ \\
\hline NEPH2-28 & 28 & $\mathrm{Ce} 2 \mathrm{O} 3$ & 0.0580 & 0.0580 & 0.0850 & -0.0270 & -0.0270 & $-31.8 \%$ & $-31.8 \%$ \\
\hline NEPH2-28 & 28 & $\mathrm{Cr} 2 \mathrm{O} 3$ & 0.1041 & 0.1001 & 0.1100 & -0.0059 & -0.0099 & $-5.3 \%$ & $-9.0 \%$ \\
\hline NEPH2-28 & 28 & $\mathrm{CuO}$ & 0.0369 & 0.0386 & 0.0330 & 0.0039 & 0.0056 & $11.9 \%$ & $16.8 \%$ \\
\hline NEPH2-28 & 28 & $\mathrm{Fe} 2 \mathrm{O} 3$ & 8.7819 & 8.9959 & 9.3980 & -0.6161 & -0.4021 & $-6.6 \%$ & $-4.3 \%$ \\
\hline NEPH2-28 & 28 & $\mathrm{~K} 2 \mathrm{O}$ & 0.6954 & 0.7723 & 0.7550 & -0.0596 & 0.0173 & $-7.9 \%$ & $2.3 \%$ \\
\hline NEPH2-28 & 28 & $\mathrm{La} 2 \mathrm{O} 3$ & 0.0305 & 0.0305 & 0.0360 & -0.0055 & -0.0055 & $-15.3 \%$ & $-15.3 \%$ \\
\hline NEPH2-28 & 28 & $\mathrm{Li} 2 \mathrm{O}$ & 4.3435 & 4.4202 & 4.4800 & -0.1365 & -0.0598 & $-3.0 \%$ & $-1.3 \%$ \\
\hline NEPH2-28 & 28 & $\mathrm{MgO}$ & 0.4146 & 0.4417 & 0.4680 & -0.0534 & -0.0263 & $-11.4 \%$ & $-5.6 \%$ \\
\hline NEPH2-28 & 28 & $\mathrm{MnO}$ & 1.7980 & 1.8928 & 2.1120 & -0.3140 & -0.2192 & $-14.9 \%$ & $-10.4 \%$ \\
\hline NEPH2-28 & 28 & $\mathrm{Na} 2 \mathrm{O}$ & 15.9401 & 15.6100 & 17.0930 & -1.1529 & -1.4830 & $-6.7 \%$ & $-8.7 \%$ \\
\hline NEPH2-28 & 28 & $\mathrm{NiO}$ & 1.3775 & 1.4082 & 1.5320 & -0.1545 & -0.1238 & $-10.1 \%$ & $-8.1 \%$ \\
\hline NEPH2-28 & 28 & $\mathrm{PbO}$ & 0.0816 & 0.0816 & 0.0860 & -0.0044 & -0.0044 & $-5.1 \%$ & $-5.1 \%$ \\
\hline NEPH2-28 & 28 & $\mathrm{SO} 4$ & 0.3895 & 0.3895 & 0.4530 & -0.0635 & -0.0635 & $-14.0 \%$ & $-14.0 \%$ \\
\hline NEPH2-28 & 28 & $\mathrm{SiO} 2$ & 41.2350 & 41.4987 & 41.5240 & -0.2890 & -0.0253 & $-0.7 \%$ & $-0.1 \%$ \\
\hline NEPH2-28 & 28 & $\mathrm{ThO} 2$ & 0.0569 & 0.0569 & 0.0180 & 0.0389 & 0.0389 & $216.1 \%$ & $216.1 \%$ \\
\hline NEPH2-28 & 28 & $\mathrm{TiO} 2$ & 0.0083 & 0.0088 & 0.0080 & 0.0003 & 0.0008 & $4.3 \%$ & $10.1 \%$ \\
\hline NEPH2-28 & 28 & U3O8 & 2.9627 & 3.1620 & 3.1200 & -0.1573 & 0.0420 & $-5.0 \%$ & $1.3 \%$ \\
\hline NEPH2-28 & 28 & $\mathrm{ZnO}$ & 0.0479 & 0.0479 & 0.0480 & -0.0001 & -0.0001 & $-0.2 \%$ & $-0.2 \%$ \\
\hline NEPH2-28 & 28 & $\mathrm{ZrO} 2$ & 0.1013 & 0.1013 & 0.1200 & -0.0187 & -0.0187 & $-15.6 \%$ & $-15.6 \%$ \\
\hline NEPH2-28 & 28 & Sum of Oxides & 95.5028 & 96.4829 & 100.0000 & -4.4972 & -3.5171 & $-4.5 \%$ & $-3.5 \%$ \\
\hline NEPH2-29 & 29 & $\mathrm{~A} 12 \mathrm{O} 3$ & 14.5208 & 14.4807 & 14.6260 & -0.1052 & -0.1453 & $-0.7 \%$ & $-1.0 \%$ \\
\hline NEPH2-29 & 29 & $\mathrm{~B} 2 \mathrm{O} 3$ & 3.7512 & 3.8202 & 4.0800 & -0.3288 & -0.2598 & $-8.1 \%$ & $-6.4 \%$ \\
\hline NEPH2-29 & 29 & $\mathrm{BaO}$ & 0.0592 & 0.0653 & 0.0710 & -0.0118 & -0.0057 & $-16.7 \%$ & $-8.0 \%$ \\
\hline NEPH2-29 & 29 & $\mathrm{CaO}$ & 0.8853 & 0.9329 & 0.9410 & -0.0557 & -0.0081 & $-5.9 \%$ & $-0.9 \%$ \\
\hline NEPH2-29 & 29 & $\mathrm{Ce} 2 \mathrm{O} 3$ & 0.0796 & 0.0796 & 0.0950 & -0.0154 & -0.0154 & $-16.2 \%$ & $-16.2 \%$ \\
\hline NEPH2-29 & 29 & $\mathrm{Cr} 2 \mathrm{O} 3$ & 0.1082 & 0.1022 & 0.1230 & -0.0148 & -0.0208 & $-12.1 \%$ & $-16.9 \%$ \\
\hline NEPH2-29 & 29 & $\mathrm{CuO}$ & 0.0422 & 0.0440 & 0.0370 & 0.0052 & 0.0070 & $14.2 \%$ & $18.9 \%$ \\
\hline NEPH2-29 & 29 & $\mathrm{Fe} 2 \mathrm{O} 3$ & 9.5325 & 9.7854 & 10.4660 & -0.9335 & -0.6806 & $-8.9 \%$ & $-6.5 \%$ \\
\hline
\end{tabular}


Table C4. Average Measured and Bias-Corrected Chemical Compositions Versus Targeted Compositions by Oxide by Nepheline Study Glass

(100-Batch 1; $200-U$ std)

\begin{tabular}{|c|c|c|c|c|c|c|c|c|c|}
\hline & & & & Measured & & & & & \\
\hline & & & Measured & Bias-Corrected & Targeted & Diff of & Diff of & $\%$ Diff of & $\%$ Diff of \\
\hline Glass ID & Glass \# & Oxide & $(w t \%)$ & $(w t \%)$ & $(w t \%)$ & Measured & Meas BC & Measured & Meas BC \\
\hline NEPH2-29 & \begin{tabular}{|l|}
29 \\
\end{tabular} & $\mathrm{~K} 2 \mathrm{O}$ & 0.8595 & 0.9683 & 0.8400 & 0.0195 & 0.1283 & $2.3 \%$ & $15.3 \%$ \\
\hline NEPH2-29 & 29 & $\mathrm{La} 2 \mathrm{O} 3$ & 0.0408 & 0.0408 & 0.0400 & 0.0008 & 0.0008 & $1.9 \%$ & $1.9 \%$ \\
\hline NEPH2-29 & 29 & $\mathrm{Li} 2 \mathrm{O}$ & 3.9560 & 3.9959 & 4.0800 & -0.1240 & -0.0841 & $-3.0 \%$ & $-2.1 \%$ \\
\hline NEPH2-29 & 29 & $\mathrm{MgO}$ & 0.5207 & 0.5491 & 0.5220 & -0.0013 & 0.0271 & $-0.2 \%$ & $5.2 \%$ \\
\hline NEPH2-29 & 29 & $\mathrm{MnO}$ & 2.2822 & 2.3235 & 2.3520 & -0.0698 & -0.0285 & $-3.0 \%$ & $-1.2 \%$ \\
\hline NEPH2-29 & 29 & $\mathrm{Na} 2 \mathrm{O}$ & 17.5240 & 16.6209 & 17.6710 & -0.1470 & -1.0501 & $-0.8 \%$ & $-5.9 \%$ \\
\hline NEPH2-29 & 29 & $\mathrm{NiO}$ & 1.4634 & 1.5333 & 1.7060 & -0.2426 & -0.1727 & $-14.2 \%$ & $-10.1 \%$ \\
\hline NEPH2-29 & 29 & $\mathrm{PbO}$ & 0.0878 & 0.0878 & 0.0960 & -0.0082 & -0.0082 & $-8.6 \%$ & $-8.6 \%$ \\
\hline NEPH2-29 & 29 & $\mathrm{SO} 4$ & 0.4868 & 0.4868 & 0.5050 & -0.0182 & -0.0182 & $-3.6 \%$ & $-3.6 \%$ \\
\hline NEPH2-29 & 29 & $\mathrm{SiO} 2$ & 37.7052 & 37.9339 & 38.0610 & -0.3558 & -0.1271 & $-0.9 \%$ & $-0.3 \%$ \\
\hline NEPH2-29 & 29 & $\mathrm{ThO} 2$ & 0.0569 & 0.0569 & 0.0200 & 0.0369 & 0.0369 & $184.5 \%$ & $184.5 \%$ \\
\hline NEPH2-29 & 29 & $\mathrm{TiO} 2$ & 0.0083 & 0.0088 & 0.0090 & -0.0007 & -0.0002 & $-7.3 \%$ & $-2.6 \%$ \\
\hline NEPH2-29 & 29 & $\mathrm{U} 3 \mathrm{O} 8$ & 3.2900 & 3.4692 & 3.4740 & -0.1840 & -0.0048 & $-5.3 \%$ & $-0.1 \%$ \\
\hline NEPH2-29 & 29 & $\mathrm{ZnO}$ & 0.0591 & 0.0591 & 0.0530 & 0.0061 & 0.0061 & $11.6 \%$ & $11.6 \%$ \\
\hline NEPH2-29 & 29 & $\mathrm{ZrO} 2$ & 0.1233 & 0.1233 & 0.1340 & -0.0107 & -0.0107 & $-8.0 \%$ & $-8.0 \%$ \\
\hline NEPH2-29 & 29 & Sum of Oxides & 97.4429 & 97.5678 & 100.0020 & -2.5591 & -2.4342 & $-2.6 \%$ & $-2.4 \%$ \\
\hline NEPH2-30 & 30 & $\mathrm{~A} 12 \mathrm{O} 3$ & 12.0030 & 12.1494 & 11.9390 & 0.0640 & 0.2104 & $0.5 \%$ & $1.8 \%$ \\
\hline NEPH2-30 & 30 & $\mathrm{~B} 2 \mathrm{O} 3$ & 4.4596 & 4.6090 & 4.8000 & -0.3404 & -0.1910 & $-7.1 \%$ & $-4.0 \%$ \\
\hline NEPH2-30 & 30 & $\mathrm{BaO}$ & 0.0469 & 0.0525 & 0.0580 & -0.0111 & -0.0055 & $-19.2 \%$ & $-9.5 \%$ \\
\hline NEPH2-30 & 30 & $\mathrm{CaO}$ & 0.7398 & 0.7707 & 0.7690 & -0.0292 & 0.0017 & $-3.8 \%$ & $0.2 \%$ \\
\hline NEPH2-30 & 30 & $\mathrm{Ce} 2 \mathrm{O} 3$ & 0.0565 & 0.0565 & 0.0770 & -0.0205 & -0.0205 & $-26.6 \%$ & $-26.6 \%$ \\
\hline NEPH2-30 & 30 & $\mathrm{Cr} 2 \mathrm{O} 3$ & 0.0943 & 0.0906 & 0.1000 & -0.0057 & -0.0094 & $-5.7 \%$ & $-9.4 \%$ \\
\hline NEPH2-30 & 30 & $\mathrm{CuO}$ & 0.0372 & 0.0389 & 0.0300 & 0.0072 & 0.0089 & $24.1 \%$ & $29.6 \%$ \\
\hline NEPH2-30 & 30 & $\mathrm{Fe} 2 \mathrm{O} 3$ & 8.0778 & 8.2755 & 8.5440 & -0.4662 & -0.2685 & $-5.5 \%$ & $-3.1 \%$ \\
\hline NEPH2-30 & 30 & $\mathrm{~K} 2 \mathrm{O}$ & 0.7282 & 0.8088 & 0.6860 & 0.0422 & 0.1228 & $6.1 \%$ & $17.9 \%$ \\
\hline NEPH2-30 & 30 & $\mathrm{La} 2 \mathrm{O} 3$ & 0.0340 & 0.0340 & 0.0330 & 0.0010 & 0.0010 & $3.1 \%$ & $3.1 \%$ \\
\hline NEPH2-30 & 30 & $\mathrm{Li} 2 \mathrm{O}$ & 4.6234 & 4.7052 & 4.8000 & -0.1766 & -0.0948 & $-3.7 \%$ & $-2.0 \%$ \\
\hline NEPH2-30 & 30 & $\mathrm{MgO}$ & 0.4142 & 0.4413 & 0.4260 & -0.0118 & 0.0153 & $-2.8 \%$ & $3.6 \%$ \\
\hline NEPH2-30 & 30 & $\mathrm{MnO}$ & 1.8690 & 1.9678 & 1.9200 & -0.0510 & 0.0478 & $-2.7 \%$ & $2.5 \%$ \\
\hline NEPH2-30 & 30 & $\mathrm{Na} 2 \mathrm{O}$ & 15.9064 & 15.5770 & 16.0300 & -0.1236 & -0.4530 & $-0.8 \%$ & $-2.8 \%$ \\
\hline NEPH2-30 & 30 & $\mathrm{NiO}$ & 1.2881 & 1.3168 & 1.3930 & -0.1049 & -0.0762 & $-7.5 \%$ & $-5.5 \%$ \\
\hline NEPH2-30 & 30 & $\mathrm{PbO}$ & 0.0716 & 0.0716 & 0.0780 & -0.0064 & -0.0064 & $-8.2 \%$ & $-8.2 \%$ \\
\hline NEPH2-30 & 30 & $\mathrm{SO} 4$ & 0.4037 & 0.4037 & 0.4120 & -0.0083 & -0.0083 & $-2.0 \%$ & $-2.0 \%$ \\
\hline NEPH2-30 & 30 & $\mathrm{SiO} 2$ & 44.6579 & 44.9437 & 44.8940 & -0.2361 & 0.0497 & $-0.5 \%$ & $0.1 \%$ \\
\hline NEPH2-30 & 30 & ThO2 & 0.0569 & 0.0569 & 0.0170 & 0.0399 & 0.0399 & $234.7 \%$ & $234.7 \%$ \\
\hline NEPH2-30 & 30 & $\mathrm{TiO} 2$ & 0.0083 & 0.0088 & 0.0070 & 0.0013 & 0.0018 & $19.1 \%$ & $25.9 \%$ \\
\hline NEPH2-30 & 30 & $\mathrm{U} 3 \mathrm{O} 8$ & 2.7505 & 2.9355 & 2.8360 & -0.0855 & 0.0995 & $-3.0 \%$ & $3.5 \%$ \\
\hline NEPH2-30 & 30 & $\mathrm{ZnO}$ & 0.1049 & 0.1049 & 0.0430 & 0.0619 & 0.0619 & $143.9 \%$ & $143.9 \%$ \\
\hline NEPH2-30 & 30 & $\mathrm{ZrO} 2$ & 0.1020 & 0.1020 & 0.1090 & -0.0070 & -0.0070 & $-6.4 \%$ & $-6.4 \%$ \\
\hline NEPH2-30 & 30 & Sum of Oxides & 98.5342 & 99.5211 & 100.0010 & -1.4668 & -0.4799 & $-1.5 \%$ & $-0.5 \%$ \\
\hline NEPH2-31 & 31 & $\mathrm{~A} 12 \mathrm{O} 3$ & 13.3304 & 13.2933 & 13.1330 & 0.1974 & 0.1603 & $1.5 \%$ & $1.2 \%$ \\
\hline NEPH2-31 & 31 & $\mathrm{~B} 2 \mathrm{O} 3$ & 4.2744 & 4.3529 & 4.4800 & -0.2056 & -0.1271 & $-4.6 \%$ & $-2.8 \%$ \\
\hline NEPH2-31 & 31 & $\mathrm{BaO}$ & 0.0572 & 0.0632 & 0.0630 & -0.0058 & 0.0002 & $-9.2 \%$ & $0.3 \%$ \\
\hline NEPH2-31 & 31 & $\mathrm{CaO}$ & 0.7986 & 0.8415 & 0.8450 & -0.0464 & -0.0035 & $-5.5 \%$ & $-0.4 \%$ \\
\hline NEPH2-31 & 31 & $\mathrm{Ce} 2 \mathrm{O} 3$ & 0.0673 & 0.0673 & 0.0850 & -0.0177 & -0.0177 & $-20.8 \%$ & $-20.8 \%$ \\
\hline NEPH2-31 & 31 & $\mathrm{Cr} 2 \mathrm{O} 3$ & 0.0961 & 0.0908 & 0.1100 & -0.0139 & -0.0192 & $-12.6 \%$ & $-17.5 \%$ \\
\hline NEPH2-31 & 31 & $\mathrm{CuO}$ & 0.0448 & 0.0466 & 0.0330 & 0.0118 & 0.0136 & $35.6 \%$ & $41.3 \%$ \\
\hline NEPH2-31 & 31 & $\mathrm{Fe} 2 \mathrm{O} 3$ & 8.6068 & 8.8343 & 9.3980 & -0.7912 & -0.5637 & $-8.4 \%$ & $-6.0 \%$ \\
\hline NEPH2-31 & 31 & $\mathrm{~K} 2 \mathrm{O}$ & 0.7682 & 0.8655 & 0.7550 & 0.0132 & 0.1105 & $1.8 \%$ & $14.6 \%$ \\
\hline NEPH2-31 & 31 & $\mathrm{La} 2 \mathrm{O} 3$ & 0.0325 & 0.0325 & 0.0360 & -0.0035 & -0.0035 & $-9.6 \%$ & $-9.6 \%$ \\
\hline NEPH2-31 & 31 & $\mathrm{Li} 2 \mathrm{O}$ & 4.3650 & 4.4091 & 4.4800 & -0.1150 & -0.0709 & $-2.6 \%$ & $-1.6 \%$ \\
\hline NEPH2-31 & 31 & $\mathrm{MgO}$ & 0.4672 & 0.4927 & 0.4680 & -0.0008 & 0.0247 & $-0.2 \%$ & $5.3 \%$ \\
\hline NEPH2-31 & 31 & $\mathrm{MnO}$ & 2.0885 & 2.1262 & 2.1120 & -0.0235 & 0.0142 & $-1.1 \%$ & $0.7 \%$ \\
\hline NEPH2-31 & 31 & $\mathrm{Na} 2 \mathrm{O}$ & 16.2434 & 15.4064 & 16.5330 & -0.2896 & -1.1266 & $-1.8 \%$ & $-6.8 \%$ \\
\hline NEPH2-31 & 31 & $\mathrm{NiO}$ & 1.3329 & 1.3959 & 1.5320 & -0.1991 & -0.1361 & $-13.0 \%$ & $-8.9 \%$ \\
\hline NEPH2-31 & 31 & $\mathrm{PbO}$ & 0.0811 & 0.0811 & 0.0860 & -0.0049 & -0.0049 & $-5.7 \%$ & $-5.7 \%$ \\
\hline
\end{tabular}


Table C4. Average Measured and Bias-Corrected Chemical Compositions Versus Targeted Compositions by Oxide by Nepheline Study Glass

(100 -Batch 1; $200-U$ std)

\begin{tabular}{|c|c|c|c|c|c|c|c|c|c|}
\hline & & & & Measured & & & & & \\
\hline & & & Measured & Bias-Corrected & Targeted & Diff of & Diff of & $\%$ Diff of & $\%$ Diff of \\
\hline Glass ID & Glass \# & Oxide & $(w t \%)$ & $(w t \%)$ & $(w t \%)$ & Measured & Meas BC & Measured & Meas BC \\
\hline NEPH2-31 & 31 & SO4 & 0.4262 & 0.4262 & 0.4530 & -0.0268 & -0.0268 & $-5.9 \%$ & $-5.9 \%$ \\
\hline NEPH2-31 & 31 & $\mathrm{SiO} 2$ & 41.5559 & 41.8079 & 42.0840 & -0.5281 & -0.2761 & $-1.3 \%$ & $-0.7 \%$ \\
\hline NEPH2-31 & 31 & $\mathrm{ThO} 2$ & 0.0569 & 0.0569 & 0.0180 & 0.0389 & 0.0389 & $216.1 \%$ & $216.1 \%$ \\
\hline NEPH2-31 & 31 & $\mathrm{TiO} 2$ & 0.0083 & 0.0088 & 0.0080 & 0.0003 & 0.0008 & $4.3 \%$ & $9.5 \%$ \\
\hline NEPH2-31 & 31 & $\mathrm{U} 3 \mathrm{O} 8$ & 2.9627 & 3.1243 & 3.1200 & -0.1573 & 0.0043 & $-5.0 \%$ & $0.1 \%$ \\
\hline NEPH2-31 & 31 & $\mathrm{ZnO}$ & 0.0517 & 0.0517 & 0.0480 & 0.0037 & 0.0037 & $7.6 \%$ & $7.6 \%$ \\
\hline NEPH2-31 & 31 & $\mathrm{ZrO} 2$ & 0.1131 & 0.1131 & 0.1200 & -0.0069 & -0.0069 & $-5.7 \%$ & $-5.7 \%$ \\
\hline NEPH2-31 & 31 & Sum of Oxides & 97.8294 & 97.9881 & 100.0000 & -2.1706 & -2.0119 & $-2.2 \%$ & $-2.0 \%$ \\
\hline NEPH2-32 & 32 & $\mathrm{Al} 2 \mathrm{O} 3$ & 13.6138 & 13.7796 & 14.3270 & -0.7132 & -0.5474 & $-5.0 \%$ & $-3.8 \%$ \\
\hline NEPH2-32 & 32 & $\mathrm{~B} 2 \mathrm{O} 3$ & 3.7029 & 3.8251 & 4.1600 & -0.4571 & -0.3349 & $-11.0 \%$ & $-8.1 \%$ \\
\hline NEPH2-32 & 32 & $\mathrm{BaO}$ & 0.0558 & 0.0625 & 0.0690 & -0.0132 & -0.0065 & $-19.1 \%$ & $-9.4 \%$ \\
\hline NEPH2-32 & 32 & $\mathrm{CaO}$ & 0.8563 & 0.8920 & 0.9220 & -0.0657 & -0.0300 & $-7.1 \%$ & $-3.2 \%$ \\
\hline NEPH2-32 & 32 & $\mathrm{Ce} 2 \mathrm{O} 3$ & 0.0627 & 0.0627 & 0.0930 & -0.0303 & -0.0303 & $-32.6 \%$ & $-32.6 \%$ \\
\hline NEPH2-32 & 32 & $\mathrm{Cr} 2 \mathrm{O} 3$ & 0.1016 & 0.0976 & 0.1200 & -0.0184 & -0.0224 & $-15.3 \%$ & $-18.6 \%$ \\
\hline NEPH2-32 & 32 & $\mathrm{CuO}$ & 0.0410 & 0.0428 & 0.0360 & 0.0050 & 0.0068 & $13.9 \%$ & $18.9 \%$ \\
\hline NEPH2-32 & 32 & $\mathrm{Fe} 2 \mathrm{O} 3$ & 9.2823 & 9.5009 & 10.2520 & -0.9697 & -0.7511 & $-9.5 \%$ & $-7.3 \%$ \\
\hline NEPH2-32 & 32 & $\mathrm{~K} 2 \mathrm{O}$ & 0.9074 & 1.0078 & 0.8230 & 0.0844 & 0.1848 & $10.3 \%$ & $22.5 \%$ \\
\hline NEPH2-32 & 32 & $\mathrm{La} 2 \mathrm{O} 3$ & 0.0331 & 0.0331 & 0.0390 & -0.0059 & -0.0059 & $-15.0 \%$ & $-15.0 \%$ \\
\hline NEPH2-32 & 32 & $\mathrm{Li} 2 \mathrm{O}$ & 3.8429 & 3.9106 & 4.1600 & -0.3171 & -0.2494 & $-7.6 \%$ & $-6.0 \%$ \\
\hline NEPH2-32 & 32 & $\mathrm{MgO}$ & 0.4788 & 0.5101 & 0.5110 & -0.0322 & -0.0009 & $-6.3 \%$ & $-0.2 \%$ \\
\hline NEPH2-32 & 32 & $\mathrm{MnO}$ & 2.1724 & 2.2873 & 2.3040 & -0.1316 & -0.0167 & $-5.7 \%$ & $-0.7 \%$ \\
\hline NEPH2-32 & 32 & $\mathrm{Na} 2 \mathrm{O}$ & 16.6815 & 16.3361 & 17.0360 & -0.3545 & -0.6999 & $-2.1 \%$ & $-4.1 \%$ \\
\hline NEPH2-32 & 32 & $\mathrm{NiO}$ & 1.4252 & 1.4552 & 1.6720 & -0.2468 & -0.2168 & $-14.8 \%$ & $-13.0 \%$ \\
\hline NEPH2-32 & 32 & $\mathrm{PbO}$ & 0.0738 & 0.0738 & 0.0940 & -0.0202 & -0.0202 & $-21.5 \%$ & $-21.5 \%$ \\
\hline NEPH2-32 & 32 & $\mathrm{SO} 4$ & 0.4711 & 0.4711 & 0.4950 & -0.0239 & -0.0239 & $-4.8 \%$ & $-4.8 \%$ \\
\hline NEPH2-32 & 32 & $\mathrm{SiO} 2$ & 38.0261 & 38.2603 & 39.2730 & -1.2469 & -1.0127 & $-3.2 \%$ & $-2.6 \%$ \\
\hline NEPH2-32 & 32 & ThO2 & 0.0569 & 0.0569 & 0.0200 & 0.0369 & 0.0369 & $184.5 \%$ & $184.5 \%$ \\
\hline NEPH2-32 & 32 & $\mathrm{TiO} 2$ & 0.0083 & 0.0088 & 0.0090 & -0.0007 & -0.0002 & $-7.3 \%$ & $-2.1 \%$ \\
\hline NEPH2-32 & 32 & $\mathrm{U} 3 \mathrm{O} 8$ & 3.1219 & 3.3318 & 3.4030 & -0.2811 & -0.0712 & $-8.3 \%$ & $-2.1 \%$ \\
\hline NEPH2-32 & 32 & $\mathrm{ZnO}$ & 0.0538 & 0.0538 & 0.0520 & 0.0018 & 0.0018 & $3.5 \%$ & $3.5 \%$ \\
\hline NEPH2-32 & 32 & $\mathrm{ZrO} 2$ & 0.1158 & 0.1158 & 0.1310 & -0.0152 & -0.0152 & $-11.6 \%$ & $-11.6 \%$ \\
\hline NEPH2-32 & 32 & Sum of Oxides & 95.1856 & 96.1760 & 100.0010 & -4.8154 & -3.8250 & $-4.8 \%$ & $-3.8 \%$ \\
\hline NEPH2-33 & 33 & $\mathrm{Al} 2 \mathrm{O} 3$ & 12.5416 & 12.6947 & 12.2380 & 0.3036 & 0.4567 & $2.5 \%$ & $3.7 \%$ \\
\hline NEPH2-33 & 33 & $\mathrm{~B} 2 \mathrm{O} 3$ & 4.3791 & 4.5258 & 4.7200 & -0.3409 & -0.1942 & $-7.2 \%$ & $-4.1 \%$ \\
\hline NEPH2-33 & 33 & $\mathrm{BaO}$ & 0.0475 & 0.0531 & 0.0590 & -0.0115 & -0.0059 & $-19.6 \%$ & $-10.0 \%$ \\
\hline NEPH2-33 & 33 & $\mathrm{CaO}$ & 0.7451 & 0.7762 & 0.7880 & -0.0429 & -0.0118 & $-5.4 \%$ & $-1.5 \%$ \\
\hline NEPH2-33 & 33 & $\mathrm{Ce} 2 \mathrm{O} 3$ & 0.0533 & 0.0533 & 0.0790 & -0.0257 & -0.0257 & $-32.5 \%$ & $-32.5 \%$ \\
\hline NEPH2-33 & 33 & $\mathrm{Cr} 2 \mathrm{O} 3$ & 0.0946 & 0.0910 & 0.1030 & -0.0084 & -0.0120 & $-8.1 \%$ & $-11.7 \%$ \\
\hline NEPH2-33 & 33 & $\mathrm{CuO}$ & 0.0369 & 0.0386 & 0.0310 & 0.0059 & 0.0076 & $19.1 \%$ & $24.4 \%$ \\
\hline NEPH2-33 & 33 & $\mathrm{Fe} 2 \mathrm{O} 3$ & 8.1278 & 8.3263 & 8.7570 & -0.6292 & -0.4307 & $-7.2 \%$ & $-4.9 \%$ \\
\hline NEPH2-33 & 33 & $\mathrm{~K} 2 \mathrm{O}$ & 0.7472 & 0.8299 & 0.7030 & 0.0442 & 0.1269 & $6.3 \%$ & $18.0 \%$ \\
\hline NEPH2-33 & 33 & $\mathrm{La} 2 \mathrm{O} 3$ & 0.0340 & 0.0340 & 0.0330 & 0.0010 & 0.0010 & $3.1 \%$ & $3.1 \%$ \\
\hline NEPH2-33 & 33 & $\mathrm{Li} 2 \mathrm{O}$ & 4.5319 & 4.6112 & 4.7200 & -0.1881 & -0.1088 & $-4.0 \%$ & $-2.3 \%$ \\
\hline NEPH2-33 & 33 & $\mathrm{MgO}$ & 0.4204 & 0.4479 & 0.4360 & -0.0156 & 0.0119 & $-3.6 \%$ & $2.7 \%$ \\
\hline NEPH2-33 & 33 & $\mathrm{MnO}$ & 1.9239 & 2.0251 & 1.9680 & -0.0441 & 0.0571 & $-2.2 \%$ & $2.9 \%$ \\
\hline NEPH2-33 & 33 & $\mathrm{Na} 2 \mathrm{O}$ & 15.1987 & 14.8839 & 15.5650 & -0.3663 & -0.6811 & $-2.4 \%$ & $-4.4 \%$ \\
\hline NEPH2-33 & 33 & $\mathrm{NiO}$ & 1.2954 & 1.3238 & 1.4280 & -0.1326 & -0.1042 & $-9.3 \%$ & $-7.3 \%$ \\
\hline NEPH2-33 & 33 & $\mathrm{PbO}$ & 0.0692 & 0.0692 & 0.0800 & -0.0108 & -0.0108 & $-13.5 \%$ & $-13.5 \%$ \\
\hline NEPH2-33 & 33 & $\mathrm{SO} 4$ & 0.3977 & 0.3977 & 0.4230 & -0.0253 & -0.0253 & $-6.0 \%$ & $-6.0 \%$ \\
\hline NEPH2-33 & 33 & $\mathrm{SiO} 2$ & 44.2300 & 44.5066 & 44.7820 & -0.5520 & -0.2754 & $-1.2 \%$ & $-0.6 \%$ \\
\hline NEPH2-33 & 33 & ThO2 & 0.0569 & 0.0569 & 0.0170 & 0.0399 & 0.0399 & $234.7 \%$ & $234.7 \%$ \\
\hline NEPH2-33 & 33 & $\mathrm{TiO} 2$ & 0.0083 & 0.0088 & 0.0080 & 0.0003 & 0.0008 & $4.3 \%$ & $10.1 \%$ \\
\hline NEPH2-33 & 33 & U3O8 & 2.7387 & 2.9239 & 2.9070 & -0.1683 & 0.0169 & $-5.8 \%$ & $0.6 \%$ \\
\hline NEPH2-33 & 33 & $\mathrm{ZnO}$ & 0.0470 & 0.0470 & 0.0440 & 0.0030 & 0.0030 & $6.8 \%$ & $6.8 \%$ \\
\hline NEPH2-33 & 33 & $\mathrm{ZrO} 2$ & 0.1003 & 0.1003 & 0.1120 & -0.0117 & -0.0117 & $-10.4 \%$ & $-10.4 \%$ \\
\hline NEPH2-33 & 33 & Sum of Oxides & 97.8254 & 98.8252 & 100.0010 & -2.1756 & -1.1758 & $-2.2 \%$ & $-1.2 \%$ \\
\hline
\end{tabular}


Table C4. Average Measured and Bias-Corrected Chemical Compositions Versus Targeted Compositions by Oxide by Nepheline Study Glass

(100 -Batch 1; $200-U$ std)

\begin{tabular}{|c|c|c|c|c|c|c|c|c|c|}
\hline & & & & Measured & & & & & \\
\hline & & & Measured & Bias-Corrected & Targeted & Diff of & Diff of & $\%$ Diff of & $\%$ Diff of \\
\hline Glass ID & Glass \# & Oxide & $(w t \%)$ & $(w t \%)$ & $(w t \%)$ & Measured & Meas BC & Measured & Meas BC \\
\hline NEPH2-34 & 34 & $\mathrm{Al} 2 \mathrm{O} 3$ & 13.6894 & 13.6517 & 13.4320 & 0.2574 & 0.2197 & $1.9 \%$ & $1.6 \%$ \\
\hline NEPH2-34 & 34 & $\mathrm{~B} 2 \mathrm{O} 3$ & 4.0893 & 4.1643 & 4.4000 & -0.3107 & -0.2357 & $-7.1 \%$ & $-5.4 \%$ \\
\hline NEPH2-34 & 34 & $\mathrm{BaO}$ & 0.0553 & 0.0610 & 0.0650 & -0.0097 & -0.0040 & $-15.0 \%$ & $-6.1 \%$ \\
\hline NEPH2-34 & 34 & $\mathrm{CaO}$ & 0.7993 & 0.8422 & 0.8650 & -0.0657 & -0.0228 & $-7.6 \%$ & $-2.6 \%$ \\
\hline NEPH2-34 & 34 & $\mathrm{Ce} 2 \mathrm{O} 3$ & 0.0612 & 0.0612 & 0.0870 & -0.0258 & -0.0258 & $-29.7 \%$ & $-29.7 \%$ \\
\hline NEPH2-34 & 34 & $\mathrm{Cr} 2 \mathrm{O} 3$ & 0.1027 & 0.0970 & 0.1130 & -0.0103 & -0.0160 & $-9.1 \%$ & $-14.2 \%$ \\
\hline NEPH2-34 & 34 & $\mathrm{CuO}$ & 0.0457 & 0.0476 & 0.0340 & 0.0117 & 0.0136 & $34.4 \%$ & $40.0 \%$ \\
\hline NEPH2-34 & 34 & $\mathrm{Fe} 2 \mathrm{O} 3$ & 8.8963 & 9.1317 & 9.6120 & -0.7157 & -0.4803 & $-7.4 \%$ & $-5.0 \%$ \\
\hline NEPH2-34 & 34 & $\mathrm{~K} 2 \mathrm{O}$ & 0.8321 & 0.9374 & 0.7720 & 0.0601 & 0.1654 & $7.8 \%$ & $21.4 \%$ \\
\hline NEPH2-34 & 34 & $\mathrm{La} 2 \mathrm{O} 3$ & 0.0337 & 0.0337 & 0.0370 & -0.0033 & -0.0033 & $-8.9 \%$ & $-8.9 \%$ \\
\hline NEPH2-34 & 34 & $\mathrm{Li} 2 \mathrm{O}$ & 4.3166 & 4.3601 & 4.4000 & -0.0834 & -0.0399 & $-1.9 \%$ & $-0.9 \%$ \\
\hline NEPH2-34 & 34 & $\mathrm{MgO}$ & 0.4585 & 0.4835 & 0.4790 & -0.0205 & 0.0045 & $-4.3 \%$ & $0.9 \%$ \\
\hline NEPH2-34 & 34 & $\mathrm{MnO}$ & 2.1498 & 2.1877 & 2.1600 & -0.0102 & 0.0277 & $-0.5 \%$ & $1.3 \%$ \\
\hline NEPH2-34 & 34 & $\mathrm{Na} 2 \mathrm{O}$ & 16.2771 & 15.4385 & 16.1080 & 0.1691 & -0.6695 & $1.0 \%$ & $-4.2 \%$ \\
\hline NEPH2-34 & 34 & $\mathrm{NiO}$ & 1.4347 & 1.5031 & 1.5670 & -0.1323 & -0.0639 & $-8.4 \%$ & $-4.1 \%$ \\
\hline NEPH2-34 & 34 & $\mathrm{PbO}$ & 0.0776 & 0.0776 & 0.0880 & -0.0104 & -0.0104 & $-11.9 \%$ & $-11.9 \%$ \\
\hline NEPH2-34 & 34 & $\mathrm{SO} 4$ & 0.4374 & 0.4374 & 0.4640 & -0.0266 & -0.0266 & $-5.7 \%$ & $-5.7 \%$ \\
\hline NEPH2-34 & 34 & $\mathrm{SiO} 2$ & 42.0907 & 42.3459 & 41.9310 & 0.1597 & 0.4149 & $0.4 \%$ & $1.0 \%$ \\
\hline NEPH2-34 & 34 & ThO2 & 0.0569 & 0.0569 & 0.0190 & 0.0379 & 0.0379 & $199.4 \%$ & $199.4 \%$ \\
\hline NEPH2-34 & 34 & $\mathrm{TiO} 2$ & 0.0083 & 0.0088 & 0.0080 & 0.0003 & 0.0008 & $4.3 \%$ & $9.5 \%$ \\
\hline NEPH2-34 & 34 & $\mathrm{U} 3 \mathrm{O} 8$ & 3.0748 & 3.2421 & 3.1900 & -0.1152 & 0.0521 & $-3.6 \%$ & $1.6 \%$ \\
\hline NEPH2-34 & 34 & $\mathrm{ZnO}$ & 0.0523 & 0.0523 & 0.0490 & 0.0033 & 0.0033 & $6.7 \%$ & $6.7 \%$ \\
\hline NEPH2-34 & 34 & $\mathrm{ZrO} 2$ & 0.1057 & 0.1057 & 0.1230 & -0.0173 & -0.0173 & $-14.1 \%$ & $-14.1 \%$ \\
\hline NEPH2-34 & 34 & Sum of Oxides & 99.1454 & 99.3274 & 100.0030 & -0.8576 & -0.6756 & $-0.9 \%$ & $-0.7 \%$ \\
\hline NEPH2-35 & 35 & $\mathrm{Al} 2 \mathrm{O} 3$ & 14.3649 & 14.3250 & 14.3270 & 0.0379 & -0.0020 & $0.3 \%$ & $0.0 \%$ \\
\hline NEPH2-35 & 35 & $\mathrm{~B} 2 \mathrm{O} 3$ & 3.7431 & 3.8119 & 4.1600 & -0.4169 & -0.3481 & $-10.0 \%$ & $-8.4 \%$ \\
\hline NEPH2-35 & 35 & $\mathrm{BaO}$ & 0.0575 & 0.0635 & 0.0690 & -0.0115 & -0.0055 & $-16.7 \%$ & $-8.0 \%$ \\
\hline NEPH2-35 & 35 & $\mathrm{CaO}$ & 0.8546 & 0.9004 & 0.9220 & -0.0674 & -0.0216 & $-7.3 \%$ & $-2.3 \%$ \\
\hline NEPH2-35 & 35 & $\mathrm{Ce} 2 \mathrm{O} 3$ & 0.0694 & 0.0694 & 0.0930 & -0.0236 & -0.0236 & $-25.4 \%$ & $-25.4 \%$ \\
\hline NEPH2-35 & 35 & $\mathrm{Cr} 2 \mathrm{O} 3$ & 0.0979 & 0.0925 & 0.1200 & -0.0221 & -0.0275 & $-18.4 \%$ & $-22.9 \%$ \\
\hline NEPH2-35 & 35 & $\mathrm{CuO}$ & 0.0432 & 0.0450 & 0.0360 & 0.0072 & 0.0090 & $20.0 \%$ & $25.0 \%$ \\
\hline NEPH2-35 & 35 & $\mathrm{Fe} 2 \mathrm{O} 3$ & 9.4039 & 9.6528 & 10.2520 & -0.8481 & -0.5992 & $-8.3 \%$ & $-5.8 \%$ \\
\hline NEPH2-35 & 35 & $\mathrm{~K} 2 \mathrm{O}$ & 0.8495 & 0.9571 & 0.8230 & 0.0265 & 0.1341 & $3.2 \%$ & $16.3 \%$ \\
\hline NEPH2-35 & 35 & $\mathrm{La} 2 \mathrm{O} 3$ & 0.0367 & 0.0367 & 0.0390 & -0.0024 & -0.0024 & $-6.0 \%$ & $-6.0 \%$ \\
\hline NEPH2-35 & 35 & $\mathrm{Li} 2 \mathrm{O}$ & 4.0313 & 4.0720 & 4.1600 & -0.1287 & -0.0880 & $-3.1 \%$ & $-2.1 \%$ \\
\hline NEPH2-35 & 35 & $\mathrm{MgO}$ & 0.4983 & 0.5255 & 0.5110 & -0.0127 & 0.0145 & $-2.5 \%$ & $2.8 \%$ \\
\hline NEPH2-35 & 35 & $\mathrm{MnO}$ & 2.2531 & 2.2936 & 2.3040 & -0.0509 & -0.0104 & $-2.2 \%$ & $-0.5 \%$ \\
\hline NEPH2-35 & 35 & $\mathrm{Na} 2 \mathrm{O}$ & 16.4456 & 15.5982 & 16.5160 & -0.0704 & -0.9178 & $-0.4 \%$ & $-5.6 \%$ \\
\hline NEPH2-35 & 35 & $\mathrm{NiO}$ & 1.4602 & 1.5296 & 1.6720 & -0.2118 & -0.1424 & $-12.7 \%$ & $-8.5 \%$ \\
\hline NEPH2-35 & 35 & $\mathrm{PbO}$ & 0.0878 & 0.0878 & 0.0940 & -0.0062 & -0.0062 & $-6.6 \%$ & $-6.6 \%$ \\
\hline NEPH2-35 & 35 & $\mathrm{SO} 4$ & 0.4614 & 0.4614 & 0.4950 & -0.0336 & -0.0336 & $-6.8 \%$ & $-6.8 \%$ \\
\hline NEPH2-35 & 35 & $\mathrm{SiO} 2$ & 39.2027 & 39.4405 & 39.7930 & -0.5903 & -0.3525 & $-1.5 \%$ & $-0.9 \%$ \\
\hline NEPH2-35 & 35 & $\mathrm{ThO} 2$ & 0.0569 & 0.0569 & 0.0200 & 0.0369 & 0.0369 & $184.5 \%$ & $184.5 \%$ \\
\hline NEPH2-35 & 35 & $\mathrm{TiO} 2$ & 0.0083 & 0.0088 & 0.0090 & -0.0007 & -0.0002 & $-7.3 \%$ & $-2.6 \%$ \\
\hline NEPH2-35 & 35 & U3O8 & 3.1986 & 3.3730 & 3.4030 & -0.2044 & -0.0300 & $-6.0 \%$ & $-0.9 \%$ \\
\hline NEPH2-35 & 35 & $\mathrm{ZnO}$ & 0.0560 & 0.0560 & 0.0520 & 0.0040 & 0.0040 & $7.7 \%$ & $7.7 \%$ \\
\hline NEPH2-35 & 35 & $\mathrm{ZrO} 2$ & 0.1145 & 0.1145 & 0.1310 & -0.0165 & -0.0165 & $-12.6 \%$ & $-12.6 \%$ \\
\hline NEPH2-35 & 35 & Sum of Oxides & 97.3954 & 97.5719 & 100.0010 & -2.6056 & -2.4291 & $-2.6 \%$ & $-2.4 \%$ \\
\hline NEPH2-36 & 36 & $\mathrm{~A} 12 \mathrm{O} 3$ & 12.4801 & 12.6323 & 12.5360 & -0.0559 & 0.0963 & $-0.4 \%$ & $0.8 \%$ \\
\hline NEPH2-36 & 36 & $\mathrm{~B} 2 \mathrm{O} 3$ & 4.2020 & 4.3422 & 4.6400 & -0.4380 & -0.2978 & $-9.4 \%$ & $-6.4 \%$ \\
\hline NEPH2-36 & 36 & $\mathrm{BaO}$ & 0.0530 & 0.0594 & 0.0600 & -0.0070 & -0.0006 & $-11.6 \%$ & $-1.1 \%$ \\
\hline NEPH2-36 & 36 & $\mathrm{CaO}$ & 0.7556 & 0.7871 & 0.8070 & -0.0514 & -0.0199 & $-6.4 \%$ & $-2.5 \%$ \\
\hline NEPH2-36 & 36 & $\mathrm{Ce} 2 \mathrm{O} 3$ & 0.0568 & 0.0568 & 0.0810 & -0.0242 & -0.0242 & $-29.9 \%$ & $-29.9 \%$ \\
\hline NEPH2-36 & 36 & $\mathrm{Cr} 2 \mathrm{O} 3$ & 0.0983 & 0.0945 & 0.1050 & -0.0067 & -0.0105 & $-6.4 \%$ & $-10.0 \%$ \\
\hline NEPH2-36 & 36 & $\mathrm{CuO}$ & 0.0394 & 0.0412 & 0.0310 & 0.0084 & 0.0102 & $27.2 \%$ & $32.8 \%$ \\
\hline NEPH2-36 & 36 & $\mathrm{Fe} 2 \mathrm{O} 3$ & 8.3137 & 8.5149 & 8.9710 & -0.6573 & -0.4561 & $-7.3 \%$ & $-5.1 \%$ \\
\hline
\end{tabular}


Table C4. Average Measured and Bias-Corrected Chemical Compositions Versus Targeted Compositions by Oxide by Nepheline Study Glass

(100-Batch 1; $200-U$ std)

\begin{tabular}{|c|c|c|c|c|c|c|c|c|c|}
\hline & & & & Measured & & & & & \\
\hline & & & Measured & Bias-Corrected & Targeted & Diff of & Diff of & $\%$ Diff of & $\%$ Diff of \\
\hline Glass ID & Glass \# & Oxide & $(w t \%)$ & $(w t \%)$ & $(w t \%)$ & Measured & Meas BC & Measured & Meas BC \\
\hline NEPH2-36 & \begin{tabular}{|l|}
36 \\
\end{tabular} & $\mathrm{~K} 2 \mathrm{O}$ & 0.7613 & 0.8456 & 0.7200 & 0.0413 & 0.1256 & $5.7 \%$ & $17.4 \%$ \\
\hline NEPH2-36 & 36 & $\mathrm{La} 2 \mathrm{O} 3$ & 0.0311 & 0.0311 & 0.0340 & -0.0029 & -0.0029 & $-8.6 \%$ & $-8.6 \%$ \\
\hline NEPH2-36 & 36 & $\mathrm{Li} 2 \mathrm{O}$ & 4.4188 & 4.4969 & 4.6400 & -0.2212 & -0.1431 & $-4.8 \%$ & $-3.1 \%$ \\
\hline NEPH2-36 & 36 & $\mathrm{MgO}$ & 0.4266 & 0.4545 & 0.4470 & -0.0204 & 0.0075 & $-4.6 \%$ & $1.7 \%$ \\
\hline NEPH2-36 & 36 & $\mathrm{MnO}$ & 1.9659 & 2.0697 & 2.0160 & -0.0501 & 0.0537 & $-2.5 \%$ & $2.7 \%$ \\
\hline NEPH2-36 & 36 & $\mathrm{Na} 2 \mathrm{O}$ & 15.2998 & 14.9830 & 15.1210 & 0.1788 & -0.1380 & $1.2 \%$ & $-0.9 \%$ \\
\hline NEPH2-36 & 36 & $\mathrm{NiO}$ & 1.2970 & 1.3257 & 1.4630 & -0.1660 & -0.1373 & $-11.3 \%$ & $-9.4 \%$ \\
\hline NEPH2-36 & 36 & $\mathrm{PbO}$ & 0.0692 & 0.0692 & 0.0820 & -0.0128 & -0.0128 & $-15.6 \%$ & $-15.6 \%$ \\
\hline NEPH2-36 & 36 & $\mathrm{SO} 4$ & 0.4022 & 0.4022 & 0.4330 & -0.0308 & -0.0308 & $-7.1 \%$ & $-7.1 \%$ \\
\hline NEPH2-36 & 36 & $\mathrm{SiO} 2$ & 44.4974 & 44.7790 & 44.6490 & -0.1516 & 0.1300 & $-0.3 \%$ & $0.3 \%$ \\
\hline NEPH2-36 & 36 & $\mathrm{ThO} 2$ & 0.0569 & 0.0569 & 0.0170 & 0.0399 & 0.0399 & $234.7 \%$ & $234.7 \%$ \\
\hline NEPH2-36 & 36 & $\mathrm{TiO} 2$ & 0.0083 & 0.0088 & 0.0080 & 0.0003 & 0.0008 & $4.3 \%$ & $10.1 \%$ \\
\hline NEPH2-36 & 36 & $\mathrm{U} 3 \mathrm{O} 8$ & 2.6945 & 2.8759 & 2.9780 & -0.2835 & -0.1021 & $-9.5 \%$ & $-3.4 \%$ \\
\hline NEPH2-36 & 36 & $\mathrm{ZnO}$ & 0.0470 & 0.0470 & 0.0450 & 0.0020 & 0.0020 & $4.4 \%$ & $4.4 \%$ \\
\hline NEPH2-36 & 36 & $\mathrm{ZrO} 2$ & 0.1057 & 0.1057 & 0.1150 & -0.0093 & -0.0093 & $-8.1 \%$ & $-8.1 \%$ \\
\hline NEPH2-36 & 36 & Sum of Oxides & 98.0807 & 99.0795 & 99.9990 & -1.9183 & -0.9195 & $-1.9 \%$ & $-0.9 \%$ \\
\hline NEPH2-37 & 37 & $\mathrm{~A} 12 \mathrm{O} 3$ & 13.2737 & 13.2369 & 13.4320 & -0.1583 & -0.1951 & $-1.2 \%$ & $-1.5 \%$ \\
\hline NEPH2-37 & 37 & $\mathrm{~B} 2 \mathrm{O} 3$ & 4.0329 & 4.1071 & 4.4000 & -0.3671 & -0.2929 & $-8.3 \%$ & $-6.7 \%$ \\
\hline NEPH2-37 & 37 & $\mathrm{BaO}$ & 0.0542 & 0.0598 & 0.0650 & -0.0108 & -0.0052 & $-16.7 \%$ & $-8.0 \%$ \\
\hline NEPH2-37 & 37 & $\mathrm{CaO}$ & 0.8038 & 0.8470 & 0.8650 & -0.0612 & -0.0180 & $-7.1 \%$ & $-2.1 \%$ \\
\hline NEPH2-37 & 37 & $\mathrm{Ce} 2 \mathrm{O} 3$ & 0.0676 & 0.0676 & 0.0870 & -0.0194 & -0.0194 & $-22.2 \%$ & $-22.2 \%$ \\
\hline NEPH2-37 & 37 & $\mathrm{Cr} 2 \mathrm{O} 3$ & 0.1019 & 0.0963 & 0.1130 & -0.0111 & -0.0167 & $-9.8 \%$ & $-14.8 \%$ \\
\hline NEPH2-37 & 37 & $\mathrm{CuO}$ & 0.0391 & 0.0407 & 0.0340 & 0.0051 & 0.0067 & $15.1 \%$ & $19.8 \%$ \\
\hline NEPH2-37 & 37 & $\mathrm{Fe} 2 \mathrm{O} 3$ & 8.8141 & 9.0476 & 9.6120 & -0.7979 & -0.5644 & $-8.3 \%$ & $-5.9 \%$ \\
\hline NEPH2-37 & 37 & $\mathrm{~K} 2 \mathrm{O}$ & 0.8194 & 0.9232 & 0.7720 & 0.0474 & 0.1512 & $6.1 \%$ & $19.6 \%$ \\
\hline NEPH2-37 & 37 & $\mathrm{La} 2 \mathrm{O} 3$ & 0.0325 & 0.0325 & 0.0370 & -0.0045 & -0.0045 & $-12.0 \%$ & $-12.0 \%$ \\
\hline NEPH2-37 & 37 & $\mathrm{Li} 2 \mathrm{O}$ & 4.1659 & 4.2079 & 4.4000 & -0.2341 & -0.1921 & $-5.3 \%$ & $-4.4 \%$ \\
\hline NEPH2-37 & 37 & $\mathrm{MgO}$ & 0.4660 & 0.4914 & 0.4790 & -0.0130 & 0.0124 & $-2.7 \%$ & $2.6 \%$ \\
\hline NEPH2-37 & 37 & $\mathrm{MnO}$ & 2.1111 & 2.1499 & 2.1600 & -0.0489 & -0.0101 & $-2.3 \%$ & $-0.5 \%$ \\
\hline NEPH2-37 & 37 & $\mathrm{Na} 2 \mathrm{O}$ & 15.7379 & 14.9269 & 15.5580 & 0.1799 & -0.6311 & $1.2 \%$ & $-4.1 \%$ \\
\hline NEPH2-37 & 37 & $\mathrm{NiO}$ & 1.3998 & 1.4668 & 1.5670 & -0.1673 & -0.1002 & $-10.7 \%$ & $-6.4 \%$ \\
\hline NEPH2-37 & 37 & $\mathrm{PbO}$ & 0.0746 & 0.0746 & 0.0880 & -0.0134 & -0.0134 & $-15.2 \%$ & $-15.2 \%$ \\
\hline NEPH2-37 & 37 & $\mathrm{SO} 4$ & 0.4232 & 0.4232 & 0.4640 & -0.0408 & -0.0408 & $-8.8 \%$ & $-8.8 \%$ \\
\hline NEPH2-37 & 37 & $\mathrm{SiO} 2$ & 42.2512 & 42.5076 & 42.4810 & -0.2298 & 0.0266 & $-0.5 \%$ & $0.1 \%$ \\
\hline NEPH2-37 & 37 & ThO2 & 0.0569 & 0.0569 & 0.0190 & 0.0379 & 0.0379 & $199.4 \%$ & $199.4 \%$ \\
\hline NEPH2-37 & 37 & $\mathrm{TiO} 2$ & 0.0083 & 0.0088 & 0.0080 & 0.0003 & 0.0008 & $4.3 \%$ & $9.5 \%$ \\
\hline NEPH2-37 & 37 & $\mathrm{U} 3 \mathrm{O} 8$ & 2.9981 & 3.1616 & 3.1900 & -0.1919 & -0.0284 & $-6.0 \%$ & $-0.9 \%$ \\
\hline NEPH2-37 & 37 & $\mathrm{ZnO}$ & 0.0513 & 0.0513 & 0.0490 & 0.0023 & 0.0023 & $4.8 \%$ & $4.8 \%$ \\
\hline NEPH2-37 & 37 & $\mathrm{ZrO} 2$ & 0.1118 & 0.1118 & 0.1230 & -0.0112 & -0.0112 & $-9.1 \%$ & $-9.1 \%$ \\
\hline NEPH2-37 & 37 & Sum of Oxides & 97.8955 & 98.0974 & 100.0030 & -2.1075 & -1.9056 & $-2.1 \%$ & $-1.9 \%$ \\
\hline NEPH2-38 & 38 & $\mathrm{Al} 2 \mathrm{O} 3$ & 14.4122 & 14.3730 & 14.0290 & 0.3832 & 0.3440 & $2.7 \%$ & $2.5 \%$ \\
\hline NEPH2-38 & 38 & $\mathrm{~B} 2 \mathrm{O} 3$ & 4.0088 & 4.0824 & 4.2400 & -0.2312 & -0.1576 & $-5.5 \%$ & $-3.7 \%$ \\
\hline NEPH2-38 & 38 & $\mathrm{BaO}$ & 0.0631 & 0.0696 & 0.0680 & -0.0049 & 0.0016 & $-7.2 \%$ & $2.4 \%$ \\
\hline NEPH2-38 & 38 & $\mathrm{CaO}$ & 0.8332 & 0.8780 & 0.9030 & -0.0698 & -0.0250 & $-7.7 \%$ & $-2.8 \%$ \\
\hline NEPH2-38 & 38 & $\mathrm{Ce} 2 \mathrm{O} 3$ & 0.0633 & 0.0633 & 0.0910 & -0.0277 & -0.0277 & $-30.5 \%$ & $-30.5 \%$ \\
\hline NEPH2-38 & 38 & $\mathrm{Cr} 2 \mathrm{O} 3$ & 0.1173 & 0.1108 & 0.1180 & -0.0007 & -0.0072 & $-0.6 \%$ & $-6.1 \%$ \\
\hline NEPH2-38 & 38 & $\mathrm{CuO}$ & 0.0432 & 0.0450 & 0.0350 & 0.0082 & 0.0100 & $23.4 \%$ & $28.5 \%$ \\
\hline NEPH2-38 & 38 & $\mathrm{Fe} 2 \mathrm{O} 3$ & 9.8864 & 10.1475 & 10.0390 & -0.1526 & 0.1085 & $-1.5 \%$ & $1.1 \%$ \\
\hline NEPH2-38 & 38 & $\mathrm{~K} 2 \mathrm{O}$ & 0.8535 & 0.9615 & 0.8060 & 0.0475 & 0.1555 & $5.9 \%$ & $19.3 \%$ \\
\hline NEPH2-38 & 38 & $\mathrm{La} 2 \mathrm{O} 3$ & 0.0320 & 0.0320 & 0.0380 & -0.0060 & -0.0060 & $-15.9 \%$ & $-15.9 \%$ \\
\hline NEPH2-38 & 38 & $\mathrm{Li} 2 \mathrm{O}$ & 4.1820 & 4.2242 & 4.2400 & -0.0580 & -0.0158 & $-1.4 \%$ & $-0.4 \%$ \\
\hline NEPH2-38 & 38 & $\mathrm{MgO}$ & 0.4933 & 0.5202 & 0.5000 & -0.0067 & 0.0202 & $-1.3 \%$ & $4.0 \%$ \\
\hline NEPH2-38 & 38 & $\mathrm{MnO}$ & 2.2822 & 2.3217 & 2.2560 & 0.0262 & 0.0657 & $1.2 \%$ & $2.9 \%$ \\
\hline NEPH2-38 & 38 & $\mathrm{Na} 2 \mathrm{O}$ & 16.1086 & 15.2787 & 15.8500 & 0.2586 & -0.5713 & $1.6 \%$ & $-3.6 \%$ \\
\hline NEPH2-38 & 38 & $\mathrm{NiO}$ & 1.5461 & 1.6190 & 1.6370 & -0.0909 & -0.0180 & $-5.6 \%$ & $-1.1 \%$ \\
\hline NEPH2-38 & 38 & $\mathrm{PbO}$ & 0.0862 & 0.0862 & 0.0920 & -0.0058 & -0.0058 & $-6.3 \%$ & $-6.3 \%$ \\
\hline
\end{tabular}


Table C4. Average Measured and Bias-Corrected Chemical Compositions Versus Targeted Compositions by Oxide by Nepheline Study Glass

(100-Batch 1; $200-U$ std)

\begin{tabular}{|c|c|c|c|c|c|c|c|c|c|}
\hline & & & & Measured & & & & & \\
\hline & & & Measured & Bias-Corrected & Targeted & Diff of & Diff of & $\%$ Diff of & $\%$ Diff of \\
\hline Glass ID & Glass \# & Oxide & $(w t \%)$ & $(w t \%)$ & $(w t \%)$ & Measured & Meas BC & Measured & Meas BC \\
\hline NEPH2-38 & 38 & SO4 & 0.4479 & 0.4479 & 0.4840 & -0.0361 & -0.0361 & $-7.5 \%$ & \begin{tabular}{|l|}
$-7.5 \%$ \\
\end{tabular} \\
\hline NEPH2-38 & 38 & $\mathrm{SiO} 2$ & 41.7164 & 41.9693 & 41.0360 & 0.6803 & 0.9333 & $1.7 \%$ & $2.3 \%$ \\
\hline NEPH2-38 & 38 & $\mathrm{ThO} 2$ & 0.0569 & 0.0569 & 0.0200 & 0.0369 & 0.0369 & $184.5 \%$ & $184.5 \%$ \\
\hline NEPH2-38 & 38 & $\mathrm{TiO} 2$ & 0.0083 & 0.0088 & 0.0090 & -0.0007 & -0.0002 & $-7.3 \%$ & $-2.6 \%$ \\
\hline NEPH2-38 & 38 & $\mathrm{U} 3 \mathrm{O} 8$ & 3.2723 & 3.4502 & 3.3320 & -0.0597 & 0.1182 & $-1.8 \%$ & $3.5 \%$ \\
\hline NEPH2-38 & 38 & $\mathrm{ZnO}$ & 0.0526 & 0.0526 & 0.0510 & 0.0016 & 0.0016 & $3.1 \%$ & $3.1 \%$ \\
\hline NEPH2-38 & 38 & $\mathrm{ZrO} 2$ & 0.1192 & 0.1192 & 0.1280 & -0.0088 & -0.0088 & $-6.9 \%$ & $-6.9 \%$ \\
\hline NEPH2-38 & 38 & Sum of Oxides & 100.6847 & 100.9180 & 100.0020 & 0.6827 & 0.9160 & $0.7 \%$ & $0.9 \%$ \\
\hline NEPH2-39 & 39 & $\mathrm{Al} 2 \mathrm{O} 3$ & 13.0139 & 13.1722 & 12.8350 & 0.1789 & 0.3372 & $1.4 \%$ & $2.6 \%$ \\
\hline NEPH2-39 & 39 & $\mathrm{~B} 2 \mathrm{O} 3$ & 4.3308 & 4.4732 & 4.5600 & -0.2292 & -0.0868 & $-5.0 \%$ & $-1.9 \%$ \\
\hline NEPH2-39 & 39 & $\mathrm{BaO}$ & 0.0533 & 0.0597 & 0.0620 & -0.0087 & -0.0023 & $-14.0 \%$ & $-3.8 \%$ \\
\hline NEPH2-39 & 39 & $\mathrm{CaO}$ & 0.7755 & 0.8079 & 0.8260 & -0.0505 & -0.0181 & $-6.1 \%$ & $-2.2 \%$ \\
\hline NEPH2-39 & 39 & $\mathrm{Ce} 2 \mathrm{O} 3$ & 0.0621 & 0.0621 & 0.0830 & -0.0209 & -0.0209 & $-25.2 \%$ & $-25.2 \%$ \\
\hline NEPH2-39 & 39 & $\mathrm{Cr} 2 \mathrm{O} 3$ & 0.0870 & 0.0836 & 0.1080 & -0.0210 & -0.0244 & $-19.5 \%$ & $-22.6 \%$ \\
\hline NEPH2-39 & 39 & $\mathrm{CuO}$ & 0.0385 & 0.0402 & 0.0320 & 0.0065 & 0.0082 & $20.3 \%$ & $25.6 \%$ \\
\hline NEPH2-39 & 39 & $\mathrm{Fe} 2 \mathrm{O} 3$ & 8.4781 & 8.6740 & 9.1840 & -0.7059 & -0.5100 & $-7.7 \%$ & $-5.6 \%$ \\
\hline NEPH2-39 & 39 & $\mathrm{~K} 2 \mathrm{O}$ & 0.7390 & 0.8209 & 0.7370 & 0.0020 & 0.0839 & $0.3 \%$ & $11.4 \%$ \\
\hline NEPH2-39 & 39 & $\mathrm{La} 2 \mathrm{O} 3$ & 0.0352 & 0.0352 & 0.0350 & 0.0002 & 0.0002 & $0.5 \%$ & $0.5 \%$ \\
\hline NEPH2-39 & 39 & $\mathrm{Li} 2 \mathrm{O}$ & 4.4888 & 4.5685 & 4.5600 & -0.0712 & 0.0085 & $-1.6 \%$ & $0.2 \%$ \\
\hline NEPH2-39 & 39 & $\mathrm{MgO}$ & 0.4569 & 0.4867 & 0.4580 & -0.0011 & 0.0287 & $-0.2 \%$ & $6.3 \%$ \\
\hline NEPH2-39 & 39 & $\mathrm{MnO}$ & 1.9755 & 2.0789 & 2.0640 & -0.0885 & 0.0149 & $-4.3 \%$ & $0.7 \%$ \\
\hline NEPH2-39 & 39 & $\mathrm{Na} 2 \mathrm{O}$ & 14.4573 & 14.1579 & 14.6970 & -0.2397 & -0.5391 & $-1.6 \%$ & $-3.7 \%$ \\
\hline NEPH2-39 & 39 & $\mathrm{NiO}$ & 1.3177 & 1.3456 & 1.4980 & -0.1803 & -0.1524 & $-12.0 \%$ & $-10.2 \%$ \\
\hline NEPH2-39 & 39 & $\mathrm{PbO}$ & 0.0789 & 0.0789 & 0.0840 & -0.0051 & -0.0051 & $-6.1 \%$ & $-6.1 \%$ \\
\hline NEPH2-39 & 39 & $\mathrm{SO} 4$ & 0.3985 & 0.3985 & 0.4430 & -0.0445 & -0.0445 & $-10.1 \%$ & $-10.1 \%$ \\
\hline NEPH2-39 & 39 & $\mathrm{SiO} 2$ & 44.7649 & 45.0471 & 44.4970 & 0.2679 & 0.5501 & $0.6 \%$ & $1.2 \%$ \\
\hline NEPH2-39 & 39 & ThO2 & 0.0569 & 0.0569 & 0.0180 & 0.0389 & 0.0389 & $216.1 \%$ & $216.1 \%$ \\
\hline NEPH2-39 & 39 & $\mathrm{TiO} 2$ & 0.0083 & 0.0088 & 0.0080 & 0.0003 & 0.0008 & $4.3 \%$ & $10.1 \%$ \\
\hline NEPH2-39 & 39 & $\mathrm{U} 3 \mathrm{O} 8$ & 2.8684 & 3.0608 & 3.0490 & -0.1806 & 0.0118 & $-5.9 \%$ & $0.4 \%$ \\
\hline NEPH2-39 & 39 & $\mathrm{ZnO}$ & 0.0501 & 0.0501 & 0.0460 & 0.0041 & 0.0041 & $8.9 \%$ & $8.9 \%$ \\
\hline NEPH2-39 & 39 & $\mathrm{ZrO} 2$ & 0.1084 & 0.1084 & 0.1170 & -0.0086 & -0.0086 & $-7.3 \%$ & $-7.3 \%$ \\
\hline NEPH2-39 & 39 & Sum of Oxides & 98.6439 & 99.6760 & 100.0010 & -1.3571 & -0.3250 & $-1.4 \%$ & $-0.3 \%$ \\
\hline NEPH2-40 & 40 & $\mathrm{Al} 2 \mathrm{O} 3$ & 13.8075 & 13.7693 & 13.7300 & 0.0775 & 0.0393 & $0.6 \%$ & $0.3 \%$ \\
\hline NEPH2-40 & 40 & $\mathrm{~B} 2 \mathrm{O} 3$ & 3.9927 & 4.0661 & 4.3200 & -0.3273 & -0.2539 & $-7.6 \%$ & $-5.9 \%$ \\
\hline NEPH2-40 & 40 & $\mathrm{BaO}$ & 0.0539 & 0.0595 & 0.0660 & -0.0121 & -0.0065 & $-18.4 \%$ & $-9.9 \%$ \\
\hline NEPH2-40 & 40 & $\mathrm{CaO}$ & 0.8238 & 0.8680 & 0.8840 & -0.0602 & -0.0160 & $-6.8 \%$ & $-1.8 \%$ \\
\hline NEPH2-40 & 40 & $\mathrm{Ce} 2 \mathrm{O} 3$ & 0.0662 & 0.0662 & 0.0890 & -0.0228 & -0.0228 & $-25.6 \%$ & $-25.6 \%$ \\
\hline NEPH2-40 & 40 & $\mathrm{Cr} 2 \mathrm{O} 3$ & 0.0972 & 0.0918 & 0.1150 & -0.0178 & -0.0232 & $-15.5 \%$ & $-20.2 \%$ \\
\hline NEPH2-40 & 40 & $\mathrm{CuO}$ & 0.0388 & 0.0404 & 0.0340 & 0.0048 & 0.0064 & $14.1 \%$ & $18.9 \%$ \\
\hline NEPH2-40 & 40 & $\mathrm{Fe} 2 \mathrm{O} 3$ & 8.9070 & 9.1427 & 9.8250 & -0.9180 & -0.6823 & $-9.3 \%$ & $-6.9 \%$ \\
\hline NEPH2-40 & 40 & $\mathrm{~K} 2 \mathrm{O}$ & 0.8459 & 0.9530 & 0.7890 & 0.0569 & 0.1640 & $7.2 \%$ & $20.8 \%$ \\
\hline NEPH2-40 & 40 & $\mathrm{La} 2 \mathrm{O} 3$ & 0.0343 & 0.0343 & 0.0370 & -0.0027 & -0.0027 & $-7.3 \%$ & $-7.3 \%$ \\
\hline NEPH2-40 & 40 & $\mathrm{Li} 2 \mathrm{O}$ & 4.1605 & 4.2025 & 4.3200 & -0.1595 & -0.1175 & $-3.7 \%$ & $-2.7 \%$ \\
\hline NEPH2-40 & 40 & $\mathrm{MgO}$ & 0.4722 & 0.4979 & 0.4900 & -0.0178 & 0.0079 & $-3.6 \%$ & $1.6 \%$ \\
\hline NEPH2-40 & 40 & $\mathrm{MnO}$ & 2.1466 & 2.1848 & 2.2080 & -0.0614 & -0.0232 & $-2.8 \%$ & $-1.0 \%$ \\
\hline NEPH2-40 & 40 & $\mathrm{Na} 2 \mathrm{O}$ & 15.4683 & 14.6712 & 15.1640 & 0.3043 & -0.4928 & $2.0 \%$ & $-3.2 \%$ \\
\hline NEPH2-40 & 40 & $\mathrm{NiO}$ & 1.3902 & 1.4564 & 1.6020 & -0.2118 & -0.1456 & $-13.2 \%$ & $-9.1 \%$ \\
\hline NEPH2-40 & 40 & $\mathrm{PbO}$ & 0.0803 & 0.0803 & 0.0900 & -0.0097 & -0.0097 & $-10.8 \%$ & $-10.8 \%$ \\
\hline NEPH2-40 & 40 & $\mathrm{SO} 4$ & 0.4292 & 0.4292 & 0.4740 & -0.0448 & -0.0448 & $-9.5 \%$ & $-9.5 \%$ \\
\hline NEPH2-40 & 40 & $\mathrm{SiO} 2$ & 42.1977 & 42.4538 & 42.2990 & -0.1013 & 0.1548 & $-0.2 \%$ & $0.4 \%$ \\
\hline NEPH2-40 & 40 & ThO2 & 0.0569 & 0.0569 & 0.0190 & 0.0379 & 0.0379 & $199.4 \%$ & $199.4 \%$ \\
\hline NEPH2-40 & 40 & $\mathrm{TiO} 2$ & 0.0083 & 0.0088 & 0.0090 & -0.0007 & -0.0002 & $-7.3 \%$ & $-2.6 \%$ \\
\hline NEPH2-40 & 40 & U3O8 & 3.1131 & 3.2828 & 3.2610 & -0.1479 & 0.0218 & $-4.5 \%$ & $0.7 \%$ \\
\hline NEPH2-40 & 40 & $\mathrm{ZnO}$ & 0.0532 & 0.0532 & 0.0500 & 0.0032 & 0.0032 & $6.4 \%$ & $6.4 \%$ \\
\hline NEPH2-40 & 40 & $\mathrm{ZrO} 2$ & 0.1152 & 0.1152 & 0.1260 & -0.0108 & -0.0108 & $-8.6 \%$ & $-8.6 \%$ \\
\hline NEPH2-40 & 40 & Sum of Oxides & 98.3589 & 98.5842 & 100.0010 & -1.6421 & -1.4168 & $-1.6 \%$ & $-1.4 \%$ \\
\hline
\end{tabular}


Table C4. Average Measured and Bias-Corrected Chemical Compositions Versus Targeted Compositions by Oxide by Nepheline Study Glass

(100 -Batch 1; $200-U$ std)

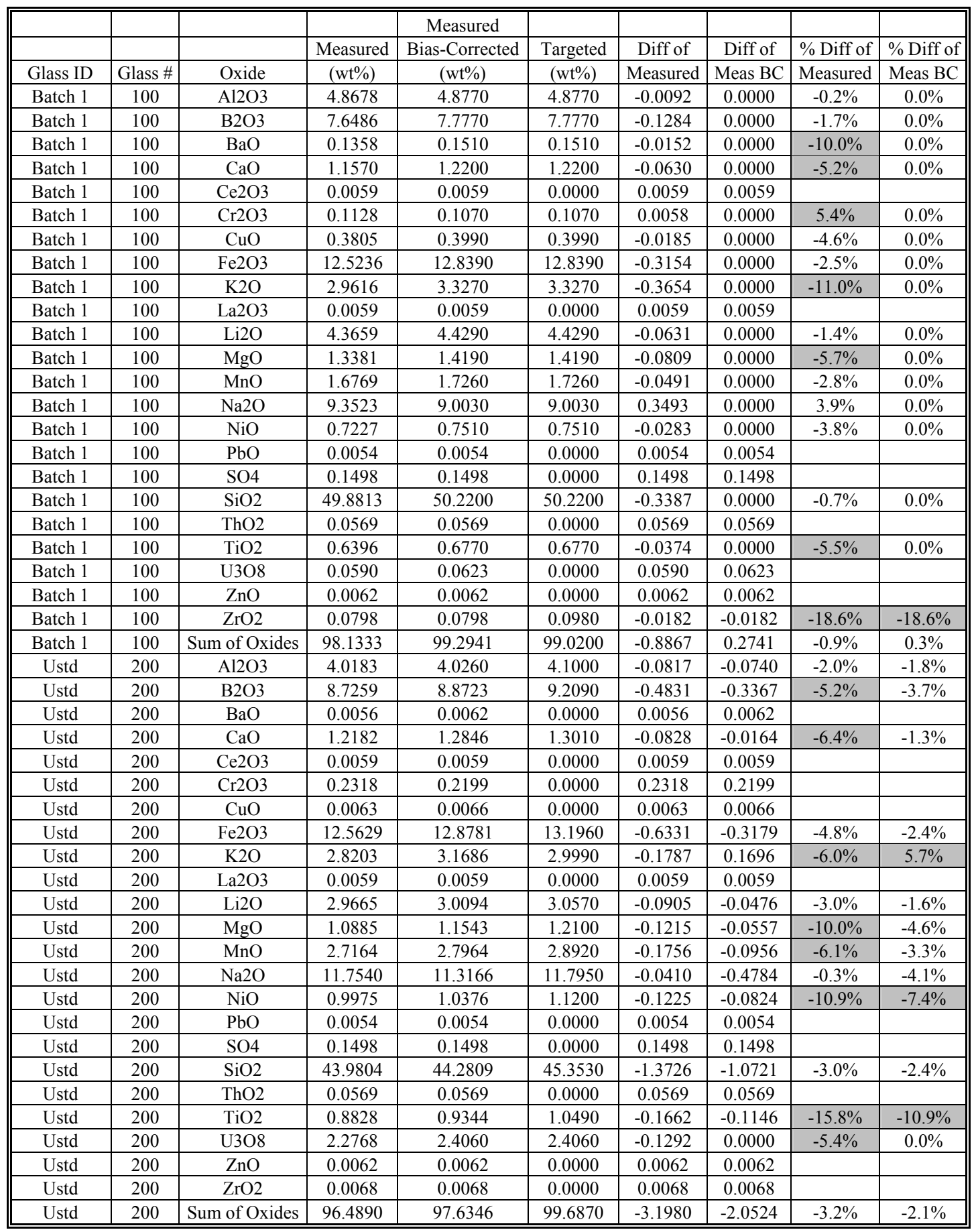


Table C5. Summary of PSAL Elemental Data for Neph2-21, Neph2-27, and Neph2-28 Remeasurements Sample Preparation: $\mathrm{LiBO}_{2}$ and $\mathrm{Na}_{2} \mathrm{O}_{2} / \mathrm{NaOH}$ fusions

\begin{tabular}{|c|c|c|c|c|c|c|}
\hline$(w t \%)$ & $\frac{\text { Neph2-21 }}{\frac{\text { (A) }}{05-1249}}$ & $\frac{\text { Neph2-21 }}{\stackrel{(B)}{05-1249}}$ & $\frac{\text { Neph2-27 }}{\frac{(A)}{05-1250}}$ & $\frac{\text { Neph2-27 }}{\stackrel{(B)}{05-1250}}$ & $\frac{\text { Neph2-28 }}{\frac{(\mathrm{A})}{05-1251}}$ & $\frac{\text { Neph2-28 }}{\frac{(B)}{05-1251}}$ \\
\hline Al & 5.71 & 5.87 & 6.71 & 6.85 & 6.38 & 6.40 \\
\hline$B$ & 1.55 & 1.55 & 1.47 & 1.49 & 1.65 & 1.65 \\
\hline$B a$ & 0.043 & 0.043 & 0.045 & 0.047 & 0.040 & 0.041 \\
\hline$C a$ & 0.694 & 0.625 & 0.613 & 0.653 & 0.585 & 0.619 \\
\hline $\mathrm{Cr}$ & 0.071 & 0.069 & 0.069 & 0.068 & 0.078 & 0.079 \\
\hline $\mathrm{Cu}$ & 0.027 & 0.027 & 0.028 & 0.028 & 0.031 & 0.028 \\
\hline Ce & 0.047 & 0.047 & 0.038 & 0.038 & 0.045 & 0.046 \\
\hline Fe & 6.78 & 6.75 & 5.95 & 6.08 & 6.92 & 6.79 \\
\hline$K$ & 0.583 & 0.572 & 0.692 & 0.662 & 0.636 & 0.661 \\
\hline $\mathrm{Li}$ & 2.08 & 2.14 & 2.17 & 2.19 & 2.11 & 2.11 \\
\hline$M n$ & 1.64 & 1.64 & 1.66 & 1.72 & 1.53 & 1.50 \\
\hline$M g$ & 0.336 & 0.334 & 0.251 & 0.266 & 0.237 & 0.240 \\
\hline $\mathrm{Na}$ & 11.8 & 11.6 & 11.9 & 12.2 & 11.1 & 11.1 \\
\hline $\mathrm{Ni}$ & 0.973 & 0.966 & 1.00 & 1.02 & 1.16 & 1.13 \\
\hline$P b$ & 0.057 & 0.06 & 0.058 & 0.059 & 0.067 & 0.068 \\
\hline$S$ & 0.168 & 0.15 & 0.156 & 0.149 & 0.158 & 0.170 \\
\hline Si & 20.9 & 21.0 & 20.8 & 21.0 & 19.7 & 20 \\
\hline Th & $<0.100$ & $<0.100$ & $<0.100$ & $<0.100$ & $<0.100$ & $<0.100$ \\
\hline$T \mathbf{T}$ & $<0.010$ & $<0.010$ & $<0.010$ & $<0.010$ & $<0.010$ & $<0.010$ \\
\hline$U$ & 2.54 & 2.6 & 2.26 & 2.33 & 2.78 & 2.77 \\
\hline $\mathrm{Zn}$ & $<0.010$ & $<0.010$ & 0.035 & 0.035 & 0.036 & 0.043 \\
\hline $\mathrm{Zr}$ & 0.075 & 0.074 & 0.077 & 0.079 & 0.076 & 0.075 \\
\hline
\end{tabular}


Table C6. Comparison of Target Versus Measured for Neph2-21, Neph2-27, and Neph2-28 Remeasurements

\begin{tabular}{|c|c|c|c|c|c|c|c|c|c|c|c|c|}
\hline Oxide & Glass & $\begin{array}{c}\text { Original } \\
\text { Measurement }\end{array}$ & Target & $\begin{array}{c}\text { Re- } \\
\text { Measurement }\end{array}$ & Glass & $\begin{array}{c}\text { Original } \\
\text { Measurement }\end{array}$ & Target & $\begin{array}{c}\text { Re- } \\
\text { Measurement }\end{array}$ & Glass & $\begin{array}{c}\text { Original } \\
\text { Measurement }\end{array}$ & Target & $\begin{array}{c}\text { Re- } \\
\text { Measurement } \\
\end{array}$ \\
\hline $\mathrm{Al} 2 \mathrm{O} 3(\mathrm{wt} \%)$ & 21 & 10.298 & 10.995 & 10.94 & 27 & 13.165 & 11.641 & 12.811 & 28 & 11.772 & 13.133 & 12.074 \\
\hline $\mathrm{B} 2 \mathrm{O} 3(\mathrm{wt} \%)$ & 21 & 4.105 & 4.64 & 4.991 & 27 & 4.057 & 4.88 & 4.765 & 28 & 4.484 & 4.48 & 5.313 \\
\hline $\mathrm{BaO}(\mathrm{wt} \%)$ & 21 & 0.045 & 0.057 & 0.048 & 27 & 0.05 & 0.056 & 0.051 & 28 & 0.046 & 0.063 & 0.045 \\
\hline $\mathrm{CaO}(\mathrm{wt} \%)$ & 21 & 0.767 & 0.836 & 0.923 & 27 & 0.786 & 0.749 & 0.886 & 28 & 0.738 & 0.845 & 0.842 \\
\hline $\mathrm{Ce} 2 \mathrm{O} 3(\mathrm{wt} \%)$ & 21 & 0.06 & 0.078 & 0.082 & 27 & 0.05 & 0.075 & 0.08 & 28 & 0.058 & 0.085 & 0.092 \\
\hline $\mathrm{Cr} 2 \mathrm{O} 3(\mathrm{wt} \%)$ & 21 & 0.101 & 0.098 & 0.039 & 27 & 0.094 & 0.098 & 0.041 & 28 & 0.104 & 0.11 & 0.043 \\
\hline $\mathrm{CuO}(\mathrm{wt} \%)$ & 21 & 0.037 & 0.031 & 0.059 & 27 & 0.038 & 0.029 & 0.048 & 28 & 0.037 & 0.033 & 0.057 \\
\hline $\mathrm{Fe} 2 \mathrm{O} 3(\mathrm{wt} \%)$ & 21 & 8.382 & 9.313 & 9.672 & 27 & 7.728 & 8.33 & 8.6 & 28 & 8.782 & 9.398 & 9.801 \\
\hline $\mathrm{K} 2 \mathrm{O}(\mathrm{wt} \%)$ & 21 & 0.651 & 0.587 & 0.696 & 27 & 0.779 & 0.669 & 0.816 & 28 & 0.695 & 0.755 & 0.781 \\
\hline $\mathrm{La} 2 \mathrm{O} 3(\mathrm{wt} \%)$ & 21 & 0.034 & 0.034 & 0 & 27 & 0.032 & 0.032 & 0 & 28 & 0.03 & 0.036 & 0 \\
\hline $\mathrm{Li} 2 \mathrm{O}(\mathrm{wt} \%)$ & 21 & 4.134 & 4.64 & 4.543 & 27 & 4.709 & 4.88 & 4.693 & 28 & 4.343 & 4.48 & 4.543 \\
\hline $\mathrm{MgO}(\mathrm{wt} \%)$ & 21 & 0.561 & 0.59 & 0.556 & 27 & 0.456 & 0.415 & 0.429 & 28 & 0.415 & 0.468 & 0.396 \\
\hline $\mathrm{MnO}(\mathrm{wt} \%)$ & 21 & 1.992 & 2.047 & 2.118 & 27 & 1.998 & 1.872 & 2.182 & 28 & 1.798 & 2.112 & 1.956 \\
\hline $\mathrm{Na} 2 \mathrm{O}(\mathrm{wt} \%)$ & 21 & 15.873 & 16.393 & 15.772 & 27 & 16.041 & 16.514 & 16.243 & 28 & 15.94 & 17.093 & 14.963 \\
\hline $\mathrm{NiO}(w t \%)$ & 21 & 1.109 & 1.284 & 1.234 & 27 & 1.206 & 1.358 & 1.285 & 28 & 1.377 & 1.532 & 1.457 \\
\hline $\mathrm{PbO}(\mathrm{wt} \%)$ & 21 & 0.065 & 0.074 & 0.063 & 27 & 0.062 & 0.076 & 0.063 & 28 & 0.082 & 0.086 & 0.073 \\
\hline $\mathrm{SO} 4(\mathrm{wt} \%)$ & 21 & 0.471 & 0.449 & 0.476 & 27 & 0.433 & 0.402 & 0.457 & 28 & 0.389 & 0.453 & 0.491 \\
\hline $\mathrm{SiO} 2(\mathrm{wt} \%)$ & 21 & 43.642 & 44.624 & 44.818 & 27 & 44.444 & 44.987 & 44.711 & 28 & 41.235 & 41.524 & 42.465 \\
\hline $\mathrm{ThO} 2(\mathrm{wt} \%)$ & 21 & 0.057 & 0.016 & 0.057 & 27 & 0.057 & 0.016 & 0.057 & 28 & 0.057 & 0.018 & 0.057 \\
\hline $\mathrm{TiO} 2(\mathrm{wt} \%)$ & 21 & 0.008 & 0.008 & 0.008 & 27 & 0.008 & 0.007 & 0.008 & 28 & 0.008 & 0.008 & 0.008 \\
\hline U3O8 (wt $\%)$ & 21 & 2.724 & 3.054 & 3.031 & 27 & 2.553 & 2.765 & 2.706 & 28 & 2.963 & 3.12 & 3.272 \\
\hline $\mathrm{ZnO}(\mathrm{wt} \%)$ & 21 & 0.014 & 0.045 & 0.006 & 27 & 0.049 & 0.042 & 0.044 & 28 & 0.048 & 0.048 & 0.049 \\
\hline $\mathrm{ZrO} 2(\mathrm{wt} \%)$ & 21 & 0.096 & 0.107 & 0.101 & 27 & 0.106 & 0.107 & 0.105 & 28 & 0.101 & 0.12 & 0.102 \\
\hline SUM & 21 & 95.225 & 100 & 100.231 & 27 & 98.9 & 100 & 101.082 & 28 & 95.503 & 100 & 98.88 \\
\hline
\end{tabular}




\section{Exhibit C1. Oxide Measurements in Analytical Sequence for Samples Prepared Using the LM Method}
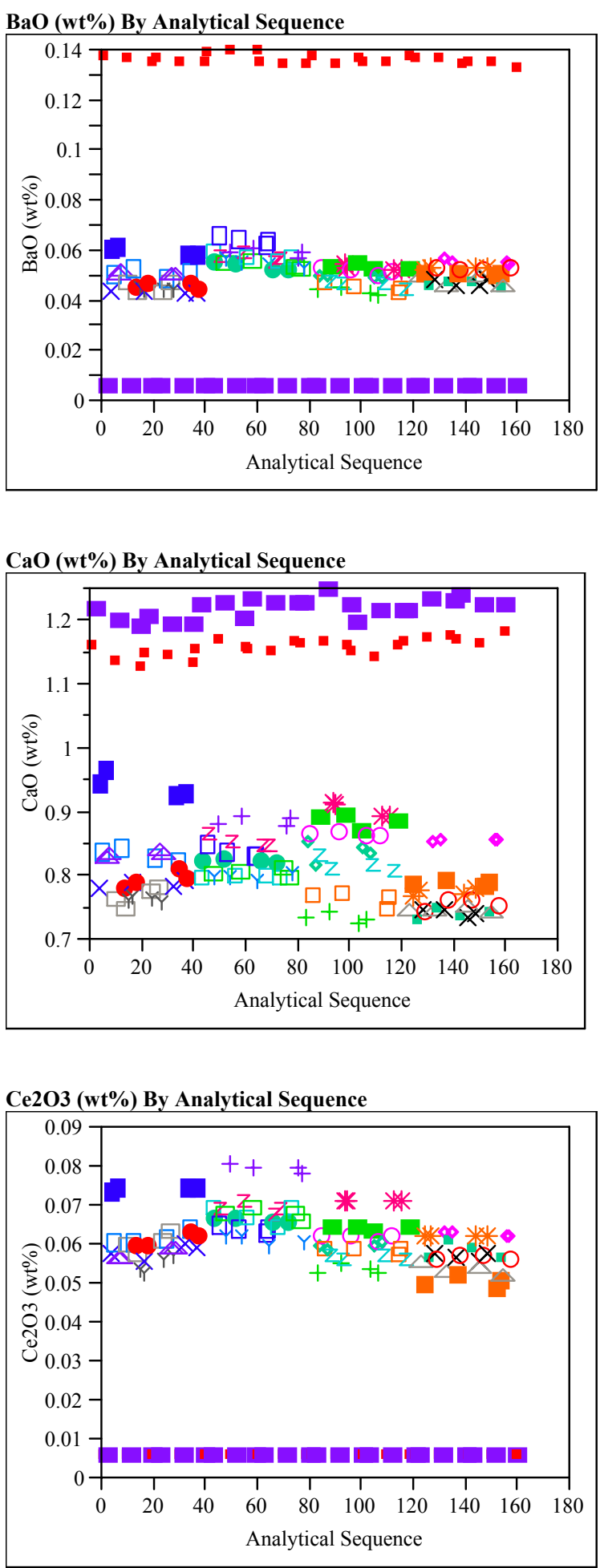

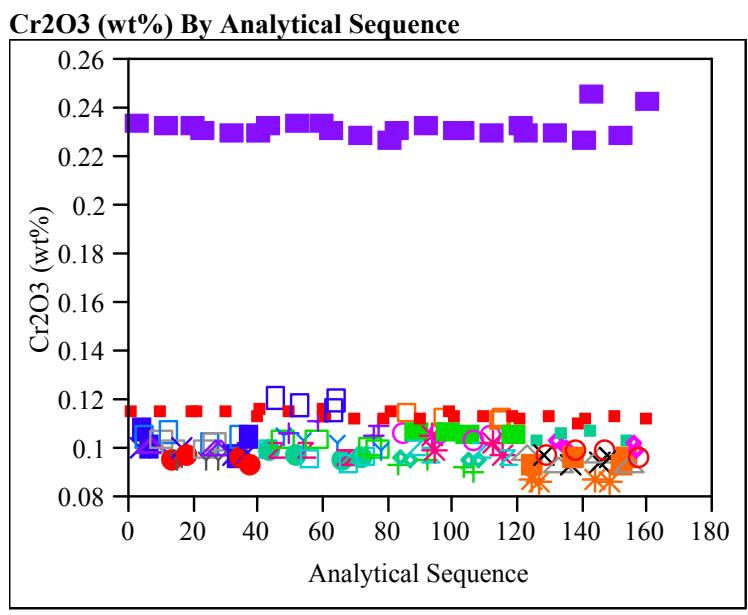

$\mathrm{CuO}(\mathrm{wt} \%)$ By Analytical Sequence
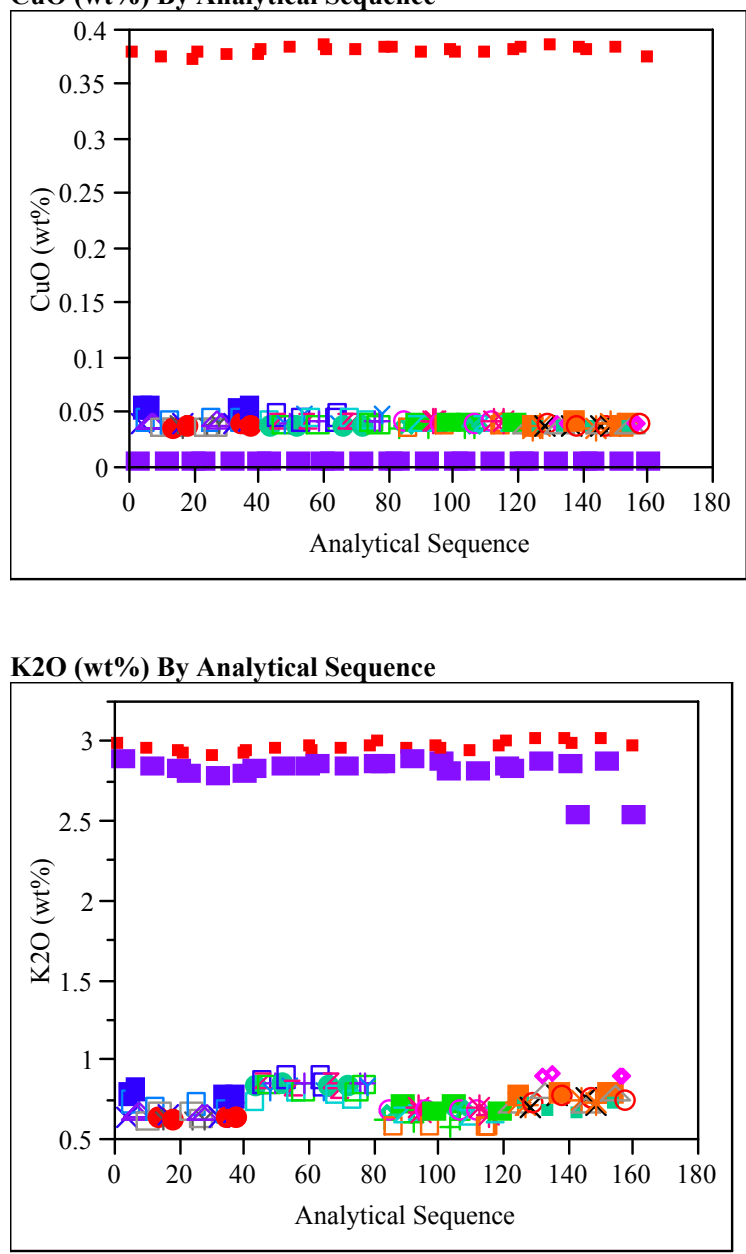


\section{Exhibit C1. Oxide Measurements in Analytical Sequence for Samples Prepared Using the LM Method}
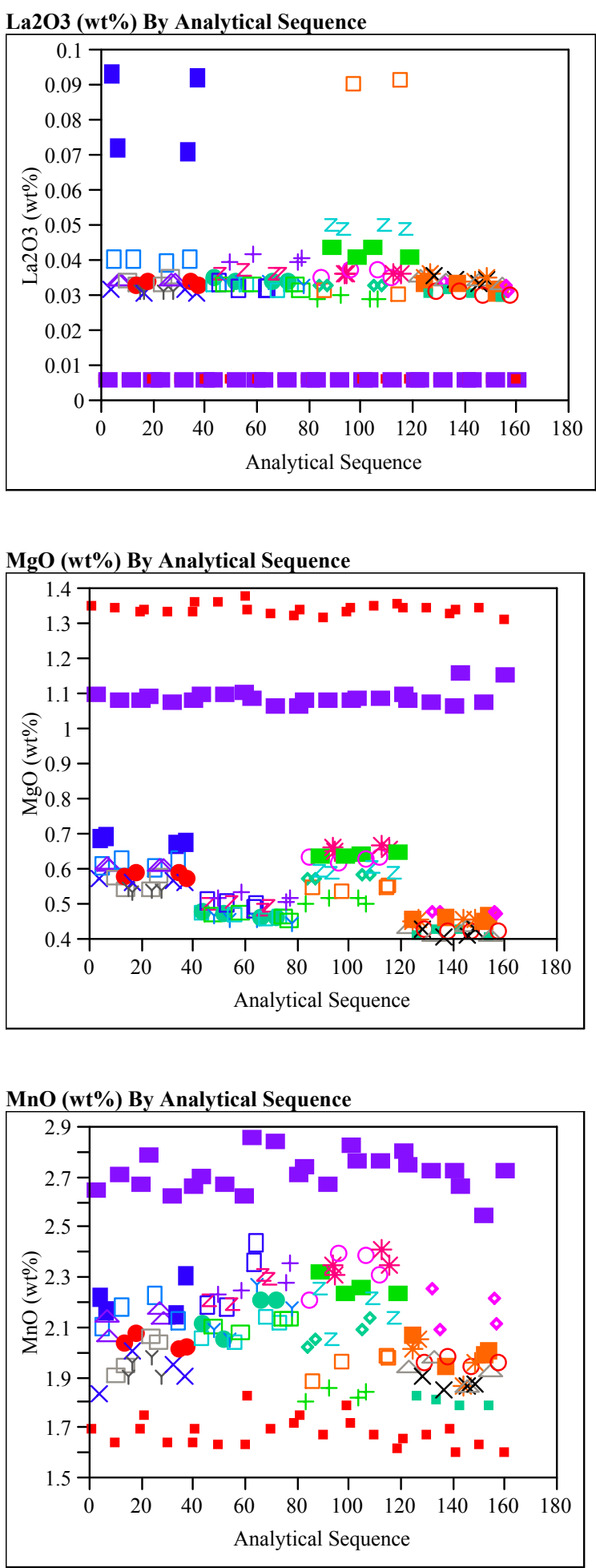

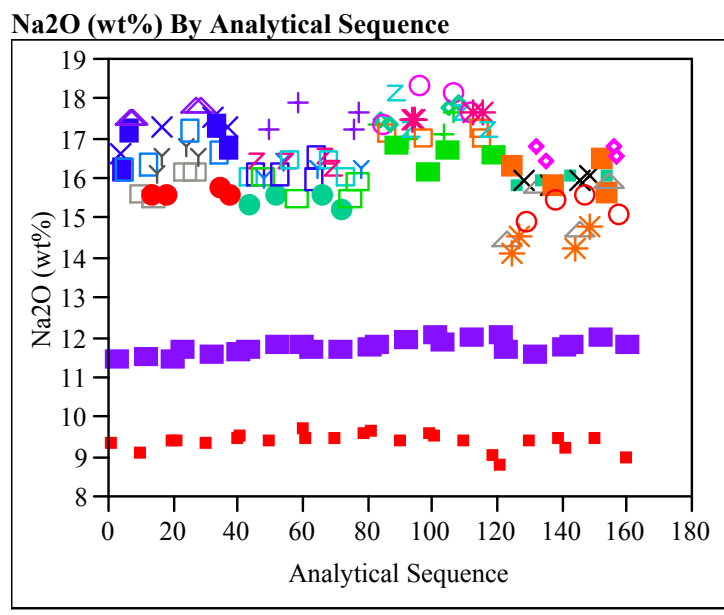

PbO (wt\%) By Analytical Sequence
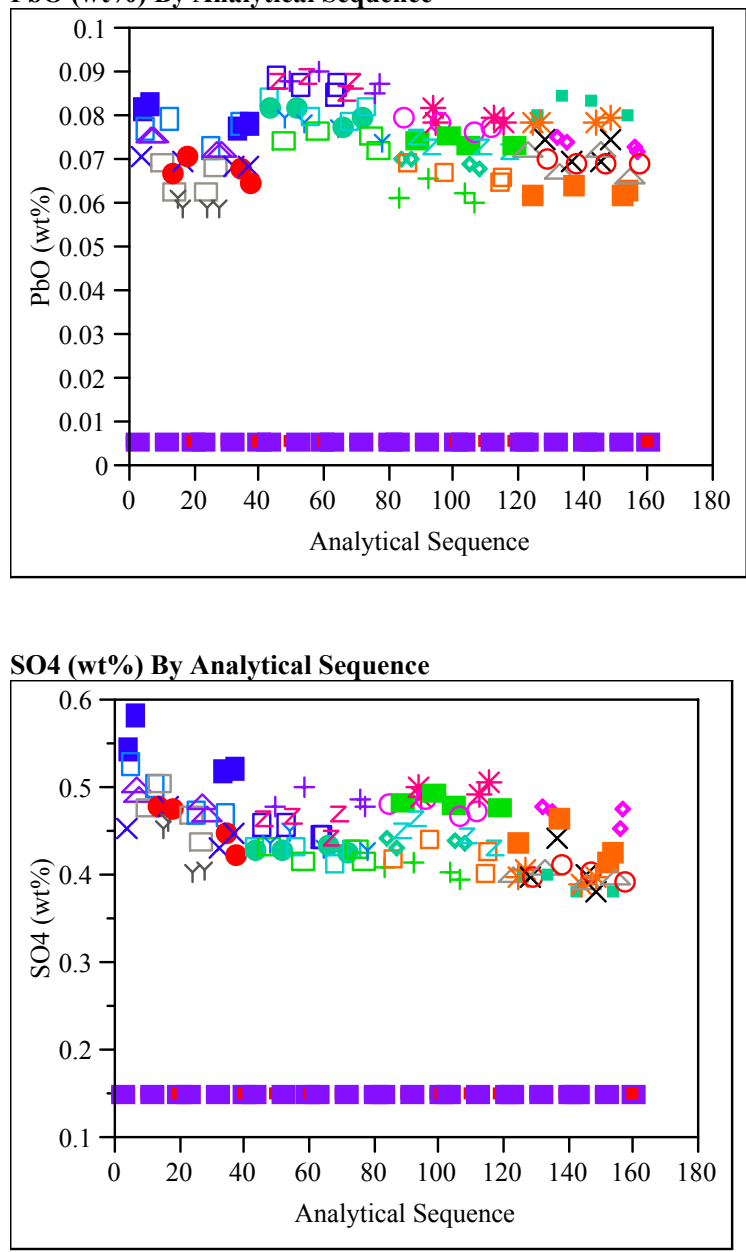


\section{Exhibit C1. Oxide Measurements in Analytical Sequence for Samples Prepared Using the LM Method}

ThO2 (wt\%) By Analytical Sequence

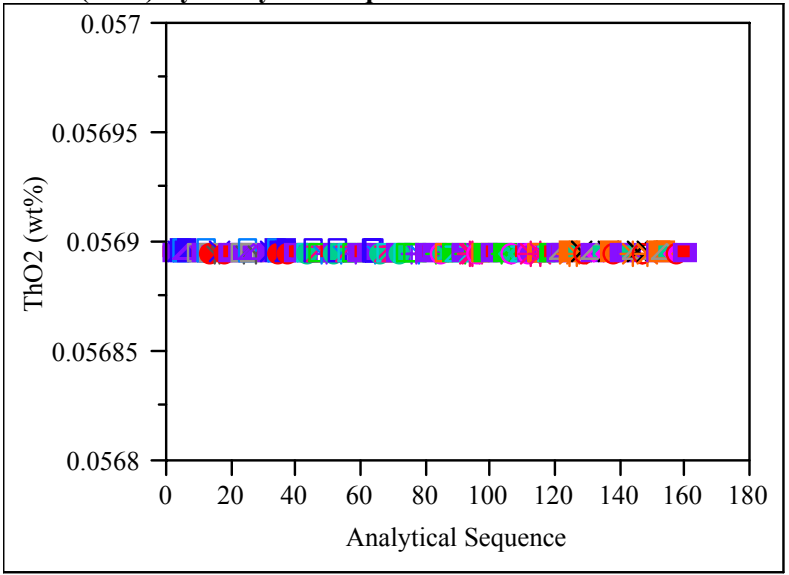

TiO2 (wt\%) By Analytical Sequence

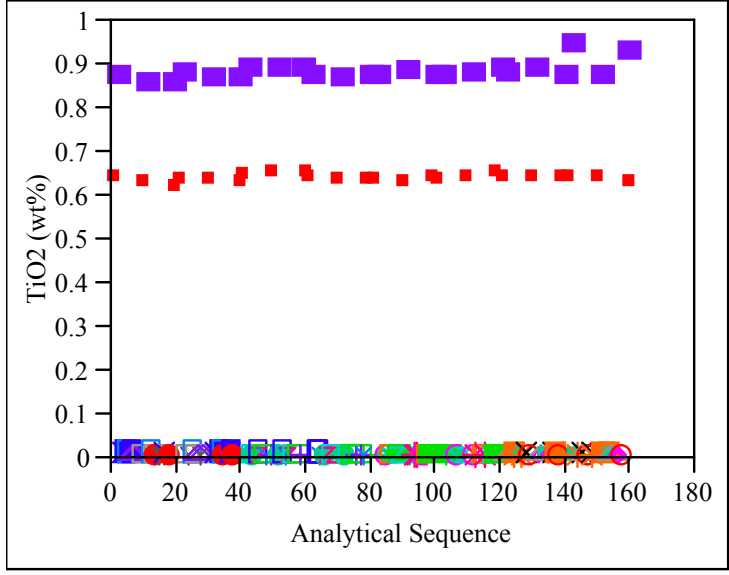

ZnO (wt\%) By Analytical Sequence

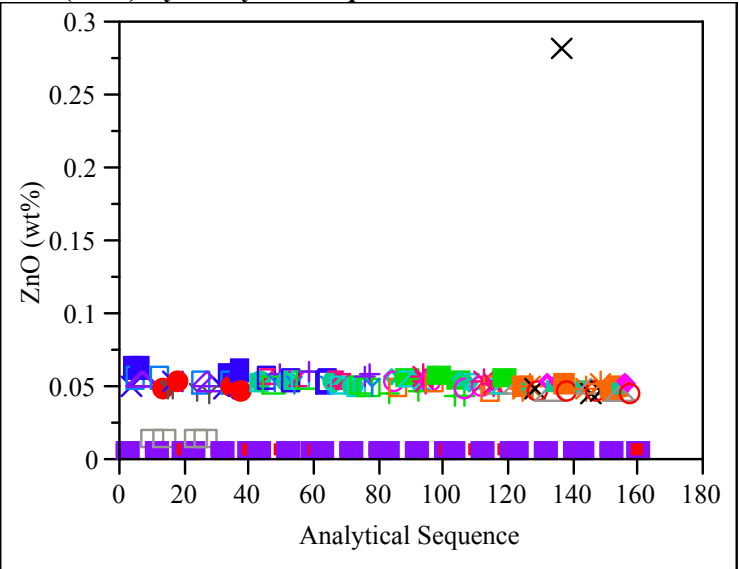

ZrO2 (wt\%) By Analytical Sequence

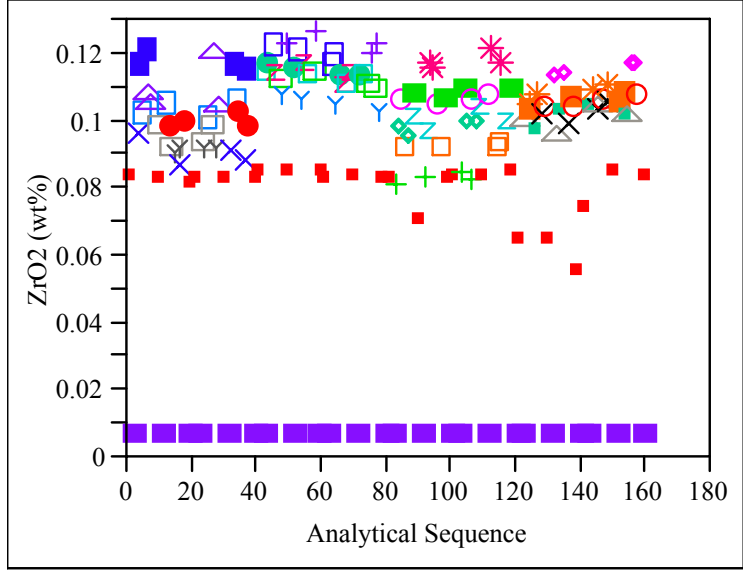




\section{Exhibit C2. Oxide Measurements in Analytical Sequence for Samples Prepared Using the PF Method}

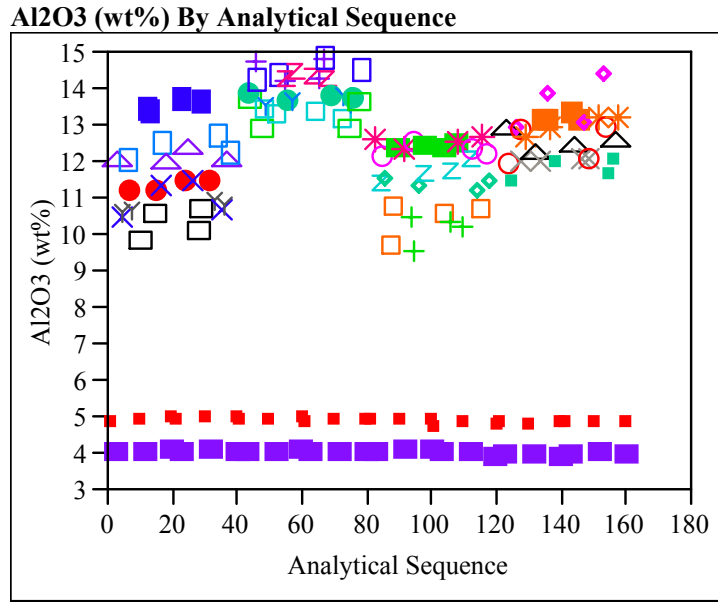

B2O3 (wt\%) By Analytical Sequence

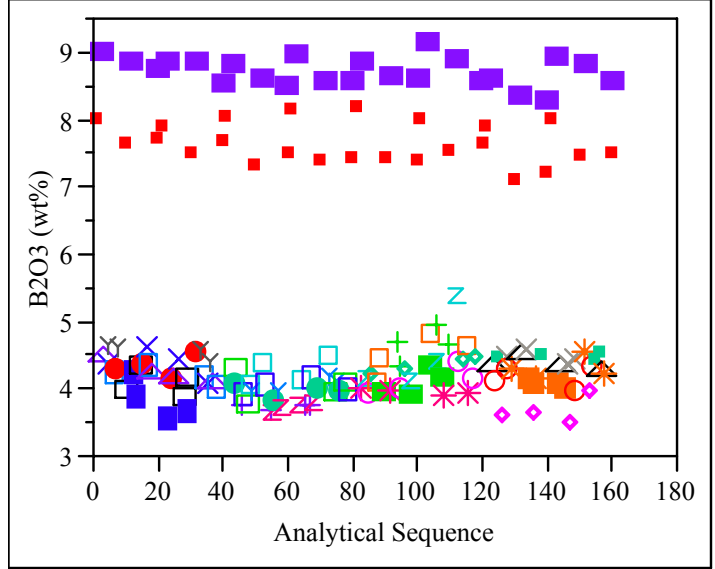

Fe2O3 (wt\%) By Analytical Sequence

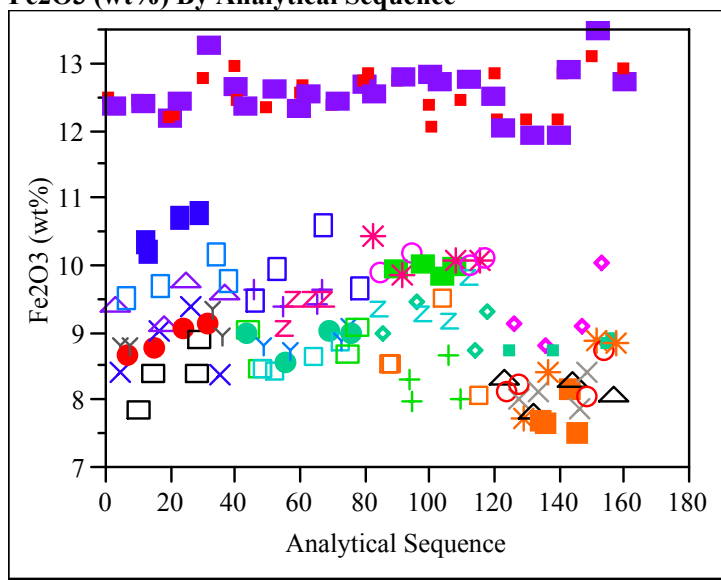

Li2O (wt\%) By Analytical Sequence
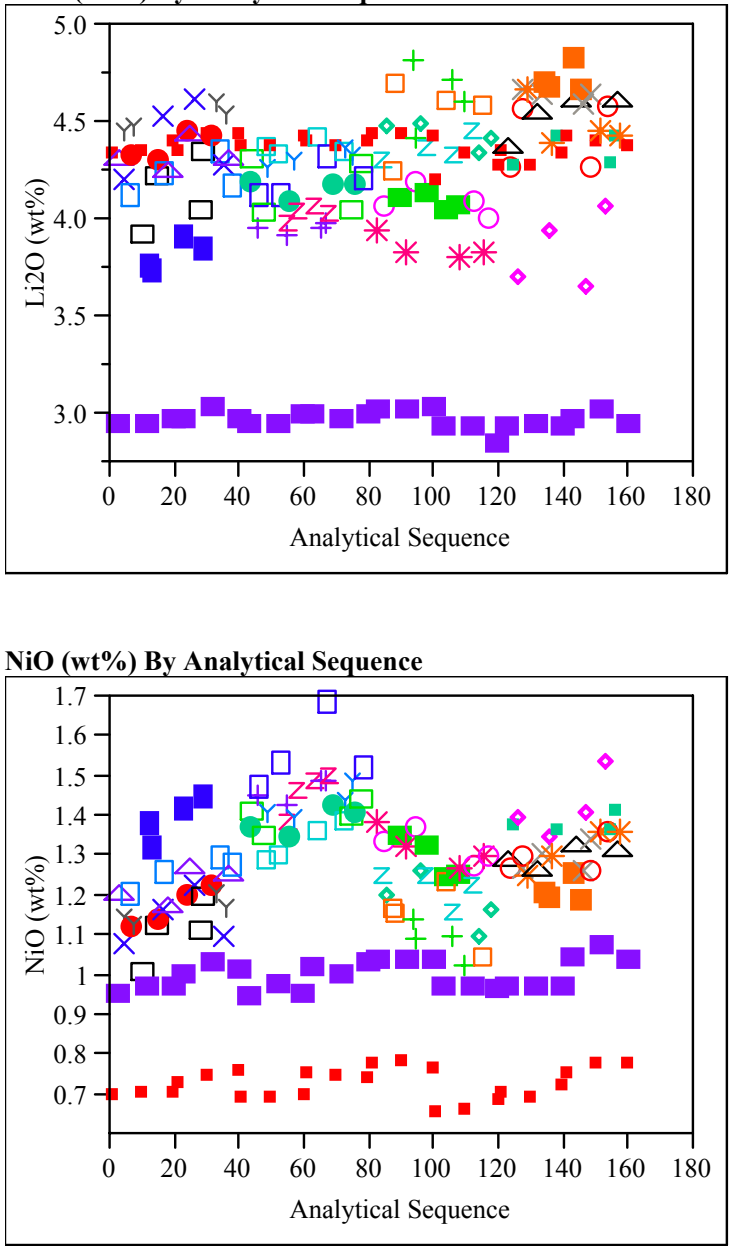

$\mathrm{SiO2}(\mathrm{wt} \%)$ By Analytical Sequence

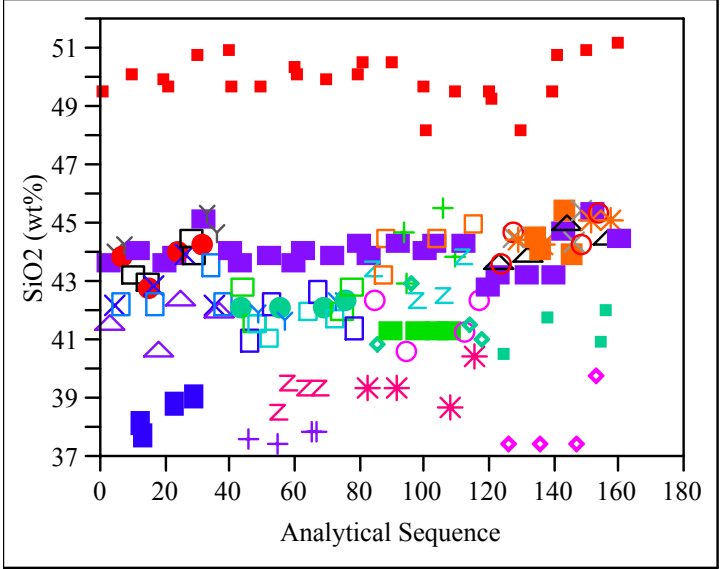


Exhibit C2. Oxide Measurements in Analytical Sequence for Samples Prepared Using the PF Method

U3O8 (wt\%) By Analytical Sequence

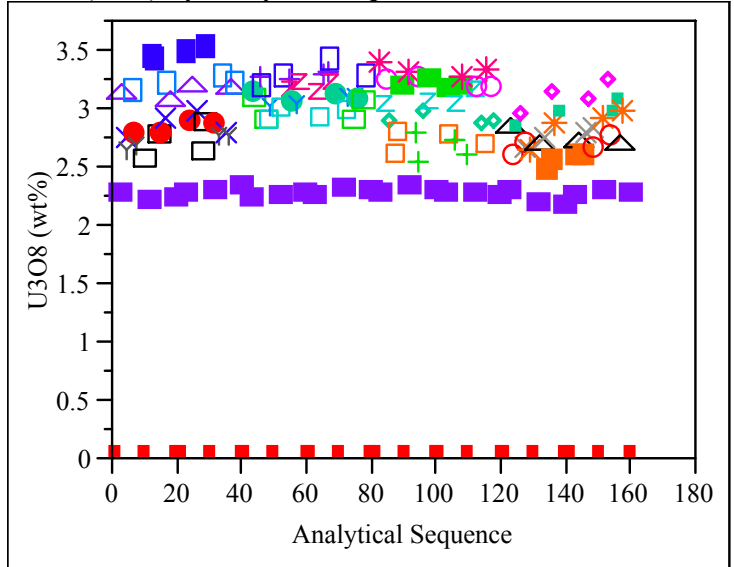




\section{Exhibit C3. PSAL Measurements by Analytical Block for Samples of the} Standard Glasses Prepared Using the LM Method

Glass ID=Batch 1

Oneway Analysis of BaO (wt\%) By Block/Sub-Block Reference value $0.151 \mathrm{wt} \%$

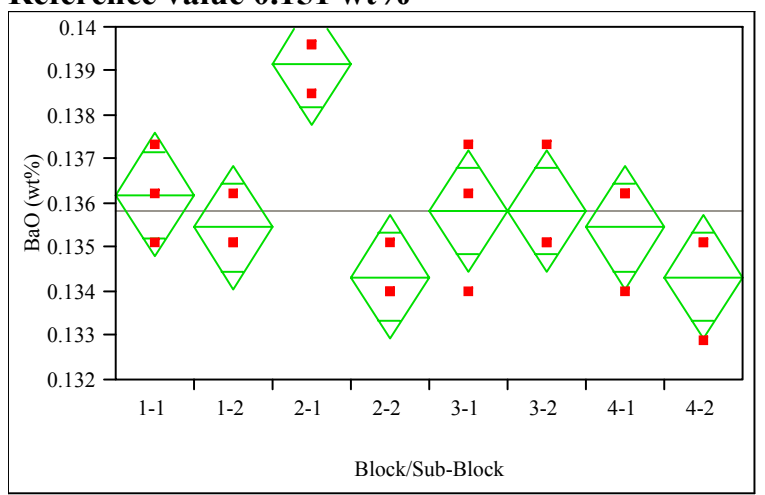

Oneway Anova

Summary of Fit

Rsquare

$\begin{array}{lr}\text { Adj Rsquare } & 0.567018 \\ \text { Root Mean Square Error } & 0.00114\end{array}$

Mean of Response 0.135841

Analysis of Variance

Source DF Sum of Squares Mean Square F Ratio Prob $>$ F

$\begin{array}{lrrrrr}\text { Block/Sub-Block } & 7 & 0.00004820 & 0.0000069 & 5.3029 & 0.0028\end{array}$

Error

0.00002078 0.0000013

\section{Means for Oneway Anova}

Level Number Mean Std Error Lower 95\% Upper 95\%

$\begin{array}{llllll}1-1 & 3 & 0.136213 & 0.00066 & 0.13482 & 0.13761 \\ 1-2 & 3 & 0.135469 & 0.00066 & 0.13407 & 0.13686 \\ 2-1 & 3 & 0.139190 & 0.00066 & 0.13780 & 0.14059 \\ 2-2 & 3 & 0.134352 & 0.00066 & 0.13296 & 0.13575 \\ 3-1 & 3 & 0.135841 & 0.00066 & 0.13445 & 0.13724 \\ 3-2 & 3 & 0.135841 & 0.00066 & 0.13445 & 0.13724 \\ 4-1 & 3 & 0.135469 & 0.00066 & 0.13407 & 0.13686 \\ 4-2 & 3 & 0.134352 & 0.00066 & 0.13296 & 0.13575\end{array}$

Std Error uses a pooled estimate of error variance
Oneway Analysis of CaO (wt\%) By Block/Sub-Block Reference value $1.220 \mathrm{wt} \%$

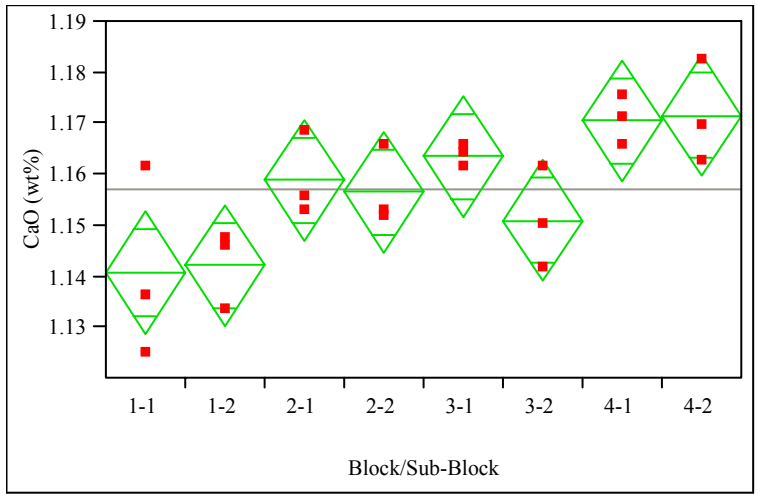

Oneway Anova

Summary of Fit

$\begin{array}{lr}\text { Rsquare } & 0.656392 \\ \text { Adj Rsquare } & 0.506063 \\ \text { Root Mean Square Error } & 0.009728 \\ \text { Mean of Response } & 1.156963 \\ \text { Observations (or Sum Wgts) } & 24\end{array}$

Observations (or Sum Wgts)

Analysis of Variance

Source DF Sum of Squares Mean Square F Ratio Prob > F $\begin{array}{llllll}\text { Block/Sub-Block } \quad 7 & 0.00289218 & 0.000413 & 4.3664 & 0.0070\end{array}$ $\begin{array}{llll}\text { Error } & 16 & 0.00151400 & 0.000095\end{array}$

C. Total $\quad 23 \quad 0.00440619$

Means for Oneway Anova

Level Number Mean Std Error Lower 95\% Upper 95\%

$\begin{array}{lllllr}1-1 & 3 & 1.14081 & 0.00562 & 1.1289 & 1.1527\end{array}$

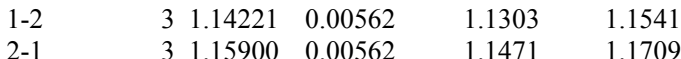

$\begin{array}{llllll}2-1 & 3 & 1.15967 & 0.00562 & 1.1471 & 1.1709 \\ 2-2 & 3 & 1.15667 & 0.00562 & 1.1448 & 1.1686\end{array}$

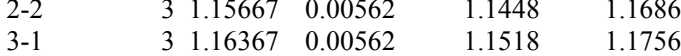

$\begin{array}{llllll}3-2 & 3 & 1.15108 & 0.00562 & 1.1392 & 1.1630\end{array}$

$\begin{array}{llllll}4-1 & 3 & 1.17066 & 0.00562 & 1.1588 & 1.1826\end{array}$

Std Error uses a pooled estimate of error variance 


\section{Exhibit C3. PSAL Measurements by Analytical Block for Samples of the} Standard Glasses Prepared Using the LM Method

Oneway Analysis of Ce2O3 (wt\%) By Block/Sub-Block Reference value 0 wt\%

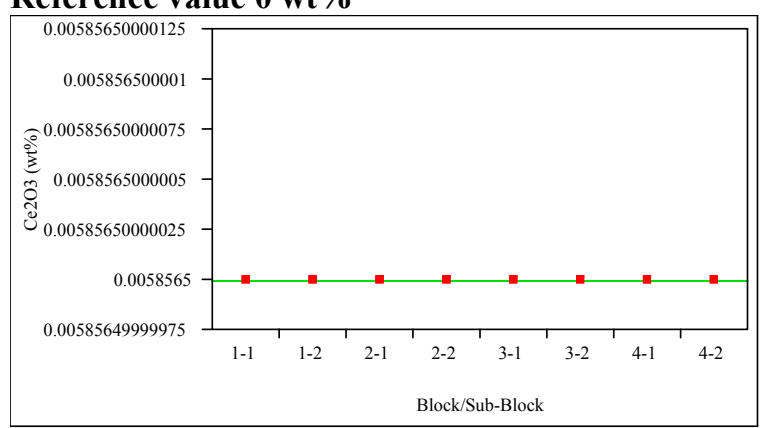

Oneway Anova

Summary of Fit

Rsquare

Adj Rsquare

Root Mean Square Error

Mean of Response

0.005857

Observations (or Sum Wgts)

Analysis of Variance

Source

DF Sum of Squares Mean Square F Ratio Prob $>$ F

Block/Sub-Block 7

Error

16
23

0

0

Means for Oneway Anova

$\begin{array}{lrrrrr}\text { Level Number } & \text { Mean } & \text { Std Error } & \text { Lower 95\% } & \text { Upper 95\% } \\ 1-1 & 3 & 0.005857 & 0 & 0.00586 & 0.00586 \\ 1-2 & 3 & 0.005857 & 0 & 0.00586 & 0.00586 \\ 2-1 & 3 & 0.005857 & 0 & 0.00586 & 0.00586 \\ 2-2 & 3 & 0.005857 & 0 & 0.00586 & 0.00586 \\ 3-1 & 3 & 0.005857 & 0 & 0.00586 & 0.00586 \\ 3-2 & 3 & 0.005857 & 0 & 0.00586 & 0.00586 \\ 4-1 & 3 & 0.005857 & 0 & 0.00586 & 0.00586 \\ 4-2 & 3 & 0.005857 & 0 & 0.00586 & 0.00586\end{array}$

Std Error uses a pooled estimate of error variance
Oneway Analysis of $\mathrm{Cr} 2 \mathrm{O3}$ (wt\%) By Block/Sub-Block

Reference value $0.107 \mathrm{wt} \%$

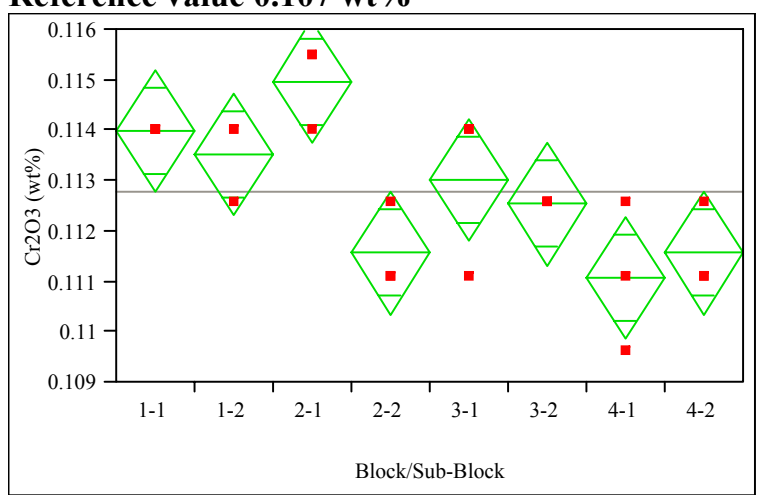

Oneway Anova

Summary of Fit

$\begin{array}{lr}\text { Rsquare } & 0.710526 \\ \text { Adj Rsquare } & 0.583882 \\ \text { Root Mean Square Error } & 0.00099 \\ \text { Mean of Response } & 0.112787 \\ \text { Observations (or Sum Wgts) } & 24 \\ \text { Analysis of Variance } & \end{array}$

Analysis of Variance

Source DF Sum of Squares Mean Square F Ratio Prob > F

$\begin{array}{llllll}\text { Block/Sub-Block } \quad 7 & 0.00003845 & 0.0000055 & 5.6104 & 0.0021\end{array}$

$\begin{array}{llll}\text { Error } & 16 & 0.00001567 & 9.7913 \mathrm{e}-7\end{array}$

$\begin{array}{lll}\text { C. Total } & 23 & 0.00005412\end{array}$

Means for Oneway Anova

Level Number Mean Std Error Lower 95\% Upper 95\%

$\begin{array}{llllll}1-1 & 3 & 0.114005 & 0.00057 & 0.11279 & 0.11522\end{array}$

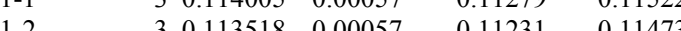

$\begin{array}{llllll}1-2 & 3 & 0.113518 & 0.00057 & 0.11231 & 0.11473 \\ 2-1 & 3 & 0.114979 & 0.00057 & 0.11377 & 0.11619\end{array}$

$\begin{array}{lllllll}2-2 & 3 & 0.111569 & 0.00057 & 0.11036 & 0.11278 \\ 3-1 & & 3 & 0.113030 & 0.00057 & 0.11182 & 0.11424\end{array}$

$\begin{array}{llllll}3-1 & 3 & 0.113030 & 0.00057 & 0.11182 & 0.11424\end{array}$

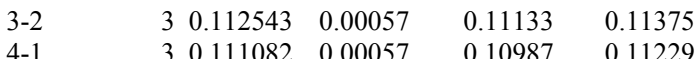

$\begin{array}{lllll}4-1 & 3 & 0.111082 & 0.00057 & 0.10987\end{array}$

Std Error uses a pooled estimate of error variance 


\section{Exhibit C3. PSAL Measurements by Analytical Block for Samples of the Standard Glasses Prepared Using the LM Method}

Oneway Analysis of $\mathrm{CuO}(w \mathrm{t} \%)$ By Block/Sub-Block

Reference value 0.399 wt\%

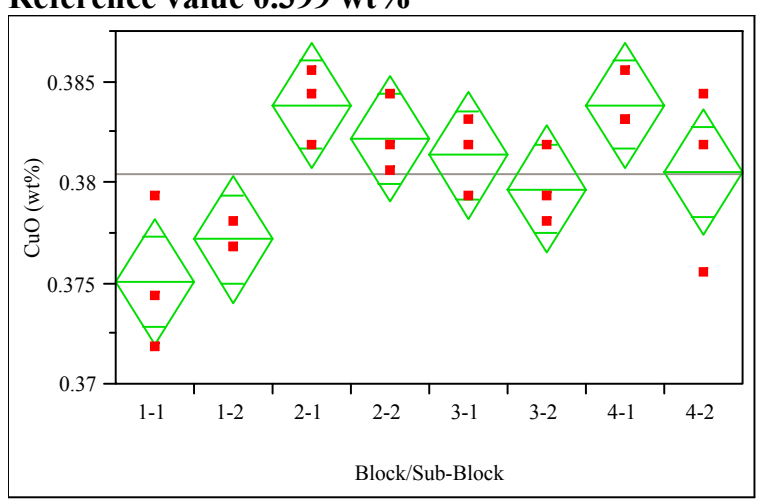

\section{Oneway Anova}

Summary of Fit

$\begin{array}{lr}\text { Rsquare } & 0.658047 \\ \text { Adj Rsquare } & 0.508442 \\ \text { Root Mean Square Error } & 0.002555 \\ \text { Mean of Response } & 0.380495 \\ \text { Observations (or Sum Wgts) } & 24 \\ \text { Analysis of Variance } & \end{array}$

Analysis of Variance

Source DF Sum of Squares Mean Square F Ratio Prob $>$ F

$\begin{array}{lllllll}\text { Block/Sub-Block } & 7 & 0.00020103 & 0.000029 & 4.3986 & 0.0067\end{array}$

$\begin{array}{llll}\text { Error } & 16 & 0.00010447 & 0.000007\end{array}$

$\begin{array}{lll}\text { C. Total } & 23 & 0.00030550\end{array}$

Means for Oneway Anova

Level Number Mean Std Error Lower 95\% Upper 95\%

$\begin{array}{llllll}1-1 & 3 & 0.375123 & 0.00148 & 0.37200 & 0.37825\end{array}$

$\begin{array}{llllll}1-2 & 3 & 0.377209 & 0.00148 & 0.37408 & 0.38034\end{array}$

$\begin{array}{llllll}2-1 & 3 & 0.383885 & 0.00148 & 0.38076 & 0.38701\end{array}$

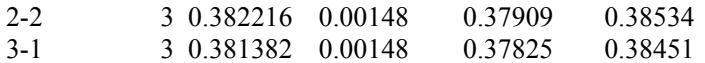

$\begin{array}{llllll}3-2 & 3 & 0.379713 & 0.00148 & 0.37659 & 0.38284\end{array}$

$\begin{array}{llllll}4-1 & 3 & 0.383885 & 0.00148 & 0.38076 & 0.38701\end{array}$

Std Error uses a pooled estimate of error variance
Oneway Analysis of K2O (wt\%) By Block/Sub-Block Reference value $3.327 \mathrm{wt} \%$

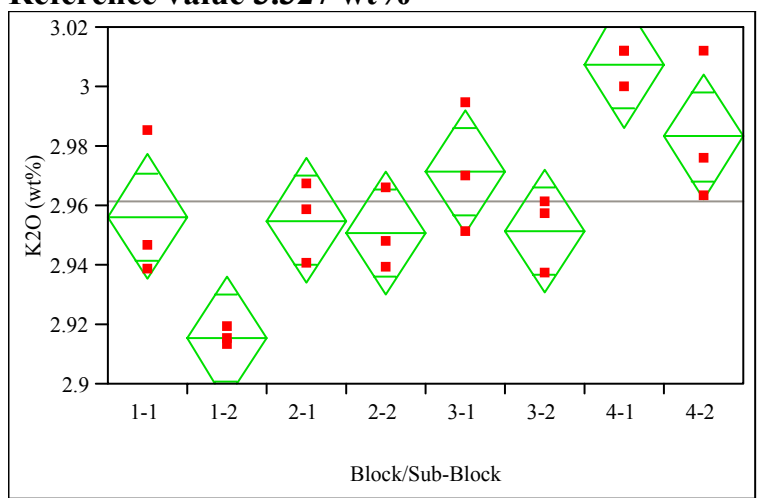

Oneway Anova

Summary of Fit

\subsection{1 \\ Rsquare \\ $\begin{array}{ll}\text { Adj Rsquare } & 0.664345 \\ \text { Root Mean Square Error } & 0.017043\end{array}$ \\ $\begin{array}{ll}\text { Root Mean Square Error } & 0.017043 \\ \text { Mean of Response } & 2.961559\end{array}$ \\ Observations (or Sum Wgts) \\ Analysis of Variance}

Source $\quad$ DF Sum of Squares Mean Square F Ratio Prob > F

$\begin{array}{lrrrrr}\text { Block/Sub-Block } \quad 7 & 0.01525543 & 0.002179 & 7.5032 & 0.0004\end{array}$

$\begin{array}{lrrr}\text { Error } & 16 & 0.00464727 & 0.000290\end{array}$

C. Total

$23 \quad 0.01990269$

Means for Oneway Anova

Level Number Mean Std Error Lower 95\% Upper 95\%

$\begin{array}{llllll}1-1 & 3 & 2.95649 & 0.00984 & 2.9356 & 2.9773\end{array}$

$\begin{array}{llllll}1-2 & 3 & 2.91553 & 0.00984 & 2.8947 & 2.9364\end{array}$

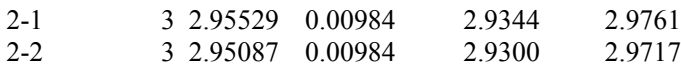

$\begin{array}{llllll}3-1 & 3 & 2.97175 & 0.00984 & 2.9509 & 2.9926\end{array}$

$\begin{array}{llllll}3-2 & 3 & 2.95167 & 0.00984 & 2.9308 & 2.9725\end{array}$

$\begin{array}{llllll}4-1 & 3 & 3.00748 & 0.00984 & 2.9866 & 3.0283\end{array}$

Std Error uses a pooled estimate of error variance 


\section{Exhibit C3. PSAL Measurements by Analytical Block for Samples of the} Standard Glasses Prepared Using the LM Method

Oneway Analysis of La2O3 (wt\%) By Block/Sub-Block Reference value 0 wt\%

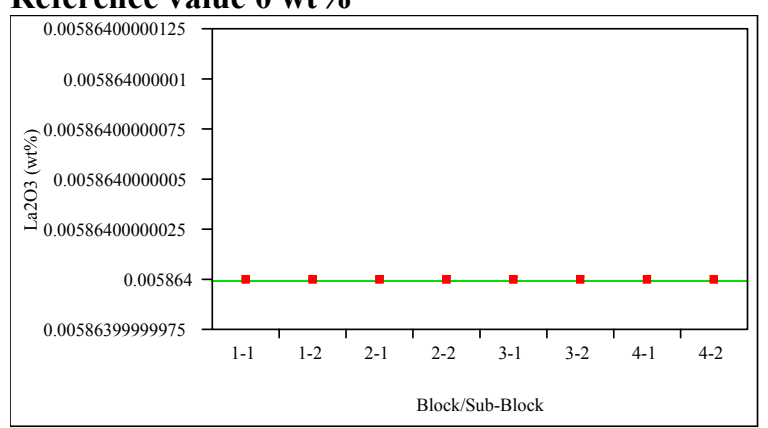

Oneway Anova

Summary of Fit

Rsquare

Adj Rsquare

Root Mean Square Error

Mean of Response 0.005864

Observations (or Sum Wgts)

Analysis of Variance

Source

DF Sum of Squares Mean Square F Ratio Prob $>$ F

Block/Sub-Block 7

Error

16
23

0

0

Means for Oneway Anova

Level Number Mean Std Error Lower 95\% Upper 95\%

$\begin{array}{llllll}1-1 & 3 & 0.005864 & 0 & 0.00586 & 0.00586\end{array}$

$\begin{array}{llllll}1-2 & 3 & 0.005864 & 0 & 0.00586 & 0.00586\end{array}$

$\begin{array}{llllll}2-1 & 3 & 0.005864 & 0 & 0.00586 & 0.00586\end{array}$

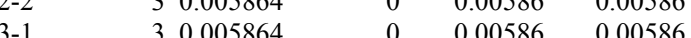

$\begin{array}{llllll}3-1 & 3 & 0.005864 & 0 & 0.00586 & 0.00586 \\ 3-2 & 3 & 0.005864 & 0 & 0.00586 & 0.00586\end{array}$

$\begin{array}{llllll}3-2 & 3 & 0.005864 & 0 & 0.00586 & 0.00586 \\ 4-1 & 3 & 0.005864 & 0 & 0.00586 & 0.00586\end{array}$

$\begin{array}{llllll}4-2 & 3 & 0.005864 & 0 & 0.00586 & 0.00586\end{array}$

Std Error uses a pooled estimate of error variance
Oneway Analysis of MgO (wt\%) By Block/Sub-Block

Reference value $1.419 \mathrm{wt} \%$

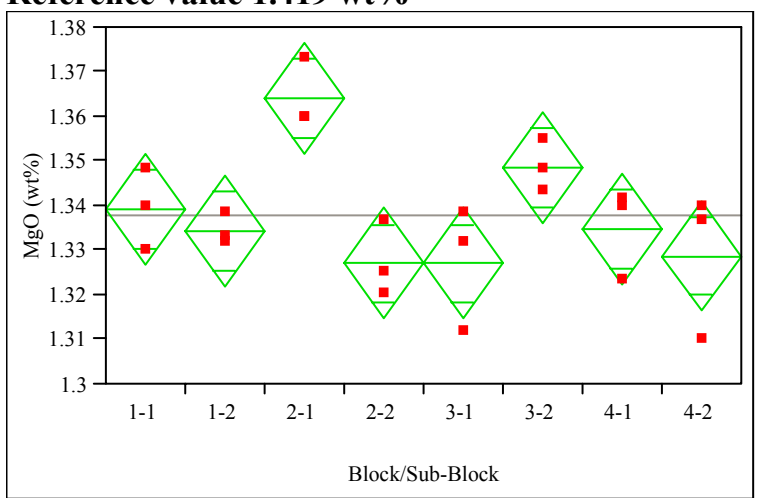

Oneway Anova

Summary of Fit

\begin{tabular}{|c|c|c|c|c|c|}
\hline \multicolumn{3}{|r|}{0.676749} & & & \\
\hline \multicolumn{2}{|l|}{ Adj Rsquare } & 0.535327 & & & \\
\hline \multicolumn{2}{|c|}{ Root Mean Square Error } & 0.010127 & & & \\
\hline \multicolumn{2}{|c|}{ Mean of Response } & 1.33811 & & & \\
\hline \multicolumn{3}{|c|}{ Observations (or Sum Wgts) } & & & \\
\hline \multicolumn{6}{|c|}{ Analysis of Variance } \\
\hline Source & DF & Sum of Squares & Mean Square & F Ratio & Prob $>F$ \\
\hline Block/Sub-Block & 7 & 0.00343516 & 0.000491 & 4.7853 & 0.0046 \\
\hline Error & 16 & 0.00164081 & 0.000103 & & \\
\hline C. Total & 23 & 0.00507597 & & & \\
\hline
\end{tabular}

Means for Oneway Anova

Level Number Mean Std Error Lower 95\% Upper 95\%

$\begin{array}{llllll}1-1 & 3 & 1.33935 & 0.00585 & 1.3270 & 1.3517\end{array}$

$\begin{array}{llllll}1-2 & 3 & 1.33438 & 0.00585 & 1.3220 & 1.3468 \\ 2-1 & 3 & 1.36423 & 0.00585 & 1.3518 & 1.3766\end{array}$

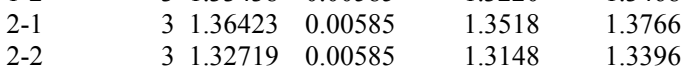

$\begin{array}{llllll}3-1 & 3 & 1.32719 & 0.00585 & 1.3148 & 1.3396\end{array}$

$\begin{array}{llllll}3-2 & 3 & 1.34875 & 0.00585 & 1.3364 & 1.3611\end{array}$

$\begin{array}{llllll}4-1 & 3 & 1.33493 & 0.00585 & 1.3225 & 1.3473 \\ 4-2 & 3 & 1.32885 & 0.00585 & 1.3165 & 1.3412\end{array}$

Std Error uses a pooled estimate of error variance 


\section{Exhibit C3. PSAL Measurements by Analytical Block for Samples of the} Standard Glasses Prepared Using the LM Method

Oneway Analysis of $\mathrm{MnO}(w \mathrm{t} \%)$ By Block/Sub-Block

Reference value $1.726 \mathrm{wt} \%$

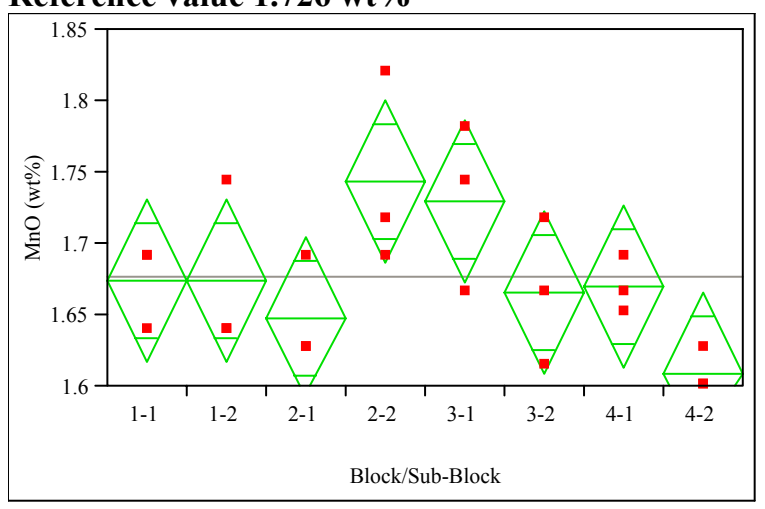

Oneway Anova

Summary of Fit

\section{Rsquare \\ Adj Rsquare \\ 0.525146 \\ 0.317397 \\ 0.04648 \\ Mean of Response \\ 1.676946 \\ Observations (or Sum Wgts)}

Analysis of Variance

Source DF Sum of Squares Mean Square F Ratio Prob $>$ F

$\begin{array}{lrrrrr}\text { Block/Sub-Block } & 7 & 0.03822745 & 0.005461 & 2.5278 & 0.0590\end{array}$

$\begin{array}{llll}\text { Error } & 16 & 0.03456656 & 0.002160\end{array}$

C. Total

$23 \quad 0.07279401$

Means for Oneway Anova

Level Number Mean Std Error Lower 95\% Upper 95\%

$31.67426 \quad 0.02684-1.6174$

$\begin{array}{llllll}1-1 & 3 & 1.67426 & 0.02684 & 1.6174 & 1.7311\end{array}$

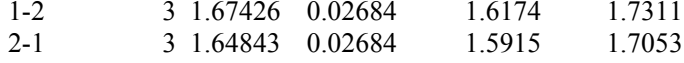

$\begin{array}{llllll}2-2 & 3 & 1.74312 & 0.02684 & 1.6862 & 1.8000\end{array}$

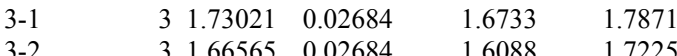

$\begin{array}{llllll}4-1 & 3 & 1.66995 & 0.02684 & 1.6131 & 1.7268\end{array}$

$\begin{array}{llllll}4-1 & 3 & 1.66995 & 0.02684 & 1.6131 & 1.7268 \\ 4-2 & 3 & 1.60970 & 0.02684 & 1.5528 & 1.6666\end{array}$

Std Error uses a pooled estimate of error variance
Oneway Analysis of Na2O (wt\%) By Block/Sub-Block

Reference value $9.003 \mathrm{wt} \%$

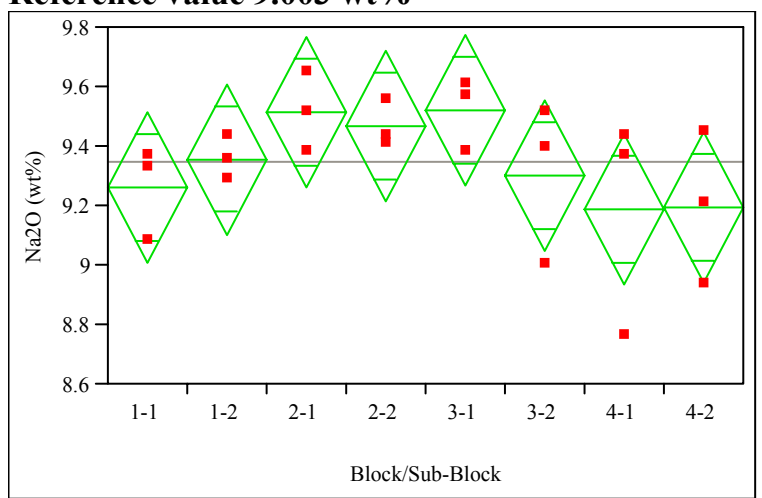

Oneway Anova

Summary of Fit

\begin{tabular}{|c|c|c|c|c|c|}
\hline \multicolumn{3}{|r|}{0.362344} & & & \\
\hline Adi Rsquare & & 0.083369 & & & \\
\hline \multicolumn{2}{|c|}{ Root Mean Square Error } & 0.207193 & & & \\
\hline \multicolumn{2}{|c|}{ Mean of Response } & 9.352312 & & & \\
\hline \multicolumn{3}{|c|}{ Observations (or Sum Wgts) $\quad 24$} & & & \\
\hline \multicolumn{6}{|c|}{ Analysis of Variance } \\
\hline Source & DF $s$ & Sum of Squares & Mean Square & e F Ratio & Prob $>$ F \\
\hline Block/Sub-Block & 7 & 0.3903064 & 0.055758 & 81.2988 & 0.3122 \\
\hline Error & 16 & 0.6868653 & 0.042929 & & \\
\hline C. Total & 23 & 1.0771717 & & & \\
\hline
\end{tabular}

Means for Oneway Anova

Level Number Mean Std Error Lower 95\% Upper 95\%

$\begin{array}{llllll}1-1 & 3 & 9.26076 & 0.11962 & 9.0072 & 9.5143\end{array}$

$\begin{array}{llllll}1-2 & 3 & 9.35961 & 0.11962 & 9.1060 & 9.6132\end{array}$

$\begin{array}{llllll}2-1 & 3 & 9.51688 & 0.11962 & 9.2633 & 9.7705\end{array}$

$\begin{array}{llllll}2-2 & 3 & 9.46745 & 0.11962 & 9.2139 & 9.7210\end{array}$

$\begin{array}{llllll}3-1 & 3 & 9.52137 & 0.11962 & 9.2678 & 9.7750 \\ 3-2 & 3 & 9.30569 & 0.11962 & 9.0521 & 9.5593\end{array}$

$\begin{array}{llllll}3-1 & 3 & 9.18887 & 0.11962 & 8.9353 & 9.4425\end{array}$

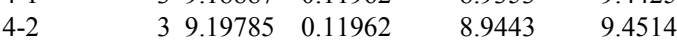

Std Error uses a pooled estimate of error variance 


\section{Exhibit C3. PSAL Measurements by Analytical Block for Samples of the} Standard Glasses Prepared Using the LM Method

Oneway Analysis of PbO (wt\%) By Block/Sub-Block

Reference value 0 wt\%

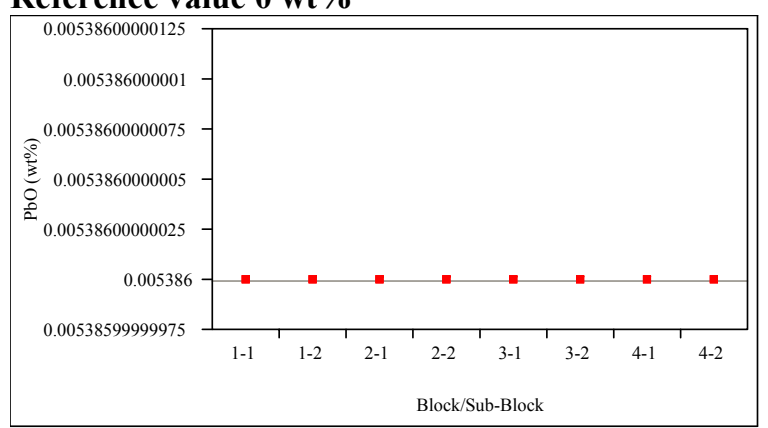

Oneway Anova

Summary of Fit

Rsquare

Adj Rsquare

Root Mean Square Erro

Mean of Response

Observations (or Sum Wgts)

Analysis of Variance

Source DF Sum of Squares Mean Square F Ratio Prob $>$ F

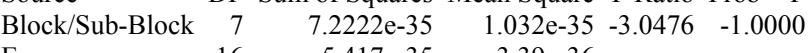

Erro

$16 \quad-5.417 \mathrm{e}-35$

$-3.39 \mathrm{e}-36$

Means for Oneway Anova

Level Number Mean Std Error Lower 95\% Upper 95\%

$\begin{array}{lll}1-1 & 3 & 0.005386\end{array}$

$\begin{array}{lll}1-2 & 3 & 0.005386\end{array}$

$2-1 \quad 30.005386$

$\begin{array}{lll}2-2 & 3 & 0.005386 \\ 3-1 & 3 & 0.005386\end{array}$

$\begin{array}{llll}3-1 & 3 & 0.005386 \\ 3-2 & 3 & 0.005386\end{array}$

$\begin{array}{lll}3-2 & 3 & 0.005386 \\ 4-1 & 3 & 0.005386\end{array}$

$4-2 \quad 30.005386$

Std Error uses a pooled estimate of error variance
Oneway Analysis of SO4 (wt\%) By Block/Sub-Block

Reference value 0 wt \%

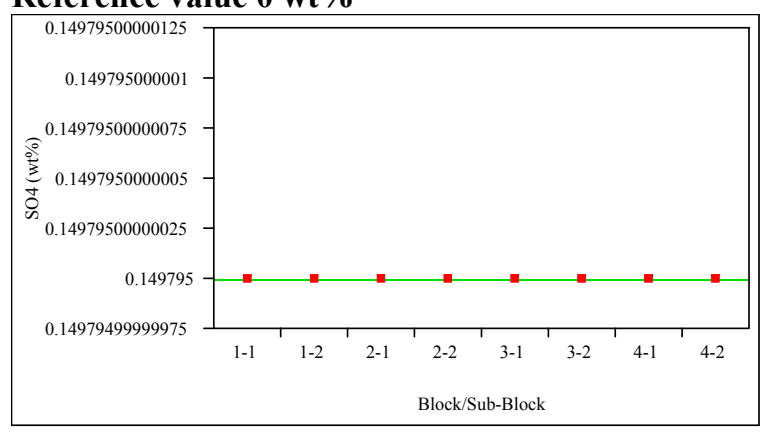

\section{Oneway Anova}

Summary of Fit

Rsquare

Root Mean Square Error

Mean of Response 0.149795

Observations (or Sum Wgts) 24

Analysis of Variance

Source DF Sum of Squares Mean Square F Ratio Prob > F

Block/Sub-Block 7

Error $\quad 16$

Means for Oneway Anova

Level Number Mean Std Error Lower 95\% Upper 95\%

$\begin{array}{llllll}1-1 & 3 & 0.149795 & 0 & 0.14979 & 0.14979\end{array}$

$\begin{array}{llllll}1-2 & 3 & 0.149795 & 0 & 0.14979 & 0.14979\end{array}$

$\begin{array}{llllll}2-1 & 3 & 0.149795 & 0 & 0.14979 & 0.14979\end{array}$

$\begin{array}{llllll}2-2 & 3 & 0.149795 & 0 & 0.14979 & 0.14979\end{array}$

$\begin{array}{llllll}3-1 & 3 & 0.149795 & 0 & 0.14979 & 0.14979\end{array}$

$\begin{array}{llllll}3-2 & 3 & 0.149795 & 0 & 0.14979 & 0.14979 \\ 4-1 & 3 & 0.149795 & 0 & 0.14979 & 0.14979\end{array}$

$\begin{array}{llllll}4-2 & 3 & 0.149795 & 0 & 0.14979 & 0.14979\end{array}$

Std Error uses a pooled estimate of error variance 


\section{Exhibit C3. PSAL Measurements by Analytical Block for Samples of the} Standard Glasses Prepared Using the LM Method

Oneway Analysis of ThO2 (wt\%) By Block/Sub-Block Reference value 0 wt\%

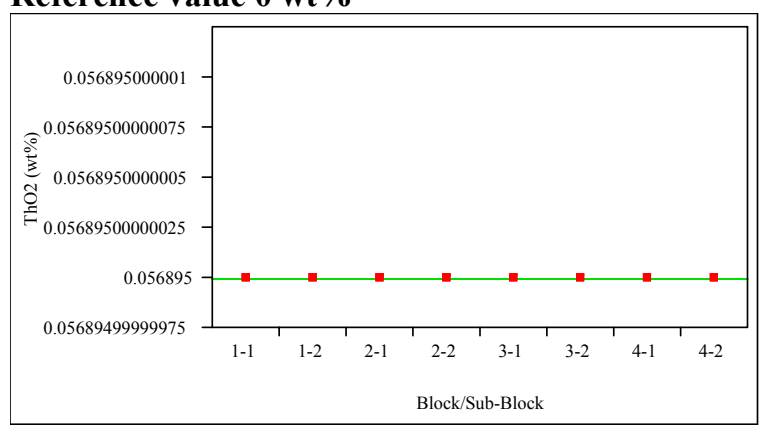

Oneway Anova

Summary of Fit

Rsquare

Adj Rsquare

Root Mean Square Error

Mean of Response $\quad 0.056895$

Observations (or Sum Wgts)

Analysis of Variance Source DF Sum of Squares Mean Square F Ratio Prob $>$ F

C. Tota 16
23

0

Means for Oneway Anova

Level Number Mean Std Error Lower 95\% Upper 95\%

$\begin{array}{llllll}1-1 & 3 & 0.056895 & 0 & 0.05690 & 0.05690\end{array}$

$\begin{array}{llllll}1-2 & 3 & 0.056895 & 0 & 0.05690 & 0.05690\end{array}$

$\begin{array}{llllll}2-1 & 3 & 0.056895 & 0 & 0.05690 & 0.05690\end{array}$

$\begin{array}{llllll}2-2 & 3 & 0.056895 & 0 & 0.05690 & 0.05690\end{array}$

$\begin{array}{llllll}3-1 & 3 & 0.056895 & 0 & 0.05690 & 0.05690\end{array}$

$\begin{array}{llllll}3-2 & 3 & 0.056895 & 0 & 0.05690 & 0.05690\end{array}$

$\begin{array}{llllll}4-1 & 3 & 0.056895 & 0 & 0.05690 & 0.05690 \\ 4-2 & 3 & 0.056895 & 0 & 0.05690 & 0.05690\end{array}$

Std Error uses a pooled estimate of error variance
Oneway Analysis of TiO2 (wt\%) By Block/Sub-Block

Reference value $0.677 \mathrm{wt} \%$

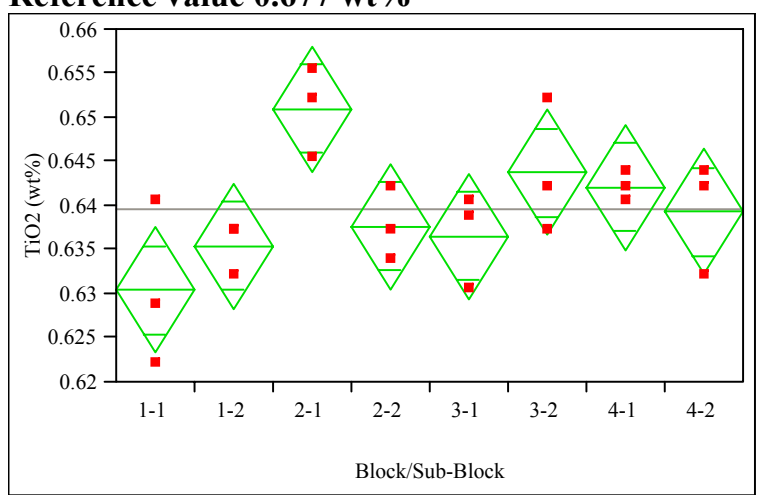

Oneway Anova

Summary of Fit

$\begin{array}{lr}\text { Rsquare } & 0.600242 \\ \text { Adj Rsquare } & 0.425348 \\ \text { Root Mean Square Error } & 0.005788 \\ \text { Mean of Response } & 0.639609 \\ \text { Observations (or Sum Wgts) } & 24 \\ \text { Analysis of Variance } & \end{array}$

Analysis of Variance

Source DF Sum of Squares Mean Square F Ratio Prob $>$ F

$\begin{array}{lrrrrr}\text { Block/Sub-Block } & 7 & 0.00080487 & 0.000115 & 3.4320 & 0.0195\end{array}$

$\begin{array}{llll}\text { Error } & 16 & 0.00053604 & 0.000034\end{array}$

$\begin{array}{lll}\text { C. Total } & 23 & 0.00134092\end{array}$

Means for Oneway Anova

Level Number Mean Std Error Lower 95\% Upper 95\%

$\begin{array}{llllll}1-1 & 3 & 0.630504 & 0.00334 & 0.62342 & 0.63759\end{array}$

$\begin{array}{llllll}1-1 & 3 & 0.635508 & 0.00334 & 0.62842 & 0.63759\end{array}$

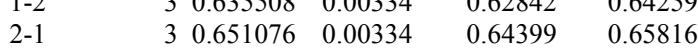

$\begin{array}{llllll}2-2 & 3 & 0.637732 & 0.00334 & 0.63065 & 0.64482\end{array}$

$\begin{array}{llllll}3-1 & 3 & 0.636620 & 0.00334 & 0.62954 & 0.64370\end{array}$

$\begin{array}{lllllll}3-2 & 3 & 0.643848 & 0.00334 & 0.63676 & 0.65093\end{array}$

$\begin{array}{llllll}4-1 & 3 & 0.642180 & 0.00334 & 0.63510 & 0.64926\end{array}$

$\begin{array}{lllll}3 & 0.639400 & 0.00334 & 0.63232 & 0.64648\end{array}$ 


\section{Exhibit C3. PSAL Measurements by Analytical Block for Samples of the} Standard Glasses Prepared Using the LM Method

Oneway Analysis of $\mathrm{ZnO}(w \mathrm{t} \%)$ By Block/Sub-Block

Reference value 0 wt\%

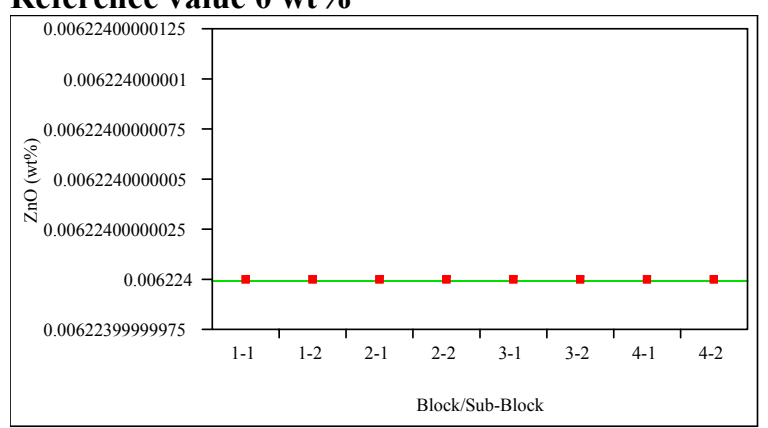

Oneway Anova

Summary of Fit

Rsquare

Adj Rsquare

Root Mean Square Error

Mean of Response 0.006224

Observations (or Sum Wgts)

Analysis of Variance Source DF Sum of Squares Mean Square F Ratio Prob $>$ F

C. Tota 16
23

0

\section{Means for Oneway Anova}

Level Number Mean Std Error Lower 95\% Upper 95\%

$\begin{array}{llllll}1-1 & 3 & 0.006224 & 0 & 0.00622 & 0.00622 \\ 1-2 & 3 & 0.006224 & 0 & 0.00622 & 0.00622 \\ 2-1 & 3 & 0.006224 & 0 & 0.00622 & 0.00622 \\ 2-2 & 3 & 0.006224 & 0 & 0.00622 & 0.00622 \\ 3-1 & 3 & 0.006224 & 0 & 0.00622 & 0.00622 \\ 3-2 & 3 & 0.006224 & 0 & 0.00622 & 0.00622 \\ 4-1 & 3 & 0.006224 & 0 & 0.00622 & 0.00622 \\ 4-2 & 3 & 0.006224 & 0 & 0.00622 & 0.00622\end{array}$

Std Error uses a pooled estimate of error variance
Oneway Analysis of ZrO2 (wt\%) By Block/Sub-Block

Reference value $0.098 \mathrm{wt} \%$

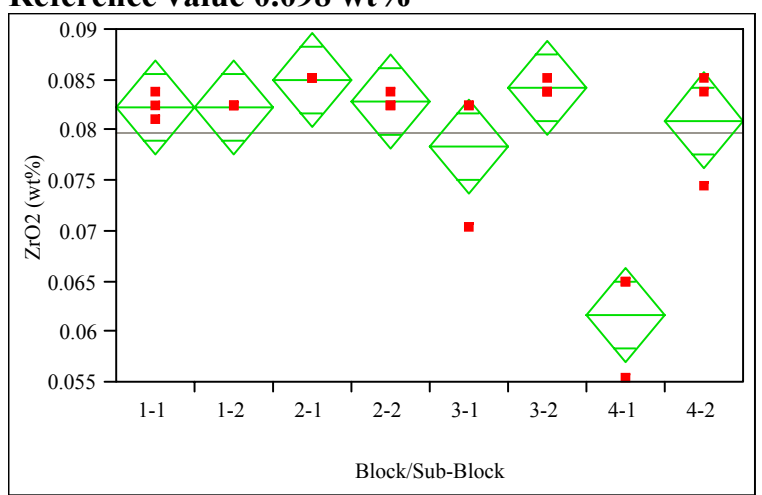

Oneway Anova

Summary of Fit

Rsquare

Adj Rsquare 0.76678

Root Mean Square Error $\quad 0.003821$

Mean of Response 0.079753

$\begin{array}{lr}\text { Observations (or Sum Wgts) } & 24\end{array}$

Analysis of Variance

Source DF Sum of Squares Mean Square F Ratio Prob $>$ F

$\begin{array}{lrrrrr}\text { Block/Sub-Block } \quad 7 & 0.00120602 & 0.000172 & 11.8028 & <.0001\end{array}$

$\begin{array}{llll}\text { Error } & 16 & 0.00023356 & 0.000015\end{array}$

$\begin{array}{lll}\text { C. Total } & 23 & 0.00143958\end{array}$

Means for Oneway Anova

Level Number Mean Std Error Lower 95\% Upper 95\%

$\begin{array}{llllll}1-1 & 3 & 0.082399 & 0.00221 & 0.07772 & 0.08707\end{array}$

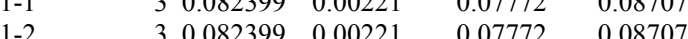

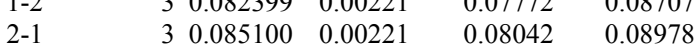

$\begin{array}{llllll}2-2 & 3 & 0.082849 & 0.00221 & 0.07817 & 0.08753\end{array}$

$\begin{array}{llllll}3-1 & 3 & 0.078346 & 0.00221 & 0.07367 & 0.08302\end{array}$

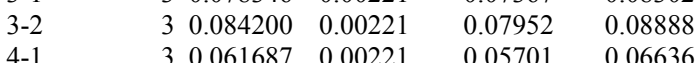

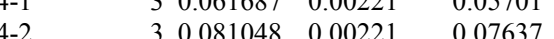

Std Error uses a pooled estimate of error variance 


\section{Exhibit C3. PSAL Measurements by Analytical Block for Samples of the} Standard Glasses Prepared Using the LM Method

Glass ID=Ustd

Oneway Analysis of BaO (wt\%) By Block/Sub-Block Reference value 0 wt\%

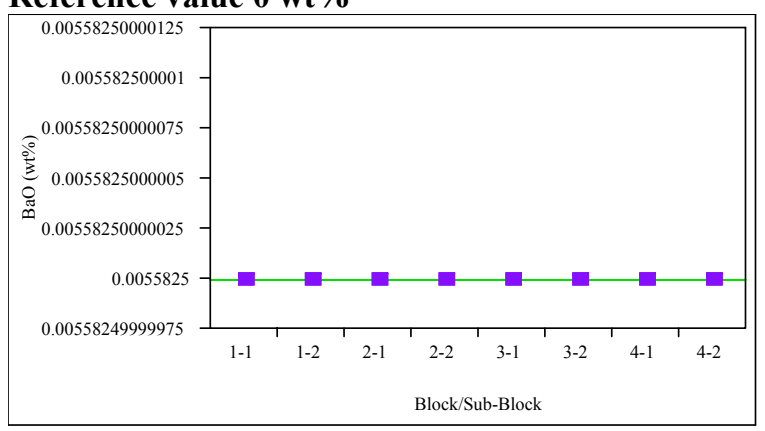

\section{Oneway Anova}

Summary of Fit

Rsquare

Adj Rsquare

Root Mean Square Error $\quad 0$

Mean of Resp

0.005583

Observations (or Sum Wgts)

Analysis of Variance

$\begin{array}{lcccc}\text { Source } & \text { DF } & \text { Sum of Squares } & \text { Mean Square F Ratio Prob }>\text { F } \\ \text { Block/Sub-Block } & 7 & 0 & 0 & \text {. }\end{array}$

Block/Sub-Block 7

$\begin{array}{ll}\text { Error } & 16 \\ \text { C. Total } & 23\end{array}$

Means for Oneway Anova

Level Number Mean Std Error Lower 95\% Upper 95\%

$\begin{array}{llllll}1-1 & 3 & 0.005583 & 0 & 0.00558 & 0.00558 \\ 1-2 & 3 & 0.005583 & 0 & 0.00558 & 0.00558 \\ 2-1 & 3 & 0.005583 & 0 & 0.00558 & 0.00558 \\ 2-2 & 3 & 0.005583 & 0 & 0.00558 & 0.00558 \\ 3-1 & 3 & 0.005583 & 0 & 0.00558 & 0.00558 \\ 3-2 & 3 & 0.005583 & 0 & 0.00558 & 0.00558 \\ 4-1 & 3 & 0.005583 & 0 & 0.00558 & 0.00558 \\ 4-2 & 3 & 0.005583 & 0 & 0.00558 & 0.00558\end{array}$

Std Error uses a pooled estimate of error variance
Oneway Analysis of CaO (wt\%) By Block/Sub-Block Reference value $1.301 \mathrm{wt} \%$

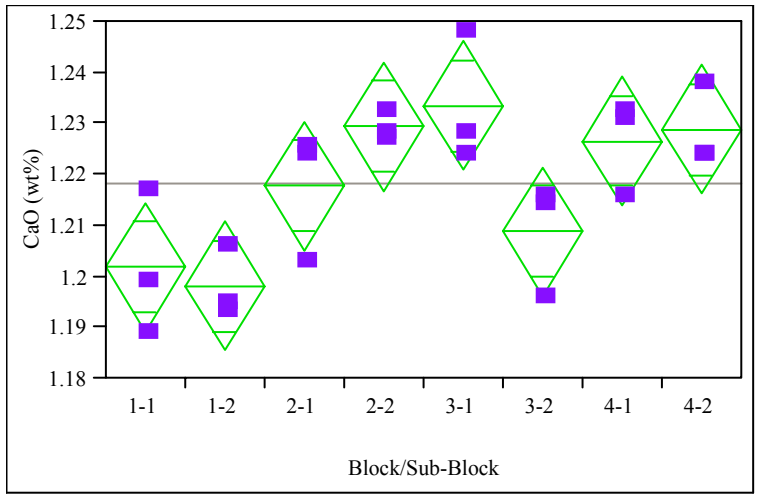

Oneway Anova

Summary of Fit

$\begin{array}{lr}\text { Rsquare } & 0.697586 \\ \text { Adj Rsquare } & 0.56528 \\ \text { Root Mean Square Error } & 0.010294 \\ \text { Mean of Response } & 1.218178 \\ \text { Observations (or Sum Wgts) } & 24\end{array}$

(24)

Analysis of Variance

Source DF Sum of Squares Mean Square F Ratio Prob > F $\begin{array}{lllllll}\text { Block/Sub-Block } \quad 7 & 0.00391087 & 0.000559 & 5.2725 & 0.0028\end{array}$

$\begin{array}{llll}\text { Error } & 16 & 0.00169542 & 0.000106\end{array}$

C. Total $23 \quad 0.00560629$

Means for Oneway Anova

Level Number Mean Std Error Lower 95\% Upper 95\%

$\begin{array}{llllll}1-1 & 3 & 1.20191 & 0.00594 & 1.1893 & 1.2145\end{array}$

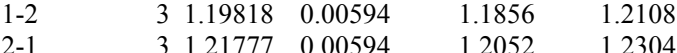

$\begin{array}{llllll}2-1 & 3 & 1.21777 & 0.00594 & 1.2052 & 1.2304 \\ 2-2 & 3 & 1.22943 & 0.00594 & 1.2168 & 1.2420\end{array}$

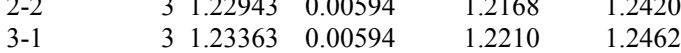

$\begin{array}{llllll}3-2 & 3 & 1.20891 & 0.00594 & 1.1963 & 1.2215\end{array}$

$\begin{array}{llllll}4-1 & 3 & 1.22663 & 0.00594 & 1.2140 & 1.2392\end{array}$

$\begin{array}{llllll}4-2 & 3 & 1.22896 & 0.00594 & 1.2164 & 1.2416\end{array}$

Std Error uses a pooled estimate of error variance 


\section{Exhibit C3. PSAL Measurements by Analytical Block for Samples of the} Standard Glasses Prepared Using the LM Method

Oneway Analysis of Ce2O3 (wt\%) By Block/Sub-Block Reference value 0 wt\%

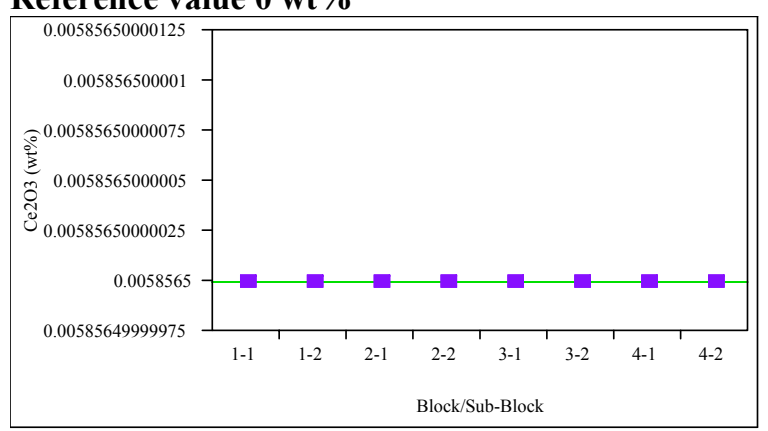

Oneway Anova

Summary of Fit

Rsquare

Adj Rsquare

Root Mean Square Error

Mean of Response

0.005857

Observations (or Sum Wgts)

Analysis of Variance

Source

DF Sum of Squares Mean Square F Ratio Prob $>$ F

Block/Sub-Block 7

Error

16
23

0

0

Means for Oneway Anova

$\begin{array}{lrrrrr}\text { Level Number } & \text { Mean } & \text { Std Error } & \text { Lower 95\% } & \text { Upper 95\% } \\ 1-1 & 3 & 0.005857 & 0 & 0.00586 & 0.00586 \\ 1-2 & 3 & 0.005857 & 0 & 0.00586 & 0.00586 \\ 2-1 & 3 & 0.005857 & 0 & 0.00586 & 0.00586 \\ 2-2 & 3 & 0.005857 & 0 & 0.00586 & 0.00586 \\ 3-1 & 3 & 0.005857 & 0 & 0.00586 & 0.00586 \\ 3-2 & 3 & 0.005857 & 0 & 0.00586 & 0.00586 \\ 4-1 & 3 & 0.005857 & 0 & 0.00586 & 0.00586 \\ 4-2 & 3 & 0.005857 & 0 & 0.00586 & 0.00586\end{array}$

Std Error uses a pooled estimate of error variance
Oneway Analysis of Cr2O3 (wt\%) By Block/Sub-Block Reference value 0 wt \%

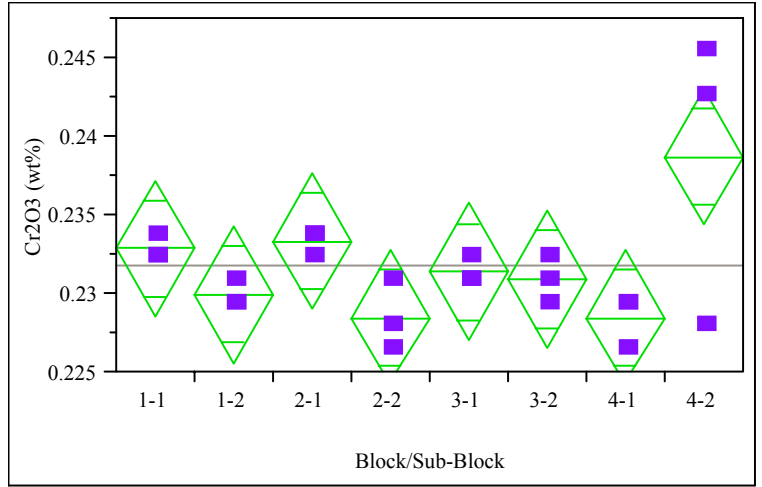

Oneway Anova

Summary of Fit

\begin{tabular}{lr} 
Rsquare & 0.535568 \\
Adj Rsquare & 0.332379 \\
Root Mean Square Error & 0.003555 \\
Mean of Response & 0.231785 \\
Observations (or Sum Wgts) & 24 \\
\hline Analysis of Variance &
\end{tabular}

Analysis of Variance

$\begin{array}{lrrrrr}\text { Source } & \text { DF } & \text { Sum of Squares } & \text { Mean Square } & \text { F Ratio } & \text { Prob }>\text { F } \\ \text { Block/Sub-Block } & 7 & 0.00023321 & 0.000033 & 2.6358 & 0.0514\end{array}$

$\begin{array}{llll}\text { Error } & 16 & 0.00020223 & 0.000013\end{array}$

$\begin{array}{lll}\text { C. Total } & 23 & 0.00043544\end{array}$

Means for Oneway Anova

Level Number Mean Std Error Lower 95\% Upper 95\%

$\begin{array}{llllll}1-1 & 3 & 0.232882 & 0.00205 & 0.22853 & 0.23723\end{array}$

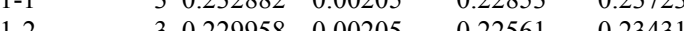

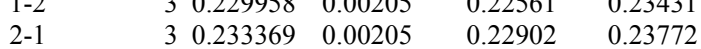

$\begin{array}{llllll}2-1 & 3 & 0.228497 & 0.00205 & 0.22415 & 0.23285\end{array}$

$\begin{array}{llllll}3-1 & 3 & 0.231420 & 0.00205 & 0.22707 & 0.23577\end{array}$

$\begin{array}{llllll}3-2 & 3 & 0.230933 & 0.00205 & 0.22658 & 0.23528\end{array}$

$\begin{array}{llllll}4-1 & 3 & 0.228497 & 0.00205 & 0.22415 & 0.23285\end{array}$

$\begin{array}{llllll}4-2 & 3 & 0.238728 & 0.00205 & 0.23438 & 0.24308\end{array}$ 


\section{Exhibit C3. PSAL Measurements by Analytical Block for Samples of the} Standard Glasses Prepared Using the LM Method

Oneway Analysis of $\mathrm{CuO}\left(\mathrm{wt}_{\mathrm{t}} \mathrm{o}\right) \mathrm{By}$ Block/Sub-Block Reference value 0 wt\%

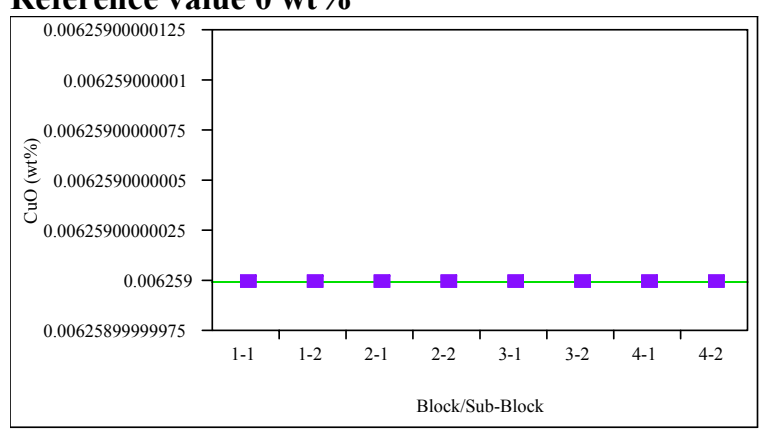

Oneway Anova

Summary of Fit

Rsquare

Adj Rsquare

Root Mean Square Error

Mean of Response $\quad 0.006259$

Observations (or Sum Wgts)

Analysis of Variance

Source DF Sum of Squares Mean Square F Ratio Prob $>$ F Block/Sub-Block 7

Error 16 0

C. Total 23

0

\section{Means for Oneway Anova}

Level Number Mean Std Error Lower 95\% Upper 95\%

$\begin{array}{llllll}1-1 & 3 & 0.006259 & 0 & 0.00626 & 0.00626 \\ 1-2 & 3 & 0.006259 & 0 & 0.00626 & 0.00626 \\ 2-1 & 3 & 0.006259 & 0 & 0.00626 & 0.00626 \\ 2-2 & 3 & 0.006259 & 0 & 0.00626 & 0.00626 \\ 3-1 & 3 & 0.006259 & 0 & 0.00626 & 0.00626 \\ 3-2 & 3 & 0.006259 & 0 & 0.00626 & 0.00626 \\ 4-1 & 3 & 0.006259 & 0 & 0.00626 & 0.00626 \\ 4-2 & 3 & 0.006259 & 0 & 0.00626 & 0.00626\end{array}$

Std Error uses a pooled estimate of error variance
Oneway Analysis of K2O (wt\%) By Block/Sub-Block

Reference value $2.999 \mathrm{wt} \%$

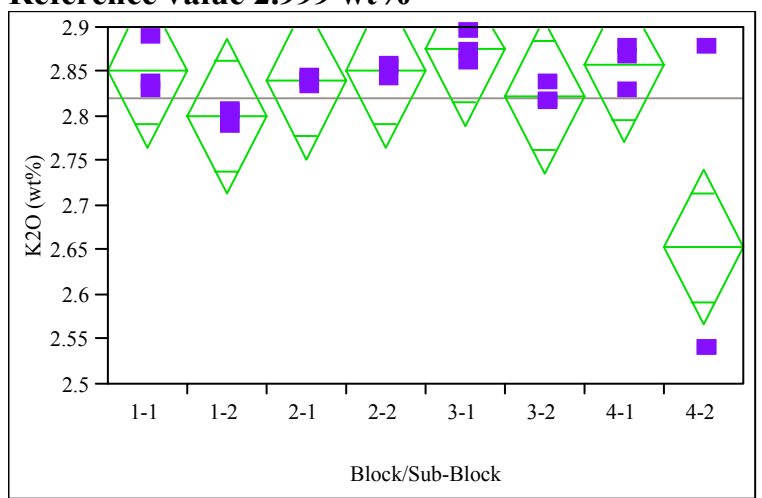

Oneway Anova

Summary of Fit

$\begin{array}{lrrrrr}\text { Rsquare } & 0.568067 & & \\ \text { Adj Rsquare } & 0.379096 & & \\ \text { Root Mean Square Error } & 0.070955 & & & \\ \text { Mean of Response } & 2.82032 & & & \\ \text { Observations (or Sum Wgts) } & 24 & & & & \\ \text { Analysis of Variance } & & & & & \\ \text { Source } & \text { DF } & \text { Sum of Squares } & \text { Mean Square } & \text { F Ratio } & \text { Prob }>\text { F } \\ \text { Block/Sub-Block } & 7 & 0.10594143 & 0.015134 & 3.0061 & 0.0323 \\ \text { Error } & 16 & 0.08055324 & 0.005035 & & \\ \text { C. Total } & 23 & 0.18649467 & & & \end{array}$

Means for Oneway Anova

Level Number Mean Std Error Lower 95\% Upper 95\%

$\begin{array}{llllll}1-1 & 3 & 2.85330 & 0.04097 & 2.7665 & 2.9401\end{array}$

$\begin{array}{llllll}1-2 & 3 & 2.80110 & 0.04097 & 2.7143 & 2.8879\end{array}$

$\begin{array}{llllll}2-1 & 3 & 2.84005 & 0.04097 & 2.7532 & 2.9269\end{array}$

$\begin{array}{llllll}2-2 & 3 & 2.85330 & 0.04097 & 2.7665 & 2.9401\end{array}$

$\begin{array}{llllll}3-1 & 3 & 2.87739 & 0.04097 & 2.7905 & 2.9642 \\ 3-2 & 3 & 2.82439 & 0.04097 & 2.7375 & 2.9112\end{array}$

$\begin{array}{llllll}3-2 & 3 & 2.82439 & 0.04097 & 2.7375 & 2.9112 \\ 4-1 & 3 & 2.85892 & 0.04097 & 2.7721 & 2.9458\end{array}$

$\begin{array}{llllll}4-2 & 3 & 2.65414 & 0.04097 & 2.5673 & 2.7410\end{array}$

Std Error uses a pooled estimate of error variance 


\section{Exhibit C3. PSAL Measurements by Analytical Block for Samples of the} Standard Glasses Prepared Using the LM Method

Oneway Analysis of La2O3 (wt\%) By Block/Sub-Block Reference value 0 wt\%

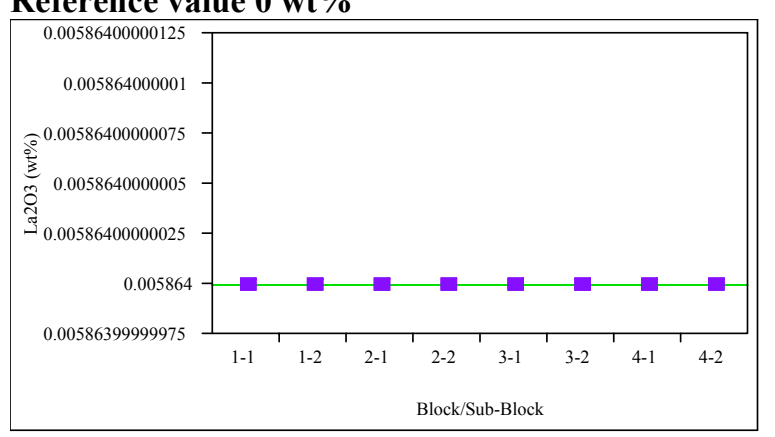

Oneway Anova

Summary of Fit

Rsquare

Adj Rsquare

Root Mean Square Error

Mean of Response

0.005864

Observations (or Sum Wgts)

Analysis of Variance

Source

DF Sum of Squares Mean Square F Ratio Prob $>$ F

Block/Sub-Block 7

Error

16
23

0
0

0

Means for Oneway Anova

Level Number Mean Std Error Lower 95\% Upper 95\%

$\begin{array}{llllll}1-1 & 3 & 0.005864 & 0 & 0.00586 & 0.00586\end{array}$

$\begin{array}{llllll}1-1 & 3 & 0.005864 & 0 & 0.00586 & 0.00586\end{array}$

$\begin{array}{llllll}2-1 & 3 & 0.005864 & 0 & 0.00586 & 0.00586\end{array}$

$\begin{array}{llllll}2-2 & 3 & 0.005864 & 0 & 0.00586 & 0.00586\end{array}$

$\begin{array}{llllll}3-1 & 3 & 0.005864 & 0 & 0.00586 & 0.00586\end{array}$

$\begin{array}{llllll}3-2 & 3 & 0.005864 & 0 & 0.00586 & 0.00586\end{array}$

$\begin{array}{llllll}4-2 & 3 & 0.005864 & 0 & 0.00586 & 0.00586\end{array}$

Std Error uses a pooled estimate of error variance
Oneway Analysis of MgO (wt\%) By Block/Sub-Block

Reference value $1.21 \mathrm{wt} \%$

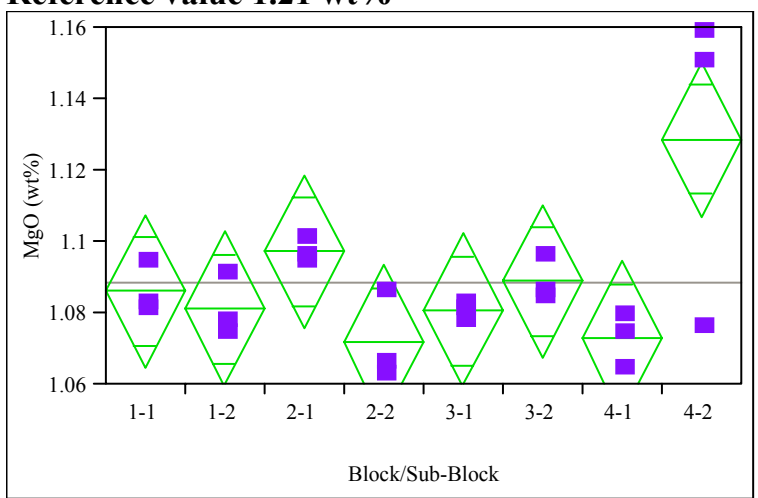

Oneway Anova

Summary of Fit

$\begin{array}{lr}\text { Rsquare } & 0.58498 \\ \text { Adj Rsquare } & 0.403408 \\ \text { Root Mean Square Error } & 0.017634 \\ \text { Mean of Response } & 1.088467 \\ \text { Observations (or Sum Wgts) } & 24 \\ \text { Analysis of Variance } & \\ \text { Anal } & \end{array}$

Analysis of Variance

Source DF Sum of Squares Mean Square F Ratio Prob $>$ F

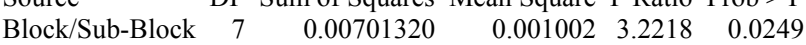

$\begin{array}{llll}\text { Error } & 16 & 0.00497559 & 0.000311 \\ \text { C. Total } & 23 & 0.01198879 & \end{array}$

Means for Oneway Anova

Level Number Mean Std Error Lower 95\% Upper 95\%

$\begin{array}{llllll}1-1 & 3 & 1.08619 & 0.01018 & 1.0646 & 1.1078\end{array}$

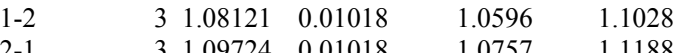

$\begin{array}{llllll}2-1 & 3 & 1.09724 & 0.01018 & 1.0757 & 1.1188\end{array}$

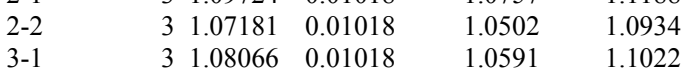

$\begin{array}{llllll}3-2 & 3 & 1.08895 & 0.01018 & 1.0674 & 1.1105 \\ 4-1 & 3 & 1.07292 & 0.01018 & 1.0513 & 1.0945\end{array}$

$\begin{array}{llllll}4-1 & 3 & 1.07292 & 0.01018 & 1.0513 & 1.0945 \\ 4-2 & 3 & 1.12875 & 0.01018 & 1.1072 & 1.1503\end{array}$

Std Error uses a pooled estimate of error variance 


\section{Exhibit C3. PSAL Measurements by Analytical Block for Samples of the} Standard Glasses Prepared Using the LM Method

Oneway Analysis of $\mathrm{MnO}(w \mathrm{t} \%)$ By Block/Sub-Block

Reference value $2.892 \mathrm{wt} \%$

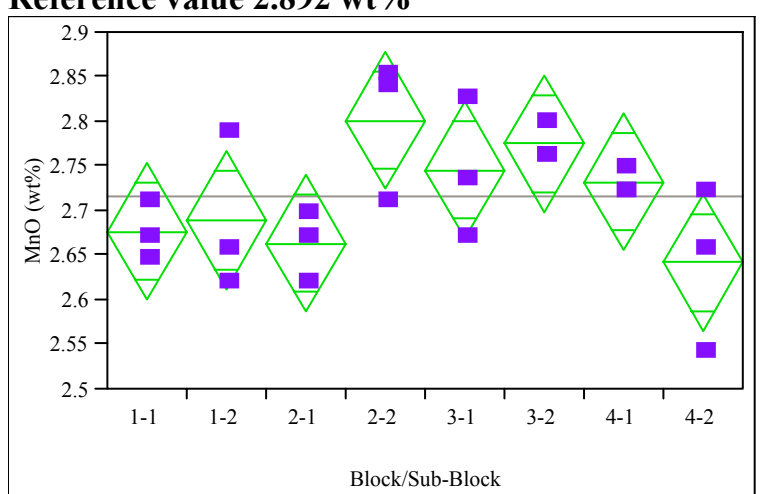

Oneway Anova

Summary of Fit

\section{Rsquare \\ Adj Rsquare \\ 0.515074 \\ Adj Rsquare $\quad 0.302919$ \\ Mean of Response 2.716362 \\ Observations (or Sum Wgts) 24}

Analysis of Variance

Source DF Sum of Squares Mean Square F Ratio Prob $>$ F

$\begin{array}{lrrrrr}\text { Source } & \text { DF } & \text { Sum of Squares } & \text { Mean Square } & \text { F Ratio } & \text { Prob }>\text { F } \\ \text { Block/Sub-Block } & 7 & 0.06729226 & 0.009613 & 2.4278 & 0.0672\end{array}$

$\begin{array}{llll}\text { Error } & 16 & 0.06335350 & 0.003960\end{array}$

C. Total

$23 \quad 0.13064576$

Means for Oneway Anova

Level Number Mean Std Error Lower 95\% Upper 95\%

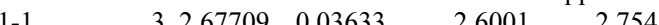

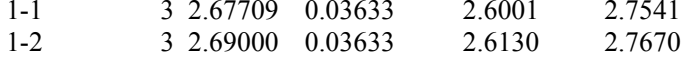

$\begin{array}{llllll}2-1 & 3 & 2.66418 & 0.03633 & 2.5872 & 2.7412\end{array}$

$\begin{array}{llllll}2-2 & 3 & 2.80190 & 0.03633 & 2.7249 & 2.8789\end{array}$

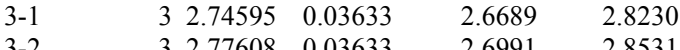

$\begin{array}{llllll}4-1 & 3 & 2.77608 & 0.03633 & 2.6991 & 2.8531 \\ 4-2 & 3 & 2.73304 & 0.03633 & 2.6560 & 2.8101\end{array}$

$\begin{array}{llllll}4-1 & 3 & 2.73304 & 0.03633 & 2.6560 & 2.8101 \\ 4-2 & 3 & 2.64266 & 0.03633 & 2.5656 & 2.7197\end{array}$

Std Error uses a pooled estimate of error variance
Oneway Analysis of Na2O (wt\%) By Block/Sub-Block

Reference value $11.795 \mathrm{wt} \%$

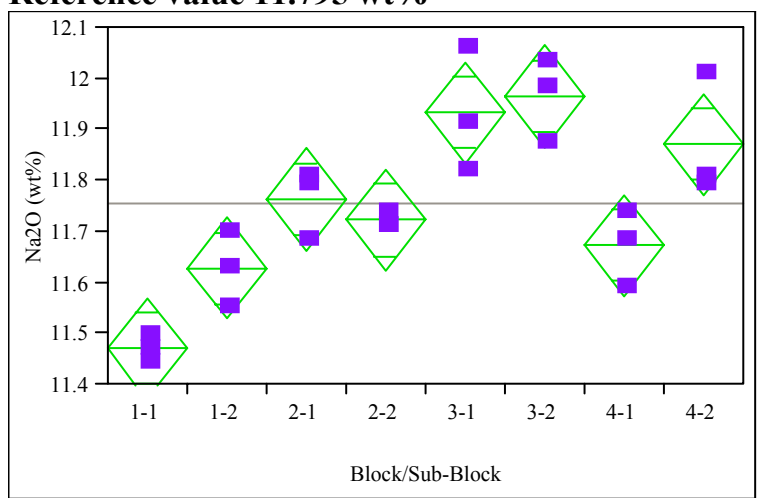

Oneway Anova

Summary of Fit

\section{Rsquare $\quad 0.846315$ \\ Adj Rsquare $\quad 0.779077$ \\ Root Mean Square Error $\quad 0.0813$ \\ $\begin{array}{lr}\text { Mean of Response } & 11.754 \\ \text { Observations (or Sum Wgts) } & 24\end{array}$ \\ Analysis of Variance}

Source DF Sum of Squares Mean Square F Ratio Prob $>$ F

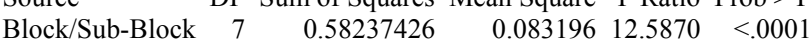

$\begin{array}{llll}\text { Error } & 16 & 0.10575545 & 0.006610 \\ \text { C. Total } & 23 & 0.68812971 & \end{array}$

$23 \quad 0.68812971$

Means for Oneway Anova

Level Number Mean Std Error Lower 95\% Upper 95\%

$\begin{array}{lllllr}1-1 & 3 & 11.4715 & 0.04694 & 11.372 & 11.571\end{array}$

$\begin{array}{llllll}1-2 & 3 & 11.6287 & 0.04694 & 11.529 & 11.728\end{array}$

$\begin{array}{llllll}2-1 & 3 & 11.7635 & 0.04694 & 11.664 & 11.863\end{array}$

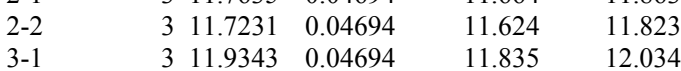

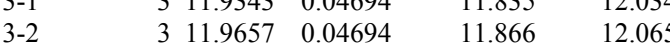

$\begin{array}{llllll}4-1 & 3 & 11.6737 & 0.04694 & 11.574 & 11.773\end{array}$

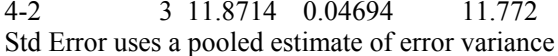




\section{Exhibit C3. PSAL Measurements by Analytical Block for Samples of the} Standard Glasses Prepared Using the LM Method

Oneway Analysis of PbO (wt\%) By Block/Sub-Block

Reference value 0 wt\%

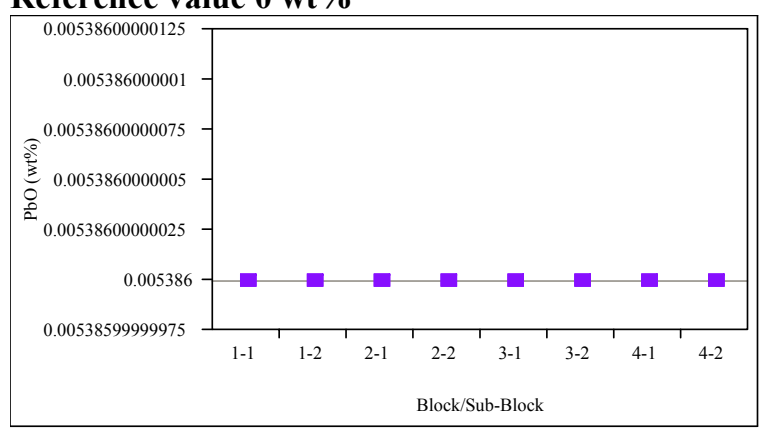

Oneway Anova

Summary of Fit

Rsquare

Adj Rsquare

Root Mean Square Erro

Mean of Response

5.3125

Observations (or Sum Wgts)

0.005386

Source

DF Sum of Squares Mean Square F Ratio Prob $>$ F

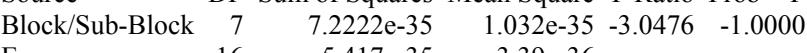

Error

$\begin{array}{ll}16 & -5.417 \mathrm{e}-35 \\ 23 & 1.8056 \mathrm{e}-35\end{array}$

$-3.39 \mathrm{e}-36$

Means for Oneway Anova

Level Number Mean Std Error Lower 95\% Upper 95\%

$\begin{array}{lll}1-1 & 3 & 0.005386\end{array}$

$\begin{array}{lll}1-2 & 3 & 0.005386\end{array}$

$2-1 \quad 30.005386$

$\begin{array}{lll}2-2 & 3 & 0.005386 \\ 3-1 & 3 & 0.005386\end{array}$

$\begin{array}{lll}3-1 & 3 & 0.005386 \\ 3-2 & 3 & 0.005386\end{array}$

$\begin{array}{lll}3-2 & 3 & 0.005386 \\ 4-1 & 3 & 0.005386\end{array}$

$4-2 \quad 30.005386$

Std Error uses a pooled estimate of error variance
Oneway Analysis of SO4 (wt\%) By Block/Sub-Block

Reference value 0 wt \%

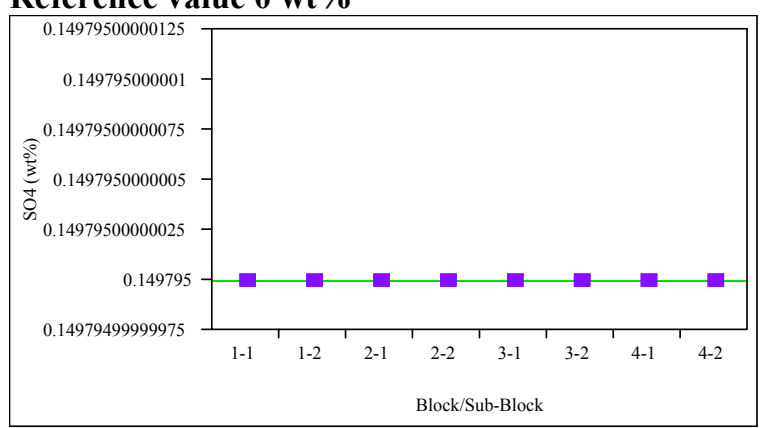

Oneway Anova

Summary of Fit

Rsquare

Root Mean Square Error

Mean of Response

0.149795

Observations (or Sum Wgts)

Analysis of Variance

Source DF Sum of Squares Mean Square F Ratio Prob > F

Block/Sub-Block 7

Error $\quad 16$

Means for Oneway Anova

Level Number Mean Std Error Lower 95\% Upper 95\%

$\begin{array}{lllllr}1-1 & 3 & 0.149795 & 0 & 0.14979 & 0.14979\end{array}$

$\begin{array}{llllll}1-2 & 3 & 0.149795 & 0 & 0.14979 & 0.14979\end{array}$

$\begin{array}{llllll}2-1 & 3 & 0.149795 & 0 & 0.14979 & 0.14979\end{array}$

$\begin{array}{llllll}2-2 & 3 & 0.149795 & 0 & 0.14979 & 0.14979\end{array}$

$\begin{array}{llllll}3-1 & 3 & 0.149795 & 0 & 0.14979 & 0.14979\end{array}$

$\begin{array}{llllll}3-2 & 3 & 0.149795 & 0 & 0.14979 & 0.14979 \\ 4-1 & 3 & 0.149795 & 0 & 0.14979 & 0.14979\end{array}$

$\begin{array}{llllll}4-2 & 3 & 0.149795 & 0 & 0.14979 & 0.14979\end{array}$

Std Error uses a pooled estimate of error variance 


\section{Exhibit C3. PSAL Measurements by Analytical Block for Samples of the} Standard Glasses Prepared Using the LM Method

Oneway Analysis of ThO2 (wt\%) By Block/Sub-Block Reference value 0 wt\%

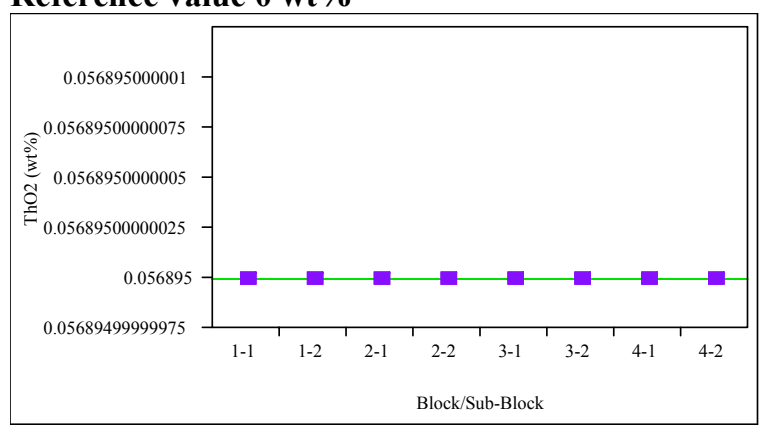

Oneway Anova

Summary of Fit

Rsquare

Adj Rsquare

Root Mean Square Error

Mean of Response 0.056895

Observations (or Sum Wgts)

Analysis of Variance Source DF Sum of Squares Mean Square F Ratio Prob $>$ F

C. Tota 16
23

0

Means for Oneway Anova

Level Number Mean Std Error Lower 95\% Upper 95\%

$\begin{array}{lllllll}1-1 & 3 & 0.056895 & 0 & 0.05690 & 0.05690\end{array}$

$\begin{array}{llllll}1-2 & 3 & 0.056895 & 0 & 0.05690 & 0.05690\end{array}$

$\begin{array}{llllll}2-1 & 3 & 0.056895 & 0 & 0.05690 & 0.05690\end{array}$

$\begin{array}{llllll}2-2 & 3 & 0.056895 & 0 & 0.05690 & 0.05690\end{array}$

$\begin{array}{llllll}3-1 & 3 & 0.056895 & 0 & 0.05690 & 0.05690\end{array}$

$\begin{array}{llllll}3-2 & 3 & 0.056895 & 0 & 0.05690 & 0.05690\end{array}$

$\begin{array}{llllll}4-1 & 3 & 0.056895 & 0 & 0.05690 & 0.05690 \\ 4-2 & 3 & 0.056895 & 0 & 0.05690 & 0.05690\end{array}$

Std Error uses a pooled estimate of error variance
Oneway Analysis of TiO2 (wt\%) By Block/Sub-Block

Reference value $1.049 \mathrm{wt} \%$

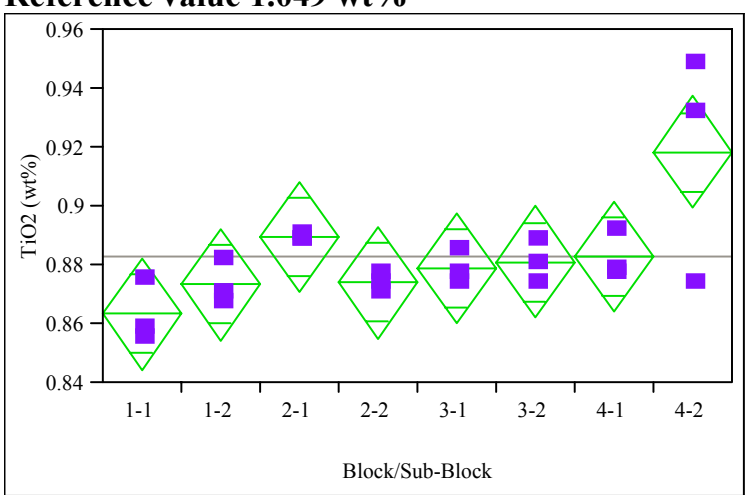

Oneway Anova

Summary of Fit

Rsquare

0.59652

Adj Rsquare

0.419997

Root Mean Square Error

Mean of Response

0.882789

Observations (or Sum Wgts)

Analysis of Variance

Source DF Sum of Squares Mean Square F Ratio Prob $>$ F

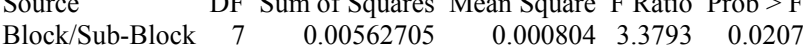

$\begin{array}{llll}\text { Error } & 16 & 0.00380608 & 0.000238\end{array}$

$\begin{array}{lll}\text { C. Total } & 23 & 0.00943313\end{array}$

Means for Oneway Anova

Level Number Mean Std Error Lower 95\% Upper 95\%

$\begin{array}{llllll}1-1 & 3 & 0.863468 & 0.00890 & 0.84459 & 0.88235\end{array}$

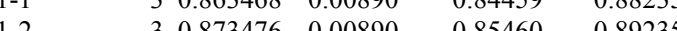

$\begin{array}{llllll}1-2 & 3 & 0.873476 & 0.00890 & 0.85460 & 0.89235 \\ 2-1 & 3 & 0.889600 & 0.00890 & 0.87072 & 0.90848\end{array}$

$\begin{array}{llllll}2-2 & 3 & 0.874032 & 0.00890 & 0.85515 & 0.89291\end{array}$

$\begin{array}{llllll}3-1 & 3 & 0.879036 & 0.00890 & 0.86016 & 0.89791 \\ 3-2 & 3 & 0.881260 & 0.00890 & 0.86238 & 0.90014\end{array}$

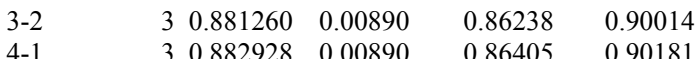

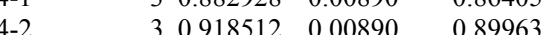

Std Error uses a pooled estimate of error variance 


\section{Exhibit C3. PSAL Measurements by Analytical Block for Samples of the} Standard Glasses Prepared Using the LM Method

Oneway Analysis of $\mathrm{ZnO}(w \mathrm{t} \%)$ By Block/Sub-Block

Reference value 0 wt\%

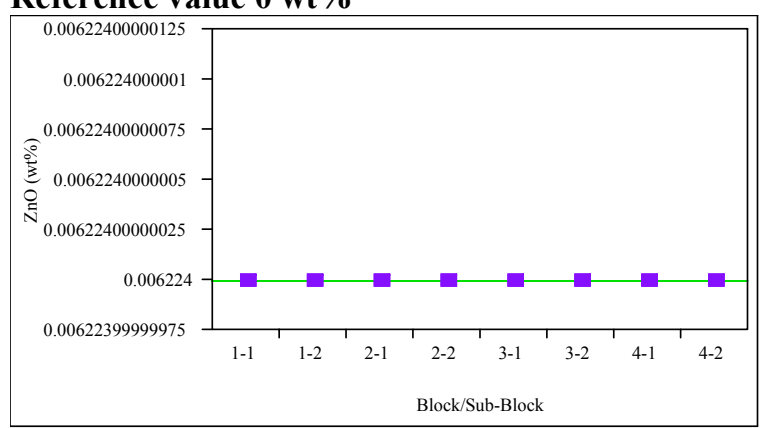

Oneway Anova

Summary of Fit

Rsquare

Adj Rsquare

Root Mean Square Error

Mean of Response

Observations (or Sum Wgts)

0
0.006224
24

Analysis of Variance

Source DF Sum of Squares Mean Square F Ratio Prob $>$ F

C. Tota

23

0

Means for Oneway Anova

Level Number Mean Std Error Lower 95\% Upper 95\%

$\begin{array}{llllll}1-1 & 3 & 0.006224 & 0 & 0.00622 & 0.00622\end{array}$

$\begin{array}{llllll}1-2 & 3 & 0.006224 & 0 & 0.00622 & 0.00622\end{array}$

$\begin{array}{llllll}2-1 & 3 & 0.006224 & 0 & 0.00622 & 0.00622\end{array}$

$\begin{array}{llllll}2-2 & 3 & 0.006224 & 0 & 0.00622 & 0.00622\end{array}$

$\begin{array}{llllll}3-1 & 3 & 0.006224 & 0 & 0.00622 & 0.00622\end{array}$

$\begin{array}{llllll}3-2 & 3 & 0.006224 & 0 & 0.00622 & 0.00622\end{array}$

$\begin{array}{llllll}4-1 & 3 & 0.006224 & 0 & 0.00622 & 0.00622\end{array}$

$\begin{array}{lllll}4-2 & 3 & 0.006224 & 0 & 0.00622\end{array}$

Std Error uses a pooled estimate of error variance
Oneway Analysis of ZrO2 (wt\%) By Block/Sub-Block

Reference value 0 wt \%

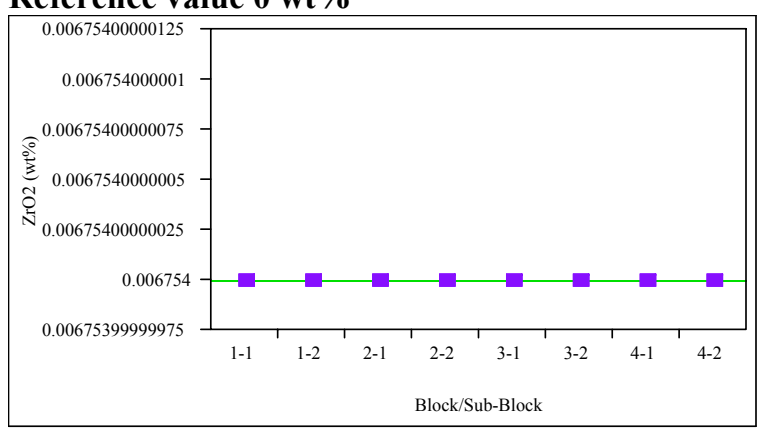

\section{Oneway Anova}

Summary of Fit

Rsquare

Root Mean Square Error

Mean of Response

Observations (or Sum Wgts) 24

Analysis of Variance

Source DF Sum of Squares Mean Square F Ratio Prob > F Block/Sub-Block 7

Error $\quad 16$

Means for Oneway Anova

Level Number Mean Std Error Lower 95\% Upper 95\%

$\begin{array}{llllll}1-1 & 3 & 0.006754 & 0 & 0.00675 & 0.00675\end{array}$

$\begin{array}{llllll}1-2 & 3 & 0.006754 & 0 & 0.00675 & 0.00675\end{array}$

$\begin{array}{llllll}2-1 & 3 & 0.006754 & 0 & 0.00675 & 0.00675 \\ 2-2 & 3 & 0.006754 & 0 & 0.00675 & 0.00675\end{array}$

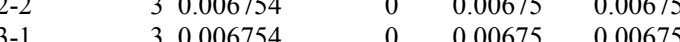

$\begin{array}{llllll}3-1 & 3 & 0.006754 & 0 & 0.00675 & 0.00675 \\ 3-2 & 3 & 0.006754 & 0 & 0.00675 & 0.00675\end{array}$

$\begin{array}{llllll}3-2 & 3 & 0.006754 & 0 & 0.00675 & 0.00675 \\ 4-1 & 3 & 0.006754 & 0 & 0.00675 & 0.00675\end{array}$

$\begin{array}{llllll}4-2 & 3 & 0.006754 & 0 & 0.00675 & 0.00675\end{array}$

Std Error uses a pooled estimate of error variance 


\section{Exhibit C4: PSAL Measurements by Analytical Block for Samples of the} Standard Glasses Prepared Using the PF Method

Glass ID=Batch 1

Oneway Analysis of Al2O3 (wt\%) By Block/Sub-Block Reference value $4.877 \mathrm{wt} \%$

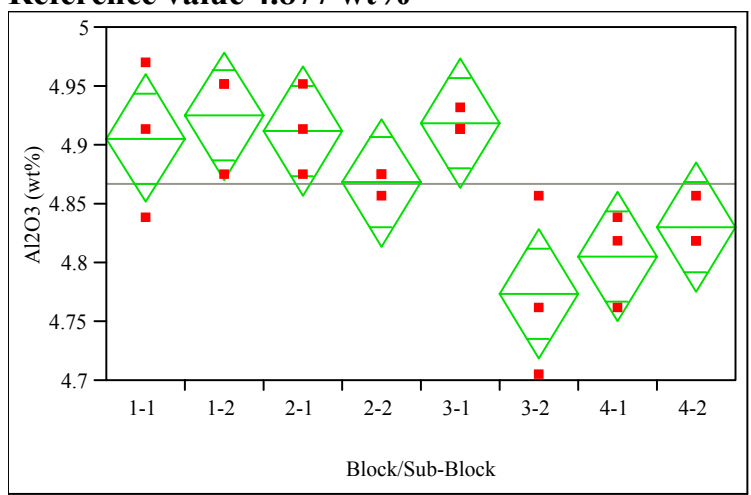

Oneway Anova

Summary of Fit

Rsquare

Adj Rsquare

0.68957

0.553756

Root Mean Square Error $\quad 0.04448$

Mean of Response

4.867824

(or Sum Wgts)

Analysis of Variance

DF Sum of Squares Mean Square F Ratio Prob $>$ F

Block/Sub-Block

0.07031827

$\begin{array}{rrr} & & \\ 0.010045 & 5.0773 & 0.0034\end{array}$

Error

$\begin{array}{ll}16 & 0.03165586 \\ 23 & 0.10197413\end{array}$

0.001978

\section{Means for Oneway Anova}

Level Number Mean Std Error Lower 95\% Upper 95\%

$\begin{array}{lrrrrr}1-1 & 3 & 4.90640 & 0.02568 & 4.8520 & 4.9608\end{array}$

$\begin{array}{llllll}1-2 & 3 & 4.92530 & 0.02568 & 4.8709 & 4.9797\end{array}$

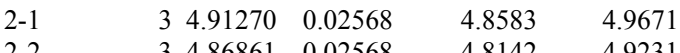

$\begin{array}{llllll}2-2 & 3 & 4.86861 & 0.02568 & 4.8142 & 4.9231 \\ 3-1 & 3 & 4.91900 & 0.02568 & 4.8646 & 4.9734\end{array}$

$\begin{array}{llllll}3-1 & 3 & 4.91900 & 0.02568 & 4.8646 & 4.9734 \\ 3-2 & 3 & 4.77414 & 0.02568 & 4.7197 & 4.8286\end{array}$

$\begin{array}{llllll}4-1 & 3 & 4.80563 & 0.02568 & 4.7512 & 4.8601\end{array}$

$\begin{array}{llllll}4-2 & 3 & 4.83082 & 0.02568 & 4.7764 & 4.885\end{array}$

Std Error uses a pooled estimate of error variance
Oneway Analysis of B2O3 (wt\%) By Block/Sub-Block Reference value $7.777 \mathrm{wt} \%$

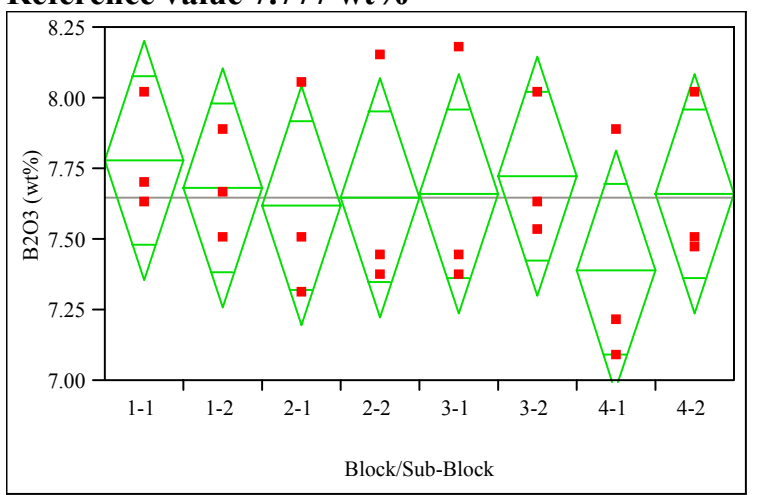

\section{Oneway Anova}

Summary of Fit

$\begin{array}{lr}\text { Rsquare } & 0.124351 \\ \text { Adj Rsquare } & -0.25874 \\ \text { Root Mean Square Error } & 0.34617 \\ \text { Mean of Response } & 7.648604 \\ \text { Observations (or Sum Wgts) } & 24\end{array}$

Observations (or Sum Wgts) $\quad 24$

\section{Analysis of Variance}

Source DF Sum of Squares Mean Square F Ratio Prob > F $\begin{array}{lrrrrr}\text { Block/Sub-Block } & 7 & 0.2722832 & 0.038898 & 0.3246 & 0.9316\end{array}$ $\begin{array}{lll}\text { Error } & 16 & 1.9173437 \\ \text { C. } & 23 & 2.1896269\end{array}$

Means for Oneway Anova

Level Number Mean Std Error Lower 95\% Upper 95\%

$\begin{array}{llllll}1-1 & 3 & 7.78143 & 0.19986 & 7.3577 & 8.205\end{array}$

$\begin{array}{llllll}1-2 & 3 & 7.68483 & 0.19986 & 7.2611 & 8.1085\end{array}$

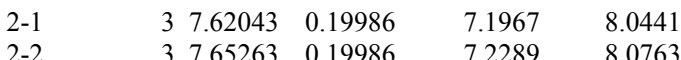

$\begin{array}{llllll}2-2 & 3 & 7.65263 & 0.19986 & 7.2289 & 8.0763 \\ 3-1 & 3 & 7.66336 & 0.19986 & 7.2397 & 8.0870\end{array}$

$\begin{array}{llllll}3-2 & 3 & 7.72776 & 0.19986 & 7.3041 & 8.1514\end{array}$

$\begin{array}{llllll}4-1 & 3 & 7.39504 & 0.19986 & 6.9713 & 7.8187\end{array}$

$\begin{array}{llllll}4-2 & 3 & 7.66336 & 0.19986 & 7.2397 & 8.0870\end{array}$

Std Error uses a pooled estimate of error variance 


\section{Exhibit C4: PSAL Measurements by Analytical Block for Samples of the} Standard Glasses Prepared Using the PF Method

Oneway Analysis of Fe2O3 (wt\%) By Block/Sub-Block

Reference value $12.839 \mathrm{wt} \%$

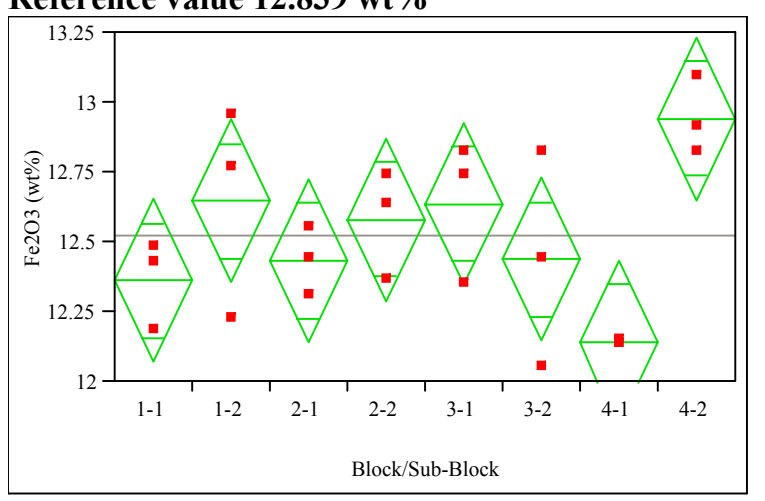

\section{Oneway Anova}

Summary of Fit

$\begin{array}{lr}\text { Rsquare } & 0.566949 \\ \text { Adj Rsquare } & 0.377489 \\ \text { Root Mean Square Error } & 0.23777 \\ \text { Mean of Response } & 12.52358 \\ \text { Observations (or Sum Wgts) } & 24 \\ \text { Analysis of Variance } & \end{array}$

Source DF Sum of Squares Mean Square F Ratio Prob > F

$\begin{array}{llllll}\text { Block/Sub-Block } & 7 & 1.1842413 & 0.169177 & 2.9924 & 0.0329\end{array}$

$\begin{array}{lll}\text { Error } & 16 & 0.9045568\end{array}$

$\begin{array}{lll}\text { C. Total } & 23 & 2.0887981\end{array}$

Means for Oneway Anova

Level Number Mean Std Error Lower 95\% Upper 95\%

\begin{tabular}{|c|c|c|c|c|}
\hline $1-1$ & 312.3621 & 0.13728 & 12.071 & 12.653 \\
\hline $1-2$ & 312.6481 & 0.13728 & 12.357 & 12.939 \\
\hline $2-1$ & 312.4336 & 0.13728 & 12.143 & 12.725 \\
\hline $2-2$ & 312.5814 & 0.13728 & 12.290 & 12.872 \\
\hline & 312.6385 & 0.13728 & 12.348 & 12.930 \\
\hline & 312.4384 & 0.13728 & 12.147 & 12.729 \\
\hline & 312.1429 & 0.13728 & 11.852 & 12.434 \\
\hline & 312.9436 & 0.13728 & 12.653 & 13.23 \\
\hline
\end{tabular}

Std Error uses a pooled estimate of error variance
Oneway Analysis of Li2O (wt\%) By Block/Sub-Block

Reference value $4.429 \mathrm{wt} \%$

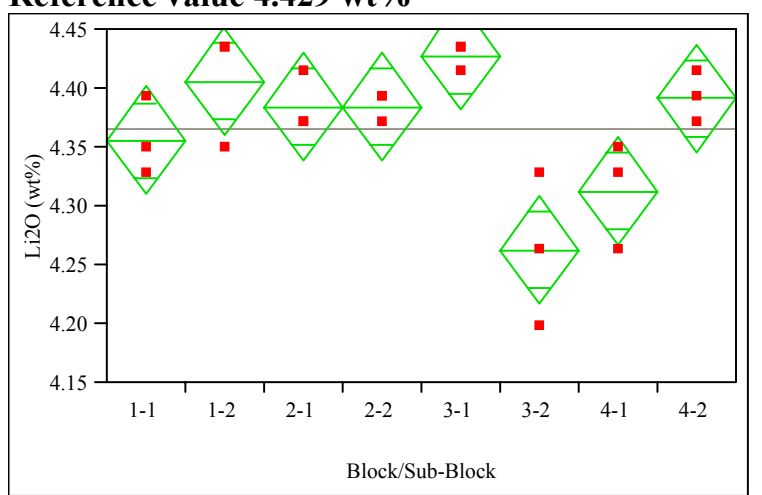

\section{Oneway Anova}

Summary of Fit

$\begin{array}{lr}\text { Rsquare } & 0.733272 \\ \text { Adj Rsquare } & 0.616578 \\ \text { Root Mean Square Error } & 0.037289 \\ \text { Mean of Response } & 4.365902 \\ \text { Observations (or Sum Wgts) } & 24 \\ \text { Analysis of Variance } & \end{array}$

Analysis of Variance

Source DF Sum of Squares Mean Square F Ratio Prob > F

$\begin{array}{lrrrrr} & \text { DF Sum of Squares } & \text { Mean Square } & \text { F Ratio Prob > F } \\ \text { Block/Sub-Block } & 7 & 0.06116240 & 0.008737 & 6.2837 & 0.0012\end{array}$

$\begin{array}{llll}\text { Error } & 16 & 0.02224790 & 0.001390\end{array}$

$\begin{array}{lll}\text { C. Total } & 23 & 0.08341030\end{array}$

Means for Oneway Anova

Level Number Mean Std Error Lower 95\% Upper 95\%

$\begin{array}{llllrr}1-1 & 3 & 4.35603 & 0.02153 & 4.3104 & 4.4017\end{array}$

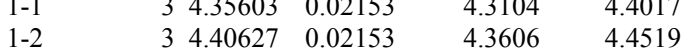

$\begin{array}{llllll}1-2 & 3 & 4.40627 & 0.02153 & 4.3606 & 4.4519 \\ 2-1 & 3 & 4.38474 & 0.02153 & 4.3391 & 4.4304\end{array}$

$\begin{array}{llllll}2-2 & 3 & 4.38474 & 0.02153 & 4.3391 & 4.4304\end{array}$

$\begin{array}{llllll}2-2 & 3 & 4.42780 & 0.02153 & 4.3822 & 4.4734\end{array}$

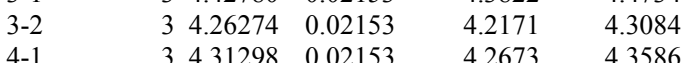

$\begin{array}{lll}4-1 & 3 & 4.31298 \\ 4-2 & 0.02153\end{array}$

Std Error uses a pooled estimate of error variance 


\section{Exhibit C4: PSAL Measurements by Analytical Block for Samples of the} Standard Glasses Prepared Using the PF Method

Oneway Analysis of NiO (wt\%) By Block/Sub-Block

Reference value $0.751 \mathrm{wt} \%$

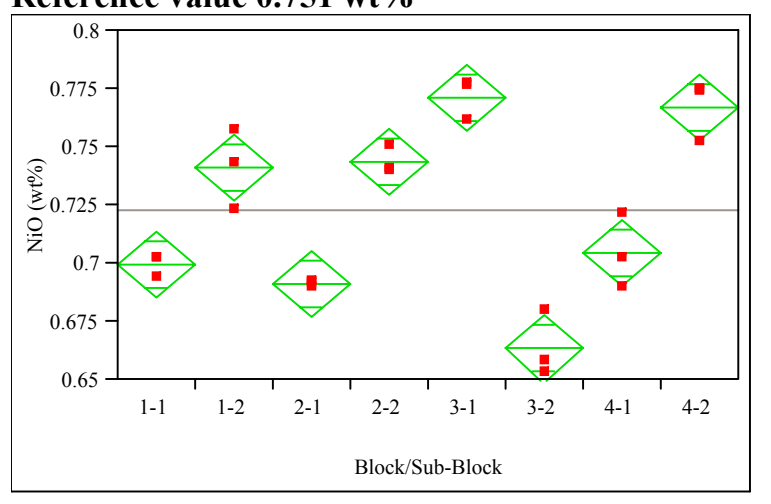

\section{Oneway Anova}

Summary of Fit

$\begin{array}{lr}\text { Rsquare } & 0.936187 \\ \text { Adj Rsquare } & 0.908268 \\ \text { Root Mean Square Error } & 0.011587 \\ \text { Mean of Response } & 0.722674 \\ \text { Observations (or Sum Wgts) } & 24 \\ \text { Analysis of Variance } & \end{array}$

Analysis of Variance

Source DF Sum of Squares Mean Square F Ratio Prob $>$ F

$\begin{array}{lllllll}\text { Block/Sub-Block } 7 & 0.03151585 & 0.004502 & 33.5331 & <.0001\end{array}$

$\begin{array}{lll}\text { Error } & 16 & 0.00214821\end{array}$

C. Total $\quad 23 \quad 0.03366407$

\section{Means for Oneway Anova}

Level Number Mean Std Error Lower 95\% Upper 95\%

$\begin{array}{llllll}1-1 & 3 & 0.699451 & 0.00669 & 0.68527 & 0.71363\end{array}$

$\begin{array}{llllll}1-2 & 3 & 0.741019 & 0.00669 & 0.72684 & 0.75520\end{array}$

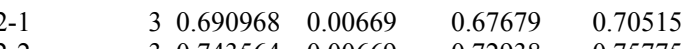

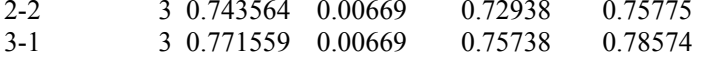

$\begin{array}{llllll}3-2 & 3 & 0.663397 & 0.00669 & 0.64921 & 0.67758\end{array}$

$\begin{array}{llllll}4-1 & 3 & 0.704541 & 0.00669 & 0.69036 & 0.71872\end{array}$

$\begin{array}{llllll}4-2 & 3 & 0.766893 & 0.00669 & 0.75271 & 0.78108\end{array}$

Std Error uses a pooled estimate of error variance
Oneway Analysis of $\mathrm{SiO2}$ (wt\%) By Block/Sub-Block

Reference value $50.22 \mathrm{wt} \%$

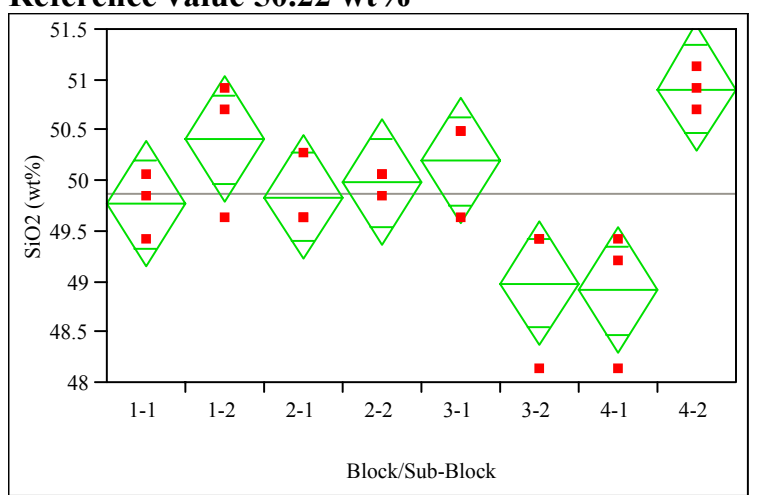

\section{Oneway Anova}

Summary of Fit

Rsquare

0.701559

Adj Rsquare

0.570991

Root Mean Square Error $\quad 0.505497$

Mean of Response

49.88135

Observations (or Sum Wgts)

Analysis of Variance

Source DF Sum of Squares Mean Square F Ratio Prob $>$ F

$\begin{array}{llllll}\text { Block/Sub-Block } & 7 & 9.610869 & 1.37298 & 5.3731 & 0.0026\end{array}$

$\begin{array}{llll}\text { Error } & 16 & 4.088433 & 0.25553\end{array}$

$\begin{array}{lll}\text { C. Total } & 23 & 13.699303\end{array}$

Means for Oneway Anova

Level Number Mean Std Error Lower 95\% Upper 95\%

$\begin{array}{lllllr}1-1 & 3 & 49.7744 & 0.29185 & 49.156 & 50.393\end{array}$

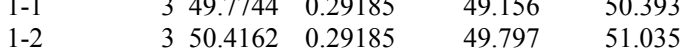

$\begin{array}{llllll}1-2 & 3 & 50.4162 & 0.29185 & 49.797 & 51.035 \\ 2-1 & 3 & 49.8457 & 0.29185 & 49.227 & 50.464\end{array}$

$\begin{array}{llllll}2-2 & 3 & 49.9883 & 0.29185 & 49.370 & 50.607\end{array}$

$\begin{array}{llllll}3-1 & 3 & 50.2022 & 0.29185 & 49.584 & 50.821\end{array}$

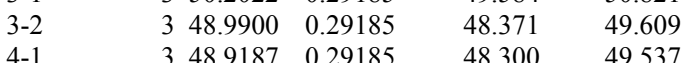

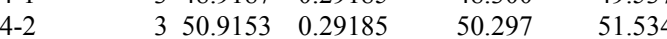

Std Error uses a pooled estimate of error variance 


\section{Exhibit C4: PSAL Measurements by Analytical Block for Samples of the} Standard Glasses Prepared Using the PF Method

Oneway Analysis of U3O8 (wt\%) By Block/Sub-Block Reference value $50.22 \mathrm{wt} \%$

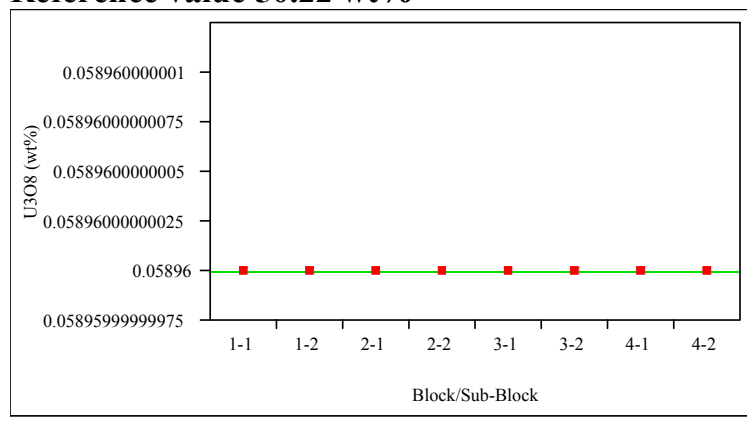

\section{Oneway Anova}

Summary of Fit

\section{Rsquare}

Adj Rsquare

Root Mean Square Error

Mean of Response

Observations (or Sum Wgts)

Analysis of Variance

Source DF Sum of Squares Mean Square F Ratio Prob $>$ F

Block/Sub-Block $7 \quad 4.6222 \mathrm{e}-33 \quad 6.603 \mathrm{e}-34$

$\begin{array}{llr}\text { Error } & 16 & 0 \\ \text { C. Total } & 23 & 4.6222 \mathrm{e}-33\end{array}$

Means for Oneway Anova

Level Number Mean Std Error Lower 95\% Upper 95\%

$\begin{array}{llllll}1-1 & 3 & 0.058960 & 0 & 0.05896 & 0.05896 \\ 1-2 & 3 & 0.058960 & 0 & 0.05896 & 0.05896 \\ 2-1 & 3 & 0.058960 & 0 & 0.05896 & 0.05896 \\ 2-2 & 3 & 0.058960 & 0 & 0.05896 & 0.05896 \\ 3-1 & 3 & 0.058960 & 0 & 0.05896 & 0.05896 \\ 3-2 & 3 & 0.058960 & 0 & 0.05896 & 0.05896 \\ 4-1 & 3 & 0.058960 & 0 & 0.05896 & 0.05896 \\ 4-2 & 3 & 0.058960 & 0 & 0.05896 & 0.05896\end{array}$

Std Error uses a pooled estimate of error variance

\section{Glass ID $=$ Ustd}

Oneway Analysis of Al2O3 (wt\%) By Block/Sub-Block

Reference value $4.1 \mathrm{wt} \%$

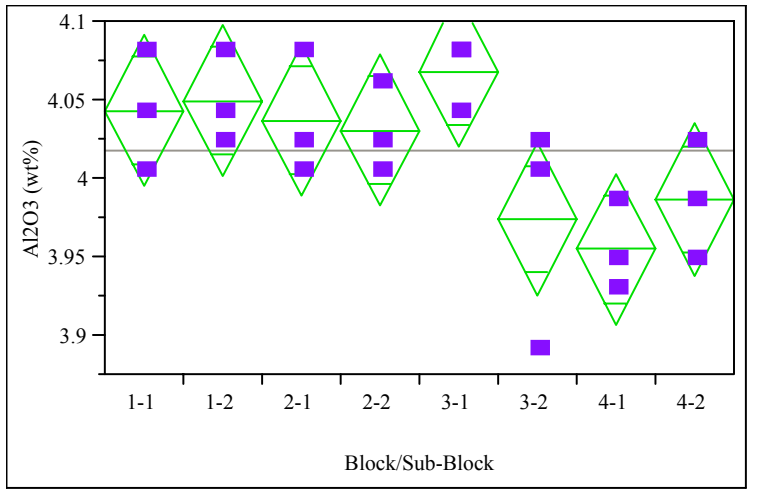

\section{Oneway Anova}

Summary of Fit

$\begin{array}{lr}\text { Rsquare } & 0.581673 \\ \text { Adj Rsquare } & 0.398655 \\ \text { Root Mean Square Error } & 0.039522 \\ \text { Mean of Response } & 4.018337 \\ \text { Observations (or Sum Wgts) } & 24\end{array}$

Observations (or Sum Wgts) 24

Analysis of Variance

Source DF Sum of Squares Mean Square F Ratio Prob > F

$\begin{array}{lrrrrr}\text { Block/Sub-Block } & 7 & 0.03475005 & 0.004964 & 3.1782 & 0.0263\end{array}$

$\begin{array}{llll}\text { Error } & 16 & 0.02499147 & 0.001562\end{array}$

0.05974152

Means for Oneway Anova

Level Number Mean Std Error Lower 95\% Upper 95\%

$\begin{array}{llllrr}1-1 & 3 & 4.04353 & 0.02282 & 3.9952 & 4.0919\end{array}$

$\begin{array}{llllll}1-2 & 3 & 4.04983 & 0.02282 & 4.0015 & 4.0982\end{array}$

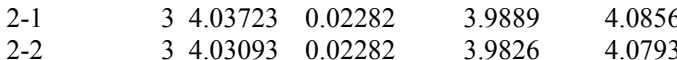

$\begin{array}{llllll}3-1 & 3 & 4.06872 & 0.02282 & 4.0204 & 4.1171\end{array}$

$\begin{array}{llllll}3-2 & 3 & 3.97425 & 0.02282 & 3.9259 & 4.0226\end{array}$

$\begin{array}{llllll}4-1 & 3 & 3.95535 & 0.02282 & 3.9070 & 4.0037\end{array}$

$\begin{array}{llllll}4-2 & 3 & 3.98684 & 0.02282 & 3.9385 & 4.0352\end{array}$

Std Error uses a pooled estimate of error variance 


\section{Exhibit C4: PSAL Measurements by Analytical Block for Samples of the} Standard Glasses Prepared Using the PF Method

Oneway Analysis of B2O3 (wt\%) By Block/Sub-Block

Reference value $9.209 \mathrm{wt} \%$

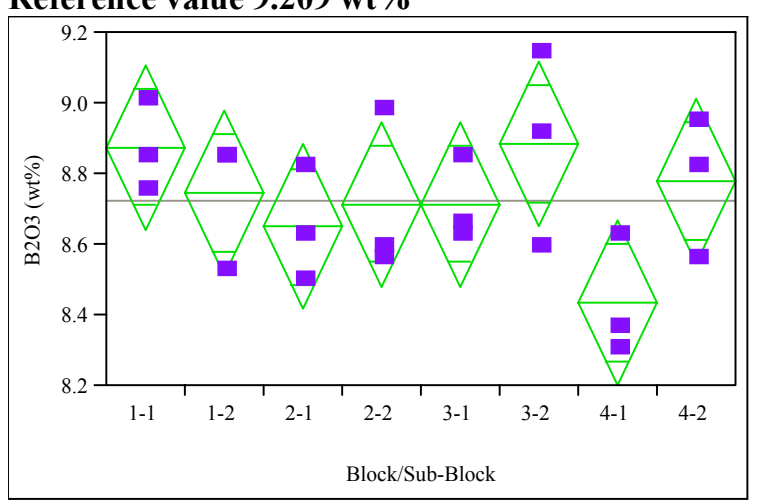

\section{Oneway Anova}

Summary of Fit

\section{Rsquare \\ Root Mean Square Error $\quad 0.190492$ \\ Mean of Response $\quad 8.725929$ \\ Observations (or Sum Wgts)}

Analysis of Variance

Source DF Sum of Squares Mean Square F Ratio Prob > F

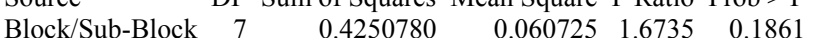

$\begin{array}{llll}\text { Error } & 16 & 0.5805943 & 0.036287\end{array}$

C. Total $23 \quad 1.0056723$

Means for Oneway Anova

Level Number Mean Std Error Lower 95\% Upper 95\%

$\begin{array}{llllll}1-1 & 3 & 8.87619 & 0.10998 & 8.6430 & 9.1093\end{array}$

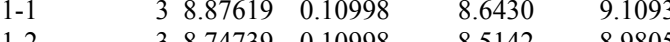

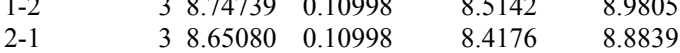

$\begin{array}{llllll}2-2 & 3 & 8.71520 & 0.10998 & 8.4820 & 8.9483\end{array}$

$\begin{array}{llllll}3-1 & 3 & 8.71520 & 0.10998 & 8.4820 & 8.9483\end{array}$

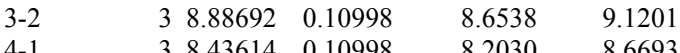

$\begin{array}{lllll}4-2 & 3 & 8.77959 & 0.10998 & 8.5464\end{array}$

Std Error uses a pooled estimate of error variance
Oneway Analysis of Fe2O3 (wt\%) By Block/Sub-Block Reference value 13.196 wt\%

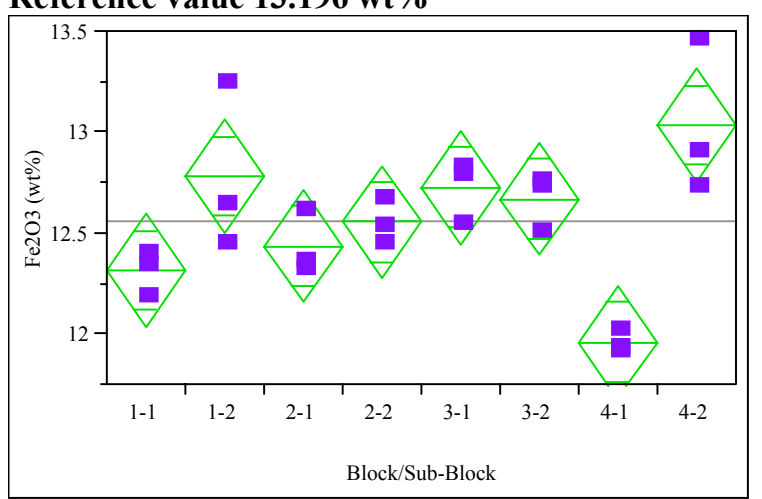

\section{Oneway Anova}

Summary of Fit

Rsquare

0.72985

$\begin{array}{lr}\text { Adj Rsquare } & 0.61166 \\ \text { Root Mean Square Error } & 0.228473\end{array}$

$\begin{array}{lr}\text { Adj Rsquare } & 0.61166 \\ \text { Root Mean Square Error } & 0.228473\end{array}$

Mean of Response $\quad 12.56289$

Observations (or Sum Wgts) $\quad 24$

Analysis of Variance

Source DF Sum of Squares Mean Square F Ratio Prob > F

$\begin{array}{lrrrrr} & & & \\ \text { Block/Sub-Block } & 7 & 2.2564095 & 0.322344 & 6.1752 & 0.0013\end{array}$

$\begin{array}{llll}\text { Error } & 16 & 0.8351956 & 0.052200\end{array}$

$\begin{array}{lll}\text { C. Total } & 23 & 3.0916051\end{array}$

Means for Oneway Anova

Level Number Mean Std Error Lower 95\% Upper 95\%

$\begin{array}{lllllr}1-1 & 3 & 12.3192 & 0.13191 & 12.040 & 12.599\end{array}$

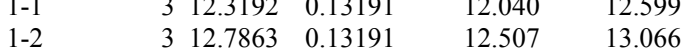

$\begin{array}{llllll}1-2 & 3 & 12.7863 & 0.13191 & 12.507 & 13.066 \\ 2-1 & 3 & 12.4384 & 0.13191 & 12.159 & 12.718\end{array}$

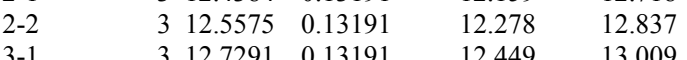

$\begin{array}{llllll}3-1 & 3 & 12.7291 & 0.13191 & 12.449 & 13.009\end{array}$

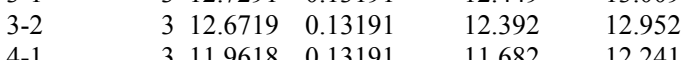

$\begin{array}{llllll}4-1 & 3 & 11.9618 & 0.13191 & 11.682 & 12.241 \\ 4-2 & 3 & 13.0389 & 0.13191 & 12.759 & 13.318\end{array}$

Std Error uses a pooled estimate of error variance 


\section{Exhibit C4: PSAL Measurements by Analytical Block for Samples of the} Standard Glasses Prepared Using the PF Method

Oneway Analysis of Li2O (wt\%) By Block/Sub-Block

Reference value $3.057 \mathrm{wt} \%$

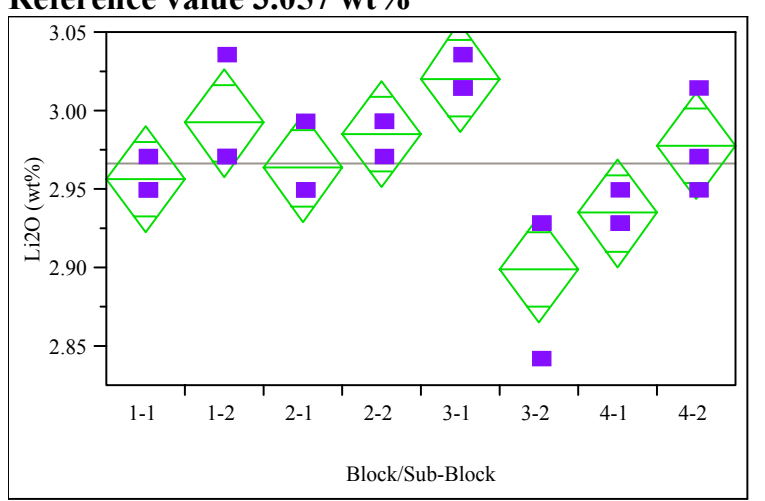

\section{Oneway Anova}

Summary of Fit

$\begin{array}{lr}\text { Rsquare } & 0.703566 \\ \text { Adj Rsquare } & 0.573877 \\ \text { Root Mean Square Error } & 0.027794 \\ \text { Mean of Response } & 2.966517 \\ \text { Observations (or Sum Wgts) } & 24 \\ \text { Analysis of Variance } & \end{array}$

Analysis of Variance

Source DF Sum of Squares Mean Square F Ratio Prob > F

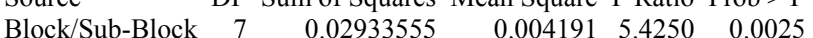

$\begin{array}{llll}\text { Error } & 16 & 0.01235994 & 0.000772\end{array}$

$\begin{array}{lll}\text { C. Total } & 23 & 0.04169549\end{array}$

Means for Oneway Anova

Level Number Mean Std Error Lower 95\% Upper 95\%

$\begin{array}{llllll}1-1 & 3 & 2.95665 & 0.01605 & 2.9226 & 2.9907\end{array}$

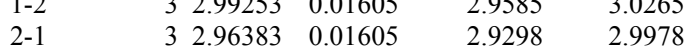

$\begin{array}{llllll}2-2 & 3 & 2.98535 & 0.01605 & 2.9513 & 3.0194\end{array}$

$\begin{array}{llllll}3-1 & 3 & 3.02124 & 0.01605 & 2.9872 & 3.0553\end{array}$

$\begin{array}{llllll}3-2 & 3 & 2.89924 & 0.01605 & 2.8652 & 2.9333 \\ 4-1 & 3 & 2.93512 & 0.01605 & 2.9011 & 2.9691\end{array}$

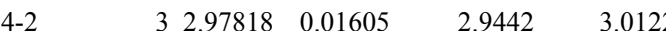

Std Error uses a pooled estimate of error variance
Oneway Analysis of $\mathrm{NiO}$ (wt\%) By Block/Sub-Block

Reference value $1.12 \mathrm{wt} \%$

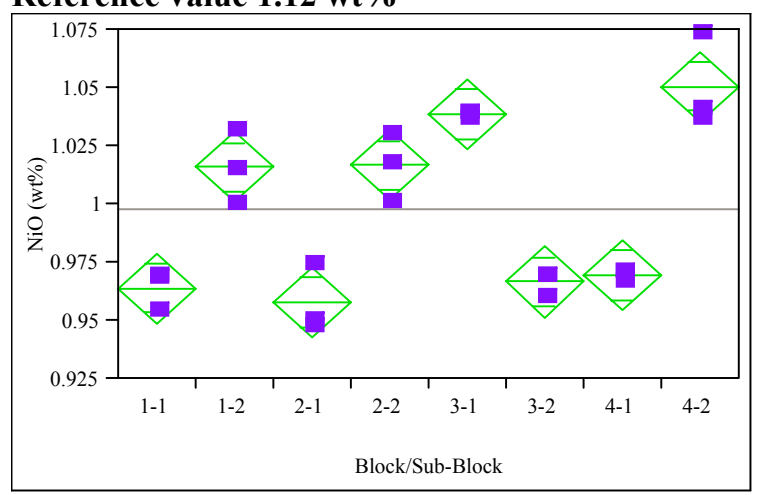

\section{Oneway Anova}

\section{Summary of Fit}

\begin{tabular}{|c|c|c|c|c|c|}
\hline \multicolumn{2}{|l|}{ Rsquare } & 0.923307 & & & \\
\hline Adj Rsquare & & 0.889753 & & & \\
\hline \multicolumn{2}{|c|}{ Root Mean Square Error } & 0.012263 & & & \\
\hline \multicolumn{2}{|c|}{ Mean of Response } & 0.997534 & & & \\
\hline \multicolumn{3}{|c|}{ Observations (or Sum Wgts) } & & & \\
\hline \multicolumn{6}{|c|}{ Analysis of Variance } \\
\hline Source & DF & Sum of Squares & Mean Square & F Ratio & Prob $>$ F \\
\hline Block/Sub-Block & 7 & 0.02896822 & 0.004138 & 27.5175 & $<.0001$ \\
\hline Error & 16 & 0.00240621 & 0.000150 & & \\
\hline C. Total & 23 & 0.03137444 & & & \\
\hline
\end{tabular}

Means for Oneway Anova

Level Number Mean Std Error Lower 95\% Upper 95\%

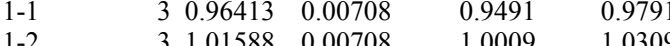

$\begin{array}{llllll}1-2 & 3 & 1.01588 & 0.00708 & 1.0009 & 1.0309 \\ 2-1 & 3 & 0.95777 & 0.00708 & 0.9428 & 0.9728\end{array}$

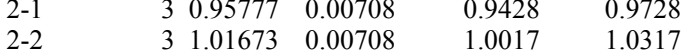

$\begin{array}{llllll}3-1 & 3 & 1.03878 & 0.00708 & 1.0238 & 1.0538\end{array}$

$\begin{array}{llllll}3-2 & 3 & 0.96668 & 0.00708 & 0.9517 & 0.9817\end{array}$

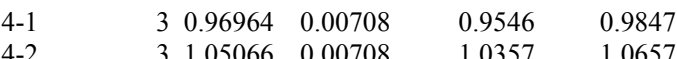

Std Error uses a pooled estimate of error variance 


\section{Exhibit C4: PSAL Measurements by Analytical Block for Samples of the} Standard Glasses Prepared Using the PF Method

Oneway Analysis of $\mathrm{SiO} 2$ (wt\%) By Block/Sub-Block

Reference value $45.353 \mathrm{wt} \%$

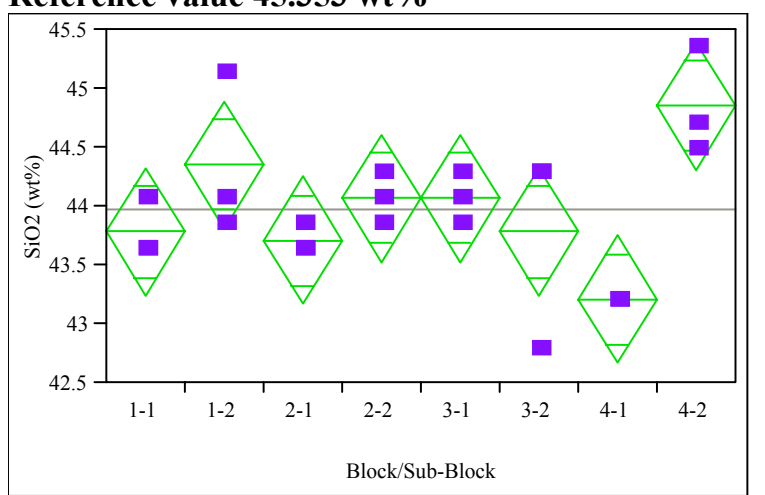

\section{Oneway Anova}

Summary of Fit

\begin{tabular}{lr} 
Rsquare & 0.610122 \\
Adj Rsquare & 0.43955 \\
Root Mean Square Error & 0.445331 \\
Mean of Response & 43.98044 \\
Observations (or Sum Wgts) & 24 \\
\hline Analysis of Variance &
\end{tabular}

Analysis of Variance

Source DF Sum of Squares Mean Square F Ratio Prob > F

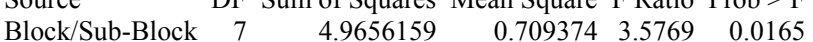

$\begin{array}{llll}\text { Error } & 16 & 3.1731124 & 0.198320\end{array}$

C. Total $23 \quad 8.1387283$

Means for Oneway Anova

Level Number Mean Std Error Lower 95\% Upper 95\%

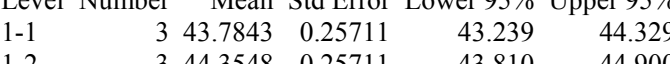

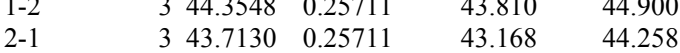

$\begin{array}{llllll}2-2 & 3 & 44.0696 & 0.25711 & 43.525 & 44.615\end{array}$

$\begin{array}{llllll}3-1 & 3 & 44.0696 & 0.25711 & 43.525 & 44.615\end{array}$

$\begin{array}{llllll}3-2 & 3 & 43.7843 & 0.25711 & 43.239 & 44.329 \\ 4-1 & 3 & 43.2139 & 0.25711 & 42.669 & 43.759\end{array}$

$4-2 \quad 3 \quad 44.8540-0.25711-44.309$

Std Error uses a pooled estimate of error variance
Oneway Analysis of U3O8 (wt\%) By Block/Sub-Block

Reference value $2.406 \mathrm{wt} \%$

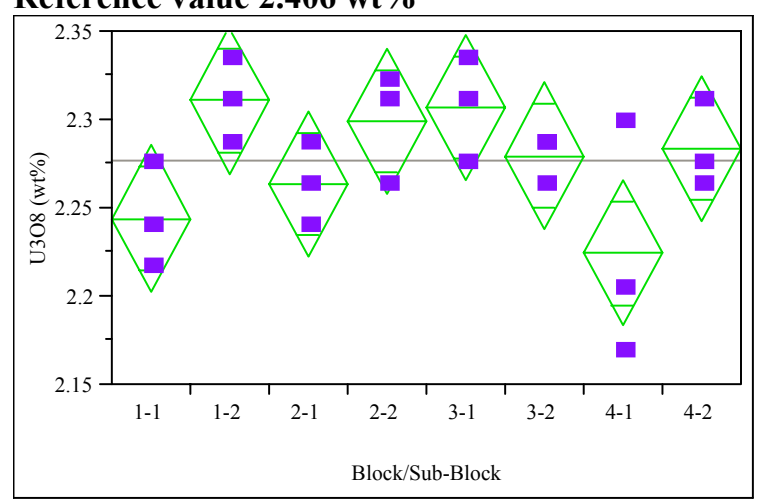

\section{Oneway Anova}

Summary of Fit

$\begin{array}{lr}\text { Rsquare } & 0.52039 \\ \text { Adj Rsquare } & 0.31056 \\ \text { Root Mean Square Error } & 0.033784 \\ \text { Mean of Response } & 2.276839 \\ \text { Observations (or Sum Wgts) } & 24\end{array}$

Observations (or Sum Wgts)

Analysis of Variance

Source DF Sum of Squares Mean Square F Ratio Prob $>$ F

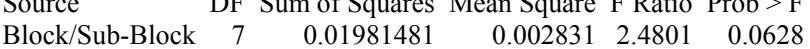

$\begin{array}{llll}\text { Error } & 16 & 0.01826207 & 0.001141\end{array}$

$\begin{array}{lll}\text { C. Total } & 23 & 0.03807687\end{array}$

Means for Oneway Anova

Level Number Mean Std Error Lower 95\% Upper 95\%

$\begin{array}{lllllr}1-1 & 3 & 2.24441 & 0.01951 & 2.2031 & 2.2858\end{array}$

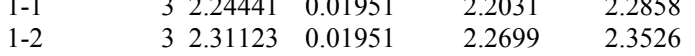

$\begin{array}{llllll}1-2 & 3 & 2.31123 & 0.01951 & 2.2699 & 2.3526 \\ 2-1 & 3 & 2.26406 & 0.01951 & 2.2227 & 2.3054\end{array}$

$\begin{array}{llllll}2-2 & 3 & 2.29944 & 0.01951 & 2.2581 & 2.3408\end{array}$

$\begin{array}{llllll}3-1 & 3 & 2.30730 & 0.01951 & 2.2660 & 2.3487\end{array}$

$\begin{array}{llllll}3-2 & 3 & 2.27979 & 0.01951 & 2.2384 & 2.3211 \\ 4-1 & 3 & 2.22476 & 0.01951 & 2.1834 & 2.2661\end{array}$

$\begin{array}{llllll}4-1 & 3 & 2.22476 & 0.01951 & 2.1834 & 2.2661 \\ 4-2 & 3 & 2.28372 & 0.01951 & 2.2424 & 2.3251\end{array}$

Std Error uses a pooled estimate of error variance 


\section{Exhibit C5. Measured and Measured Bias-Corrected Oxide Weight Percents by Glass \# for the Glasses Prepared Using the LM Method}

(100 - Batch 1;200 - Ustd)

$\mathrm{BaO}(\mathrm{wt} \%)$ By Study Glass \#

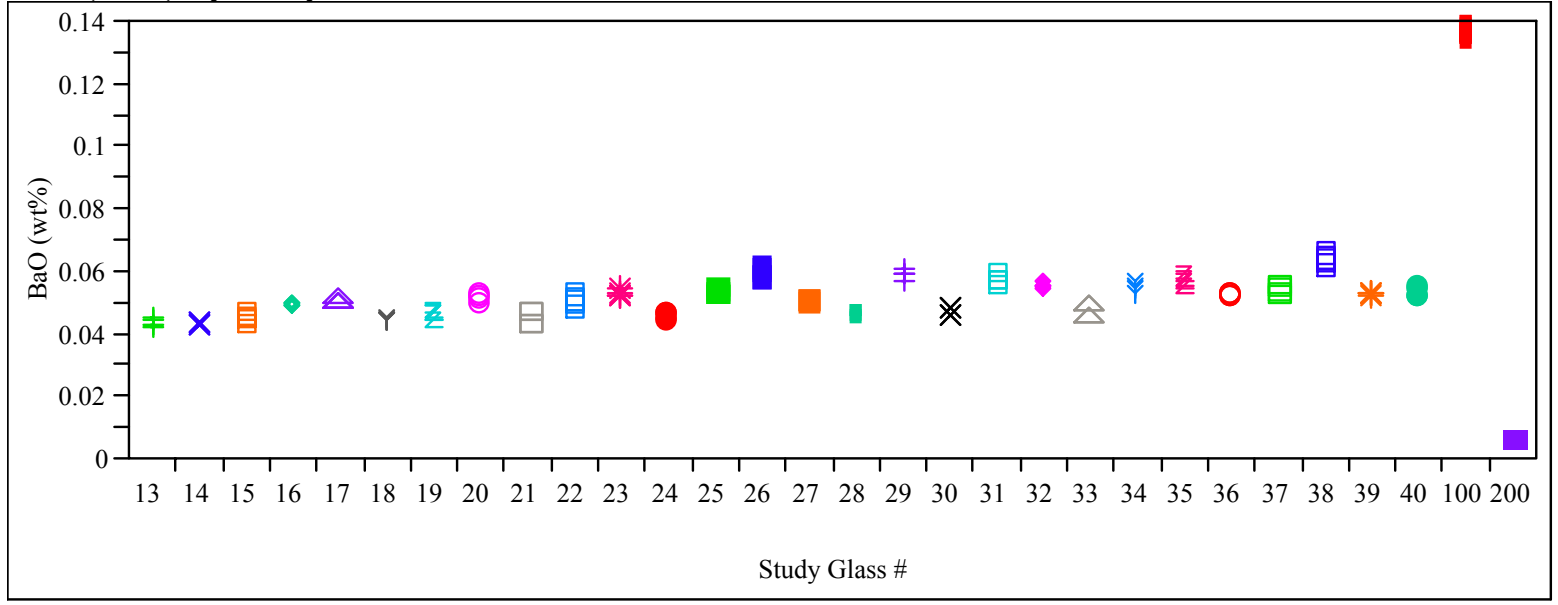

$\mathrm{CaO}(\mathrm{wt} \%)$ By Study Glass \#

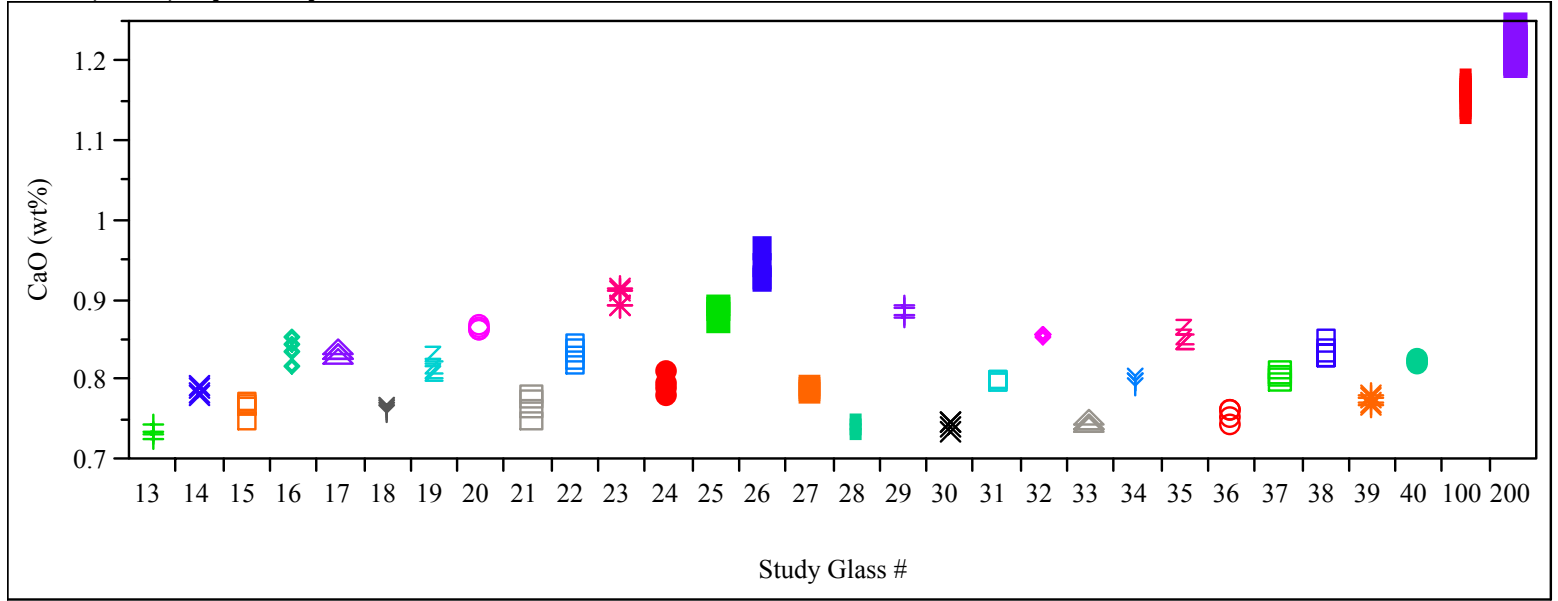

\section{Ce2O3 (wt\%) By Study Glass \#}

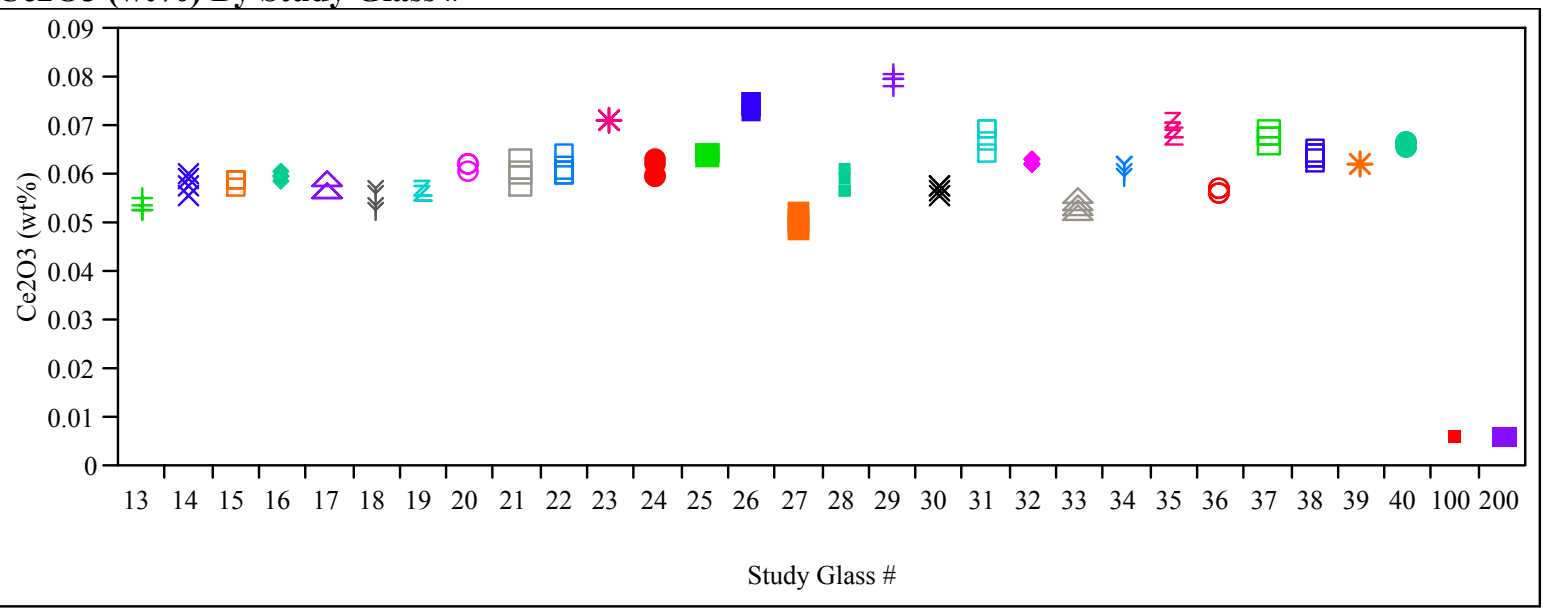




\section{Exhibit C5. Measured and Measured Bias-Corrected Oxide Weight Percents by Glass \# for the Glasses Prepared Using the LM Method}

(100 - Batch 1; 200 - Ustd)

Cr2O3 (wt\%) By Study Glass \#

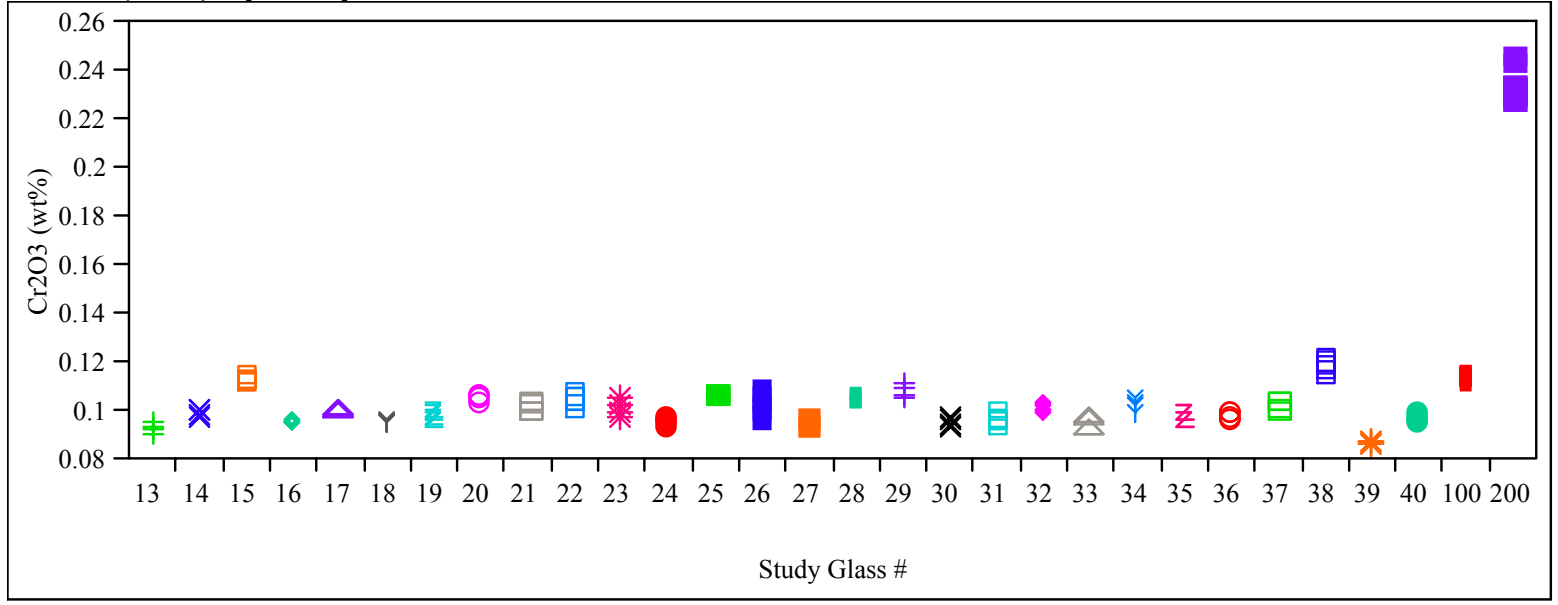

$\mathrm{CuO}(\mathrm{wt} \%)$ By Study Glass \#

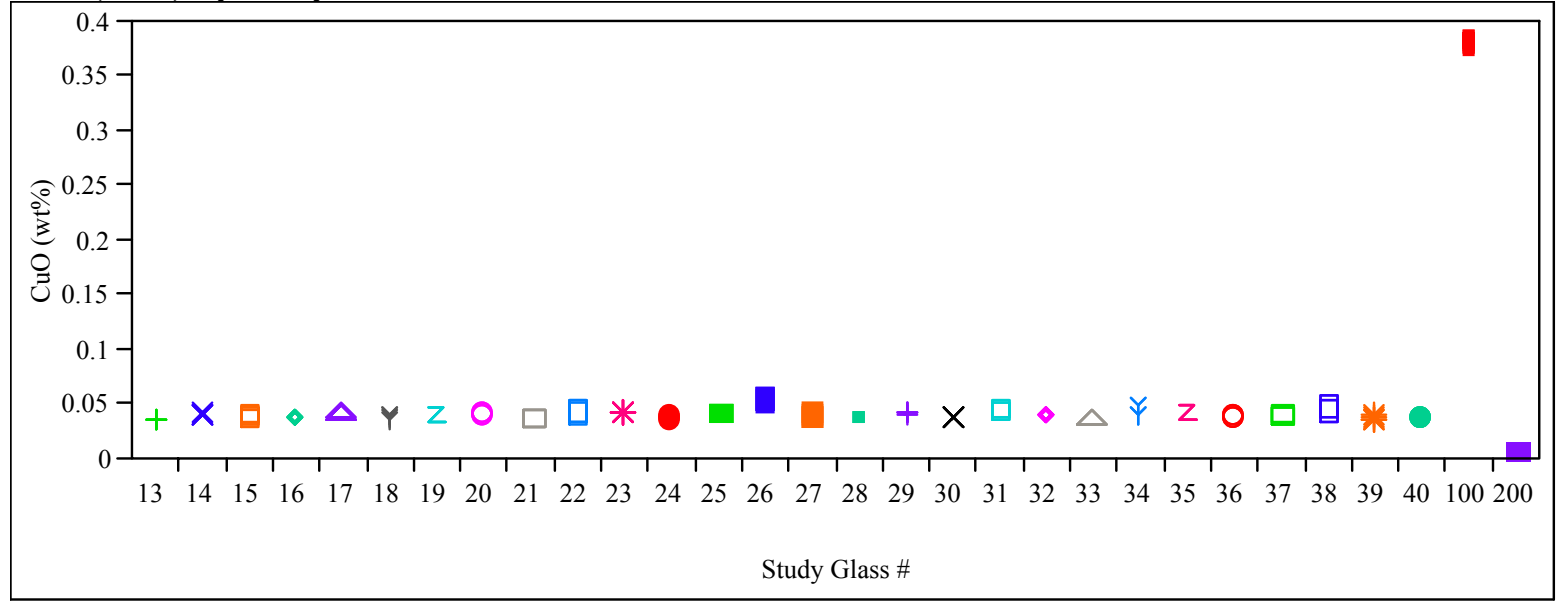

K2O (wt\%) By Study Glass \#

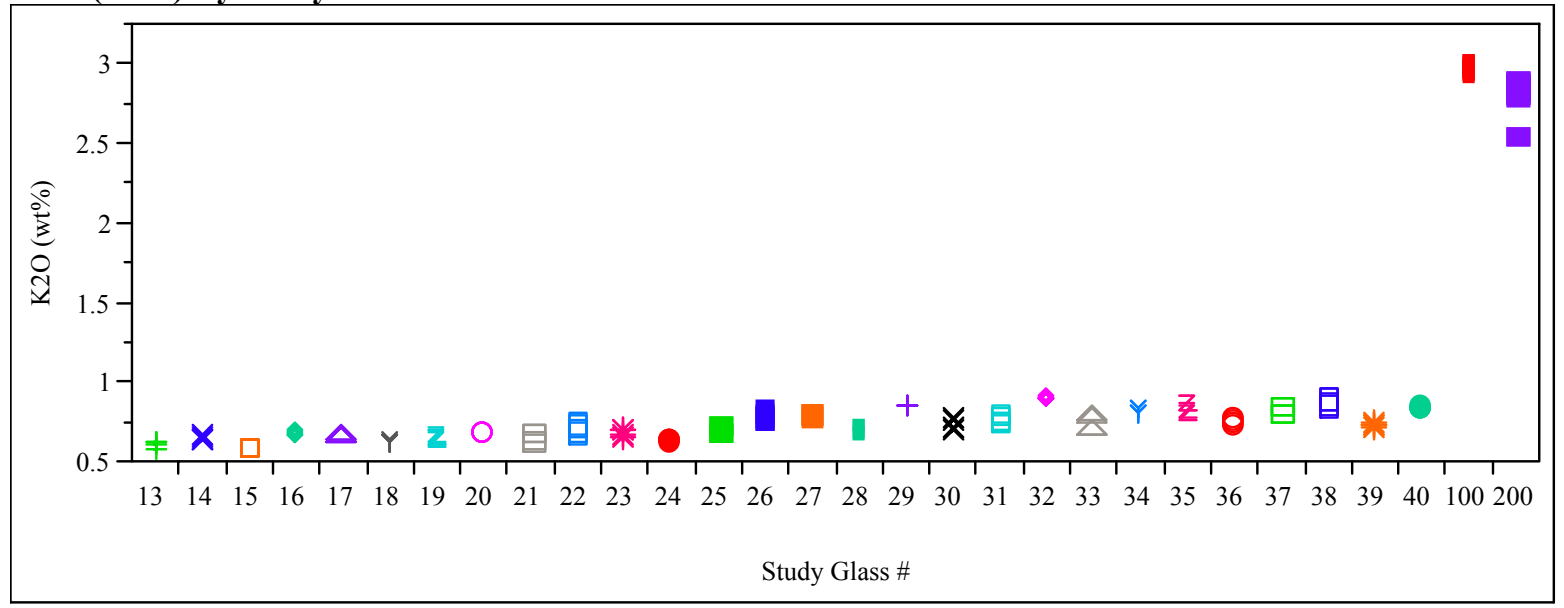




\section{Exhibit C5. Measured and Measured Bias-Corrected Oxide Weight Percents by Glass \# for the Glasses Prepared Using the LM Method}

(100 - Batch 1; 200 - Ustd)

\section{La2O3 (wt\%) By Study Glass \#}

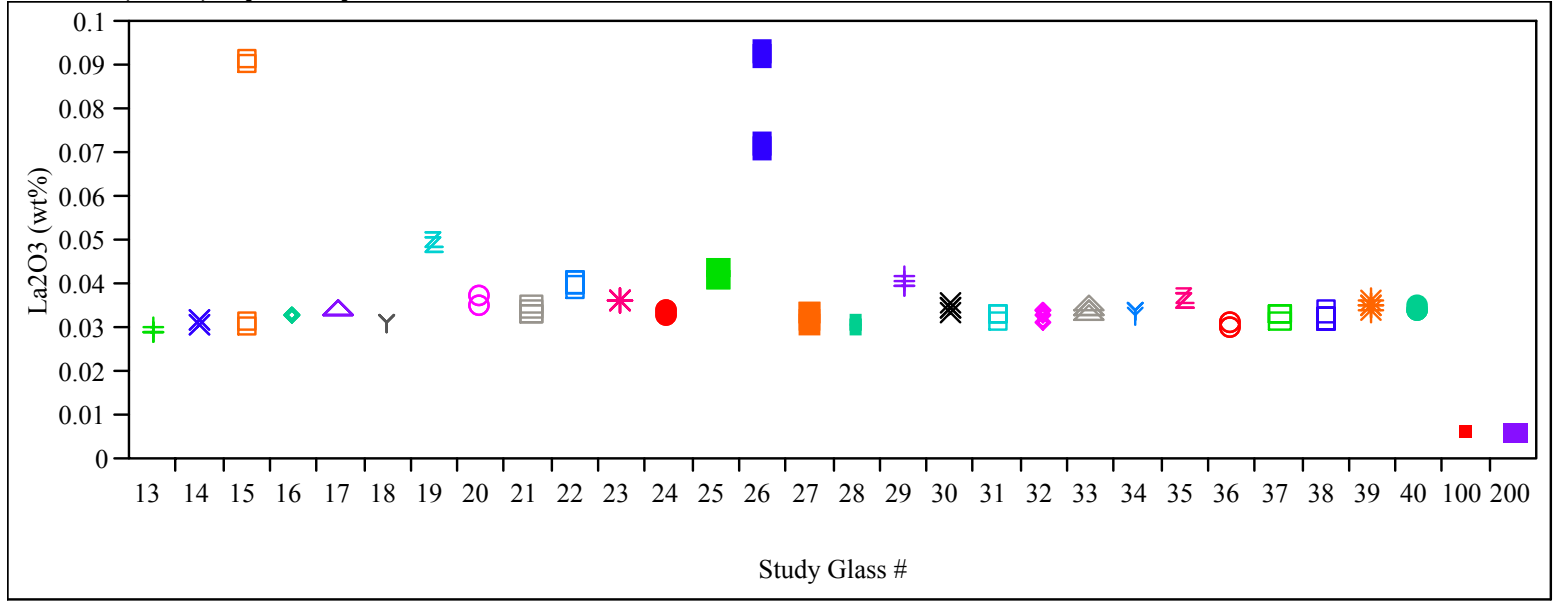

MgO (wt\%) By Study Glass \#

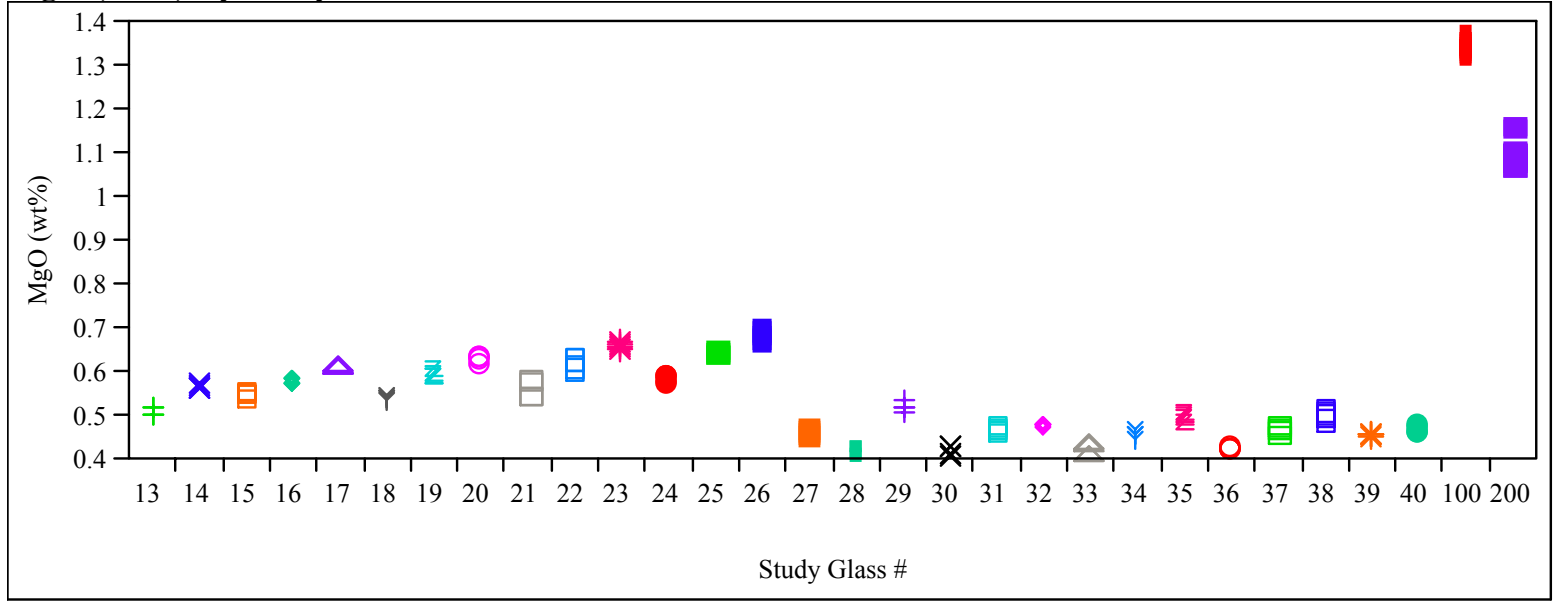

MnO (wt\%) By Study Glass \#

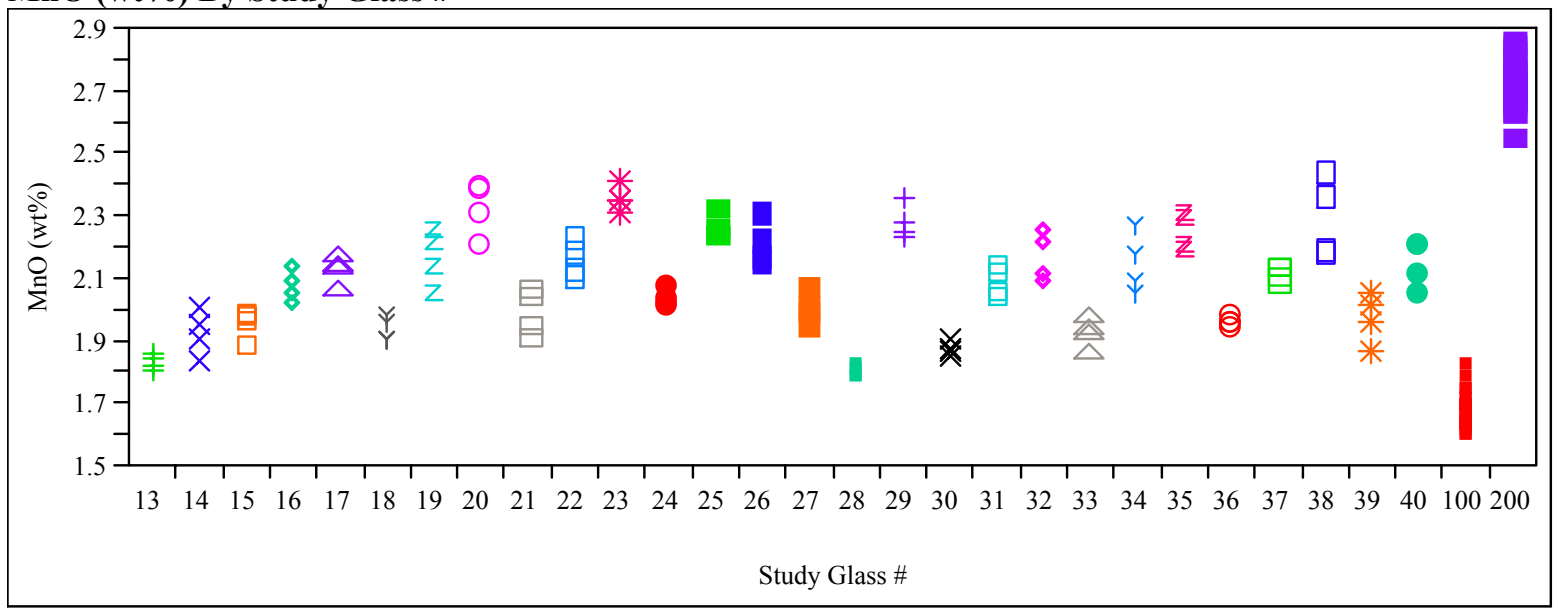




\section{Exhibit C5. Measured and Measured Bias-Corrected Oxide Weight Percents by Glass \# for the Glasses Prepared Using the LM Method}

(100 - Batch 1;200 - Ustd)

Na2O (wt\%) By Study Glass \#

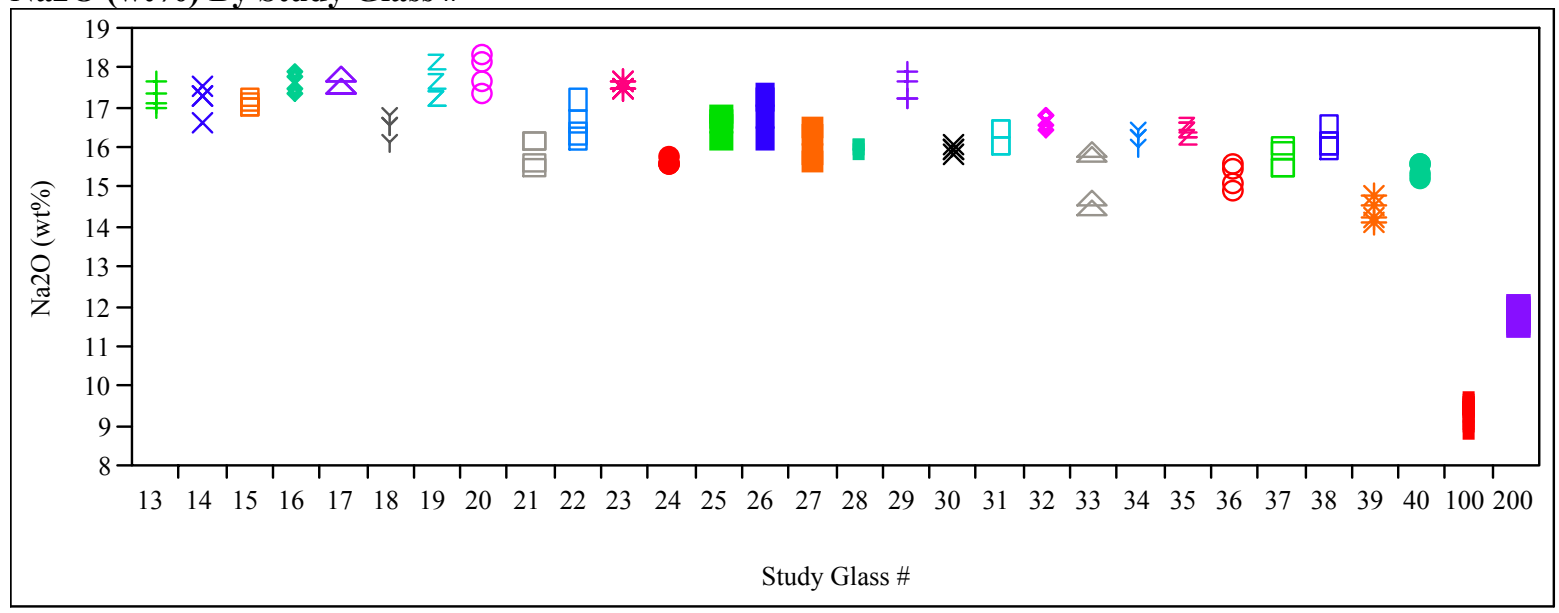

PbO (wt\%) By Study Glass \#

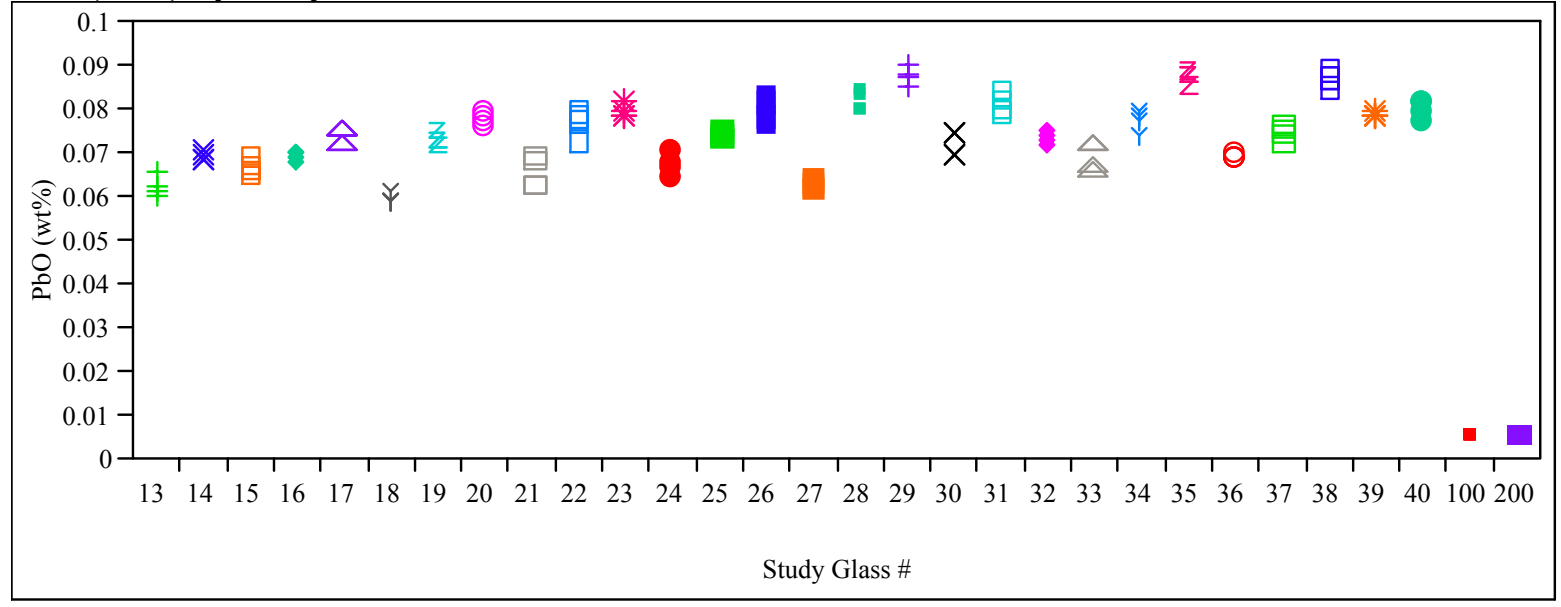

\section{SO4 (wt\%) By Study Glass \#}

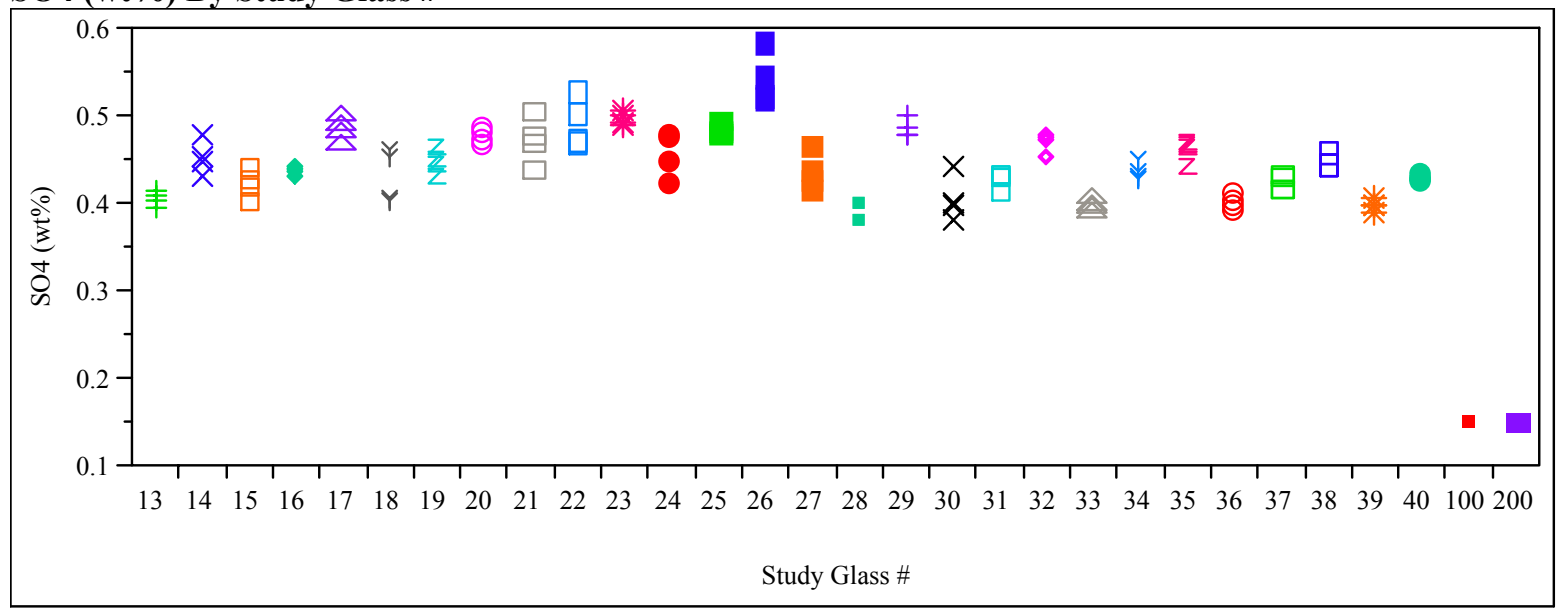




\section{Exhibit C5. Measured and Measured Bias-Corrected Oxide Weight Percents by Glass \# for the Glasses Prepared Using the LM Method}

(100 - Batch 1;200 - Ustd)

ThO2 (wt\%) By Study Glass \#

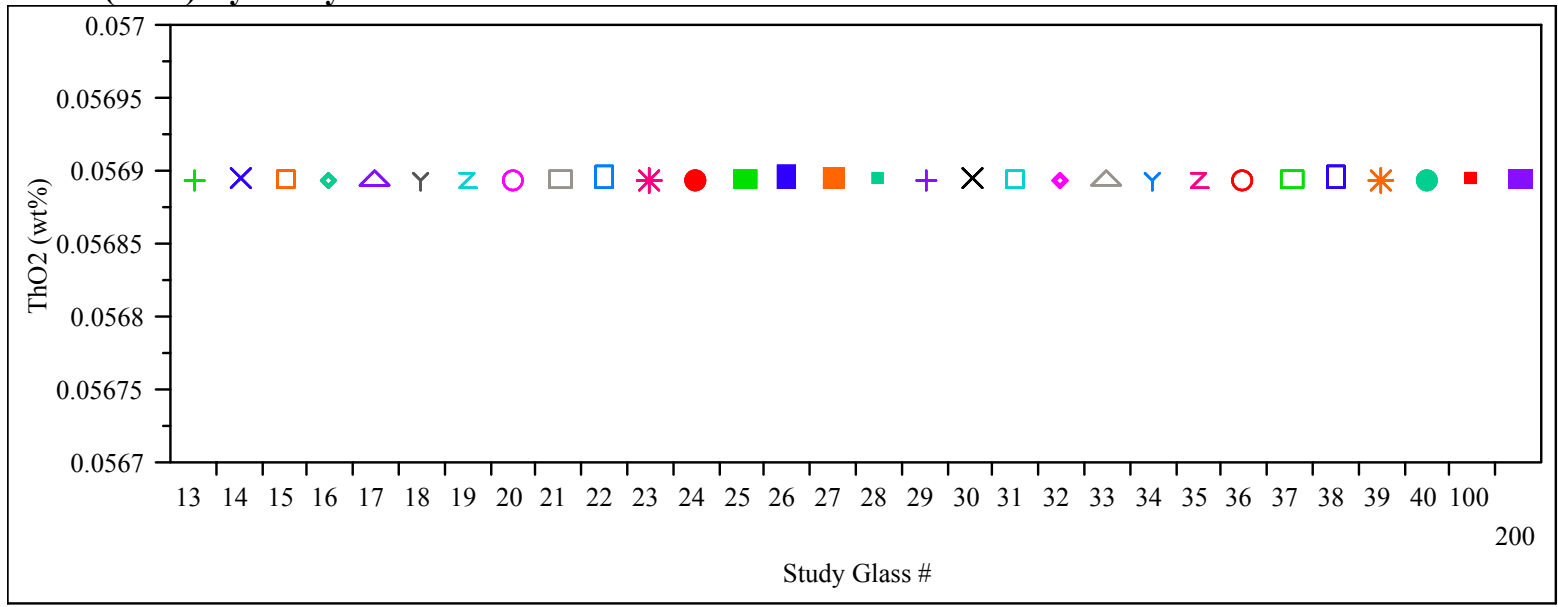

TiO2 (wt\%) By Study Glass \#

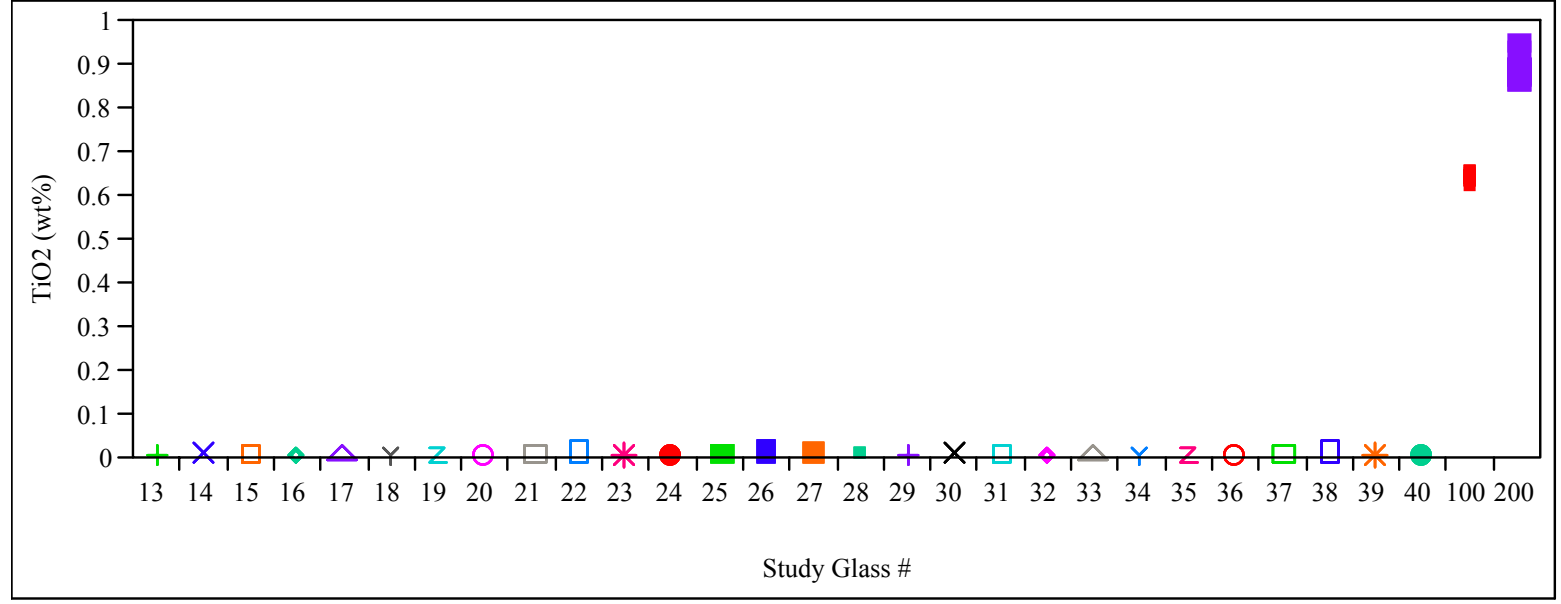

\section{ZnO (wt\%) By Study Glass \#}

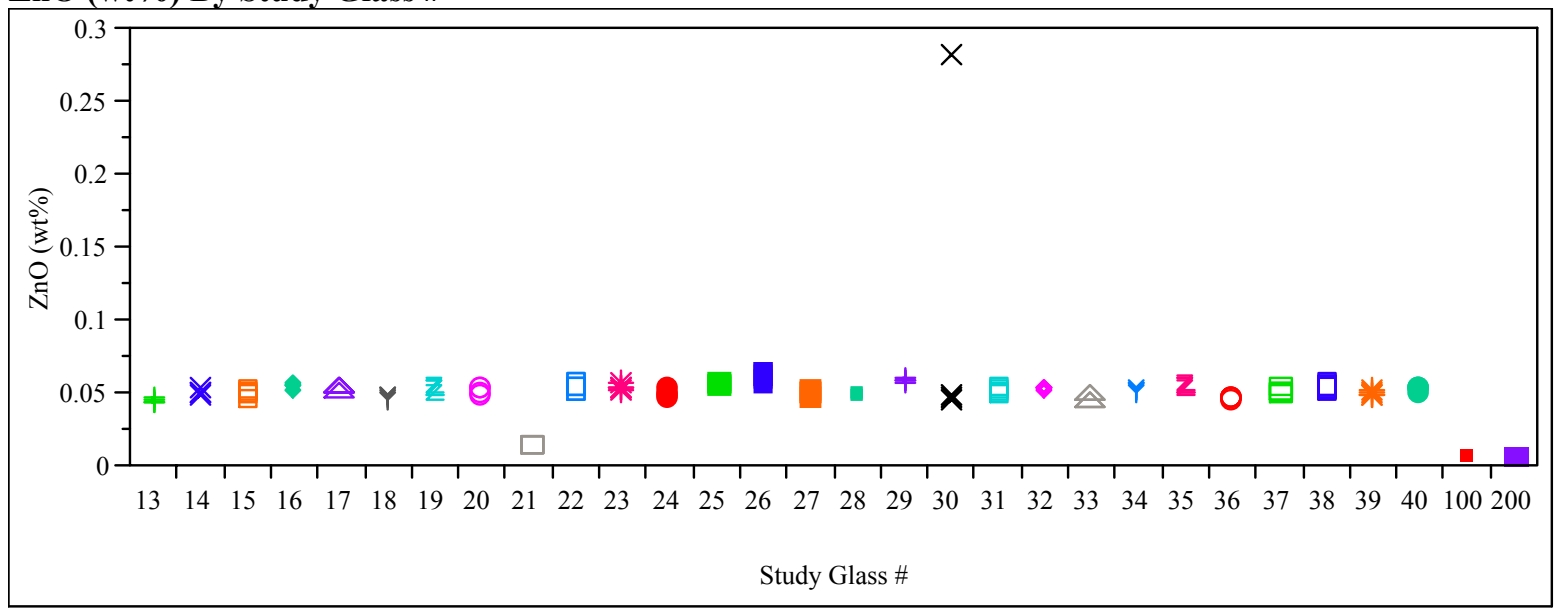




\section{Exhibit C5. Measured and Measured Bias-Corrected Oxide Weight Percents by Glass \# for the Glasses Prepared Using the LM Method}

(100 - Batch 1;200 - Ustd)

ZrO2 (wt\%) By Study Glass \#

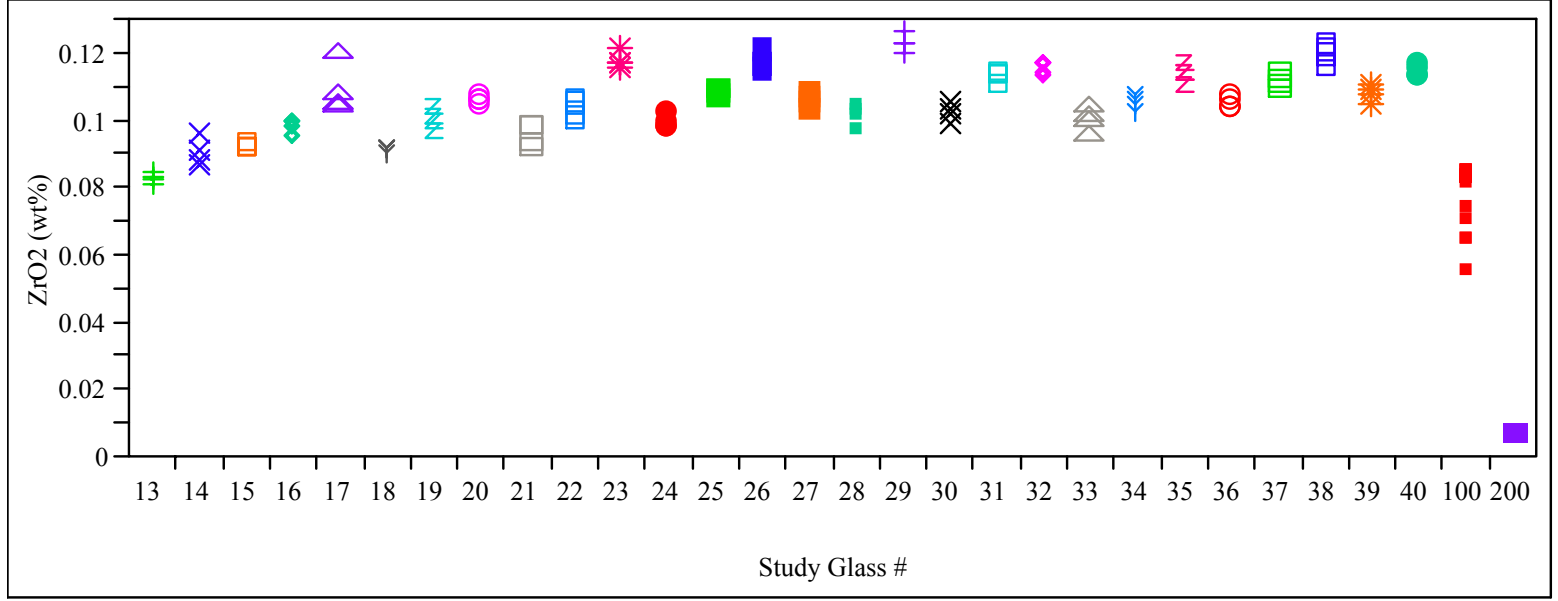

\section{BaO bc (wt\%) By Study Glass \#}

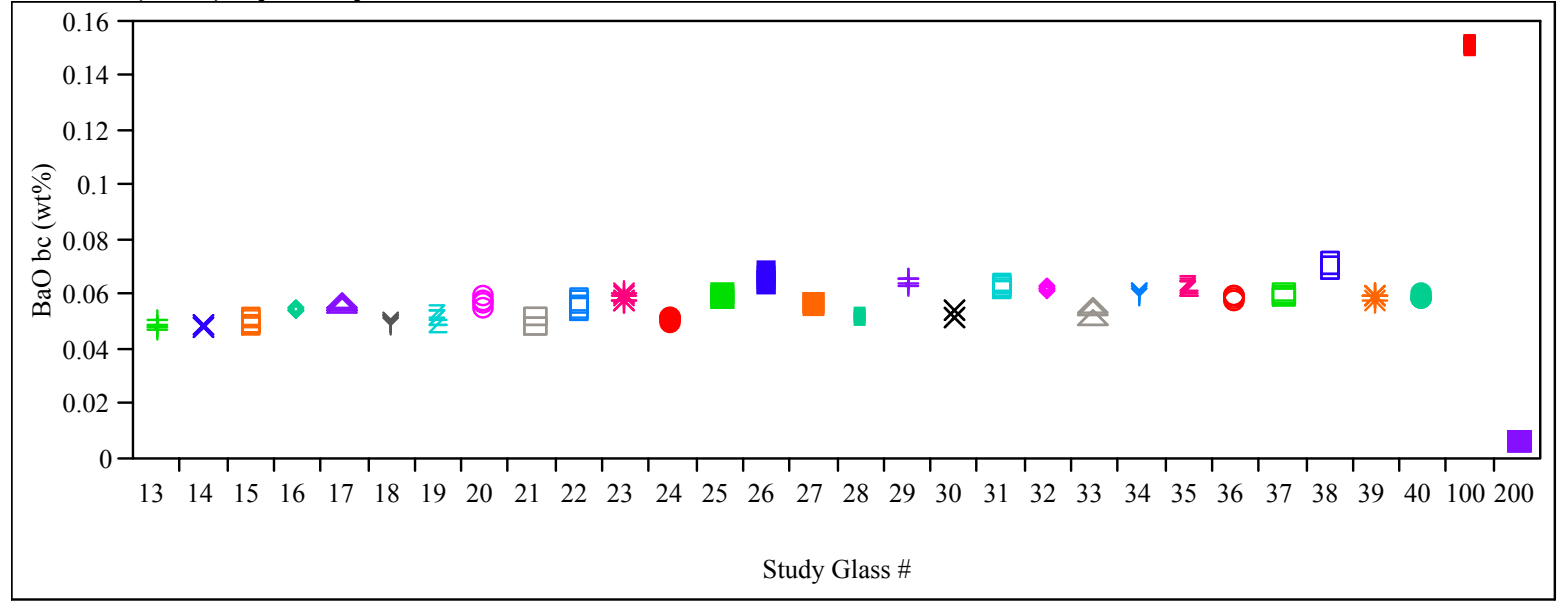

CaO bc (wt\%) By Study Glass \#

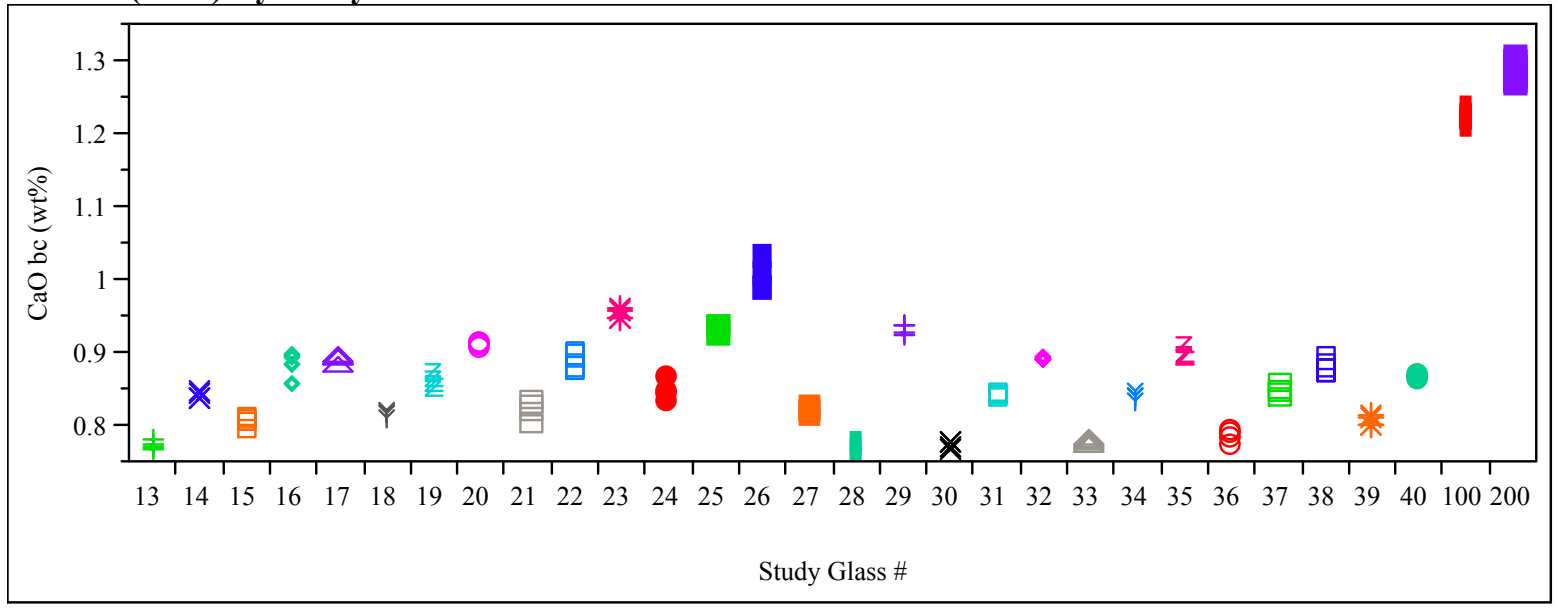




\section{Exhibit C5. Measured and Measured Bias-Corrected Oxide Weight Percents by Glass \# for the Glasses Prepared Using the LM Method}

(100 - Batch 1; 200 - Ustd)

Ce2O3 bc (wt\%) By Study Glass \#

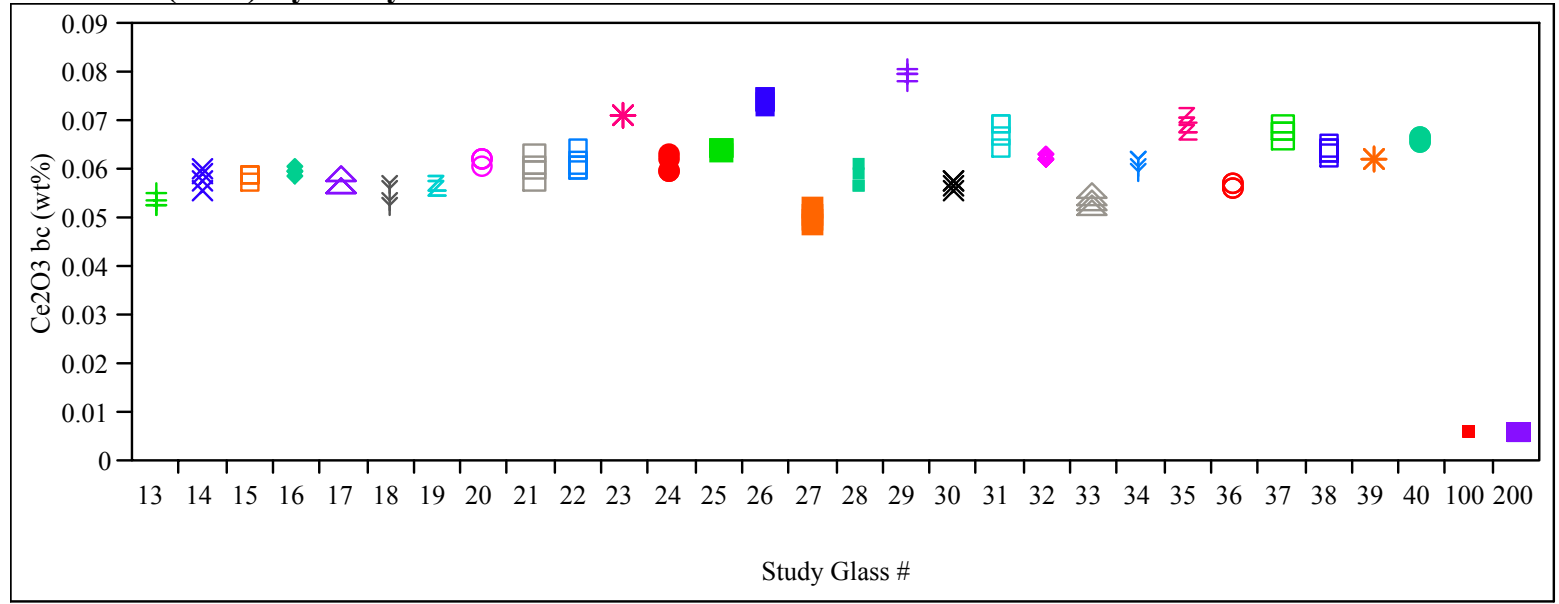

Cr2O3 bc (wt\%) By Study Glass \#

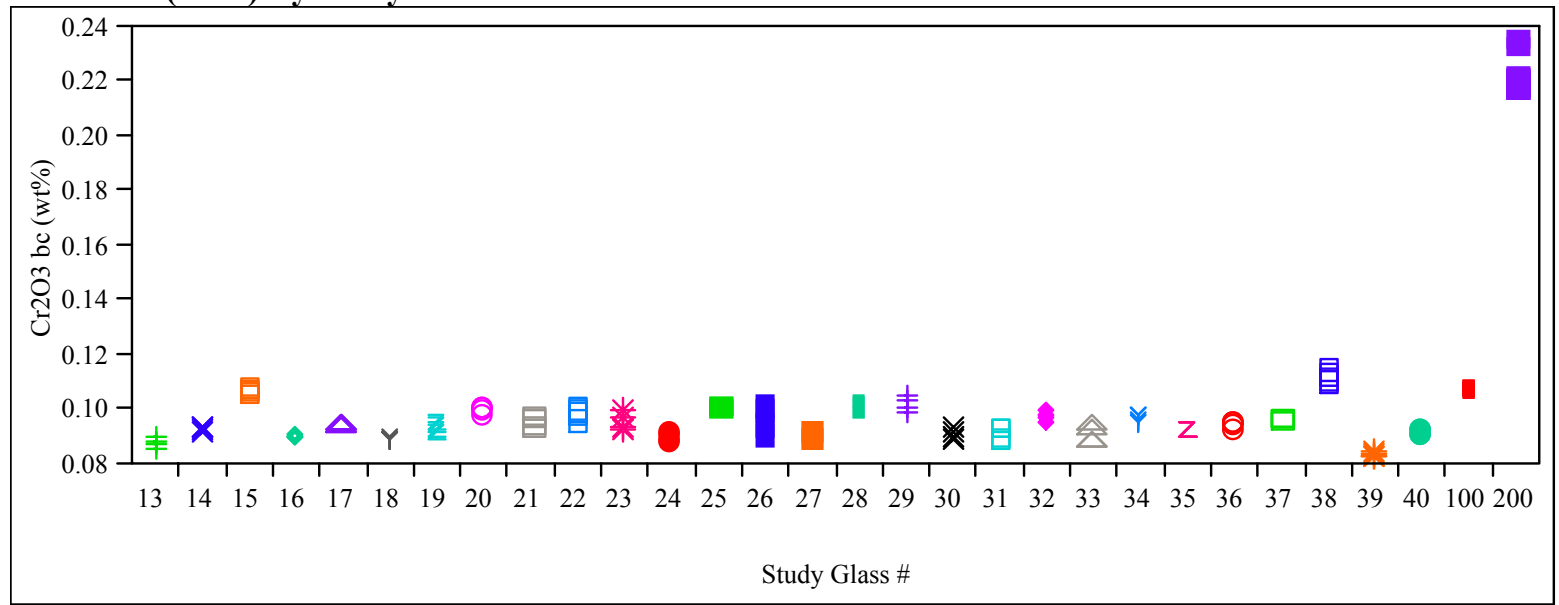

\section{CuO be (wt\%) By Study Glass \#}

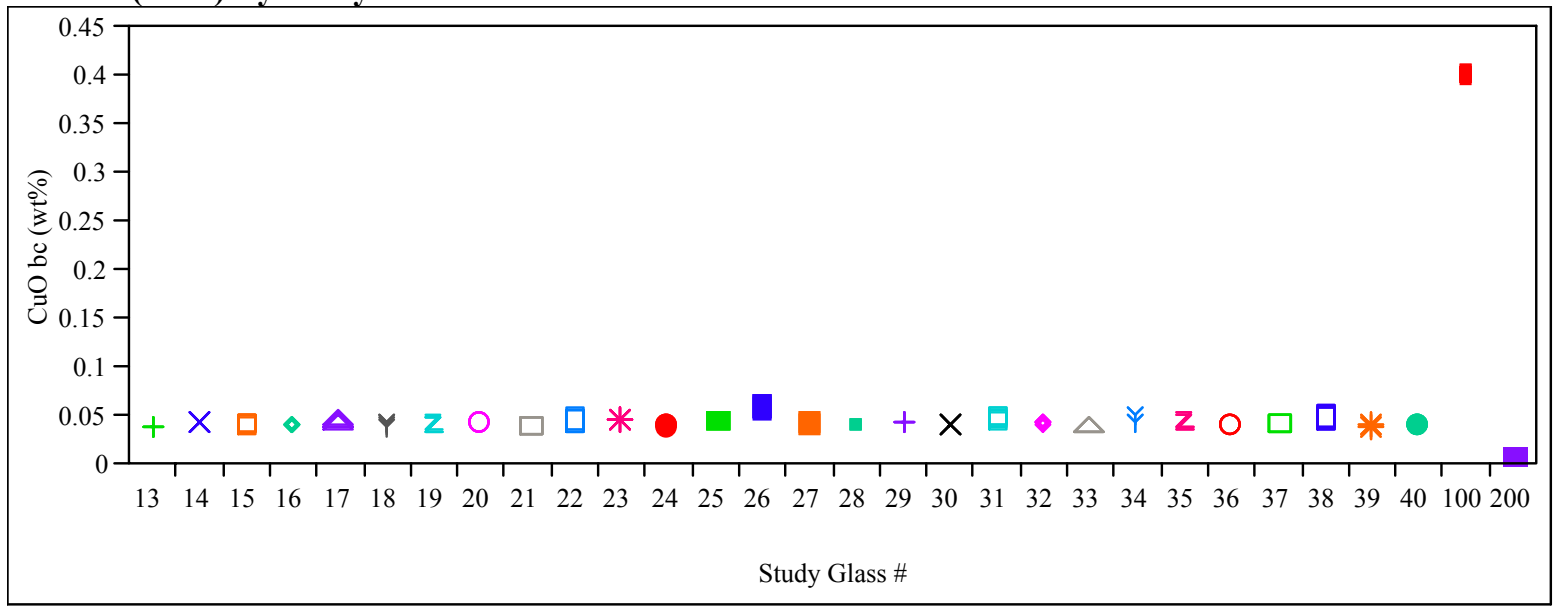




\section{Exhibit C5. Measured and Measured Bias-Corrected Oxide Weight Percents by Glass \# for the Glasses Prepared Using the LM Method}

(100 - Batch 1; 200 - Ustd)

K2O bc (wt\%) By Study Glass \#

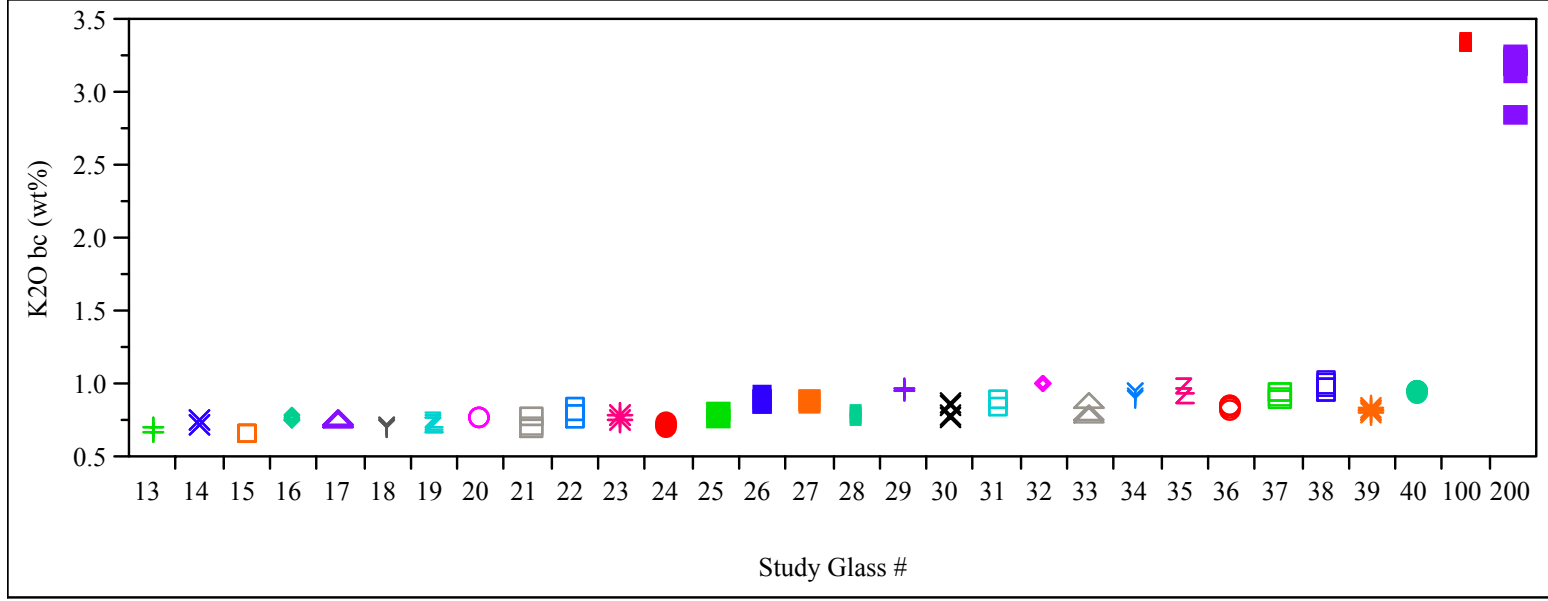

\section{La2O3 bc (wt\%) By Study Glass \#}

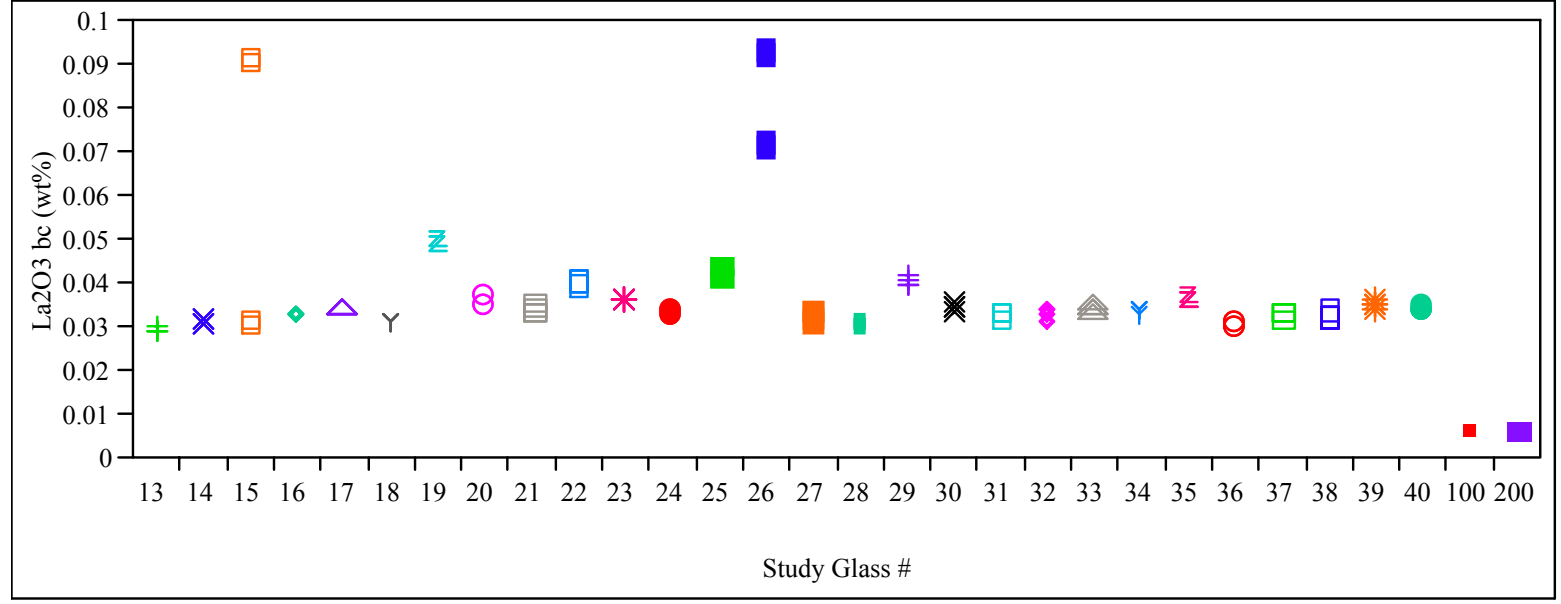

MgO bc (wt\%) By Study Glass \#

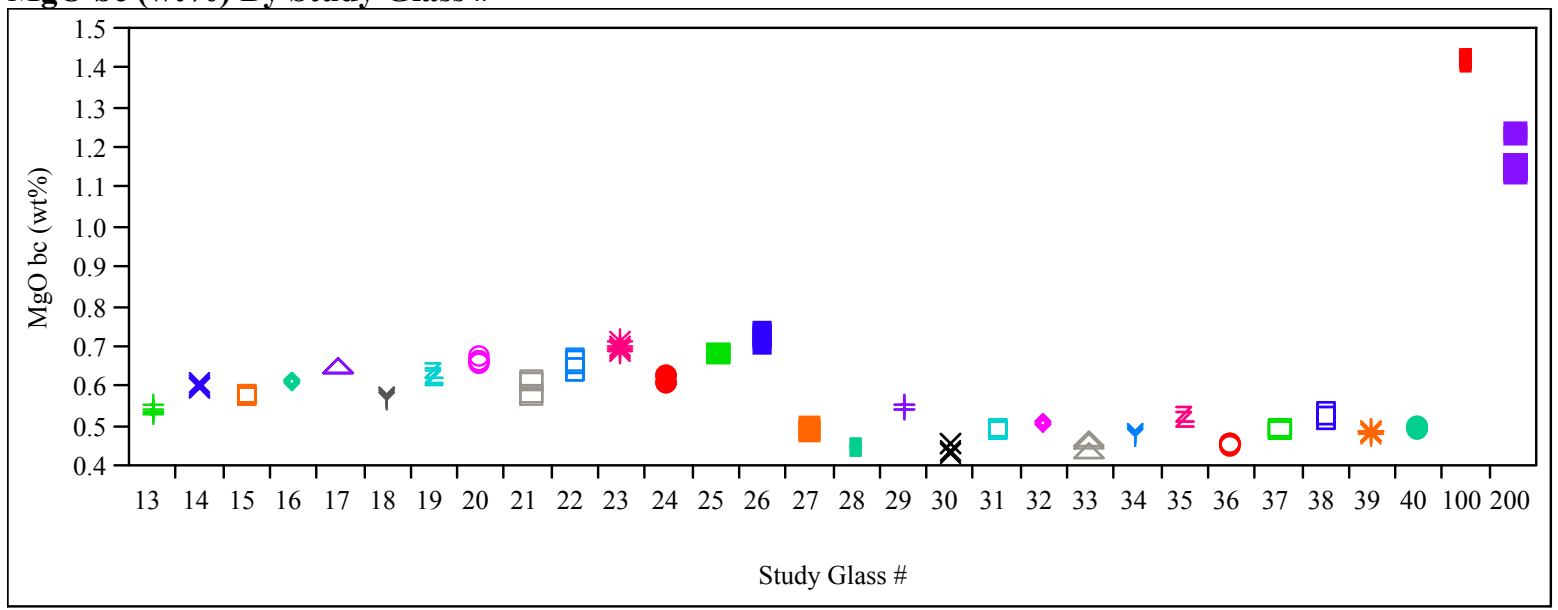




\section{Exhibit C5. Measured and Measured Bias-Corrected Oxide Weight Percents by Glass \# for the Glasses Prepared Using the LM Method}

(100 - Batch 1;200 - Ustd)

MnO bc (wt\%) By Study Glass \#

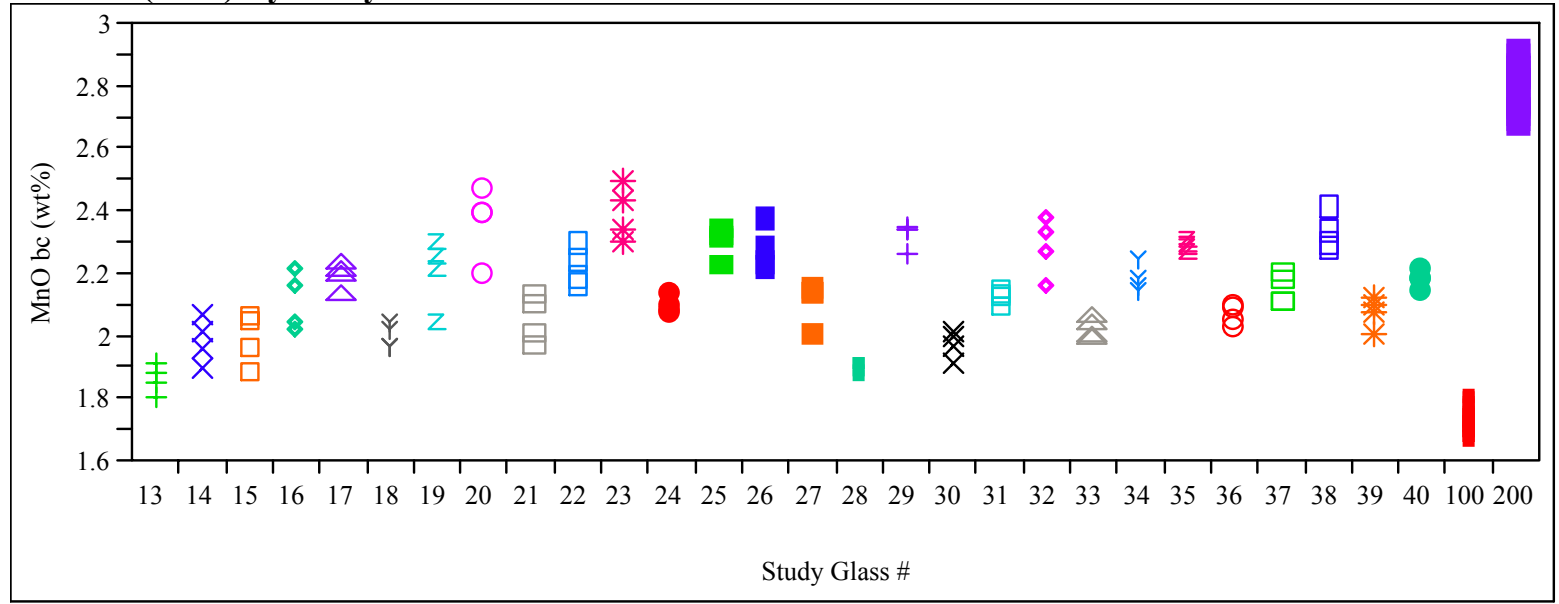

Na2O bc (wt\%) By Study Glass \#

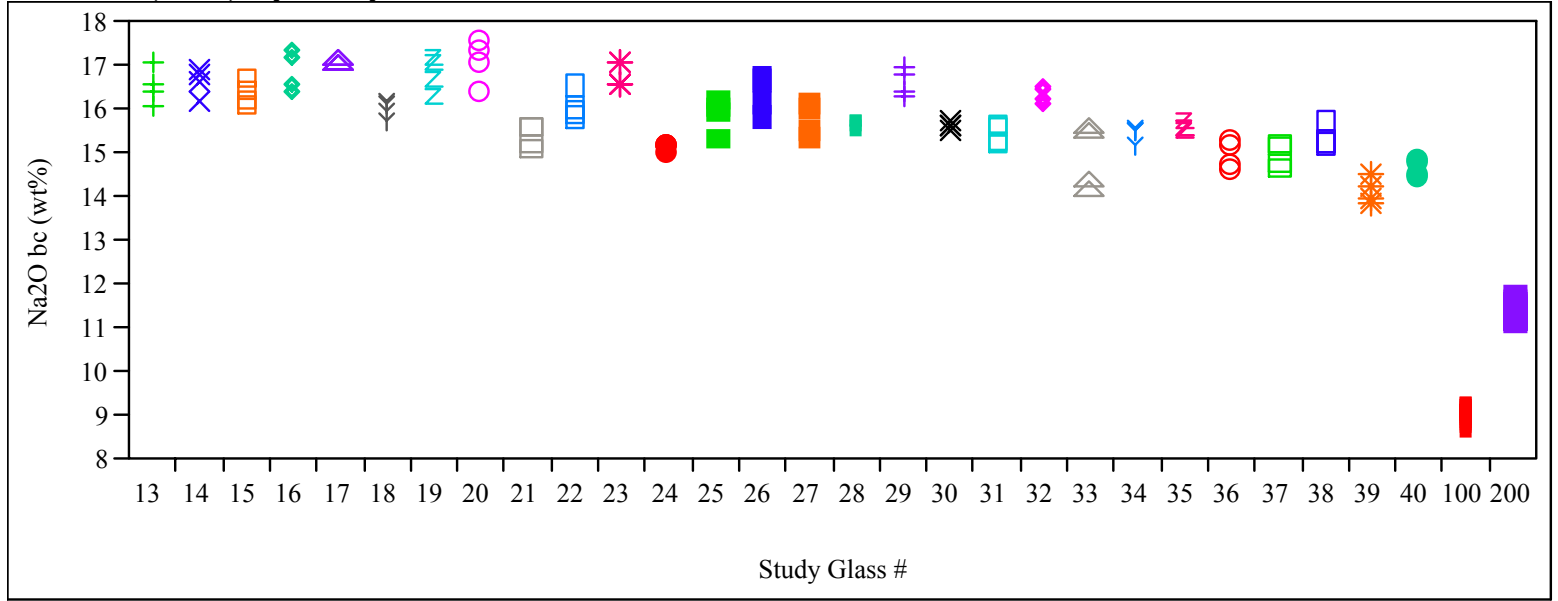

PbO bc (wt\%) By Study Glass \#

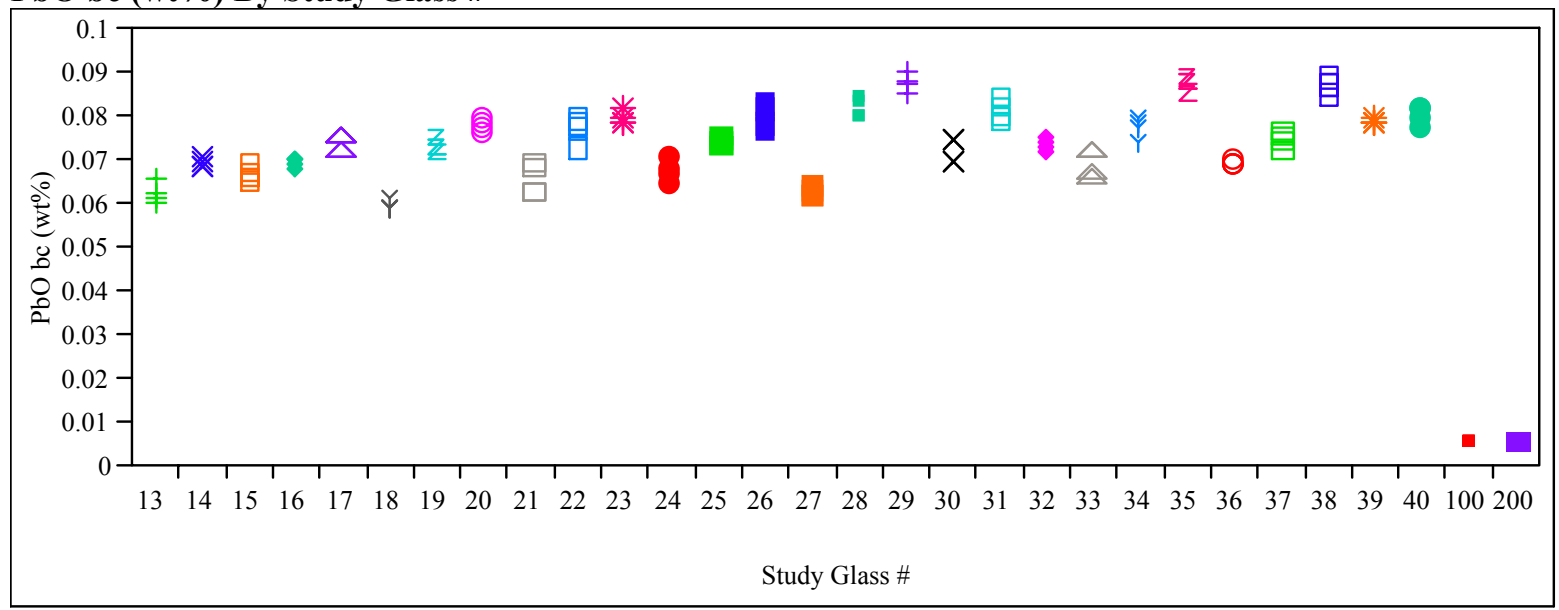




\section{Exhibit C5. Measured and Measured Bias-Corrected Oxide Weight Percents by Glass \# for the Glasses Prepared Using the LM Method}

(100 - Batch 1; 200 - Ustd)

SO4 bc (wt\%) By Study Glass \#

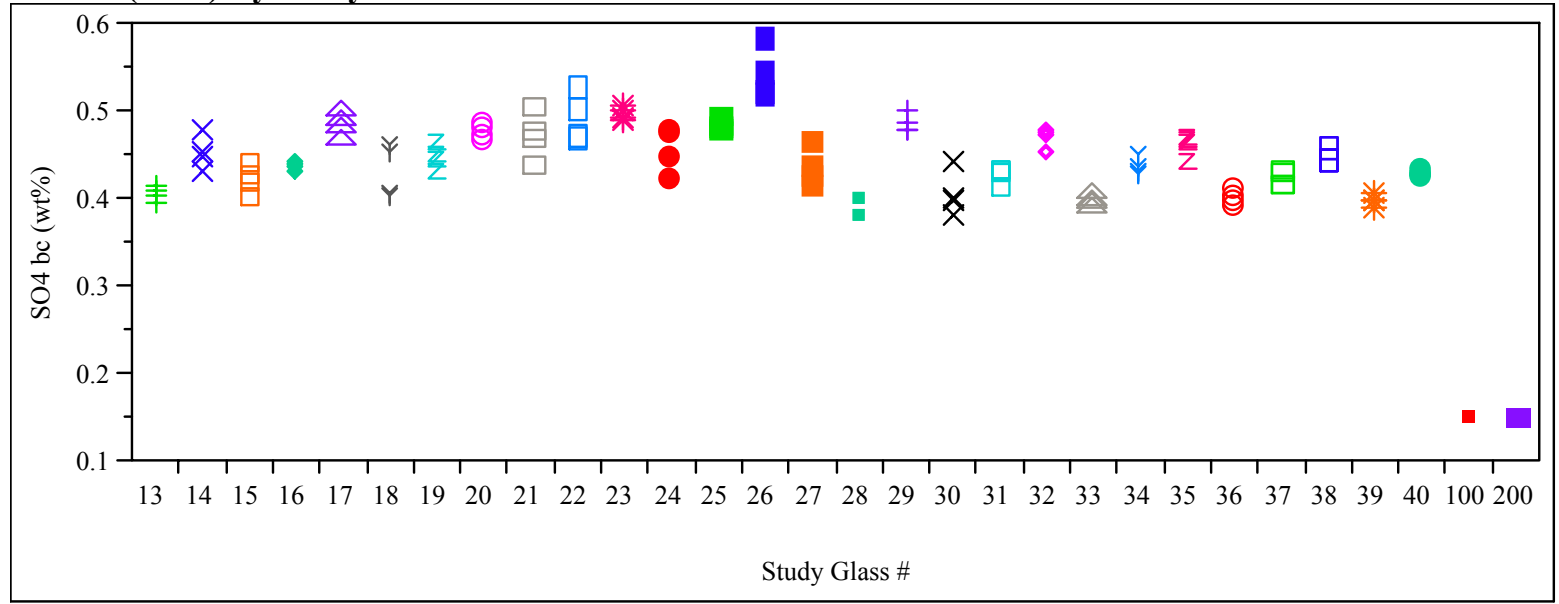

ThO2 bc (wt\%) By Study Glass \#

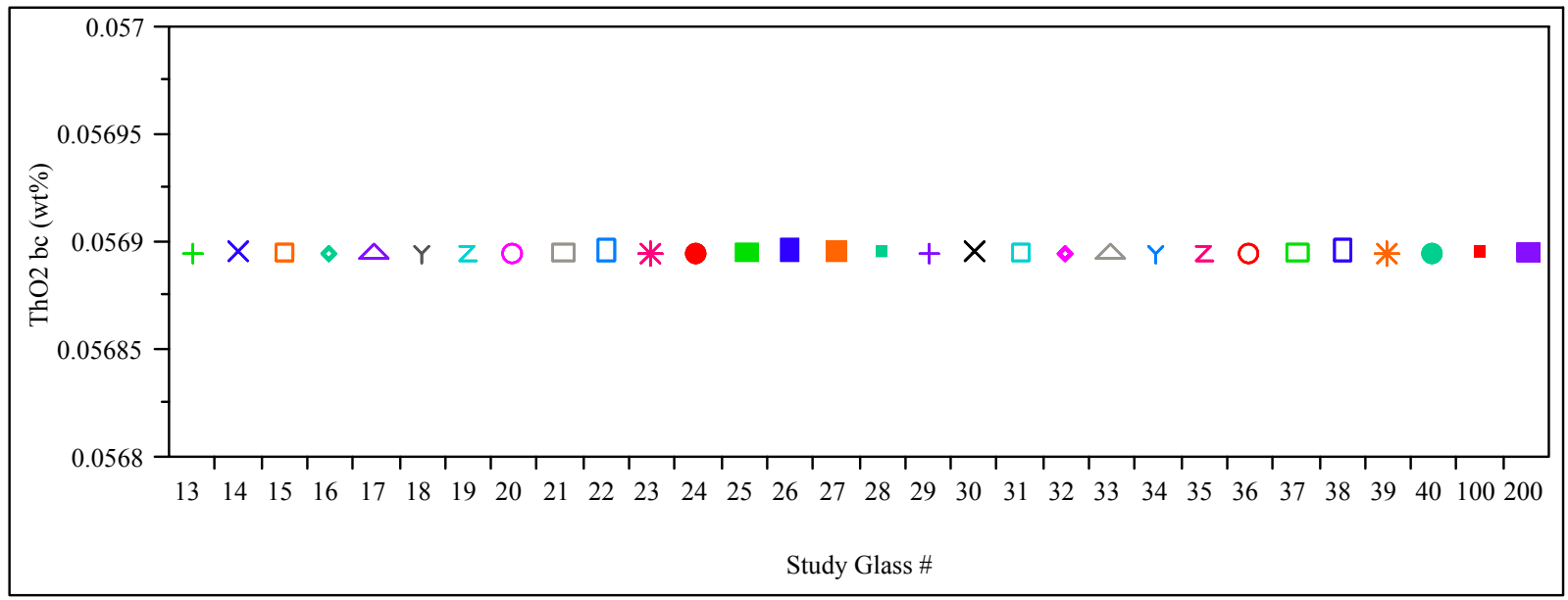

\section{TiO2 bc (wt\%) By Study Glass \#}

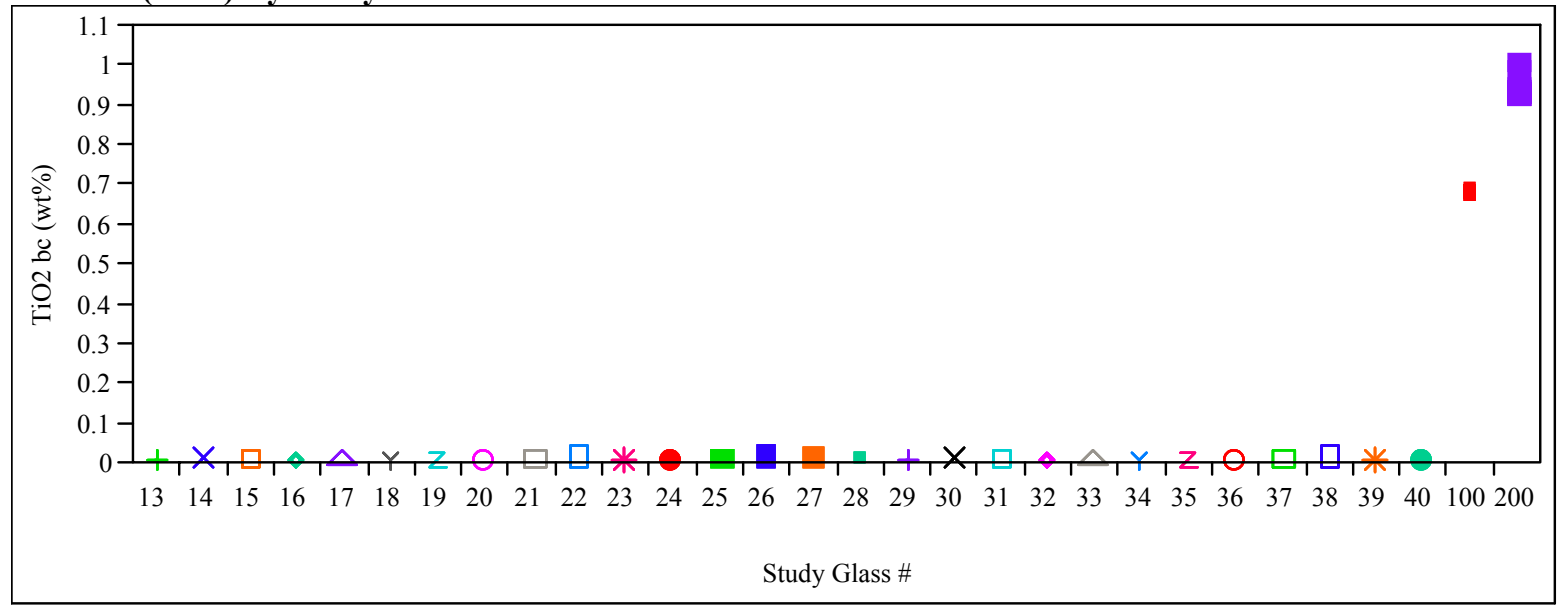




\section{Exhibit C5. Measured and Measured Bias-Corrected Oxide Weight Percents by Glass \# for the Glasses Prepared Using the LM Method}

(100 - Batch 1;200 - Ustd)

ZnO bc (wt\%) By Study Glass \#

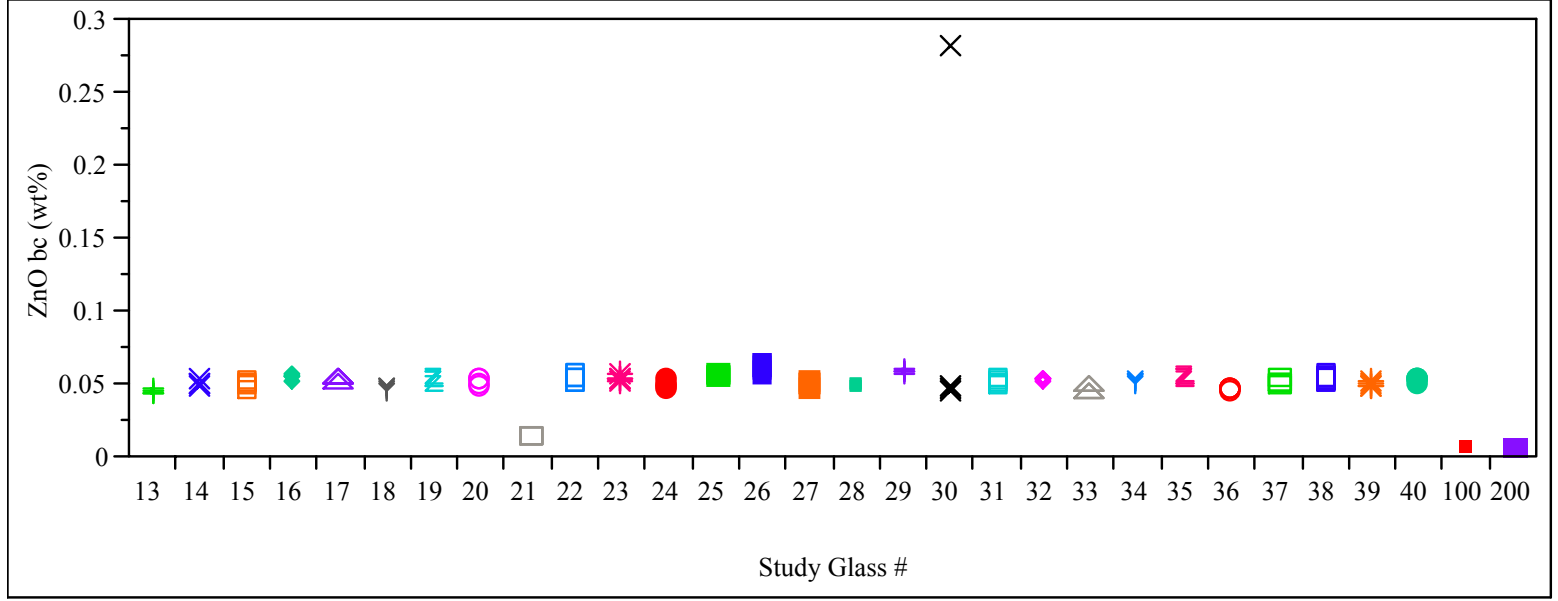

ZrO2 bc (wt\%) By Study Glass \#

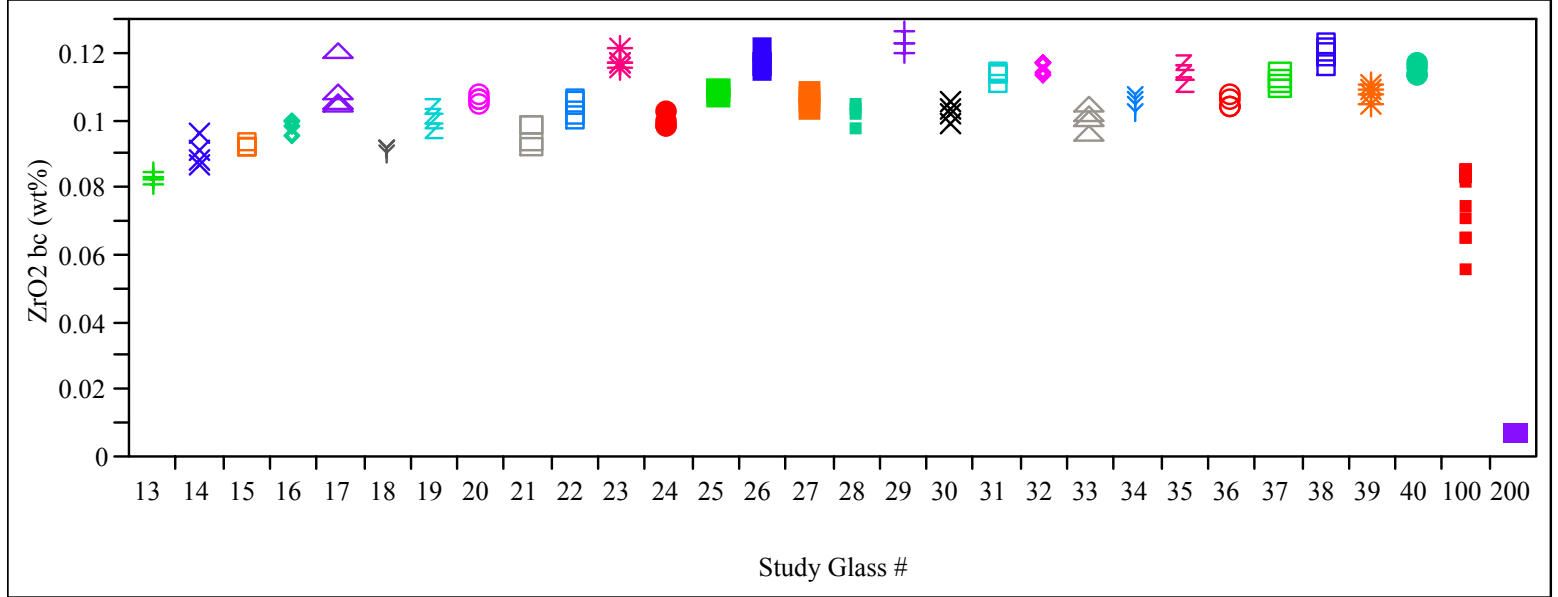




\section{Exhibit C6. Measured and Measured Bias-Corrected Oxide Weight Percents by Glass \# for the Glasses Prepared Using the PF Method}

$(100-$ Batch $1 ; 200-$ Ustd $)$

$\operatorname{Al203~(wt\% )~By~Glass~\# ~}$

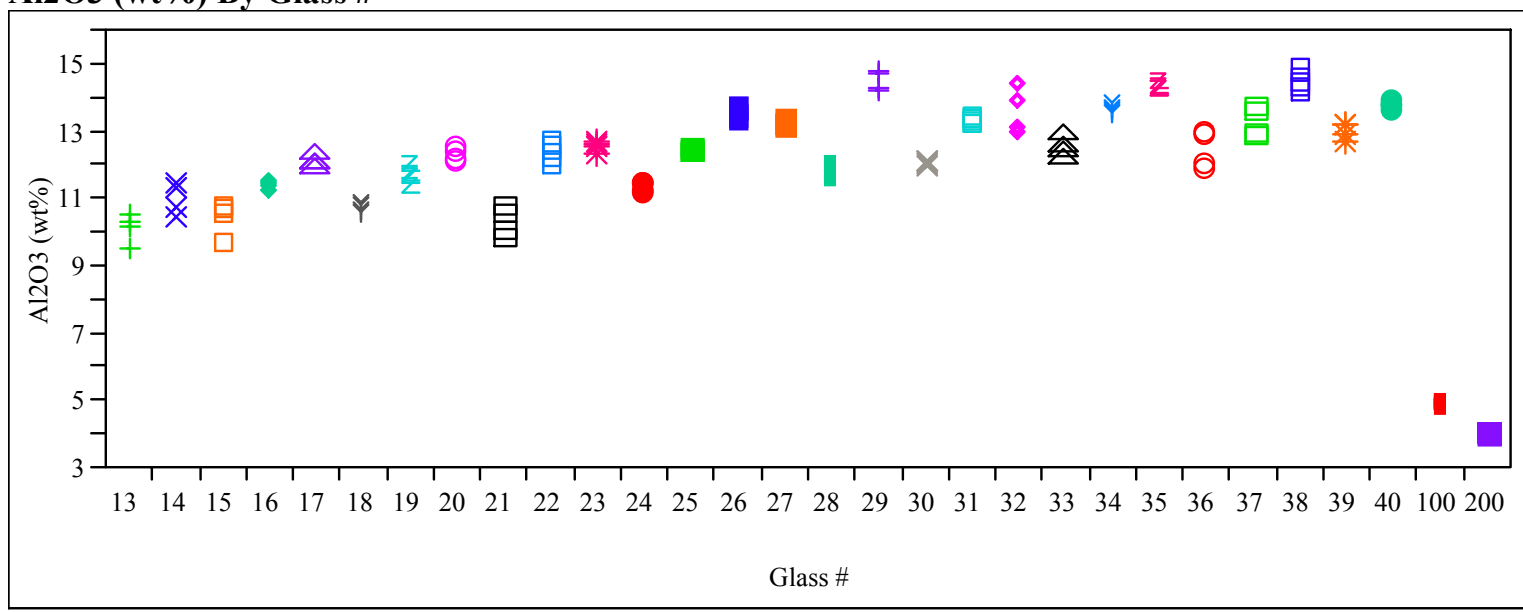

B2O3 (wt\%) By Glass \#

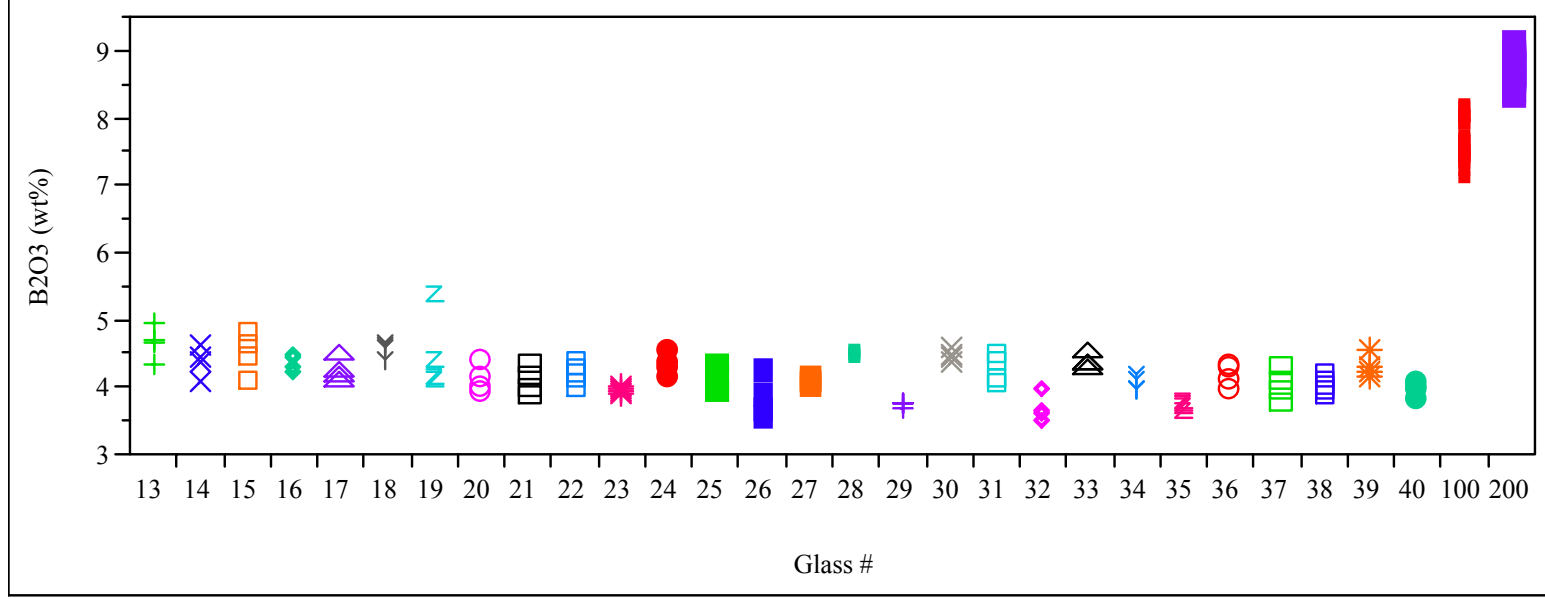

Fe2O3 (wt\%) By Glass \#

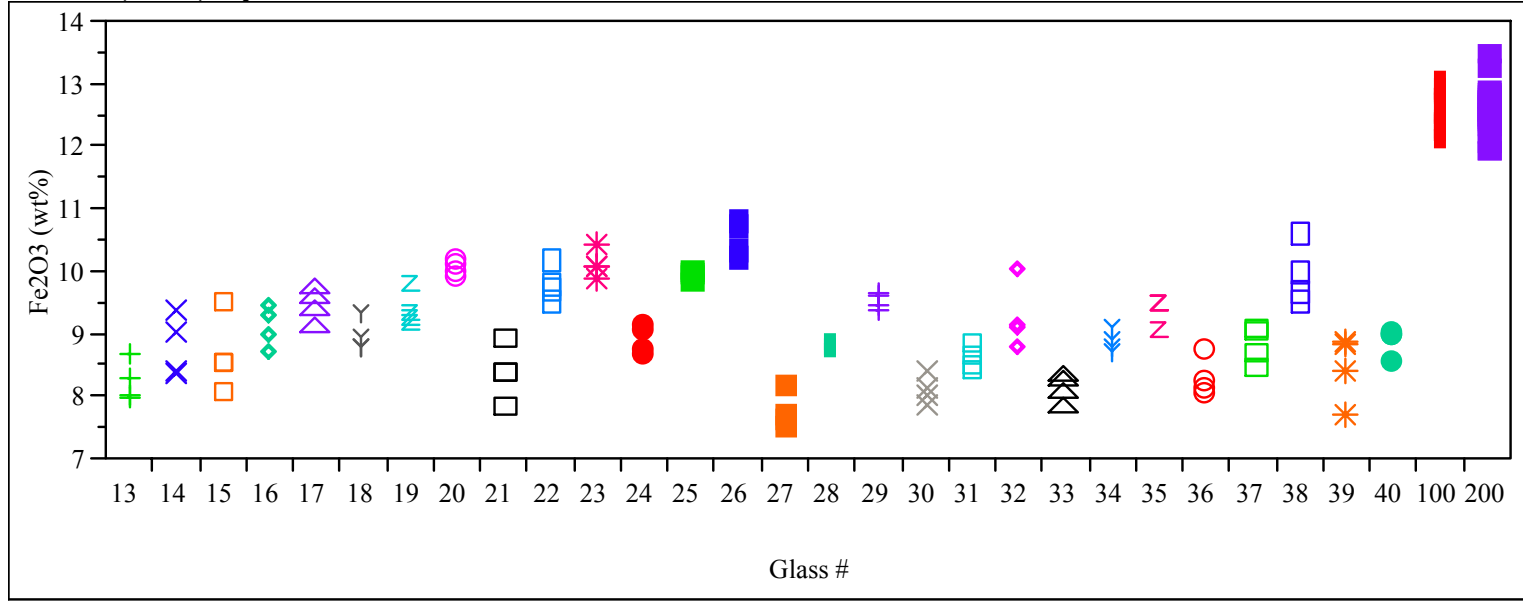




\section{Exhibit C6. Measured and Measured Bias-Corrected Oxide Weight Percents by Glass \# for the Glasses Prepared Using the PF Method}

(100 - Batch 1; 200 - Ustd)

Li2O (wt\%) By Glass \#

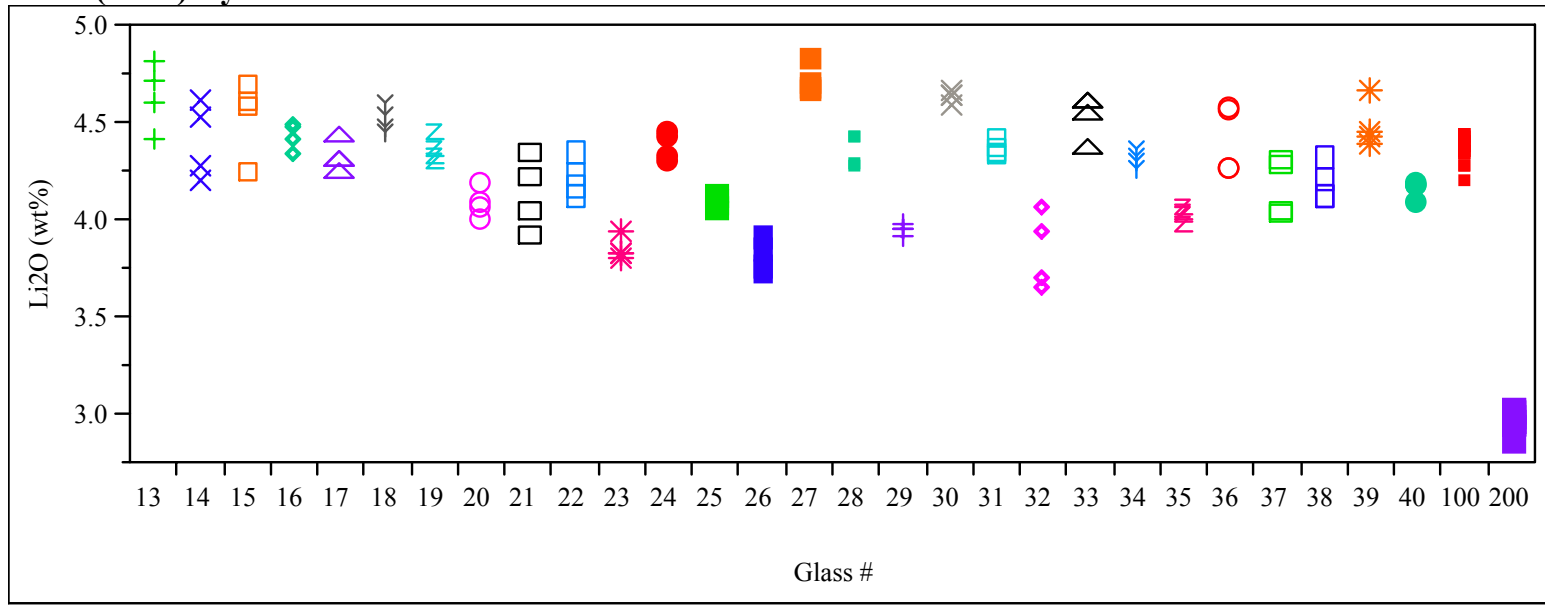

$\mathrm{NiO}(\mathbf{w t} \%)$ By Glass \#

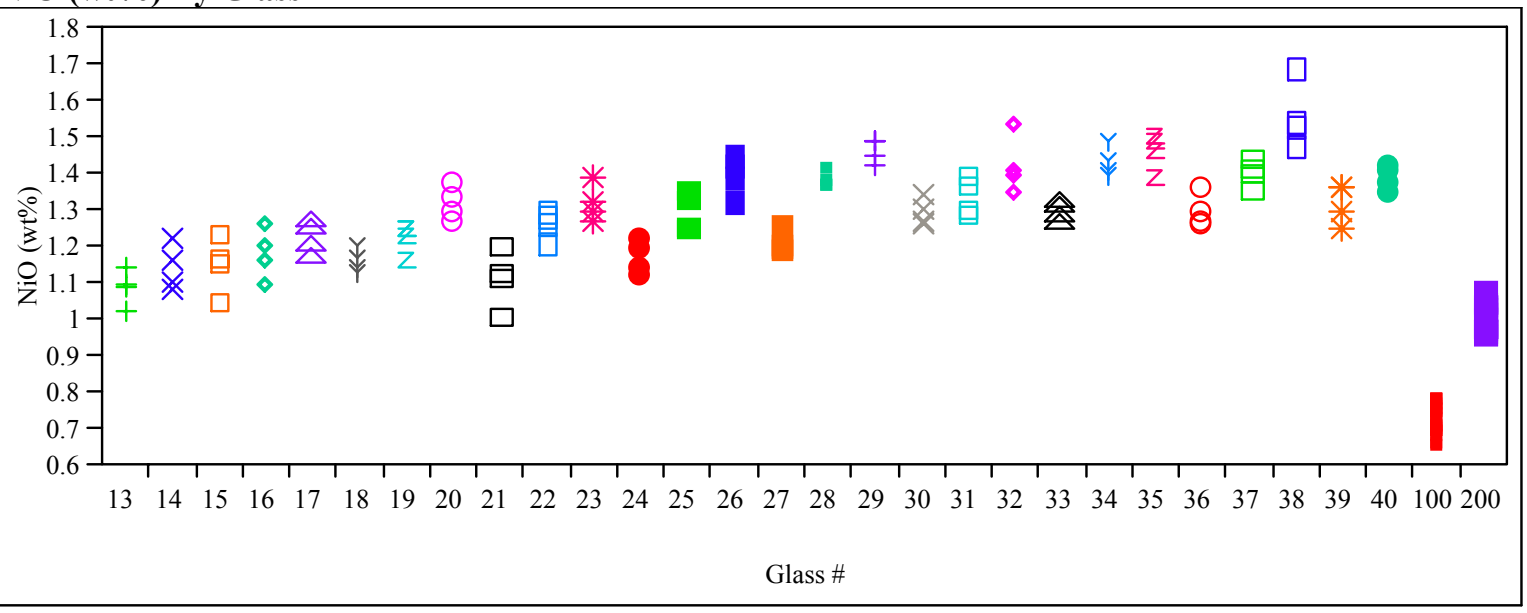

SiO2 (wt\%) By Glass \#

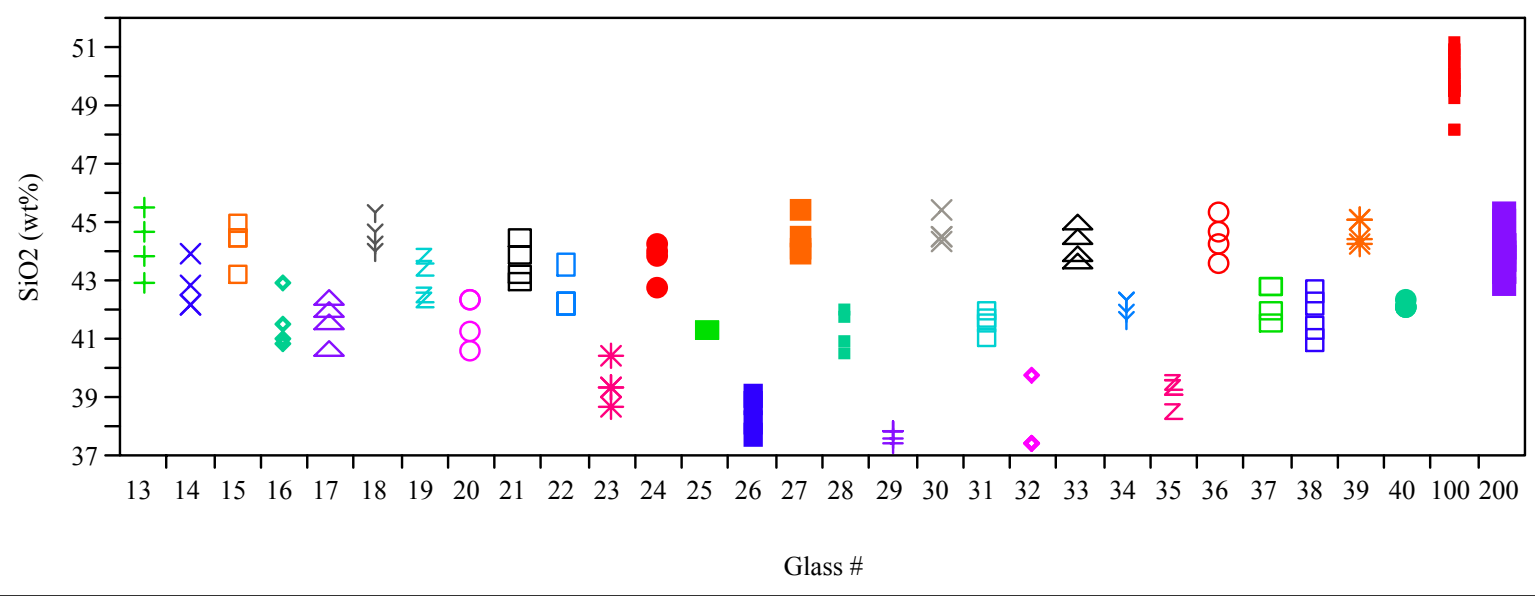




\section{Exhibit C6. Measured and Measured Bias-Corrected Oxide Weight Percents by Glass \# for the Glasses Prepared Using the PF Method}

$(100-$ Batch $1 ; 200-$ Ustd $)$

U3O8 (wt\%) By Glass \#

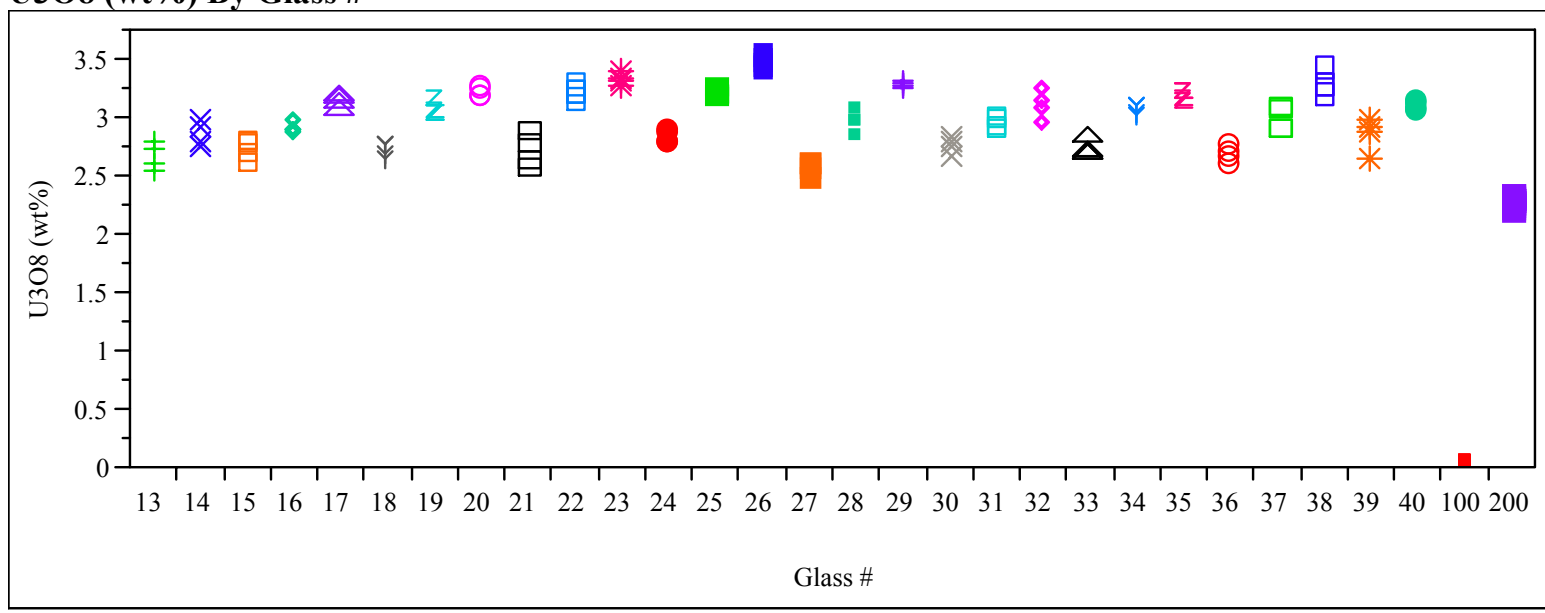

Al203 bc (wt\%) By Glass \#

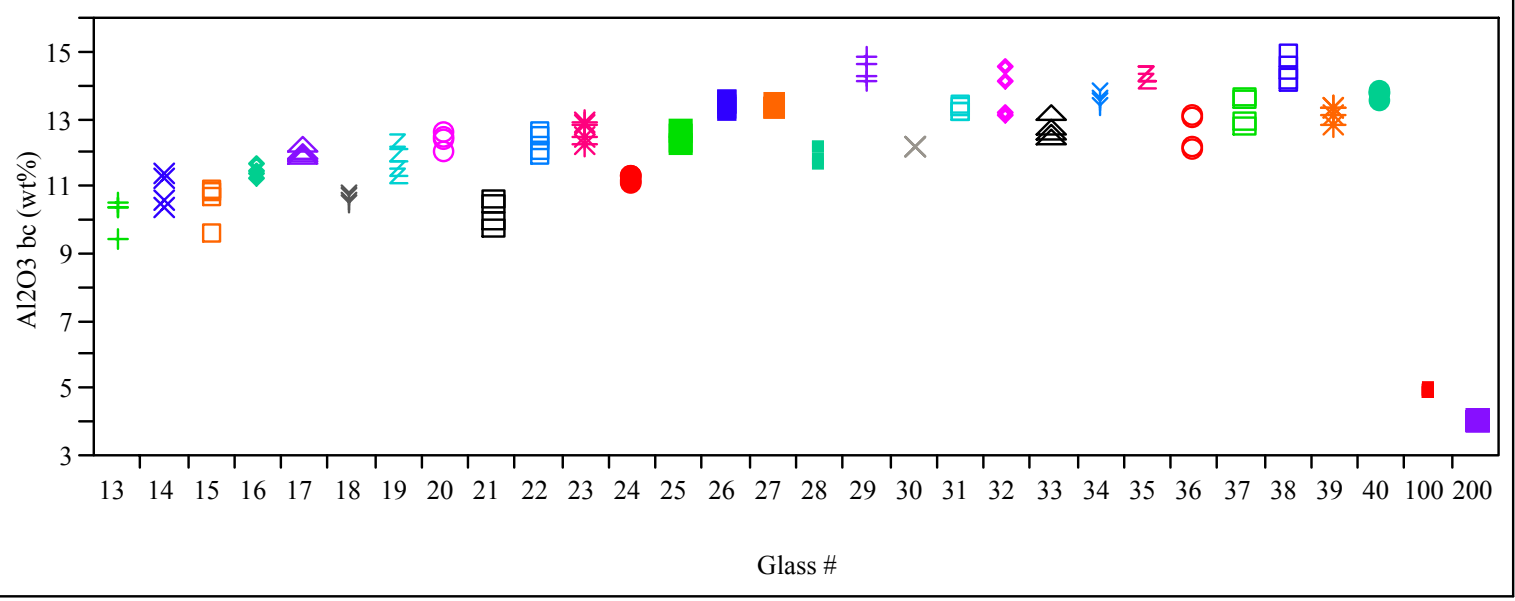

B2O3 bc (wt\%) By Glass \#

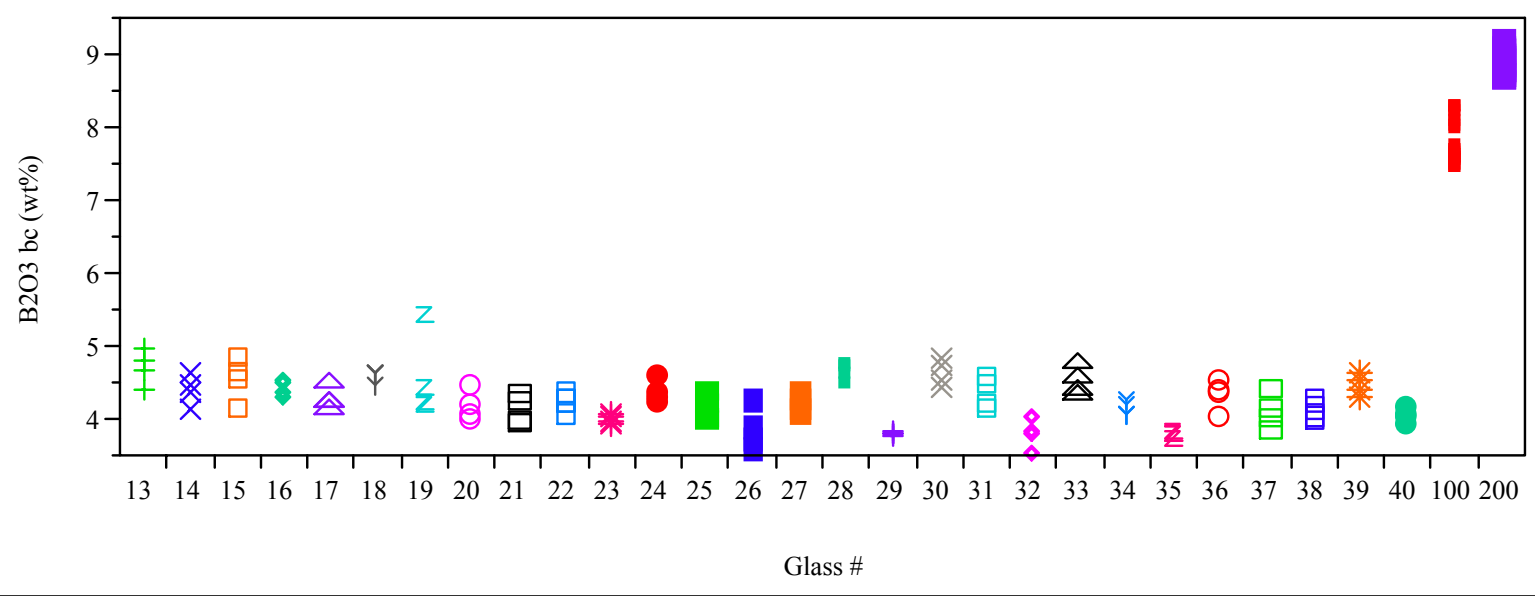




\section{Exhibit C6. Measured and Measured Bias-Corrected Oxide Weight Percents by Glass \# for the Glasses Prepared Using the PF Method}

(100 - Batch 1; 200 - Ustd)

Fe2O3 bc (wt\%) By Glass \#

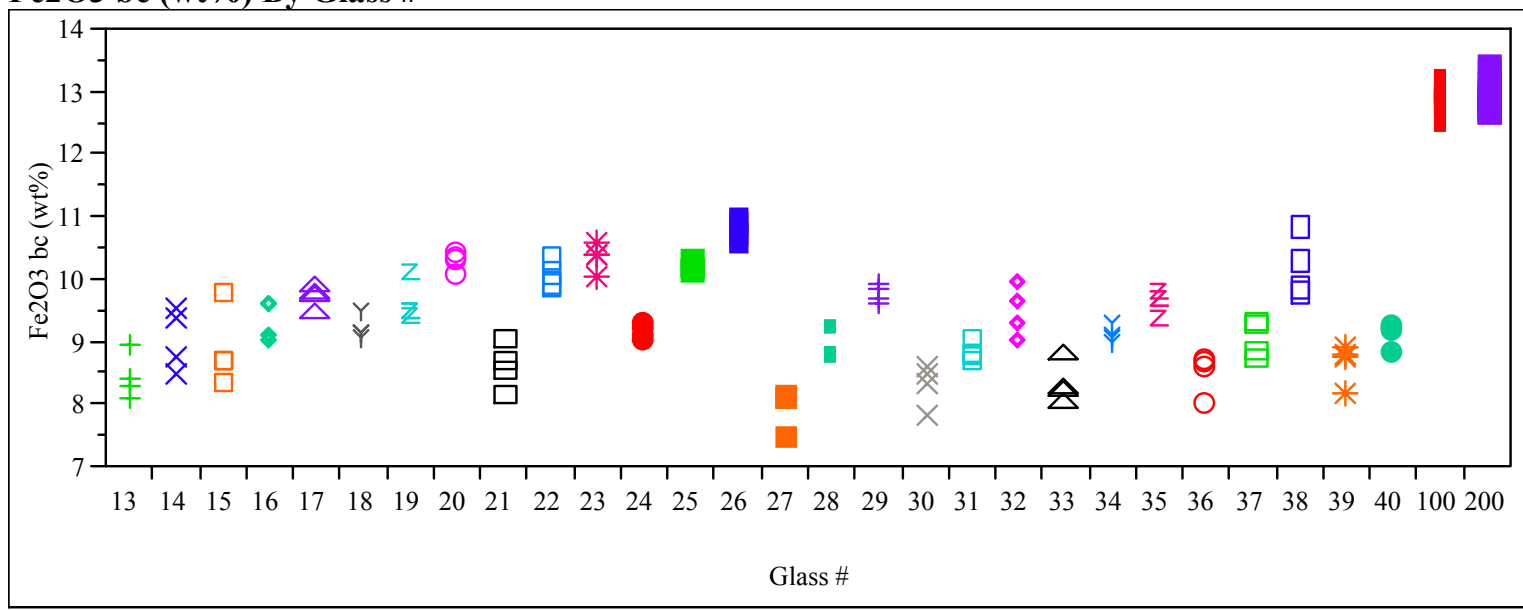

Li2O bc (wt\%) By Glass \#

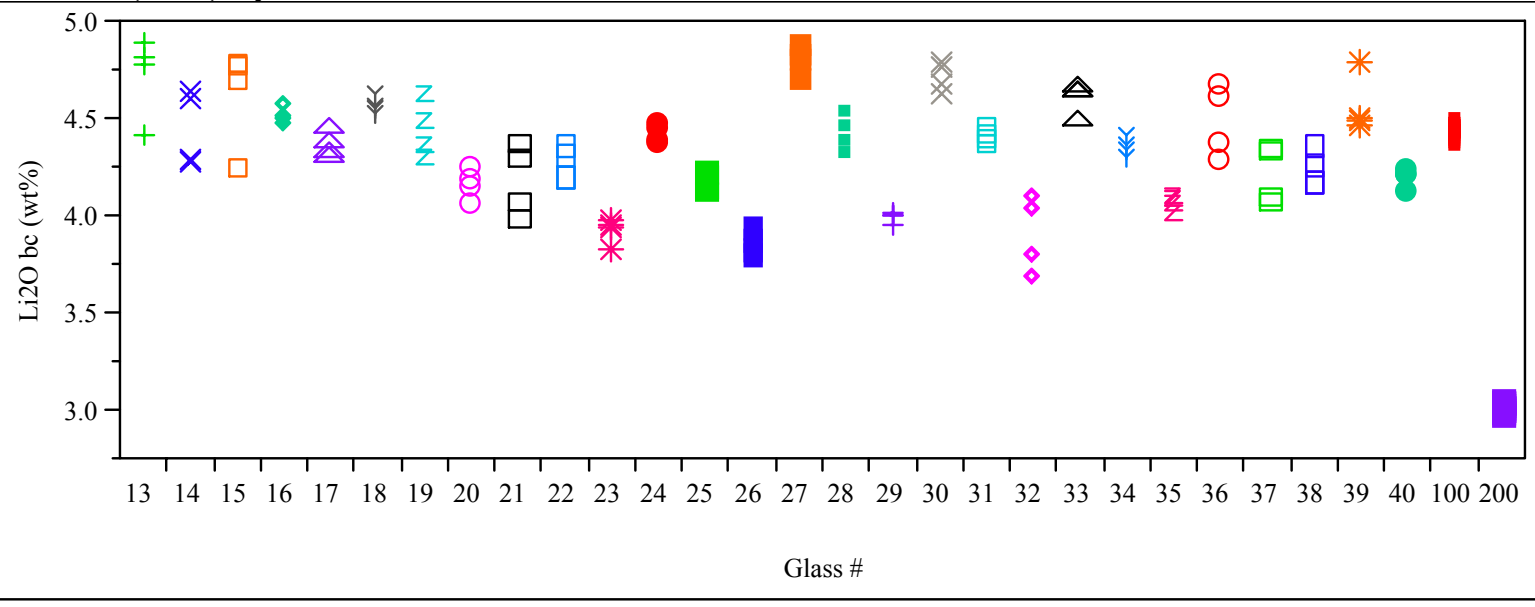

NiO bc (wt\%) By Glass \#

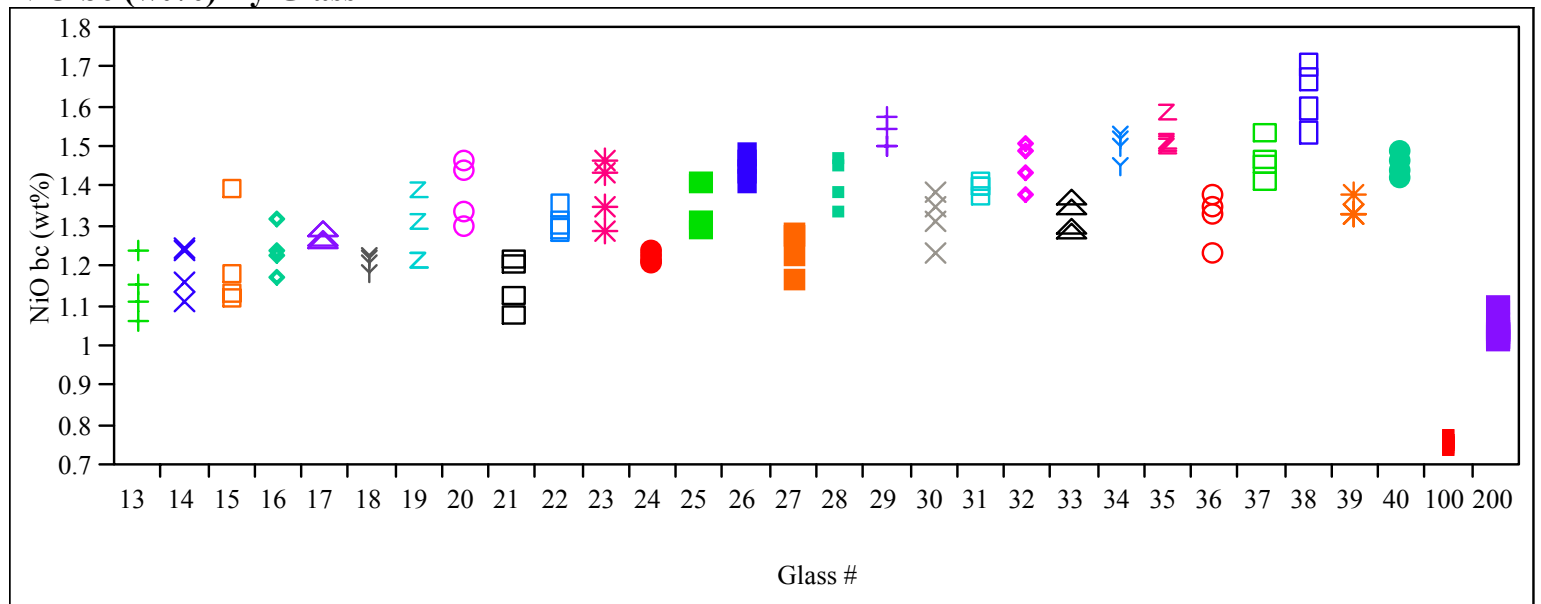




\section{Exhibit C6. Measured and Measured Bias-Corrected Oxide Weight Percents by Glass \# for the Glasses Prepared Using the PF Method}

$(100-$ Batch $1 ; 200-$ Ustd $)$

SiO2 bc (wt\%) By Glass \#

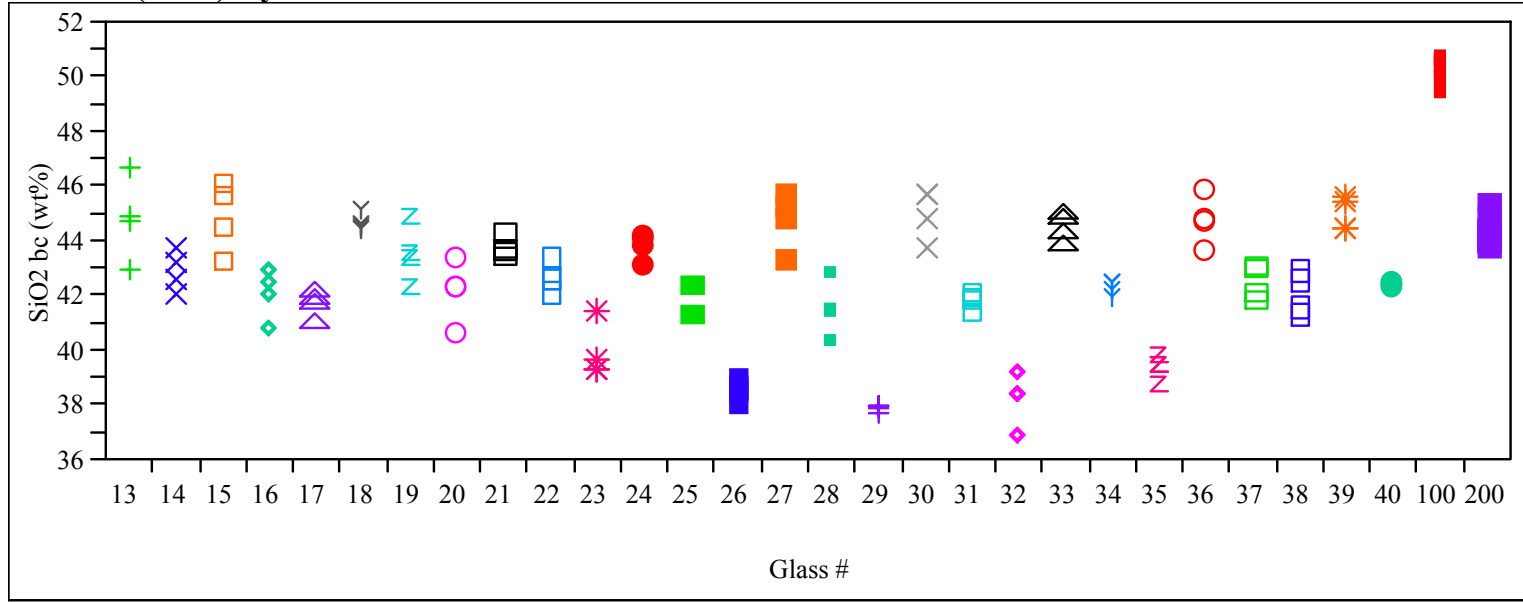

U308 bc (wt\%) By Glass \#

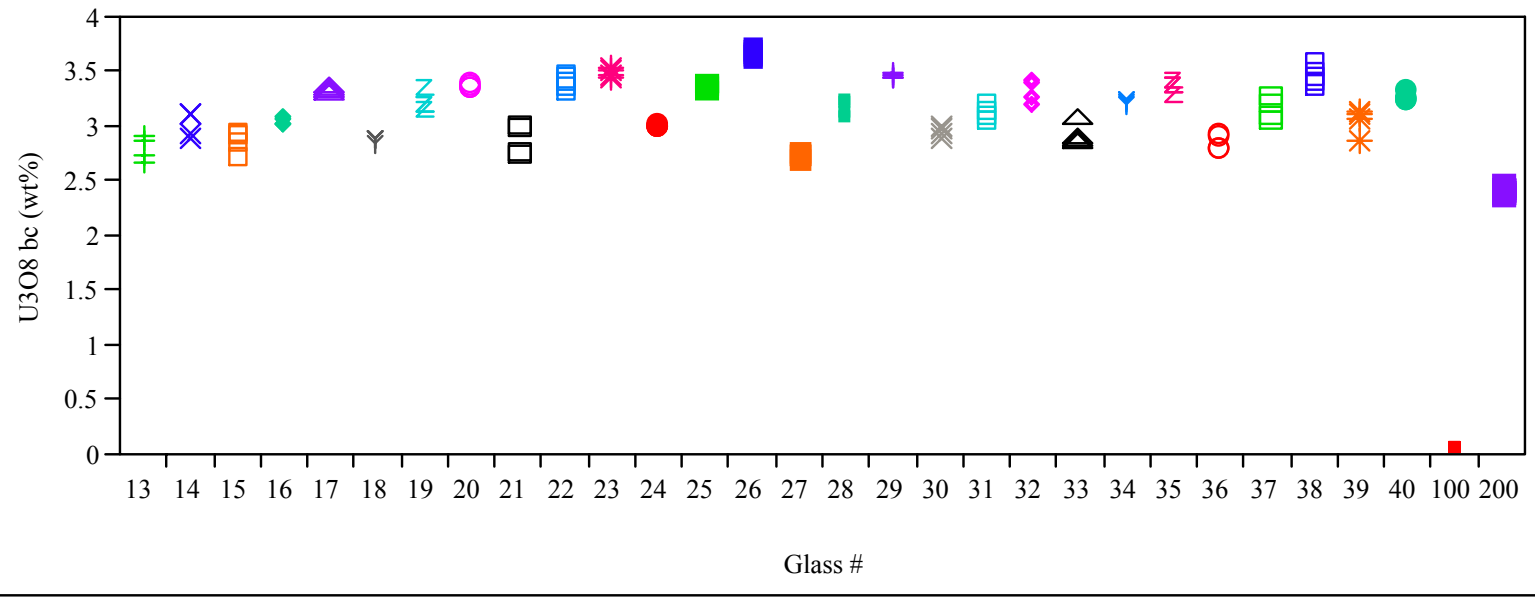




\section{Exhibit C7. Average Measured and Bias-Corrected (bc) Versus Targeted Compositions by Glass \# by Oxide}

(100-Batch 1;200 - Ustd)
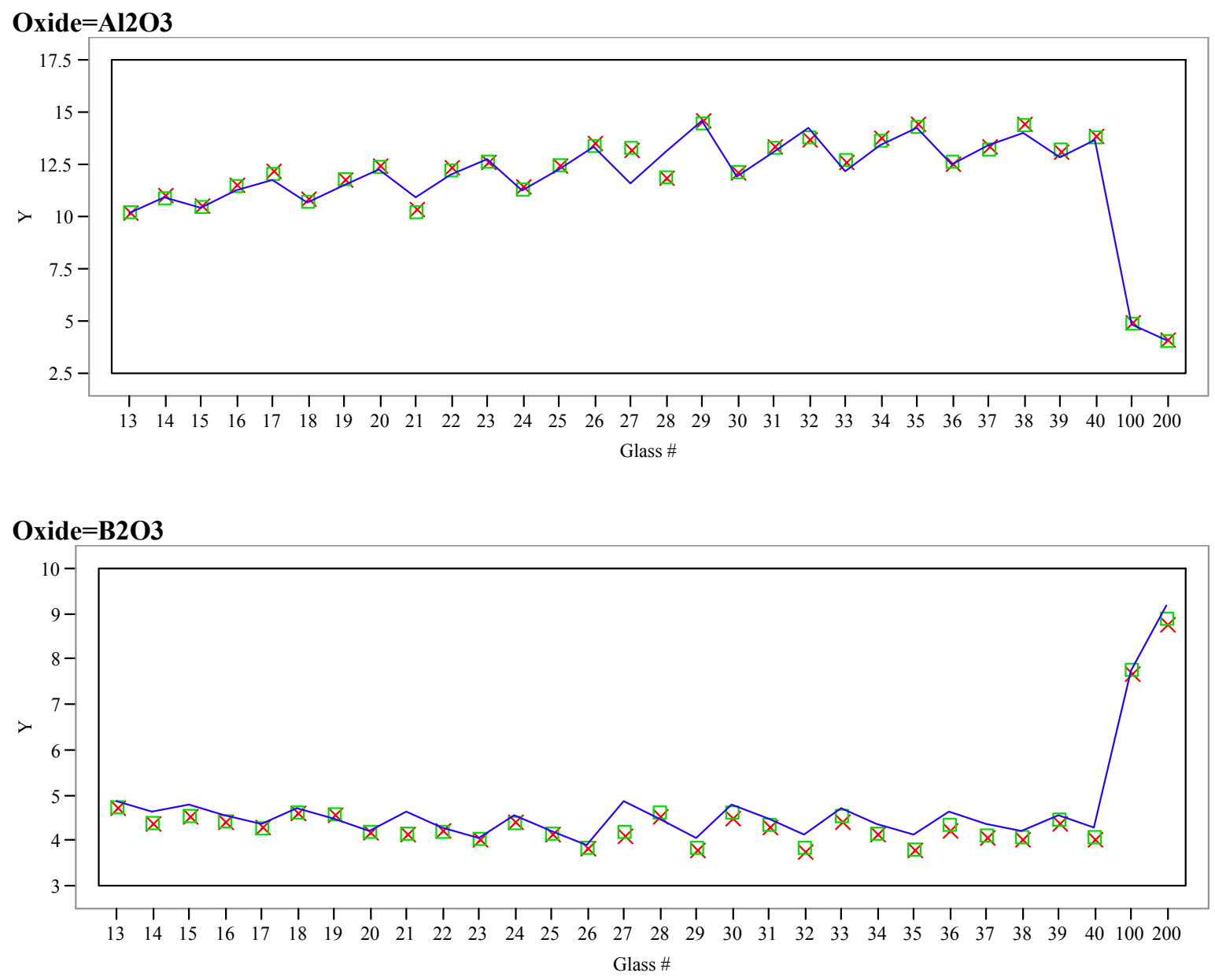

\section{Oxide $=\mathrm{BaO}$}

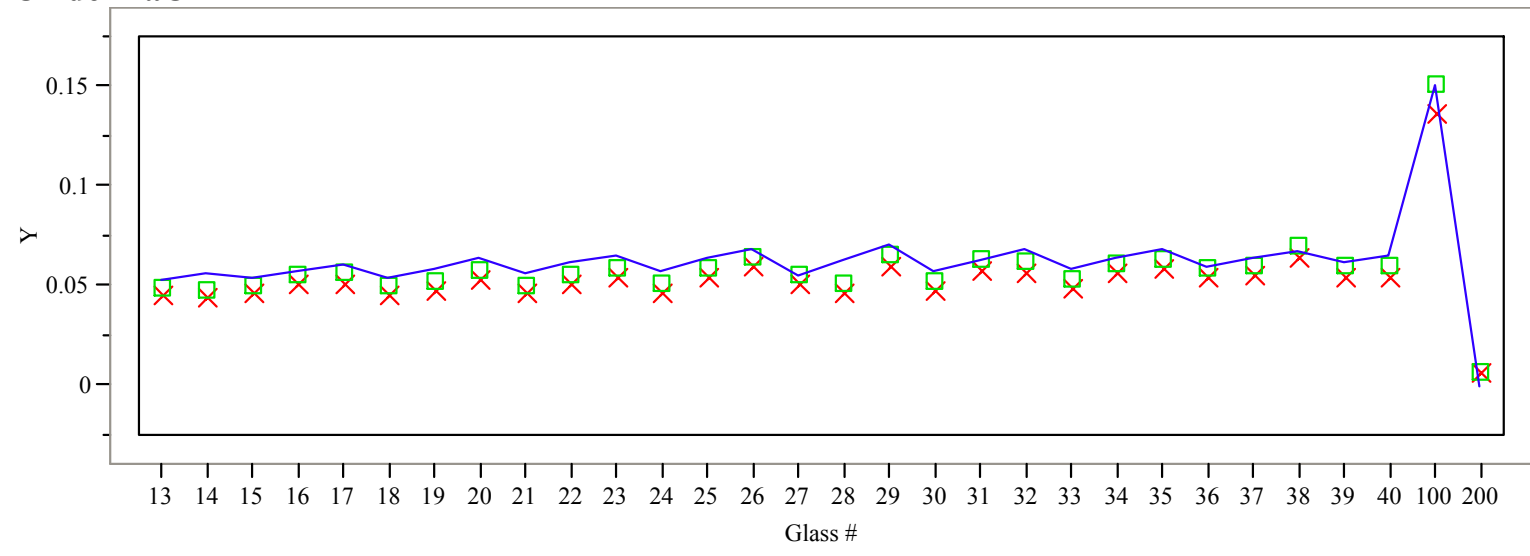

$\mathrm{Y} \times$ Measured $(\mathrm{wt} \%) \square$ Measured bc $(\mathrm{wt} \%) \quad$ Targeted $(\mathrm{wt} \%)$ 


\section{Exhibit C7. Average Measured and Bias-Corrected (bc) Versus Targeted Compositions by Glass \# by Oxide}

(100 - Batch 1; 200 - Ustd)

\section{Oxide $=\mathbf{C a O}$}

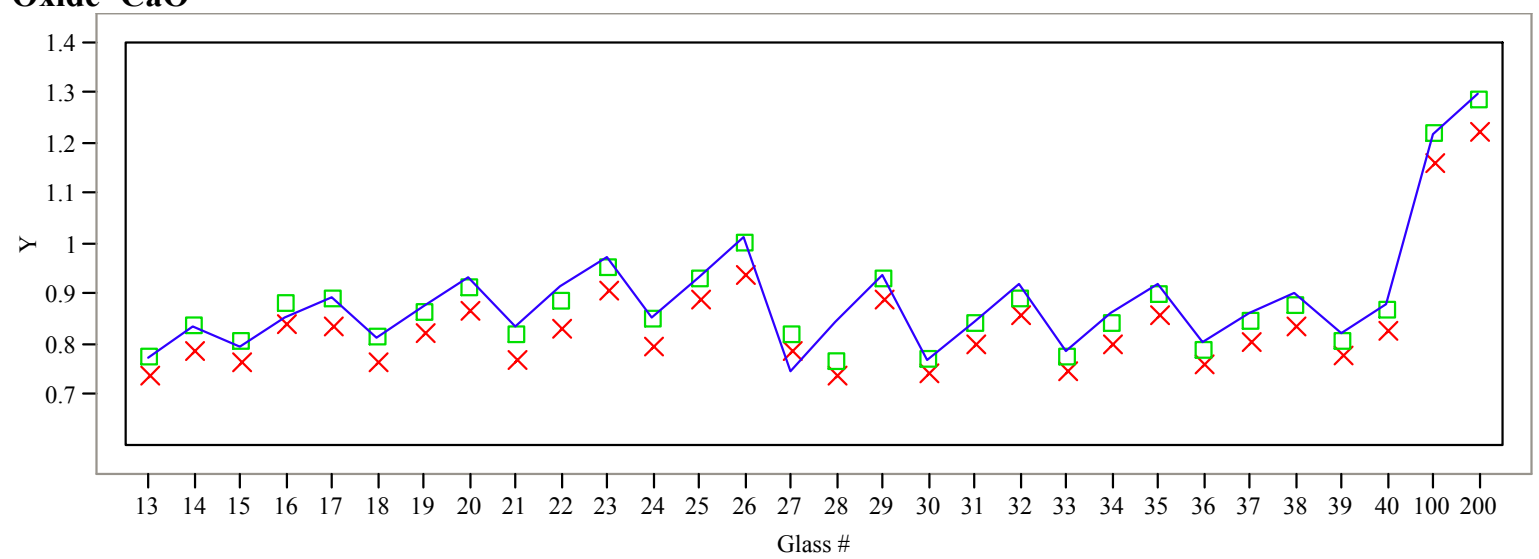

\section{Oxide $=\mathrm{Ce} 2 \mathrm{O3}$}

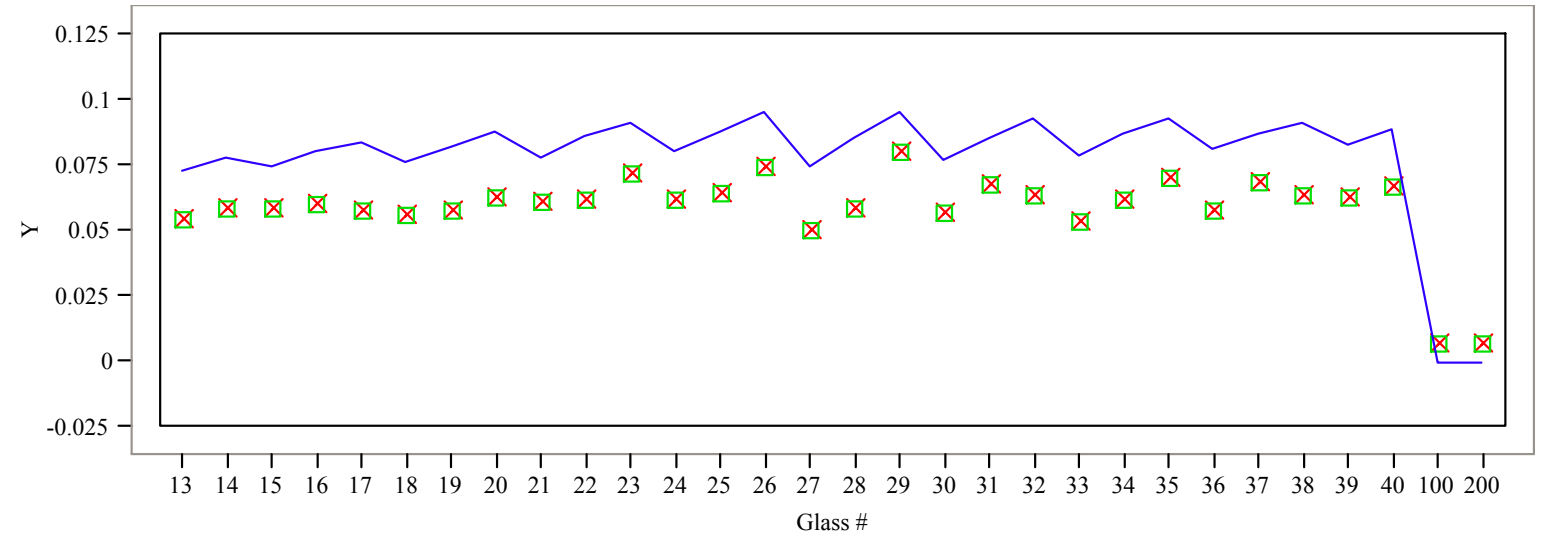

\section{Oxide $=\mathbf{C r 2 O 3}$}

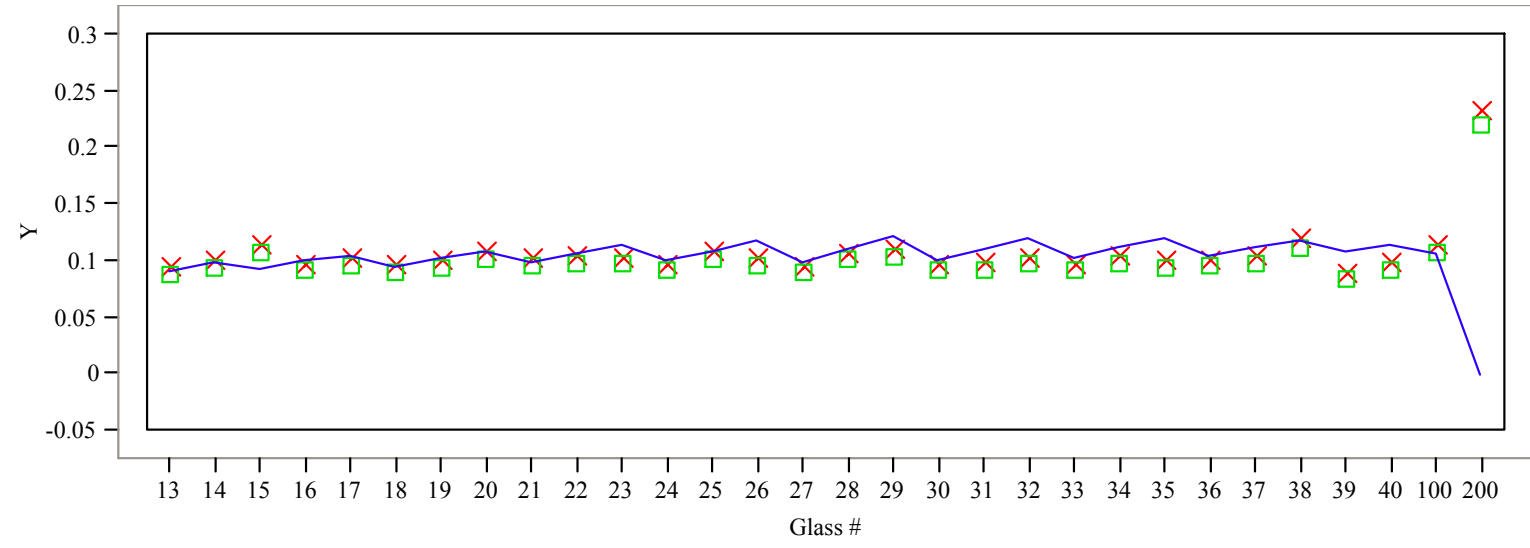

$\mathrm{Y} \times$ Measured $(\mathrm{wt} \%) \quad \square$ Measured bc (wt \%) - Targeted (wt $\%)$ 


\section{Exhibit C7. Average Measured and Bias-Corrected (bc) Versus Targeted} Compositions by Glass \# by Oxide

(100 - Batch 1;200 - Ustd)

\section{Oxide $=\mathbf{C u O}$}

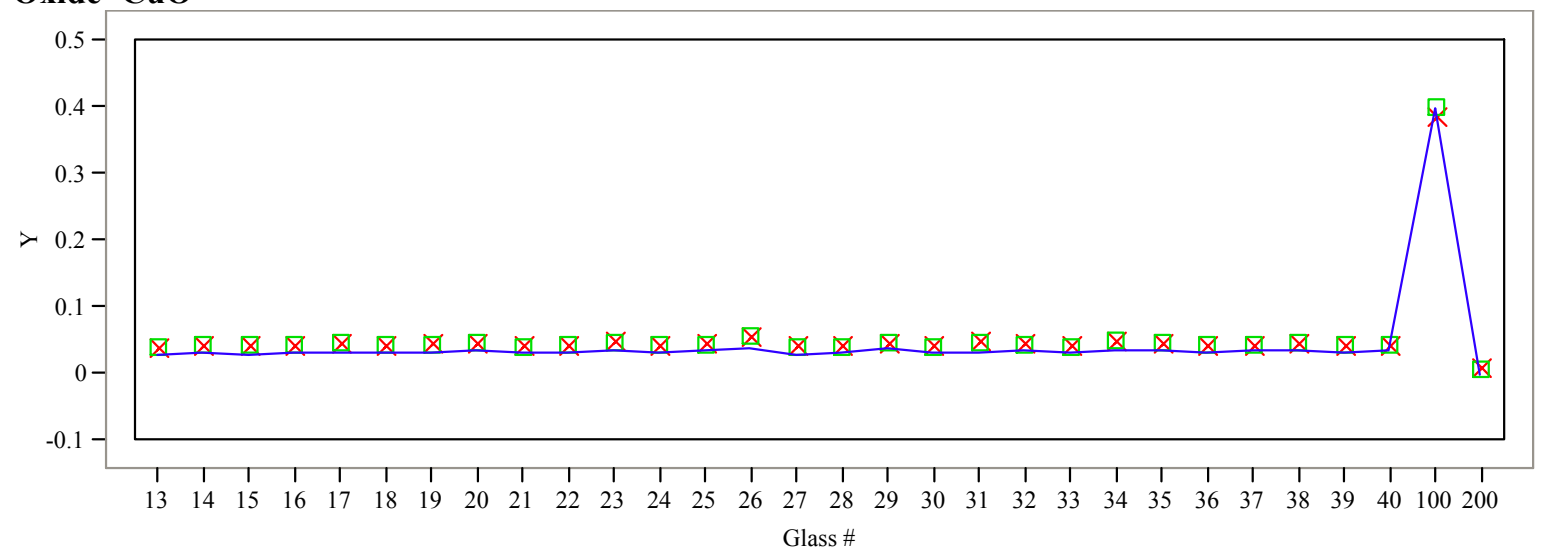

\section{Oxide $=\mathrm{Fe} 2 \mathrm{O3}$}

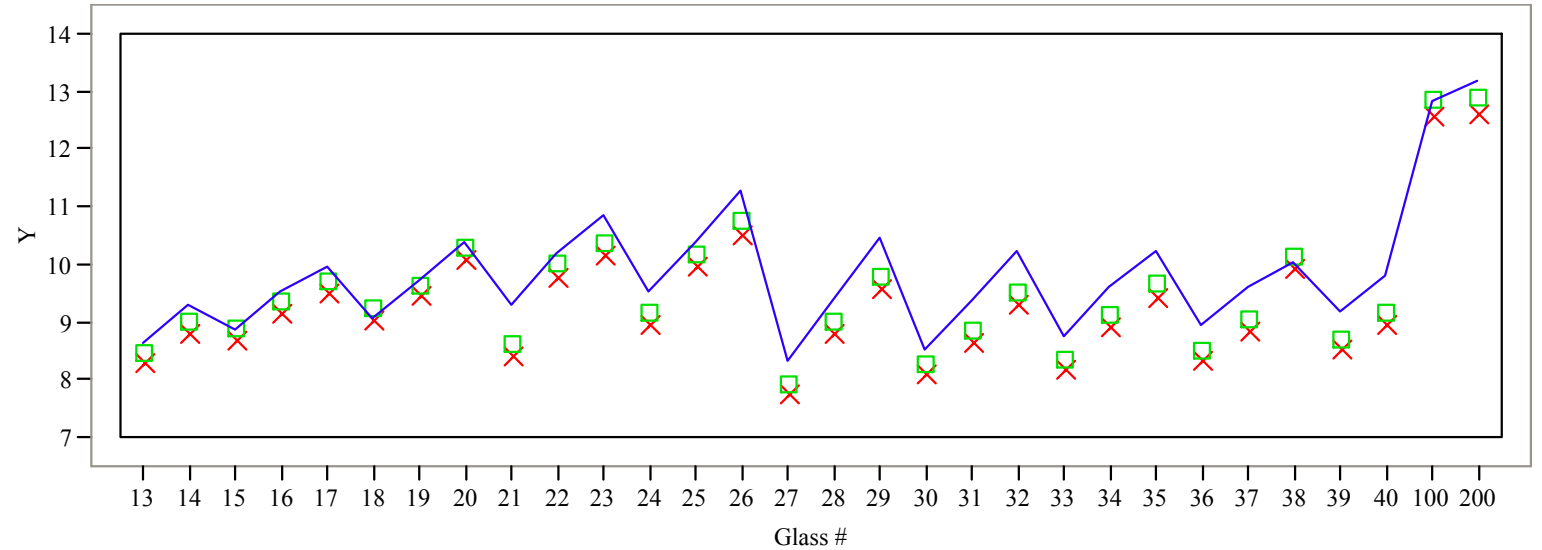

\section{Oxide $=$ K2O}

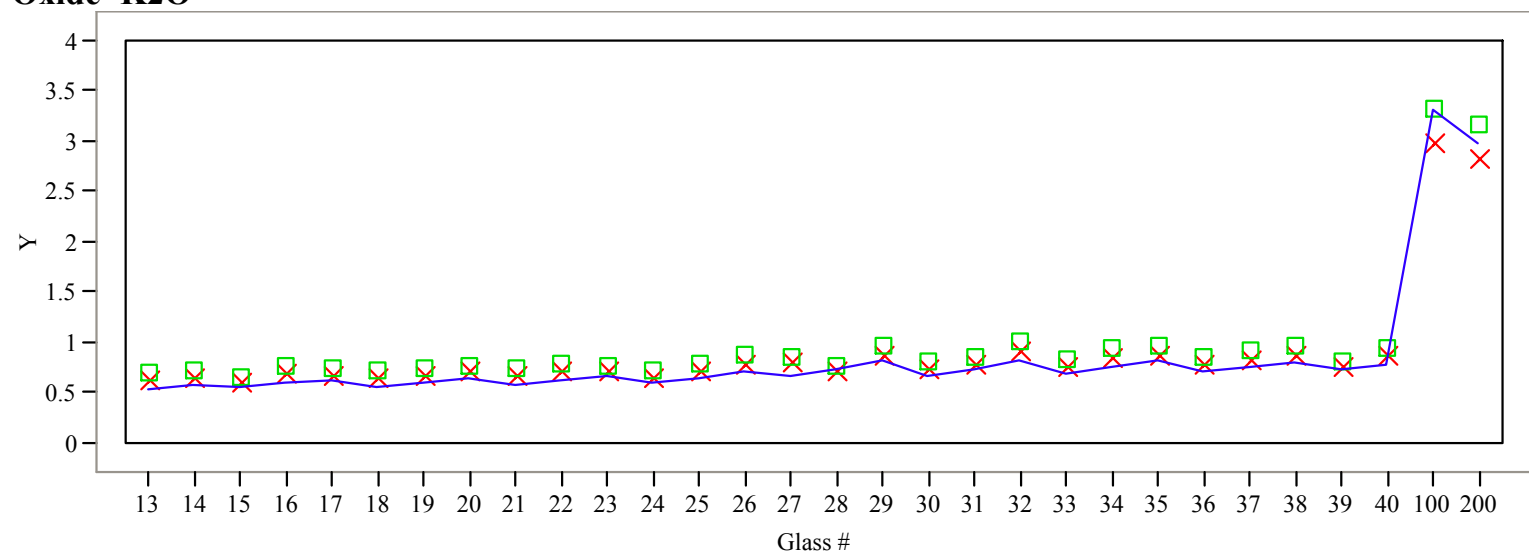

$\mathrm{Y} \times$ Measured (wt \%) $\square$ Measured bc (wt \%) - Targeted (wt $\%)$ 


\section{Exhibit C7. Average Measured and Bias-Corrected (bc) Versus Targeted Compositions by Glass \# by Oxide}

$(100-$ Batch $1 ; 200-$ Ustd $)$

\section{Oxide $=\mathbf{L a 2 O 3}$}

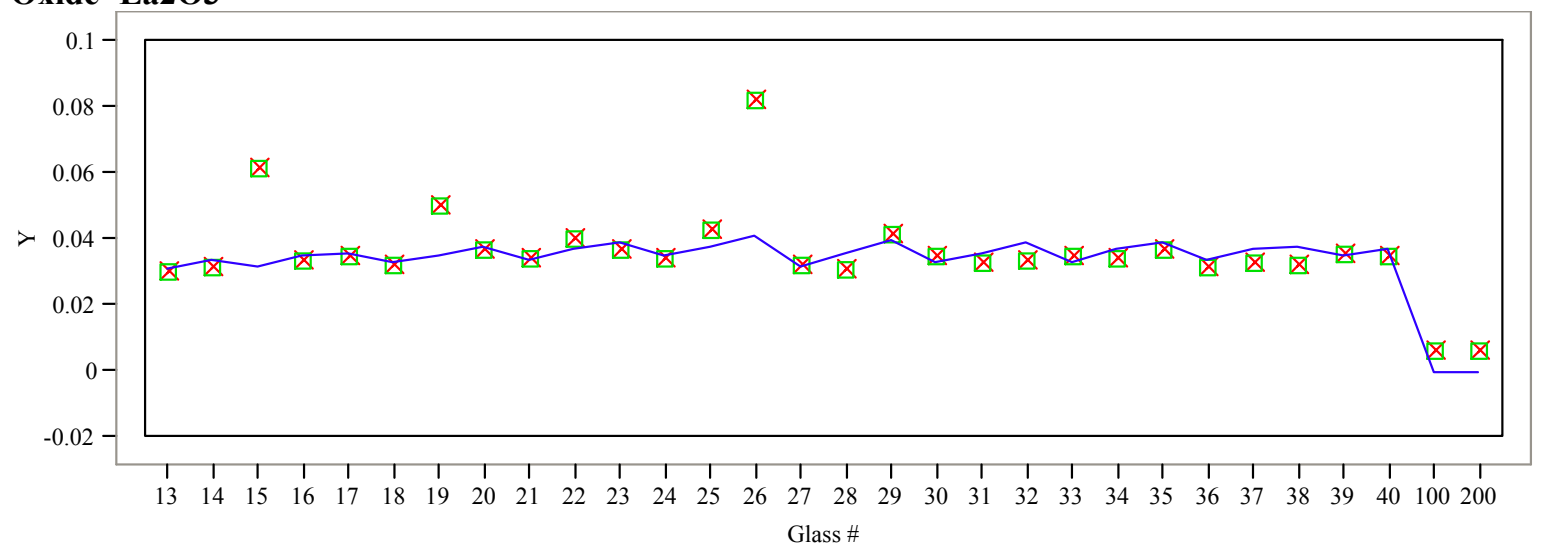

\section{Oxide $=$ Li2O}

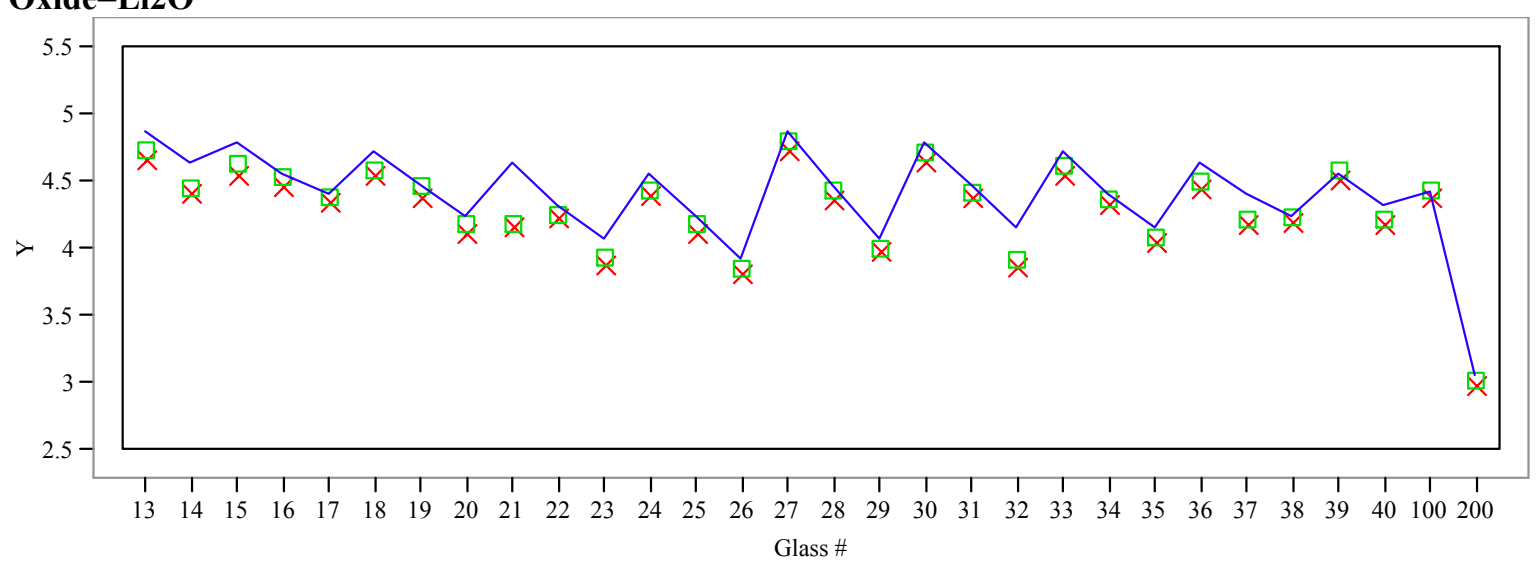

\section{Oxide $=\mathbf{M g O}$}

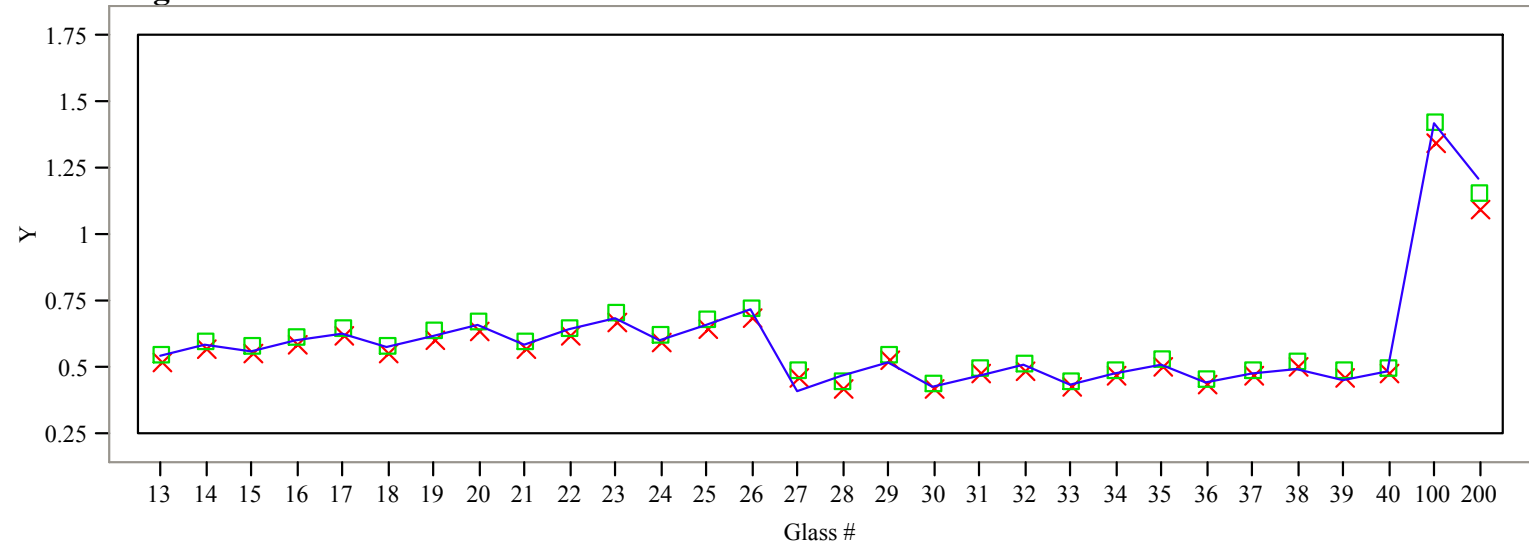

$\mathrm{Y} \times$ Measured (wt \%) $\square$ Measured bc (wt \%) - Targeted (wt \%) 


\section{Exhibit C7. Average Measured and Bias-Corrected (bc) Versus Targeted Compositions by Glass \# by Oxide}

(100 - Batch 1;200 - Ustd)

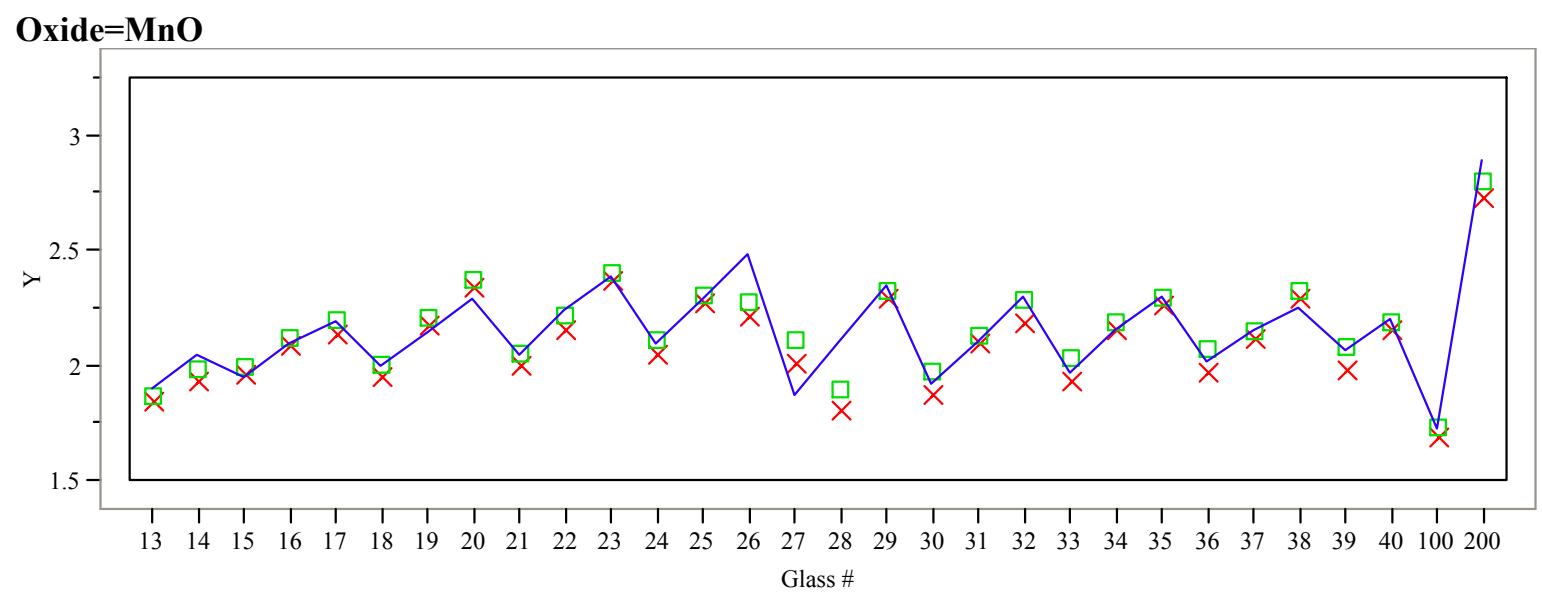

Oxide $=\mathrm{Na2O}$

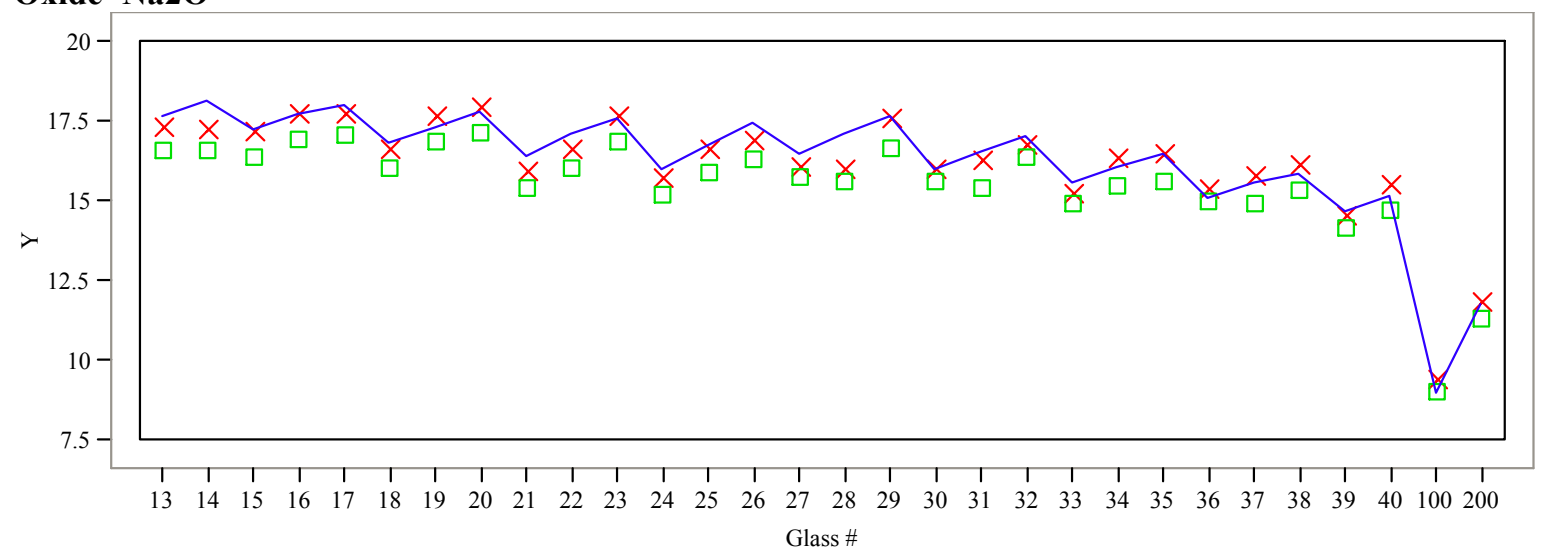

\section{Oxide $=\mathrm{NiO}$}

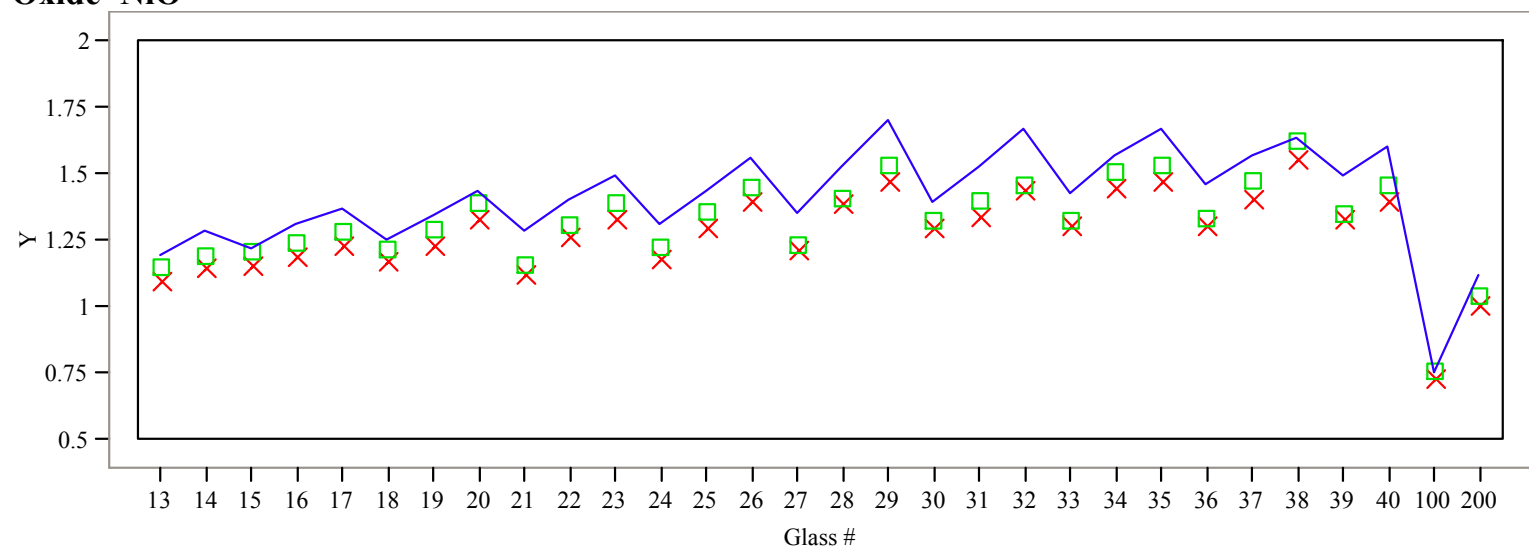

$\mathrm{Y} \times$ Measured $(\mathrm{wt} \%) \quad \square$ Measured bc (wt $\%) \quad-$ Targeted $(\mathrm{wt} \%)$ 


\section{Exhibit C7. Average Measured and Bias-Corrected (bc) Versus Targeted Compositions by Glass \# by Oxide}

$(100-$ Batch $1 ; 200-$ Ustd)

\section{Oxide $=\mathbf{P b O}$}

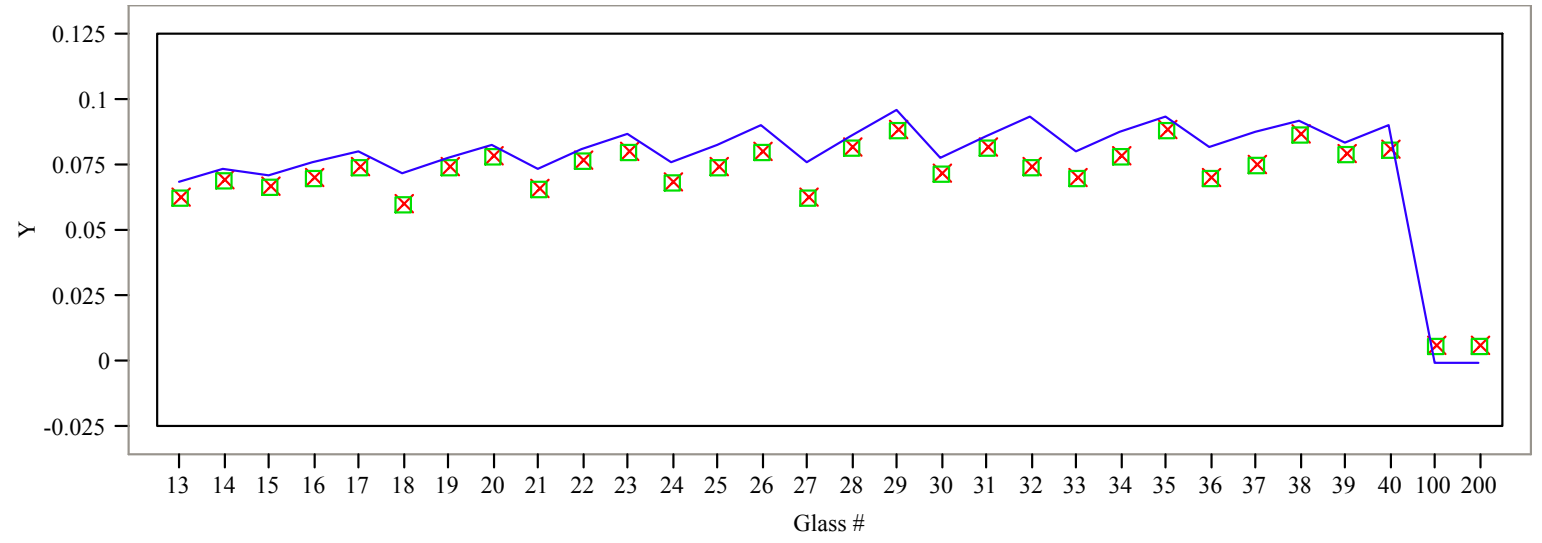

\section{Oxide $=$ SO4}

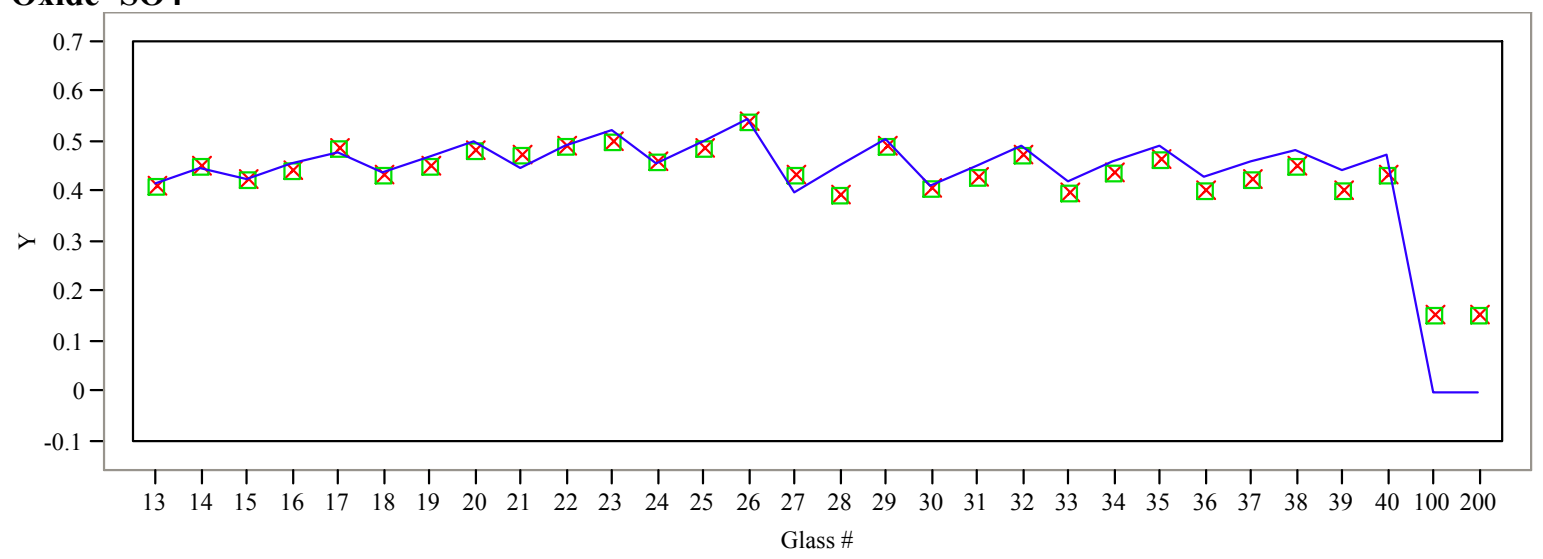

\section{Oxide $=\mathrm{SiO} 2$}

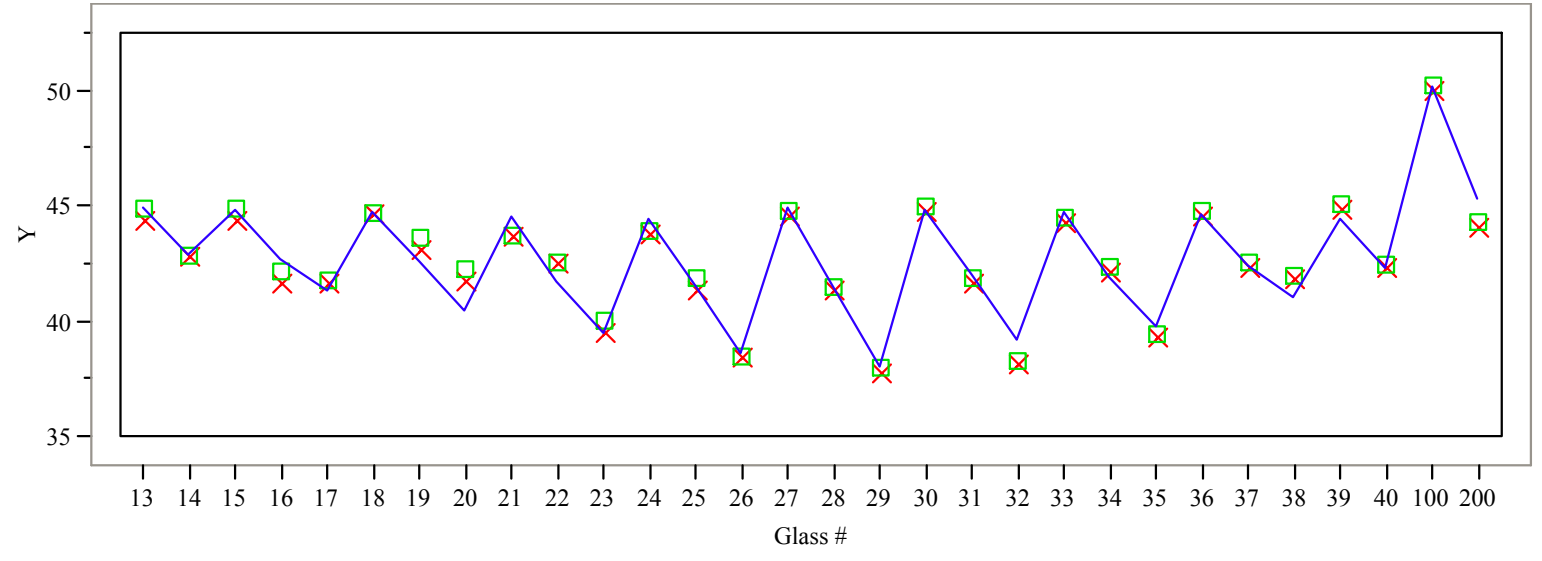

$\mathrm{Y} \times$ Measured $(\mathrm{wt} \%) \quad$ Measured bc $(\mathrm{wt} \%)-$ Targeted $(\mathrm{wt} \%)$ 


\section{Exhibit C7. Average Measured and Bias-Corrected (bc) Versus Targeted Compositions by Glass \# by Oxide}

$(100-$ Batch $1 ; 200-$ Ustd $)$

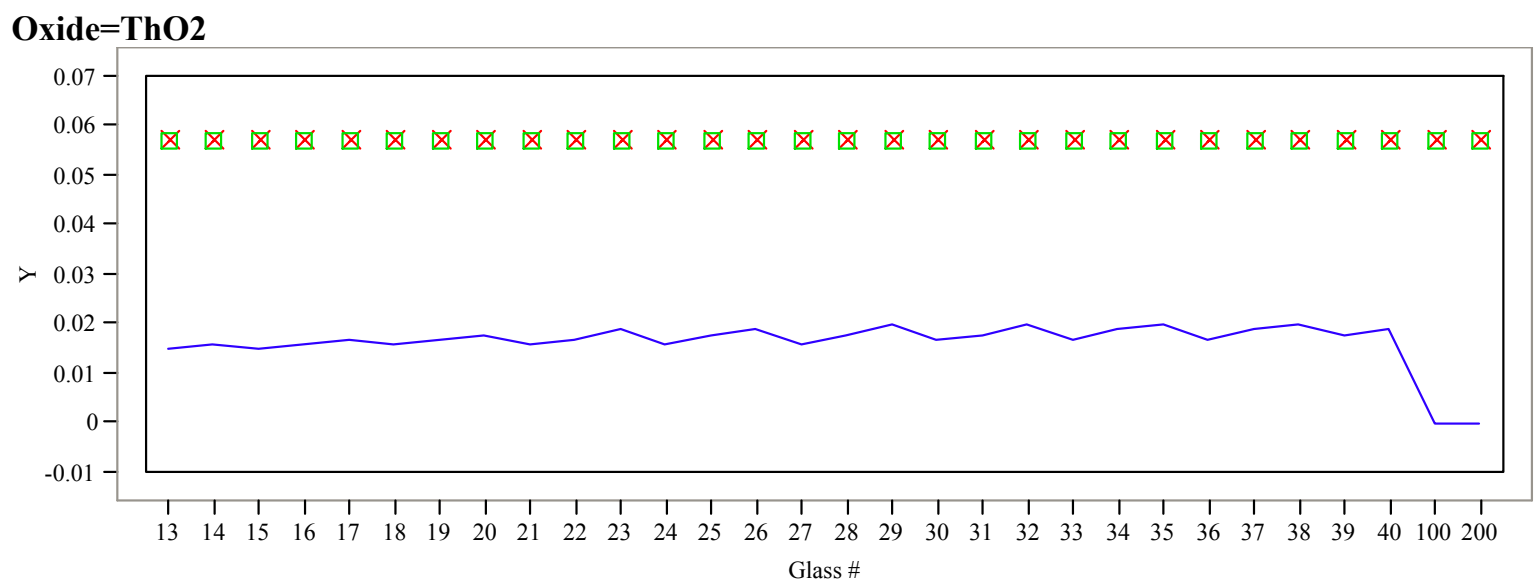

\section{Oxide $=\mathrm{TiO} 2$}

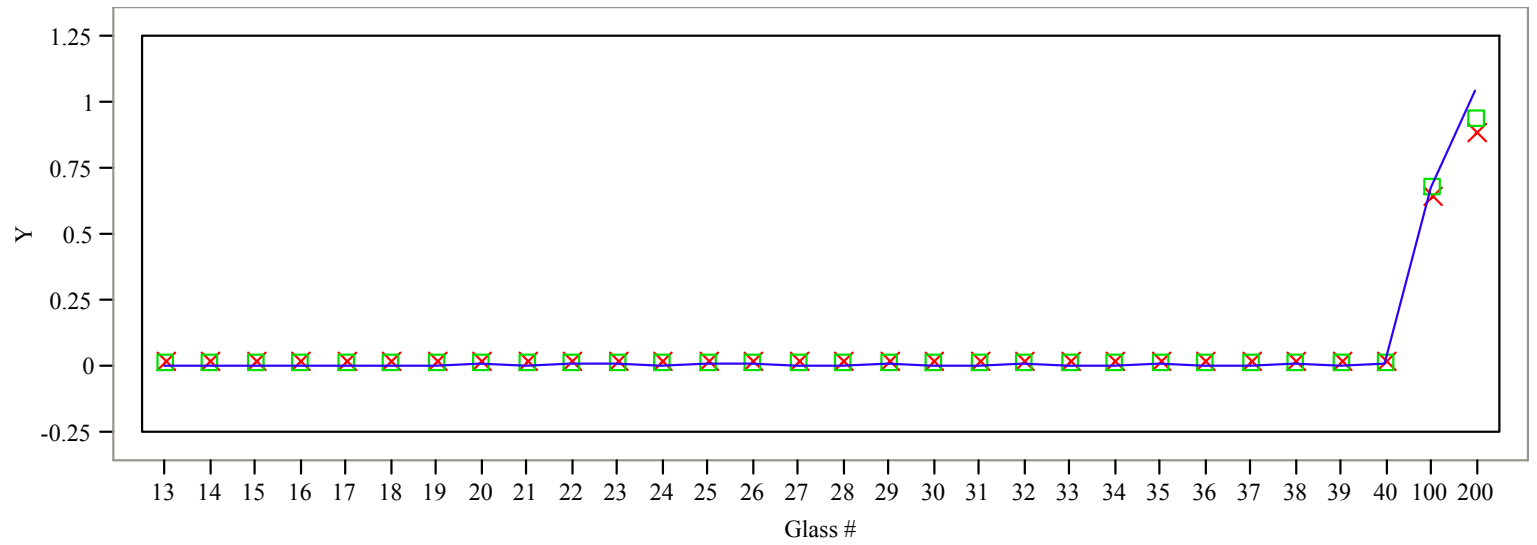

\section{Oxide $=\mathbf{U 3 0 8}$}

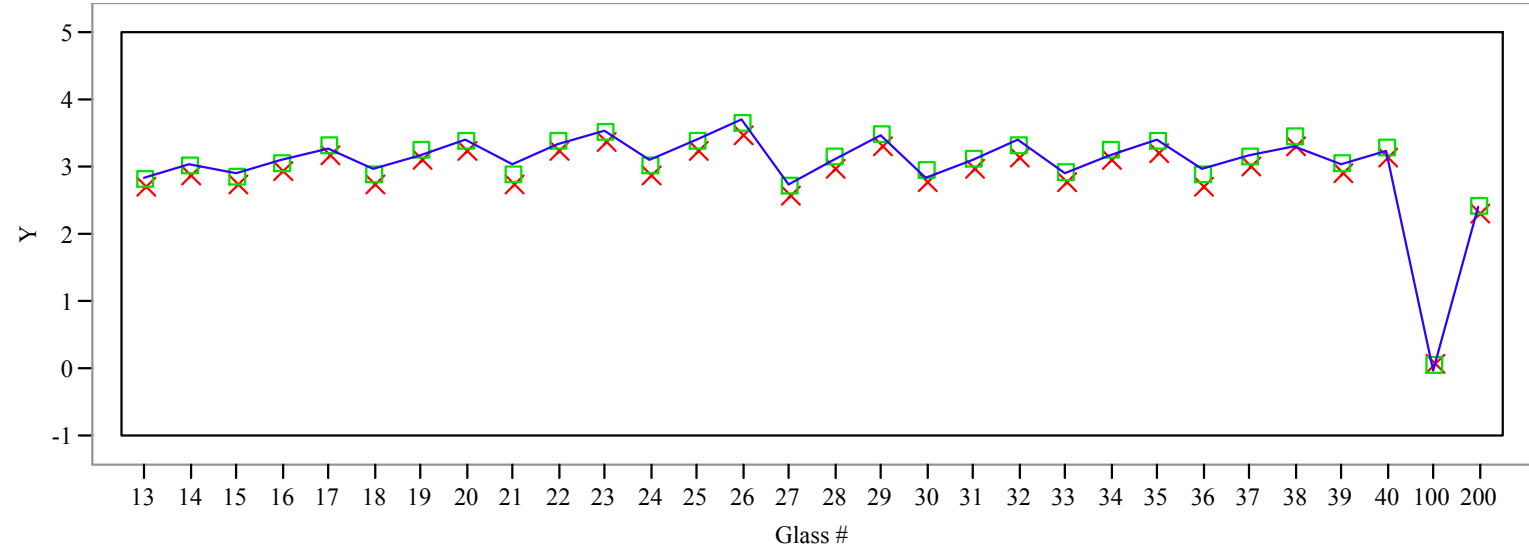

$\mathrm{Y} \times$ Measured (wt\%) $\square$ Measured bc (wt\%) - Targeted (wt $\%)$ 


\section{Exhibit C7. Average Measured and Bias-Corrected (bc) Versus Targeted Compositions by Glass \# by Oxide}

(100- Batch 1;200 - Ustd)

\section{Oxide $=\mathbf{Z n O}$}

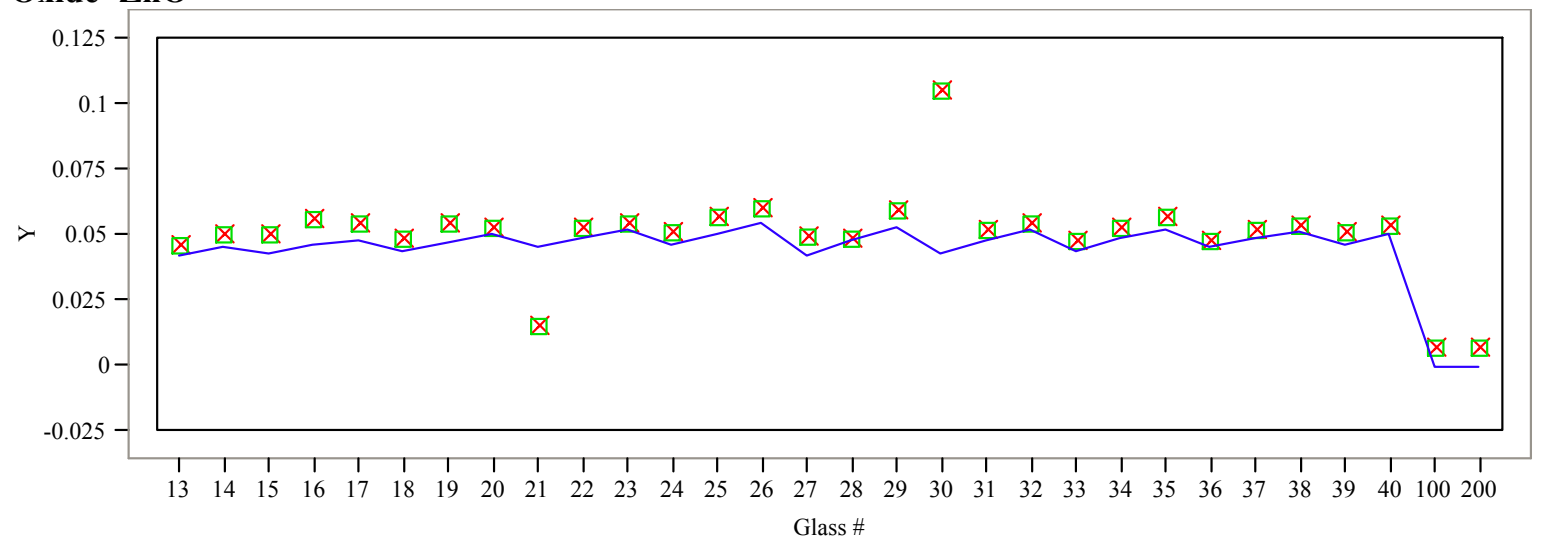

\section{Oxide $=\mathbf{Z r O 2}$}

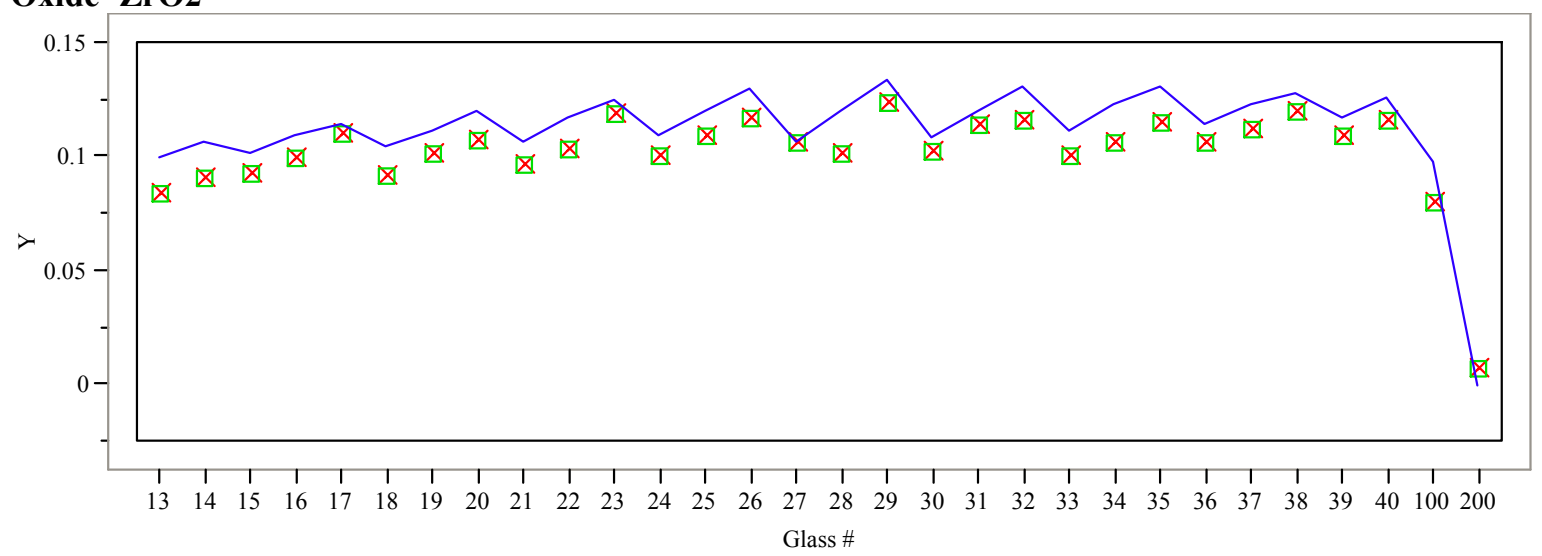

\section{Oxide $=$ Sum of Oxides}

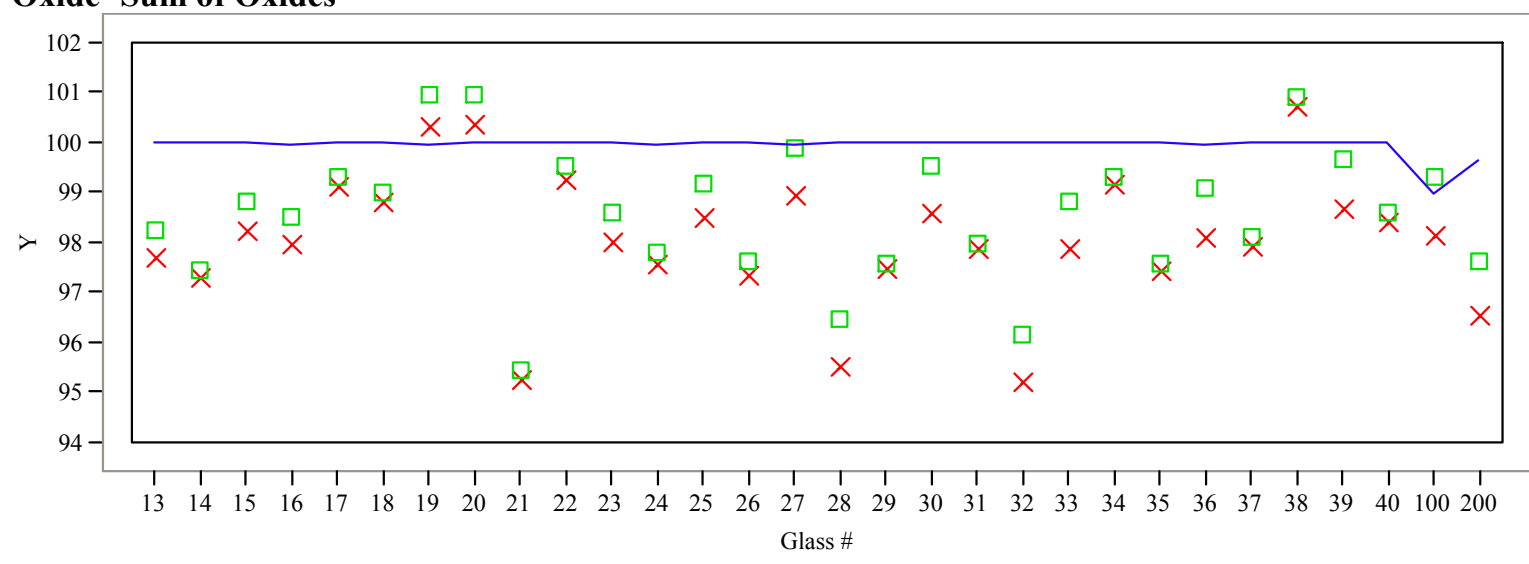

$\mathrm{Y} \times$ Measured $(\mathrm{wt} \%) \quad \square$ Measured bc (wt \%) - Targeted (wt \%) 


\section{Exhibit C8. Measurement and Re-Measurement of Select Study Glasses}
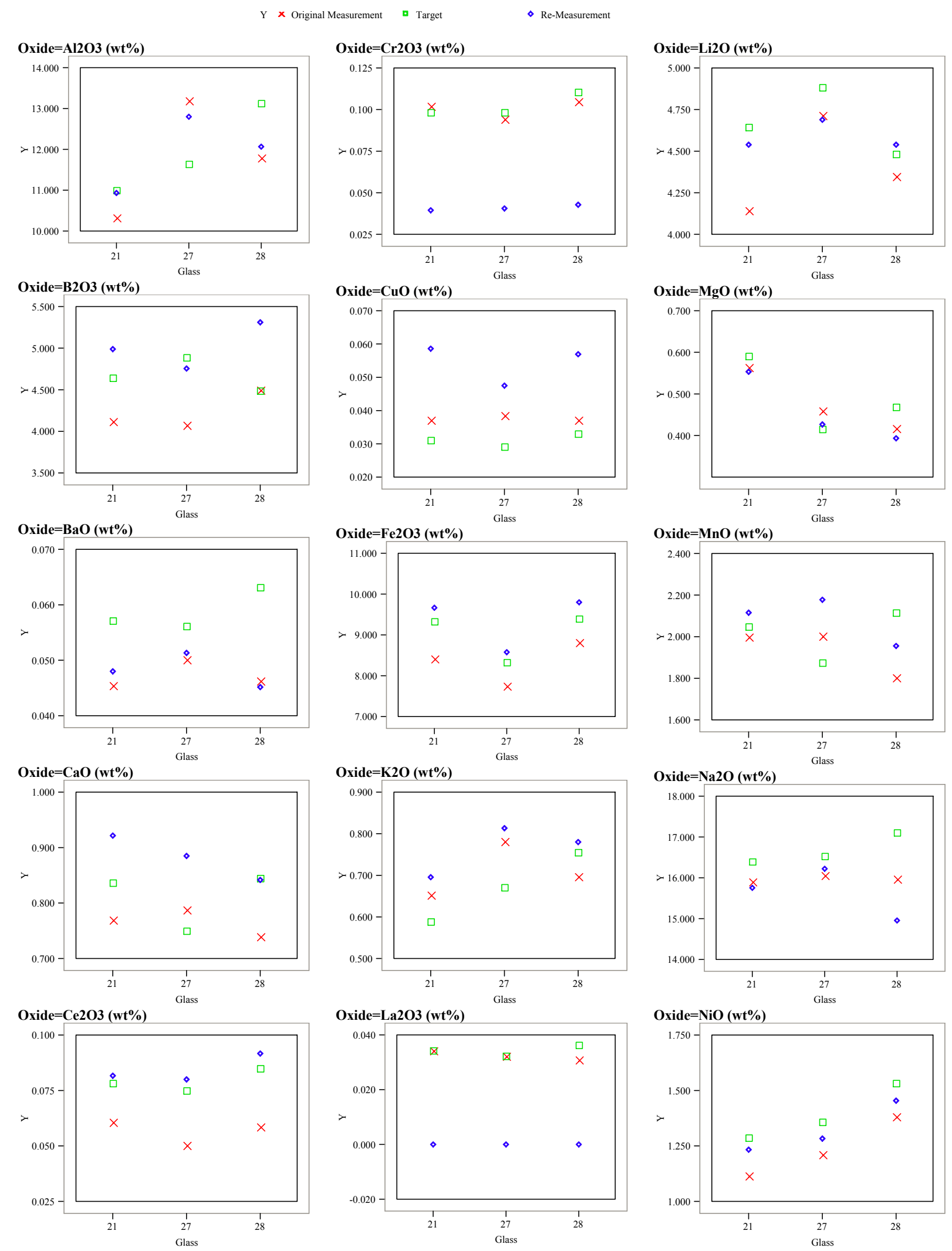


\section{Exhibit C8. Measurement and Re-Measurement of Select Study Glasses}
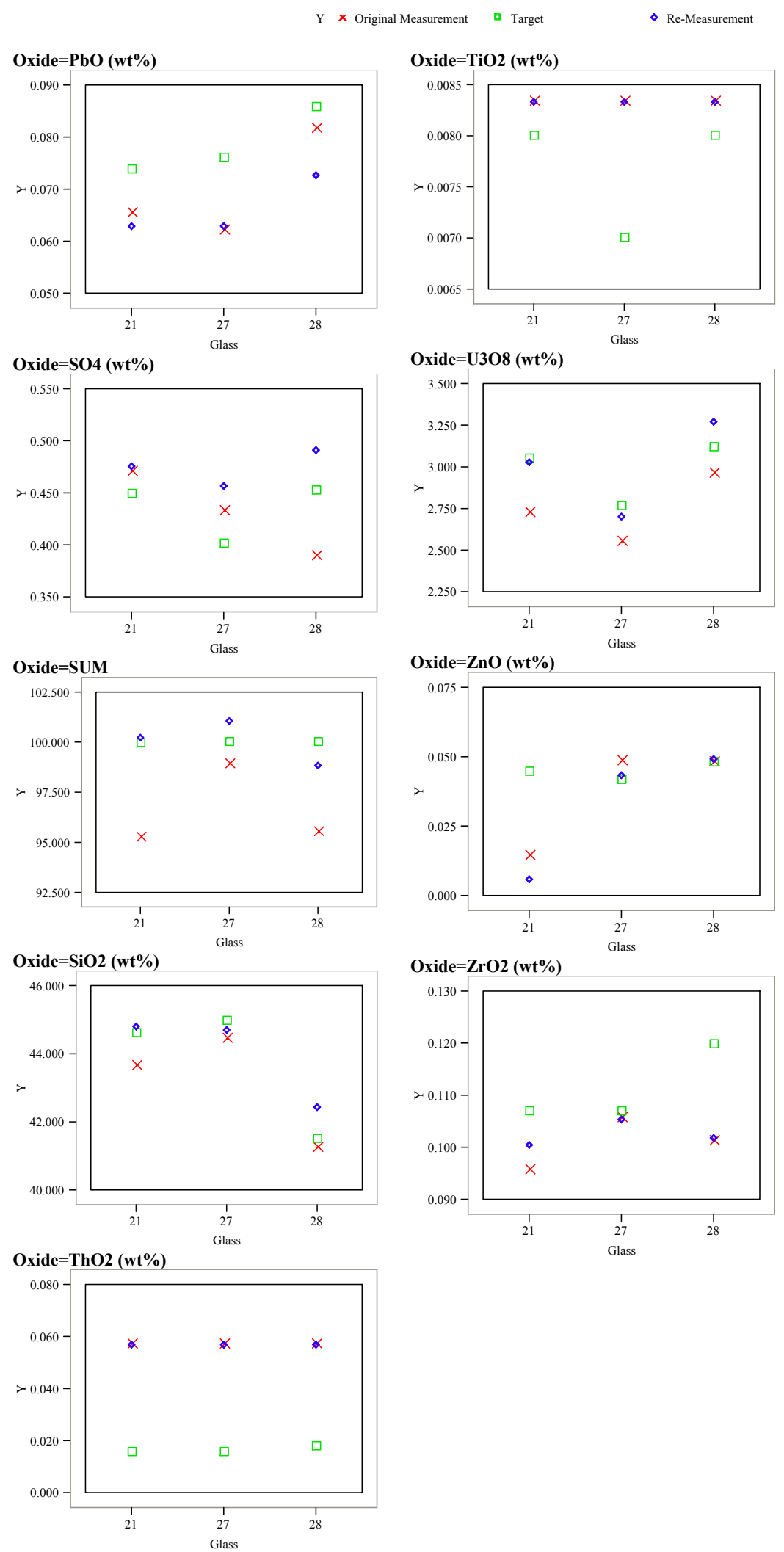


\section{APPENDIX D}

Tables and Exhibits Supporting the Analysis of the PCT Results for the Nepheline Phase 2 Study Glasses 
Table D1. Laboratory Measurements of the PCT Solutions (ppm) for the Nepheline Study Glasses

\begin{tabular}{|c|c|c|c|c|c|c|c|c|c|c|c|c|c|c|c|c|}
\hline Part & Glass ID & $\begin{array}{c}\text { Heat } \\
\text { Treatment }\end{array}$ & $\begin{array}{c}\text { Laboratory } \\
\text { ID }\end{array}$ & Block & Seq & B ar & Ba ar & Cd ar & Cr ar & $\mathrm{Fe}$ ar & Li ar & $\mathrm{Na}$ ar & $\mathrm{Pb}$ ar & Si ar & Th ar & $\mathbf{U}$ ar \\
\hline 1 & Soln Std & & std-b1-1 & 1 & 1 & 20.5 & $<0.010$ & $<0.010$ & $<0.050$ & 4.33 & 10.1 & 82.1 & $<0.020$ & 49.9 & $<0.500$ & $<0.100$ \\
\hline 1 & NEPH2-21ccc & $\mathrm{ccc}$ & $\mathrm{C} 51$ & 1 & 2 & 8.38 & $<0.010$ & $<0.010$ & $<0.050$ & 7.94 & 12.5 & 83.4 & $<0.020$ & 78.2 & $<0.500$ & 2.32 \\
\hline 1 & NEPH2-17 & quenched & $\mathrm{C} 92$ & 1 & 3 & 8.89 & $<0.010$ & $<0.010$ & $<0.050$ & 10.1 & 12.3 & 119 & $<0.020$ & 82.9 & $<0.500$ & 2.63 \\
\hline 1 & NEPH2-22 & quenched & C67 & 1 & 4 & 7.64 & $<0.010$ & $<0.010$ & $<0.050$ & 7.83 & 10.6 & 94.5 & $<0.020$ & 74.4 & $<0.500$ & 2.05 \\
\hline 1 & NEPH2-26 & quenched & C59 & 1 & 5 & 7.74 & $<0.010$ & $<0.010$ & $<0.050$ & 9.65 & 10.4 & 111 & $<0.020$ & 75 & $<0.500$ & 2.24 \\
\hline 1 & NEPH2-18 & quenched & C69 & 1 & 6 & 8 & $<0.010$ & $<0.010$ & $<0.050$ & 9.64 & 12.1 & 95 & $<0.020$ & 82.3 & $<0.500$ & 2.19 \\
\hline 1 & NEPH2-13ccc & $\mathrm{ccc}$ & $\mathrm{C} 83$ & 1 & 7 & 9.4 & $<0.010$ & $<0.010$ & $<0.050$ & 12.6 & 15.2 & 106 & $<0.020$ & 93.3 & $<0.500$ & 3.35 \\
\hline 1 & NEPH2-24 & quenched & $\mathrm{C} 34$ & 1 & 8 & 7.41 & $<0.010$ & $<0.010$ & $<0.050$ & 7.61 & 11 & 84 & $<0.020$ & 76.8 & $<0.500$ & 1.98 \\
\hline 1 & NEPH2-18ccc & $\mathrm{ccc}$ & $\mathrm{C} 15$ & 1 & 9 & 8.64 & $<0.010$ & $<0.010$ & $<0.050$ & 9.57 & 13.3 & 91.1 & $<0.020$ & 85.8 & $<0.500$ & 2.69 \\
\hline 1 & NEPH2-15 & quenched & $\mathrm{C} 52$ & 1 & 10 & 8.71 & $<0.010$ & $<0.010$ & $<0.050$ & 12.1 & 12.8 & 104 & $<0.020$ & 90.6 & $<0.500$ & 2.7 \\
\hline 1 & NEPH2-23 & quenched & $\mathrm{C} 70$ & 1 & 11 & 8.05 & $<0.010$ & $<0.010$ & $<0.050$ & 9.84 & 10.5 & 112 & $<0.020$ & 77 & $<0.500$ & 2.91 \\
\hline 1 & NEPH2-13 & quenched & C89 & 1 & 12 & 8.85 & $<0.010$ & $<0.010$ & $<0.050$ & 12.6 & 13.6 & 113 & $<0.020$ & 92.9 & $<0.500$ & 2.8 \\
\hline 1 & ARM-1 & & $\mathrm{C} 84$ & 1 & 13 & 11.3 & $<0.010$ & $<0.010$ & $<0.050$ & 0.448 & 9.06 & 24.1 & $<0.020$ & 39.7 & $<0.500$ & $<0.100$ \\
\hline 1 & EA & & C44 & 1 & 14 & 38.9 & $<0.010$ & $<0.010$ & $<0.050$ & $<0.010$ & 12 & 105 & $<0.020$ & 56.9 & $<0.500$ & $<0.100$ \\
\hline 1 & NEPH2-15ccc & $\mathrm{ccc}$ & $\mathrm{C} 76$ & 1 & 15 & 9.34 & $<0.010$ & $<0.010$ & $<0.050$ & 11.2 & 14.8 & 96 & $<0.020$ & 89.9 & $<0.500$ & 2.51 \\
\hline 1 & NEPH2-21 & quenched & $\mathrm{C} 03$ & 1 & 16 & 7.75 & $<0.010$ & $<0.010$ & $<0.050$ & 7.91 & 11.6 & 89.9 & $<0.020$ & 78.8 & $<0.500$ & 2.24 \\
\hline 1 & Soln Std & & std-b1-2 & 1 & 17 & 20 & $<0.010$ & $<0.010$ & $<0.050$ & 4.17 & 10.1 & 83 & $<0.020$ & 49.6 & $<0.500$ & $<0.100$ \\
\hline 1 & NEPH2-16ccc & $\mathrm{ccc}$ & $\mathrm{C} 32$ & 1 & 18 & 15.5 & $<0.010$ & $<0.010$ & $<0.050$ & 10.6 & 21.2 & 128 & $<0.020$ & 106 & $<0.500$ & 3.12 \\
\hline 1 & NEPH2-20ccc & $\mathrm{ccc}$ & C14 & 1 & 19 & 70.2 & $<0.010$ & $<0.010$ & $<0.050$ & 0.174 & 74.5 & 405 & $<0.020$ & 199 & $<0.500$ & 9.76 \\
\hline 1 & NEPH2-19 & quenched & $\mathrm{C} 71$ & 1 & 20 & 8.41 & $<0.010$ & $<0.010$ & $<0.050$ & 9.94 & 11.4 & 99.2 & $<0.020$ & 78.2 & $<0.500$ & 2.32 \\
\hline 1 & NEPH2-24ccc & $\mathrm{ccc}$ & C49 & 1 & 21 & 8.09 & $<0.010$ & $<0.010$ & $<0.050$ & 7.15 & 12.3 & 76.7 & $<0.020$ & 76.5 & $<0.500$ & 2 \\
\hline 1 & NEPH2-14 & quenched & $\mathrm{C} 82$ & 1 & 22 & 9.24 & $<0.010$ & $<0.010$ & $<0.050$ & 12.1 & 13.5 & 123 & $<0.020$ & 90.8 & $<0.500$ & 2.63 \\
\hline 1 & NEPH2-20 & quenched & $\mathrm{C} 06$ & 1 & 23 & 8.43 & $<0.010$ & $<0.010$ & $<0.050$ & 9.13 & 11.5 & 115 & $<0.020$ & 78 & $<0.500$ & 2.2 \\
\hline 1 & NEPH2-19ccc & $\mathrm{ccc}$ & $\begin{array}{ll}\mathrm{C} 68 \\
\end{array}$ & 1 & 24 & 17.4 & $<0.010$ & $<0.010$ & $<0.050$ & 11.5 & 23.9 & 133 & $<0.020$ & 112 & $<0.500$ & 3.6 \\
\hline 1 & NEPH2-23ccc & $\mathrm{ccc}$ & C56 & 1 & 25 & 77.1 & $<0.010$ & $<0.010$ & $<0.050$ & 0.538 & 80.7 & 443 & $<0.020$ & 190 & $<0.500$ & 10.71 \\
\hline 1 & blank & & $\mathrm{C} 85$ & 1 & 26 & 0.799 & $<0.010$ & $<0.010$ & $<0.050$ & 0.442 & 0.852 & 0.193 & $<0.020$ & $<0.010$ & $<0.500$ & $<0.100$ \\
\hline 1 & NEPH2-22ccc & $\mathrm{ccc}$ & $\mathrm{C} 81$ & 1 & 27 & 19.6 & $<0.010$ & $<0.010$ & $<0.050$ & 15.1 & 31.7 & 138 & $<0.020$ & 127 & $<0.500$ & 3.8 \\
\hline 1 & NEPH2-25 & quenched & C66 & 1 & 28 & 7.86 & $<0.010$ & $<0.010$ & $<0.050$ & 8.28 & 10.8 & 92.7 & $<0.020$ & 73 & $<0.500$ & 1.82 \\
\hline 1 & NEPH2-26ccc & $\mathrm{ccc}$ & $\mathrm{C} 29$ & 1 & 29 & 276 & $<0.010$ & $<0.010$ & $<0.050$ & 0.08 & 142 & 1320 & $<0.020$ & 590 & $<0.500$ & 4.54 \\
\hline 1 & NEPH2-14ccc & $\mathrm{ccc}$ & $\mathrm{C} 42$ & 1 & 30 & 18.5 & $<0.010$ & $<0.010$ & $<0.050$ & 14.9 & 23.9 & 145 & $<0.020$ & 116 & $<0.500$ & 3.48 \\
\hline 1 & NEPH2-17ccc & $\mathrm{ccc}$ & $\mathrm{C} 09$ & 1 & 31 & 29.3 & $<0.010$ & $<0.010$ & $<0.050$ & 17.9 & 44.9 & 226 & $<0.020$ & 157 & $<0.500$ & 5.24 \\
\hline 1 & NEPH2-16 & quenched & $\mathrm{C} 72$ & 1 & 32 & 9.36 & $<0.010$ & $<0.010$ & $<0.050$ & 12.5 & 12.8 & 111 & $<0.020$ & 87.3 & $<0.500$ & 2.48 \\
\hline 1 & NEPH2-25ccc & $\mathrm{ccc}$ & $\mathrm{C} 20$ & 1 & 33 & 36.1 & $<0.010$ & $<0.010$ & $<0.050$ & 19.1 & 50.5 & 224 & $<0.020$ & 156 & $<0.500$ & 6.21 \\
\hline 1 & Soln Std & & std-b1-3 & 1 & 34 & 20.4 & $<0.010$ & $<0.010$ & $<0.050$ & 4.08 & 10.3 & 82.3 & $<0.020$ & 48.9 & $<0.500$ & $<0.100$ \\
\hline 1 & Soln Std & & std-b2-1 & 2 & 1 & 20.2 & $<0.010$ & $<0.010$ & $<0.050$ & 3.96 & 10.3 & 83.3 & $<0.020$ & 50.8 & $<0.500$ & $<0.100$ \\
\hline 1 & NEPH2-26ccc & $\mathrm{ccc}$ & $\mathrm{C} 10$ & 2 & 2 & 284 & $<0.010$ & $<0.010$ & $<0.050$ & $<0.010$ & 142 & 1350 & $<0.020$ & 600 & $<0.500$ & 4.94 \\
\hline 1 & NEPH2-15 & quenched & C47 & 2 & 3 & 10.7 & $<0.010$ & $<0.010$ & $<0.050$ & 11 & 12.9 & 104 & $<0.020$ & 92.7 & $<0.500$ & 2.53 \\
\hline 1 & NEPH2-19ccc & ccc & $\mathrm{C} 33$ & 2 & 4 & 18.1 & $<0.010$ & $<0.010$ & $<0.050$ & 16.9 & 23.5 & 135 & $<0.020$ & 120 & $<0.500$ & 3.61 \\
\hline 1 & NEPH2-14ccc & $\mathrm{ccc}$ & $\mathrm{C} 18$ & 2 & 5 & 16.3 & $<0.010$ & $<0.010$ & $<0.050$ & 12.8 & 23.1 & 144 & $<0.020$ & 119 & $<0.500$ & 3.31 \\
\hline 1 & NEPH2-23 & quenched & C11 & 2 & 6 & 8.01 & $<0.010$ & $<0.010$ & $<0.050$ & 8.94 & 10.9 & 112 & $<0.020$ & 78.2 & $<0.500$ & 2.18 \\
\hline
\end{tabular}


Table D1. Laboratory Measurements of the PCT Solutions (ppm) for the Nepheline Study Glasses

\begin{tabular}{|c|c|c|c|c|c|c|c|c|c|c|c|c|c|c|c|c|}
\hline Part & Glass ID & $\begin{array}{c}\text { Heat } \\
\text { Treatment }\end{array}$ & $\begin{array}{c}\text { Laboratory } \\
\text { ID }\end{array}$ & Block & Seq & B ar & Ba ar & Cd ar & Cr ar & $\mathrm{Fe}$ ar & Li ar & $\mathrm{Na}$ ar & $\mathrm{Pb}$ ar & Si ar & Th ar & $\mathbf{U}$ ar \\
\hline 1 & NEPH2-17 & quenched & C58 & 2 & 7 & 8.38 & $<0.010$ & $<0.010$ & $<0.050$ & 10.2 & 12.2 & 116 & $<0.020$ & 84.3 & $<0.500$ & 2.61 \\
\hline 1 & NEPH2-21ccc & $\mathrm{ccc}$ & $\mathrm{C} 02$ & 2 & 8 & 7.69 & $<0.010$ & $<0.010$ & $<0.050$ & 8.65 & 12.6 & 81.7 & $<0.020$ & 80.1 & $<0.500$ & 2.18 \\
\hline 1 & NEPH2-13ccc & $\mathrm{ccc}$ & C62 & 2 & 9 & 9.01 & $<0.010$ & $<0.010$ & $<0.050$ & 11.7 & 15.6 & 109 & $<0.020$ & 96.2 & $<0.500$ & 2.42 \\
\hline 1 & ARM-1 & & $\mathrm{C} 38$ & 2 & 10 & 10.8 & $<0.010$ & $<0.010$ & $<0.050$ & $<0.010$ & 9.03 & 26.2 & $<0.020$ & 40.3 & $<0.500$ & $<0.100$ \\
\hline 1 & NEPH2-26 & quenched & C63 & 2 & 11 & 7.25 & $<0.010$ & $<0.010$ & $<0.050$ & 9.19 & 10.3 & 111 & $<0.020$ & 77.2 & $<0.500$ & 2.48 \\
\hline 1 & NEPH2-20 & quenched & $\mathrm{C} 40$ & 2 & 12 & 7.94 & $<0.010$ & $<0.010$ & $<0.050$ & 7.83 & 11.3 & 115 & $<0.020$ & 80.4 & $<0.500$ & 2.09 \\
\hline 1 & NEPH2-16 & quenched & C19 & 2 & 13 & 8.2 & $<0.010$ & $<0.010$ & $<0.050$ & 10.2 & 12.6 & 112 & $<0.020$ & 88 & $<0.500$ & 2.37 \\
\hline 1 & NEPH2-18ccc & $\mathrm{ccc}$ & $\mathrm{C} 16$ & 2 & 14 & 7.86 & $<0.010$ & $<0.010$ & $<0.050$ & 10.6 & 13.5 & 88.6 & $<0.020$ & 85.5 & $<0.500$ & 3.17 \\
\hline 1 & NEPH2-25 & quenched & $\mathrm{C} 88$ & 2 & 15 & 7.03 & $<0.010$ & $<0.010$ & $<0.050$ & 7.22 & 10.8 & 94 & $<0.020$ & 74.8 & $<0.500$ & 1.59 \\
\hline 1 & NEPH2-19 & quenched & $\mathrm{C} 07$ & 2 & 16 & 7.36 & $<0.010$ & $<0.010$ & $<0.050$ & 7.4 & 11.4 & 102 & $<0.020$ & 78.7 & $<0.500$ & 1.99 \\
\hline 1 & Soln Std & & std-b2-2 & 2 & 17 & 19.1 & $<0.010$ & $<0.010$ & $<0.050$ & 3.72 & 10 & 83.3 & $<0.020$ & 49.7 & $<0.500$ & $<0.100$ \\
\hline 1 & NEPH2-14 & quenched & $\mathrm{C} 36$ & 2 & 18 & 8.77 & $<0.010$ & $<0.010$ & $<0.050$ & 11.8 & 13 & 121 & $<0.020$ & 89.5 & $<0.500$ & 3.5 \\
\hline 1 & NEPH2-17ccc & $\mathrm{ccc}$ & $\mathrm{C} 22$ & 2 & 19 & 27.4 & $<0.010$ & $<0.010$ & $<0.050$ & 17.6 & 42.7 & 211 & $<0.020$ & 145 & $<0.500$ & 5.73 \\
\hline 1 & NEPH2-18 & quenched & $\mathrm{C} 75$ & 2 & 20 & 7.55 & $<0.010$ & $<0.010$ & $<0.050$ & 8.6 & 11.9 & 92.9 & $<0.020$ & 82.2 & $<0.500$ & 2.2 \\
\hline 1 & NEPH2-24 & quenched & $\mathrm{C} 73$ & 2 & 21 & 6.78 & $<0.010$ & $<0.010$ & $<0.050$ & 7.21 & 11.1 & 83.1 & $<0.020$ & 76.3 & $<0.500$ & 1.83 \\
\hline 1 & NEPH2-22 & quenched & $\mathrm{C} 17$ & 2 & 22 & 6.96 & $<0.010$ & $<0.010$ & $<0.050$ & 7.26 & 10.5 & 93.1 & $<0.020$ & 75.2 & $<0.500$ & 2.12 \\
\hline 1 & NEPH2-15ccc & $\mathrm{ccc}$ & $\mathrm{C} 01$ & 2 & 23 & 8.31 & $<0.010$ & $<0.010$ & $<0.050$ & 9.27 & 14.7 & 97.4 & $<0.020$ & 87.4 & $<0.500$ & 2.12 \\
\hline 1 & NEPH2-21 & quenched & $\mathrm{C} 43$ & 2 & 24 & 6.38 & $<0.010$ & $<0.010$ & $<0.050$ & 7.87 & 10.7 & 83.5 & $<0.020$ & 72.7 & $<0.500$ & 2.08 \\
\hline 1 & NEPH2-23ccc & $\mathrm{ccc}$ & $\mathrm{C} 86$ & 2 & 25 & 74.1 & $<0.010$ & $<0.010$ & $<0.050$ & $<0.010$ & 77.4 & 433 & $<0.020$ & 187 & $<0.500$ & 10.11 \\
\hline 1 & NEPH2-16ccc & $\mathrm{ccc}$ & $\mathrm{C} 25$ & 2 & 26 & 15.2 & $<0.010$ & $<0.010$ & $<0.050$ & 11.9 & 21.4 & 133 & $<0.020$ & 109 & $<0.500$ & 3.32 \\
\hline 1 & NEPH2-20 ccc & $\mathrm{ccc}$ & $\mathrm{C} 08$ & 2 & 27 & 70.8 & $<0.010$ & $<0.010$ & $<0.050$ & $<0.010$ & 75.8 & 413 & $<0.020$ & 197 & $<0.500$ & 9.82 \\
\hline 1 & NEPH2-25ccc & $\mathrm{ccc}$ & $\mathrm{C} 55$ & 2 & 28 & 37.3 & $<0.010$ & $<0.010$ & $<0.050$ & 16.1 & 51.4 & 237 & $<0.020$ & 160 & $<0.500$ & 5.6 \\
\hline 1 & EA & & $\mathrm{C} 53$ & 2 & 29 & 36.4 & $<0.010$ & $<0.010$ & $<0.050$ & $<0.010$ & 11.5 & 101 & $<0.020$ & 54 & $<0.500$ & $<0.100$ \\
\hline 1 & NEPH2-22ccc & $\mathrm{ccc}$ & $\mathrm{C} 35$ & 2 & 30 & 19.6 & $<0.010$ & $<0.010$ & $<0.050$ & 15.5 & 32.4 & 141 & $<0.020$ & 130 & $<0.500$ & 4.02 \\
\hline 1 & NEPH2-13 & quenched & C64 & 2 & 31 & 8.54 & $<0.010$ & $<0.010$ & $<0.050$ & 14.3 & 14.3 & 115 & $<0.020$ & 92.1 & $<0.500$ & 2.55 \\
\hline 1 & NEPH2-24ccc & $\mathrm{ccc}$ & $\mathrm{C} 27$ & 2 & 32 & 7.24 & $<0.010$ & $<0.010$ & $<0.050$ & 6.78 & 12.3 & 78.4 & $<0.020$ & 75.2 & $<0.500$ & 1.86 \\
\hline 1 & Soln Std & & std-b2-3 & 2 & 33 & 19 & $<0.010$ & $<0.010$ & $<0.050$ & 4.31 & 10.1 & 81.7 & $<0.020$ & 49.5 & $<0.500$ & $<0.100$ \\
\hline 1 & Soln Std & & std-b-3-1 & 3 & 1 & 20.5 & $<0.010$ & $<0.010$ & $<0.050$ & 4.19 & 10 & 88 & $<0.020$ & 51.6 & $<0.500$ & $<0.100$ \\
\hline 1 & NEPH2-22 & quenched & C91 & 3 & 2 & 7.56 & $<0.010$ & $<0.010$ & $<0.050$ & 6.62 & 10.6 & 96.6 & $<0.020$ & 76.8 & $<0.500$ & 1.94 \\
\hline 1 & NEPH2-16ccc & $\mathrm{ccc}$ & $\mathrm{C} 41$ & 3 & 3 & 15.5 & $<0.010$ & $<0.010$ & $<0.050$ & 13.1 & 21.2 & 137 & $<0.020$ & 114 & $<0.500$ & 3.73 \\
\hline 1 & NEPH2-25ccc & $\mathrm{ccc}$ & $\mathrm{C} 23$ & 3 & 4 & 38.5 & $<0.010$ & $<0.010$ & $<0.050$ & 18.6 & 52.3 & 231 & $<0.020$ & 153 & $<0.500$ & 6.68 \\
\hline 1 & NEPH2-14ccc & $\mathrm{ccc}$ & $\mathrm{C} 26$ & 3 & 5 & 16.4 & $<0.010$ & $<0.010$ & $<0.050$ & 11.4 & 22.8 & 144 & $<0.020$ & 119 & $<0.500$ & 3.24 \\
\hline 1 & NEPH2-15 & quenched & $\mathrm{C} 30$ & 3 & 6 & 8.12 & $<0.010$ & $<0.010$ & $<0.050$ & 11.1 & 12.6 & 105 & $<0.020$ & 90.1 & $<0.500$ & 2.34 \\
\hline 1 & NEPH2-19 & quenched & C65 & 3 & 7 & 7.72 & $<0.010$ & $<0.010$ & $<0.050$ & 7.99 & 11.4 & 102 & $<0.020$ & 81.4 & $<0.500$ & 2.24 \\
\hline 1 & NEPH2-24 & quenched & $\mathrm{C} 74$ & 3 & 8 & 6.87 & $<0.010$ & $<0.010$ & $<0.050$ & 7.43 & 11 & 85.1 & $<0.020$ & 78 & $<0.500$ & 1.95 \\
\hline 1 & NEPH2-15ccc & $\mathrm{ccc}$ & $\mathrm{C} 37$ & 3 & 9 & 8.94 & $<0.010$ & $<0.010$ & $<0.050$ & 11.1 & 15 & 101 & $<0.020$ & 94.5 & $<0.500$ & 2.48 \\
\hline 1 & NEPH2-13ccc & $\mathrm{ccc}$ & $\mathrm{C} 87$ & 3 & 10 & 8.96 & $<0.010$ & $<0.010$ & $<0.050$ & 12.3 & 15.5 & 112 & $<0.020$ & 97.6 & $<0.500$ & 2.49 \\
\hline 1 & NEPH2-17 & quenched & $\mathrm{C} 04$ & 3 & 11 & 8.21 & $<0.010$ & $<0.010$ & $<0.050$ & 8.84 & 11.9 & 119 & $<0.020$ & 85 & $<0.500$ & 2.5 \\
\hline 1 & NEPH2-13 & quenched & $\mathrm{C} 50$ & 3 & 12 & 8.34 & $<0.010$ & $<0.010$ & $<0.050$ & 13.4 & 13.1 & 118 & $<0.020$ & 95.9 & $<0.500$ & 3.41 \\
\hline 1 & NEPH2-20 & quenched & C39 & 3 & 13 & 7.85 & $<0.010$ & $<0.010$ & $<0.050$ & 7.9 & 11 & 116 & $<0.020$ & 79.9 & $<0.500$ & 2.25 \\
\hline
\end{tabular}


Table D1. Laboratory Measurements of the PCT Solutions (ppm) for the Nepheline Study Glasses

\begin{tabular}{|c|c|c|c|c|c|c|c|c|c|c|c|c|c|c|c|c|}
\hline Part & Glass ID & $\begin{array}{c}\text { Heat } \\
\text { Treatment }\end{array}$ & $\begin{array}{c}\text { Laboratory } \\
\text { ID }\end{array}$ & Block & Seq & B ar & Ba ar & Cd ar & Cr ar & $\mathrm{Fe}$ ar & Li ar & Na ar & $\mathrm{Pb}$ ar & Si ar & Th ar & U ar \\
\hline 1 & NEPH2-24ccc & $\mathrm{ccc}$ & $\mathrm{C} 90$ & 3 & 14 & 7.38 & $<0.010$ & $<0.010$ & $<0.050$ & 7 & 12.1 & 80.9 & $<0.020$ & 78.6 & $<0.500$ & 1.77 \\
\hline 1 & NEPH2-19ccc & $\mathrm{ccc}$ & $\mathrm{C} 78$ & 3 & 15 & 16.8 & $<0.010$ & $<0.010$ & $<0.050$ & 10.8 & 23.2 & 138 & $<0.020$ & 114 & $<0.500$ & 3.24 \\
\hline 1 & NEPH2-17ccc & $\mathrm{ccc}$ & $\mathrm{C} 80$ & 3 & 16 & 27.1 & $<0.010$ & $<0.010$ & $<0.050$ & 16.7 & 42.2 & 204 & $<0.020$ & 142 & $<0.500$ & 6.41 \\
\hline 1 & Soln Std & & std-b3-2 & 3 & 17 & 19.6 & $<0.010$ & $<0.010$ & $<0.050$ & 4.15 & 10 & 83.6 & $<0.020$ & 51.2 & $<0.500$ & $<0.100$ \\
\hline 1 & NEPH2-18 & quenched & $\mathrm{C} 12$ & 3 & 18 & 8.06 & $<0.010$ & $<0.010$ & $<0.050$ & 9.36 & 11.8 & 95.2 & $<0.020$ & 85.2 & $<0.500$ & 2.41 \\
\hline 1 & NEPH2-26ccc & $\mathrm{ccc}$ & $\mathrm{C} 77$ & 3 & 19 & 269 & $<0.010$ & $<0.010$ & $<0.050$ & $<0.010$ & 138 & 1280 & $<0.020$ & 575 & $<0.500$ & 4.61 \\
\hline 1 & NEPH2-21 & quenched & C57 & 3 & 20 & 9.49 & $<0.010$ & $<0.010$ & $<0.050$ & 7.89 & 11.2 & 89.1 & $<0.020$ & 78.1 & $<0.500$ & 2.2 \\
\hline 1 & NEPH2-14 & quenched & $\mathrm{C} 28$ & 3 & 21 & 9.26 & $<0.010$ & $<0.010$ & $<0.050$ & 13.6 & 13.4 & 125 & $<0.020$ & 94.9 & $<0.500$ & 3.02 \\
\hline 1 & EA & & C61 & 3 & 22 & 37.5 & $<0.010$ & $<0.010$ & $<0.050$ & $<0.010$ & 11.4 & 105 & $<0.020$ & 56 & $<0.500$ & $<0.100$ \\
\hline 1 & NEPH2-25 & quenched & $\mathrm{C} 79$ & 3 & 23 & 7.69 & $<0.010$ & $<0.010$ & $<0.050$ & 7.06 & 10.7 & 97.6 & $<0.020$ & 75.5 & $<0.500$ & 1.76 \\
\hline 1 & blank & & $\mathrm{C} 21$ & 3 & 24 & $<0.030$ & $<0.010$ & $<0.010$ & $<0.050$ & $<0.010$ & 0.749 & $<0.100$ & $<0.020$ & $<0.010$ & $<0.500$ & $<0.100$ \\
\hline 1 & NEPH2-18ccc & $\mathrm{ccc}$ & $\mathrm{C} 05$ & 3 & 25 & 7.84 & $<0.010$ & $<0.010$ & $<0.050$ & 8.93 & 13.5 & 94.1 & $<0.020$ & 84.6 & $<0.500$ & 2.27 \\
\hline 1 & NEPH2-26 & quenched & $\mathrm{C} 48$ & 3 & 26 & 7.29 & $<0.010$ & $<0.010$ & $<0.050$ & 7.96 & 10.3 & 117 & $<0.020$ & 76.1 & $<0.500$ & 2.26 \\
\hline 1 & NEPH2-21ccc & $\mathrm{ccc}$ & C60 & 3 & 27 & 7.63 & $<0.010$ & $<0.010$ & $<0.050$ & 6.47 & 12.4 & 89.2 & $<0.020$ & 80.4 & $<0.500$ & 2.01 \\
\hline 1 & NEPH2-23ccc & $\mathrm{ccc}$ & $\mathrm{C} 54$ & 3 & 28 & 77.5 & $<0.010$ & $<0.010$ & $<0.050$ & $<0.010$ & 79.4 & 441 & $<0.020$ & 180 & $<0.500$ & 11.2 \\
\hline 1 & NEPH2-23 & quenched & $\mathrm{C} 31$ & 3 & 29 & 8.53 & $<0.010$ & $<0.010$ & $<0.050$ & 8.71 & 10.9 & 117 & $<0.020$ & 78.9 & $<0.500$ & 2.4 \\
\hline 1 & ARM-1 & & $\mathrm{C} 46$ & 3 & 30 & 11.9 & $<0.010$ & $<0.010$ & $<0.050$ & $<0.010$ & 9.39 & 26 & $<0.020$ & 42 & $<0.500$ & $<0.100$ \\
\hline 1 & NEPH2-16 & quenched & $\mathrm{C} 24$ & 3 & 31 & 12.1 & $<0.010$ & $<0.010$ & $<0.050$ & 10.8 & 12.4 & 115 & $<0.020$ & 86.9 & $<0.500$ & 2.4 \\
\hline 1 & NEPH2-20ccc & $\mathrm{ccc}$ & $\mathrm{C} 13$ & 3 & 32 & 71 & $<0.010$ & $<0.010$ & $<0.050$ & $<0.010$ & 75.3 & 414 & $<0.020$ & 200 & $<0.500$ & 8.78 \\
\hline 1 & NEPH2-22ccc & $\mathrm{ccc}$ & C45 & 3 & 33 & 19.6 & $<0.010$ & $<0.010$ & $<0.050$ & 16 & 31.5 & 143 & $<0.020$ & 131 & $<0.500$ & 4.32 \\
\hline 1 & Soln Std & & std-b3-3 & 3 & 34 & 19.9 & $<0.010$ & $<0.010$ & $<0.050$ & 4.3 & 10.1 & 84.8 & $<0.020$ & 51.1 & $<0.500$ & $<0.100$ \\
\hline 2 & Std Soln & & std-b1-1 & 1 & 1 & 20.6 & $<0.010$ & $<0.010$ & $<0.050$ & 4.01 & 9.88 & 84.7 & $<0.020$ & 51.9 & $<0.500$ & $<0.100$ \\
\hline 2 & NEPH2-27ccc & $\mathrm{ccc}$ & D49 & 1 & 2 & 18.3 & $<0.010$ & $<0.010$ & $<0.050$ & 10.2 & 31.2 & 122 & $<0.020$ & 126 & $<0.500$ & 4.06 \\
\hline 2 & NEPH2-36 & quenched & D63 & 1 & 3 & 6.31 & $<0.010$ & $<0.010$ & $<0.050$ & 6.13 & 9.34 & 63.1 & $<0.020$ & 67.6 & $<0.500$ & 1.5 \\
\hline 2 & NEPH2-33ccc & $\mathrm{ccc}$ & $\mathrm{D} 78$ & 1 & 4 & 88.4 & $<0.010$ & $<0.010$ & $<0.050$ & 0.125 & 104 & 311 & $<0.020$ & 204 & $<0.500$ & 7.99 \\
\hline 2 & NEPH2-39ccc & $\mathrm{ccc}$ & D56 & 1 & 5 & 9.61 & $<0.010$ & $<0.010$ & $<0.050$ & 8.37 & 13.5 & 64.6 & $<0.020$ & 78.3 & $<0.500$ & 1.97 \\
\hline 2 & NEPH2-29 & quenched & D05 & 1 & 6 & 7.69 & $<0.010$ & $<0.010$ & $<0.050$ & 9.78 & 9.45 & 106 & $<0.020$ & 73.7 & $<0.500$ & 2.63 \\
\hline 2 & NEPH2-32ccc & $\mathrm{ccc}$ & D53 & 1 & 7 & 256 & $<0.010$ & $<0.010$ & $<0.050$ & $<0.010$ & 130 & 1100 & $<0.020$ & 488 & $<0.500$ & 3.7 \\
\hline 2 & NEPH2-32 & quenched & D87 & 1 & 8 & 10.6 & $<0.010$ & $<0.010$ & $<0.050$ & 7.27 & 9.43 & 95.2 & $<0.020$ & 70.7 & $<0.500$ & 1.79 \\
\hline 2 & NEPH2-31ccc & $\mathrm{ccc}$ & D09 & 1 & 9 & 45.4 & $<0.010$ & $<0.010$ & $<0.050$ & 11.3 & 55.4 & 193 & $<0.020$ & 165 & $<0.500$ & 6.31 \\
\hline 2 & NEPH2-29ccc & $\mathrm{ccc}$ & D02 & 1 & 10 & 311 & $<0.010$ & $<0.010$ & $<0.050$ & 0.118 & 123 & 1410 & $<0.020$ & 495 & $<0.500$ & 3.58 \\
\hline 2 & NEPH2-28 & quenched & D44 & 1 & 11 & 12.8 & $<0.010$ & $<0.010$ & $<0.050$ & 8.95 & 10.5 & 91.6 & $<0.020$ & 76.4 & $<0.500$ & 1.87 \\
\hline 2 & NEPH2-35ccc & $\mathrm{ccc}$ & D36 & 1 & 12 & 8.94 & $<0.010$ & $<0.010$ & $<0.050$ & 7.27 & 12.2 & 69.2 & $<0.020$ & 75.7 & $<0.500$ & 1.75 \\
\hline 2 & NEPH2-28ccc & $\mathrm{ccc}$ & D37 & 1 & 13 & 21 & $<0.010$ & $<0.010$ & $<0.050$ & 14.1 & 25.4 & 130 & $<0.020$ & 113 & $<0.500$ & 3.28 \\
\hline 2 & NEPH2-34ccc & $\mathrm{ccc}$ & D54 & 1 & 14 & 254 & $<0.010$ & $<0.010$ & $<0.050$ & $<0.010$ & 153 & 1020 & $<0.020$ & 491 & $<0.500$ & 3.81 \\
\hline 2 & EA & & D07 & 1 & 15 & 41 & $<0.010$ & $<0.010$ & $<0.050$ & 0.118 & 11 & 100 & $<0.020$ & 55.2 & $<0.500$ & $<0.100$ \\
\hline 2 & NEPH2-38ccc & $\mathrm{ccc}$ & D20 & 1 & 16 & 74.8 & $<0.010$ & $<0.010$ & $<0.050$ & 1.13 & 75.2 & 239 & $<0.020$ & 172 & $<0.500$ & 7.13 \\
\hline 2 & Std Soln & & std-b1-2 & 1 & 17 & 22.1 & $<0.010$ & $<0.010$ & $<0.050$ & 4.12 & 9.78 & 86 & $<0.020$ & 51.2 & $<0.500$ & $<0.100$ \\
\hline 2 & NEPH2-38 & quenched & D01 & 1 & 18 & 7.48 & $<0.010$ & $<0.010$ & $<0.050$ & 6.14 & 8.73 & 77.5 & $<0.020$ & 64.1 & $<0.500$ & 1.52 \\
\hline 2 & NEPH2-40 & quenched & D03 & 1 & 19 & 6.47 & $<0.010$ & $<0.010$ & $<0.050$ & 5.67 & 8.58 & 66 & $<0.020$ & 62.1 & $<0.500$ & 1.2 \\
\hline
\end{tabular}


Table D1. Laboratory Measurements of the PCT Solutions (ppm) for the Nepheline Study Glasses

\begin{tabular}{|c|c|c|c|c|c|c|c|c|c|c|c|c|c|c|c|c|}
\hline Part & Glass ID & $\begin{array}{c}\text { Heat } \\
\text { Treatment }\end{array}$ & $\begin{array}{c}\text { Laboratory } \\
\text { ID }\end{array}$ & Block & Seq & B ar & Ba ar & Cd ar & Cr ar & $\mathrm{Fe}$ ar & Li ar & Na ar & Pb ar & Si ar & Th ar & $\mathbf{U}$ ar \\
\hline 2 & NEPH2-30 & quenched & D32 & 1 & 20 & 7.28 & $<0.010$ & $<0.010$ & $<0.050$ & 10.3 & 10.5 & 79.6 & $<0.020$ & 76.4 & $<0.500$ & 1.97 \\
\hline 2 & NEPH2-31 & quenched & D45 & 1 & 21 & 7.2 & $<0.010$ & $<0.010$ & $<0.050$ & 7.69 & 9.73 & 85.2 & $<0.020$ & 70.1 & $<0.500$ & 1.67 \\
\hline 2 & NEPH2-36ccc & ccc & D52 & 1 & 22 & 8.85 & $<0.010$ & $<0.010$ & $<0.050$ & 7.66 & 13.1 & 69.6 & $<0.020$ & 75.9 & $<0.500$ & 1.85 \\
\hline 2 & NEPH2-40ccc & $\mathrm{ccc}$ & D10 & 1 & 23 & 18.3 & $<0.010$ & $<0.010$ & $<0.050$ & 11.2 & 28.1 & 104 & $<0.020$ & 104 & $<0.500$ & 3.33 \\
\hline 2 & NEPH2-34 & quenched & D92 & 1 & 24 & & & & & & & & & & & \\
\hline 2 & NEPH2-37 & quenched & D16 & 1 & 25 & 6.47 & $<0.010$ & $<0.010$ & $<0.050$ & 6.07 & 8.51 & 70.3 & $<0.020$ & 62.6 & $<0.500$ & 1.55 \\
\hline 2 & NEPH2-37ccc & ccc & D14 & 1 & 26 & 30.4 & $<0.010$ & $<0.010$ & $<0.050$ & 13.6 & 44.4 & 146 & $<0.020$ & 136 & $<0.500$ & 4.66 \\
\hline 2 & NEPH2-30ccc & $\mathrm{ccc}$ & D06 & 1 & 27 & 7.8 & $<0.010$ & $<0.010$ & $<0.050$ & 9.58 & 11.8 & 75.5 & $<0.020$ & 73.4 & $<0.500$ & 1.93 \\
\hline 2 & NEPH2-39 & quenched & D58 & 1 & 28 & 6.08 & $<0.010$ & $<0.010$ & $<0.050$ & 6.34 & 9.08 & 61.6 & $<0.020$ & 64.8 & $<0.500$ & 1.29 \\
\hline 2 & NEPH2-35 & quenched & $\mathrm{D} 40$ & 1 & 29 & 6.48 & $<0.010$ & $<0.010$ & $<0.050$ & 5.87 & 9.62 & 69.4 & $<0.020$ & 68.6 & $<0.500$ & 1.32 \\
\hline 2 & ARM-1 & & D81 & 1 & 30 & 12.2 & $<0.010$ & $<0.010$ & $<0.050$ & $<0.010$ & 9.25 & 26.1 & $<0.020$ & 42.2 & $<0.500$ & $<0.100$ \\
\hline 2 & blank & & D76 & 1 & 31 & 0.112 & $<0.010$ & $<0.010$ & $<0.050$ & 0.023 & 0.767 & $<0.100$ & $<0.020$ & $<0.010$ & $<0.500$ & $<0.100$ \\
\hline 2 & NEPH2-27 & quenched & D19 & 1 & 32 & 6.3 & $<0.010$ & $<0.010$ & $<0.050$ & 9.67 & 10.4 & 88.6 & $<0.020$ & 75.2 & $<0.500$ & 2.11 \\
\hline 2 & NEPH2-33 & quenched & D59 & 1 & 33 & 6.58 & $<0.010$ & $<0.010$ & $<0.050$ & 7.41 & 9.49 & 80.8 & $<0.020$ & 68.6 & $<0.500$ & 1.54 \\
\hline 2 & Std Soln & & std-b1-3 & 1 & 34 & 20.4 & $<0.010$ & $<0.010$ & $<0.050$ & 4.19 & 9.78 & 85 & $<0.020$ & 51.5 & $<0.500$ & $<0.100$ \\
\hline 2 & Std Soln & & std-b2-1 & 2 & 1 & 21.4 & $<0.010$ & $<0.010$ & $<0.050$ & 3.84 & 9.83 & 83 & $<0.020$ & 51.5 & $<0.500$ & $<0.100$ \\
\hline 2 & NEPH2-36ccc & $\operatorname{ccc}$ & D74 & 2 & 2 & 9.27 & $<0.010$ & $<0.010$ & $<0.050$ & 6.76 & 13.5 & 68 & $<0.020$ & 78.2 & $<0.500$ & 1.95 \\
\hline 2 & NEPH2-40ccc & $\mathrm{ccc}$ & D38 & 2 & 3 & 18 & $<0.010$ & $<0.010$ & $<0.050$ & 10.7 & 28.3 & 98.2 & $<0.020$ & 109 & $<0.500$ & 3.22 \\
\hline 2 & NEPH2-30 & quenched & D69 & 2 & 4 & 6.93 & $<0.010$ & $<0.010$ & $<0.050$ & 9.25 & 10.6 & 76.5 & $<0.020$ & 75.1 & $<0.500$ & 2.17 \\
\hline 2 & NEPH2-31 & quenched & D51 & 2 & 5 & 6.88 & $<0.010$ & $<0.010$ & $<0.050$ & 7.06 & 9.96 & 83.7 & $<0.020$ & 71.7 & $<0.500$ & 1.7 \\
\hline 2 & NEPH2-35ccc & $\mathrm{ccc}$ & D31 & 2 & 6 & 7.29 & $<0.010$ & $<0.010$ & $<0.050$ & 6.82 & 12.3 & 67.5 & $<0.020$ & 76.5 & $<0.500$ & 1.73 \\
\hline 2 & NEPH2-29ccc & $\mathrm{ccc}$ & D04 & 2 & 7 & 304 & $<0.010$ & $<0.010$ & $<0.050$ & $<0.010$ & 123 & 1370 & $<0.020$ & 482 & $<0.500$ & 3.2 \\
\hline 2 & NEPH2-30ccc & $\mathrm{ccc}$ & D68 & 2 & 8 & 12 & $<0.010$ & $<0.010$ & $<0.050$ & 9.72 & 12.5 & 75.2 & $<0.020$ & 78.9 & $<0.500$ & 2.18 \\
\hline 2 & NEPH2-33ccc & $\mathrm{ccc}$ & D50 & 2 & 9 & 81.4 & $<0.010$ & $<0.010$ & $<0.050$ & 0.136 & 92.6 & 292 & $<0.020$ & 181 & $<0.500$ & 8.48 \\
\hline 2 & NEPH2-39ccc & $\mathrm{ccc}$ & D57 & 2 & 10 & 9.58 & $<0.010$ & $<0.010$ & $<0.050$ & 7.41 & 13.2 & 62.7 & $<0.020$ & 74.6 & $<0.500$ & 1.92 \\
\hline 2 & NEPH2-29 & quenched & D67 & 2 & 11 & 7.62 & $<0.010$ & $<0.010$ & $<0.050$ & 8.77 & 9.71 & 105 & $<0.020$ & 73.1 & $<0.500$ & 2.13 \\
\hline 2 & NEPH2-38 & quenched & D84 & 2 & 12 & 6.41 & $<0.010$ & $<0.010$ & $<0.050$ & 5.79 & 9.01 & 76.5 & $<0.020$ & 66.2 & $<0.500$ & 1.48 \\
\hline 2 & NEPH2-27ccc & $\mathrm{ccc}$ & D71 & 2 & 13 & 18.8 & $<0.010$ & $<0.010$ & $<0.050$ & 11.2 & 32.1 & 119 & $<0.020$ & 125 & $<0.500$ & 3.28 \\
\hline 2 & NEPH2-28 & quenched & D22 & 2 & 14 & 8.26 & $<0.010$ & $<0.010$ & $<0.050$ & 8.22 & 10.3 & 87.8 & $<0.020$ & 74.2 & $<0.500$ & 2.24 \\
\hline 2 & NEPH2-38ccc & $\mathrm{ccc}$ & $\mathrm{D} 89$ & 2 & 15 & 73.5 & $<0.010$ & $<0.010$ & $<0.050$ & 0.584 & 74.4 & 245 & $<0.020$ & 169 & $<0.500$ & 6.99 \\
\hline 2 & NEPH2-31 ccc & $\mathrm{ccc}$ & D08 & 2 & 16 & 45.6 & $<0.010$ & $<0.010$ & $<0.050$ & 9.24 & 55.8 & 191 & $<0.020$ & 164 & $<0.500$ & 6.83 \\
\hline 2 & Std Soln & & std-b2-2 & 2 & 17 & 21.1 & $<0.010$ & $<0.010$ & $<0.050$ & 3.9 & 9.99 & 82.4 & $<0.020$ & 51.8 & $<0.500$ & $<0.100$ \\
\hline 2 & NEPH2-35 & quenched & D83 & 2 & 18 & 7.14 & $<0.010$ & $<0.010$ & $<0.050$ & 5.72 & 9.69 & 65.4 & $<0.020$ & 67.7 & $<0.500$ & 1.44 \\
\hline 2 & ARM-1 & & $\mathrm{D} 75$ & 2 & 19 & 11.9 & $<0.010$ & $<0.010$ & $<0.050$ & 0.2 & 9.25 & 23.7 & $<0.020$ & 41.8 & $<0.500$ & $<0.100$ \\
\hline 2 & NEPH2-37ccc & $\mathrm{ccc}$ & D35 & 2 & 20 & 30.1 & $<0.010$ & $<0.010$ & $<0.050$ & 13 & 43.8 & 131 & $<0.020$ & 131 & $<0.500$ & 5.37 \\
\hline 2 & NEPH2-33 & quenched & $\mathrm{D} 73$ & 2 & 21 & 6.45 & $<0.010$ & $<0.010$ & $<0.050$ & 8.08 & 9.08 & 71.4 & $<0.020$ & 64.9 & $<0.500$ & 1.78 \\
\hline 2 & NEPH2-32 & quenched & $\mathrm{D} 79$ & 2 & 22 & 6.61 & $<0.010$ & $<0.010$ & $<0.050$ & 6.92 & 9.15 & 91.9 & $<0.020$ & 67.4 & $<0.500$ & 1.67 \\
\hline 2 & NEPH2-27 & quenched & D24 & 2 & 23 & 6 & $<0.010$ & $<0.010$ & $<0.050$ & 8.95 & 9.96 & 81.7 & $<0.020$ & 71.8 & $<0.500$ & 2.36 \\
\hline 2 & NEPH2-28ccc & $\mathrm{ccc}$ & D15 & 2 & 24 & 20 & $<0.010$ & $<0.010$ & $<0.050$ & 14.3 & 25.4 & 125 & $<0.020$ & 111 & $<0.500$ & 3.28 \\
\hline 2 & NEPH2-34ccc & $\mathrm{ccc}$ & D17 & 2 & 25 & 251 & $<0.010$ & $<0.010$ & $<0.050$ & $<0.010$ & 147 & 1010 & $<0.020$ & 486 & $<0.500$ & 3.82 \\
\hline
\end{tabular}


Table D1. Laboratory Measurements of the PCT Solutions (ppm) for the Nepheline Study Glasses

\begin{tabular}{|c|c|c|c|c|c|c|c|c|c|c|c|c|c|c|c|c|}
\hline Part & Glass ID & $\begin{array}{c}\text { Heat } \\
\text { Treatment }\end{array}$ & $\begin{array}{c}\text { Laboratory } \\
\text { ID }\end{array}$ & Block & Seq & B ar & Ba ar & Cd ar & Cr ar & $\mathrm{Fe}$ ar & Li ar & Na ar & $\mathrm{Pb}$ ar & Si ar & Th ar & $\mathbf{U}$ ar \\
\hline 2 & NEPH2-32ccc & $\mathrm{ccc}$ & D21 & 2 & 26 & 257 & $<0.010$ & $<0.010$ & $<0.050$ & $<0.010$ & 128 & 1110 & $<0.020$ & 482 & $<0.500$ & 3.83 \\
\hline 2 & NEPH2-40 & quenched & $\mathrm{D} 86$ & 2 & 27 & 10.1 & $<0.010$ & $<0.010$ & $<0.050$ & 5.82 & 8.4 & 60.9 & $<0.020$ & 62 & $<0.500$ & 1.49 \\
\hline 2 & NEPH2-36 & quenched & D34 & 2 & 28 & 7.47 & $<0.010$ & $<0.010$ & $<0.050$ & 6 & 9.45 & 61.5 & $<0.020$ & 67.6 & $<0.500$ & 1.54 \\
\hline 2 & NEPH2-34 & quenched & $\mathrm{D} 25$ & 2 & 29 & 6.86 & $<0.010$ & $<0.010$ & $<0.050$ & 6.26 & 8.94 & 81.2 & $<0.020$ & 65.6 & $<0.500$ & 1.6 \\
\hline 2 & EA & & $\mathrm{D} 27$ & 2 & 30 & 38.2 & $<0.010$ & $<0.010$ & $<0.050$ & $<0.010$ & 11.2 & 97.8 & $<0.020$ & 56.2 & $<0.500$ & $<0.100$ \\
\hline 2 & NEPH2-37 & quenched & $\mathrm{D} 70$ & 2 & 31 & 6.86 & $<0.010$ & $<0.010$ & $<0.050$ & 5.74 & 8.81 & 66.6 & $<0.020$ & 64.2 & $<0.500$ & 1.47 \\
\hline 2 & NEPH2-39 & quenched & D55 & 2 & 32 & 6.06 & $<0.010$ & $<0.010$ & $<0.050$ & 6.23 & 9.12 & 57.2 & $<0.020$ & 65.1 & $<0.500$ & 1.38 \\
\hline 2 & Std Soln & & std-b2-3 & 2 & 33 & 20.4 & $<0.010$ & $<0.010$ & $<0.050$ & 4.11 & 9.81 & 79.3 & $<0.020$ & 51 & $<0.500$ & $<0.100$ \\
\hline 2 & Std Soln & & std-b-3-1 & 3 & 1 & 21.2 & $<0.010$ & $<0.010$ & $<0.050$ & 3.9 & 9.74 & 81.8 & $<0.020$ & 52 & $<0.500$ & $<0.100$ \\
\hline 2 & NEPH2-36 & quenched & D91 & 3 & 2 & 6.27 & $<0.010$ & $<0.010$ & $<0.050$ & 6.5 & 9.01 & 60.8 & $<0.020$ & 67.1 & $<0.500$ & 1.73 \\
\hline 2 & NEPH2-37 & quenched & $\mathrm{D} 42$ & 3 & 3 & 6.02 & $<0.010$ & $<0.010$ & $<0.050$ & 5.24 & 9 & 69.3 & $<0.020$ & 65.8 & $<0.500$ & 1.4 \\
\hline 2 & NEPH2-29ccc & $\mathrm{ccc}$ & $\mathrm{D} 48$ & 3 & 4 & 300 & $<0.010$ & $<0.010$ & $<0.050$ & $<0.010$ & 122 & 1370 & $<0.020$ & 480 & $<0.500$ & 3.14 \\
\hline 2 & NEPH2-40 & quenched & $\mathrm{D} 33$ & 3 & 5 & 9.7 & $<0.010$ & $<0.010$ & $<0.050$ & 5.42 & 8.67 & 62.5 & $<0.020$ & 64.1 & $<0.500$ & 1.4 \\
\hline 2 & blank & & D72 & 3 & 6 & 0.559 & $<0.010$ & $<0.010$ & $<0.050$ & $<0.010$ & 0.691 & $<0.100$ & $<0.020$ & $<0.010$ & $<0.500$ & $<0.100$ \\
\hline 2 & NEPH2-32 & quenched & $\mathrm{D} 85$ & 3 & 7 & 6.81 & $<0.010$ & $<0.010$ & $<0.050$ & 7.41 & 9.32 & 94.4 & $<0.020$ & 70.2 & $<0.500$ & 1.76 \\
\hline 2 & NEPH2-39 & quenched & D11 & 3 & 8 & 5.69 & $<0.010$ & $<0.010$ & $<0.050$ & 5.94 & 8.87 & 56.2 & $<0.020$ & 64.8 & $<0.500$ & 1.41 \\
\hline 2 & NEPH2-38 & quenched & D66 & 3 & 9 & 5.91 & $<0.010$ & $<0.010$ & $<0.050$ & 6.13 & 8.79 & 76.2 & $<0.020$ & 66.4 & $<0.500$ & 1.37 \\
\hline 2 & NEPH2-32ccc & $\mathrm{ccc}$ & D61 & 3 & 10 & 260 & $<0.010$ & $<0.010$ & $<0.050$ & $<0.010$ & 127 & 1130 & $<0.020$ & 482 & $<0.500$ & 3.56 \\
\hline 2 & NEPH2-34ccc & $\mathrm{ccc}$ & D77 & 3 & 11 & 254 & $<0.010$ & $<0.010$ & $<0.050$ & $<0.010$ & 146 & 1010 & $<0.020$ & 487 & $<0.500$ & 3.63 \\
\hline 2 & NEPH2-31 ccc & $\mathrm{ccc}$ & $\mathrm{D} 43$ & 3 & 12 & 47.5 & $<0.010$ & $<0.010$ & $<0.050$ & 9.23 & 54.8 & 190 & $<0.020$ & 164 & $<0.500$ & 6.8 \\
\hline 2 & NEPH2-39ccc & $\mathrm{ccc}$ & $\mathrm{D} 46$ & 3 & 13 & 9.6 & $<0.010$ & $<0.010$ & $<0.050$ & 7.7 & 13 & 63 & $<0.020$ & 76 & $<0.500$ & 1.89 \\
\hline 2 & NEPH2-33 ccc & $\mathrm{ccc}$ & D64 & 3 & 14 & 77.1 & $<0.010$ & $<0.010$ & $<0.050$ & 0.317 & 90 & 281 & $<0.020$ & 192 & $<0.500$ & 8.81 \\
\hline 2 & ARM-1 & & D90 & 3 & 15 & 13.8 & $<0.010$ & $<0.010$ & $<0.050$ & $<0.010$ & 9.37 & 24.8 & $<0.020$ & 43.3 & $<0.500$ & $<0.100$ \\
\hline 2 & NEPH2-36ccc & $\mathrm{ccc}$ & D30 & 3 & 16 & 9.09 & $<0.010$ & $<0.010$ & $<0.050$ & 7.37 & 13.3 & 68.5 & $<0.020$ & 77.1 & $<0.500$ & 2.03 \\
\hline 2 & Std Soln & & std-b3-2 & 3 & 17 & 20.2 & $<0.010$ & $<0.010$ & $<0.050$ & 4.02 & 9.69 & 80.8 & $<0.020$ & 51.3 & $<0.500$ & $<0.100$ \\
\hline 2 & NEPH2-38ccc & $\mathrm{ccc}$ & D28 & 3 & 18 & 72.6 & $<0.010$ & $<0.010$ & $<0.050$ & 0.898 & 73.1 & 246 & $<0.020$ & 169 & $<0.500$ & 6.75 \\
\hline 2 & NEPH2-30ccc & $\mathrm{ccc}$ & D47 & 3 & 19 & 8.66 & $<0.010$ & $<0.010$ & $<0.050$ & 9.72 & 11.7 & 72.4 & $<0.020$ & 75.2 & $<0.500$ & 2.14 \\
\hline 2 & NEPH2-33 & quenched & D12 & 3 & 20 & 6.33 & $<0.010$ & $<0.010$ & $<0.050$ & 5.79 & 9 & 74.4 & $<0.020$ & 64.6 & $<0.500$ & 1.59 \\
\hline 2 & NEPH2-40ccc & $\mathrm{ccc}$ & D60 & 3 & 21 & 16.6 & $<0.010$ & $<0.010$ & $<0.050$ & 9.82 & 26.6 & 95.7 & $<0.020$ & 102 & $<0.500$ & 3.71 \\
\hline 2 & NEPH2-35ccc & $\mathrm{ccc}$ & D18 & 3 & 22 & 7.3 & $<0.010$ & $<0.010$ & $<0.050$ & 6.93 & 11.9 & 68.4 & $<0.020$ & 74.9 & $<0.500$ & 1.65 \\
\hline 2 & NEPH2-27ccc & $\mathrm{ccc}$ & D26 & 3 & 23 & 17.9 & $<0.010$ & $<0.010$ & $<0.050$ & 11.3 & 31.2 & 118 & $<0.020$ & 121 & $<0.500$ & 3.35 \\
\hline 2 & NEPH2-37ccc & $\mathrm{ccc}$ & D41 & 3 & 24 & 29.2 & $<0.010$ & $<0.010$ & $<0.050$ & 12.1 & 43.1 & 133 & $<0.020$ & 132 & $<0.500$ & 5.39 \\
\hline 2 & NEPH2-34 & quenched & D13 & 3 & 25 & 6.36 & $<0.010$ & $<0.010$ & $<0.050$ & 6.93 & 8.74 & 83.5 & $<0.020$ & 65.3 & $<0.500$ & 1.6 \\
\hline 2 & NEPH2-29 & quenched & D82 & 3 & 26 & 6.71 & $<0.010$ & $<0.010$ & $<0.050$ & 8.51 & 9.25 & 104 & $<0.020$ & 70 & $<0.500$ & 2.07 \\
\hline 2 & EA & & D65 & 3 & 27 & 36.8 & $<0.010$ & $<0.010$ & $<0.050$ & $<0.010$ & 11.1 & 100 & $<0.020$ & 56.1 & $<0.500$ & $<0.100$ \\
\hline 2 & NEPH2-35 & quenched & D39 & 3 & 28 & 6.34 & $<0.010$ & $<0.010$ & $<0.050$ & 5.86 & 9.45 & 67.1 & $<0.020$ & 66.4 & $<0.500$ & 1.3 \\
\hline 2 & NEPH2-31 & quenched & D62 & 3 & 29 & 6.47 & $<0.010$ & $<0.010$ & $<0.050$ & 7.03 & 9.63 & 83.5 & $<0.020$ & 69.7 & $<0.500$ & 1.62 \\
\hline 2 & NEPH2-28ccc & $\mathrm{ccc}$ & D23 & 3 & 30 & 19.1 & $<0.010$ & $<0.010$ & $<0.050$ & 14.3 & 24.9 & 123 & $<0.020$ & 115 & $<0.500$ & 3.42 \\
\hline 2 & NEPH2-27 & quenched & $\mathrm{D} 80$ & 3 & 31 & 5.92 & $<0.010$ & $<0.010$ & $<0.050$ & 9.76 & 9.85 & 84.1 & $<0.020$ & 71.1 & $<0.500$ & 2.34 \\
\hline 2 & NEPH2-28 & quenched & D29 & 3 & 32 & 7.63 & $<0.010$ & $<0.010$ & $<0.050$ & 10.5 & 10.4 & 90.4 & $<0.020$ & 74.4 & $<0.500$ & 1.91 \\
\hline
\end{tabular}


Table D1. Laboratory Measurements of the PCT Solutions (ppm) for the Nepheline Study Glasses

\begin{tabular}{|c|c|c|c|c|c|c|c|c|c|c|c|c|c|c|c|c|}
\hline Part & Glass ID & $\begin{array}{c}\text { Heat } \\
\text { Treatment }\end{array}$ & $\begin{array}{c}\text { Laboratory } \\
\text { ID }\end{array}$ & Block & Seq & B ar & Ba ar & Cd ar & Cr ar & Fe ar & Li ar & Na ar & Pb ar & Si ar & Th ar & $\mathbf{U}$ ar \\
\hline 2 & NEPH2-30 & quenched & D88 & 3 & 33 & 6.12 & $<0.010$ & $<0.010$ & $<0.050$ & 10.1 & 10.2 & 75.5 & $<0.020$ & 72 & $<0.500$ & 1.99 \\
\hline 2 & Std Soln & & std-b3-3 & 3 & 34 & 19.4 & $<0.010$ & $<0.010$ & $<0.050$ & 3.99 & 9.62 & 81.7 & $<0.020$ & 51.1 & $<0.500$ & $<0.100$ \\
\hline 3 & Std Soln & & STD-B1-1 & 1 & 1 & 19.3 & $<0.100$ & $<0.100$ & $<0.100$ & 3.99 & 9.65 & 86.7 & $<0.200$ & 48.6 & $<0.100$ & $<0.100$ \\
\hline 3 & ARM-1 & & E06 & 1 & 2 & 8.69 & $<0.100$ & $<0.100$ & $<0.100$ & 0.171 & 8.43 & 24.8 & $<0.200$ & 37.9 & $<0.100$ & $<0.100$ \\
\hline 3 & EA & & E03 & 1 & 3 & 19 & $<0.100$ & $<0.100$ & $<0.100$ & 0.26 & 7.16 & 64.5 & $<0.200$ & 37.4 & $<0.100$ & $<0.100$ \\
\hline 3 & NEPH2-35 & quenched & E01 & 1 & 4 & 4.74 & $<0.100$ & $<0.100$ & $<0.100$ & 6.87 & 9.25 & 95.5 & $<0.200$ & 68 & $<0.100$ & 1.43 \\
\hline 3 & NEPH2-33 & quenched & E12 & 1 & 5 & 4.55 & $<0.100$ & $<0.100$ & $<0.100$ & 6.24 & 9.98 & 77.1 & $<0.200$ & 68.8 & $<0.100$ & 1.34 \\
\hline 3 & Std Soln & & STD-B1-2 & 1 & 6 & 18.4 & $<0.100$ & $<0.100$ & $<0.100$ & 4.04 & 9.73 & 88.6 & $<0.200$ & 49.5 & $<0.100$ & $<0.100$ \\
\hline 3 & NEPH2-34 & quenched & E25 & 1 & 7 & 5.66 & $<0.100$ & $<0.100$ & $<0.100$ & 5.68 & 9.28 & 86.2 & $<0.200$ & 66 & $<0.100$ & 1.25 \\
\hline 3 & NEPH2-33ccc & $\mathrm{ccc}$ & E24 & 1 & 8 & $<0.100$ & $<0.100$ & $<0.100$ & $<0.100$ & 7.31 & 14.7 & 84.4 & $<0.200$ & 74.7 & $<0.100$ & 1.46 \\
\hline 3 & NEPH2-35ccc & $\mathrm{ccc}$ & E05 & 1 & 9 & 260 & $<0.100$ & $<0.100$ & $<0.100$ & 6.35 & 132 & 1145 & $<0.200$ & 527 & $<0.100$ & 15.9 \\
\hline 3 & NEPH2-34ccc & $\mathrm{ccc}$ & E21 & 1 & 10 & 55.2 & $<0.100$ & $<0.100$ & $<0.100$ & $<0.040$ & 77.6 & 304 & $<0.200$ & 174 & $<0.100$ & 8.01 \\
\hline 3 & blank & & E22 & 1 & 11 & $<0.100$ & $<0.100$ & $<0.100$ & $<0.100$ & $<0.040$ & $<1.00$ & 0.398 & $<0.200$ & $<0.200$ & $<0.100$ & $<0.100$ \\
\hline 3 & Std Soln & & STD-B-1-3 & 1 & 12 & 18.4 & $<0.100$ & $<0.100$ & $<0.100$ & 4.1 & 9.67 & 88 & $<0.200$ & 50 & $<0.100$ & $<0.100$ \\
\hline 3 & Std Soln & & STD-B2-1 & 2 & 1 & 20.6 & $<0.100$ & $<0.100$ & $<0.100$ & 4.05 & 9.89 & 86 & $<0.200$ & 48.1 & $<0.100$ & $<0.100$ \\
\hline 3 & NEPH2-33ccc & $\mathrm{ccc}$ & E19 & 2 & 2 & 8.44 & $<0.100$ & $<0.100$ & $<0.100$ & 10.2 & 18 & 83.1 & $<0.200$ & 69.9 & $<0.100$ & 1.65 \\
\hline 3 & NEPH2-34 & quenched & E13 & 2 & 3 & 6.25 & $<0.100$ & $<0.100$ & $<0.100$ & 5.4 & 9.5 & 84.9 & $<0.200$ & 62.9 & $<0.100$ & 1.42 \\
\hline 3 & EA & & E02 & 2 & 4 & 20.3 & $<0.100$ & $<0.100$ & $<0.100$ & 0.287 & 7.49 & 65.8 & $<0.200$ & 36.2 & $<0.100$ & $<0.100$ \\
\hline 3 & ARM-1 & & E11 & 2 & 5 & 10.7 & $<0.100$ & $<0.100$ & $<0.100$ & $<0.040$ & 8.73 & 24.9 & $<0.200$ & 37.2 & $<0.100$ & $<0.100$ \\
\hline 3 & Std Soln & & STD-B2-2 & 2 & 6 & 19.8 & $<0.100$ & $<0.100$ & $<0.100$ & 4.04 & 9.91 & 86.2 & $<0.200$ & 48.2 & $<0.100$ & $<0.100$ \\
\hline 3 & NEPH2-35 & quenched & E14 & 2 & 7 & 6.94 & $<0.100$ & $<0.100$ & $<0.100$ & 7.02 & 9.38 & 93.5 & $<0.200$ & 64.8 & $<0.100$ & 1.59 \\
\hline 3 & NEPH2-35 ccc & $\mathrm{ccc}$ & E20 & 2 & 8 & 269 & $<0.100$ & $<0.100$ & $<0.100$ & 7.33 & 134 & 1124 & $<0.200$ & 504 & $<0.100$ & 14 \\
\hline 3 & NEPH2-33 & quenched & E04 & 2 & 9 & 6.77 & $<0.100$ & $<0.100$ & $<0.100$ & 6.57 & 10.1 & 76 & $<0.200$ & 67 & $<0.100$ & 1.63 \\
\hline 3 & NEPH2-34ccc & $\mathrm{ccc}$ & E23 & 2 & 10 & 67.1 & $<0.100$ & $<0.100$ & $<0.100$ & 8.73 & 77 & 287 & $<0.200$ & 170 & $<0.100$ & 8.25 \\
\hline 3 & Std Soln & & STDB2-3 & 2 & 11 & 19.8 & $<0.100$ & $<0.100$ & $<0.100$ & 4.09 & 9.95 & 85.9 & $<0.200$ & 48.6 & $<0.100$ & $<0.100$ \\
\hline 3 & Std Soln & & STD-B3-1 & 3 & 1 & 20 & $<0.100$ & $<0.100$ & $<0.100$ & 3.85 & 9.63 & 86.3 & $<0.200$ & 47.5 & $<0.100$ & $<0.100$ \\
\hline 3 & EA & & E18 & 3 & 2 & 26.8 & $<0.100$ & $<0.100$ & $<0.100$ & $<0.040$ & 8.14 & 79.8 & $<0.200$ & 39.5 & $<0.100$ & $<0.100$ \\
\hline 3 & ARM-1 & & E09 & 3 & 3 & 11.3 & $<0.100$ & $<0.100$ & $<0.100$ & 0.424 & 8.63 & 25.4 & $<0.200$ & 37.4 & $<0.100$ & $<0.100$ \\
\hline 3 & blank & & E10 & 3 & 4 & $<0.100$ & $<0.100$ & $<0.100$ & $<0.100$ & 0.625 & $<1.00$ & 0.719 & $<0.200$ & $<0.200$ & $<0.100$ & $<0.100$ \\
\hline 3 & NEPH2-35ccc & $\mathrm{ccc}$ & E08 & 3 & 5 & 273 & $<0.100$ & $<0.100$ & $<0.100$ & 6.07 & 133 & 1116 & $<0.200$ & 509 & $<0.100$ & 13.1 \\
\hline 3 & Std Soln & & STD-B3-2 & 3 & 6 & 20.5 & $<0.100$ & $<0.100$ & $<0.100$ & 4.15 & 9.82 & 85.3 & $<0.200$ & 48.8 & $<0.100$ & $<0.100$ \\
\hline 3 & NEPH2-33ccc & $\mathrm{ccc}$ & E17 & 3 & 7 & 15.7 & $<0.100$ & $<0.100$ & $<0.100$ & 9.74 & 15.9 & 86.4 & $<0.200$ & 77.9 & $<0.100$ & 2.39 \\
\hline 3 & NEPH2-34ccc & $\mathrm{ccc}$ & E26 & 3 & 8 & 70.9 & $<0.100$ & $<0.100$ & $<0.100$ & 18 & 76.7 & 299 & $<0.200$ & 187 & $<0.100$ & 8.39 \\
\hline 3 & NEPH2-34 & quenched & E15 & 3 & 9 & 6.53 & $<0.100$ & $<0.100$ & $<0.100$ & 5.36 & 9.36 & 85 & $<0.200$ & 64 & $<0.100$ & 1.56 \\
\hline 3 & NEPH2-35 & quenched & E07 & 3 & 10 & 6.58 & $<0.100$ & $<0.100$ & $<0.100$ & 6.82 & 9.12 & 93.5 & $<0.200$ & 64.9 & $<0.100$ & 1.6 \\
\hline 3 & NEPH2-33 & quenched & E16 & 3 & 11 & 6.87 & $<0.100$ & $<0.100$ & $<0.100$ & 6.5 & 10.2 & 78 & $<0.200$ & 68.9 & $<0.100$ & 1.68 \\
\hline 3 & Std Soln & & STD-B3-3 & 3 & 12 & 20 & $<0.100$ & $<0.100$ & $<0.100$ & 4.13 & 9.77 & 84.5 & $<0.200$ & 48.5 & $<0.100$ & $<0.100$ \\
\hline
\end{tabular}


Table D2. PSAL Measurements of the PCT Solutions for the Study Glasses After Appropriate Adjustments

\begin{tabular}{|c|c|c|c|c|c|c|c|c|c|c|c|c|c|c|c|c|}
\hline Part & Glass ID & Heat Treatment & Laboratory ID & Block & Seq & B (ppm) & $\mathrm{Ba}(\mathrm{ppm})$ & Cd (ppm) & $\mathrm{Cr}(\mathrm{pp})$ & $\overline{\mathrm{Fe}}(\mathrm{ppm})$ & Li (ppm) & $\mathrm{Na}(\mathrm{ppm})$ & $\mathrm{Pb}$ (ppm) & Si (ppm) & Th (ppm) & $\mathrm{U}(\mathrm{ppm})$ \\
\hline 1 & Soln Std & & std-b1-1 & 1 & 1 & 20.500 & 0.005 & 0.005 & 0.025 & 4.330 & 10.100 & 82.100 & 0.010 & 49.900 & 0.250 & 0.050 \\
\hline 1 & NEPH2-21ccc & $\mathrm{ccc}$ & C51 & 1 & 2 & 13.967 & 0.008 & 0.008 & 0.042 & 13.234 & 20.834 & 139.003 & 0.017 & 130.336 & 0.417 & 3.867 \\
\hline 1 & NEPH2-17 & quenched & C92 & 1 & 3 & 14.817 & 0.008 & 0.008 & 0.042 & 16.834 & 20.500 & 198.337 & 0.017 & 138.169 & 0.417 & 4.383 \\
\hline 1 & NEPH2-22 & quenched & C67 & 1 & 4 & 12.734 & 0.008 & 0.008 & 0.042 & 13.050 & 17.667 & 157.503 & 0.017 & 124.002 & 0.417 & 3.417 \\
\hline 1 & NEPH2-26 & quenched & C59 & 1 & 5 & 12.900 & 0.008 & 0.008 & 0.042 & 16.084 & 17.334 & 185.004 & 0.017 & 125.003 & 0.417 & 3.733 \\
\hline 1 & NEPH2-18 & quenched & C69 & 1 & 6 & 13.334 & 0.008 & 0.008 & 0.042 & 16.067 & 20.167 & 158.337 & 0.017 & 137.169 & 0.417 & 3.650 \\
\hline 1 & NEPH2-13ccc & $\mathrm{ccc}$ & $\mathrm{C} 83$ & 1 & 7 & 15.667 & 0.008 & 0.008 & 0.042 & 21.000 & 25.334 & 176.670 & 0.017 & 155.503 & 0.417 & 5.583 \\
\hline 1 & NEPH2-24 & quenched & C34 & 1 & 8 & 12.350 & 0.008 & 0.008 & 0.042 & 12.684 & 18.334 & 140.003 & 0.017 & 128.003 & 0.417 & 3.300 \\
\hline 1 & NEPH2-18ccc & $\mathrm{ccc}$ & $\mathrm{C} 15$ & 1 & 9 & 14.400 & 0.008 & 0.008 & 0.042 & 15.950 & 22.167 & 151.836 & 0.017 & 143.003 & 0.417 & 4.483 \\
\hline 1 & NEPH2-15 & quenched & C52 & 1 & 10 & 14.517 & 0.008 & 0.008 & 0.042 & 20.167 & 21.334 & 173.337 & 0.017 & 151.003 & 0.417 & 4.500 \\
\hline 1 & NEPH2-23 & quenched & $\mathrm{C} 70$ & 1 & 11 & 13.417 & 0.008 & 0.008 & 0.042 & 16.400 & 17.500 & 186.670 & 0.017 & 128.336 & 0.417 & 4.850 \\
\hline 1 & NEPH2-13 & quenched & C89 & 1 & 12 & 14.750 & 0.008 & 0.008 & 0.042 & 21.000 & 22.667 & 188.337 & 0.017 & 154.836 & 0.417 & 4.667 \\
\hline 1 & ARM-1 & & $\mathrm{C} 84$ & 1 & 13 & 18.834 & 0.008 & 0.008 & 0.042 & 0.747 & 15.100 & 40.167 & 0.017 & 66.168 & 0.417 & 0.083 \\
\hline 1 & EA & & $\mathrm{C} 44$ & 1 & 14 & 648.335 & 0.083 & 0.083 & 0.417 & 0.083 & 200.000 & 1750.004 & 0.167 & 948.335 & 4.167 & 0.833 \\
\hline 1 & NEPH2-15ccc & $\mathrm{ccc}$ & C76 & 1 & 15 & 15.567 & 0.008 & 0.008 & 0.042 & 18.667 & 24.667 & 160.003 & 0.017 & 149.836 & 0.417 & 4.183 \\
\hline 1 & NEPH2-21 & quenched & $\mathrm{C} 03$ & 1 & 16 & 12.917 & 0.008 & 0.008 & 0.042 & 13.184 & 19.334 & 149.836 & 0.017 & 131.336 & 0.417 & 3.733 \\
\hline 1 & Soln Std & & std-b1-2 & 1 & 17 & 20.000 & 0.005 & 0.005 & 0.025 & 4.170 & 10.100 & 83.000 & 0.010 & 49.600 & 0.250 & 0.050 \\
\hline 1 & NEPH2-16ccc & $\mathrm{ccc}$ & $\mathrm{C} 32$ & 1 & 18 & 25.834 & 0.008 & 0.008 & 0.042 & 17.667 & 35.334 & 213.338 & 0.017 & 176.670 & 0.417 & 5.200 \\
\hline 1 & NEPH2-20ccc & $\mathrm{ccc}$ & C14 & 1 & 19 & 117.002 & 0.008 & 0.008 & 0.042 & 0.290 & 124.169 & 675.014 & 0.017 & 331.673 & 0.417 & 16.267 \\
\hline 1 & NEPH2-19 & quenched & C71 & 1 & 20 & 14.017 & 0.008 & 0.008 & 0.042 & 16.567 & 19.000 & 165.337 & 0.017 & 130.336 & 0.417 & 3.867 \\
\hline 1 & NEPH2-24ccc & $\mathrm{ccc}$ & C49 & 1 & 21 & 13.484 & 0.008 & 0.008 & 0.042 & 11.917 & 20.500 & 127.836 & 0.017 & 127.503 & 0.417 & 3.333 \\
\hline 1 & NEPH2-14 & quenched & $\mathrm{C} 82$ & 1 & 22 & 15.400 & 0.008 & 0.008 & 0.042 & 20.167 & 22.500 & 205.004 & 0.017 & 151.336 & 0.417 & 4.383 \\
\hline 1 & NEPH2-20 & quenched & $\mathrm{C} 06$ & 1 & 23 & 14.050 & 0.008 & 0.008 & 0.042 & 15.217 & 19.167 & 191.671 & 0.017 & 130.003 & 0.417 & 3.667 \\
\hline 1 & NEPH2-19ccc & $\mathrm{ccc}$ & C68 & 1 & 24 & 29.001 & 0.008 & 0.008 & 0.042 & 19.167 & 39.834 & 221.671 & 0.017 & 186.670 & 0.417 & 6.000 \\
\hline 1 & NEPH2-23ccc & $\mathrm{ccc}$ & C56 & 1 & 25 & 128.503 & 0.008 & 0.008 & 0.042 & 0.897 & 134.503 & 738.348 & 0.017 & 316.673 & 0.417 & 17.850 \\
\hline 1 & blank & & $\mathrm{C} 85$ & 1 & 26 & 1.332 & 0.008 & 0.008 & 0.042 & 0.737 & 1.420 & 0.322 & 0.017 & 0.008 & 0.417 & 0.083 \\
\hline 1 & NEPH2-22ccc & $\mathrm{ccc}$ & $\mathrm{C} 81$ & 1 & 27 & 32.667 & 0.008 & 0.008 & 0.042 & 25.167 & 52.834 & 230.005 & 0.017 & 211.671 & 0.417 & 6.333 \\
\hline 1 & NEPH2-25 & quenched & C66 & 1 & 28 & 13.100 & 0.008 & 0.008 & 0.042 & 13.800 & 18.000 & 154.503 & 0.017 & 121.669 & 0.417 & 3.033 \\
\hline 1 & NEPH2-26ccc & $\mathrm{ccc}$ & $\mathrm{C} 29$ & 1 & 29 & 460.009 & 0.008 & 0.008 & 0.042 & 0.133 & 236.671 & 2200.044 & 0.017 & 983.353 & 0.417 & 7.567 \\
\hline 1 & NEPH2-14ccc & $\mathrm{ccc}$ & $\mathrm{C} 42$ & 1 & 30 & 30.834 & 0.008 & 0.008 & 0.042 & 24.834 & 39.834 & 241.672 & 0.017 & 193.337 & 0.417 & 5.800 \\
\hline 1 & NEPH2-17ccc & $\mathrm{ccc}$ & $\mathrm{C} 09$ & 1 & 31 & 48.834 & 0.008 & 0.008 & 0.042 & 29.834 & 74.835 & 376.674 & 0.017 & 261.672 & 0.417 & 8.734 \\
\hline
\end{tabular}


Table D2. PSAL Measurements of the PCT Solutions for the Study Glasses After Appropriate Adjustments

\begin{tabular}{|c|c|c|c|c|c|c|c|c|c|c|c|c|c|c|c|c|}
\hline Part & Glass ID & Heat Treatment & Laboratory ID & Block & Seq & B (ppm) & $\mathrm{Ba}(\mathrm{ppm})$ & Cd (ppm) & $\mathrm{Cr}(\mathrm{pp})$ & Fe (ppm) & Li (ppm) & Na (ppm) & $\mathrm{Pb}$ (ppm) & Si (ppm) & Th (ppm) & $\mathrm{U}(\mathrm{ppm})$ \\
\hline 1 & NEPH2-16 & quenched & $\mathrm{C} 72$ & 1 & 32 & 15.600 & 0.008 & 0.008 & 0.042 & 20.834 & 21.334 & 185.004 & 0.017 & 145.503 & 0.417 & 4.133 \\
\hline 1 & NEPH2-25ccc & $\mathrm{ccc}$ & $\mathrm{C} 20$ & 1 & 33 & 60.168 & 0.008 & 0.008 & 0.042 & 31.834 & 84.168 & 373.341 & 0.017 & 260.005 & 0.417 & 10.350 \\
\hline 1 & Soln Std & & std-b1-3 & 1 & 34 & 20.400 & 0.005 & 0.005 & 0.025 & 4.080 & 10.300 & 82.300 & 0.010 & 48.900 & 0.250 & 0.050 \\
\hline 1 & Soln Std & & std-b2-1 & 2 & 1 & 20.200 & 0.005 & 0.005 & 0.025 & 3.960 & 10.300 & 83.300 & 0.010 & 50.800 & 0.250 & 0.050 \\
\hline 1 & NEPH2-26ccc & ccc & $\mathrm{C} 10$ & 2 & 2 & 473.343 & 0.008 & 0.008 & 0.042 & 0.008 & 236.671 & 2250.045 & 0.017 & 1000.020 & 0.417 & 8.233 \\
\hline 1 & NEPH2-15 & quenched & C47 & 2 & 3 & 17.834 & 0.008 & 0.008 & 0.042 & 18.334 & 21.500 & 173.337 & 0.017 & 154.503 & 0.417 & 4.217 \\
\hline 1 & NEPH2-19ccc & $\mathrm{ccc}$ & $\mathrm{C} 33$ & 2 & 4 & 30.167 & 0.008 & 0.008 & 0.042 & 28.167 & 39.167 & 225.005 & 0.017 & 200.004 & 0.417 & 6.017 \\
\hline 1 & NEPH2-14ccc & $\overline{c c c}$ & $\mathrm{C} 18$ & 2 & 5 & 27.167 & 0.008 & 0.008 & 0.042 & 21.334 & 38.501 & 240.005 & 0.017 & 198.337 & 0.417 & 5.517 \\
\hline 1 & NEPH2-23 & quenched & C11 & 2 & 6 & 13.350 & 0.008 & 0.008 & 0.042 & 14.900 & 18.167 & 186.670 & 0.017 & 130.336 & 0.417 & 3.633 \\
\hline 1 & NEPH2-17 & quenched & C58 & 2 & 7 & 13.967 & 0.008 & 0.008 & 0.042 & 17.000 & 20.334 & 193.337 & 0.017 & 140.503 & 0.417 & 4.350 \\
\hline 1 & NEPH2-21ccc & $\mathrm{ccc}$ & $\mathrm{C} 02$ & 2 & 8 & 12.817 & 0.008 & 0.008 & 0.042 & 14.417 & 21.000 & 136.169 & 0.017 & 133.503 & 0.417 & 3.633 \\
\hline 1 & NEPH2-13ccc & $\mathrm{ccc}$ & C62 & 2 & 9 & 15.017 & 0.008 & 0.008 & 0.042 & 19.500 & 26.001 & 181.670 & 0.017 & 160.337 & 0.417 & 4.033 \\
\hline 1 & ARM-1 & & $\mathrm{C} 38$ & 2 & 10 & 18.000 & 0.008 & 0.008 & 0.042 & 0.008 & 15.050 & 43.668 & 0.017 & 67.168 & 0.417 & 0.083 \\
\hline 1 & NEPH2-26 & quenched & $\mathrm{C} 63$ & 2 & 11 & 12.084 & 0.008 & 0.008 & 0.042 & 15.317 & 17.167 & 185.004 & 0.017 & 128.669 & 0.417 & 4.133 \\
\hline 1 & NEPH2-20 & quenched & $\mathrm{C} 40$ & 2 & 12 & 13.234 & 0.008 & 0.008 & 0.042 & 13.050 & 18.834 & 191.671 & 0.017 & 134.003 & 0.417 & 3.483 \\
\hline 1 & NEPH2-16 & quenched & C19 & 2 & 13 & 13.667 & 0.008 & 0.008 & 0.042 & 17.000 & 21.000 & 186.670 & 0.017 & 146.670 & 0.417 & 3.950 \\
\hline 1 & NEPH2-18ccc & $\mathrm{ccc}$ & C16 & 2 & 14 & 13.100 & 0.008 & 0.008 & 0.042 & 17.667 & 22.500 & 147.670 & 0.017 & 142.503 & 0.417 & 5.283 \\
\hline 1 & NEPH2-25 & quenched & $\mathrm{C} 88$ & 2 & 15 & 11.717 & 0.008 & 0.008 & 0.042 & 12.034 & 18.000 & 156.670 & 0.017 & 124.669 & 0.417 & 2.650 \\
\hline 1 & NEPH2-19 & quenched & $\mathrm{C} 07$ & 2 & 16 & 12.267 & 0.008 & 0.008 & 0.042 & 12.334 & 19.000 & 170.003 & 0.017 & 131.169 & 0.417 & 3.317 \\
\hline 1 & Soln Std & & std-b2-2 & 2 & 17 & 19.100 & 0.005 & 0.005 & 0.025 & 3.720 & 10.000 & 83.300 & 0.010 & 49.700 & 0.250 & 0.050 \\
\hline 1 & NEPH2-14 & quenched & $\mathrm{C} 36$ & 2 & 18 & 14.617 & 0.008 & 0.008 & 0.042 & 19.667 & 21.667 & 201.671 & 0.017 & 149.170 & 0.417 & 5.833 \\
\hline 1 & NEPH2-17ccc & $\mathrm{ccc}$ & $\mathrm{C} 22$ & 2 & 19 & 45.668 & 0.008 & 0.008 & 0.042 & 29.334 & 71.168 & 351.674 & 0.017 & 241.672 & 0.417 & 9.550 \\
\hline 1 & NEPH2-18 & quenched & $\mathrm{C} 75$ & 2 & 20 & 12.584 & 0.008 & 0.008 & 0.042 & 14.334 & 19.834 & 154.836 & 0.017 & 137.003 & 0.417 & 3.667 \\
\hline 1 & NEPH2-24 & quenched & C73 & 2 & 21 & 11.300 & 0.008 & 0.008 & 0.042 & 12.017 & 18.500 & 138.503 & 0.017 & 127.169 & 0.417 & 3.050 \\
\hline 1 & NEPH2-22 & quenched & C17 & 2 & 22 & 11.600 & 0.008 & 0.008 & 0.042 & 12.100 & 17.500 & 155.170 & 0.017 & 125.336 & 0.417 & 3.533 \\
\hline 1 & NEPH2-15ccc & $\mathrm{ccc}$ & $\mathrm{C} 01$ & 2 & 23 & 13.850 & 0.008 & 0.008 & 0.042 & 15.450 & 24.500 & 162.337 & 0.017 & 145.670 & 0.417 & 3.533 \\
\hline 1 & NEPH2-21 & quenched & $\mathrm{C} 43$ & 2 & 24 & 10.634 & 0.008 & 0.008 & 0.042 & 13.117 & 17.834 & 139.169 & 0.017 & 121.169 & 0.417 & 3.467 \\
\hline 1 & NEPH2-23ccc & ccc & C86 & 2 & 25 & 123.502 & 0.008 & 0.008 & 0.042 & 0.008 & 129.003 & 721.681 & 0.017 & 311.673 & 0.417 & 16.850 \\
\hline 1 & NEPH2-16ccc & $\mathrm{ccc}$ & $\mathrm{C} 25$ & 2 & 26 & 25.334 & 0.008 & 0.008 & 0.042 & 19.834 & 35.667 & 221.671 & 0.017 & 181.670 & 0.417 & 5.533 \\
\hline 1 & NEPH2-20ccc & $\mathrm{ccc}$ & $\mathrm{C} 08$ & 2 & 27 & 118.002 & 0.008 & 0.008 & 0.042 & 0.008 & 126.336 & 688.347 & 0.017 & 328.340 & 0.417 & 16.367 \\
\hline 1 & NEPH2-25ccc & $\mathrm{ccc}$ & $\mathrm{C} 55$ & 2 & 28 & 62.168 & 0.008 & 0.008 & 0.042 & 26.834 & 85.668 & 395.008 & 0.017 & 266.672 & 0.417 & 9.334 \\
\hline
\end{tabular}


Table D2. PSAL Measurements of the PCT Solutions for the Study Glasses After Appropriate Adjustments

\begin{tabular}{|c|c|c|c|c|c|c|c|c|c|c|c|c|c|c|c|c|}
\hline Part & Glass ID & Heat Treatment & Laboratory ID & Block & Seq & B (ppm) & $\mathrm{Ba}(\mathrm{ppm})$ & Cd (ppm) & $\mathrm{Cr}(\mathrm{pp})$ & $\overline{\mathrm{Fe}}(\mathrm{ppm})$ & Li (ppm) & $\mathrm{Na}(\mathrm{ppm})$ & $\mathrm{Pb}$ (ppm) & Si (ppm) & Th (ppm) & U (ppm) \\
\hline 1 & EA & & $\mathrm{C} 53$ & 2 & 29 & 606.668 & 0.083 & 0.083 & 0.417 & 0.083 & 191.667 & 1683.337 & 0.167 & 900.002 & 4.167 & 0.833 \\
\hline 1 & NEPH2-22ccc & $\mathrm{ccc}$ & $\mathrm{C} 35$ & 2 & 30 & 32.667 & 0.008 & 0.008 & 0.042 & 25.834 & 54.001 & 235.005 & 0.017 & 216.671 & 0.417 & 6.700 \\
\hline 1 & NEPH2-13 & quenched & C64 & 2 & 31 & 14.234 & 0.008 & 0.008 & 0.042 & 23.834 & 23.834 & 191.671 & 0.017 & 153.503 & 0.417 & 4.250 \\
\hline 1 & NEPH2-24ccc & $\mathrm{ccc}$ & $\mathrm{C} 27$ & 2 & 32 & 12.067 & 0.008 & 0.008 & 0.042 & 11.300 & 20.500 & 130.669 & 0.017 & 125.336 & 0.417 & 3.100 \\
\hline 1 & Soln Std & & std-b2-3 & 2 & 33 & 19.000 & 0.005 & 0.005 & 0.025 & 4.310 & 10.100 & 81.700 & 0.010 & 49.500 & 0.250 & 0.050 \\
\hline 1 & Soln Std & & std-b-3-1 & 3 & 1 & 20.500 & 0.005 & 0.005 & 0.025 & 4.190 & 10.000 & 88.000 & 0.010 & 51.600 & 0.250 & 0.050 \\
\hline 1 & NEPH2-22 & quenched & C91 & 3 & 2 & 12.600 & 0.008 & 0.008 & 0.042 & 11.034 & 17.667 & 161.003 & 0.017 & 128.003 & 0.417 & 3.233 \\
\hline 1 & NEPH2-16ccc & $\mathrm{ccc}$ & $\mathrm{C} 41$ & 3 & 3 & 25.834 & 0.008 & 0.008 & 0.042 & 21.834 & 35.334 & 228.338 & 0.017 & 190.004 & 0.417 & 6.217 \\
\hline 1 & NEPH2-25ccc & $\mathrm{ccc}$ & $\mathrm{C} 23$ & 3 & 4 & 64.168 & 0.008 & 0.008 & 0.042 & 31.001 & 87.168 & 385.008 & 0.017 & 255.005 & 0.417 & 11.134 \\
\hline 1 & NEPH2-14ccc & $\mathrm{ccc}$ & $\mathrm{C} 26$ & 3 & 5 & 27.334 & 0.008 & 0.008 & 0.042 & 19.000 & 38.001 & 240.005 & 0.017 & 198.337 & 0.417 & 5.400 \\
\hline 1 & NEPH2-15 & quenched & $\mathrm{C} 30$ & 3 & 6 & 13.534 & 0.008 & 0.008 & 0.042 & 18.500 & 21.000 & 175.004 & 0.017 & 150.170 & 0.417 & 3.900 \\
\hline 1 & NEPH2-19 & quenched & C65 & 3 & 7 & 12.867 & 0.008 & 0.008 & 0.042 & 13.317 & 19.000 & 170.003 & 0.017 & 135.669 & 0.417 & 3.733 \\
\hline 1 & NEPH2-24 & quenched & C74 & 3 & 8 & 11.450 & 0.008 & 0.008 & 0.042 & 12.384 & 18.334 & 141.836 & 0.017 & 130.003 & 0.417 & 3.250 \\
\hline 1 & NEPH2-15ccc & $\mathrm{ccc}$ & $\mathrm{C} 37$ & 3 & 9 & 14.900 & 0.008 & 0.008 & 0.042 & 18.500 & 25.001 & 168.337 & 0.017 & 157.503 & 0.417 & 4.133 \\
\hline 1 & NEPH2-13ccc & $\mathrm{ccc}$ & C87 & 3 & 10 & 14.934 & 0.008 & 0.008 & 0.042 & 20.500 & 25.834 & 186.670 & 0.017 & 162.670 & 0.417 & 4.150 \\
\hline 1 & NEPH2-17 & quenched & $\mathrm{C} 04$ & 3 & 11 & 13.684 & 0.008 & 0.008 & 0.042 & 14.734 & 19.834 & 198.337 & 0.017 & 141.670 & 0.417 & 4.167 \\
\hline 1 & NEPH2-13 & quenched & $\mathrm{C} 50$ & 3 & 12 & 13.900 & 0.008 & 0.008 & 0.042 & 22.334 & 21.834 & 196.671 & 0.017 & 159.837 & 0.417 & 5.683 \\
\hline 1 & NEPH2-20 & quenched & C39 & 3 & 13 & 13.084 & 0.008 & 0.008 & 0.042 & 13.167 & 18.334 & 193.337 & 0.017 & 133.169 & 0.417 & 3.750 \\
\hline 1 & NEPH2-24ccc & $\mathrm{ccc}$ & C90 & 3 & 14 & 12.300 & 0.008 & 0.008 & 0.042 & 11.667 & 20.167 & 134.836 & 0.017 & 131.003 & 0.417 & 2.950 \\
\hline 1 & NEPH2-19ccc & $\mathrm{ccc}$ & $\mathrm{C} 78$ & 3 & 15 & 28.001 & 0.008 & 0.008 & 0.042 & 18.000 & 38.667 & 230.005 & 0.017 & 190.004 & 0.417 & 5.400 \\
\hline 1 & NEPH2-17ccc & $\mathrm{ccc}$ & $\mathrm{C} 80$ & 3 & 16 & 45.168 & 0.008 & 0.008 & 0.042 & 27.834 & 70.335 & 340.007 & 0.017 & 236.671 & 0.417 & 10.684 \\
\hline 1 & Soln Std & & std-b3-2 & 3 & 17 & 19.600 & 0.005 & 0.005 & 0.025 & 4.150 & 10.000 & 83.600 & 0.010 & 51.200 & 0.250 & 0.050 \\
\hline 1 & NEPH2-18 & quenched & $\mathrm{C} 12$ & 3 & 18 & 13.434 & 0.008 & 0.008 & 0.042 & 15.600 & 19.667 & 158.670 & 0.017 & 142.003 & 0.417 & 4.017 \\
\hline 1 & NEPH2-26ccc & $\mathrm{ccc}$ & C77 & 3 & 19 & 448.342 & 0.008 & 0.008 & 0.042 & 0.008 & 230.005 & 2133.376 & 0.017 & 958.353 & 0.417 & 7.683 \\
\hline 1 & NEPH2-21 & quenched & C57 & 3 & 20 & 15.817 & 0.008 & 0.008 & 0.042 & 13.150 & 18.667 & 148.503 & 0.017 & 130.169 & 0.417 & 3.667 \\
\hline 1 & NEPH2-14 & quenched & $\mathrm{C} 28$ & 3 & 21 & 15.434 & 0.008 & 0.008 & 0.042 & 22.667 & 22.334 & 208.338 & 0.017 & 158.170 & 0.417 & 5.033 \\
\hline 1 & EA & & C61 & 3 & 22 & 625.001 & 0.083 & 0.083 & 0.417 & 0.083 & 190.000 & 1750.004 & 0.167 & 933.335 & 4.167 & 0.833 \\
\hline 1 & NEPH2-25 & quenched & C79 & 3 & 23 & 12.817 & 0.008 & 0.008 & 0.042 & 11.767 & 17.834 & 162.670 & 0.017 & 125.836 & 0.417 & 2.933 \\
\hline 1 & blank & & $\mathrm{C} 21$ & 3 & 24 & 0.025 & 0.008 & 0.008 & 0.042 & 0.008 & 1.248 & 0.083 & 0.017 & 0.008 & 0.417 & 0.083 \\
\hline 1 & NEPH2-18ccc & $\mathrm{ccc}$ & $\mathrm{C} 05$ & 3 & 25 & 13.067 & 0.008 & 0.008 & 0.042 & 14.884 & 22.500 & 156.836 & 0.017 & 141.003 & 0.417 & 3.783 \\
\hline 1 & NEPH2-26 & quenched & $\mathrm{C} 48$ & 3 & 26 & 12.150 & 0.008 & 0.008 & 0.042 & 13.267 & 17.167 & 195.004 & 0.017 & 126.836 & 0.417 & 3.767 \\
\hline
\end{tabular}


Table D2. PSAL Measurements of the PCT Solutions for the Study Glasses After Appropriate Adjustments

\begin{tabular}{|c|c|c|c|c|c|c|c|c|c|c|c|c|c|c|c|c|}
\hline Part & Glass ID & Heat Treatment & Laboratory ID & Block & Seq & B (ppm) & $\mathrm{Ba}(\mathrm{ppm})$ & $\mathrm{Cd}(\mathrm{ppm})$ & $\mathrm{Cr}(\mathrm{pp})$ & $\mathrm{Fe}(\mathrm{ppm})$ & $\mathrm{Li}(\mathrm{ppm})$ & $\mathrm{Na}(\mathrm{ppm})$ & $\mathrm{Pb}(\mathrm{ppm})$ & $\mathrm{Si}$ (ppm) & Th (ppm) & $\mathrm{U}(\mathrm{ppm})$ \\
\hline 1 & NEPH2-21ccc & ccc & C60 & 3 & 27 & 12.717 & 0.008 & 0.008 & 0.042 & 10.784 & 20.667 & 148.670 & 0.017 & 134.003 & 0.417 & 3.350 \\
\hline 1 & NEPH2-23ccc & $\mathrm{ccc}$ & C54 & 3 & 28 & 129.169 & 0.008 & 0.008 & 0.042 & 0.008 & 132.336 & 735.015 & 0.017 & 300.006 & 0.417 & 18.667 \\
\hline 1 & NEPH2-23 & quenched & C31 & 3 & 29 & 14.217 & 0.008 & 0.008 & 0.042 & 14.517 & 18.167 & 195.004 & 0.017 & 131.503 & 0.417 & 4.000 \\
\hline 1 & ARM-1 & & $\mathrm{C} 46$ & 3 & 30 & 19.834 & 0.008 & 0.008 & 0.042 & 0.008 & 15.650 & 43.334 & 0.017 & 70.001 & 0.417 & 0.083 \\
\hline 1 & NEPH2-16 & quenched & $\mathrm{C} 24$ & 3 & 31 & 20.167 & 0.008 & 0.008 & 0.042 & 18.000 & 20.667 & 191.671 & 0.017 & 144.836 & 0.417 & 4.000 \\
\hline 1 & NEPH2-20ccc & ccc & $\mathrm{C} 13$ & 3 & 32 & 118.336 & 0.008 & 0.008 & 0.042 & 0.008 & 125.503 & 690.014 & 0.017 & 333.340 & 0.417 & 14.634 \\
\hline 1 & NEPH2-22ccc & $\overline{c c c}$ & $\mathrm{C} 45$ & 3 & 33 & 32.667 & 0.008 & 0.008 & 0.042 & 26.667 & 52.501 & 238.338 & 0.017 & 218.338 & 0.417 & 7.200 \\
\hline 1 & Soln Std & & std-b3-3 & 3 & 34 & 19.900 & 0.005 & 0.005 & 0.025 & 4.300 & 10.100 & 84.800 & 0.010 & 51.100 & 0.250 & 0.050 \\
\hline 2 & Std Soln & & std-b1-1 & 1 & 1 & 20.600 & 0.005 & 0.005 & 0.025 & 4.010 & 9.880 & 84.700 & 0.010 & 51.900 & 0.250 & 0.050 \\
\hline 2 & NEPH2-27ccc & $\mathrm{ccc}$ & D49 & 1 & 2 & 30.501 & 0.008 & 0.008 & 0.042 & 17.000 & 52.001 & 203.337 & 0.017 & 210.004 & 0.417 & 6.767 \\
\hline 2 & NEPH2-36 & quenched & D63 & 1 & 3 & 10.517 & 0.008 & 0.008 & 0.042 & 10.217 & 15.567 & 105.169 & 0.017 & 112.669 & 0.417 & 2.500 \\
\hline 2 & NEPH2-33ccc & $\mathrm{ccc}$ & $\bar{D} 78$ & 1 & 4 & 147.336 & 0.008 & 0.008 & 0.042 & 0.208 & 173.337 & 518.344 & 0.017 & 340.007 & 0.417 & 13.317 \\
\hline 2 & NEPH2-39ccc & $\mathrm{ccc}$ & D56 & 1 & 5 & 16.017 & 0.008 & 0.008 & 0.042 & 13.950 & 22.500 & 107.669 & 0.017 & 130.503 & 0.417 & 3.283 \\
\hline 2 & NEPH2-29 & quenched & D05 & 1 & 6 & 12.817 & 0.008 & 0.008 & 0.042 & 16.300 & 15.750 & 176.670 & 0.017 & 122.836 & 0.417 & 4.383 \\
\hline 2 & NEPH2-32ccc & $\mathrm{ccc}$ & D53 & 1 & 7 & 426.675 & 0.008 & 0.008 & 0.042 & 0.008 & 216.671 & 1833.370 & 0.017 & 813.350 & 0.417 & 6.167 \\
\hline 2 & NEPH2-32 & quenched & D87 & 1 & 8 & 17.667 & 0.008 & 0.008 & 0.042 & 12.117 & 15.717 & 158.670 & 0.017 & 117.836 & 0.417 & 2.983 \\
\hline 2 & NEPH2-31ccc & $\mathrm{ccc}$ & D09 & 1 & 9 & 75.668 & 0.008 & 0.008 & 0.042 & 18.834 & 92.335 & 321.673 & 0.017 & 275.006 & 0.417 & 10.517 \\
\hline 2 & NEPH2-29ccc & $\mathrm{ccc}$ & D02 & 1 & 10 & 518.344 & 0.008 & 0.008 & 0.042 & 0.197 & 205.004 & 2350.047 & 0.017 & 825.017 & 0.417 & 5.967 \\
\hline 2 & NEPH2-28 & quenched & D44 & 1 & 11 & 21.334 & 0.008 & 0.008 & 0.042 & 14.917 & 17.500 & 152.670 & 0.017 & 127.336 & 0.417 & 3.117 \\
\hline 2 & NEPH2-35ccc & $\mathrm{ccc}$ & D36 & 1 & 12 & 14.900 & 0.008 & 0.008 & 0.042 & 12.117 & 20.334 & 115.336 & 0.017 & 126.169 & 0.417 & 2.917 \\
\hline 2 & NEPH2-28ccc & $\mathrm{ccc}$ & D37 & 1 & 13 & 35.001 & 0.008 & 0.008 & 0.042 & 23.500 & 42.334 & 216.671 & 0.017 & 188.337 & 0.417 & 5.467 \\
\hline 2 & NEPH2-34ccc & $\mathrm{ccc}$ & D54 & 1 & 14 & 423.342 & 0.008 & 0.008 & 0.042 & 0.008 & 255.005 & 1700.034 & 0.017 & 818.350 & 0.417 & 6.350 \\
\hline 2 & EA & & D07 & 1 & 15 & 683.335 & 0.083 & 0.083 & 0.417 & 1.967 & 183.334 & 1666.670 & 0.167 & 920.002 & 4.167 & 0.833 \\
\hline 2 & NEPH2-38ccc & $\mathrm{ccc}$ & D20 & 1 & 16 & 124.669 & 0.008 & 0.008 & 0.042 & 1.883 & 125.336 & 398.341 & 0.017 & 286.672 & 0.417 & 11.884 \\
\hline 2 & Std Soln & & std-b1-2 & 1 & 17 & 22.100 & 0.005 & 0.005 & 0.025 & 4.120 & 9.780 & 86.000 & 0.010 & 51.200 & 0.250 & 0.050 \\
\hline 2 & NEPH2-38 & quenched & D01 & 1 & 18 & 12.467 & 0.008 & 0.008 & 0.042 & 10.234 & 14.550 & 129.169 & 0.017 & 106.835 & 0.417 & 2.533 \\
\hline 2 & NEPH2-40 & quenched & D03 & 1 & 19 & 10.784 & 0.008 & 0.008 & 0.042 & 9.450 & 14.300 & 110.002 & 0.017 & 103.502 & 0.417 & 2.000 \\
\hline 2 & NEPH2-30 & quenched & D32 & 1 & 20 & 12.134 & 0.008 & 0.008 & 0.042 & 17.167 & 17.500 & 132.669 & 0.017 & 127.336 & 0.417 & 3.283 \\
\hline 2 & NEPH2-31 & quenched & $\overline{\mathrm{D} 45}$ & 1 & 21 & 12.000 & 0.008 & 0.008 & 0.042 & 12.817 & 16.217 & 142.003 & 0.017 & 116.836 & 0.417 & 2.783 \\
\hline 2 & NEPH2-36ccc & $\mathrm{ccc}$ & D52 & 1 & 22 & 14.750 & 0.008 & 0.008 & 0.042 & 12.767 & 21.834 & 116.002 & 0.017 & 126.503 & 0.417 & 3.083 \\
\hline 2 & NEPH2-40ccc & $\mathrm{ccc}$ & D10 & 1 & 23 & 30.501 & 0.008 & 0.008 & 0.042 & 18.667 & 46.834 & 173.337 & 0.017 & 173.337 & 0.417 & 5.550 \\
\hline
\end{tabular}


Table D2. PSAL Measurements of the PCT Solutions for the Study Glasses After Appropriate Adjustments

\begin{tabular}{|c|c|c|c|c|c|c|c|c|c|c|c|c|c|c|c|c|}
\hline Part & Glass ID & Heat Treatment & Laboratory ID & Block & Seq & B (ppm) & $\mathrm{Ba}(\mathrm{ppm})$ & $\mathrm{Cd}(\mathrm{ppm})$ & $\mathrm{Cr}(\mathrm{pp})$ & $\mathrm{Fe}(\mathrm{ppm})$ & $\mathrm{Li}(\mathrm{ppm})$ & $\mathrm{Na}(\mathrm{ppm})$ & $\mathrm{Pb}(\mathrm{ppm})$ & $\mathrm{Si}$ (ppm) & Th (ppm) & $\mathrm{U}(\mathrm{ppm})$ \\
\hline 2 & NEPH2-34 & quenched & D92 & 1 & 24 & . & . & . & . & . & . & 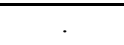 & . & . & . & . \\
\hline 2 & NEPH2-37 & quenched & D16 & 1 & 25 & 10.784 & 0.008 & 0.008 & 0.042 & 10.117 & 14.184 & 117.169 & 0.017 & 104.335 & 0.417 & 2.583 \\
\hline 2 & NEPH2-37ccc & $\mathrm{ccc}$ & D14 & 1 & 26 & 50.668 & 0.008 & 0.008 & 0.042 & 22.667 & 74.001 & 243.338 & 0.017 & 226.671 & 0.417 & 7.767 \\
\hline 2 & NEPH2-30ccc & $\mathrm{ccc}$ & D06 & 1 & 27 & 13.000 & 0.008 & 0.008 & 0.042 & 15.967 & 19.667 & 125.836 & 0.017 & 122.336 & 0.417 & 3.217 \\
\hline 2 & NEPH2-39 & quenched & D58 & 1 & 28 & 10.134 & 0.008 & 0.008 & 0.042 & 10.567 & 15.134 & 102.669 & 0.017 & 108.002 & 0.417 & 2.150 \\
\hline 2 & NEPH2-35 & quenched & $\mathrm{D} 40$ & 1 & 29 & 10.800 & 0.008 & 0.008 & 0.042 & 9.784 & 16.034 & 115.669 & 0.017 & 114.336 & 0.417 & 2.200 \\
\hline 2 & ARM-1 & & D81 & 1 & 30 & 20.334 & 0.008 & 0.008 & 0.042 & 0.008 & 15.417 & 43.501 & 0.017 & 70.335 & 0.417 & 0.083 \\
\hline 2 & blank & & D76 & 1 & 31 & 0.187 & 0.008 & 0.008 & 0.042 & 0.038 & 1.278 & 0.083 & 0.017 & 0.008 & 0.417 & 0.083 \\
\hline 2 & NEPH2-27 & quenched & D19 & 1 & 32 & 10.500 & 0.008 & 0.008 & 0.042 & 16.117 & 17.334 & 147.670 & 0.017 & 125.336 & 0.417 & 3.517 \\
\hline 2 & NEPH2-33 & quenched & D59 & 1 & 33 & 10.967 & 0.008 & 0.008 & 0.042 & 12.350 & 15.817 & 134.669 & 0.017 & 114.336 & 0.417 & 2.567 \\
\hline 2 & Std Soln & & std-b1-3 & 1 & 34 & 20.400 & 0.005 & 0.005 & 0.025 & 4.190 & 9.780 & 85.000 & 0.010 & 51.500 & 0.250 & 0.050 \\
\hline 2 & Std Soln & & std-b2-1 & 2 & 1 & 21.400 & 0.005 & 0.005 & 0.025 & 3.840 & 9.830 & 83.000 & 0.010 & 51.500 & 0.250 & 0.050 \\
\hline 2 & NEPH2-36ccc & $\mathrm{ccc}$ & D74 & 2 & 2 & 15.450 & 0.008 & 0.008 & 0.042 & 11.267 & 22.500 & 113.336 & 0.017 & 130.336 & 0.417 & 3.250 \\
\hline 2 & NEPH2-40ccc & $\mathrm{ccc}$ & D38 & 2 & 3 & 30.001 & 0.008 & 0.008 & 0.042 & 17.834 & 47.168 & 163.670 & 0.017 & 181.670 & 0.417 & 5.367 \\
\hline 2 & NEPH2-30 & quenched & D69 & 2 & 4 & 11.550 & 0.008 & 0.008 & 0.042 & 15.417 & 17.667 & 127.503 & 0.017 & 125.169 & 0.417 & 3.617 \\
\hline 2 & NEPH2-31 & quenched & D51 & 2 & 5 & 11.467 & 0.008 & 0.008 & 0.042 & 11.767 & 16.600 & 139.503 & 0.017 & 119.502 & 0.417 & 2.833 \\
\hline 2 & NEPH2-35ccc & $\mathrm{ccc}$ & D31 & 2 & 6 & 12.150 & 0.008 & 0.008 & 0.042 & 11.367 & 20.500 & 112.502 & 0.017 & 127.503 & 0.417 & 2.883 \\
\hline 2 & NEPH2-29ccc & $\mathrm{ccc}$ & D04 & 2 & 7 & 506.677 & 0.008 & 0.008 & 0.042 & 0.008 & 205.004 & 2283.379 & 0.017 & 803.349 & 0.417 & 5.333 \\
\hline 2 & NEPH2-30ccc & $\mathrm{ccc}$ & D68 & 2 & 8 & 20.000 & 0.008 & 0.008 & 0.042 & 16.200 & 20.834 & 125.336 & 0.017 & 131.503 & 0.417 & 3.633 \\
\hline 2 & NEPH2-33ccc & $\mathrm{ccc}$ & D50 & 2 & 9 & 135.669 & 0.008 & 0.008 & 0.042 & 0.227 & 154.336 & 486.676 & 0.017 & 301.673 & 0.417 & 14.134 \\
\hline 2 & NEPH2-39ccc & $\mathrm{ccc}$ & D57 & 2 & 10 & 15.967 & 0.008 & 0.008 & 0.042 & 12.350 & 22.000 & 104.502 & 0.017 & 124.336 & 0.417 & 3.200 \\
\hline 2 & NEPH2-29 & quenched & D67 & 2 & 11 & 12.700 & 0.008 & 0.008 & 0.042 & 14.617 & 16.184 & 175.004 & 0.017 & 121.836 & 0.417 & 3.550 \\
\hline 2 & NEPH2-38 & quenched & D84 & 2 & 12 & 10.684 & 0.008 & 0.008 & 0.042 & 9.650 & 15.017 & 127.503 & 0.017 & 110.336 & 0.417 & 2.467 \\
\hline 2 & NEPH2-27ccc & $\mathrm{ccc}$ & D71 & 2 & 13 & 31.334 & 0.008 & 0.008 & 0.042 & 18.667 & 53.501 & 198.337 & 0.017 & 208.338 & 0.417 & 5.467 \\
\hline 2 & NEPH2-28 & quenched & $\mathrm{D} 22$ & 2 & 14 & 13.767 & 0.008 & 0.008 & 0.042 & 13.700 & 17.167 & 146.336 & 0.017 & 123.669 & 0.417 & 3.733 \\
\hline 2 & NEPH2-38ccc & $\mathrm{ccc}$ & D89 & 2 & 15 & 122.502 & 0.008 & 0.008 & 0.042 & 0.973 & 124.002 & 408.342 & 0.017 & 281.672 & 0.417 & 11.650 \\
\hline 2 & NEPH2-31ccc & $\mathrm{ccc}$ & D08 & 2 & 16 & 76.002 & 0.008 & 0.008 & 0.042 & 15.400 & 93.002 & 318.340 & 0.017 & 273.339 & 0.417 & 11.384 \\
\hline 2 & Std Soln & & std-b2-2 & 2 & 17 & 21.100 & 0.005 & 0.005 & 0.025 & 3.900 & 9.990 & 82.400 & 0.010 & 51.800 & 0.250 & 0.050 \\
\hline 2 & NEPH2-35 & quenched & D83 & 2 & 18 & 11.900 & 0.008 & 0.008 & 0.042 & 9.534 & 16.150 & 109.002 & 0.017 & 112.836 & 0.417 & 2.400 \\
\hline 2 & ARM-1 & & D75 & 2 & 19 & 19.834 & 0.008 & 0.008 & 0.042 & 0.333 & 15.417 & 39.501 & 0.017 & 69.668 & 0.417 & 0.083 \\
\hline 2 & NEPH2-37ccc & $\mathrm{ccc}$ & D35 & 2 & 20 & 50.168 & 0.008 & 0.008 & 0.042 & 21.667 & 73.001 & 218.338 & 0.017 & 218.338 & 0.417 & 8.950 \\
\hline
\end{tabular}


Table D2. PSAL Measurements of the PCT Solutions for the Study Glasses After Appropriate Adjustments

\begin{tabular}{|c|c|c|c|c|c|c|c|c|c|c|c|c|c|c|c|c|}
\hline Part & Glass ID & Heat Treatment & Laboratory ID & Block & Seq & B (ppm) & $\mathrm{Ba}(\mathrm{ppm})$ & $\mathrm{Cd}(\mathrm{ppm})$ & $\mathrm{Cr}(\mathrm{pp})$ & $\mathrm{Fe}(\mathrm{ppm})$ & $\mathrm{Li}(\mathrm{ppm})$ & $\mathrm{Na}(\mathrm{ppm})$ & $\mathrm{Pb}(\mathrm{ppm})$ & $\mathrm{Si}$ (ppm) & Th (ppm) & $\mathrm{U}(\mathrm{ppm})$ \\
\hline 2 & NEPH2-33 & quenched & D73 & 2 & 21 & 10.750 & 0.008 & 0.008 & 0.042 & 13.467 & 15.134 & 119.002 & 0.017 & 108.169 & 0.417 & 2.967 \\
\hline 2 & NEPH2-32 & quenched & D79 & 2 & 22 & 11.017 & 0.008 & 0.008 & 0.042 & 11.534 & 15.250 & 153.170 & 0.017 & 112.336 & 0.417 & 2.783 \\
\hline 2 & NEPH2-27 & quenched & D24 & 2 & 23 & 10.000 & 0.008 & 0.008 & 0.042 & 14.917 & 16.600 & 136.169 & 0.017 & 119.669 & 0.417 & 3.933 \\
\hline 2 & NEPH2-28ccc & $\mathrm{ccc}$ & D15 & 2 & 24 & 33.334 & 0.008 & 0.008 & 0.042 & 23.834 & 42.334 & 208.338 & 0.017 & 185.004 & 0.417 & 5.467 \\
\hline 2 & NEPH2-34ccc & $\mathrm{ccc}$ & D17 & 2 & 25 & 418.342 & 0.008 & 0.008 & 0.042 & 0.008 & 245.005 & 1683.367 & 0.017 & 810.016 & 0.417 & 6.367 \\
\hline 2 & NEPH2-32ccc & $\mathrm{ccc}$ & $\bar{D} 21$ & 2 & 26 & 428.342 & 0.008 & 0.008 & 0.042 & 0.008 & 213.338 & 1850.037 & 0.017 & 803.349 & 0.417 & 6.383 \\
\hline 2 & NEPH2-40 & quenched & D86 & 2 & 27 & 16.834 & 0.008 & 0.008 & 0.042 & 9.700 & 14.000 & 101.502 & 0.017 & 103.335 & 0.417 & 2.483 \\
\hline 2 & NEPH2-36 & quenched & D34 & 2 & 28 & 12.450 & 0.008 & 0.008 & 0.042 & 10.000 & 15.750 & 102.502 & 0.017 & 112.669 & 0.417 & 2.567 \\
\hline 2 & NEPH2-34 & quenched & D25 & 2 & 29 & 11.434 & 0.008 & 0.008 & 0.042 & 10.434 & 14.900 & 135.336 & 0.017 & 109.336 & 0.417 & 2.667 \\
\hline 2 & EA & & D27 & 2 & 30 & 636.668 & 0.083 & 0.083 & 0.417 & 0.083 & 186.667 & 1630.003 & 0.167 & 936.669 & 4.167 & 0.833 \\
\hline 2 & NEPH2-37 & quenched & D70 & 2 & 31 & 11.434 & 0.008 & 0.008 & 0.042 & 9.567 & 14.684 & 111.002 & 0.017 & 107.002 & 0.417 & 2.450 \\
\hline 2 & NEPH2-39 & quenched & $\overline{\text { D55 }}$ & 2 & 32 & 10.100 & 0.008 & 0.008 & 0.042 & 10.384 & 15.200 & 95.335 & 0.017 & 108.502 & 0.417 & 2.300 \\
\hline 2 & Std Soln & & std-b2-3 & 2 & 33 & 20.400 & 0.005 & 0.005 & 0.025 & 4.110 & 9.810 & 79.300 & 0.010 & 51.000 & 0.250 & 0.050 \\
\hline 2 & Std Soln & & std-b-3-1 & 3 & 1 & 21.200 & 0.005 & 0.005 & 0.025 & 3.900 & 9.740 & 81.800 & 0.010 & 52.000 & 0.250 & 0.050 \\
\hline 2 & NEPH2-36 & quenched & D91 & 3 & 2 & 10.450 & 0.008 & 0.008 & 0.042 & 10.834 & 15.017 & 101.335 & 0.017 & 111.836 & 0.417 & 2.883 \\
\hline 2 & NEPH2-37 & quenched & D42 & 3 & 3 & 10.034 & 0.008 & 0.008 & 0.042 & 8.734 & 15.000 & 115.502 & 0.017 & 109.669 & 0.417 & 2.333 \\
\hline 2 & NEPH2-29ccc & ccc & D48 & 3 & 4 & 500.010 & 0.008 & 0.008 & 0.042 & 0.008 & 203.337 & 2283.379 & 0.017 & 800.016 & 0.417 & 5.233 \\
\hline 2 & NEPH2-40 & quenched & D33 & 3 & 5 & 16.167 & 0.008 & 0.008 & 0.042 & 9.034 & 14.450 & 104.169 & 0.017 & 106.835 & 0.417 & 2.333 \\
\hline 2 & blank & & $\overline{\mathrm{D} 72}$ & 3 & 6 & 0.932 & 0.008 & 0.008 & 0.042 & 0.008 & 1.152 & 0.083 & 0.017 & 0.008 & 0.417 & 0.083 \\
\hline 2 & NEPH2-32 & quenched & D85 & 3 & 7 & 11.350 & 0.008 & 0.008 & 0.042 & 12.350 & 15.534 & 157.336 & 0.017 & 117.002 & 0.417 & 2.933 \\
\hline 2 & NEPH2-39 & quenched & D11 & 3 & 8 & 9.484 & 0.008 & 0.008 & 0.042 & 9.900 & 14.784 & 93.669 & 0.017 & 108.002 & 0.417 & 2.350 \\
\hline 2 & NEPH2-38 & quenched & D66 & 3 & 9 & 9.850 & 0.008 & 0.008 & 0.042 & 10.217 & 14.650 & 127.003 & 0.017 & 110.669 & 0.417 & 2.283 \\
\hline 2 & NEPH2-32ccc & $\mathrm{ccc}$ & D61 & 3 & 10 & 433.342 & 0.008 & 0.008 & 0.042 & 0.008 & 211.671 & 1883.371 & 0.017 & 803.349 & 0.417 & 5.933 \\
\hline 2 & NEPH2-34ccc & $\mathrm{ccc}$ & D77 & 3 & 11 & 423.342 & 0.008 & 0.008 & 0.042 & 0.008 & 243.338 & 1683.367 & 0.017 & 811.683 & 0.417 & 6.050 \\
\hline 2 & NEPH2-31ccc & $\mathrm{ccc}$ & D43 & 3 & 12 & 79.168 & 0.008 & 0.008 & 0.042 & 15.384 & 91.335 & 316.673 & 0.017 & 273.339 & 0.417 & 11.334 \\
\hline 2 & NEPH2-39ccc & ccc & D46 & 3 & 13 & 16.000 & 0.008 & 0.008 & 0.042 & 12.834 & 21.667 & 105.002 & 0.017 & 126.669 & 0.417 & 3.150 \\
\hline 2 & NEPH2-33ccc & $\mathrm{ccc}$ & D64 & 3 & 14 & 128.503 & 0.008 & 0.008 & 0.042 & 0.528 & 150.003 & 468.343 & 0.017 & 320.006 & 0.417 & 14.684 \\
\hline 2 & ARM-1 & & D90 & 3 & 15 & 23.000 & 0.008 & 0.008 & 0.042 & 0.008 & 15.617 & 41.334 & 0.017 & 72.168 & 0.417 & 0.083 \\
\hline 2 & NEPH2-36ccc & $\mathrm{ccc}$ & D30 & 3 & 16 & 15.150 & 0.008 & 0.008 & 0.042 & 12.284 & 22.167 & 114.169 & 0.017 & 128.503 & 0.417 & 3.383 \\
\hline 2 & Std Soln & & std-b3-2 & 3 & 17 & 20.200 & 0.005 & 0.005 & 0.025 & 4.020 & 9.690 & 80.800 & 0.010 & 51.300 & 0.250 & 0.050 \\
\hline 2 & NEPH2-38ccc & $\mathrm{ccc}$ & D28 & 3 & 18 & 121.002 & 0.008 & 0.008 & 0.042 & 1.497 & 121.836 & 410.008 & 0.017 & 281.672 & 0.417 & 11.250 \\
\hline
\end{tabular}


Table D2. PSAL Measurements of the PCT Solutions for the Study Glasses After Appropriate Adjustments

\begin{tabular}{|c|c|c|c|c|c|c|c|c|c|c|c|c|c|c|c|c|}
\hline Part & Glass ID & Heat Treatment & Laboratory ID & Block & Seq & B (ppm) & $\mathrm{Ba}(\mathrm{ppm})$ & $\mathrm{Cd}(\mathrm{ppm})$ & $\mathrm{Cr}(\mathrm{pp})$ & $\mathrm{Fe}(\mathrm{ppm})$ & Li (ppm) & $\mathrm{Na}(\mathrm{ppm})$ & $\mathrm{Pb}(\mathrm{ppm})$ & $\mathrm{Si}$ (ppm) & Th (ppm) & $\mathrm{U}(\mathrm{ppm})$ \\
\hline 2 & NEPH2-30ccc & ccc & D47 & 3 & 19 & 14.434 & 0.008 & 0.008 & 0.042 & 16.200 & 19.500 & 120.669 & 0.017 & 125.336 & 0.417 & 3.567 \\
\hline 2 & NEPH2-33 & quenched & D12 & 3 & 20 & 10.550 & 0.008 & 0.008 & 0.042 & 9.650 & 15.000 & 124.002 & 0.017 & 107.669 & 0.417 & 2.650 \\
\hline 2 & NEPH2-40ccc & ccc & D60 & 3 & 21 & 27.667 & 0.008 & 0.008 & 0.042 & 16.367 & 44.334 & 159.503 & 0.017 & 170.003 & 0.417 & 6.183 \\
\hline 2 & NEPH2-35ccc & $\mathrm{ccc}$ & D18 & 3 & 22 & 12.167 & 0.008 & 0.008 & 0.042 & 11.550 & 19.834 & 114.002 & 0.017 & 124.836 & 0.417 & 2.750 \\
\hline 2 & NEPH2-27ccc & $\mathrm{ccc}$ & D26 & 3 & 23 & 29.834 & 0.008 & 0.008 & 0.042 & 18.834 & 52.001 & 196.671 & 0.017 & 201.671 & 0.417 & 5.583 \\
\hline 2 & NEPH2-37ccc & $\mathrm{ccc}$ & $\overline{\mathrm{D} 41}$ & 3 & 24 & 48.668 & 0.008 & 0.008 & 0.042 & 20.167 & 71.835 & 221.671 & 0.017 & 220.004 & 0.417 & 8.984 \\
\hline 2 & NEPH2-34 & quenched & D13 & 3 & 25 & 10.600 & 0.008 & 0.008 & 0.042 & 11.550 & 14.567 & 139.169 & 0.017 & 108.836 & 0.417 & 2.667 \\
\hline 2 & NEPH2-29 & quenched & D82 & 3 & 26 & 11.184 & 0.008 & 0.008 & 0.042 & 14.184 & 15.417 & 173.337 & 0.017 & 116.669 & 0.417 & 3.450 \\
\hline 2 & EA & & D65 & 3 & 27 & 613.335 & 0.083 & 0.083 & 0.417 & 0.083 & 185.000 & 1666.670 & 0.167 & 935.002 & 4.167 & 0.833 \\
\hline 2 & NEPH2-35 & quenched & D39 & 3 & 28 & 10.567 & 0.008 & 0.008 & 0.042 & 9.767 & 15.750 & 111.836 & 0.017 & 110.669 & 0.417 & 2.167 \\
\hline 2 & NEPH2-31 & quenched & D62 & 3 & 29 & 10.784 & 0.008 & 0.008 & 0.042 & 11.717 & 16.050 & 139.169 & 0.017 & 116.169 & 0.417 & 2.700 \\
\hline 2 & NEPH2-28ccc & $\mathrm{ccc}$ & $\bar{D} 23$ & 3 & 30 & 31.834 & 0.008 & 0.008 & 0.042 & 23.834 & 41.501 & 205.004 & 0.017 & 191.671 & 0.417 & 5.700 \\
\hline 2 & NEPH2-27 & quenched & $\bar{D} 80$ & 3 & 31 & 9.867 & 0.008 & 0.008 & 0.042 & 16.267 & 16.417 & 140.169 & 0.017 & 118.502 & 0.417 & 3.900 \\
\hline 2 & NEPH2-28 & quenched & D29 & 3 & 32 & 12.717 & 0.008 & 0.008 & 0.042 & 17.500 & 17.334 & 150.670 & 0.017 & 124.002 & 0.417 & 3.183 \\
\hline 2 & NEPH2-30 & quenched & D88 & 3 & 33 & 10.200 & 0.008 & 0.008 & 0.042 & 16.834 & 17.000 & 125.836 & 0.017 & 120.002 & 0.417 & 3.317 \\
\hline 2 & Std Soln & & std-b3-3 & 3 & 34 & 19.400 & 0.005 & 0.005 & 0.025 & 3.990 & 9.620 & 81.700 & 0.010 & 51.100 & 0.250 & 0.050 \\
\hline 3 & Std Soln & & STD-B1-1 & 1 & 1 & 19.300 & 0.050 & 0.050 & 0.050 & 3.990 & 9.650 & 86.700 & 0.100 & 48.600 & 0.050 & 0.050 \\
\hline 3 & ARM-1 & & E06 & 1 & 2 & 14.484 & 0.083 & 0.083 & 0.083 & 0.285 & 14.050 & 41.334 & 0.167 & 63.168 & 0.083 & 0.083 \\
\hline 3 & EA & & E03 & 1 & 3 & 316.667 & 0.833 & 0.833 & 0.833 & 4.333 & 119.334 & 1075.002 & 1.667 & 623.335 & 0.833 & 0.833 \\
\hline 3 & NEPH2-35 & quenched & E01 & 1 & 4 & 7.900 & 0.083 & 0.083 & 0.083 & 11.450 & 15.417 & 159.170 & 0.167 & 113.336 & 0.083 & 2.383 \\
\hline 3 & NEPH2-33 & quenched & E12 & 1 & 5 & 7.583 & 0.083 & 0.083 & 0.083 & 10.400 & 16.634 & 128.503 & 0.167 & 114.669 & 0.083 & 2.233 \\
\hline 3 & Std Soln & & STD-B1-2 & 1 & 6 & 18.400 & 0.050 & 0.050 & 0.050 & 4.040 & 9.730 & 88.600 & 0.100 & 49.500 & 0.050 & 0.050 \\
\hline 3 & NEPH2-34 & quenched & E25 & 1 & 7 & 9.434 & 0.083 & 0.083 & 0.083 & 9.467 & 15.467 & 143.670 & 0.167 & 110.002 & 0.083 & 2.083 \\
\hline 3 & NEPH2-33ccc & $\mathrm{ccc}$ & E24 & 1 & 8 & 0.083 & 0.083 & 0.083 & 0.083 & 12.184 & 24.500 & 140.669 & 0.167 & 124.502 & 0.083 & 2.433 \\
\hline 3 & NEPH2-35ccc & $\mathrm{ccc}$ & E05 & 1 & 9 & 433.342 & 0.083 & 0.083 & 0.083 & 10.584 & 220.004 & 1908.372 & 0.167 & 878.351 & 0.083 & 26.501 \\
\hline 3 & NEPH2-34ccc & $\mathrm{ccc}$ & E21 & 1 & 10 & 92.002 & 0.083 & 0.083 & 0.083 & 0.033 & 129.336 & 506.677 & 0.167 & 290.006 & 0.083 & 13.350 \\
\hline 3 & blank & & E22 & 1 & 11 & 0.083 & 0.083 & 0.083 & 0.083 & 0.033 & 0.833 & 0.663 & 0.167 & 0.167 & 0.083 & 0.083 \\
\hline 3 & Std Soln & & STD-B-1-3 & 1 & 12 & 18.400 & 0.050 & 0.050 & 0.050 & 4.100 & 9.670 & 88.000 & 0.100 & 50.000 & 0.050 & 0.050 \\
\hline 3 & Std Soln & & STD-B2-1 & 2 & 1 & 20.600 & 0.050 & 0.050 & 0.050 & 4.050 & 9.890 & 86.000 & 0.100 & 48.100 & 0.050 & 0.050 \\
\hline 3 & NEPH2-33ccc & $\mathrm{ccc}$ & E19 & 2 & 2 & 14.067 & 0.083 & 0.083 & 0.083 & 17.000 & 30.001 & 138.503 & 0.167 & 116.502 & 0.083 & 2.750 \\
\hline 3 & NEPH2-34 & quenched & E13 & 2 & 3 & 10.417 & 0.083 & 0.083 & 0.083 & 9.000 & 15.834 & 141.503 & 0.167 & 104.835 & 0.083 & 2.367 \\
\hline
\end{tabular}


Table D2. PSAL Measurements of the PCT Solutions for the Study Glasses After Appropriate Adjustments

\begin{tabular}{|c|c|c|c|c|c|c|c|c|c|c|c|c|c|c|c|c|}
\hline Part & Glass ID & Heat Treatment & Laboratory ID & Block & Seq & B (ppm) & $\mathrm{Ba}(\mathrm{ppm})$ & $\mathrm{Cd}(\mathrm{ppm})$ & $\mathrm{Cr}(\mathrm{pp})$ & $\mathrm{Fe}(\mathrm{ppm})$ & $\mathrm{Li}(\mathrm{ppm})$ & $\mathrm{Na}(\mathrm{ppm})$ & $\mathrm{Pb}(\mathrm{ppm})$ & $\mathrm{Si}$ (ppm) & Th (ppm) & $\mathrm{U}(\mathrm{ppm})$ \\
\hline 3 & EA & & E02 & 2 & 4 & 338.334 & 0.833 & 0.833 & 0.833 & 4.783 & 124.834 & 1096.669 & 1.667 & 603.335 & 0.833 & 0.833 \\
\hline 3 & ARM-1 & & E11 & 2 & 5 & 17.834 & 0.083 & 0.083 & 0.083 & 0.033 & 14.550 & 41.501 & 0.167 & 62.001 & 0.083 & 0.083 \\
\hline 3 & Std Soln & & STD-B2-2 & 2 & 6 & 19.800 & 0.050 & 0.050 & 0.050 & 4.040 & 9.910 & 86.200 & 0.100 & 48.200 & 0.050 & 0.050 \\
\hline 3 & NEPH2-35 & quenched & E14 & 2 & 7 & 11.567 & 0.083 & 0.083 & 0.083 & 11.700 & 15.634 & 155.836 & 0.167 & 108.002 & 0.083 & 2.650 \\
\hline 3 & NEPH2-35ccc & $\mathrm{ccc}$ & E20 & 2 & 8 & 448.342 & 0.083 & 0.083 & 0.083 & 12.217 & 223.338 & 1873.371 & 0.167 & 840.017 & 0.083 & 23.334 \\
\hline 3 & NEPH2-33 & quenched & E04 & 2 & 9 & 11.284 & 0.083 & 0.083 & 0.083 & 10.950 & 16.834 & 126.669 & 0.167 & 111.669 & 0.083 & 2.717 \\
\hline 3 & NEPH2-34ccc & $\mathrm{ccc}$ & E23 & 2 & 10 & 111.836 & 0.083 & 0.083 & 0.083 & 14.550 & 128.336 & 478.343 & 0.167 & 283.339 & 0.083 & 13.750 \\
\hline 3 & Std Soln & & STDB2-3 & 2 & 11 & 19.800 & 0.050 & 0.050 & 0.050 & 4.090 & 9.950 & 85.900 & 0.100 & 48.600 & 0.050 & 0.050 \\
\hline 3 & Std Soln & & STD-B3-1 & 3 & 1 & 20.000 & 0.050 & 0.050 & 0.050 & 3.850 & 9.630 & 86.300 & 0.100 & 47.500 & 0.050 & 0.050 \\
\hline 3 & EA & & E18 & 3 & 2 & 446.668 & 0.833 & 0.833 & 0.833 & 0.333 & 135.667 & 1330.003 & 1.667 & 658.335 & 0.833 & 0.833 \\
\hline 3 & ARM-1 & & E09 & 3 & 3 & 18.834 & 0.083 & 0.083 & 0.083 & 0.707 & 14.384 & 42.334 & 0.167 & 62.335 & 0.083 & 0.083 \\
\hline 3 & blank & & E10 & 3 & 4 & 0.083 & 0.083 & 0.083 & 0.083 & 1.042 & 0.833 & 1.198 & 0.167 & 0.167 & 0.083 & 0.083 \\
\hline 3 & NEPH2-35ccc & $\mathrm{ccc}$ & E08 & 3 & 5 & 455.009 & 0.083 & 0.083 & 0.083 & 10.117 & 221.671 & 1860.037 & 0.167 & 848.350 & 0.083 & 21.834 \\
\hline 3 & Std Soln & & STD-B3-2 & 3 & 6 & 20.500 & 0.050 & 0.050 & 0.050 & 4.150 & 9.820 & 85.300 & 0.100 & 48.800 & 0.050 & 0.050 \\
\hline 3 & NEPH2-33ccc & $\mathrm{ccc}$ & E17 & 3 & 7 & 26.167 & 0.083 & 0.083 & 0.083 & 16.234 & 26.501 & 144.003 & 0.167 & 129.836 & 0.083 & 3.983 \\
\hline 3 & NEPH2-34ccc & $\mathrm{ccc}$ & E26 & 3 & 8 & 118.169 & 0.083 & 0.083 & 0.083 & 30.001 & 127.836 & 498.343 & 0.167 & 311.673 & 0.083 & 13.984 \\
\hline 3 & NEPH2-34 & quenched & E15 & 3 & 9 & 10.884 & 0.083 & 0.083 & 0.083 & 8.934 & 15.600 & 141.670 & 0.167 & 106.669 & 0.083 & 2.600 \\
\hline 3 & NEPH2-35 & quenched & E07 & 3 & 10 & 10.967 & 0.083 & 0.083 & 0.083 & 11.367 & 15.200 & 155.836 & 0.167 & 108.169 & 0.083 & 2.667 \\
\hline 3 & NEPH2-33 & quenched & E16 & 3 & 11 & 11.450 & 0.083 & 0.083 & 0.083 & 10.834 & 17.000 & 130.003 & 0.167 & 114.836 & 0.083 & 2.800 \\
\hline 3 & Std Soln & & STD-B3-3 & 3 & 12 & 20.000 & 0.050 & 0.050 & 0.050 & 4.130 & 9.770 & 84.500 & 0.100 & 48.500 & 0.050 & 0.050 \\
\hline
\end{tabular}




\section{Exhibit D1. Laboratory PCT Measurements in Analytical Sequence for Study Glasses, EA, ARM,} Blanks, and Solution Standards
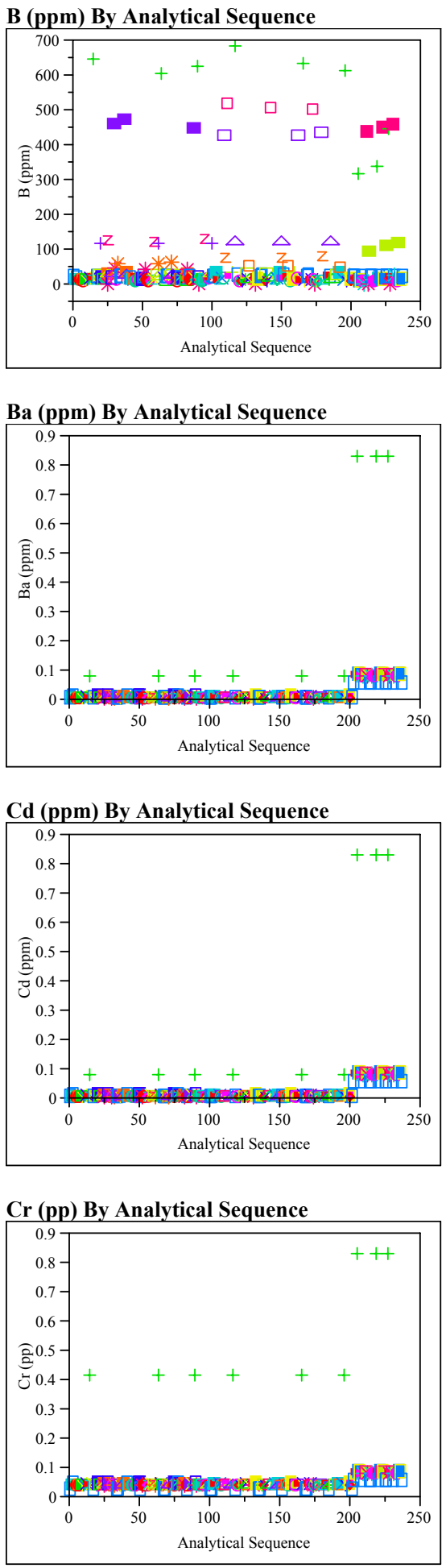
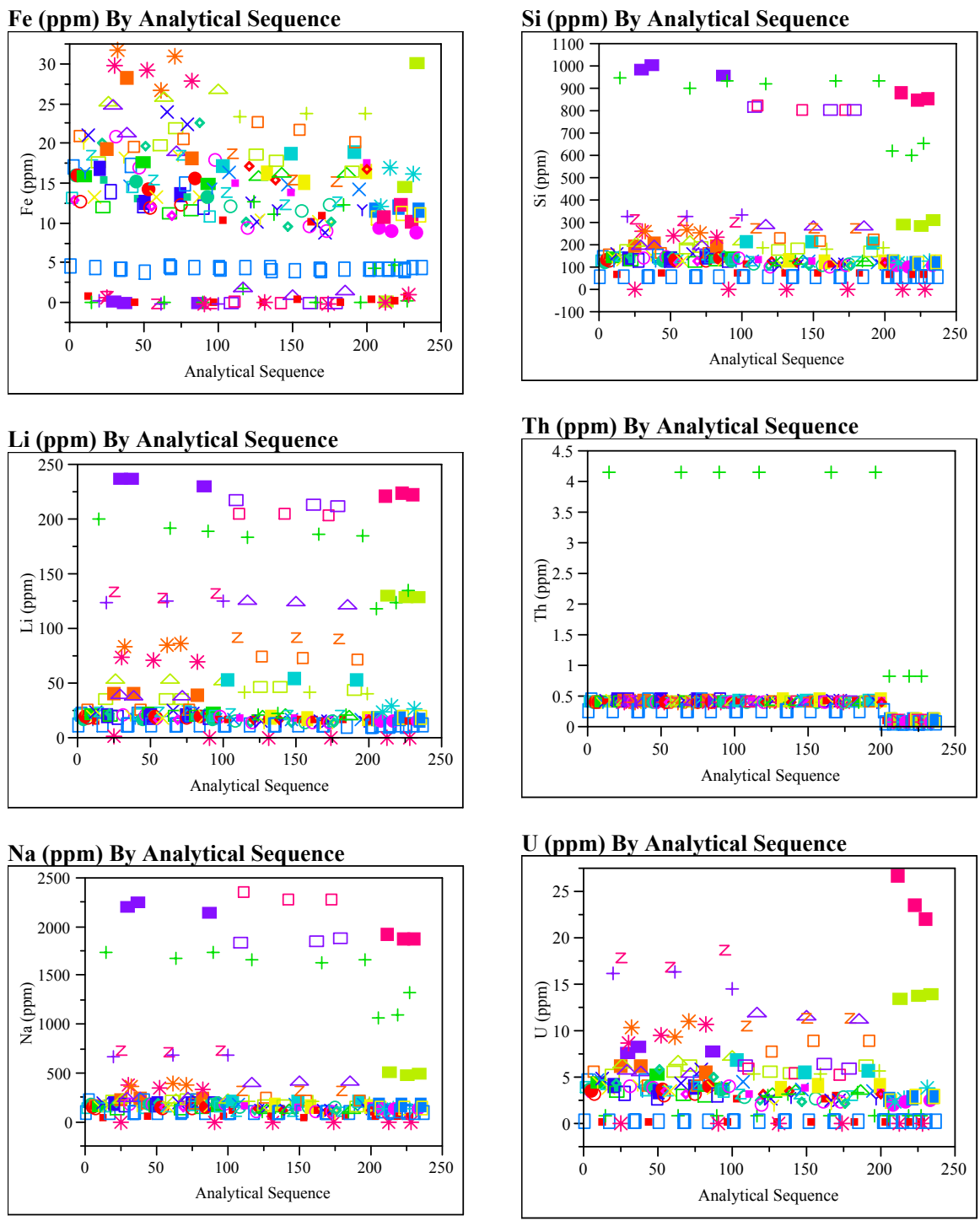

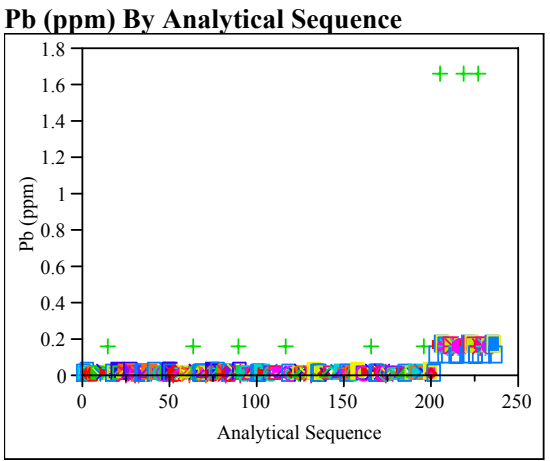




\section{Exhibit D2. Laboratory PCT Measurements in Analytical Sequence for Study Glasses}
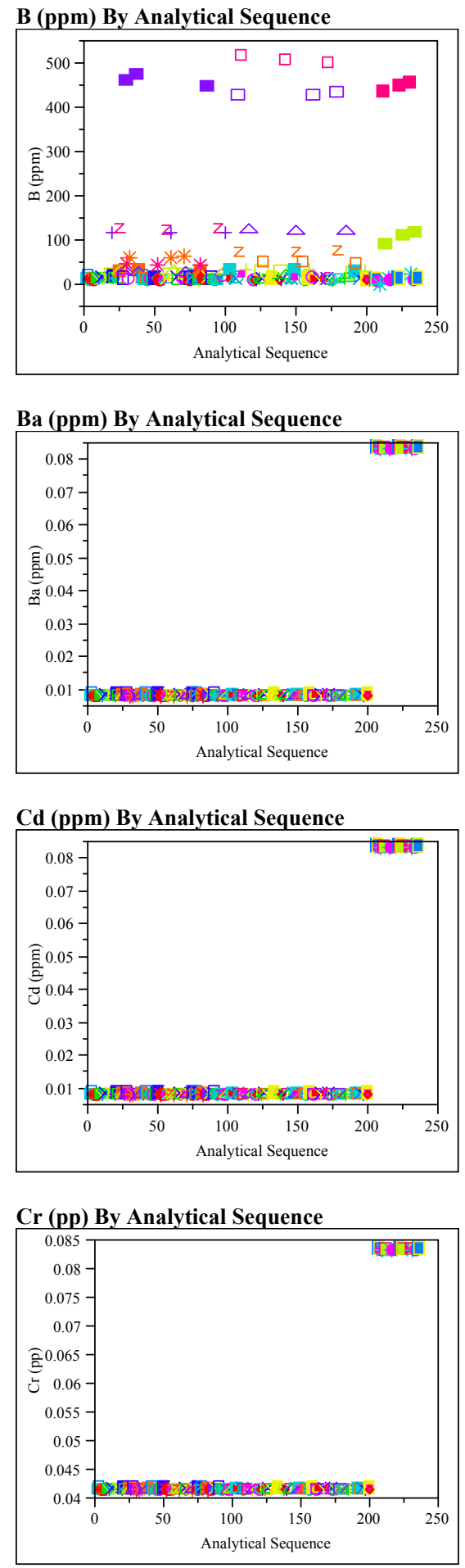

Fe (ppm) By Analytical Sequence

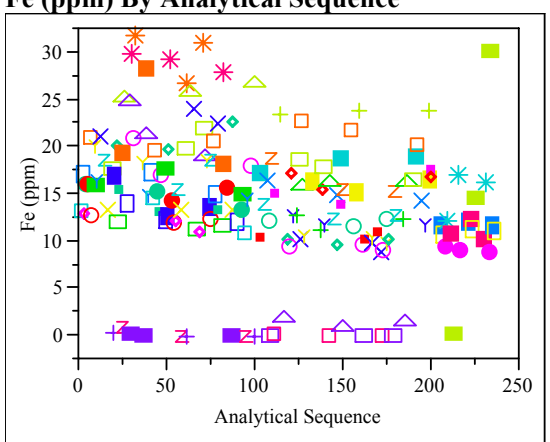

Li (ppm) By Analytical Sequence

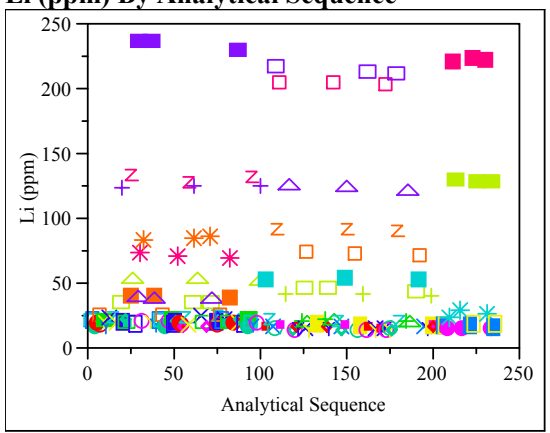

Na (ppm) By Analytical Sequence

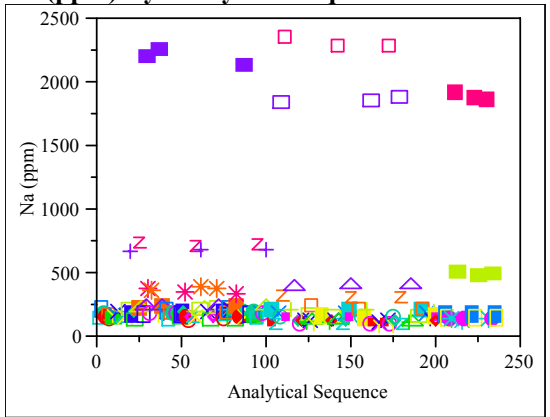

Pb (ppm) By Analytical Sequence

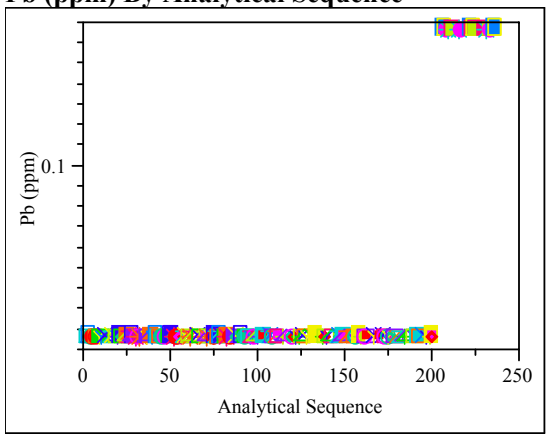

Si (ppm) By Analytical Sequence

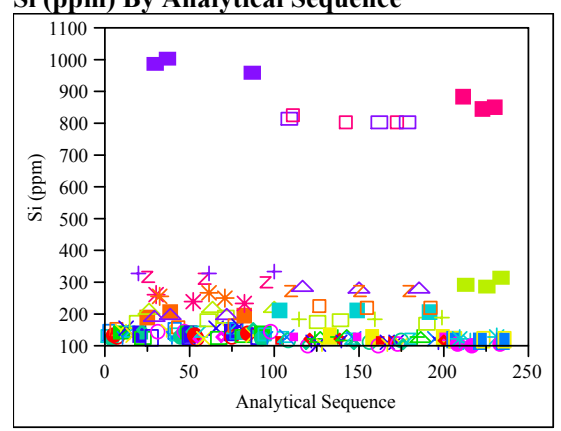

Th (ppm) By Analytical Sequence

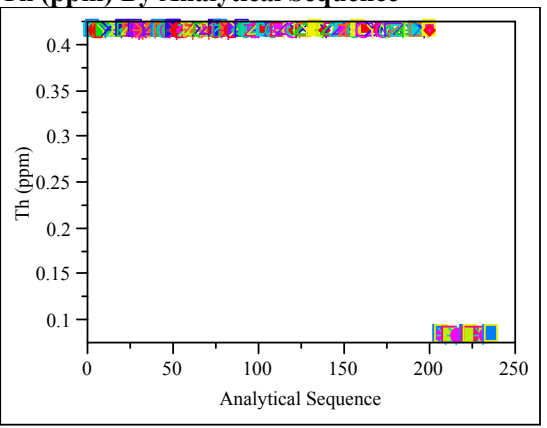

U (ppm) By Analytical Sequence

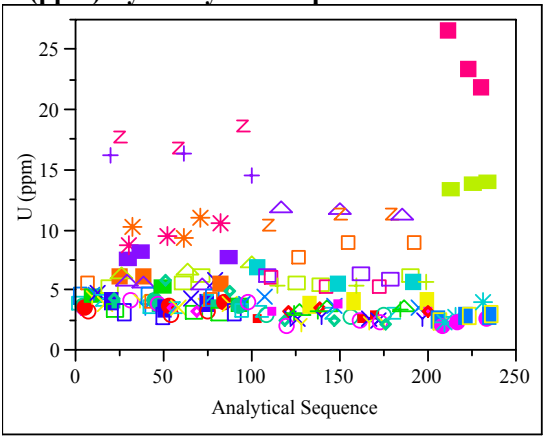


Exhibit D3. Measurements of the Multi-Element Solution Standard by Set and ICP Block

Oneway Analysis of B (ppm) By Part/Block

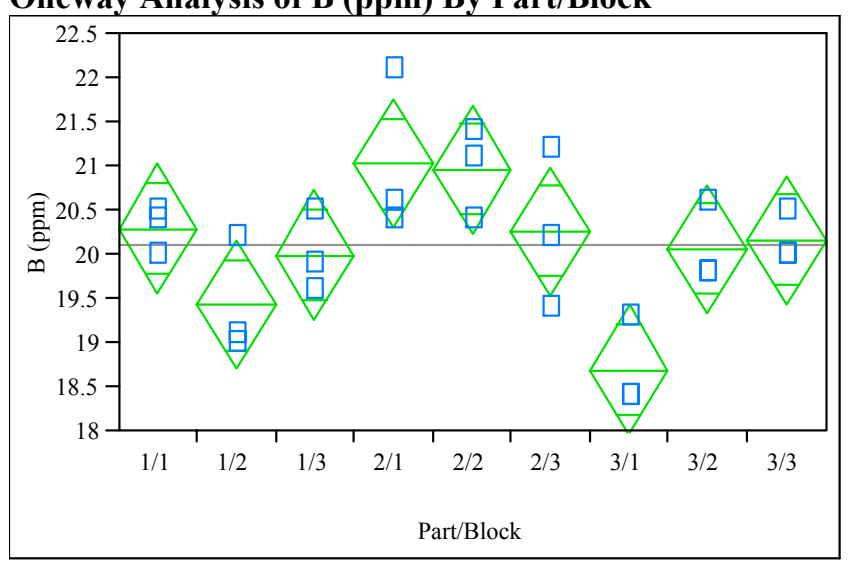

\section{Oneway Anova}

\section{Summary of Fit}

Rsquare

Adj Rsquare

0.656193

Root Mean Square Erro

0.50339

Mean of Response

0.599073

Observations (or Sum Wgts)

Analysis of Variance

Source DF Sum of Squares Mean Square F Ratio Prob $>$ F

$\begin{array}{lrrrrr}\text { Part/Block } & 8 & 12.329630 & 1.54120 & 4.2944 & 0.0049\end{array}$

Error $18-6.460000$

$\begin{array}{lll}1.54120 & 4.2944 & 0.0049 \\ 0.35889 & & \end{array}$

C. Total 26

6.460000

\section{Means for Oneway Anova}

Level Number Mean Std Error Lower 95\% Upper 95\%

$\begin{array}{llllll}1 / 1 & 3 & 20.3000 & 0.34588 & 19.573 & 21.027\end{array}$

$\begin{array}{llllll}1 / 2 & 3 & 19.4333 & 0.34588 & 18.707 & 20.160\end{array}$

$\begin{array}{llllll}1 / 3 & 3 & 20.0000 & 0.34588 & 19.273 & 20.727\end{array}$

$\begin{array}{llllll}2 / 1 & 3 & 21.0333 & 0.34588 & 20.307 & 21.760\end{array}$

$\begin{array}{llllll}2 / 2 & 3 & 20.9667 & 0.34588 & 20.240 & 21.693 \\ 2 / 3 & 3 & 20.2667 & 0.34588 & 19.540 & 20.993\end{array}$

$\begin{array}{llllll}2 / 3 & 3 & 20.2667 & 0.34588 & 19.540 & 20.993 \\ 3 / 1 & 3 & 18.7000 & 0.34588 & 17.973 & 19.427\end{array}$

$\begin{array}{llllll}3 / 1 & 3 & 18.7000 & 0.34588 & 17.973 & 19.427 \\ 3 / 2 & 3 & 20.0667 & 0.34588 & 19.340 & 20.793\end{array}$

$\begin{array}{llllll}3 / 3 & 3 & 20.1667 & 0.34588 & 19.440 & 20.893\end{array}$

Std Error uses a pooled estimate of error variance

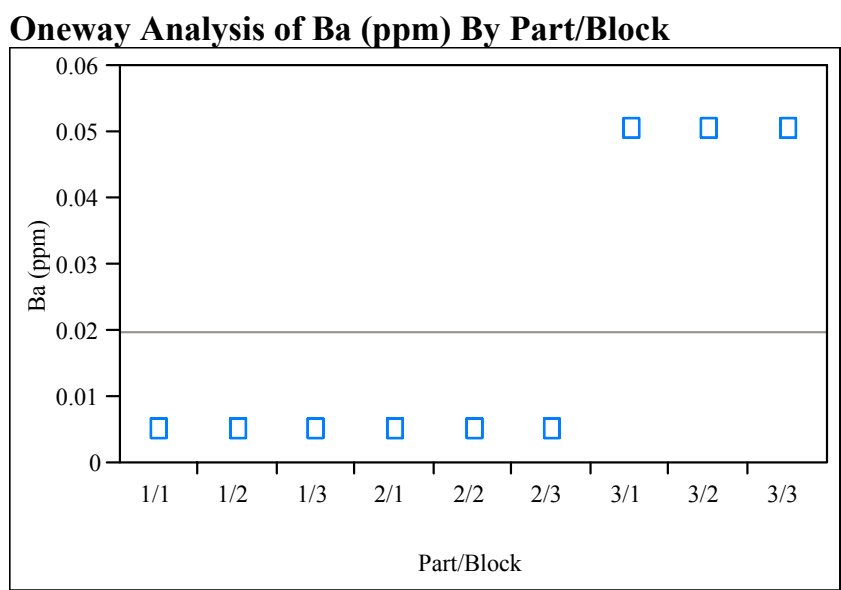

\section{Oneway Anova}

\section{Summary of Fit}

Rsquare

Adj Rsquare

Root Mean Square Error

Mean of Response

Observations (or Sum Wgts) 27

Analysis of Variance

Source DF Sum of Squares Mean Square F Ratio Prob > F

$\begin{array}{lrrrrr}\text { Part/Block } 8 & 0.0121500 & 0.00152 & -3.94 \mathrm{e} 15 & -1.0000\end{array}$

$\begin{array}{llll}\text { Error } & 18 & -6.939 \mathrm{e}-18 & -3.9 \mathrm{e}-19\end{array}$

C. Total $26 \quad 0.0121500$

Means for Oneway Anova

Level Number Mean Std Error Lower 95\% Upper 95\%

$1 / 1 \quad 30.005000$

30.005000

30.005000

30.005000

30.005000

30.005000

$\begin{array}{ll}3 & 0.050000 \\ 3 & 0.050000\end{array}$

$\begin{array}{ll}3 & 0.050000\end{array}$

Std Error uses a pooled estimate of error variance 
Exhibit D3. Measurements of the Multi-Element Solution Standard

\section{by Set and ICP Block}

Oneway Analysis of Cd (ppm) By Part/Block

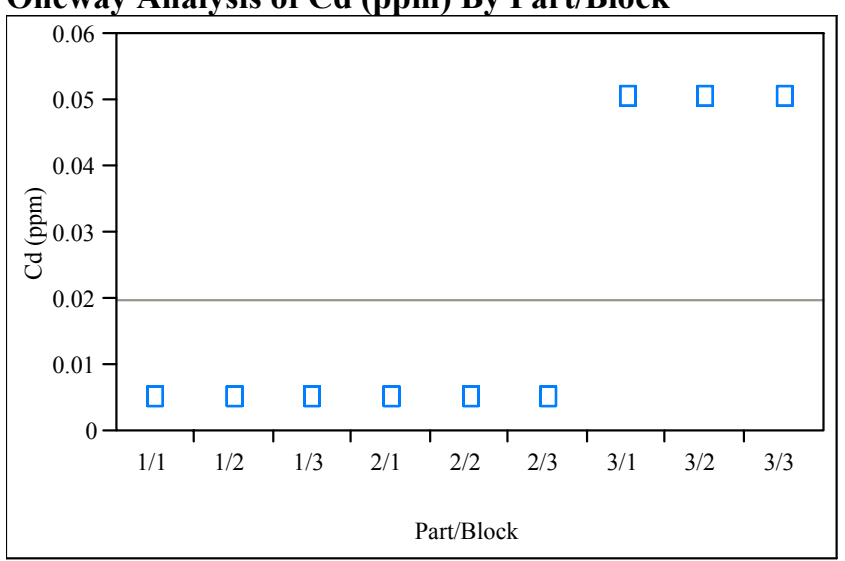

\section{Oneway Anova}

\section{Summary of Fit}

Rsquare

Adj Rsquare

Root Mean Square Error

Mean of Response

Observations (or Sum Wgts) 27

Analysis of Variance

Source DF Sum of Squares Mean Square F Ratio Prob $>$ F

$\begin{array}{llllll}\text { Part/Block } & 8 & 0.0121500 & 0.00152 & -3.94 \mathrm{e} 15 & -1.0000\end{array}$

$\begin{array}{lrr}\text { Error } & 18 & -6.939 \mathrm{e}-18\end{array}$

C. Total 26

0.0121500

\section{Means for Oneway Anova}

Level Number Mean Std Error Lower 95\% Upper 95\%

$1 / 1 \quad 30.005000$

$1 / 2 \quad 3 \quad 30.005000$

$1 / 3 \quad 30.005000$

$\begin{array}{lll}2 / 1 & 3 & 0.005000 \\ 2 / 2 & 3 & 0.005000\end{array}$

$2 / 3 \quad 3 \quad 0.005000$

$3 / 1 \quad 3 \quad 30.050000$

$3 / 2 \quad 30.050000$

$3 / 3 \quad 30.050000$

Std Error uses a pooled estimate of error variance

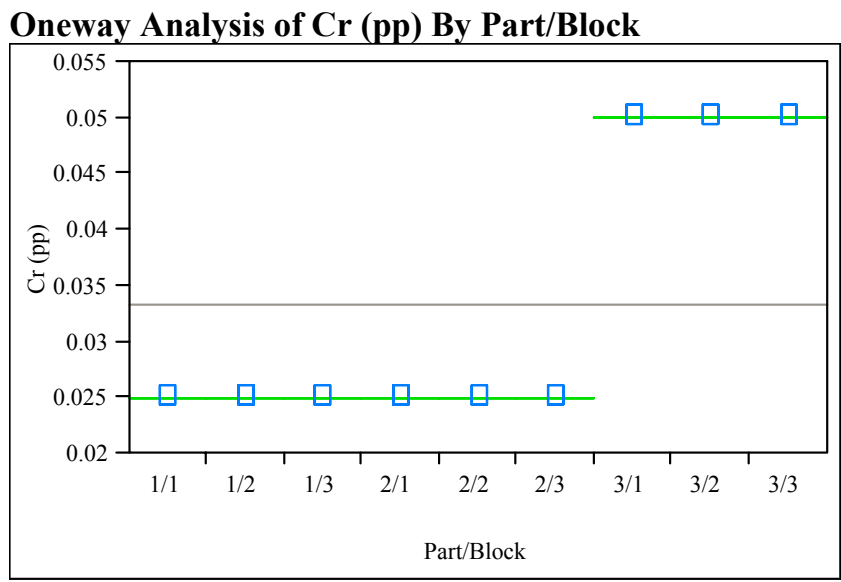

\section{Oneway Anova}

Summary of Fit

Rsquare

Adj Rsquare

Root Mean Square Error

Mean of Response

1
1
0
0.033333

Observations (or Sum Wgts)

Analysis of Variance

Source DF Sum of Squares Mean Square F Ratio Prob > F

$\begin{array}{llll}\text { Part/Block } 8 & 0.00375000 & 0.000469\end{array}$

$\begin{array}{llll}\text { Error } & 18 & 0.00000000 & 0.000000\end{array}$

C. Total $26 \quad 0.00375000$

Means for Oneway Anova

Level Number Mean Std Error Lower 95\% Upper 95\%

$\begin{array}{llllll}1 / 1 & 3 & 0.025000 & 0 & 0.02500 & 0.02500\end{array}$

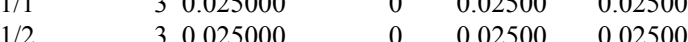

$\begin{array}{llllll}1 / 2 & 3 & 0.025000 & 0 & 0.02500 & 0.02500 \\ 1 / 3 & 3 & 0.025000 & 0 & 0.02500 & 0.02500\end{array}$

$\begin{array}{llllll}1 / 3 & 3 & 0.025000 & 0 & 0.02500 & 0.02500 \\ 2 / 1 & 3 & 0.025000 & 0 & 0.02500 & 0.02500\end{array}$

$\begin{array}{llllll}2 / 2 & 3 & 0.025000 & 0 & 0.02500 & 0.02500\end{array}$

$\begin{array}{llllll}2 / 3 & 3 & 0.025000 & 0 & 0.02500 & 0.02500\end{array}$

$\begin{array}{llllll}3 / 1 & 3 & 0.050000 & 0 & 0.05000 & 0.05000 \\ 3 / 2 & 3 & 0.050000 & 0 & 0.05000 & 0.05000\end{array}$

$\begin{array}{llllll}3 / 3 & 3 & 0.050000 & 0 & 0.05000 & 0.05000\end{array}$

Std Error uses a pooled estimate of error variance 


\section{Exhibit D3. Measurements of the Multi-Element Solution Standard}

\section{by Set and ICP Block}

Oneway Analysis of Fe (ppm) By Part/Block

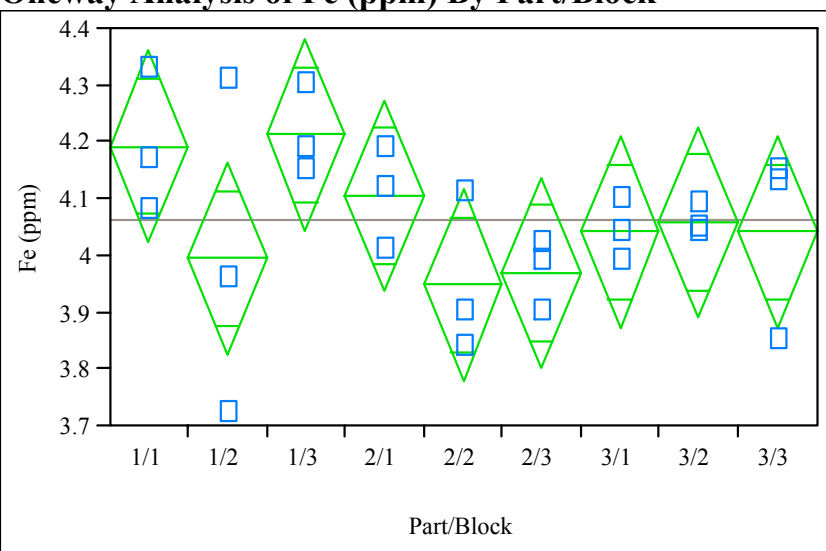

\section{Oneway Anova}

\section{Summary of Fit}

Rsquare

Adj Rsquare

0.369585

Root Mean Square Error

0.08940

Mean of Respons

0.139124

Observations (or Sum Wgts)

27

Analysis of Variance

Source DF Sum of Squares Mean Square F Ratio Prob > F

$\begin{array}{llllll}\text { Part/Block } & 8 & 0.20425185 & 0.025531 & 1.3191 & 0.2957\end{array}$

Error $18 \quad 0.34840000$

0.34840000

0.019356

\section{Means for Oneway Anova}

Level Number Mean Std Error Lower 95\% Upper 95\%

$\begin{array}{lllllr}1 / 1 & 3 & 4.19333 & 0.08032 & 4.0246 & 4.3621\end{array}$

$\begin{array}{llllll}1 / 2 & 3 & 3.99667 & 0.08032 & 3.8279 & 4.1654\end{array}$

$\begin{array}{llllll}1 / 3 & 3 & 4.21333 & 0.08032 & 4.0446 & 4.3821\end{array}$

$\begin{array}{llllll}2 / 1 & 3 & 4.10667 & 0.08032 & 3.9379 & 4.2754\end{array}$

$\begin{array}{llllll}2 / 2 & 3 & 3.95000 & 0.08032 & 3.7812 & 4.1188\end{array}$

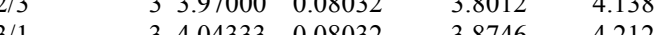

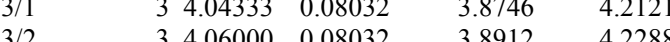

$\begin{array}{llllll}3 / 3 & 3 & 4.04333 & 0.08032 & 3.8746 & 4.212\end{array}$

Std Error uses a pooled estimate of error variance
Oneway Analysis of Li (ppm) By Part/Block

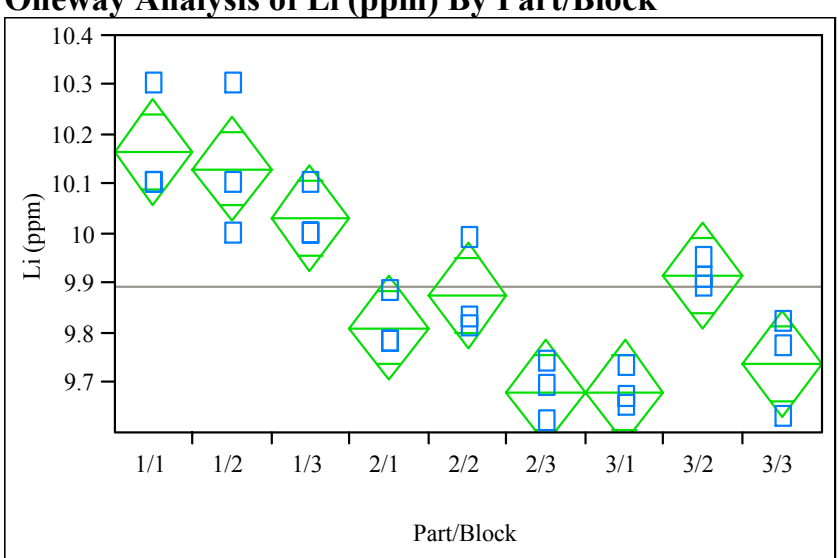

\section{Oneway Anova}

\section{Summary of Fit}

Rsquare

Adj Rsquare $\quad 0.790117$

0.854696

Root Mean Square Error $\quad 0.087602$

Mean of Response

9.894074

Observations (or Sum Wgts)

Analysis of Variance

Source DF Sum of Squares Mean Square F Ratio Prob $>$ F

$\begin{array}{lllllll}\text { Part/Block } & 8 & 0.81251852 & 0.101565 & 13.2348 & <.0001\end{array}$

$\begin{array}{lrrr}\text { Error } & 18 & 0.13813333 & 0.007674\end{array}$

C. Total $26 \quad 0.95065185$

Means for Oneway Anova

Level Number Mean Std Error Lower 95\% Upper 95\%

$\begin{array}{llllll}1 / 1 & 3 & 10.1667 & 0.05058 & 10.060 & 10.273\end{array}$

$\begin{array}{rrrrrr}1 / 2 & 3 & 10.1333 & 0.05058 & 10.027 & 10.240\end{array}$

$\begin{array}{rrrrrr}1 / 3 & 3 & 10.0333 & 0.05058 & 9.927 & 10.140\end{array}$

$\begin{array}{llllll}2 / 1 & 3 & 9.8133 & 0.05058 & 9.707 & 9.920 \\ 2 / 2 & 3 & 9.8767 & 0.05058 & 9.770 & 9.983\end{array}$

$\begin{array}{llllll}2 / 3 & 3 & 9.8767 & 0.05058 & 9.770 & 9.983 \\ 3 / 1 & 3 & 9.6833 & 0.05058 & 9.577 & 9.790\end{array}$

$\begin{array}{rrrrrr}3 / 1 & 3 & 9.6833 & 0.05058 & 9.577 & 9.790\end{array}$

$\begin{array}{rrrrrr}3 / 2 & 3 & 9.9167 & 0.05058 & 9.810 & 10.023 \\ 3 / 3 & 3 & 9.7400 & 0.05058 & 9.634 & 9.846\end{array}$

Std Error uses a pooled estimate of error variance 
Exhibit D3. Measurements of the Multi-Element Solution Standard by Set and ICP Block

Oneway Analysis of Na (ppm) By Part/Block

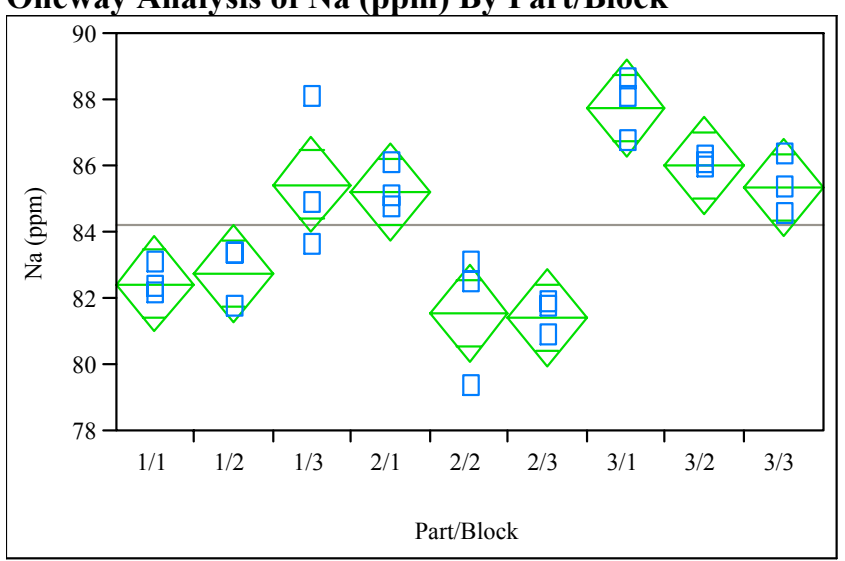

\section{Oneway Anova}

\section{Summary of Fit}

Rsquare

Adj Rsquare

Root Mean Square Erro

0.82396

0.74572

1.189771

Mean of Response

84.23333

Observations (or Sum Wgts)

\section{Analysis of Variance}

Source DF Sum of Squares Mean Square F Ratio Prob $>$ F

$\begin{array}{lrrrrr}\text { Part/Block } & 8 & 119.26000 & 14.9075 & 10.5312 & <.0001\end{array}$

$\begin{array}{lrr}\text { Error } & 18 & 25.48000\end{array}$

C. Total 26

144.74000

\section{Means for Oneway Anova}

Level Number Mean Std Error Lower 95\% Upper 95\%

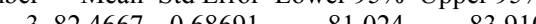

$\begin{array}{llllll}1 / 2 & 3 & 82.7667 & 0.68691 & 81.324 & 84.210\end{array}$

$\begin{array}{llllll}1 / 3 & 3 & 85.4667 & 0.68691 & 84.024 & 86.910\end{array}$

$\begin{array}{llllll}2 / 1 & 3 & 85.2333 & 0.68691 & 83.790 & 86.676\end{array}$

$\begin{array}{llllll}2 / 2 & 3 & 81.5667 & 0.68691 & 80.124 & 83.010\end{array}$

$\begin{array}{llllll}2 / 3 & 3 & 81.4333 & 0.68691 & 79.990 & 82.876\end{array}$

$\begin{array}{llllll}3 / 1 & 3 & 87.7667 & 0.68691 & 86.324 & 89.210\end{array}$

$\begin{array}{llllll}3 / 2 & 3 & 86.0333 & 0.68691 & 84.590 & 87.476 \\ 3 / 3 & 3 & 85.3667 & 0.68691 & 83.924 & 86.810\end{array}$

Std Error uses a pooled estimate of error variance

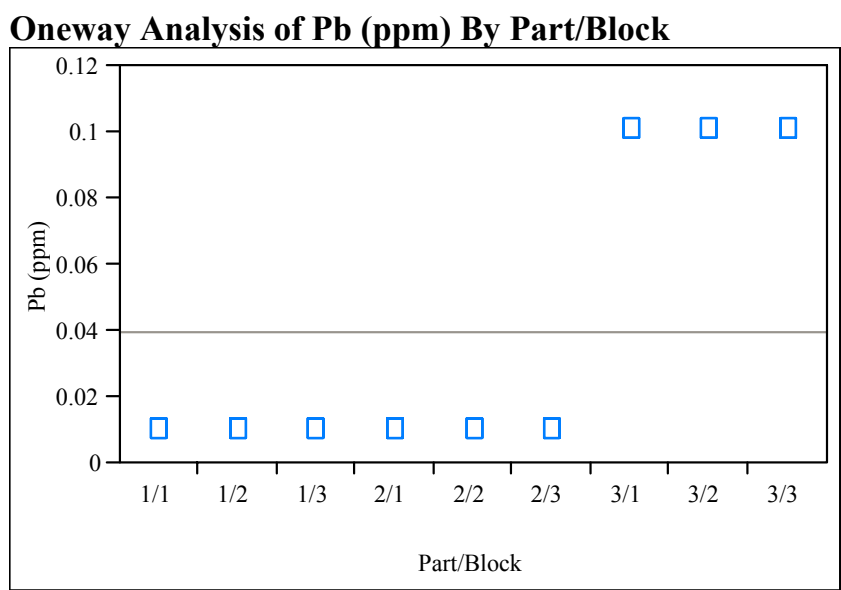

\section{Oneway Anova}

\section{Summary of Fit}

Rsquare

Adj Rsquare

Root Mean Square Error

Mean of Response

1
0.04

Observations (or Sum Wgts) 27

Analysis of Variance

Source DF Sum of Squares Mean Square F Ratio Prob $>$ F

$\begin{array}{lrrrrr}\text { Part/Block } 8 & 0.0486000 & 0.00608 & -3.94 \mathrm{e} 15 & -1.0000\end{array}$

$\begin{array}{llll}\text { Error } & 18 & -2.776 \mathrm{e}-17 & -1.5 \mathrm{e}-18\end{array}$

C. Total $26 \quad 0.0486000$

Means for Oneway Anova

Level Number Mean Std Error Lower 95\% Upper 95\%

$1 / 1 \quad 30.010000$

$\begin{array}{lll}1 / 2 & 3 & 0.010000 \\ 1 / 3 & 3 & 0.010000\end{array}$

$2 / 1 \quad 30.010000$

$2 / 2 \quad 3 \quad 0.010000$

$\begin{array}{ll}3 & 0.010000 \\ 3 & 0.100000\end{array}$

$\begin{array}{ll}3 & 0.100000 \\ 3 & 0.100000\end{array}$

$\begin{array}{ll}3 & 0.100000 \\ 3 & 0.100000\end{array}$

$\begin{array}{lll}3 / 3 & 30.100000 \\ \text { Std Error uses a pooled estimate of error variance }\end{array}$ 
Exhibit D3. Measurements of the Multi-Element Solution Standard by Set and ICP Block

Oneway Analysis of Si (ppm) By Part/Block

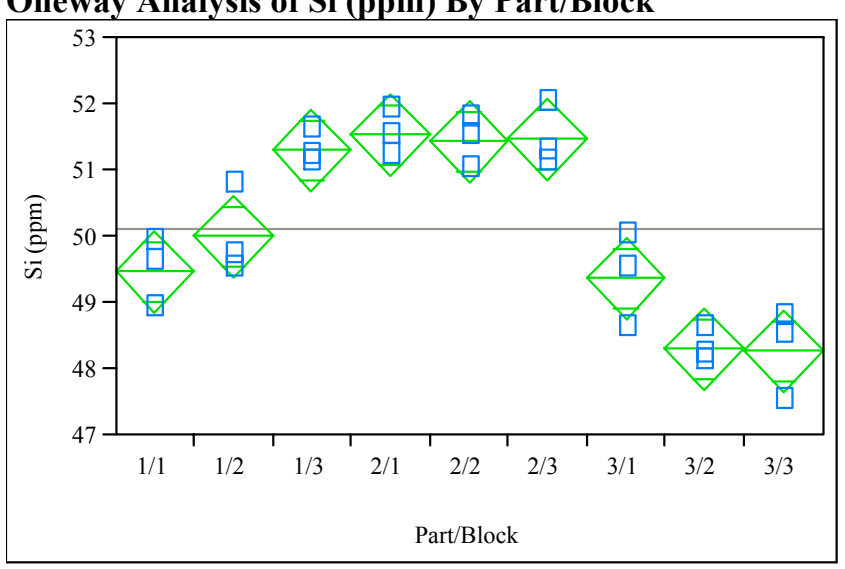

\section{Oneway Anova}

\section{Summary of Fit}

Rsquare

Adj Rsquare

0.902853

Root Mean Square Error

0.859676

0.51316

50.12593

Mean of Response

ervations (or Sum Wgts)

Analysis of $V$ ariance

Source DF Sum of Squares Mean Square F Ratio Prob $>$ F

$\begin{array}{lrrrrr}\text { Part/Block } & 8 & 44.051852 & 5.50648 & 20.9107 & <.0001\end{array}$

Error $18-4.740000$

C. Total 26

4.740000

0.26333

\section{Means for Oneway Anova}

Level Number Mean Std Error Lower 95\% Upper 95\%

$\begin{array}{llllrr}1 / 1 & 3 & 49.4667 & 0.29627 & 48.844 & 50.089\end{array}$

$\begin{array}{llllll}1 / 2 & 3 & 50.0000 & 0.29627 & 49.378 & 50.622\end{array}$

$\begin{array}{llllll}1 / 3 & 3 & 51.3000 & 0.29627 & 50.678 & 51.922\end{array}$

$\begin{array}{llllll}2 / 1 & 3 & 51.5333 & 0.29627 & 50.911 & 52.156\end{array}$

$\begin{array}{llllll}2 / 2 & 3 & 51.4333 & 0.29627 & 50.811 & 52.056\end{array}$

$\begin{array}{lllll}3 / 1 & 3 & 49.3667 & 0.29627 & 40.844\end{array}$

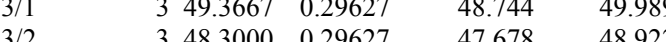

$\begin{array}{llllll}3 / 3 & 3 & 48.2667 & 0.29627 & 47.644 & 48.889\end{array}$

Std Error uses a pooled estimate of error variance

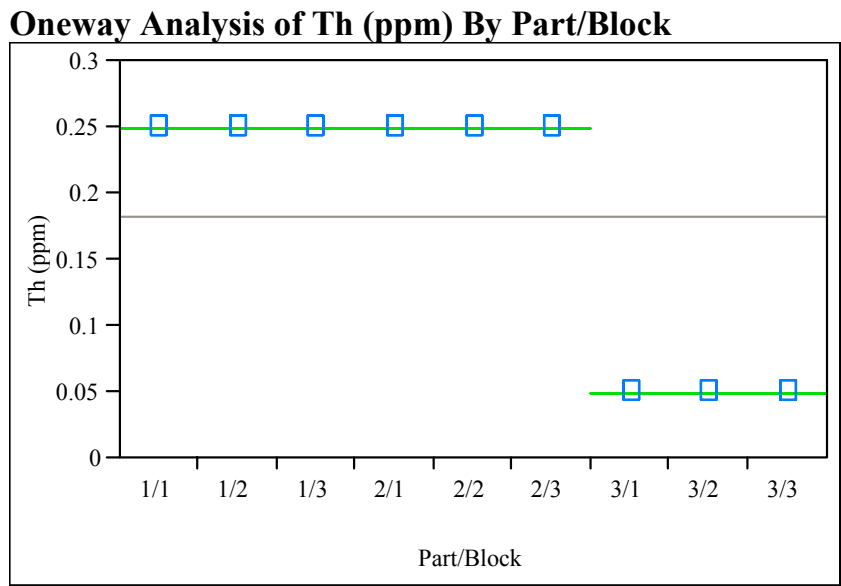

\section{Oneway Anova}

\section{Summary of Fit}

Rsquare

Adj Rsquare

Root Mean Square Error

Mean of Response

1
0
0.183333

Observations (or Sum Wgts)

Analysis of Variance

Source DF Sum of Squares Mean Square F Ratio Prob $>$ F

$\begin{array}{llll}\text { Part/Block } & 8 & 0.24000000 & 0.030000\end{array}$

$\begin{array}{lrrr}\text { Error } & 18 & 0.00000000 & 0.000000\end{array}$

C. Total $26 \quad 0.24000000$

Means for Oneway Anova

Level Number Mean Std Error Lower 95\% Upper 95\%

$\begin{array}{llllrr}1 / 1 & 3 & 0.250000 & 0 & 0.25000 & 0.25000\end{array}$

$\begin{array}{llllll}1 / 2 & 3 & 0.250000 & 0 & 0.25000 & 0.25000\end{array}$

$\begin{array}{llllll}1 / 3 & 3 & 0.250000 & 0 & 0.25000 & 0.25000\end{array}$

$\begin{array}{llllll}2 / 1 & 3 & 0.250000 & 0 & 0.25000 & 0.25000 \\ 2 / 2 & 3 & 0.250000 & 0 & 0.25000 & 0.25000\end{array}$

$\begin{array}{llllll}2 / 3 & 3 & 0.250000 & 0 & 0.25000 & 0.25000\end{array}$

$\begin{array}{llllll}3 / 1 & 3 & 0.050000 & 0 & 0.05000 & 0.05000\end{array}$

$\begin{array}{llllll}3 / 2 & 3 & 0.050000 & 0 & 0.05000 & 0.05000 \\ 3 / 3 & 3 & 0.050000 & 0 & 0.05000 & 0.0500\end{array}$

Std Error uses a pooled estimate of error variance 
Exhibit D3. Measurements of the Multi-Element Solution Standard

by Set and ICP Block

Oneway Analysis of U (ppm) By Part/Block

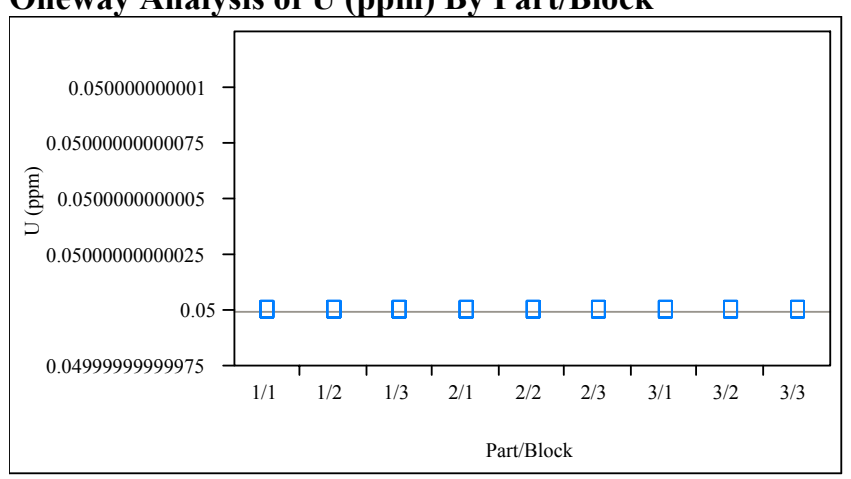

Oneway Anova

Summary of Fit

Rsquare

Adj Rsquare

Root Mean Square Error

Mean of Response

Observations (or Sum Wgts) 27

Analysis of Variance

Source DF Sum of Squares Mean Square F Ratio Prob $>$ F

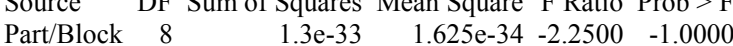

$\begin{array}{llll}\text { Error } & 18 & -1.3 \mathrm{e}-33 & -7.22 \mathrm{e}-35\end{array}$

C. Total 26

Means for Oneway Anova

Level Number Mean Std Error Lower 95\% Upper 95\%

$\begin{array}{lll}1 / 1 & 3 & 0.050000\end{array}$

$1 / 2-30.050000$

$\begin{array}{lll}1 / 3 & 3 & 0.050000\end{array}$

$\begin{array}{lll}2 / 1 & 3 & 0.050000\end{array}$

$2 / 2 \quad 30.050000$

30.050000

$3 / 2 \quad 30.050000$

$3 / 2 \quad 30.050000$

Std Error uses a pooled estimate of error variance 


\section{Exhibit D4. Laboratory PCT Measurements by Glass Number for Study Glasses and Standards}

(100 - Solution Standard; 101 - EA; 102 - ARM; 103 - Blanks)
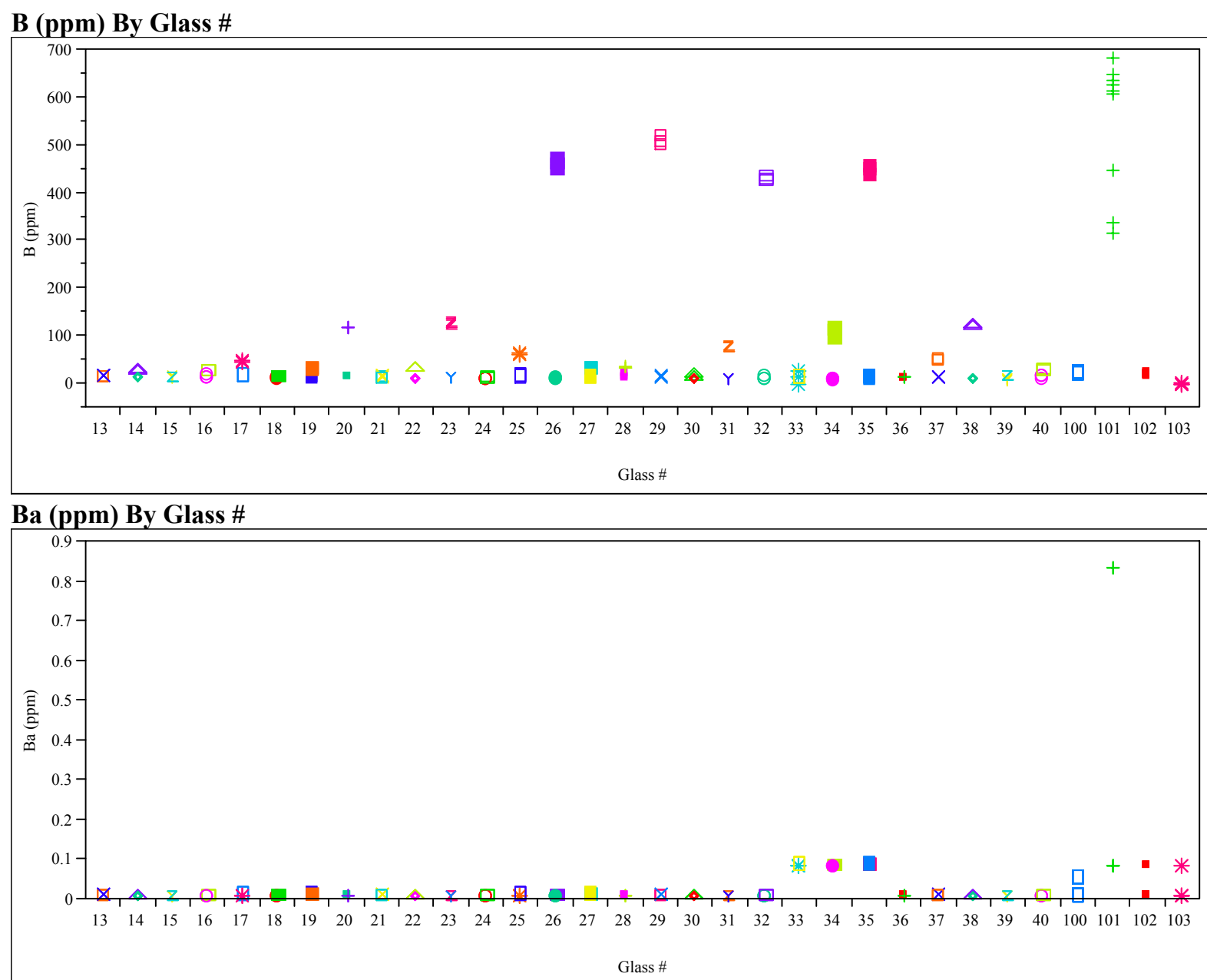

\section{Cd (ppm) By Glass \#}

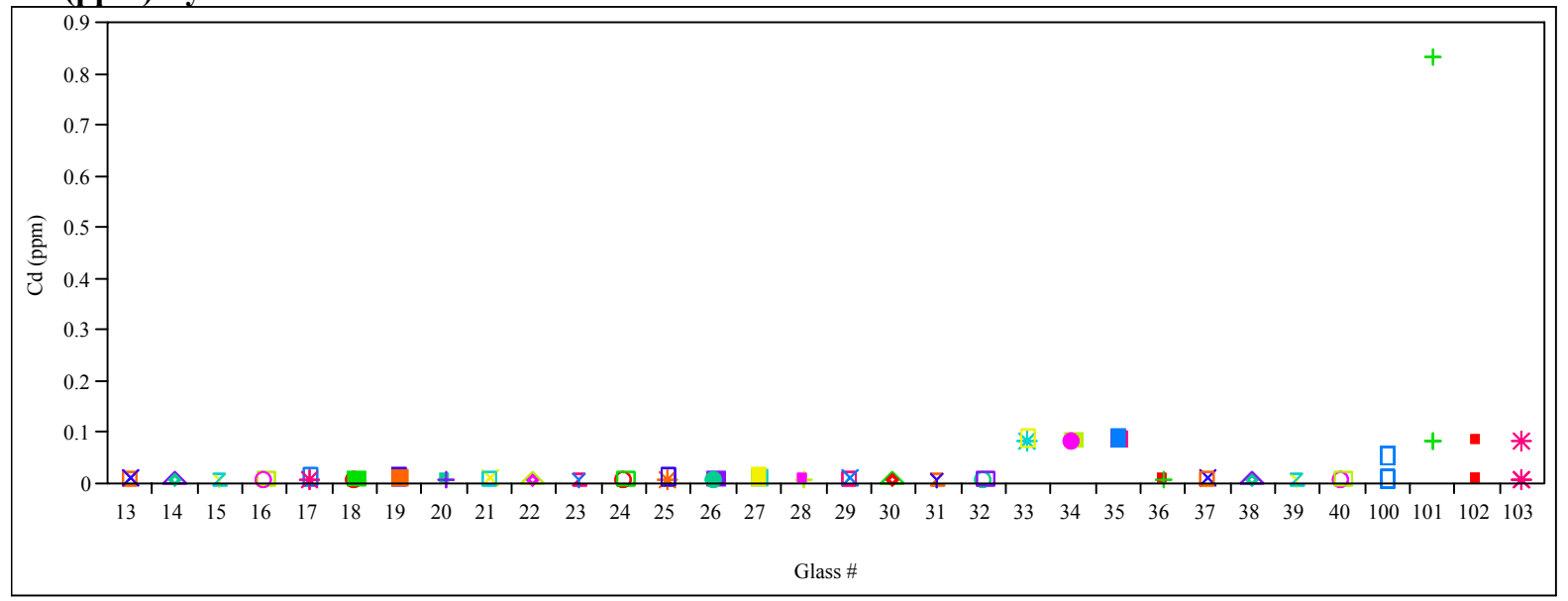

Excluded Rows 18 


\section{Exhibit D4. Laboratory PCT Measurements by Glass Number for Study Glasses and Standards}

(100 - Solution Standard; 101 - EA; 102 - ARM; 103 - Blanks)
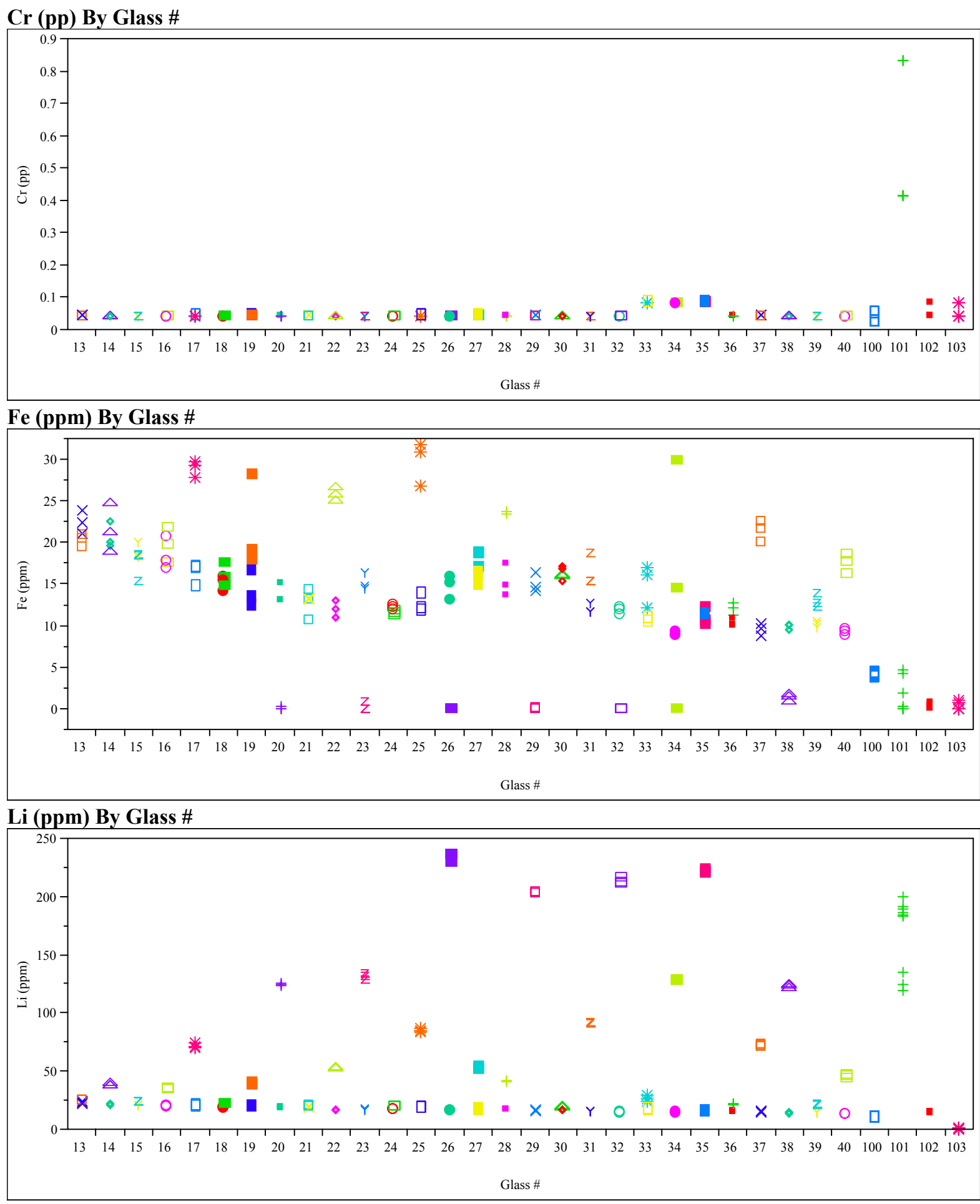

Excluded Rows 18 


\section{Exhibit D4. Laboratory PCT Measurements by Glass Number for Study Glasses and Standards}

(100 - Solution Standard; 101 - EA; 102 - ARM; 103 - Blanks)

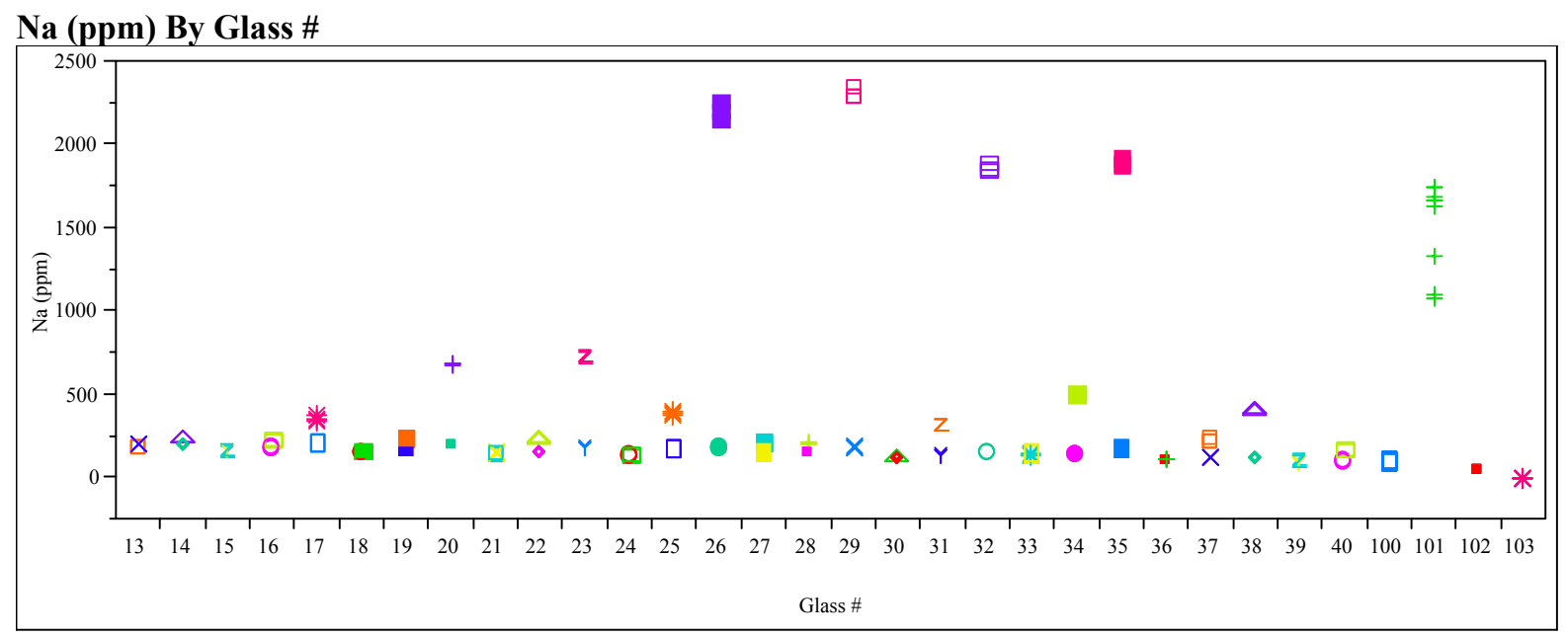

\section{Pb (ppm) By Glass \#}

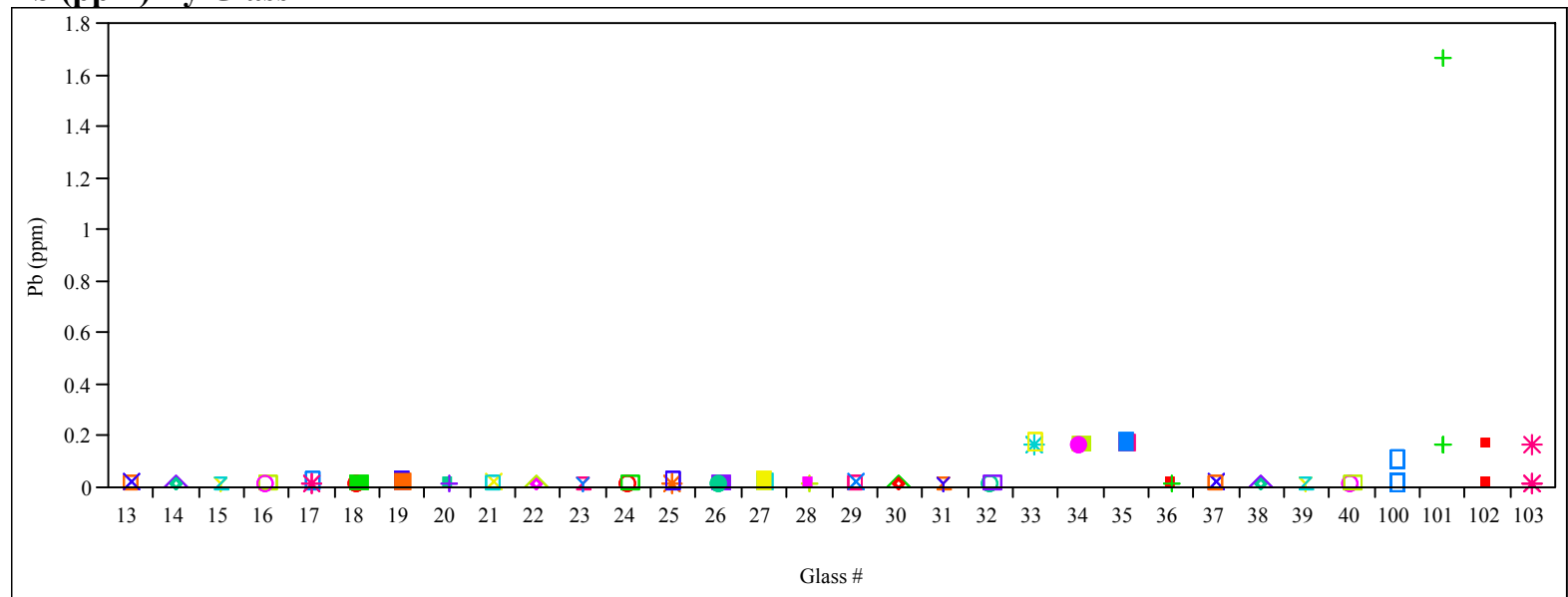

Si (ppm) By Glass \#

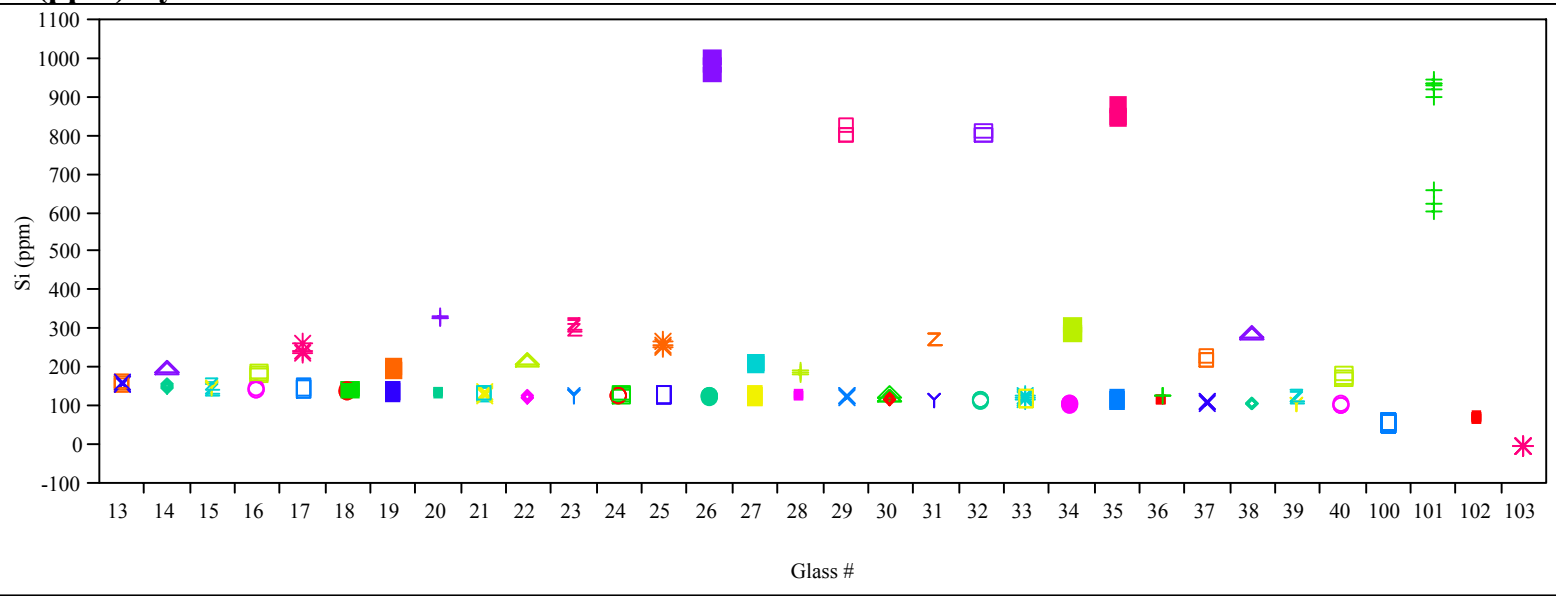

Excluded Rows 18 


\section{Exhibit D4. Laboratory PCT Measurements by Glass Number} for Study Glasses and Standards

(100 - Solution Standard; 101 - EA; 102 - ARM; 103 - Blanks)

Th (ppm) By Glass \#

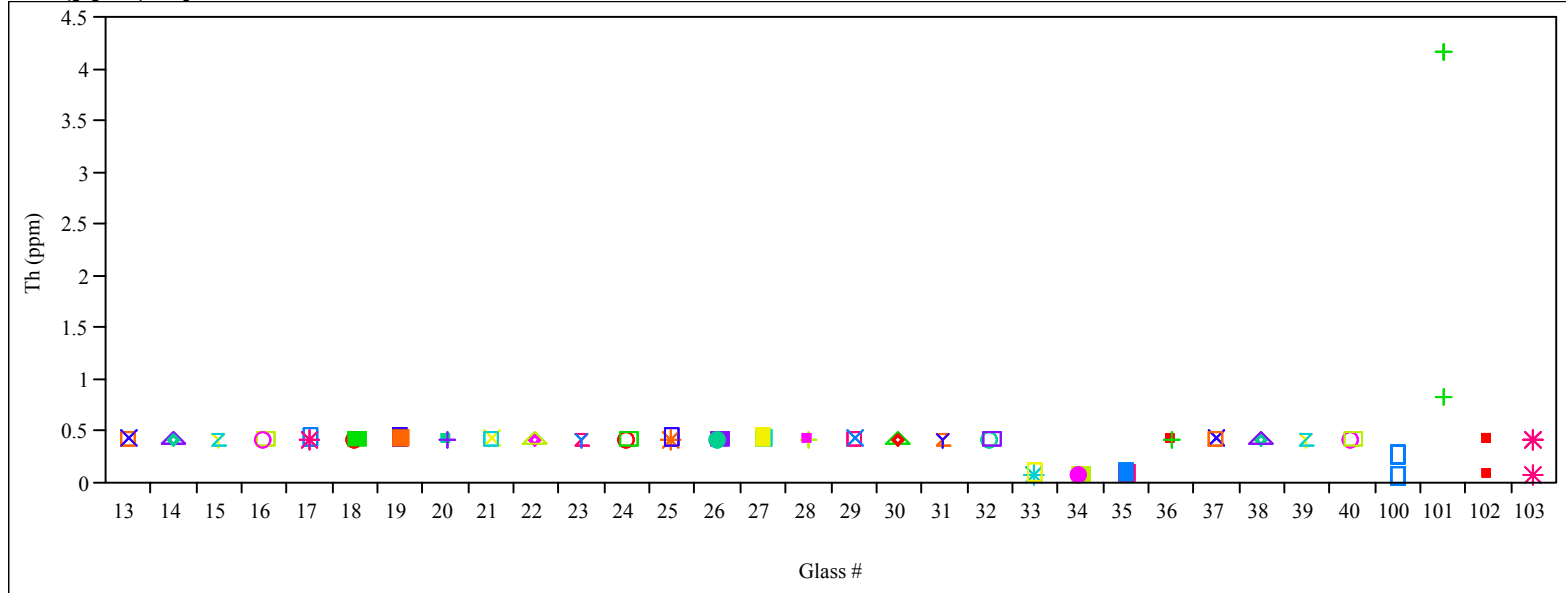

U (ppm) By Glass \#

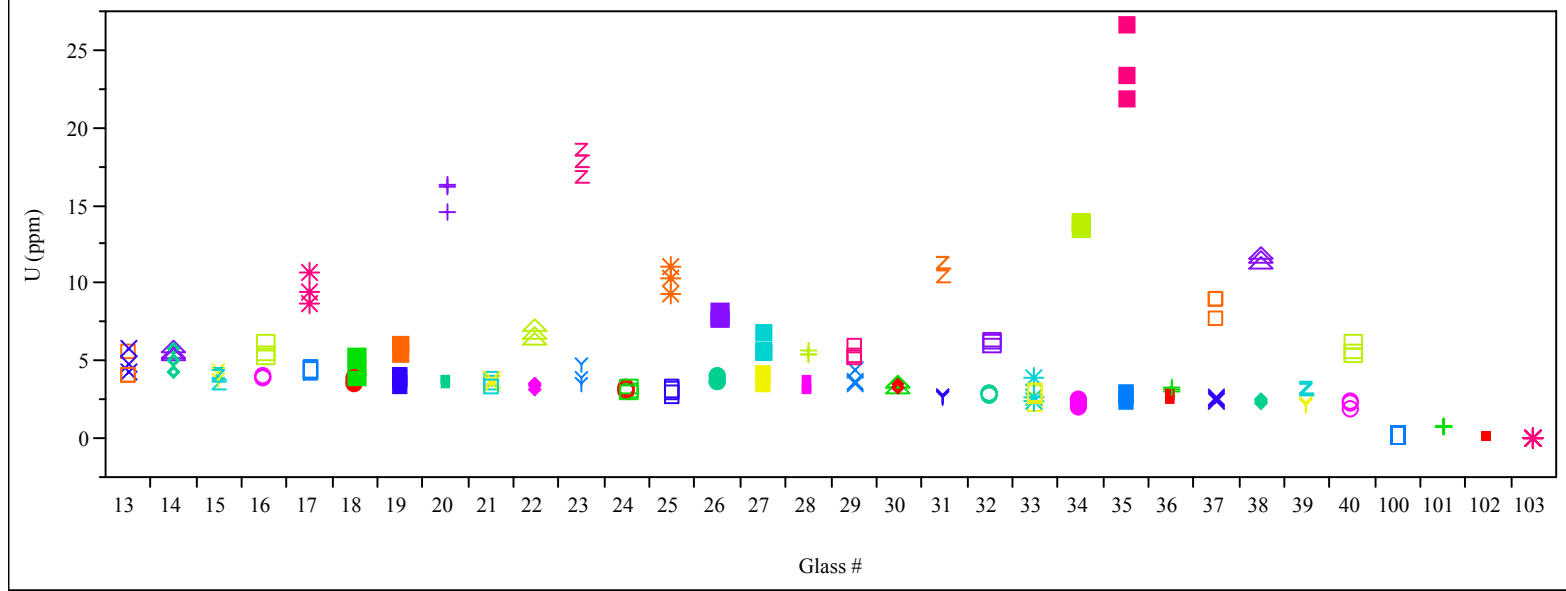

Excluded Rows 18 


\section{Exhibit D5. Laboratory PCT Measurements by Glass Number for cce Study Glasses and EA (101)}
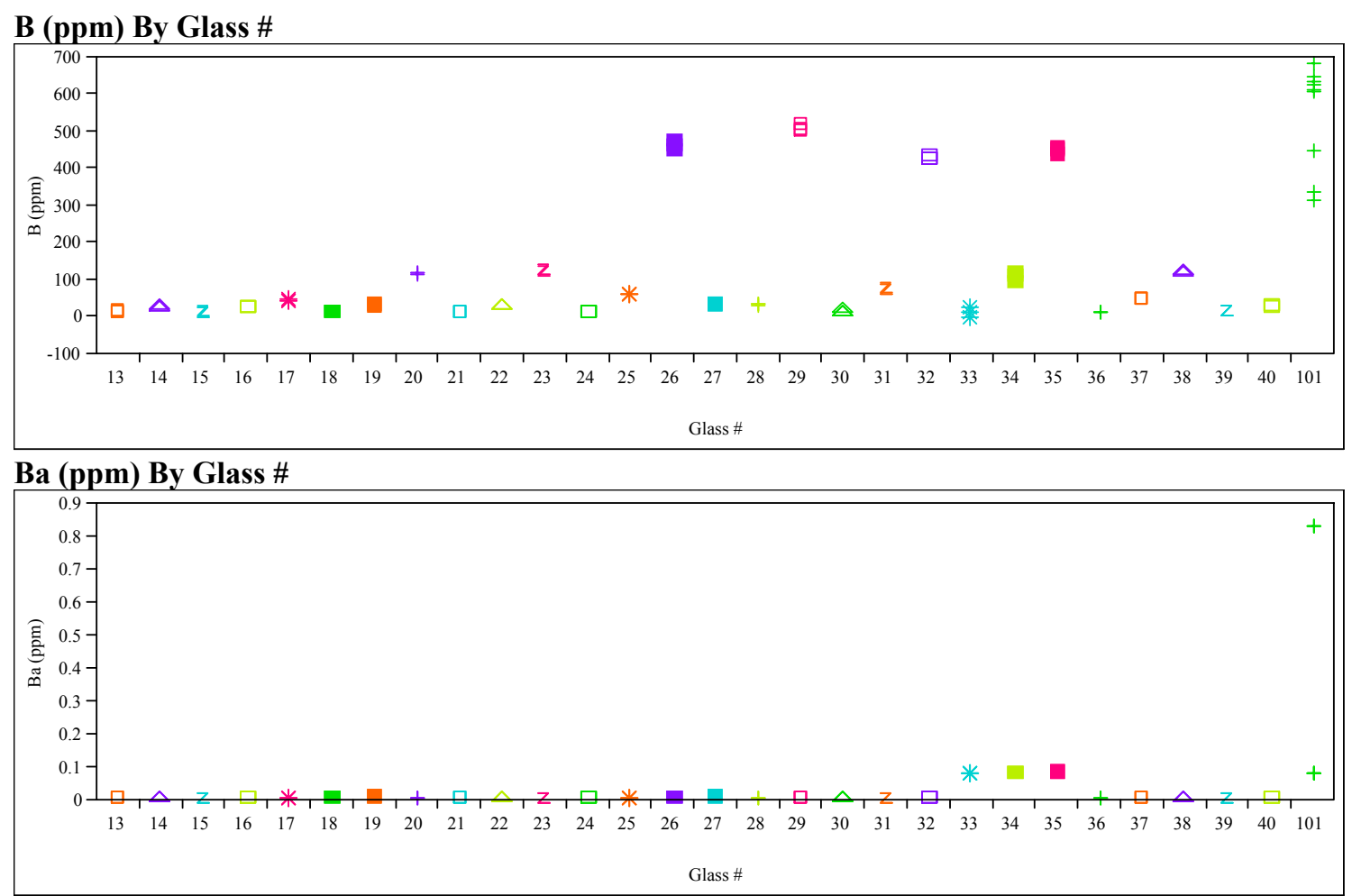

\section{Cd (ppm) By Glass \#}
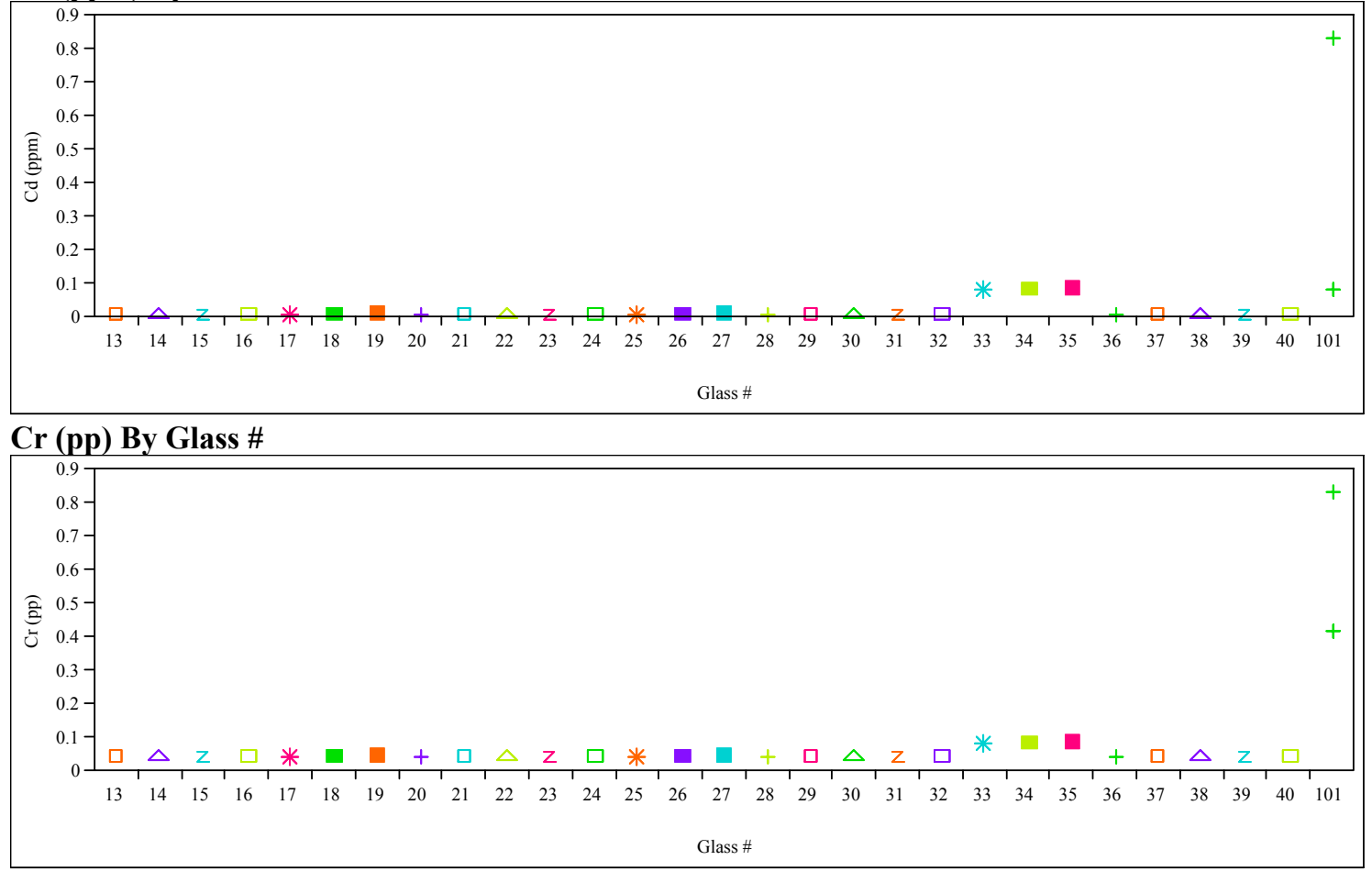

Excluded Rows 9 


\section{Exhibit D5. Laboratory PCT Measurements by Glass Number for cce Study Glasses and EA (101)}

Fe (ppm) By Glass \#

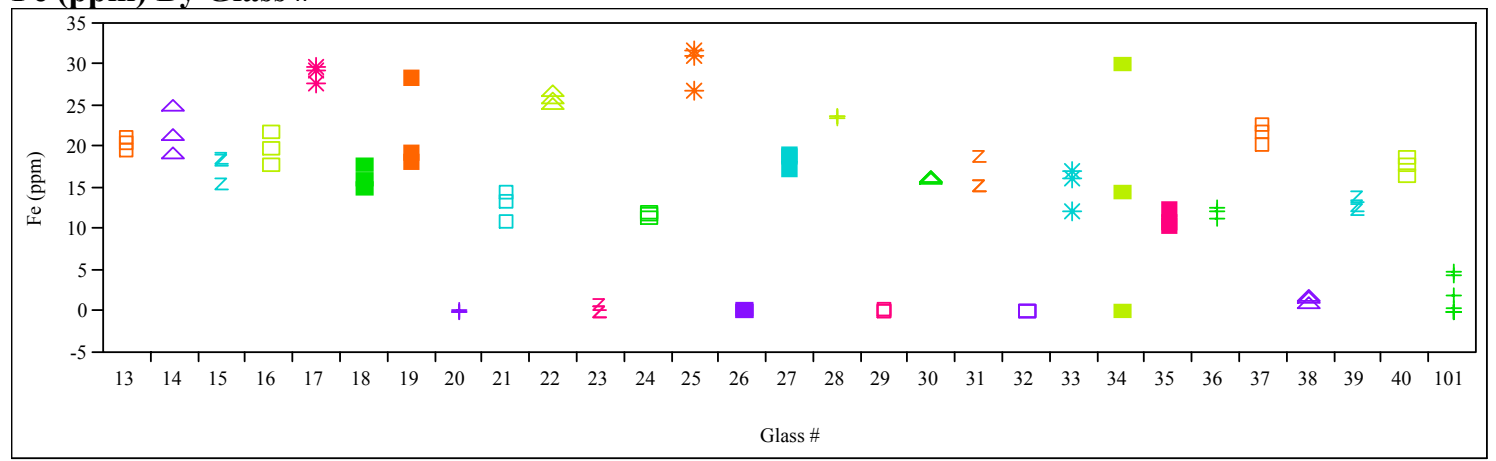

Li (ppm) By Glass \#

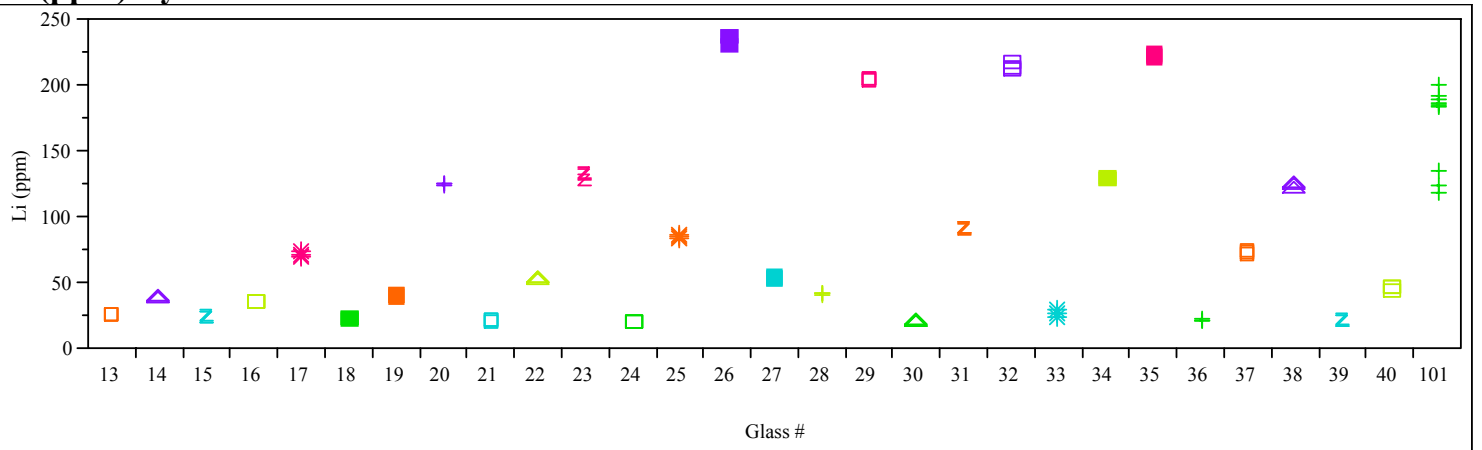

Na (ppm) By Glass \#

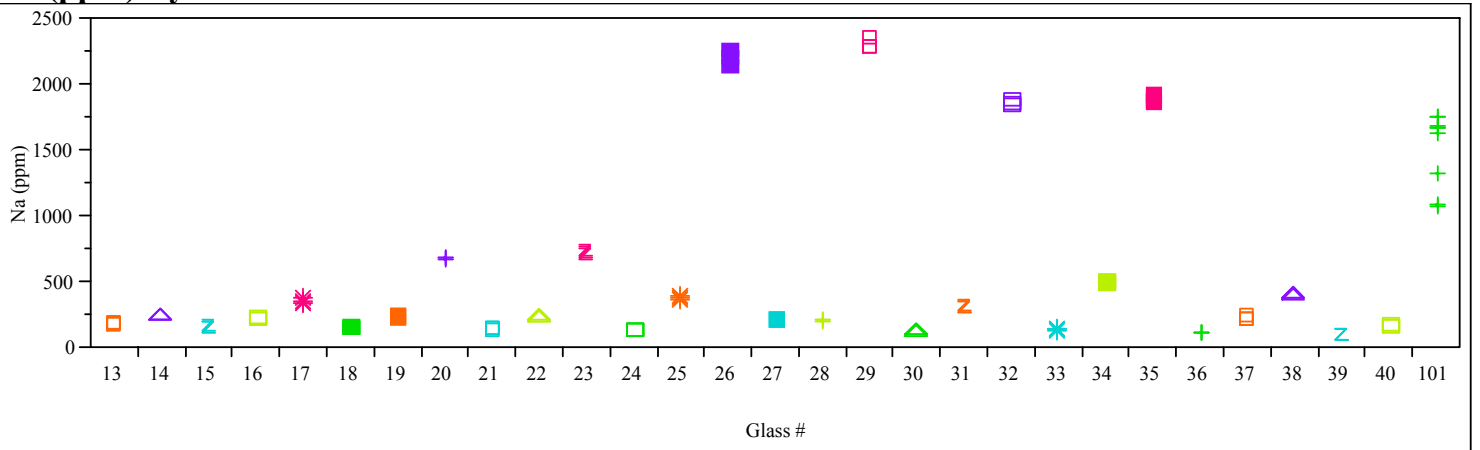

\section{Pb (ppm) By Glass \#}

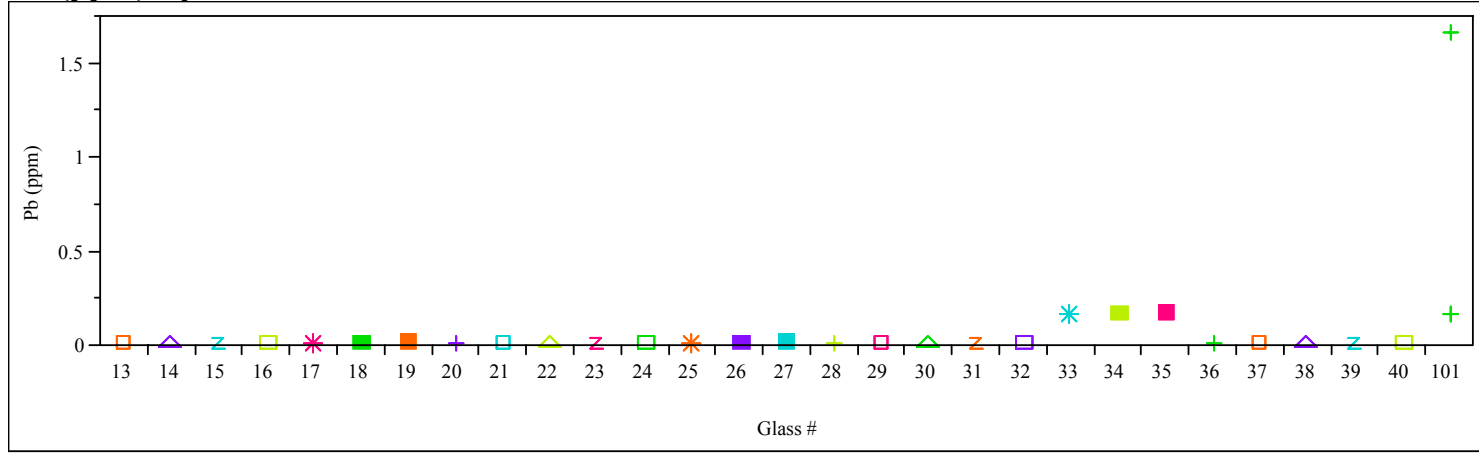

Excluded Rows 9 


\section{Exhibit D5. Laboratory PCT Measurements by Glass Number for cec Study Glasses and EA (101)}
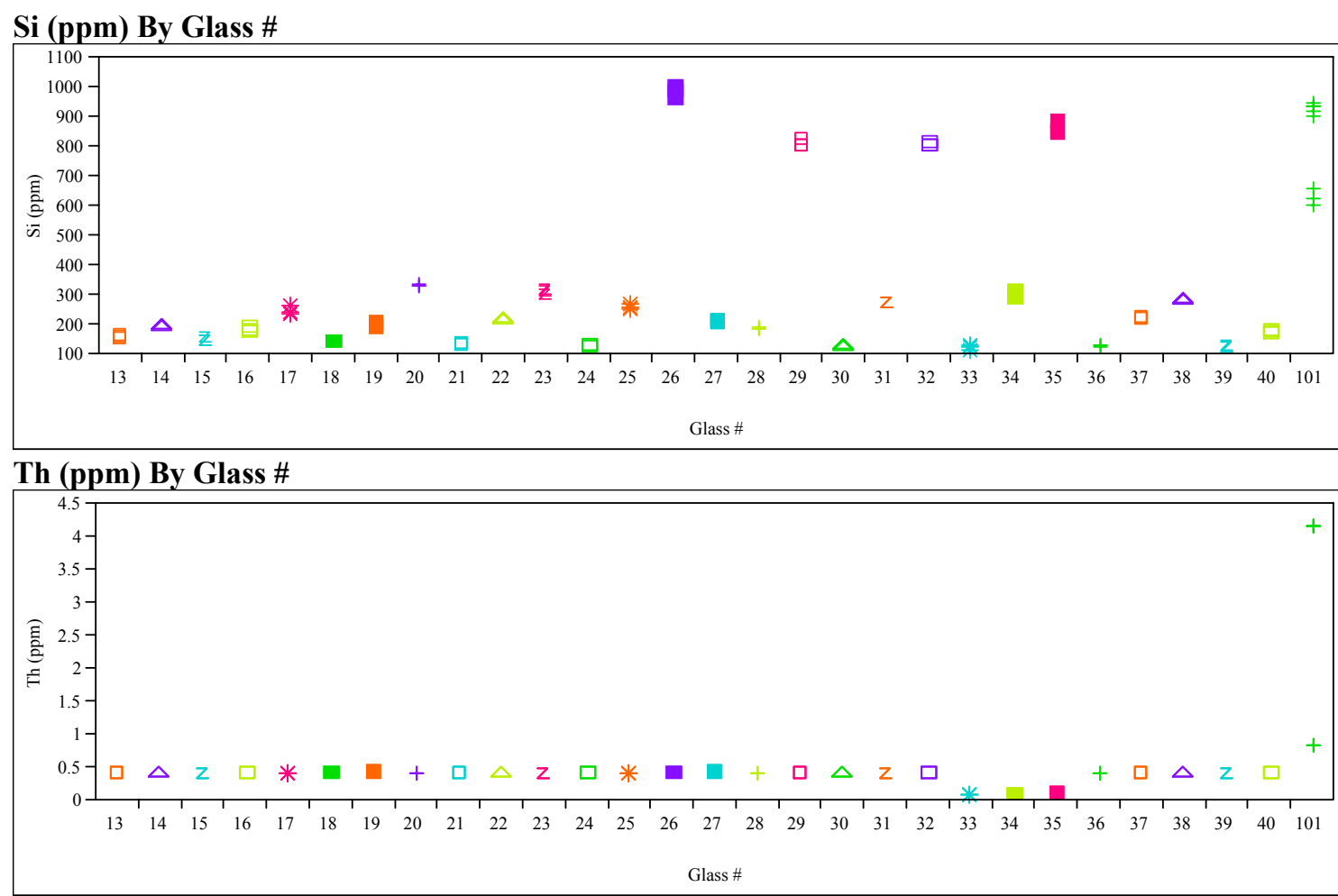

U (ppm) By Glass \#

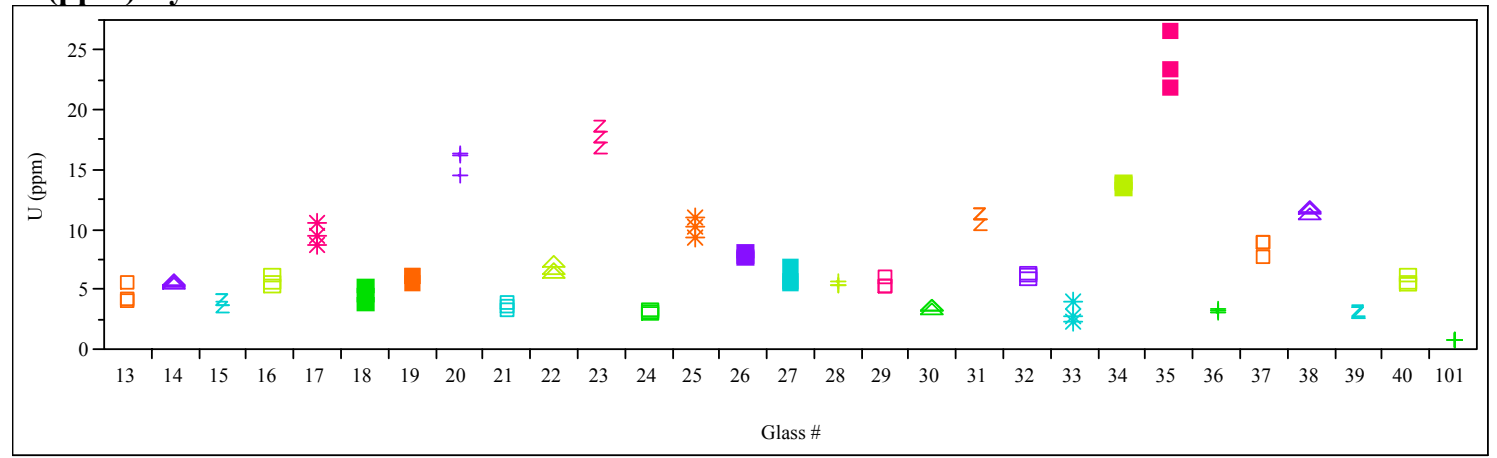

Excluded Rows 9 


\section{Exhibit D6. Correlations and Scatter Plots of Normalized PCTs Over All Compositional Views and Heat Treatments}

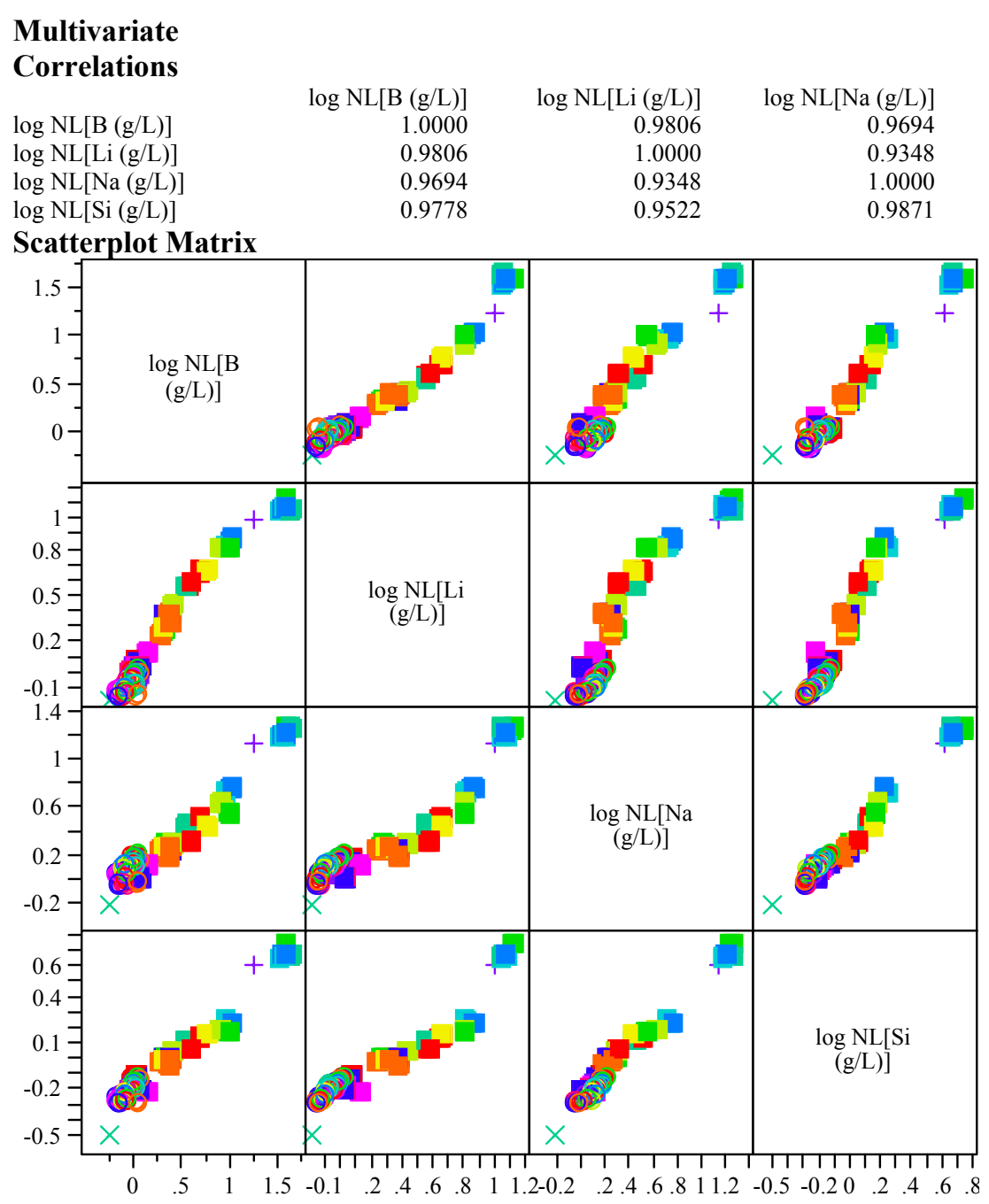


Exhibit D7. Effects of Heat Treatment for Study Glasses Using Targeted Compositions
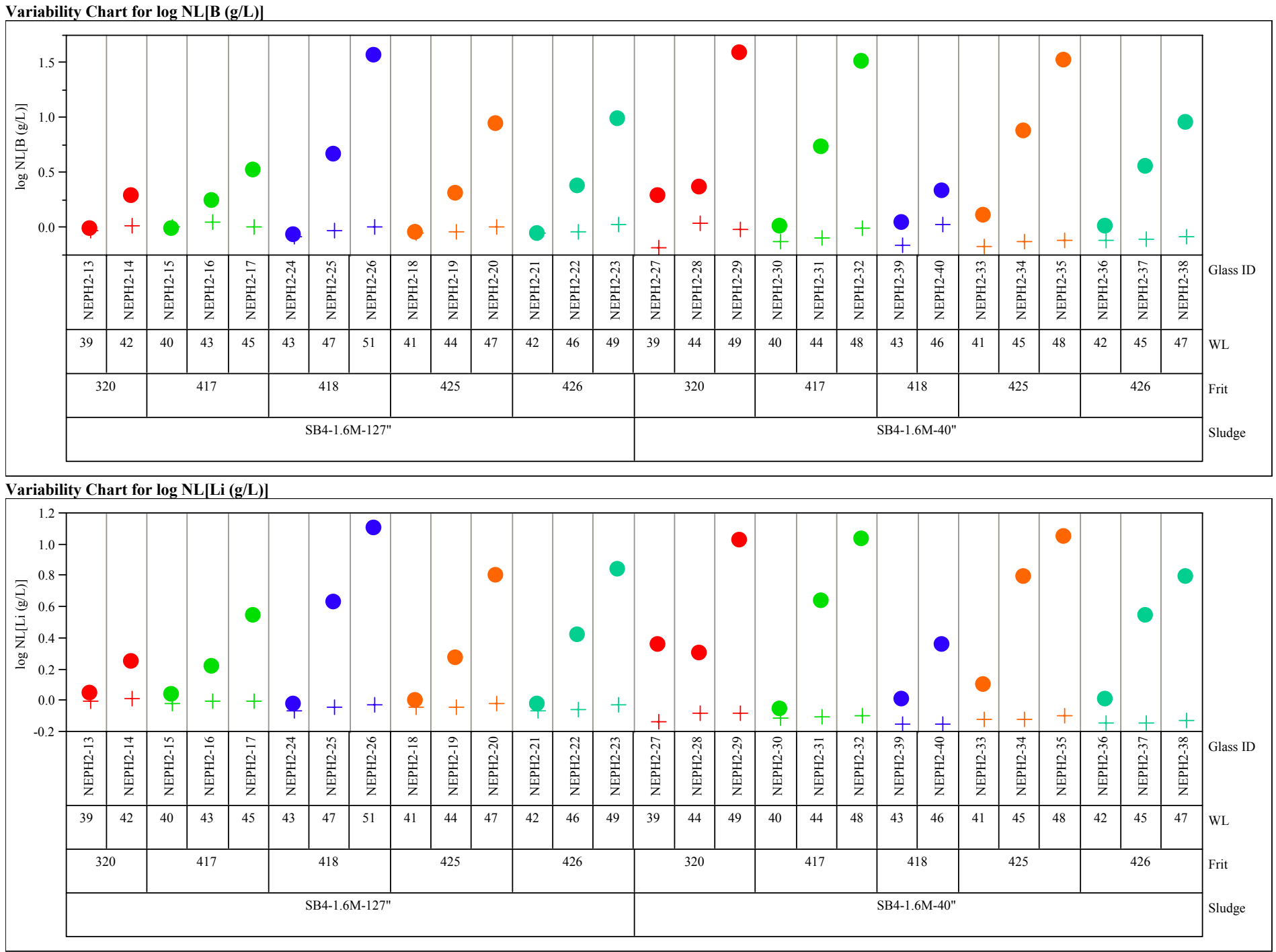


\section{Exhibit D7. Effects of Heat Treatment for Study Glasses Using Targeted Compositions}
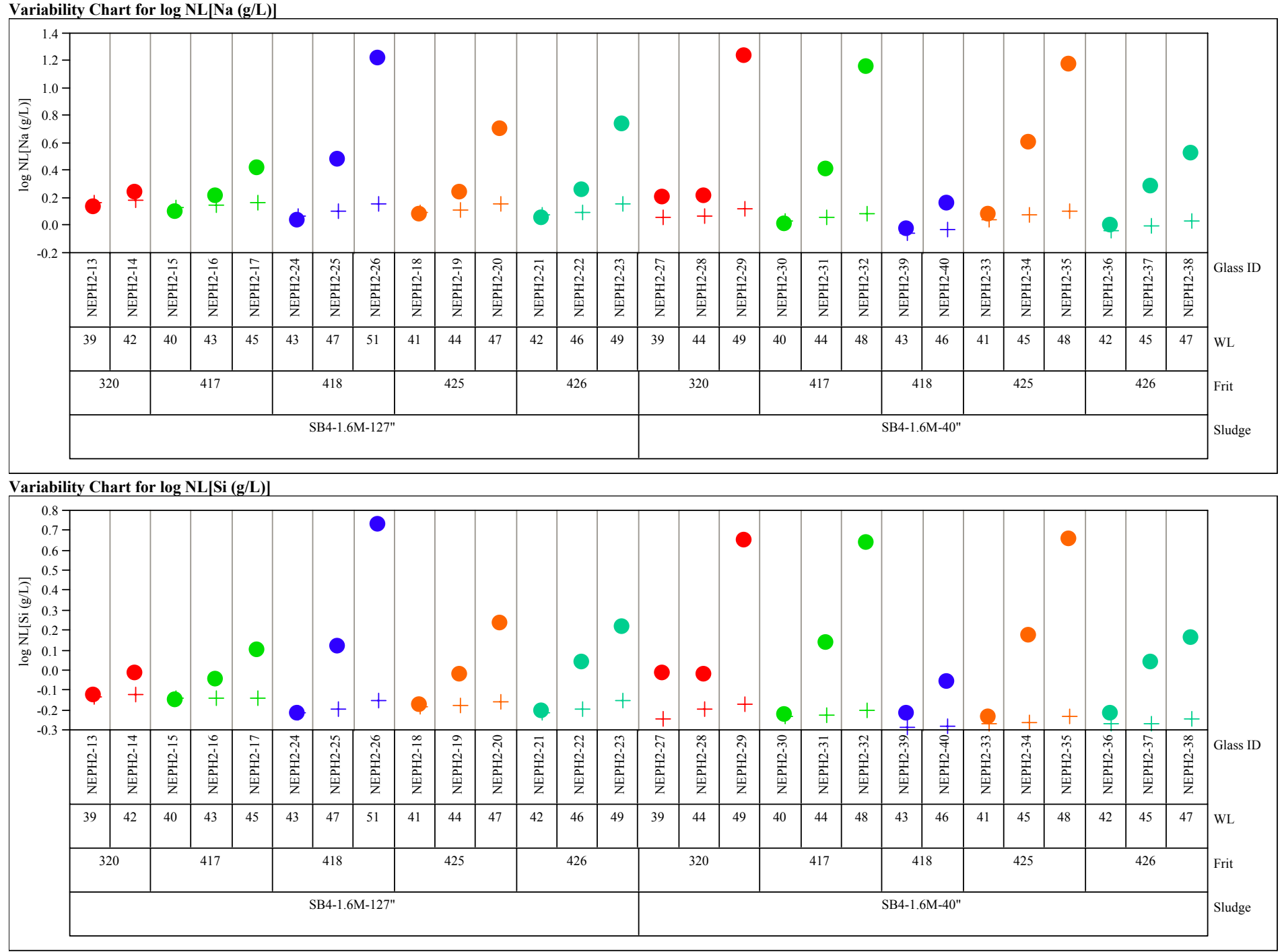


\section{Exhibit D8. Effects of Heat Treatment for Study Glasses Using Measured Compositions}
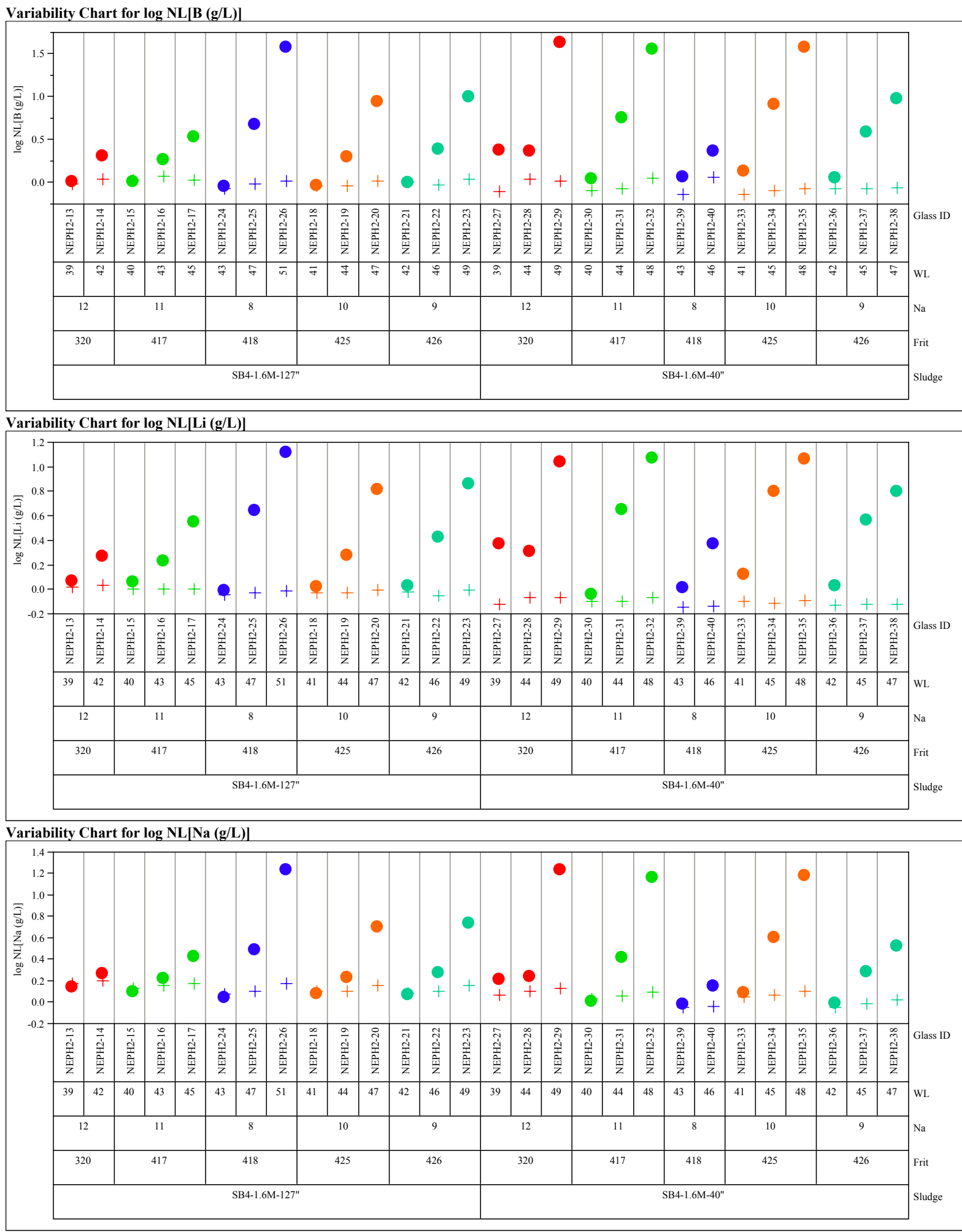
Exhibit D8. Effects of Heat Treatment for Study Glasses Using Measured Compositions

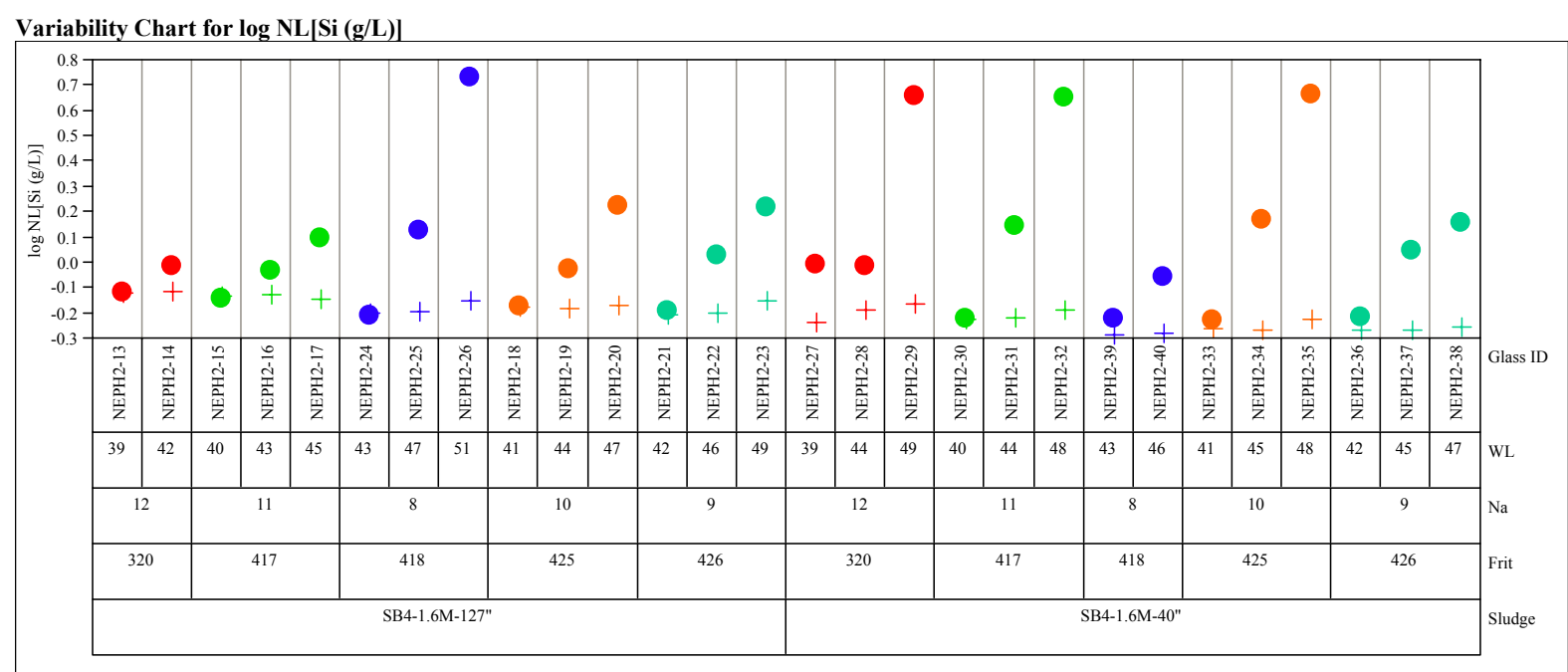


Exhibit D9. Effects of Heat Treatment for Study Glasses Using Measured-Bias Corrected Compositions
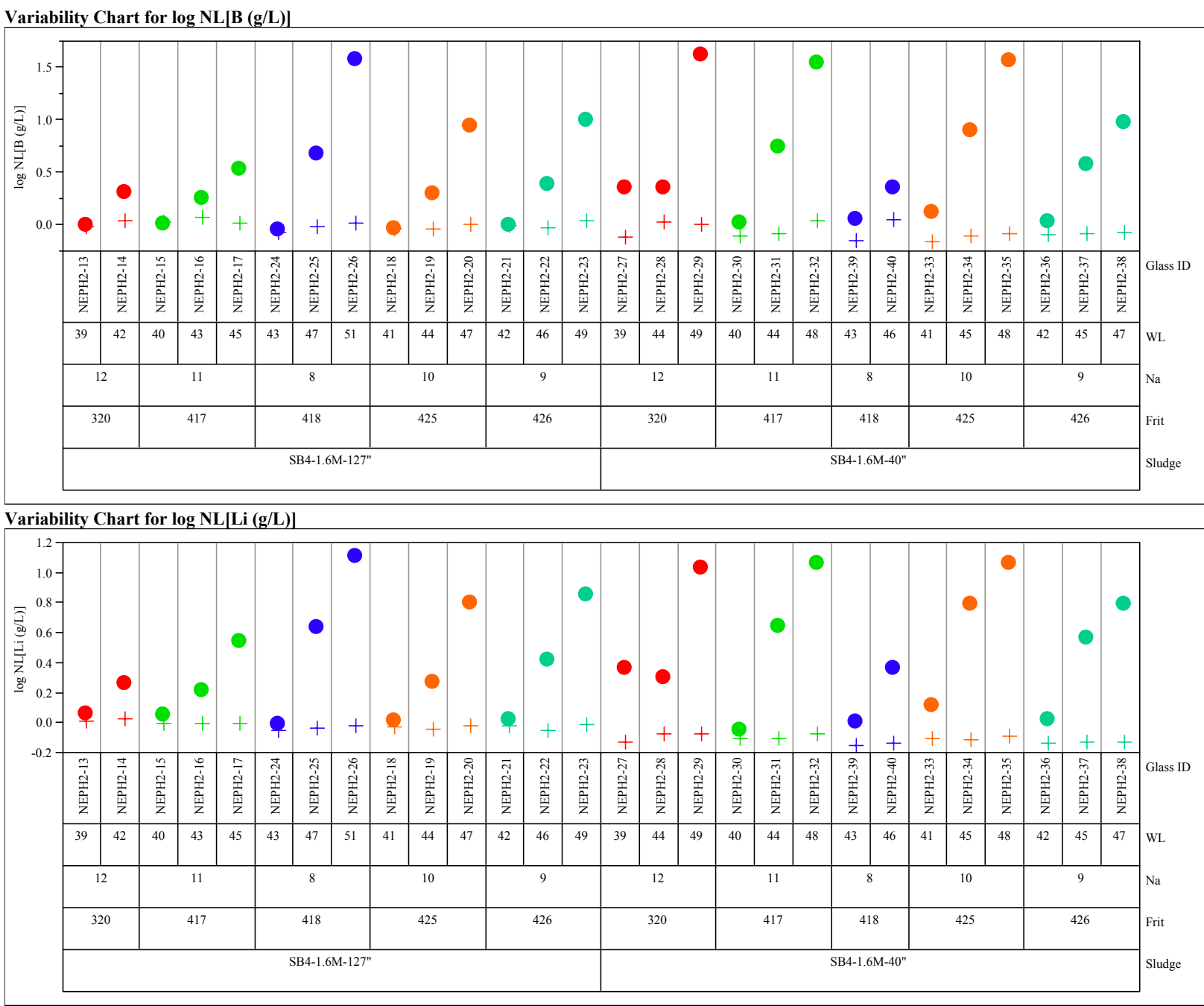
Exhibit D9. Effects of Heat Treatment for Study Glasses Using Measured-Bias Corrected Compositions
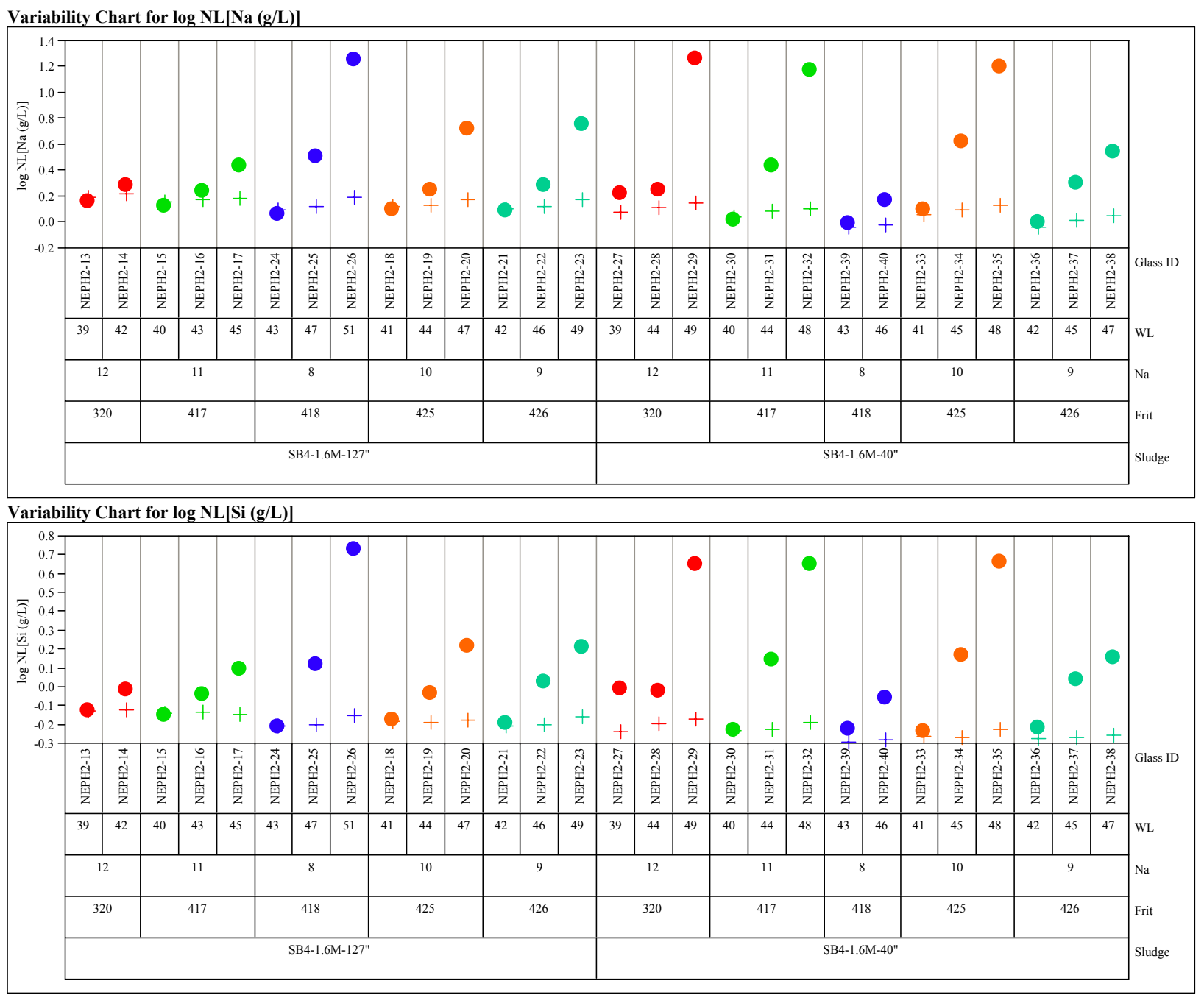


\section{Exhibit D10. del Gp $\left(\Delta \mathbf{G}_{\mathrm{p}}\right)$ Predictions versus Common Logarithm Normalized} Leachate $(\log \mathrm{NL}[]$.$) for \mathrm{B}, \mathrm{Li}, \mathrm{Na}$, and $\mathrm{Si}$

Over All Compositional Views and Heat Treatments

Bivariate Fit of $\log$ NL[B (g/L)] By del Gp

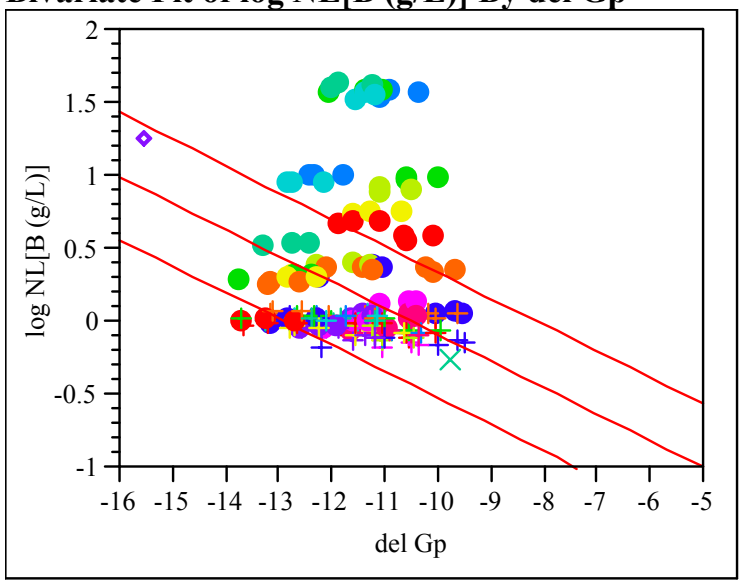

Bivariate Fit of $\log \mathrm{NL}[\mathrm{Li}(\mathrm{g} / \mathrm{L})]$ By del Gp

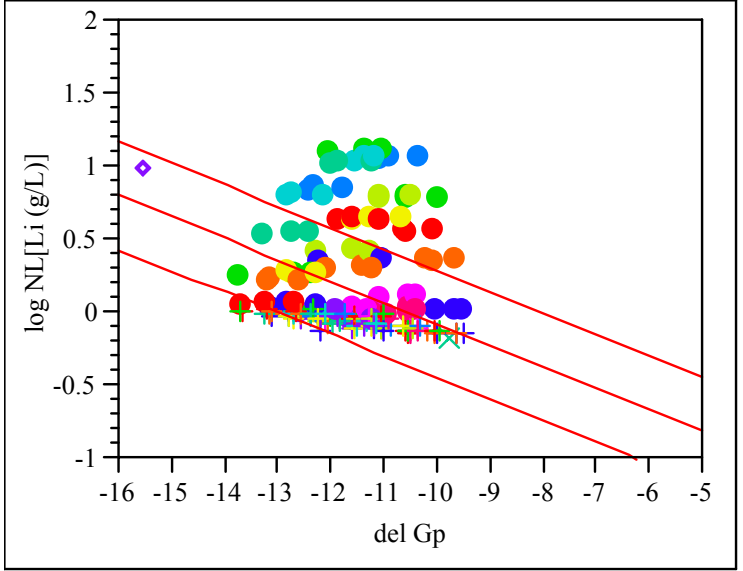

Bivariate Fit of $\log \mathrm{NL}[\mathrm{Na}(\mathrm{g} / \mathrm{L})]$ By del Gp

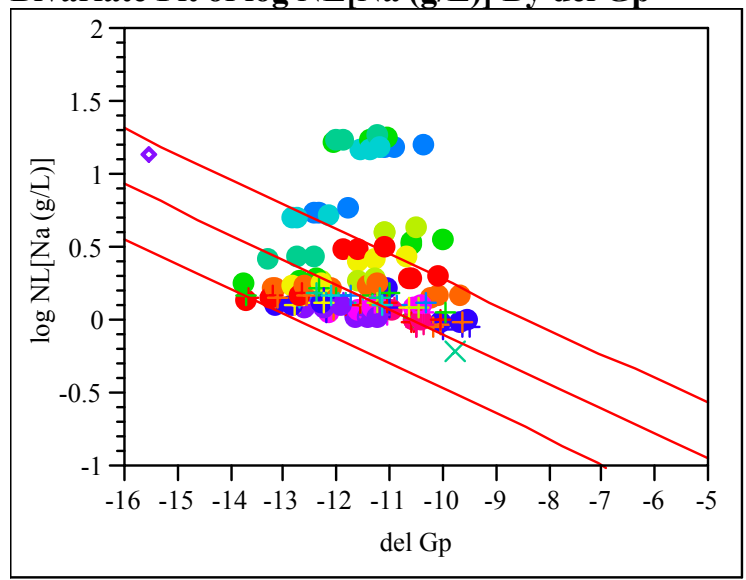

Bivariate Fit of $\log \mathrm{NL}[\mathrm{Si}(\mathrm{g} / \mathrm{L})]$ By del Gp

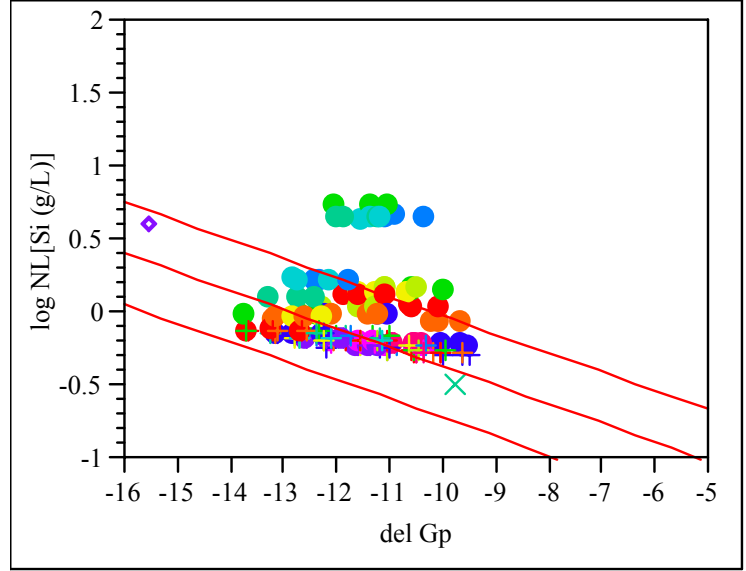




\section{Exhibit D11. del $G p\left(\Delta G_{p}\right)$ Predictions versus Common Logarithm Normalized Leachate (log NL[.]) for B, Li, Na, and Si Over All Compositional Views for Quenched Glasses}

Bivariate Fit of $\log$ NL[B (g/L)] By del Gp

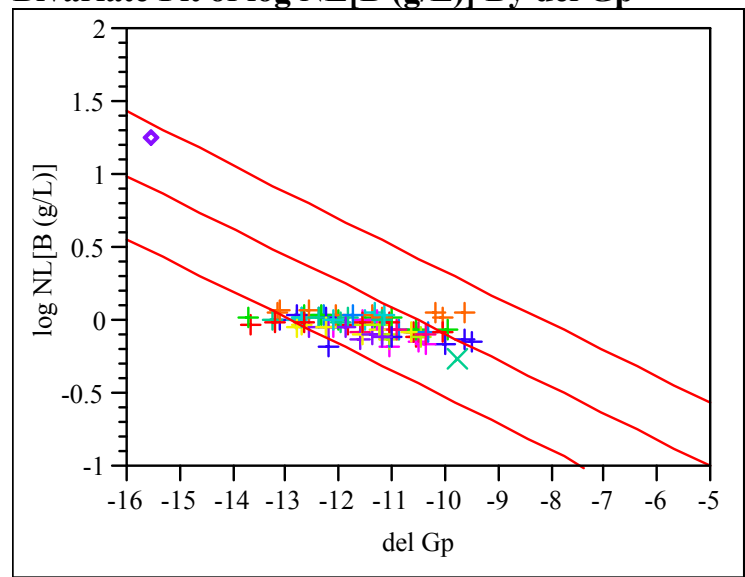

Bivariate Fit of log NL[Li (g/L)] By del Gp

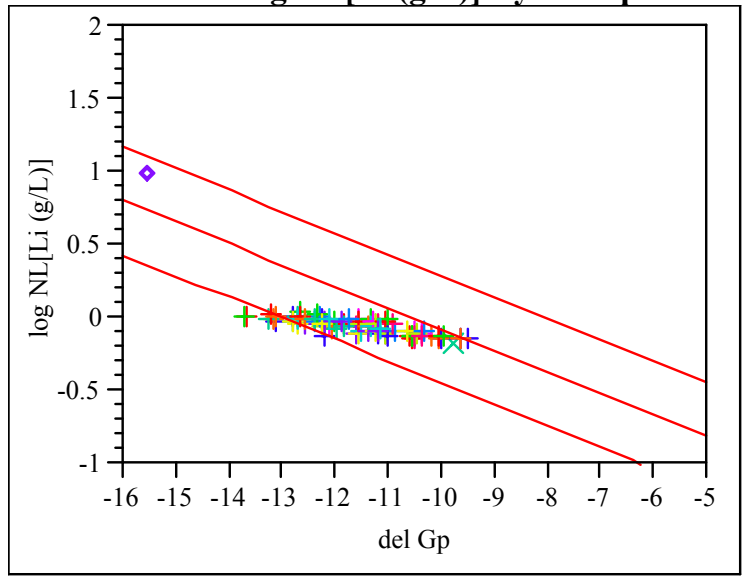

Bivariate Fit of $\log \mathrm{NL}[\mathrm{Na}(\mathrm{g} / \mathrm{L})]$ By del Gp

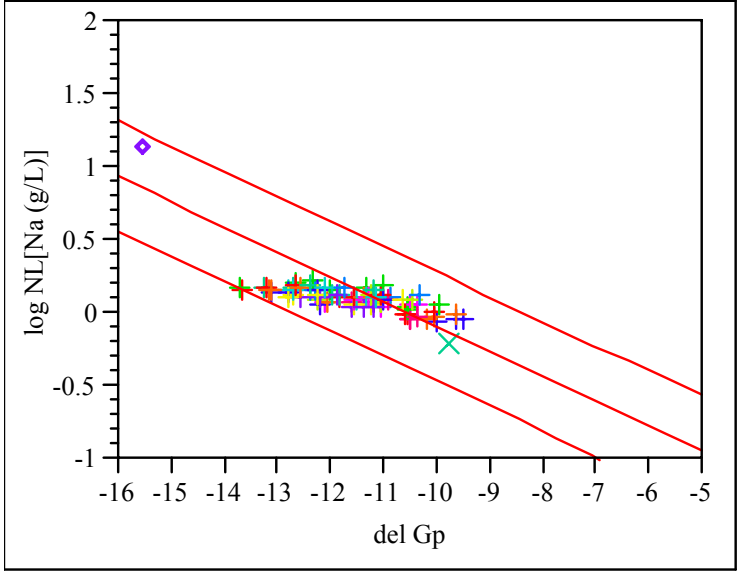

Bivariate Fit of $\log$ NL[Si (g/L)] By del Gp

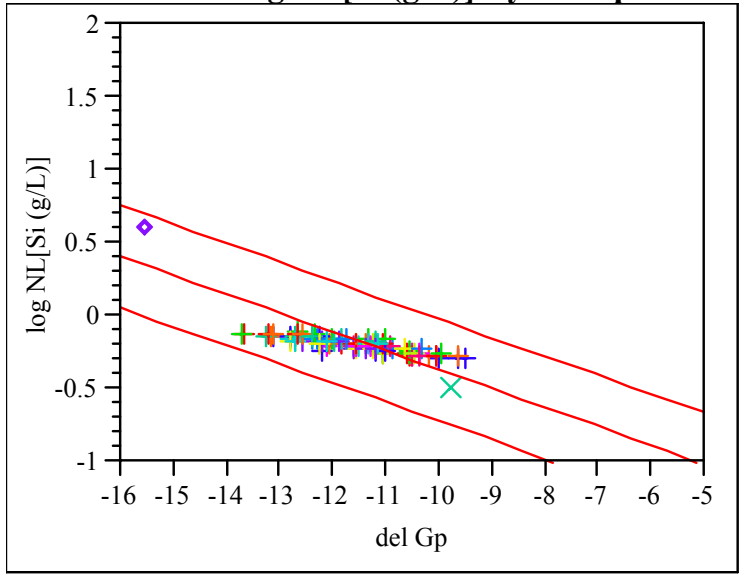




\section{Exhibit D12. del $G p\left(\Delta G_{p}\right)$ Predictions versus Common Logarithm Normalized} Leachate (log NL[.]) for B, Li, Na, and Si Over All Compositional Views for cce Glasses

Bivariate Fit of $\log$ NL[B (g/L)] By del Gp

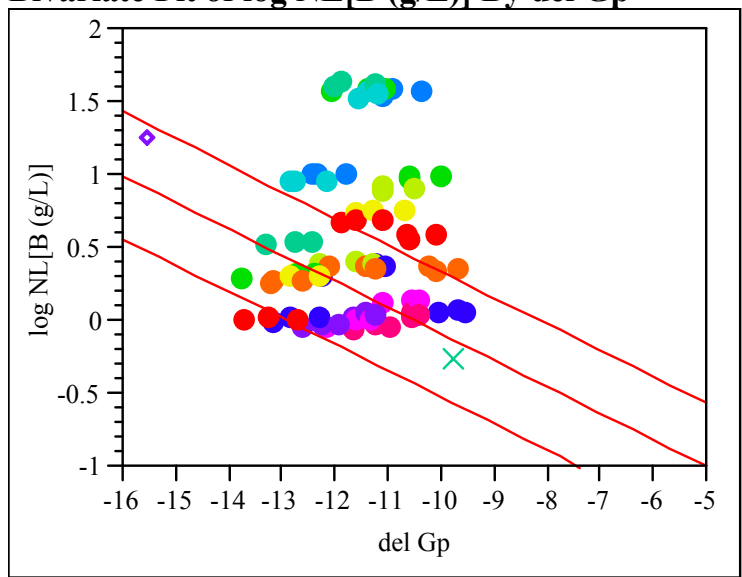

Linear Fit

Bivariate Fit of $\log \mathrm{NL}[\mathrm{Li}(\mathrm{g} / \mathrm{L})]$ By del Gp

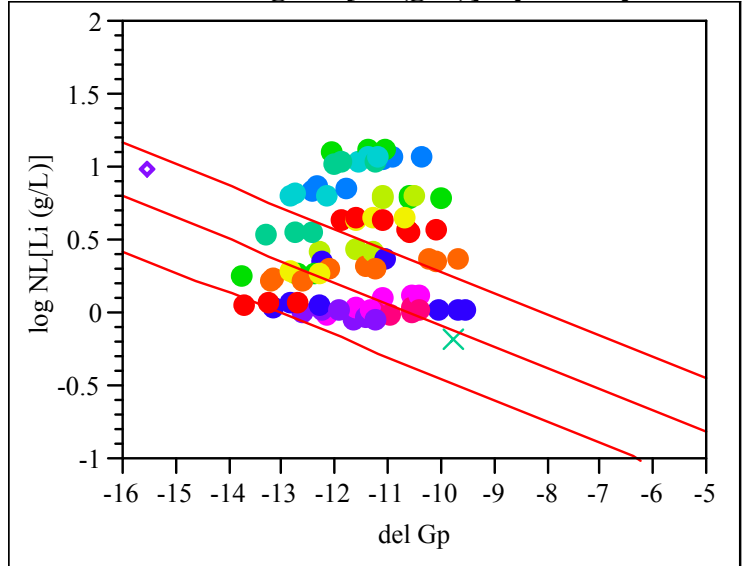

Linear Fit
Bivariate Fit of $\log \mathrm{NL}[\mathrm{Na}(\mathrm{g} / \mathrm{L})]$ By del Gp

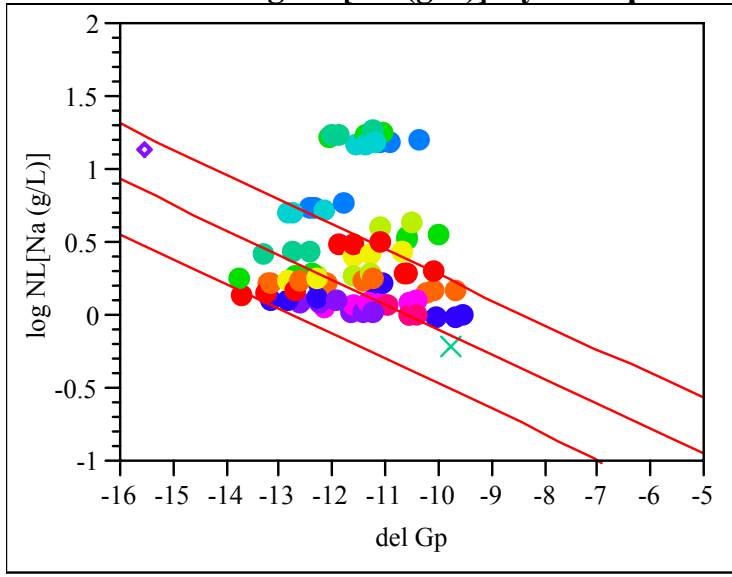

Linear Fit

Bivariate Fit of $\log$ NL[Si (g/L)] By del Gp

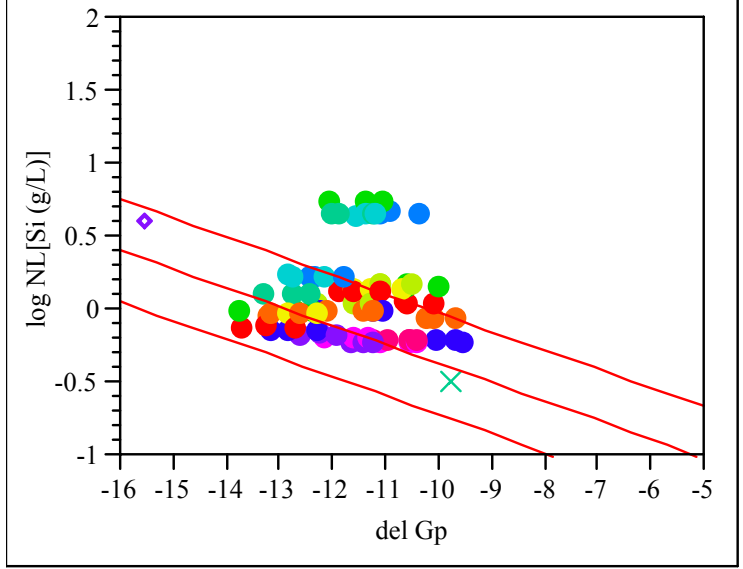

Linear Fit 


\section{Distribution:}

J.E. Marra, SRNL

R.E. Edwards, SRNL

E. W. Holtzscheiter, SRNL

D. A. Crowley, 999-W

S. L. Marra, 999-W

T. B. Calloway, 999-W

N. E. Bibler, SRNL

C.M. Jantzen, SRNL

J. R. Harbour, 773-42A

G. G. Wicks, SRNL

R. C. Tuckfield, 773-42A

T. B. Edwards, 773-42A

K.M. Fox, SRNL

C. C. Herman, 773-42A

M. E. Smith, 773-42A

M. E. Stone, 999-W

D. H. Miller, 999-W

M.J. Barnes, 999-W

M. S. Miller, 704-S

J. E. Occhipinti, 704-S

R. M. Hoeppel, 704-27S

B. A. Davis, 704-27S

P.M. Patel, 704-27S

H. H. Elder, 766-H

J. F. Iaukea, 704-30S

J. W. Ray, 704-S

M. A. Rios-Armstrong, 766-H

W. B. Van-Pelt, 704-S

H.B. Shah, 766-H 